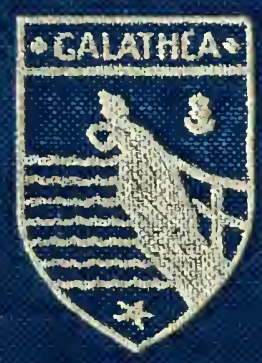




\section{Given in Loving Memory of}

\section{Raymond Braislin Montgomery}

Scientist, $R / V$ Atlantis maiden voyage

$$
2 \text { Julv - } 26 \text { August, } 1931
$$

Woods Hole Oceanographic Institution Physical Oceanographer 1940-1949

Non-Resident Staff 1950-1960

Visiting Committee 1962-1963

Corporation Member 1970-1980 $* * * * * *$

Faculty, New York University 1940-1944

Faculty, Brown University 1949-1954

Faculty, Johns Hopkins University 1954-1961 Professor of Oceanography, Johns Hopkins University 1961-1975 
R.B. Montgemery 

THE GALATHEA DEEP SEA EXPEDITION 



\section{THE GALATHEA DEE P SEA EXPEDITION I950-I952}

DESGRIBED BY MEMBERS OF THE EXPEDITION

\section{Edited by \\ ANTON F. BRUUN, SV. GREVE, HAKON MIELGHE and RAGNAR SPÄRGK}

\section{Translated from the Danish by REGINALD SPIN K}

MARINE BIOLOGICAL LAEORATOYY

LIEFIFY

1.005 loci- :

W. $H . \circ$

\section{LONDON}

GEORGE ALLEN AdPG IN LTD

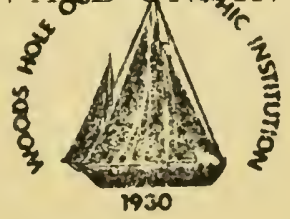


This book is copyright under the Berne Convention. Apart from any fair dealing for the purposes of private study, research, criticism or review, as permitted under the Copyright Act I9I I, no portion may be reproduced by any process without written permission. Enquiry should be made to the publisher.

Translated from the Danish

Galatheas JordomsejLing I 950-52

(J. H. Schultz Forlag I 953) 
Drawings by

POUL H. WINTHER and others

Photography by

KAJ BIRKET-SMITH - LORENZ FERDINAND

MOGENS HOYER - POUL HOLMELUND JAGOBSEN

ALF KIILERIGH - HARRY KNUDSEN - HENNING LEMGHE

HANS MADSEN - ULRICH MOHL-HANSEN

JORGEN NIELSEN - H. PAULY

PETER RASMUSSEN - TORBEN WOLFF

Scripps Institution of Oceanography 



\section{GONTENTS}

Background and Origin of the Expedition. By R. Spärck II

The Ship and her Complement. By Sv. Greve 18

Objects of the Expedition. By A. F. Bruun 26

Echo-Sounding and Hydrographical Studies. By A. Kiilerich 29

The Seychelles - Islands of the Giant Palms. By Torben Wolff 42

Measuring the Productivity of the Sea. By E. Stemann Nielsen 53

Pelagic Fauna. By P. L. Kramp 65

Sea Snakes. By H. Volsoe $\quad 87$

Our Visit to the Nicobars. By H. Volsoe $\quad 9^{6}$

The Technique of Trawling. By B. Kullenberg I 2

Lower Coastal Animals. By Henning Lemche I I 9

Coastal Fish. By 7. R. Pfaff $\quad$ I 34

Animal Life of the Deep Sea Bottom. By A. F. Bruun I 49

The Density of Animals on the Ocean Floor. By R. Spärck $\quad$ I 96

Bacteria in the Deep Sea. By Claude E. ZoBell and Richard $Y$. Morita

Rennell - An Out-of-the-way Coral Island. By Torben Wolff 2 I I

Oceanic Bird Life. By L. Ferdinand

224

Geomagnetic Investigations. By Niels Arley 237

Ethnological Studies. By Kaj Birket-Smith $\quad 246$

Campbell Island - Home of Elephant Seals and Albatrosses. By Magnus Degerbol

Contact with International Science. By Torben Wolff 272

Films, Press, and Radio on the Expedition. By Hakon Mielche 282 Index 



\section{CONVERSION TABLE}

\begin{tabular}{|c|c|c|c|c|c|c|c|}
\hline & & & & & & & \\
\hline & & & & & & & $\mathrm{OO}$ \\
\hline METRES & I & & 3 & 2 & 8 & I & \\
\hline & 2 & & 6 & 5 & 6 & 2 & \\
\hline & 3 & & g & 8 & 4 & & \\
\hline & 4 & I & 3 & I & 2 & 4 & \\
\hline & 5 & I & 6 & 4 & o & 5 & \\
\hline & 6 & I & c & 6 & 8 & ( & \\
\hline & 7 & 2 & 2 & 9 & 6 & 7 & \\
\hline & 8 & 2 & 6 & 2 & 4 & $\xi$ & \\
\hline & 9 & 2 & 9 & 5 & 2 & s & \\
\hline & & & & & & & \\
\hline
\end{tabular}

Danish Kroner $=$ I 9.35 to $\mathfrak{f I}_{\mathrm{I}}$ Sterling

, $\quad=6.89$ to $\$ \mathrm{I}$, American Currency

Kilometre $\quad=0.62 \mathrm{I}$ of a mile

Centimetre $=0.3937$ of an inch 



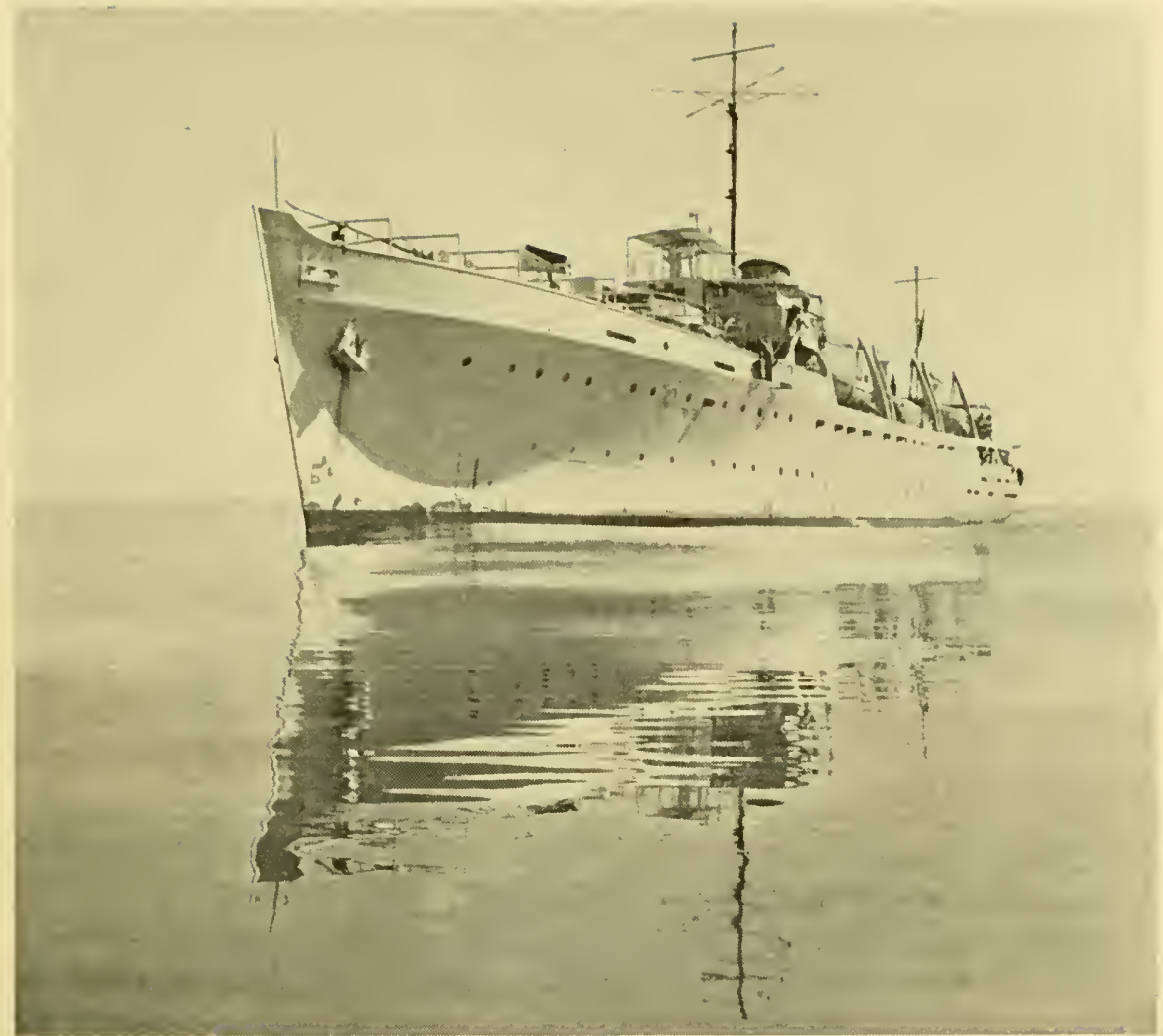

\title{
BAGKGROUND AND ORIGIN OF THE EXPEDITION
}

\author{
By R. SPÄrCK
}

The mere fact that the sea covers nearly three-fourths of the earth's surface is a sufficient indication of its vast expanse. Yet the difference between the areas of land and of water is slight compared with the difference between their volumes. Supposing that we were able to scoop off all the land down to sea-level and deposit it in the sea, we should not even fill the Pacific. The amount of dry land inhabited by living creatures is therefore small in proportion to the amount of inhabited sea. On dry land, life is mainly 
suspected, and it was then that the first real deep-sea expeditions began. They were started by Britain in the eighteen-sixties, the first large-scale expedition being that of the British naval vessel the Challenger ( $1872-76$ ). Now, for the first time, it was shown that there was a rich and varied fauna at least as far down as 5,000-6,000 metres, both on the ocean bed and in the deeper reaches of the free water masses. The pace of deep-sea exploration then began to quicken.

It was about this time that another branch of marine research was founded, that of fisheries biology. The modernization and growing importance of the fishing industry, together with the continued development of natural science, was accompanied by systematic studies of the habits, migrations, and growth of commercially useful fish and consequently of factors influencing the stock. The study of marine fauna by marine-biological and fishery-biological laboratories and research stations began at about the same time, one of the first and most famous of the stations being that at Naples, founded in 1872 .

Then, in 1902, came the establishment of the International Council for the Exploration of the Sea, with headquarters in Copenhagen. Its object was to coordinate the work of fishery-research institutions in northwest Europe. Although principally concerned with practical problems, it has been of great importance to the exploration of north-west European coastal waters as well as the Arctic and north-east Atlantic.

Danish participation in this international marine research was the basis of the extensive work carried out by Johannes Schmidt, who established the breeding biology and migrations of the fresh-water eel. It took many expeditions to complete this work: first the voyages of the Thor in the north-east Atlantic and Mediterranean, then the Atlantic cruises of the Margrethe, the Dana $I$, and the Dana II, and finally the great Dana World Expedition of 1928-30. All these expeditions yielded very large and valuable collections of the fauna of the free water masses down to depths of $3,000-4,000$ metres, equal in importance to the collections of bottom fauna made by the Challenger Expedition.

Thanks to nearly two centuries of work, the Danish collections of marine fauna, from all over the world, were among the richest in existence. All that was needed to complete them was a representative collection of the bottom fauna of the greatest depths, if there was any. The Galathea Expedition must be viewed against this background.

The idea of a new Danish deep-sea expedition had often been mooted but for various reasons never realized. The outbreak of war in 1939 meant the indefinite postponement of any such plans. However, one day 


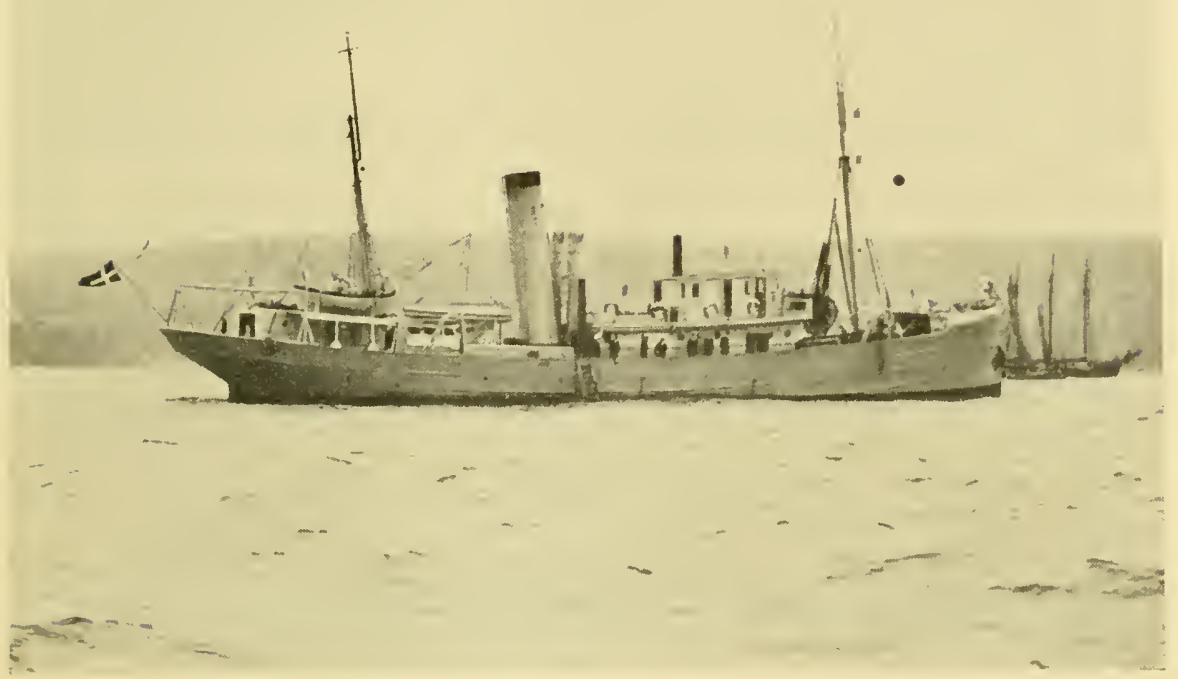

The research ship Dana II at Plymouth, 1930.

in I94 I Dr. Anton Bruun gave a lecture on the possibility of the existence of sea serpents, and a report of it was read by the author Hakon Mielche. Mr. Mielche approached Dr. Bruun, and the idea of the Galathea Expedition grew out of their talks. Mielche felt that the general public should be kept better informed about the work of such expeditions and he suggested that the programme should include the taking of film-strips, lecturing to Danes overseas, and other work of an educational and national character. As a result of private discussions with interested scientific circles it seemed possible that the expedition could be launched in June 1945, the centenary year of the first Danish world expedition on the corvette Galathea. The duration of the war, however, necessitated the postponement of the expedition.

As the Danish Admiralty had shown great interest in the project, it had been envisaged that the expedition might take the form of an ordinary naval cruise, the cost of the ship's upkeep being met out of the Admiralty's normal budget. Other costs, which would be comparatively moderate, it was hoped to cover privately. At a meeting held for this purpose shortly after the war the Danish Expeditions Fund was founded, with an energetic general secretary in Leif B. Hendil. Through gifts 


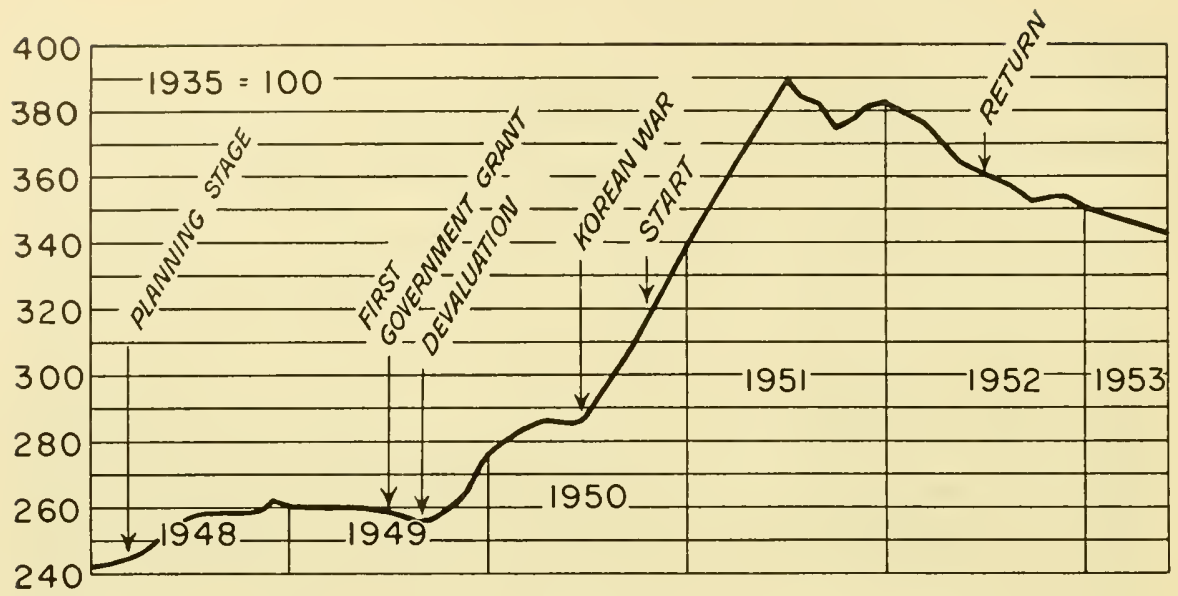

The price trend, as reflected in the index of wholesale prices, before and during the expedition.

from overseas Danes in cash and in kind, and through the conversion of cash gifts into goods which could be sold in Denmark at a profit, the fund was able to provide substantial sums not only for the Galathea Expedition but also for the Danish Pearyland Expedition and the Danish Central Asian Expedition.

The plans now began to take definite shape. In the spring of 1948 a committee was set up with $\mathrm{H}$. R. H. Prince Axel as chairman, and the first grant of 250,000 kroner was obtained. The next step was to procure a ship and equipment. A unique opportunity to purchase a substantial proportion of the gear at a favourable price was presented by the return of the Swedish Albatross Expedition in October the same year. All the Albatross's winches were bought, including the large trawl winch, together with wires, water samplers, thermometers, and a good deal more.

There was no lack of available ships, but none seemed to have the requisite seaworthiness, deck space, accommodation for the installation of laboratory facilities, manoeuvrability, and so forth, and it was begirnning to look rather doubtful whether the expedition could be launched in the foreseeable future when the World Friendship Association offered its vessel Friendship for sale. Like all ships which have been for some months laid up, she was rusty and dirty; but she had the right size, a fairly spacious quarter-deck, a large saloon aft suitable for conversion into a laboratory, and a convenient speed. She was also certified as being rery seaworthy. Accordingly the Admiralty was approached with a suggestion that the ship be bought with Government funds and that a grant of 50,000 kroner a month for two years be made to cover the cost of main- 
taining her as a naval vessel. A further grant of 350,000 kroner towards the scientific costs of the expedition had by this time been received from the Expeditions Fund. The application was granted, and by June 29, I 949 , the expedition could be regarded as certain.

But more difficulties were to comc. The cost of the ship was I, 200,000 kroner, and a further 800,000 kroner was allocated for her conversion and re-fitting. The latter sum fell short of requirements, and even when raised to a little over $\mathrm{I}, 000,000$ kroner still failed to cover the costs of installations not directly connected with the scientific objects of the expedition. The extra costs were met by the Expeditions Fund, which also provided the ship's radar and echo-sounder, thereby bringing the fund's total expenditure on the ship's equipment to about 80o,0oo kroner.

By' the end of August 1950 the Galathea was ready to sail; she went into commission on September I, and the expedition set out on October I 5, after a fortnight's delay due to repairs and alterations arising out of the two trial trips.

The allocation of 50,00o kroner a month for maintaining the ship as a naval vessel also proved inadequate. A year later Denmark devalued her currency; the Korean war had broken out and prices had risen enormously. A supplementary allocation of 600,000 kroner was made to cover direct increases in costs, along with the offer of a further 250,000 kroner conditional on a like sum being forthcoming from other sources. This last sum was also provided by the Expeditions Fund, as was a further 250,000 kroner necessitated by heavy dock charges and high cost of fuel oil in the Pacific. Even so, it was necessary to curtail the expedition by about three months and return home in July instead of October as planned.

Altogether, then, the expedition cost about 3,000,000 kroner in capital expenditure, mainly on ship and gear, and 2,500,000 kroner in working expenses. The Government provided about 2,250,00o kroner of the capital expenditure and about 2,00o,ooo kroner of the working expenses, the Expeditions Fund the balance of about 800,000 kroner and 500,000 kroner respectively. 


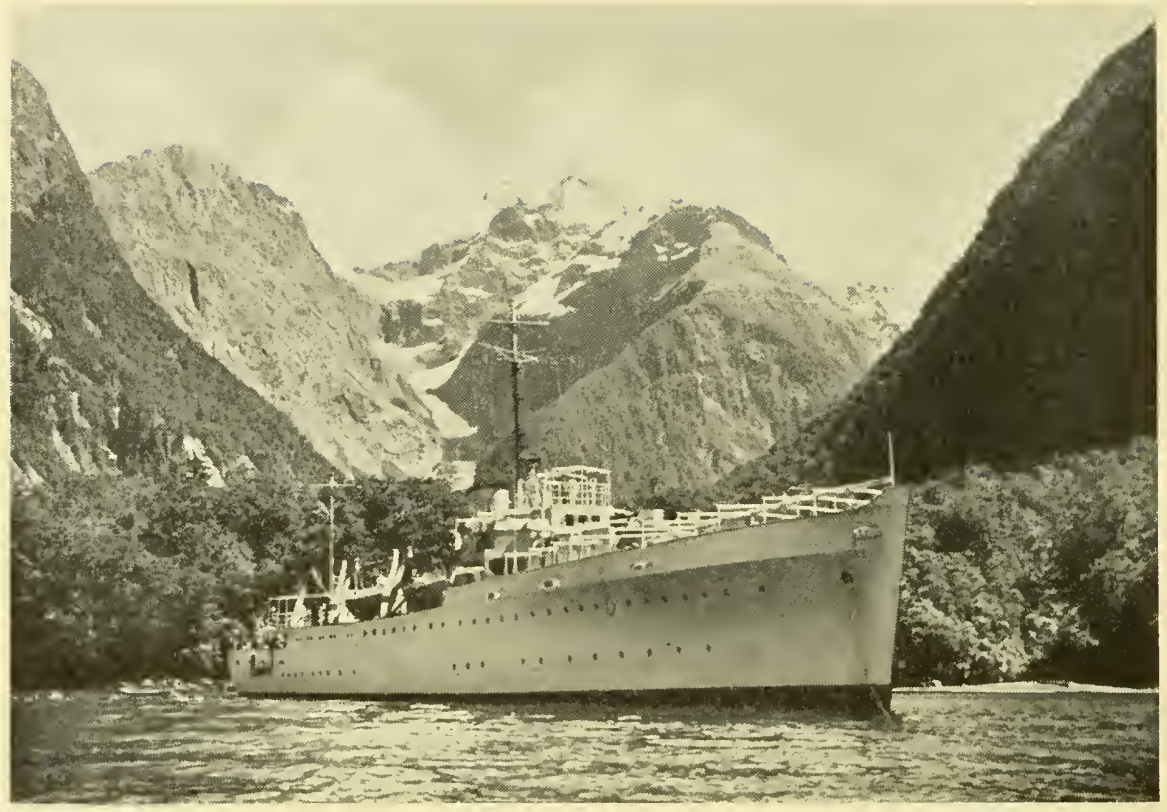

THE SHIP AND HER COMPLEMENT

By Sv. Greve

The Galathea was a former naval sloop with a displacement of 1,600 tons, built at Devonport in 1934. As H. M. S. Leith she had served with the New Zealand Navy as a survey and charting vessel, and when we called at Milford Sound in New Zealand we ourselves used charts marked: "Charted by H. M. S. Leith". It gave us an extra feeling of security!

During the war she had been engaged on various towage tests and on minesweeping operations in the Atlantic. Sold for civilian service after the war, she was acquired by the Danish section of the World Friendship Association and was renamed Friendship. After a short period of service she had to be laid up for financial reasons, and so it came about that in I949 she was purchased by the Danish Admiralty with a view to her use on the projected deep-sea expedition.

The Galathea in Milford Sound, New Zealand. 
The vessel's length was about 80 metres ( $266 \mathrm{ft}$.), the width about I r metres ( $34 \mathrm{ft}$.$) , and the draught about 3.5$ metres $(11 \mathrm{ft}$.$) . The main$ machinery consisted of two Parson's geared high-pressure and low-pressure turbines with a combined horsepower of 2,000. The ship had two oil-fired boilers and two three-bladed propellers. On two boilers her maximum speed was 12 knots. On one boiler she did eight knots, a more economic speed at which we normally travelled when only short distances separated the scientific stations. On longer cruises we usually did I 2 knots. Fouling of the ship's bottom, which in the Tropics is both intense and rapid, would entail an average loss of one knot. Our oil reserves were 3 I 4 tons, and our action range at an economic speed about 6,0oo nautical miles, corresponding to about 32 days' sailing. The electric equipment consisted of two steam engines for use when under way and one diesel dynamo used when in port. An up-to-date radio installation enabled us to maintain contact with home throughout the voyage. In addition to the standard magnetic compasses, the navigational equipment and gear included steering and main compass, a gyro compass, a Decca radar, Sperry Loran equipment, a direction finder, and an Atlas navigational echo-sounder. She carried no armament other than three 57-millimetre salute guns.

Reconditioning and fitting out as an oceanic research vessel took

$A$ view of the engine-room.

The Galathea's turbines made ro,000,000,000 revolutions during the voyage.

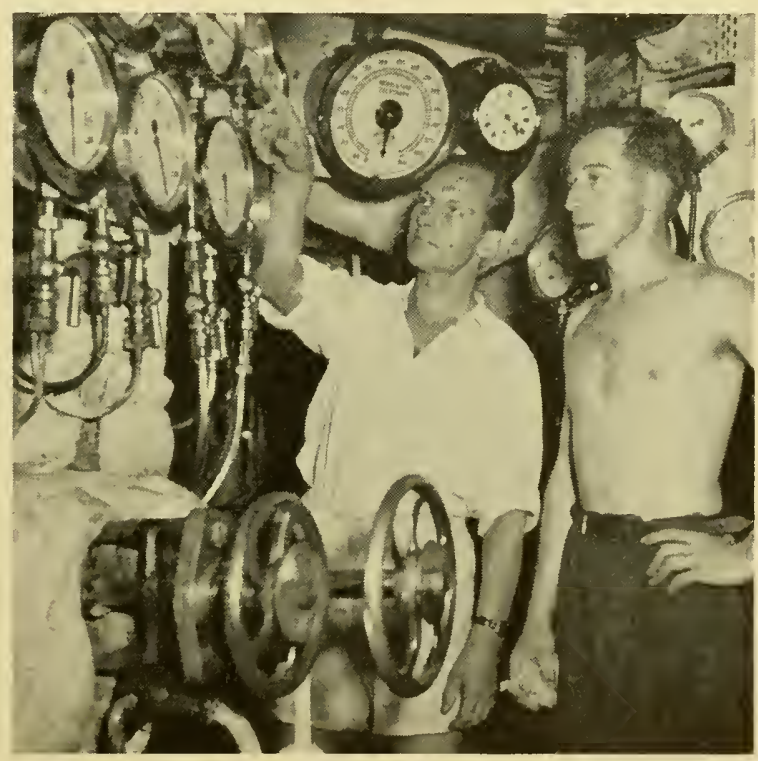


place at the Royal Naval Dockyards in Copenhagen, and in accommodation and equipment the Galathea was both up-to-date and well-adapted to decp-sea research. Her size was exactly right and her installations and gear just what the scientists wanted; only one thing was lacking which we would have liked had funds permitted - an air-conditioning plant. Air-conditioning is one of the great modern conveniences of the Tropics; and though normally it is a little cooler at sea than on land owing to wind and the ship's movement, the Galathea's research work often compelled us to travel at a slow speed, and all whose quarters were over the cngine-room had a hot time.

For exploring the sea the ship had a large trawl winch on the quarterdeck, coupled to an electric manoeuvring winch. The trawl winch weighed about ro tons and the trawl wire something like it. At first we employed an eight-kilometre wire, with a four-kilometre wire held in reserve, but at Singapore we exchanged the eight-kilometre wire for a i2-kilometre one with a view to the approaching study of the Philippine Trench. In order to save weight, this was specially spun so as to give it a diameter of 22 millimetres at one end tapering to nine millimetres at the other end. It was tested for strengths between seven and 34 tons, breaking stress varying with diameter.

We had a further reserve wire measuring eight kilometres which was kept on shore and transferred from port to port, first to Singapore and then to Manila, as we proceeded. There is always a risk of a wire breaking, either by fouling rocks or stones on the bottom or by getting a kink owing to being paid out too fast in relation to the ship's speed. In both cases the

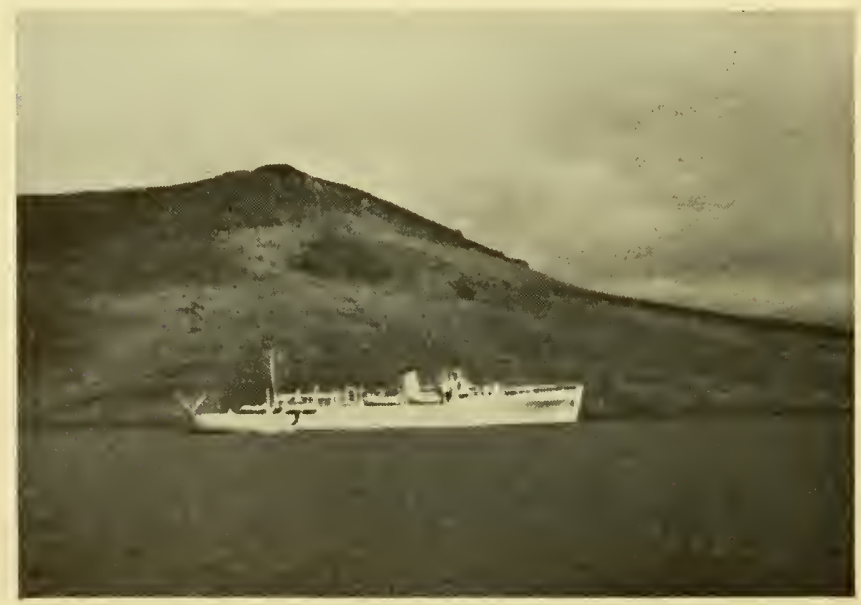

The Galathea in Perseverance Harbour, Campbell Island. 


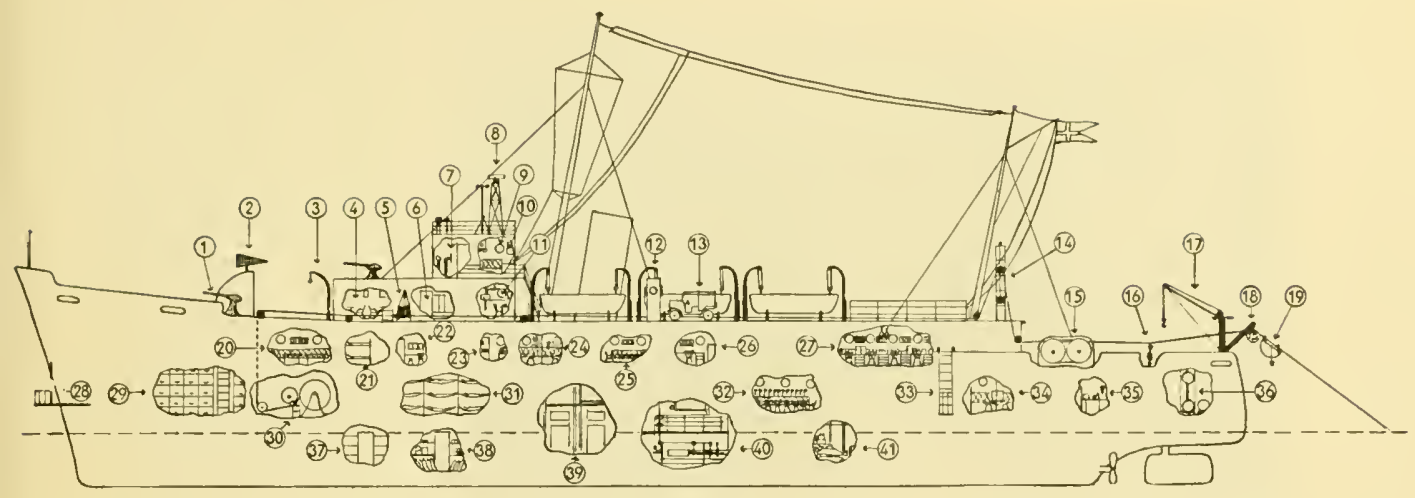

Rough lay-out of the Galathea. I Salute gun. 2 Fixed insect-catching net. 3 Starboard davit for hauling up bottom samples from shallow water. 4 Reception mess. 5 Hydrography winch on port side. 6 Commander's cabin. 7 Wheel house. 8 Radar. 9 Chart-house. Io Echo-sounder. II Radio station. I 2 Photographic tank for taking under-water fllms. 13 Jeep. I4 Accumulator for regulating tension of wire between winch and drum. 15 The big trawling winch. I6 Dynamometer for gauging tension of wire. 17 Crane for putting out heavy gear. I8 The big trawl gallows. 19 Angle gauge fixed to wire. 20 Orlop deck. 21 Sick cabin. 22 Consulting cabin. 23 Canteen. 24 Petty officers' cabin. 25 Petty officers' mess. 26 Leader's cabin. 27 Laboratory. 28 Removable harpooning platform. 29 Hold for scientific collections. 30 Drum for the large wire, course of the latter over the deck being as shown. 31 Sleeping deck. 32 Officers' and scientists' mess. 33 Removable angling chair. 34 Officers' cabins. 35 Dark-room. 36 Gear hold containing spheres for magnetic surveys. 37 Cold stores. 38 Pantry. 3.9 Stokehold. 40 Engine-room. 41 Deep-freezing store.

wire will snap like sewing-thread. Happily, however, we never needed this extra reserve wire.

Considerations of weight distribution prevented us from having this wire rolled up on its drum on the quarter-deck; and so it was kept forward in a special space below deck, from where it was drawn up over the boat deck to the trawl winch on the quarter-deck. From the winch the wire was led over a large trawl gallows situated in the stern. The various trawling and research gear was fixed to the end of the wire.

In the forepart of the ship, on the port side, was an electric hydrographical winch, a duplicate being installed on the starboard side as a reserve. Also on the starboard side was a Lucas sounding machine. This, however, was never used, as all deep soundings were made with the Kelvin-Hughes echo-sounder specially designed for the expedition.

Among other installations, of a more primitive kind but very useful, we had two specially designed platforms, or boatswains' chairs. One of these could be fixed to the stem near the surface and used as a station from which to harpoon dolphins or take photographs; the other could be suspended over the ship's side as an angling platform when the ship was stationary or proceeding slowly during night trawling. Angling from 

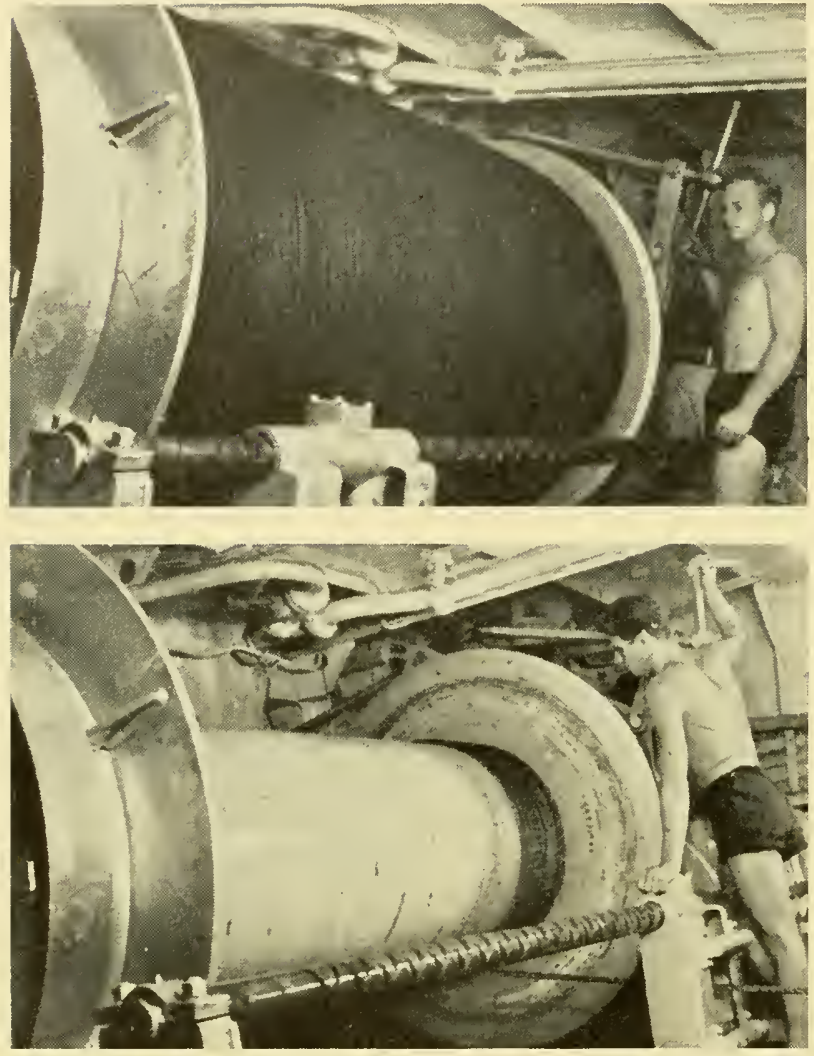

The winch drum with 12 kilonetres of wire wound on it -

and with the wire almost unwound. The 12 kilometres of wire are now dragging the trawl aft of the ship.

this platform was a very popular pastime with all on board, and also yiclded much valuable scientific material.

Scientific headquarters were in the biological laboratory, which was accommodated in the superstructure aft. This arrangement afforded convenient access to the quarter-deck, from which fishing and all other research work except hydrography were carried out.

The spacious laboratory could accommodate I I scientists, and as ships' laboratories go it was well equipped. Connected with the laboratory was a deep-freezing plant with $-4^{\circ} \mathrm{C}$. in the entrance and $-20^{\circ} \mathrm{C}$. in the main chamber.

The scientific personnel varied between 10 and 16 , some of the scientists being on the expedition for only a part of the voyage. They included several young zoologists, chemists, and technicians doing their national service as laboratory assistants. Altogether, the scientific staff numbered $3^{8}$ persons, including seven from Sweden and the United States. 
All members of the expedition not belonging to the civilian scientific staff were naval personnel: officers and warrant officers, able seamen, and national servicemen, including a number of engineers. Our full complement was a little over a hundred. Occasionally, we had a few women scientists on board.

'The route taken by the Galathea is shown on the map at the back of the book, but the salient points of the voyage are as follows: ship commissioned September I, I950; two trial trips in Norwegian and Danish waters; departure from Copenhagen, October I 5, I 950; English Channel; Bay of Biscay; west coast of Africa; Capetown, New Year I95I ; east coast of Africa; Madagascar; Mombasa; the Seychelles Islands; Ceylon; Bay

A corner of the laboratory.

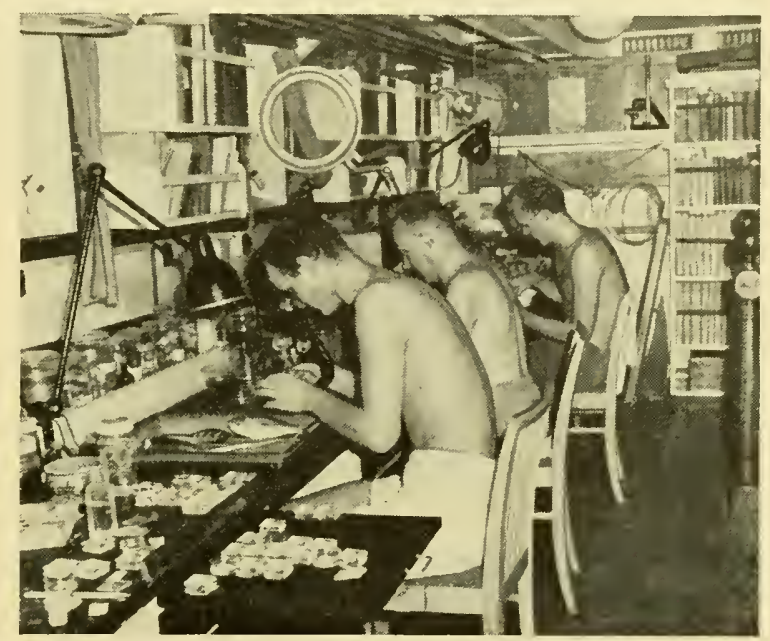

Some of the material collected in the Indian Ocean ready for despatch at Colombo.

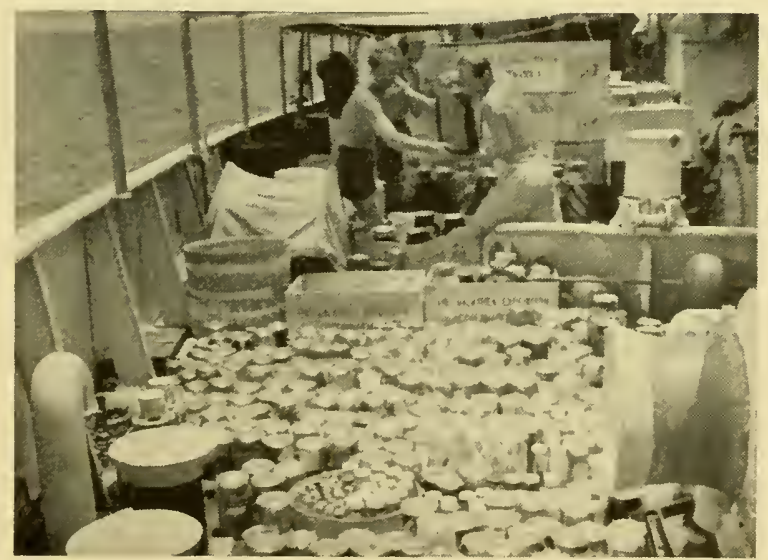


of Bengal; Calcutta; the Nicobar Islands; Singapore, Bangkok, the Philippines; Indonesia; Thursday Island; New Guinea; the Solomons; east and south coasts of Australia; the Tasman Sea; Wellington; Campbell Island, New Year 1952; Auckland; Kermadec; Tonga; Samoa; Hawaii;
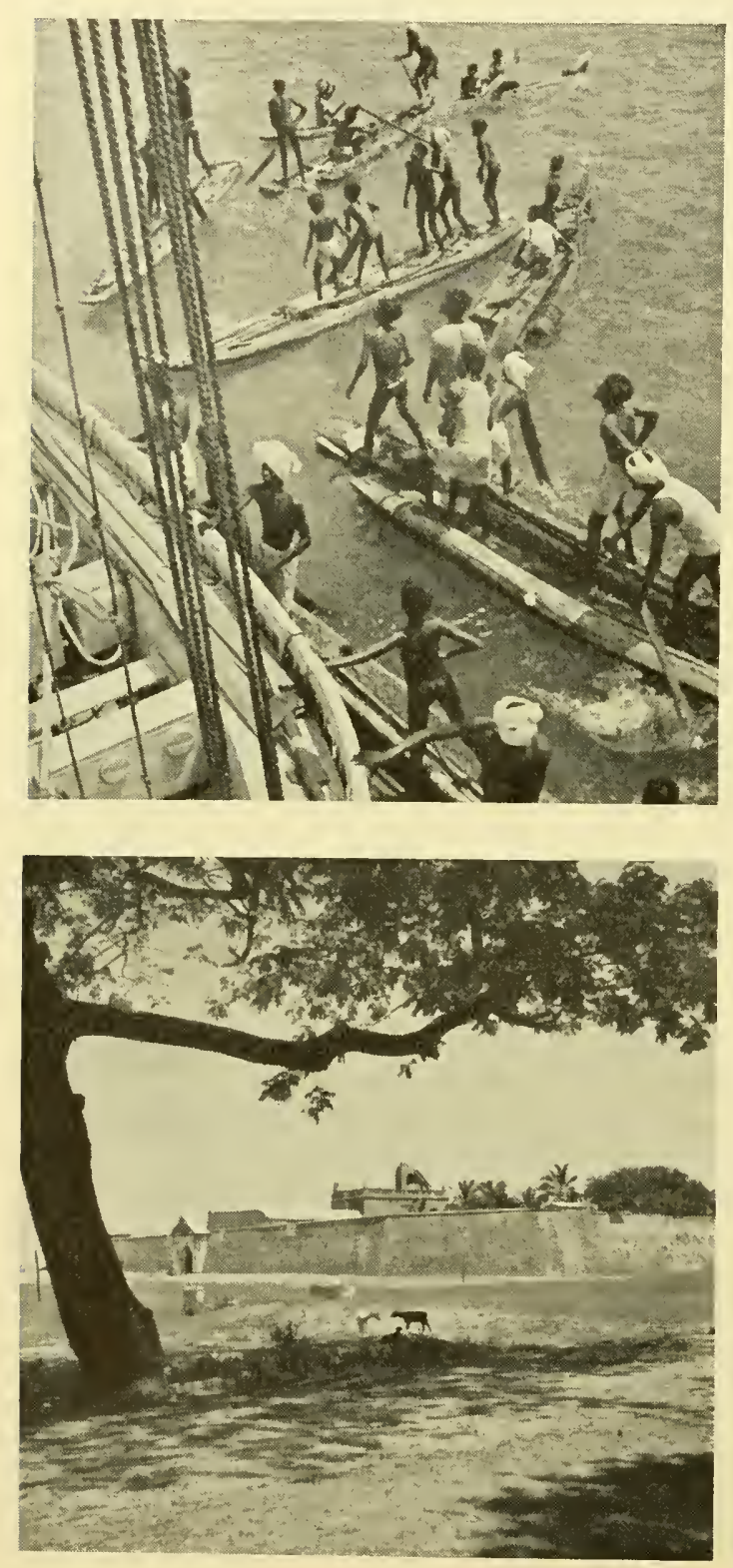

At anchor off Tranquebar.

Dansborg, the old Danish fort at Tranquebar. 


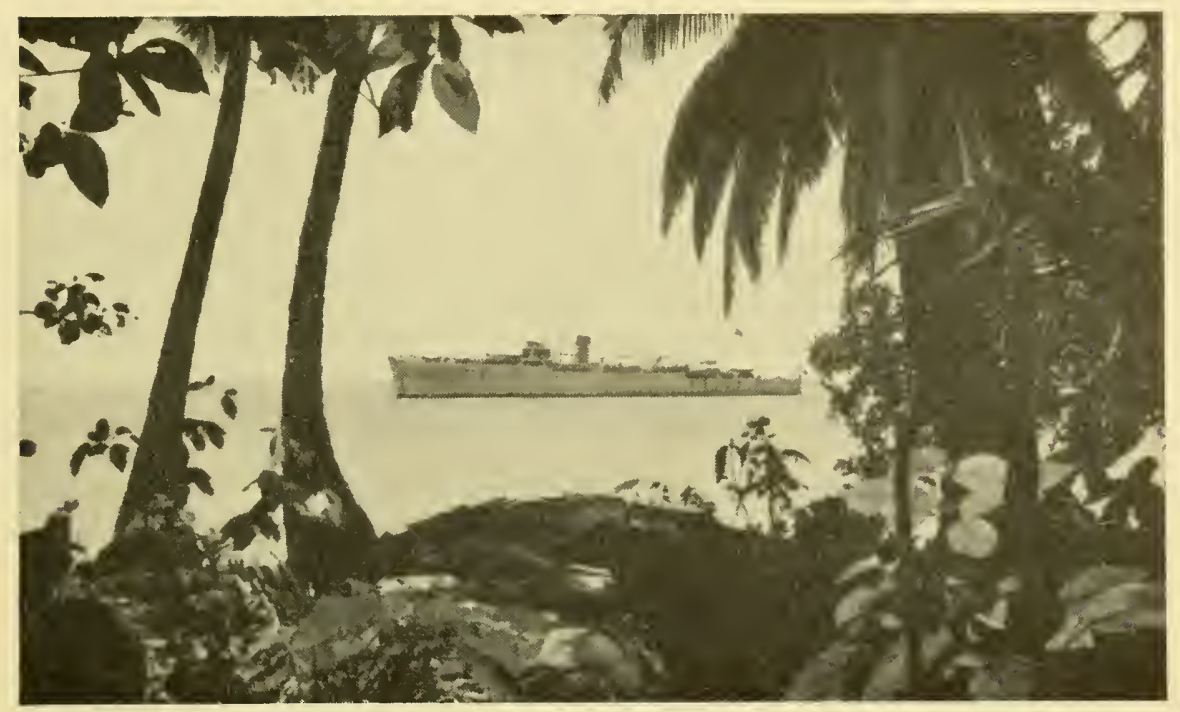

The Galathea at anchor off Kondul, Nicobar Islands.

California; Mexico; Panama; West Indies; the Azores; English Channel; arrival Copenhagen, June 29; ship put out of commission, July I 7, I952.

And so on October I5, I950, the Galathea left Copenhagen; the next day she rounded the Skaw and the Danish deep-sea expedition had begun. A hundred men, most for the duration of the expedition, a few for only a part of it, were to spend their life on board her, discharging their various tasks but all cooperating to the common good in a national and international scientific operation.

We carried all sorts of people: civilian scientists, young students and others from all walks of life and localities doing their national service, and regular naval personnel. It was a cross-section of the Danish nation which thus went out to represent their country on this round-the-world voyage. We visited 26 countries and called at about 70 different ports. Altogether, we travelled a distance of 63,700 nautical miles, or some I 18 , o0o kilometres; that is to say, about three times round the earth at the Equator. Our propellers made nearly 85,000,000 revolutions, and our turbines over $10,000,000,000$ ! 


\title{
OBJEGTS OF THE EXPEDITION
}

\author{
By A. F. Bruun
}

Earlier deep-sea expeditions, such as the Challenger and those of the Prince of Monaco, although they had explored depths down to between 5,000 and 6,00o metres, had fished only a few times and with small gear. When the Galathea Expedition was planned nothing was known about the fauna in depths beyond 6,00o metres, and very little of that in the reaches between 4,000 and 6,000 metres. Indeed, it was problematical whether at the very lowest depths there was any life at all. These regions - below 6,ooo metres - make up I.3 per cent of the earth's surface, an area which may not sound very much, but which is over 4,000,000 square kilometres, or nearly half that of Europe.

The first knowledge of these abyssal waters was obtained as late as 1948, when the Swedish Albatross Expedition succeeded in making a single trawl north of the West Indies at depths ranging from 7,625 to 7,900 metres.

Accordingly, the primary purpose of the Galathea Expedition was to explore the ocean trenches in order to find out whether life occurred under the extreme conditions prevailing there — and if so, to what extent. Our second object was to seek more information, by making greater use of large-scale dredging implements than had been done in the past, as to whether, and to what extent, there are large and active animals in the abyss, also at somewhat higher levels. Thirdly, we wished to study the bottom fauna; that is to say, to gauge the amount of living animals per square metre of sea-bed, by a method first employed in Danish waters. It seemed a natural task for a Danish expedition to extend this method to the unknown decp and the unfamiliar coastal waters in the tropical regions which we proposed to visit, and which had never been explored by such methods.

Since the projected deep-sea research called for a large vessel able to carry heavy gear, it followed that there would be relatively good space on board, which in turn would provide facillities for undertaking a number of other objects, both scientific and representative.

The objects of the expedition are summarized in these extracts from the instructions given to the leader by the committee:

I. The scientific objects of the expedition are to carry out biological and oceanographical research and make collections, principally in abyssal 
waters. Particular attention will be paid to the sorting and studying of the material on board. The following objects and departments will be the subject of special concern:

a. Benthic fauna at depths beyond 4,0oo metres will be explored, both by the use of dredging or trawling gear and by grab.

b. Fishing for large fish and cephalopods with long line, trap, trawl, etc. will be attempted at all depths beyond $\mathrm{r}, 000$ metres.

c. Quantitative examinations of the bottom fauna in tropical, subtropical, and south temperate waters will be attempted, such examinations to take the form of sectional examinations using quantitative grabs, working from the coast outwards, and down to as great depths as possible. They will concentrate on particular areas off coasts of various types (river cstuaries, sandy shores, etc.). Comparative studies will be attempted of continental east and west coasts, etc.

d. Bathypelagic collections, supplemented by plankton collections in the surface layers, will be made in association with production-biological research. Collections of neritic plankton will be made in certain selected, tropical areas, and near isolated islands.

e. Every effort will be exerted to elucidate the ecology of deep-sea organisms by studying the contents of stomachs, possibly also by physiological examinations, preservation of sexual organs (by special methods), etc.

f. Hydrographical investigations will be undertaken as required by biological research.

g. Geomagnetic surveys will be carried out in the abyss. Variation tests will be made to the maximum possible extent.

h. When in port, collections will be made in the littoral zone, though chiefly in less well-studied regions, off isolated islands, etc.

i. Only occasional land collections will be made, and these must not interfere with the primary object of the expedition. In south boreal regions, however, and off isolated islands, more attention will be paid to land collecting, especially of soil microfauna.

j. In so far as is possible without detriment to its primary purpose, the expedition will place itself at the disposal of such scientists as may wish, in association with the expedition, to make special studies of a biological, oceanographical, or ethnographical nature.

In so far as is possible without detriment to its primary purpose, the expedition will endeavour to procure ethnological, historical, and similar material, possibly in exchange for similar Danish material.

2. In addition to its scientific objects, the expedition will endeavour to spread a knowledge of Danish culture and economic life by means of 
lectures, films, etc. It will seek contact with Danes in overseas ports. In former Danish colonies it will endeavour to procure illustrative material and if possible will collect Danish relics, at the responsibility of the leader and the ship's commander.

Other work permitting, the expedition will take short educational films of places visited and will endeavour to have recordings made of important events, interesting visits, and the like, for broadcasting by the Danish radio.

It will be clear from the above that a variety of tasks fell to the expedition besides its primary objects. Obviously, it was impossible to discharge all of them, if only because of the shortage of time. As originally planned the expedition should have lasted 24 months, but, as already related, we were a fortnight late in starting and had to econonize and cut the expedition short by three months. On a world voyage a certain amount of time is taken up in navigation and this cannot be curtailed. More time is spent in port on provisioning and repairs, shore leave for crew, routine and emergency inspections, and so forth, and this too cannot be much reduced. Consequently, the period of three and a half months that was lost was taken almost entirely from the working time, the programme being cut correspondingly.

The chief credit for discharging the tasks as described in the chapters that follow is due to the interest and spirit of cooperation. shown by an increasing number of people, from the time when Captain Greve first listened to my vague outlines of a deep-sea expedition, many years ago, till the realization of all our dreams in a fully manned and well-equipped ship. To be in charge of such an expedition on the day of our departure was a heavy responsibility. But soon the burden was shared by all on board, just as all may take justified pleasure in the results achieved. 


\title{
ECHO-SOUNDING
}

\section{AND HYDROGRAPHICAL STUDIES}

\author{
By A. Killerich
}

For as long as man has sailed the seas he has naturally acquired knowledge of depths of water ncar coasts, where there was reason to be on his guard. But once he was clear of land and sounding ceased to be necessary his interest in exploring the sca diminished, and was never strong cnough to make him stop and measure its depths.

So it remained for many centurics until the first, ineffectual attempt to ascertain ocean depths was made by Magellan, on his voyage round the world. When passing the Tuamotu Islands in the south-east Pacific, in $152 \mathrm{I}$, he caused his ro leadlines to be tied together to form a total length of 700 metres; but failing to reach the bottom with this, he simply concluded that he had found the lowest ocean depths. The first fairly reliable oceanic soundings were made by Sir James Ross in 1840 . But though methods steadily improved, every measurement which depended on lead and line was so laborious and took so much time that the charted soundings of the ocean bed remained extremely sparse until the development of the echo-sounder in the nineteen-twenties. This was the invention of the Frenchman P. Marti and was first used in I9I9.

The principle of the echo-sounder is based on the simple fact that sound travels through water - as through air - with a definite velocity, in this case about 1,500 metres per second. If it takes one second for a sound impulse emitted from a ship to reach the bottom and return, it follows that the depth is 750 metres. The sound transmitter is either a diaphragm or a column of nickel rings, rapidly vibrated by electricity. A corresponding installation on the opposite side of the ship picks up the echo and transmits the impulse to the bridge, where it can be read. In older receivers a pointer moves rapidly round a graduated dial, the moment of reception being indicated by a brief flash. Instead of observing the flash it is possible to hear the echo on earphones, while watching the pointer. This method demands much practice and close attention on the part of the observer, and no matter how skilled he is the reading will always be subject to a good deal of uncertainty. Consequently, in newer types the pointer records the depths on a strip of paper, and as the paper moves forward at a constant speed the result is a curve of points showing the profile of the sea bed over which the ship is passing. In this case accuracy depends en- 

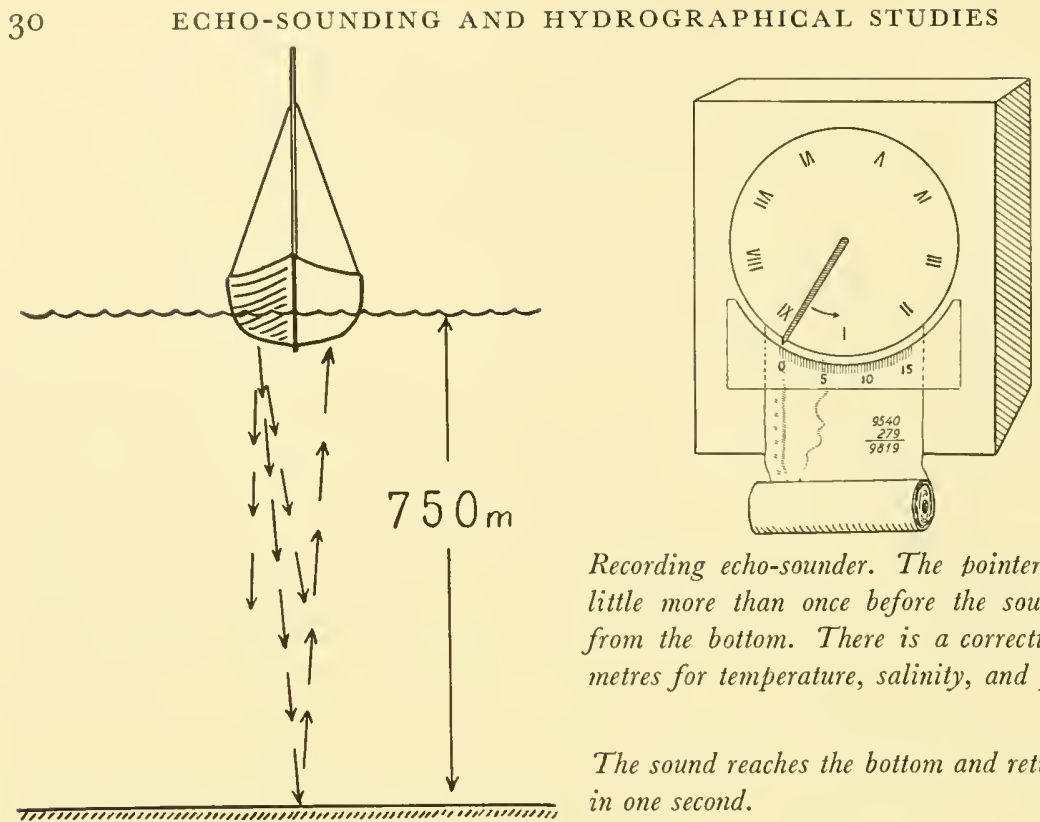

Recording echo-sounder. The pointer rotates a little more than once before the sound returns from the bottom. There is a correction of 279 metres for temperature, salinity, and pressure.

The sound reaches the bottom and returns in one second.

tirely on the installation, and in particular on the stability of the motor and paper. Echo-sounders of this type are now installed in nearly all ships, cargo as well as passenger, though usually their range is restricted to a depth of a few hundred metres.

It is vital to an oceanographical research ship that she should be able to obtain the maximum possible knowledge of the topography of the ocean floor, if she is to avoid the risk of having her gear destroyed. A cardinal feature of the Galathea's equipment, therefore, was an echo-sounder of the very latest type, a self-registering unit specially constructed for this expedition and powerful enough to record the greatest depths without difficulty. The makers were Kelvin-Hughes Ltd. of London.

The sound impulse is a high-pitched whistling tone of Io,00o oscillations per second, produced by a column of nickel rings surrounding an electric coil. Behind the rings is an air-charged reflector that concentrates the sound waves in a beam which, through the ship's bottom, is directed vertically into the water, with a dispersal of only $8^{\circ}$ from the vertical. This transmitting mechanism is mounted on one side of the ship's bottom, where in place of one of the iron plates is an unpainted stainless steel plate six millimetres thick. The receiver is identical in form and is mounted on the opposite side of the ship's bottom. The impulse received is transmitted by way of a transformer to the bridge and is there recorded. The right-hand figure gives a rough idea of the recording mechanism. It 
takes the pointer exactly 12 seconds to go round, and cach time it passes zero it marks a dot on the paper, a sound impulse being dispatched towards the bottom at the same time. The marking of the paper is caused by an electric current flowing at the moment of transmission and reception from the pointer through the paper to the paper roller. The paper is kept moist, and as it is impregnated with potassium iodide and starch, a mark is left at the point where it is pierced by the electric current. By means of the transparent scale fitted to the apparatus, the depth is read at brief intervals and recorded on the paper direct. In later supplementary readings of the echo curve a loose scale is used which is rather shorter, corresponding to the contraction of the paper as it drics. But as paper does not always act uniformly, even when of the same make, and furthermore is affected by the climate, the original readings are always to be regarded as the correct ones, later rcadings being adjusted accordingly.

The iodine marks on the paper will gradually evaporate and fade; consequently, it is necessary to go over the curves with a fine pencil if they are to be preserved.

It is a complicating factor in echo-sounding that the velocity of sound varies with the nature of the water, being greater with greater warmth, salinity, and pressure. Readings must therefore be corrected in accordance with tables provided for various regions.

The installation functioned perfectly throughout the expedition; and as

Time and depth are recorded on the echo-sounder's paper every quarter of an hour. An electric current passes through the flex to the pencil, and the writing medium is iodine.

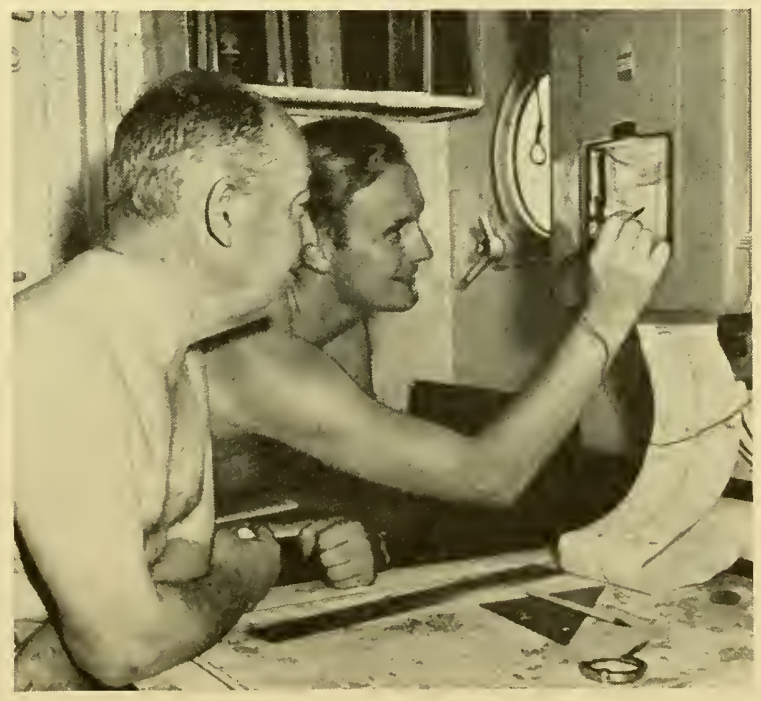


speed of rotation was checked several times daily with the aid of a stop watch and a chronometer, and adjusted to give a maximum margin of error of \pm 0.2 per cent, the Galathea's soundings may be considered extremely accurate.

The echo-sounder was in continuous operation both while the ship was under way and when we were working at stations, with the result that our knowledge of the ocean floors has been increased by curves covering many thousands of kilometres. While in general the registered depths agree with previously recorded measurements, we also found "new" submarine mountains as well as deeps greater than any before known. Our first big discorery was a mountain 2.800 metres in height which rises stecply in the Indian Ocean between the Seychelles and Ceylon. from an otherwise level bed 4.000 metres deep. Our most exciting operation. however, was the sounding of the great troughs in the Pacific, notably that of the Philippine Trench.

This, which at the time of our researches was regarded as the decpest trench on earth, runs parallel with the eastern side of the Philippines, 50 - I oo kilometres from land. Its great depth was first observed by the German Planet Expedition in I912. when 9.789 metres was measured by wire-sounding. The next sounding was made by the German cruiser Emden on April 29. 1927. when a depth of 10.800 metres was found at two points a few nautical miles south of the Planet Deep. For years these two very deep soundings have appeared on charts and in books as the greatest ocean depths. However, doubts have arisen as to their reliability, and it has been pointed out that the Emden employed a non-directional beam, so that misleading echoes may have been obtained from slopes on the bed well to the side of the ship's position. The Dutch research ship Ifillebrord Snellius (I930), the U.S. naval vessel Cape Johnson (I944-45), and our own Galatheo all made careful soundings round the Emden's position, and all agreed in finding a depth of just orer 10.000 metres. The greatest depth found anywhere in the Philippine Trench by the Snellius was 10.160 metres: but in I945 the Cape Johnson, at a position some 40 nautical miles north of that of the Emden, measured 10.197 metres with a directional echo-sounder, though using headphones. This was the greatest known depths in the Philippine Trench.

It is possible, however, that the position of the Cape Johnson when she made her deep sounding was three and a half nautical miles in crror. All expeditions, unfortumately, experience the same difficulty of accurately determining the ship's position and keeping that position while working at their station. The Galathea had to contend with several periods of 
Four sections of the bollom of the Philippine Trench at distances of a little over roo kilometres. The bollom of each block is 10 kilometres deep.

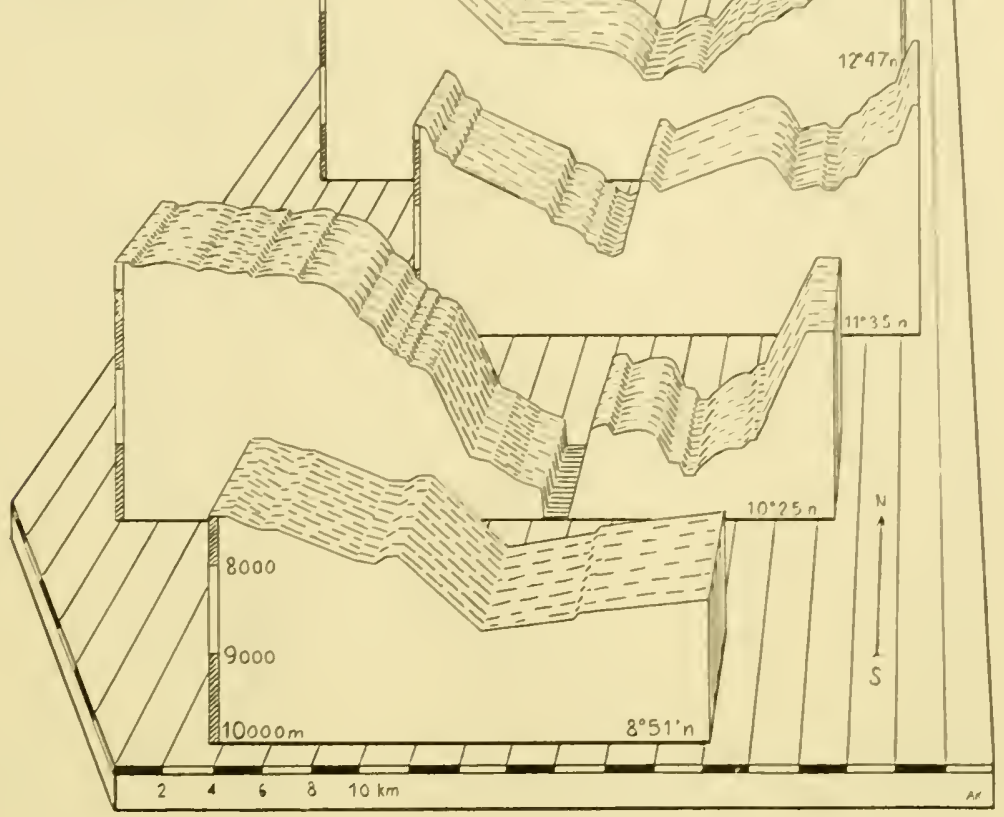

overclouded skies which precluded astronomical observations for days on end; and as the current often ran at a speed of one or two knots, mostly in a westerly or south-westerly direction but very irregularly, many conjectured positions are rather uncertain and echo curves obtained on these days can only be supplementary to more accurately determined sections.

The large number of sections which we sounded across the trench provided us with so much information about the course of certain characteristic features that the position of many sections could actually be checked by the form of the echo curves.

The trench extends from about latitude $13^{\circ} 30^{\prime} \mathrm{N}$ to about $4^{\circ} 30^{\prime} \mathrm{N}$ - that is, not less than 540 nautical miles ( 1,000 kilometres) - at depths beyond 7,500 metres. But the actual deep on which research was mainly concentrated is the stretch of about 300 kilometres along the northern tip of Mindanao. The above diagram shows in schematic form some typical sections of the trench at intervals of rather more than roo kilometres. From the coast the floor shelves more or less steadily down to a 
depth of 6,00o-70oo metres, after which it drops quickly, by means of stecp cliffs of varying height alternating with terraces, down towards the bottom of the trench at a depth up to about ro kilometres.

From the terraces we got clear echoes revealing a gradient of less than one in five or one in six $\left(\right.$ some $\left.10^{\circ}\right)$; but whenever we passed over the steep cliffs thcre was a total absence of ccho, and it was of no avail to reduce speed or stop. Echoes returned just as suddenly, but at a new level, as soon as we were once more over a bottom with a sufficiently gentle slope. The Cape Johnson often lost the echo in the same way and had to send out impulses up to ro times before getting any response. The presumed reason was that the bed was too soft to throw off an echo. The reason suggested by our experience is that in getting an echo from the tenth cmission when she had not done so from the previous ones she was by then located over a sufficiently level floor. We alwars got a clear echo from a level bed, regardless of the softness of the bottom material brought up by our gear.

The lowermost terrace on the western incline of the trench was frequently so ncar to the bottom that parts of the two levels fell within range of the echo-sounder simultaneously (the range being the circle of horizontal floor from which it is possible for the ship to obtain an echo). As a result we got two series of dots on the echogram, showing two depths with a difference of perhaps 200 metres, a picture so characteristic that we were able to take it as a sign that the current was carrying us too far west. The eastern incline, on the other hand, often had such high cliffs that for a time we got no echo at all. Since all work with trawl or grab is confined to the flat floor of the trench, and this is mostly very narrow - down to as little as 750 metres - these "cliff echocs" are very valuable; indeed, are the only means by which it is possible to navigate with sufficient accuracy.

The eastern slope is more irregular than the western slope, not only in regard to gradient but also in the course which it takes along the trench, and in some places there seem to be promontories, in others small plains io kilometres in depth. It was near one such plain that the Cape Johnson found the greatest depth; namely, 10,497 metres at latitude $10^{\circ} 27^{\prime} \mathrm{N}$. And as we found suitable trawling ground at the same position, we cruised about the area, crossing the indicated position of the Cape Johnson on a number of occasions. We found the level floor mostly at a depth of about I 0,000 metres, and the greatest depth registered on our expedition 10,265 metres - was at this place, about three and a half nautical miles south of the Cape Johnson's position. As the Cape Johnson's position is 
uncertain to that extent, it is possible that our sounding was made in the immediate vicinity of her actual station. On the other hand, she may have been further north, in which case we failed to strike it on our cruise. There is thus no basis for either confirming or invalidating the Cape Johnson's sounding, so that we must assume the existence, either inside or just outside our trawling area, of a restricted pocket of 10,497 metres, which thus remains the greatest known depth of the Philippine Trench. However, since the discovery of depths of 10,863 metres in the Mariana Trench, by the British Challenger Expedition in the autumm of $195^{\mathrm{I}}$, the Philippine Trench has lost its supremacy as the greatest ocean deep.

The eastern slope of the northern and central portion of the Philippine Trench rises steeply from the bottom for the first 1,000-I,500 metres, but then, immediately to the east, falls again by $500-700$ metres to a new valley parallel with the main valley. The greatest depth measured by us here, opposite the great depths in the main valley, was about 9,500 metres. Further south we had no opportunity of exploring it; but our southernmost section, at about latitude $9^{\circ} \mathrm{N}$, shows the valley as having no cliff to the east but giving place immediately to a level floor at a depth of $8,500-9,000$ metres.

A comparison of all the sectors obtained by the Galathea Expedition gives the general picture that, though the stretch of the Philippine Trench between latitudes $12^{\circ} 50^{\prime} \mathrm{N}$ and $9^{\circ} \mathrm{N}$ is one coherent and extensive depression of the ocean bed, it falls into several sections. Southward to latitude $10^{\circ} 45^{\prime} \mathrm{N}$ it seems to proceed regularly, its depth steadily increasing from 8,000 metres to 10,000 metres. At this point irregularities in the eastern slope cause a sudden contraction of the valley, but then follow the great depths of the central valley. Further south come fresh irregularities and a stretch less than 10,000 metres deep. Between lalitudes $10^{\circ} \mathrm{N}$ and $9^{\circ} \mathrm{N}$ we have two areas where the trench widens out a little and where it just passes the 10,000 -metre mark, the more northerly of the two areas being at about the position of the Emden.

This picture of the topography of the Philippine Trench, based on the Galathea's echogram, conforms extremely well to the mode of its formation. Like other trough faults along the fringe of the ocean, it originated at the same time as the inland mountain ranges, and in association with volcanic eruptions and earthquakes. There are still 20 active volcanoes in the Philippines and, on an average, between one and two recorded earthquakes annually with their centres along the western edge of the Philippine Trench. The terraced structure of the trench sides is due to displacements in the earth's crust along lines of fracture. That such dis- 
placements still occur, and are liable to alter the depth levels at any time, is shown by the fact that we trawled fresh fragments of rock at the very lowest depths. Another interesting fact is that the centres of earthquakes have been recorded at the same place as many as five times in ro years. It is precisely at these brittle spots in the earth's crust that the character of the Philippine Trench suddenly changes.

Just as we must have a knowledge of the depths in order to work the gear, so too we must know the physical and chemical nature of the water if we are to judge the biological potentialities. Consequently, we carried out continuous hydrographical studies in close association with the biological work. The choice of hydrographical stations was dictated by the desire to obtain the utmost possible information about the sea area concerned; but, the Philippine Trench apart, we established, as a general rule, only one deep station in each area, owing to shortage of time.

Some information about water at a depth is given in ancient literature; Aristotle, for example, deduced that deep water is cold from the fact that a plummet is cold when it comes up. Thermometer readings are of far more recent date, and the technique remained imperfect down to the adoption of the reversing thermometer in the present century. The first was designed in 1874 by Negretti and Zambra of London. The instruments now made, in several countries, work to an accuracy of $0.0 \mathrm{I}^{\circ} \mathrm{C}$. 'The distinguishing feature of a reversing thermometer is a constriction in the bore and a back-twist between this and the bulb. When the thermometer has adjusted itself to the underwater temperature, it is reversed. The mercury column then breaks at the constriction and runs down into the opposite end of the bore, where the temperature is read off a scale which is now upright. An auxiliary thermometer mounted alongside the main instrument gives the temperature on deck, and it is then possible to reckon the extent by which the temperature recording of the main thermometer has changed since its reversal under water. The two thermometers are enclosed together in a stout glass sheath, factory-tested for a pressure of 500 atmospheres, which is the pressure at a depth of 5,000 metres. The object of the sheath is to prevent the thermometer bulb from being compressed and squeezing the mercury too far up the bore. A protected thermometer mounted alongside an unprotected one is the means of checking the depth of the instruments.

The thermometers are mounted in pairs on a reversing water bottle, which when lowered is open at both ends. By means of a messenger weight which is slid down the wire the bottle is made to reverse, and the same operation closes the end plates on the sample of water inside. Below the water 
bottle is another weight, and the reversing of the bottle releases this, which slides down the wire and releases in turn another bottle. The process may be continued, so as to give temperatures and water samples from anything between five and ro depths in one operation.

Reliable reversing thermometers and water bottles of this kind have been the principal means by which expeditions such as the Meteor, the Dana, and the Snellius have provided us with knowledge of the hydrography of the oceans even at great depths.

The sea, like the atmosphere, is divided into two strata. The rather narrow upper stratum is called the thermosphere, the rest down to the bottom being the psychrosphere. In the thermosphere are located all the currents which we observe at the surface and which are mostly driven by the prevailing winds; for instance, the great circumpolar current flowing west to east southward of the continents, the equatorial currents flowing east to west on both sides of the Equator, the Gulf Stream in the Atlantic, and its counterpart the Kuro-Siwo in the north Pacific. As the thernısphere currents are only 400 metres deep at most, the Galathea Expedition was chiefly concerned with the hydrography of the psycrosphere.

It is a common feature of all the oceans that psychrospheric water moves very slowly, so that water masses bearing salts and oxygen which have sunk down from the thermosphere may take years to move from one ocean region to another.

The three world oceans all extend southward to the Antarctic coast. In a way they may be regarded as three vast bays of a great southern, circular ocean, up to $4,000-5,000$ metres deep, which forms a mutual connection. Owing to their different sizes and their connections with various secondary seas they have their own special hydrographical characters; but because the currents of this southern circular ocean, from surface to bottom, hourly carry about 350 cubic kilometres of water in an easterly direction, the three oceans strongly influence one another.

The northward extension of the Atlantic (to Greenland, Iceland, and the Faroes)

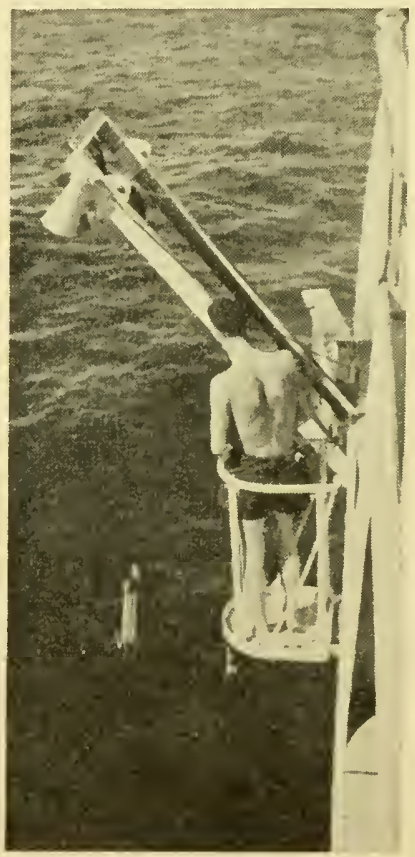

Reversing bottle coming up in released position. 
is greater than that of either of the other oceans, and it gets deep and bottom water from the north as well as from east and west. Consequently, it is in the Atlantic that we find the greatest renewal of the psychrospheric water masses and the most active horizontal interchange of water in the abyss. The North Atlantic abyssal current is supplied by the sinking of cold water in the north-west and of highly saline water from the Mediterranean. It has a temperature of $2-3^{\circ} \mathrm{C}$, a salinity of about 34.9 per thousand, and an oxygen content exceeding that of any other abyssal current. It is the greatest of all oceanic currents, moving southward at depths between 1,500 and 4,500 metres to about latitude $40^{\circ} \mathrm{S}$, where it rises above the cold water that sinks near the shores of the Antarctic continent and penetrates to all the deepest parts of the Atlantic along the bottom. The North Atlantic current carries some of the water from the Antarctic bottom current southward again, along with water from the overlying layer; and, after mixing with these water masses and attaining a temperature of $0.5-2.0^{\circ} \mathrm{C}$, a salinity of about 34.75 per thousand, and a persistently high oxygen content, reaches the Antarctic regions, where it forms the main constituent of the circumpolar current which supplies the abysses of both the Indian Ocean and the Pacific Ocean with large volumes of water rich in oxygen and plant nutrients.

In the Indian Ocean also there is a sinking of cold bottom water along the Antarctic coast, but here a southward-flowing current like that in the Atlantic is absent or nearly absent. It is true that a current of highly saline water poor in oxygen comes in from the Red Sea, but, owing to the small volume of water involved, its effect south of the Equator is slight. The great bulk of the deep water in this ocean is influenced by a flow from the Atlantic.

While current systems in the upper layers of the Pacific are more complex than they are in either of the other oceans, the characteristics of the deep layers are great horizontal and vertical uniformity and very slow movement. Here, of course, there is no significant influx of new water masses except for those coming in with the Antarctic circumpolar current. The oxygen content and salinity of the deep water layers reveal a very slow, circular, and clockwise movement; that is to say, northward in the western part and southward in the eastern part of the ocean. But though these water masses will take decades and even centuries to reach the various regions of the Pacific, we shall find at all the deep levels water which can be traced back to its origin in the southern Atlantic, in spite of the volumes which have flowed in on the way.

On the Galathea Expedition we took about 270 stations: 200 in connec- 


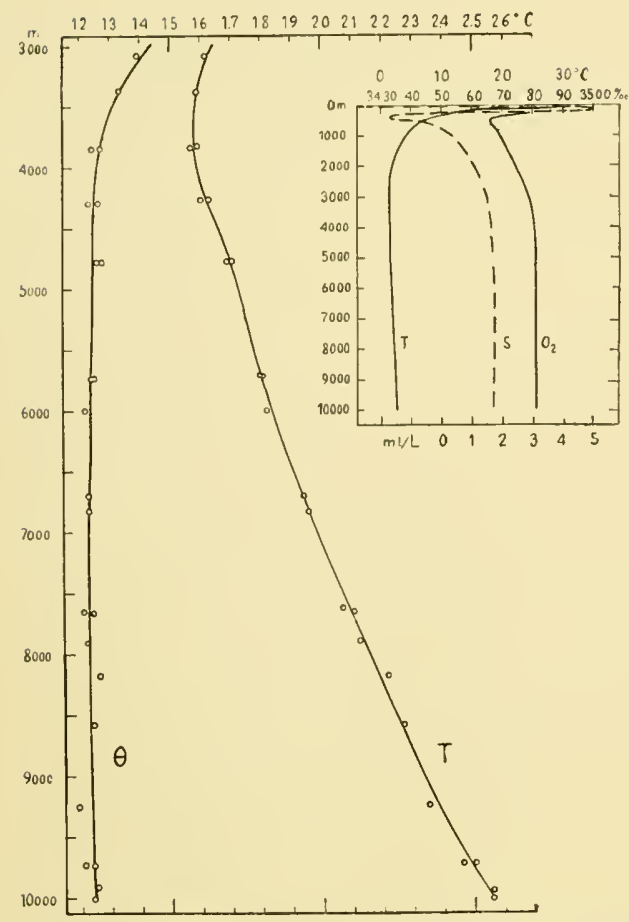

Temperature $(T)$, salinity $(S)$, and oxygen content $\left(\mathrm{O}_{2}\right)$ in the Philippine Trench. $\Theta$ is the potential temperature.

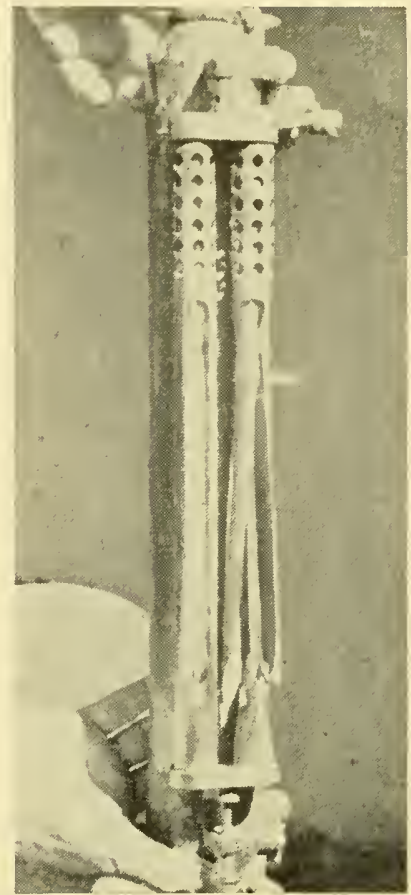

Thermometers crushed by the pressure of the water.

tion with light and production measurements in the upper layers, and 70 down to the bottom, some at great depths.

At deep stations we would use four or five reversing water bottles to the wire, with two thermometers mounted on each. But when five bottles and 10 thermometers were lost owing to the breaking of a wire with 3,000 metres paid out, and when some other thermometers showed doubtful accuracy, we were obliged increasingly to use only one thermometer to the bottle.

The first station was in the Bay of Biscay, where the high oxygen content and salinity of the North Atlantic were immediately apparent at deep levels; but here a comparison with the data of earlier observations would be interesting. Off the west coast of South Africa we encountered the cold but highly nutritious surface water which is sucked up from some depth by the persistent easterly winds; and the deep water off the southern tip of Africa clearly displayed the cold mixture of the eastwardbound, south circumpolar current.

It was with considerable excitement that we began work, on July i 2, 
195 I, in the deep water of the Philippine Trench, where previously only the Snellius Expedition had recorded a full station down to the bottom. Our operations with the uppermost series of water bottles went smoothly and successfully, but in the great depths we encountered every sort of unforeseen difficulty. In the first deep series we lost four thermometers owing to the heavy pressure of the water. One thermometer of the bottle lowered down to 7,700 metres was crushed, and the force of the explosion broke the other (Fig. p. 39). On the same occasion the thermometers of the lowermost bottle, 8,503 metres deep, exploded with a violence which tore off their metal frame. The surface of the bottle showed marks of glass splinters from the thermometers. After this we could not afford to put more than one thermometer on each bottle.

Another frequent source of trouble was the inability of the messenger weights to release the bottles at depths beyond 7,00o metres. The whole series came up un-released on no fewer than five occasions, with the loss of many valuable hours' work. Earlier on, defective release had been caused by the twisting of the tentacles of jellyfish and squids round the wire. They are so strong that they can only be removed with a knife. We had to cut these off here also; yet still the bottles failed to function, and even two weights tied together were ineffective. We eventually located the source of the trouble as the grease in which the funnel of the wire is spun. It was squeezed from the top by the heavy weight of wire; and though the messenger slid without difficulty through the warm upper levels, when it passed through the cold water at 3,00o-4,00o metres the grease which it picked up on the way became stiff and acted as a brake. By constantly wiping the wire while it was being paid out we were able to remove enough grease to enable the weight to slide easily, and the last station in the Philippine Trench was completed without difficulty. Altogether, we obtained four successful series from the deepest layers of the trench, down to a depth of 9,864 metres.

The principal data from the observations in the Philippine Trench have been collated in the figure on page 39. From the outline diagram on the right it will be seen that the high surface temperature of about $29^{\circ} \mathrm{C}$ extends no further down than 100 metres; already at 300 metres the temperature is only $10^{\circ} \mathrm{C}$. The lowest temperature $\left(1.58^{\circ} \mathrm{C}\right)$ is at nearly 4,000 metres, after which there is a steady rise of nearly one degree down to the bottom. The salinity at the surface is comparatively low, as it is everywhere near the Equator. A small maximum is found at I $5^{\circ}$ metres, and after the minimum at 400 metres there is a steady progression to the absolute uniformity of the abyssal waters. The oxygen content is greatest 
at the surface and lowest at about 500 metres, where some of the oxygen is consumed by decaying organic matter. Lower down, the southern water rich in oxygen makes itself felt.

The curve $\mathrm{T}$ in the main figure shows, on a larger scale, the temperature from 3,000 metres down to the bottom. Just as the salinity is virtually constant from about 4,000 metres down to the bottom, so in effect is the temperature, despite the observed rise of onc degree. Coming originally from the south at depths round about 4,00o metres, and slowly sinking in the Philippine Trench, the water has been slightly compressed by the increased pressure. Compression causes a rise in the temperature of water as of air; but should the water subsequently rise, the temperature will fall by as much as it previously rose. The term "potential temperature" denotes the temperature of the water if it were raised to the surface. The curve for this temperature $(\Theta)$ is vertical; in short, the water column is in neutral equilibrium, and does not exchange heat with its surroundings.

Only close to the bottom, where the Snellius Expedition had found a somewhat lower temperature, did we find a rise of $0.03^{\circ} \mathrm{C}$ in the potential temperature. Probably there is a slight increase due to heat from the interior of the earth.

Bay of Biscay, $4^{\circ} 6^{\circ} 8^{\prime} \mathcal{N}$. lat., $8^{\circ}$ or' W. long.

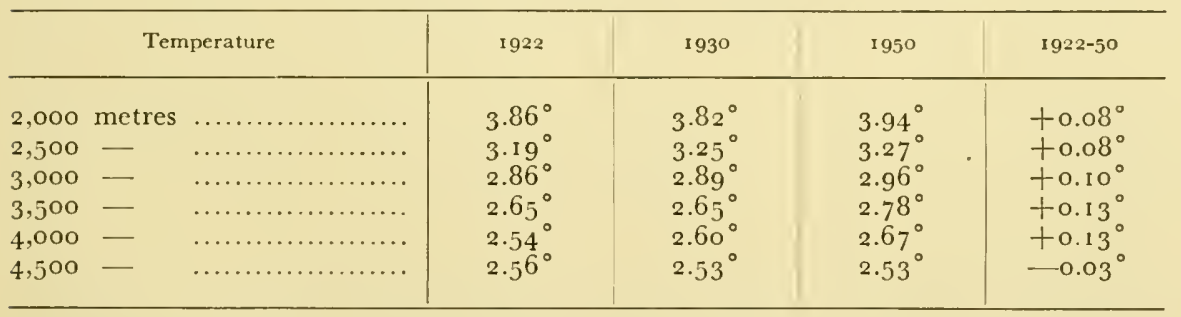

Temperature readings in the Bay of Bisçay: Dana 1922, Dana 1930, and Galathea 1950. Whereas the upper layers of water are subject to irregular fluctuations, partly due to the influence of supplies from the Mediterranean, the temperature in the abyss is very constant. A slight rise of about $0.1^{\circ}$ is observable since 1922 , except at the very bottom.

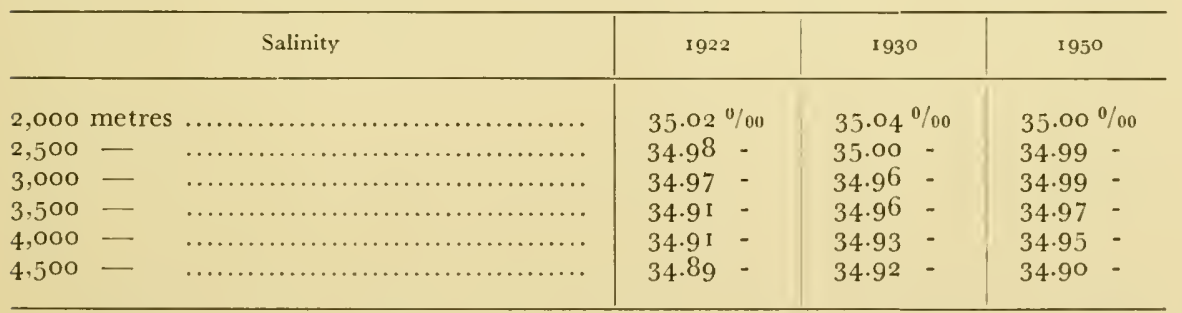

Salinity is determined with exactly the same accuracy as temperature, and this also shows great constancy in the abyss. 


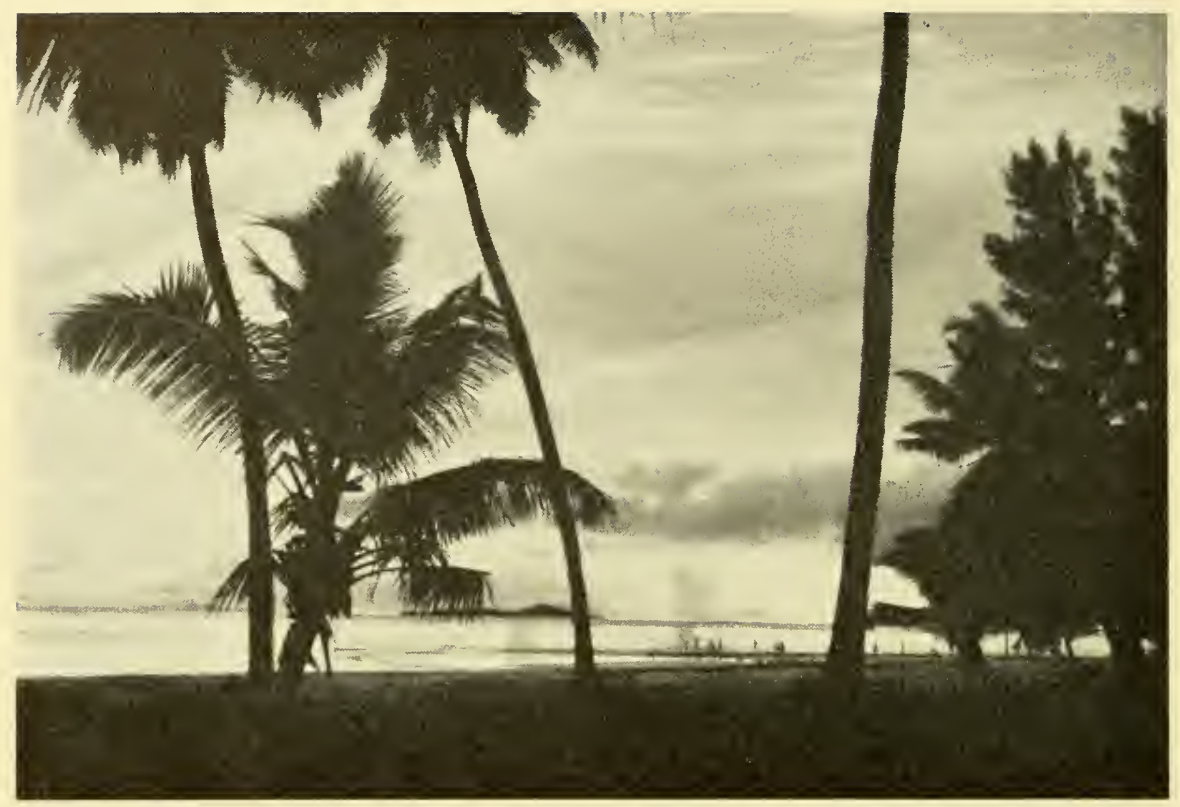

\section{THE SEYCHELLES - \\ ISLANDS OF THE GIANT PALMS \\ By TORBEN WOLFF}

Scattered about the world are islands, or groups of islands, which occupy a special place in natural science owing to their distinctive fauna and flora.

One such group is the Seychelles, situated in the Indian Ocean just south of the Equator and a little over I,00o kilometres north-east of Madagascar. It consists of close on 30 large and small islands which lie on a broad coral-crowned bank several hundred kilometres in length. They are separated by channels between $5^{\circ}$ and roo metres decp and are mostly of granite formation. Their total area is 264 square kilometres.

It was the Portuguese who discovered the islands and they called them the "Seven Sisters". But they were colonized from the middle of the eighteenth century onwards by the French, and renamed Iles Séchelles after a French Minister of Finance of the period. The " $y$ " 
in the name was inserted by the British, by whom they were captured during the Napoleonic Wars. In spite of 150 years of British rule the bulk of the population of 36,000 Negroes and Creoles still speak a French patois, and most of the place-names have remained French.

Many geologists and zoogeographers down to our own time have believed that in the Tertiary period, between 20 and 30 million years ago, a land-bridge connected Africa and India by way of Madagascar and the Seychelles. There is supposed to have been either a southern continent called Gondwanaland or a mythical land of Lemuria, embracing Madagascar, the Seychelles, and the islands of Mauritius and Réunion, which has met with the same fate as the famous lost Atlantis.

However, not only are all these mainlands and islands separated by ocean depths of between 3,000 and 4,000 metres, but recent studies of their fauna and flora strongly contradict the idea of any connection, at any rate since the beginning of the Cretaceous period 60 million years ago.

A study of the fauna of the Seychelles, for instance, reveals a total absence of non-flying mammals, as well as the fact that nearly all the resident species of birds, reptiles, and amphibians are endemic, or peculiar, to this group. Similarly with the insects, 65 per cent. of all species of which are endemic to the islands. These facts indicate that the group has been cut off from immigration for a very long time and so has been able both to preserve ancient forms and evolve many new species and genera not met with elsewhere.

Nevertheless, the fauna of the Seychelles is not typically oceanic like that of, say, Hawaii, where as many as 80 per cent. of the insect species are endemic, and where each endemic genus averages five species against barely two in the Seychelles. Unlike the volcanically formed Hawaiian Islands, moreover, the Seychelles seem to have been broken up into the small islands of the present day at a relatively recent period, by strong denudation and a partial subsidence of an area about twice the size of Denmark. Whereas each island of the Hawaii group has a fairly large element of endemic fauna, indicating that the islands have been mutually isolated for a very long time, the fauna of the Seychelles is astonishingly uniform from island to island.

If, furthermose, we look for the nearest relations to the fauna of the Seychelles, we find that an overwhelming proportion are of Oriental, especially Indian, origin. This suggests immigration from the east or northeast, not necessarily orer a land-bridge but rather via groups of islands, which have now mostly disappeared but which in the past may have crowned the banks and ridges - in particular the Carlsberg Ridge iden- 
tified by the Dana Expedition of I928-30 - which lie between the Seychelles and India.

Similar considerations apply to the flora. Forty per cent. of the species are endemic, but in snite of the luxuriance of the vegetation their total number is small. Doubtless the heavy denudation already referred to has had something to do with this, so that only species which were exceptionally numerous or well equipped in the relentless struggle for existence have managed to survive.

It will be understood from what has been said that we looked forward eagerly to visiting the Seychelles when, late one afternoon at the end of March 195I, we entered the harbour of the main island of Mahé to fill up with oil. Our hopes of finding a distinctive flora and fauna and scenery unlike any other were certainly not disappointed.

During the two-day stay on Mahé the scientists and national-service laboratory assistants made some extremely strenuous collecting excursions in rugged mountain country, and in an oppressive hot-house atmosphere. The object of these as of other excursions was to find animals (and in a lesser degree plants) of outstanding interest, either because they were little known or would provide comparative material for museum scientists at home, or because they were suitable for exhibition in our zoological museums, where - in natural surroundings when possible - they would help to illustrate the variety of Nature.

Our collecting in the Seychelles had the added interest that a number of the endemic species are becoming increasingly rare; indeed, a few birds and amphibians seem in the last 100 years to have been extcrminated. This sad fact is due partly to environmental changes - notably the felling of the tropical rain forest - and partly to the competition for food forced on the native fauna by the introduction of voracious animals such as the tenrec (Centetes) of Madagascar, the black rat, and various other adaptable and aggressive animals.

Some of the scientists of the Dana, which visited the Seychelles on her world voyage in 1929 , had gone on a collecting expedition on the Mamelle Estate, a large plantation south of Victoria, the capital, on Mahé island. Here they had found some of the extremely primitive cæcilians, amphibians with a worm-like life history and appearance except for their jaws and weakly developed eyes. Wishing to emulate our predecessors, we managed after a certain amount of haggling to hire a lorry to take us there at a reasonable charge. The proprietor of the estate, a Swiss named Leyte, proved to be an interesting character. He had lived on the islands for a 
couple of generations and had welcomed the Gcrman decp-sea expedition on the Valdivia in 1899, the Dana Expedition in 1929, and the Swedish Albatross Expedition in 1948, as he now welcomed us. We wcre allowed to go where we liked and to shoot what we liked, with the exception of his poultry.

We climbed a narrow path through an exceedingly fertile, mixed forest of coconuts and other palms, tropical deciduous trees, and giant ferns. In a small grove of nutmeg trees we split up. One party concentrated its attentions on minute animals - mites, spring-tails (primitive wingless insects), tardigrada, and similar disregarded creatures whose importance to zoogeography is often inversely proportional to their size. A second party rummaged among dry-rotten tree stumps, withered leaves, and mould for cæcilians (which we failed to find), and for insects, centipedes and millipedes, wood-lice, and earthworms, as well as in the abundant small streams for aquatic insects, shrimps, and crabs. A third party, consisting of Dr. Volsoe and myself, went hunting for birds, nimble lizards, and dull-green geckos - a kind of lizard with adhesive toes which lives on palm-leaves.

Both then and on a similar expedition the next day we needed all our energy as we climbed about the densely tangled palm forest in extremely rugged and sometimes pathless and trackless country, at a temperature and in an atmosphere as hot, oppressive, and humid as in a very small bathroom when one is taking a very hot bath.

Nevertheless, we succeeded in getting a fairly good collection of reptiles and birds for preserving and stuffing. In addition to various other cndemic birds we found the brilliantly coloured honey-eaters (Cyanomitra dussumieri), tiny, agile birds with long, curved beaks, rather like humning-birds, and we also obtained one of their elaborately woven nests with side entrance. Of the three species of pigeon found, the endemic Seychelle Pigeon Hollandais (Alectroenas pulcherrima) bears the prize; sky-blue with a scarlet crown, it is surely one of the handsomest species of pigeon in the world, as it is one of the rarest. There was also the lovely chalkwhite tern, Gy'gis alba monte, which we were greatly surprised to find breeding in pairs at the top of large trees in the gorges - a somewhat unusual breeding place for a tern! The single egg is laid on the bare branch without semblance of a nest, and strangely enough it seems a rare thing for an egg to roll off.

Easily the commonest of the birds was the beautiful scarlet Madagascar fody (Foudia madagascariensis), which we had also observed in Madagascar, from where it was imported by an over-astute business man. This 
man had got a monopoly of the local rice trade, but his customers had decided to grow their own rice and in the rainy climate had been very successful. The trader's simple response to this was to import a few fodies, which battened on the rice and with the help of innumerable progeny made short work of it, forcing the population to buy from the trader as before or go without. The monopoly has long since been abolished but the fodies have remained and have grown accustomed to other food. We succeeded in bringing down a yellow variety, said to be extremely rare.

On leaving Mahé after these two strenuous days we took with us, as our colleagues of the Dana had done, a male and female of the famous giant tortoises, a gift for the Zoological Gardens in Copenhagen. Their original home is the small island of Aldabra, where, because they are strictly protected, several thousand still survive. A few of them have been introduced into the Seychelles and other islands. Our two magnificent specimens were "folded" on the quarter-deck and transhipped at Colombo, and now live in the best of health in the Copenhagen Zoo.

It is not only the fauna of the Seychelles but also the flora which is exceptional. There is scarcely another place in the Tropics where palms dominate the vegetations as they do here. All six genera of palms native to the group are endemic and also two species of screw pine, a relation of our reed-mace, are found nowhere else. Palms and screw pines are considered to be the most primitive of all arborescent plants. In most other places palms are outstripped by deciduous trees, and the extraordinary abundance of them in the Seychelles, taken together with the great age and isolation of the islands, suggests that they have here found favourable conditions for survival.

Of none is this more true than of Lodoicea maldivica, the palm which bears the largest fruit in the world, the great, legendary double coconut. The only places where this is found growing wild are in two isolated valleys on the island of Praslin and on an adjacent islet. It would be illogical to suppose that it evolved under the conditions and in the limited area where it now grows. It must be considered a last relic of a period in which its distribution was much wider.

The only other places where this palm can be found are a few botanical gardens in the Tropics. A single specimen which grew in the Palm House at Kew has died; and though a few nuts were brought home to Copenhagen by the Dana, all had lost their germinating power on arrival.

We decided to stop at Praslin and procure a few nuts to take home for a further attempt at germination. 


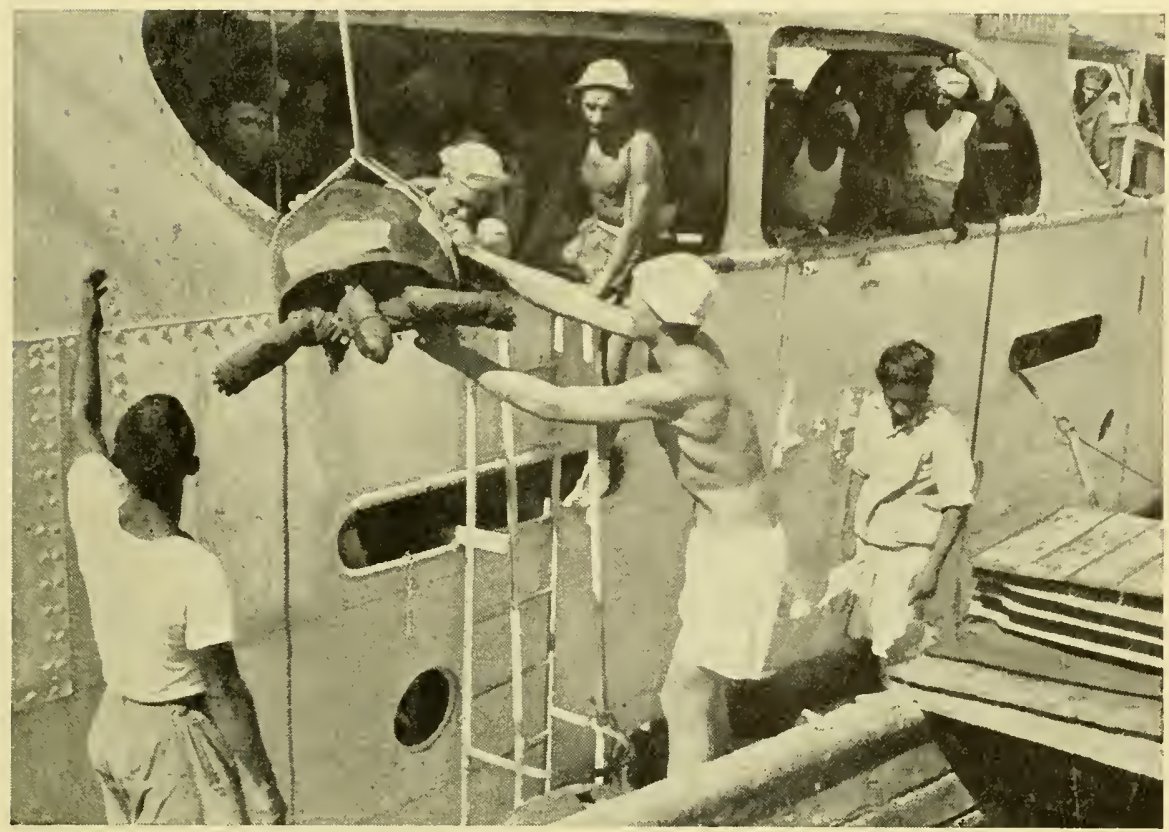

Transhipping one of the giant tortoises at Colombo.

Approaching Praslin from the west we saw the coconut palms growing along the coast behind the white sandy beach, and beyond this towered high hills overgrown to the summit with palms and scattered deciduous trees. A Negro policeman was placed at our disposal as a guide, and, following a beautiful path past well-kept native huts, we made our way southward along the coast. Soon the path turned inland and ascended alongside a mountain stream. Then the bed-rock began to potrude, the coconut palms came to an end, and the first screw pines appeared, with their strange prop roots several metres long. Following the steep ascent, we passed a small plantation of vanilla, which is a climbing orchid. The most aromatic vanilla in the world is said to come from Praslin and this, with copra and oil of cinnamon, is the principal export product of the Seychelles.

The vegetation grew denser as the rain forest closed in over our heads, the forest here consisting of a few deciduous trees and screw pines and many palms of different species. To the right of the path we would get occasional views of a valley and beyond it of a steep, rocky incline, several hundred metres high, where rounded granite formations would stand out like bastions among palms and scrub, and where on the crown grew 


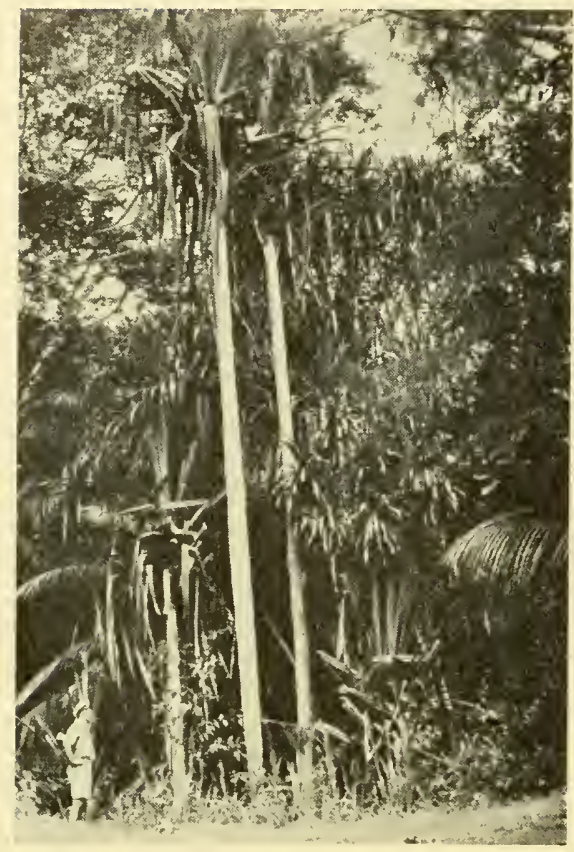

One of the two endemic species of screw pine.

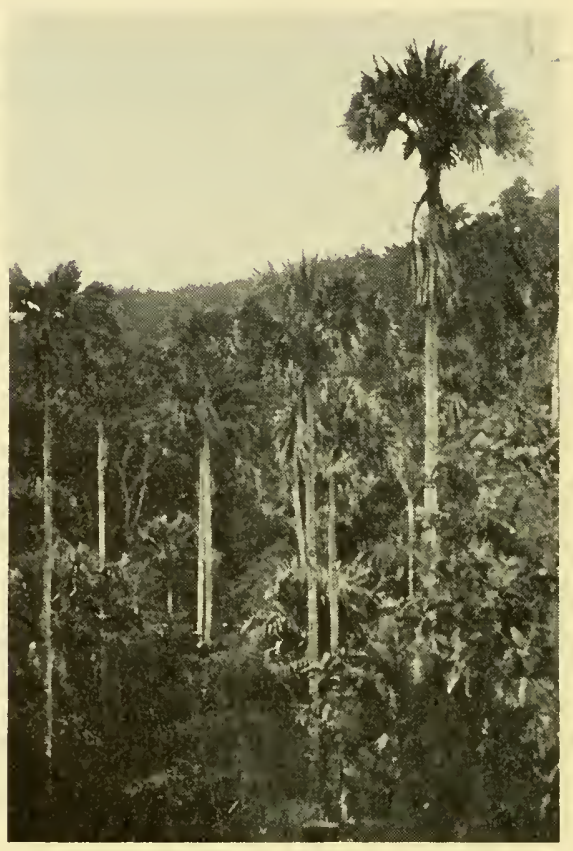

The world's largest palm, Lodoicea maldivica.

the delicately leaved endemic palm Deckenia nobilis. Flocking round some large deciduous trees were flying-foxes, which are big bats with a wingspan of $60-70$ centimetres. They have a steady and easy flight and from a distance bear a striking resemblance to crows. Unlike our own bats they are diurnal and live on fruit. We succeeded in getting within range of one, and it was brought home deep-frozen to our Zoological Museum.

Rounding a bend in the path we caught sight of our first specimen of the celebrated Seychelles palm, the majestic Lodoicea. Unlike the graceful stem of the coconut palm, which is more or less curved, the Lodoicea's trunk is as straight as a mast, and this, together with a height of anything up to 40 metres and an immense crown, gives the tree a regal aspect which justifies its title of the "Queen of Palms". The leaves are fan-shaped, the stalks, which may be up to i 5 centimetres thick and from two to four metres long, bearing a giant grooved leaf-blade which may measure up to six metres long and four metres wide.

The flowers of the male palm are borne in large numbers on an unbranched, fleshy cob as thick as a man's arm and up to twice as long. Though the cobs have a penetrating smell, I saw no insects on them. The 


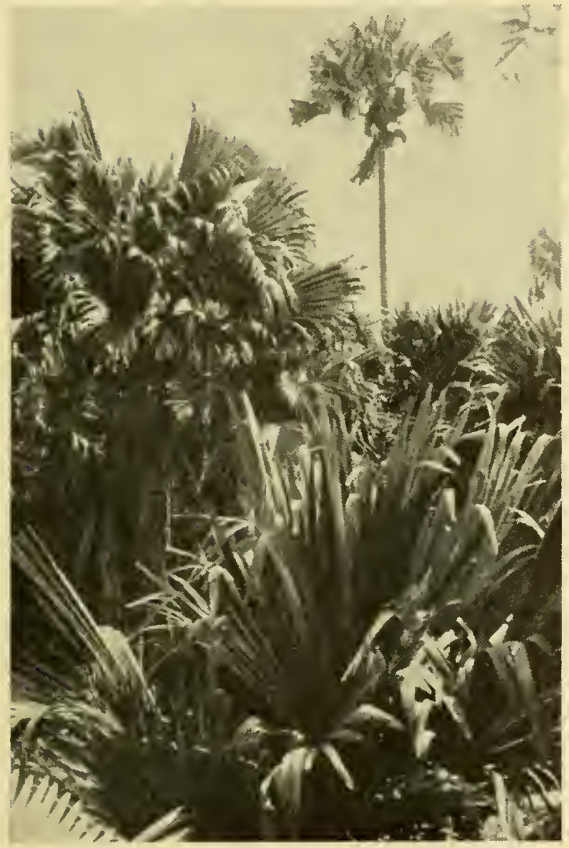

The fronds may measure as much as five metres across.

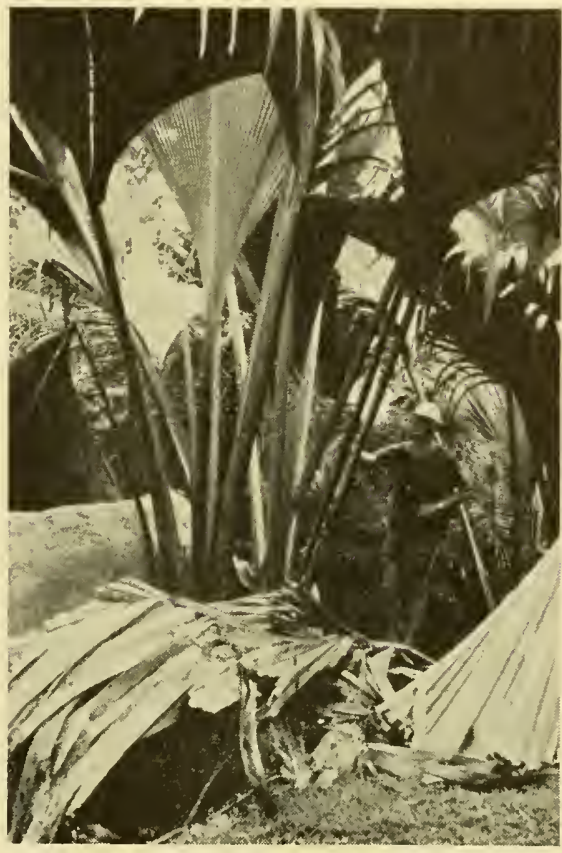

Young palms with leaf-stalks over four metres long. Compare height of man.

female flowers, as big as a clenched fist, are borne on a sinuate or zigzag axis between one and two metres long. But most striking of all is the fruit, which resembles two kidney-shaped nuts joined together, and which has been vividly called "Negro's buttocks". It is both the largest and the heaviest fruit in the vegetable kingdom, being between 30 and 40 centimetres long and weighing 25 kilograms or more. When unripe it is covered by a rather thick layer of coir, which gradually shrinks to a thickness of a little over a centimetre. Under this fibre layer, in fallen fruits, we found a whole animal community of beetle larvæ, earwigs, mites, earthworms, and other creatures which shun the light. Inside the coir, as in the coconut, we get the hard, dark-brown shell (with the characteristic bilobed form. The unripe nut is found, when cut open, to contain a greyish-white, gelatinous endosperm, which gradually hardens from the outside. When fully hardened just before germination, it is nearly as hard as ivory and of the same yellowish-white colour.

No wonder that these immense nuts, so remarkable outside as well as inside, should have given rise to fantastic legends when they were found drifting in the Indian Ocean or washed ashore in the Maldives, in India, 
or as far away as Java. They were called cocos-de-mer (sea-coconuts), or Maldive nuts because of their supposed place of origin. Nobody knew for sure whether they were an animal, vegetable, or marine product. According to one legend they grew under the surface of the sea on giant trees which sprouted from the coral reefs near Java, and when sailors dived for them their branches mysteriously bent down into the deep. According to another, the tree grew out of remote tropical seas and the fabulous animal the griffin lived in its branches, occasionally leaving them to fly ashore and feed on elephants, tigers, and rhinoceroses. Sailors had to watch out or they would be carried on the waves to the place where the tree grew, and then this dreadful monster would devour them. Credited with mysterious powers, these rare nuts were nearly worth their weight in gold, and Indian and European princes would pay fabulous sums for them because they were supposed to provide an antidote against poison. Accustomed to employ poisons against their enemies, they themselves went in perpetual fear of assassination by the same means; but they firmly believed that water when kept in a hollow double coconut was purified and proof against all poison. There were even countries where no person but the king might own one. The flesh was also believed to possess miraculous properties; for example, as a remedy for snake-bite, and by certain Indian sects as an aphrodisiac useful for hanging up in temples in order to promote the fertility of the orthodox. But as soon as the habitat became known and the market was flooded with the nuts

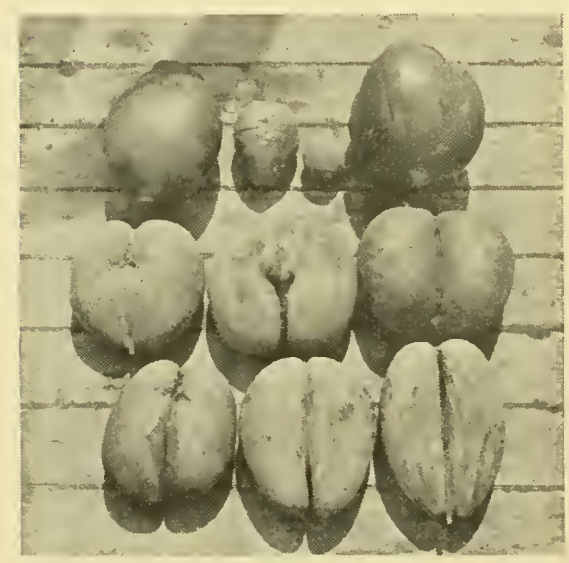

Above, two giant coconuts with coir, and an ordinary coconut with and without coir. Below, six giant coconuts without coir.

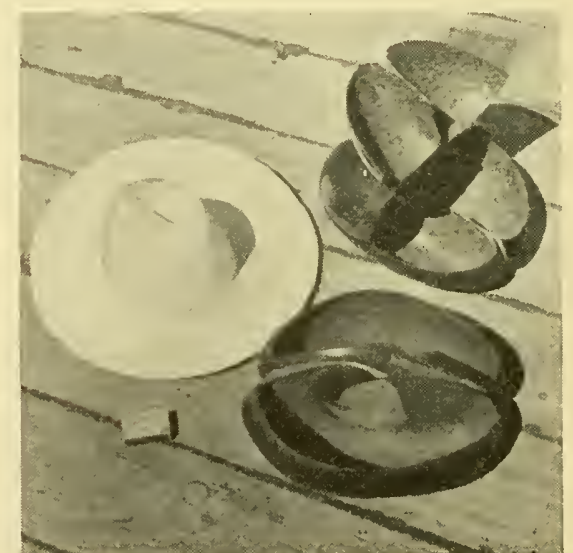

Hat woven from giant palm leaves, and 'boxes' made from hollowed and polished nuts. 


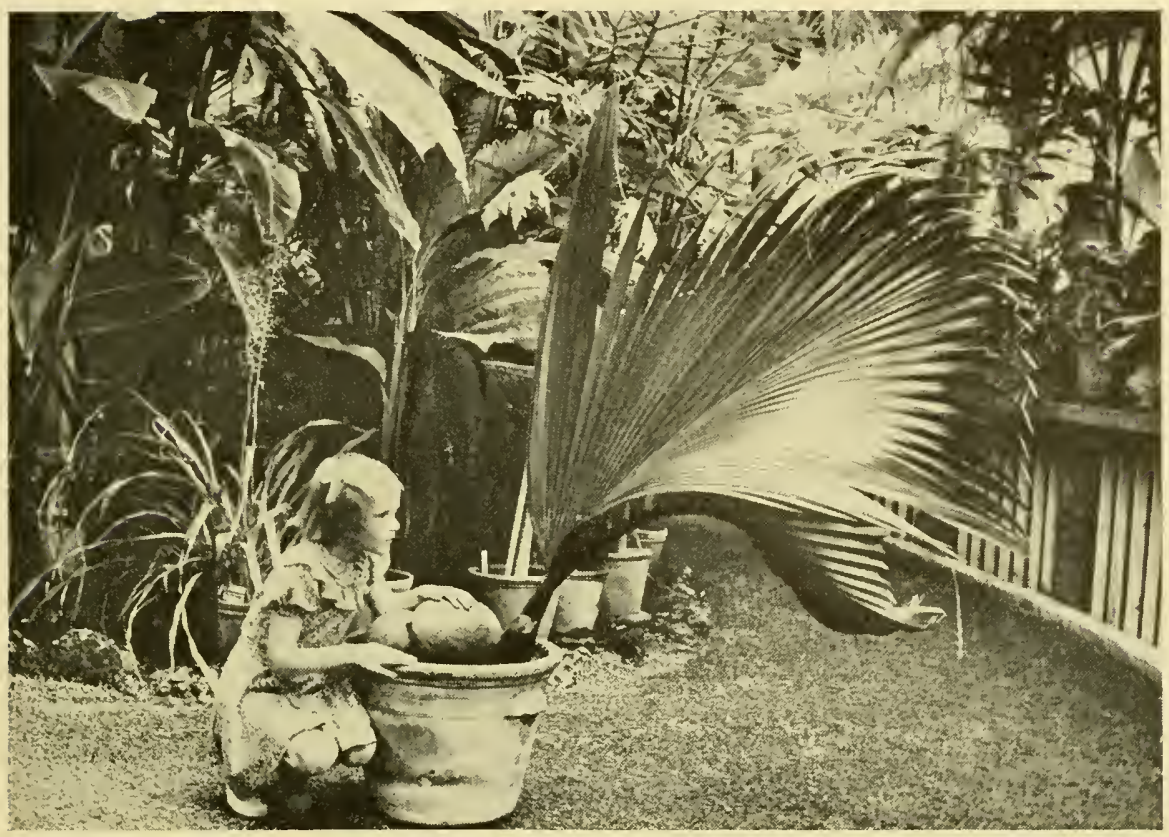

After the return of the expedition four giant coconuts were successfully germinated. The first to germinate was photographed in the Botanical Gardens of Copenhagen in May 1953. The nut and first leaf, partly unfolded, can be seen.

the price, of course, fell heavily. A few unscrupulous Frenchmen tried to bolster the market by setting fire to parts of the Praslin valleys, but fortunately this vandalism was soon stopped.

Today, the two localities on Praslin where the palm grows are owned and controlled by the Government. It is of little commercial value, though the local population use the trunks for house-building, its blackish timber being harder and more weather-proof than other palm timber. The immense leaves make excellent material for thatching native huts, and fine broad-brimmed hats are woven from the leaf fibres. The nut is in little use as food; but while gelatinous the flesh can be refreshing, if rather sweet and insipid. The bulk of the nuts are sent to the main island of the group, where they are made into original souvenirs. There is also a certain market for them among Moslem pilgrims to Mecca. The only water bottles which may be carried are those made by Allah Himself, and the double coconut being in this respect His greatest achievement, it has a high value among thirsty pilgrims.

Let me conclude by trying to convey a picture of the natural habitat 
of this in so many ways remarkable palm. We followed the path already described into the Valley de Mai - May Valley — a somewhat potshaped depression about 200 metres above sea-level, surrounded on all sides by undulating granite formations. At the entrance to this valley we found an almost virgin forest of Lodoicea, unfortunately small in extent, where this is virtually the only vegetation. Here, under the immense leaves which form an arch overhead, a mysterious greenish half-light prevails. Hanging stiffly down the sides of the straight trunks, which stand like pillars in a temple, are giant dead leaves, and others lie like bridges across the little mountain stream which ripples between great boulders. The silence is occasionally broken by the sound of small, dead fruits falling like the crack of down on to the stiff leaves, and once we heard the swish of a double coconut as it fell through the air, followed by the flop which it gave as it hit the always moist soil. Here and there palegreen seedlings peep out from among the boulders, and in places young, non-fruit-bearing palms form a characteristic undergrowth with their great circular fan of leaves which seem to rise straight out of the ground. It stands like a palisade of leaf-stalks four metres high topped by the enormous leaves, and is so entangled with fallen and withered leaves that any idea of trying to force a way through it can be abandoned at once.

On our laborious way back to the Galathea we took with us besides the I 5 giant nuts with which we were loaded the memory of a narrow valley on remote Praslin island, where the mysterious, almost temple-like forest and the myths and legends associated with the great fruits hanging there above our heads had left with us an impression of Nature at once fascinating and unforgettable. 


\title{
MEASURING \\ THE PRODUGTIVITY OF THE SEA
}

\author{
By E. Stemann Nielsen
}

What a dull word "productivity" is! Yet it explains everything: all life on land and in the sea, politics, even wars. For though wars are ostensibly waged for other reasons, their underlying causes are usually "productivity"; too little of it at home and a tempting amount in other territory owned unfortunately by other people.

Replace the word "productivity" with "volume of food" and the meaning is clear.

Man cannot live on inorganic matter but, like other animals, must have organic food; that is to say, carbohydrates, fats, and proteins. Plants are different; they are able to convert inorganic matter into organic, producing both carbohydrates and fats from carbon dioxide and water.

Conversion of inorganic into organic matter, however, requires a supply of energy. When we burn wood, thereby forming carbon dioxide and water, we release energy which may be applied, let us say, to driving a steam engine. It follows from the law of the conservation of energy that the same amount of energy must be supplied when the tree is originally formed from carbon dioxide and water. In fact, it is supplied by the rays of the sun, which are absorbed by the green pigment of the plant. That is why plants need sunlight.

All animals, including man, live on vegetable matter. Herbivorous animals obviously do, but so, ultimately, do lions, though they get their vegetable matter through the medium of herbivora like antelopes and gazelles.

This is the law of all life on land, and the law of life in the sea is exactly the same. Here also plants are the basis of all other life. If there were no plants there would be no fish. In fact, there is an abundance of plants in the sea. This is obvious by the shores, where we find green, brown, and red sea-weed clinging to rocks and stones and marine grasses growing on a sandy bottom, and forming in sheltered places whole "pastures".

Attached plants, however, are not found in deep waters, since marine plants need light just as much as land plants. In Danish waters, for example, there are no attached plants living at depths greater than 30 metres, and though in certain parts of the world they are found below roo metres, 
they obviously have no means of existence in the oceans, where the average depth is more than 4,000 metres.

But if the fauna of the oceans was obliged to live on plants which grow in the narrow coastal fringes marine animals would be rare, at least at some distance from the coast. Yet animals occur in large numbers all over the seas, even in the middle of the oceans. It follows that there must be other marine plants than the ones which we observe by the shores.

If you were to row out from the coast on a summer's day and haul in a bucket of water, it might surprise you to learn that it contained several million plants. This is no exaggeration, and the plants are real ones if, of course, very minute. Their average diameter is one-hundredth of a millimetre. The microscope reveals them as an infinite variety of diminutive green, brown, and golden plants to which we give the same plankton algæ. The word "plankton" comes from a Greek word meaning "wandering", and it aptly describes these plants which are found drifting all over the upper reaches of the seas. But it is only in the upper reaches that they occur, for only there is there adequate light to supply the energy which they require for converting inorganic into organic matter.

Sunlight in penetrating the sea is absorbed both by the water itself and by what it contains, including plankton algæ. We shall be returning to this question later in the chapter.

To supply their requirements of light energy plants need at least one per cent. of the light which strikes the surface. Thus only a thin layer of the total occan masses is able to produce vegetable matter. The uppermost 100 metres, in fact, provides all organic matter on which all marine animals live, including those which inhabit the abyss at 10,000 metres.

The existence of oceanic plankton algæ has been known since the latter half of the nineteenth century, but it is only in the present century that we have gained any real knowlcdge of them. Their production of organic matter - the basis of all marine life — was first measured by the Galathea Expedition, employing radioactive carbon.

In a few coastal waters with a high volume of plankton algx the amount of organic matter formed by them had previously been measured by normal chemical means. When plants assimilate carbon dioxide they give off an equivalent amount of oxygen, and there is a sensitive chemical method by which the amount can be determined. The principle is very simple. Samples of water are taken at various depths and measured for oxygen. Then, in glass bottles, they are lowered to the depths from which they were taken and kept suspended there for 24 hours. They are hauled up again and then measured for oxygen content. Given the difference in 
oxygen content before and after suspension, it is possible by means of a simple calculation to find out the production of organic matter per volume unit at each depth. By adding together the production at the various depths we get a measurement of 24 hours of production under a given surface.

During the war fortnightly tests of this kind were made in the Isefjord, in Denmark, over a period of two years. The annual production under a surface of one square metre proved to be 600 grams, or about the equivalent of a season's production in a Danish cornfield.

Why cannot the same method be employed in the ocean? Mainly because production in the open ocean is spread over a much greater depth. In the Isefjord the productive layer is between five and seven metres thick; in the ocean it is about I oo metres thick. As the measurement can only be made per volume unit the same effort would give only between one-tenth and one-twentieth of the same result, even supposing that productivity area for arca were the same. But as production per area is also considerably less in the ocean than it is in the Isefjord, its measurement by amount of oxygen produced is quite impossible. The method is altogether too insensitive.

The elaboration of new methods based on chemical analyses and sensitive cnough for measuring the production of the ocean must be considered impossible.

A heaven-sent opportunity to devise a new method was provided by the arrival in Denmark, just as the final plans of the expedition were being laid, of the first consignment of radioactive carbon I4. By concentrated effort a new method had been worked out by the spring of $195^{\circ}$; the equipment was obtained and a supply of $\mathrm{C}^{14}$ purchased from America. It is expensive, a quarter of a gram of barium carbonate, of which only about 0.5 per cent. is carbon $I_{4}$, costing about $£_{100}$. But it goes a long way, as only a very small quantity is used at a time. Let us take a look at this material.

The carbon normally occurring in nature is carbon 12 , or $\mathrm{C}^{12}$, the figure indicating the number of particles in the nucleus of the atom. An atom of $\mathrm{C}^{12}$ is made up of a nucleus round which rotate six ncgatively charged particles, the electrons. There are always six electrons to a carbon atom, whether this is $\mathrm{C}^{12}$ or $\mathrm{C}^{14}$, for the simple reason that there are six positively charged particles, the protons, in the nucleus and in an atom there must be equilibrium. It is the fact, that there are six protons in the nucleus which makes it a carbon atom. Every clement has its own particular number of protons in the nucleus.

In the nucleus there are also a number of particles, called neutrons, 
which are not electrically charged. These are without importance to the number of rotating electrons and so have nothing to do with the chemical classification of the atom. Physically, however, it is a different matter; a neutron weighs about the same as a proton, while, compared to the nuclear particles, the electron weighs very little.

In the nucleus of $\mathrm{C}^{12}$, then, there are six protons and six neutrons, totalling $\mathrm{I} 2$; in $\mathrm{C}^{14}$ there are six protons plus eight neutrons, totalling $\mathrm{I} 4$. An atom of $\mathrm{C}^{14}$ thus weighs one-sixth more than an atom of $\mathrm{C}^{12}$.

The various physical modifications of a chemically identical element are known as isotopes, and there are several carbon isotopes; namely, $\mathrm{C}^{10}$, $\mathrm{C}^{11}, \mathrm{C}^{12}, \mathrm{C}^{13}$ and $\mathrm{C}^{14}$. Of these only two are stable $-\mathrm{C}^{12}$ and $\mathrm{C}^{13}$. The others are unstable, $\mathrm{C}^{10}$ and $\mathrm{C}^{11}$ in a very high degree and $\mathrm{C}^{14}$ much less. In a nucleus of a $\mathrm{C}^{14}$ atom, however, a neutron may suddenly be converted into a proton during the emission of an electron. We then no longer have six protons in the nucleus but seven, and the carbon atom has become a nitrogen atom.

In a given quantity of $\mathrm{C}^{14}$ it takes 5,000 years for half the atoms to become nitrogen. This is a very long time, and yet a number of conversions take place every moment. Every minute in one gram of $\mathrm{C}^{14}$ there are ${ }_{2} \times \mathrm{IO}^{13}$ conversions (two followed by $\mathrm{I} 3$ ciphers - an astronomical figure). In as little as one-millionth of a gram there are 20,000,000 conversions from carbon atom to nitrogen atom per minute. The reason why there are so many, of course, is the great number of atoms present. In one gram of $\mathrm{C}^{14}$ there are no fewer than $43 \times \mathrm{IO}^{21}$ ( 43 followed by 2 I ciphers).

While in chemical analyses a comparatively large amount of material must be used (rarely less than one-millionth of a gram), with a physical method employing $\mathrm{C}^{14}$ much smaller quantities will suffice (down to one I oo, oooth part of a millionth of a gram).

The small quantity of $\mathrm{C}^{14}$ is possible because in fact a measurement is made every time a single $\mathrm{C}^{14}$ atom is converted into nitrogen. This conversion, as stated above, is associated with the emission of an electron from the nucleus. The emission takes place with so much force that the electron may penetrate the thin window of a Geiger-Müller tube, where it will ionize the air and effect a brief electric discharge in the tube. The discharge is amplified in roughly the same manner as a radio receiver amplifies impulses, and the effect is to set going a mechanical counter.

Bccause $\mathrm{C}^{14}$ emits electrons we call it radioactive, though elements can be radioactive in other ways. They are often dangerous to work with, but in the concentrations used on the Galathea $\mathrm{C}^{14}$ is perfectly harmless, provided a few simple precautions are taken. 

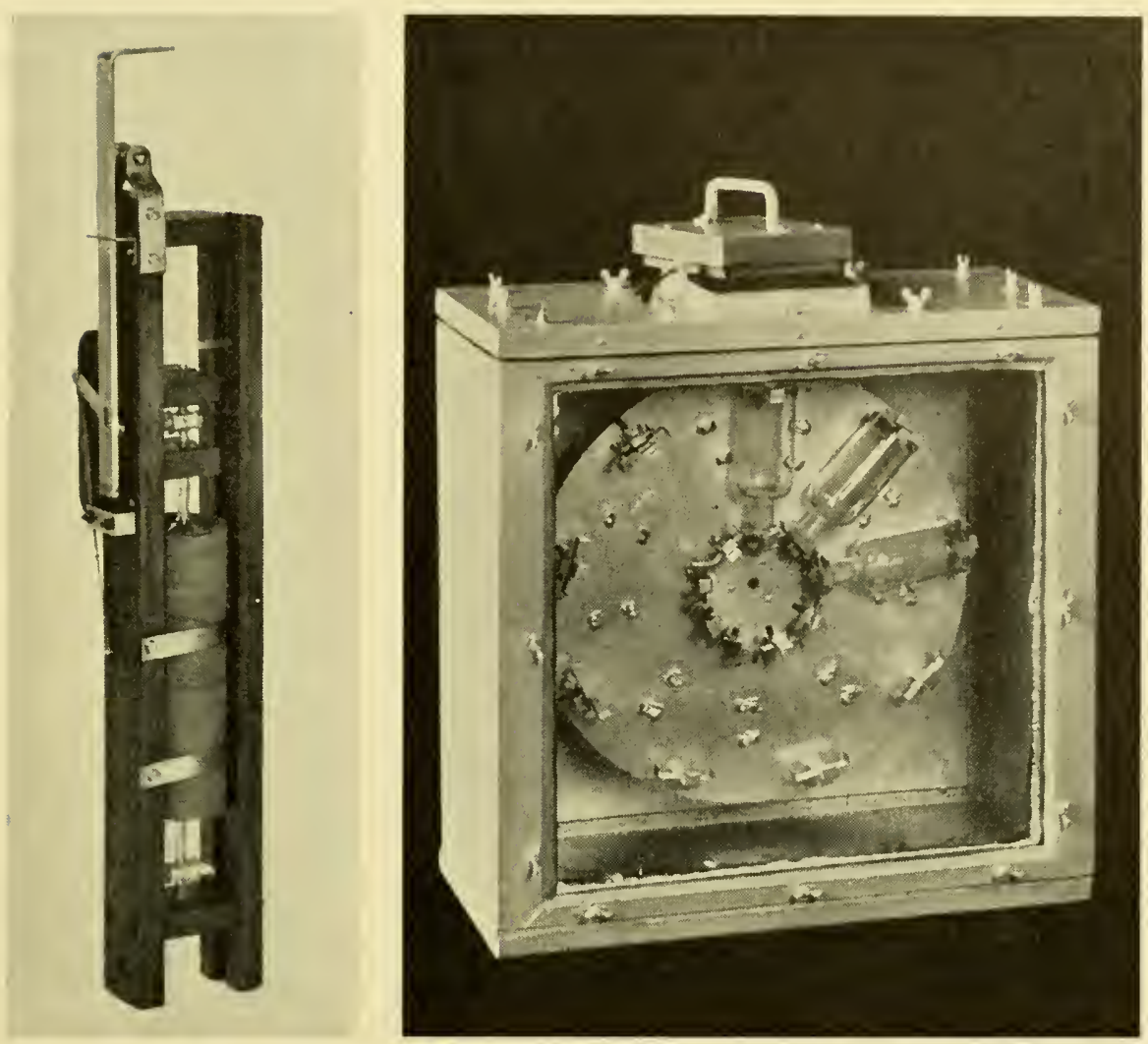

Left, samples of water for production tests were collected in this specially designed sampler. The water was in contact with glass only. The samples were placed on a rotating dial, right, and illuminated.

Briefly, the method adopted was as follows. Plankton algæ cannot distinguish between normal carbon dioxide and carbon dioxide which contains radioactive carbon, $\mathrm{C}^{14}$. Consequently, if a small quantity of $\mathrm{C}^{14}$ is added to the sea water the algæ will assimilate it in the same proportion. The amount can be determined by measuring the radioactivity in the algæ with a Geiger-Müller counter, the total amount of assimilated carbon being then obtained by simple calculation.

To measure the radioactivity the algæ are filtered off by a collodion filter with pores of about $1 / 5$, oooth of a millimetre.

The routine of measuring the production of organic matter below a unit area is to take samples of water from the various depths, pour the water into bottles, add radioactive carbon dioxide, and then lower the 
bottles to the depths from which the samples were taken, keeping them suspended there for 24 hours. They are then taken up and the algx filtered off. When the radioactivity has been measured, the rest is a matter of straightforward calculation.

Usually, a costly research ship will be unable to stand by for so long as 24 hours. A period of six hours, from sunrise to noon or from noon to sunset, will, however, suffice. There being no production at night, the result will be correct if the amount obtained is multiplied by two. But even six hours is a long time, and on the Galathea would have cost about $£_{50}$.

In order to collect a large amount of data in a short space of time we were obliged to make a small alteration in the method. Instead of lowering the samples to their original depth after the addition of $\mathrm{C}^{14}$, we placed them in a sort of aquarium at the same temperature as in the sea, illuminating them with artificial light of a known intensity.

To be able to use this method it is necessary to know how the intensity of light diminishes from the surface downwards. The submarine light is therefore measured with a submarine photometer, to which we will return later. Once we know the effect of light intensity on production and the variations in the light intensity at the surface throughout the day, it becomes a matter of calculation to find out the rate of organic production per unit area. By means of this modification of the $\mathrm{C}^{14}$ method we succeeded in carrying out a large number of measurements.

Our first scientific study, made on the trial trip, was a measurement of the organic production off the Skaw. The last was a similar measurement at the same place on our return. We measured the production of the sea in every area which we visited. While the life nerve of the ship's zoological deep-sea research - the large winch - occasionally failed, this never happened to the equipment used for measuring production. The hand-winch employed for bringing up samples of water for these studies is sturdier than the large and complicated winch used for deepsea trawling. The highly complex equipment used in radioactive work also proved reliable. We had two complete sets, and one at least was always functioning.

We had expected to see the rate of production vary from region to region; by how much we could not say as there has been no previous studies of the oceans. Although we found large variations in the rate, they were smaller than we had expected. It is not easy to sit at a desk and work out the behaviour of Nature.

The principle factor which influences the rate of production is the amount of nutrient salts present in the water, chief among these being 
nitrates and phosphates, constituents which often determine the size of land crops. Both nitrates and phosphates are required for building up in plants important substances like protein. The intensity of light might have been thought the main conditioning factor. This may be so in the dark months of a Danish winter, but even in Denmark light ceases to be the major factor by March, when nutrient salts become more important.

Where do they come from? A small quantity is carried out to sea from the land, but on the whole this is extremely little. We found practically no inorganic phosphate in the water of the Congo River, the only estuary which we studied, though it is true that some rivers, such as the Elbe, carry fairly large quantities of nitrate and phosphate out to sea.

In the open ocean supplies from land have no signifiance at all. The nutrient salts there originate from the deeper water layers, where they are found in fairly large quantities. There is a steady sinking of organic matter in the sea and it is re-converted in the ocean depths into nutrient salts by bacterial decomposition. In the abyss these salts cannot be utilized by plants as there is no light, but they can be if the deep water rises to the surface, where light is plentiful.

All the ocean regions where organic production is high are notable for the upwelling of water from deeper layers to the surface, though the means by which the water rises may vary. Let us take as an example the eastern side of the South Atlantic along the coast of South Africa. Here there is nearly always an off-shore wind which takes the surface water along with it. There cannot, of course, be a vacuum, and so the water blown away is replaced by water from below. It is not surprising that the greatest production measured on the Galathea Expedition was in this very region (Fig. alongside). Similar regions along the west coast of South America and the west coast of Australia are probably equally productive.

There are various other means by which deep water is brought to the surface, one being the formation of eddies near the boundaries of different systems of currents. There is a typical example in the Pacific south of Hawaii, where the counter-current meets the North and South Equatorial currents (see map, p. 6r).

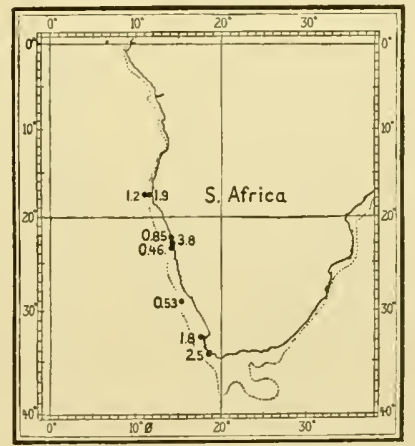

Food production off the west coast of South Africa is exceptionally high. Grams of carbon per square metre of surface per day. 
Now there are also ocean regions where the water slowly sinks, a typical example being the Sargasso Sea, in the south-western area of the North Atlantic. The only way by which nutrient salts can reach the surface of this area is with the surface currents from adjacent regions. As a result, the production of the Sargasso Sea is small (see map below).

A measurement of the production of the Sargasso Sea will prove to be fairly typical of production throughout the year, as the conditions governing it - light, supply of nutrient salts, and temperature - are practically uniform all the year round.

In the North Sea, however, there is a considerable seasonal variation, and to obtain the annual production we must take samples at least a few times a month. Our studies on the Galathea, being mostly in the Tropics, give a much better picture than we should have got by adopting the same procedure in temperate or cold regions.

The map on p. 6r, giving measurements of production in the section extending from New Zealand to California, shows astonishing uniformity. Only the coastal regions of New Zealand and California, and the abovementioned area of eddies just north of the Equator, show appreciably different values. The variations between the remaining stations range from

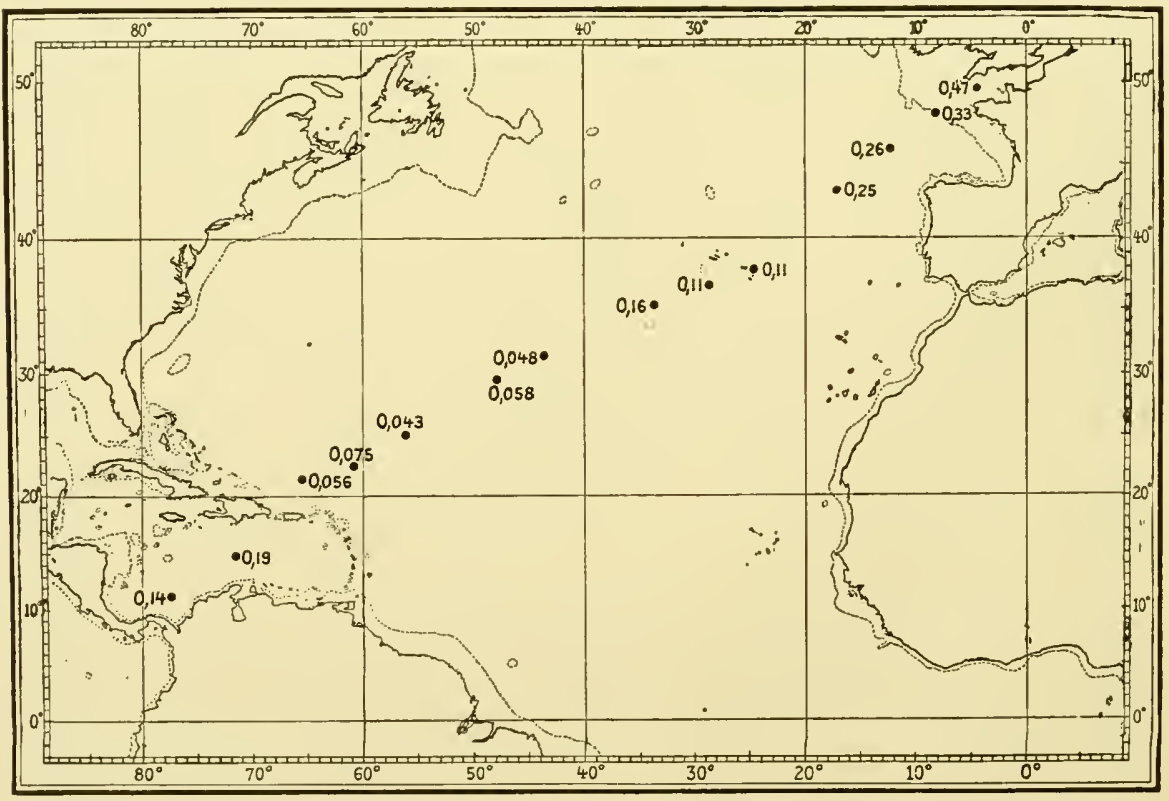

The explored section between Panama and Europe passed through the Sargosso Sea, where production was very small. Grams of carbon per square metre of surface per day. 
In the section across the Pacific from New Zealand to California a highly productive region was found a little to the north of the Equator. Grams of carbon per square metre of surface per day.

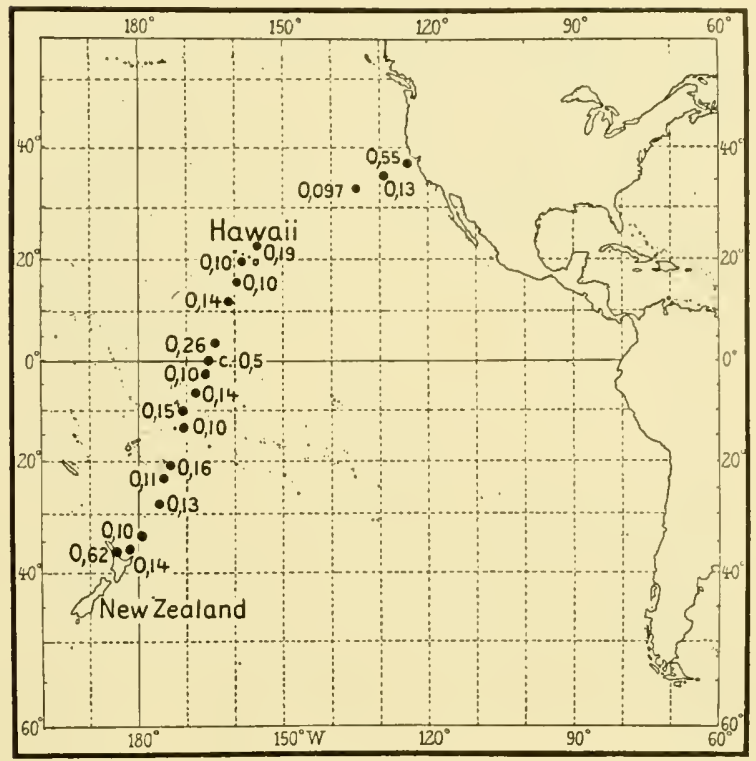

0.097 to o. I 9 grams of carbon assimilated by plankton algæ per 24 hours per square metre of surface. In the coastal regions and the equatorial area referred to the production was about 0.5 grams. There was really no poor area. A striking difference was found between this section and the one extending from Panama to Denmark. Production in the Sargasso Sea was only 0.05 grams. Even so, this is Io per cent. of the production in the rich areas of the Pacific, and 2 per cent. of that in the richest region off the south-west coast of Africa. There are no "deserts" in the oceans.

What is the annual production of all the oceans? It is true that the Galathea's studies covered large areas and showed that variation is comparatively small. Even so, the data available is by no means adequate for a final answer. No attempt has been made to measure the production of large sea areas such as the Antarctic Ocean. Nevertheless, an approximate answer can be given. Our calculation is 15,000 million tons of carbon, corresponding to about 40,000 million tons of organic matter, a year. This is roughly the same as the estimated annual production of organic matter on land.

Many people will be surprised to hear that the sea can rival the land in production, but there is not the slightest doubt that the most productive areas of the sea can produce as much as our best cornfields. Two further points which should be borne in mind are that large areas of the earth 
are virtually unproductive deserts and that the total sea area is about two and a half times the land area.

The Galathea set out at the right moment. Two years earlier and an adequate quantity of $\mathrm{C}^{14}$ would have been unobtainable. $\mathrm{A}$ few years later and others might have forestalled us in this work.

Oceanographers have many reasons for studying the penetration of light in the sea. The physicist seeks information about heating, because absorption of the sun's visible and invisible rays causes the water masses to rise in temperature. The zoologist is interested in the effects of light penetration on the conditions governing animal life at various depths. The illumination of the sea is of particular interest to the botanist because it is the factor which determines where plants can live.

On the Galathea Expedition measurements of light penetration were absolutely essential because the measurement of production at the various levels was dependent upon them. Many measurements were therefore made, and as previous measurements of light penetration had been on a small scale we were able to provide a good deal of new information.

Up to 25 years ago we had to use photographic plates, and the method was both laborious and of doubtful accuracy. The invention of the photo-electric cell considerably facilitated the work, and when in the nineteen-thirties a type of cell was developed which dispensed with the need to amplify the electric current the measuring of light penetration in the sea began to make headway, though measurements were still largely confined to coastal regions. Most of the oceanic measurements, and the best, were made by the Swedish Albatross Expedition of 194748. Even so, they were made at only 26 positions scattered over the Atlantic, the Pacific, the Indian Ocean, and the Mediterranean. The number of stations was deliberately restricted because, though the expedition was equipped with all the latest devices, it was desired to confine operations to days when conditions were perfect; in calm weather without appreciable swell, and in clear sunshine with the sun near zenith. As a result the measurements are of the highest possible quality.

We employed a different procedure, taking as many measurements as possible, sometimes when conditions could not give high quality. In scientific work, however, accuracy must always be adapted to the object in view, and our main object was to procure information for use in estimating planktonic production. We did not need the same accuracy as purely physical tests demand.

In studying heat the fact that the sun's radiation is a sum of rays of varying wavelengths can be disregarded. Not so when we study the in- 
The photometer used on the expedition. The photo-electric cell is enclosed in the three-armed container.

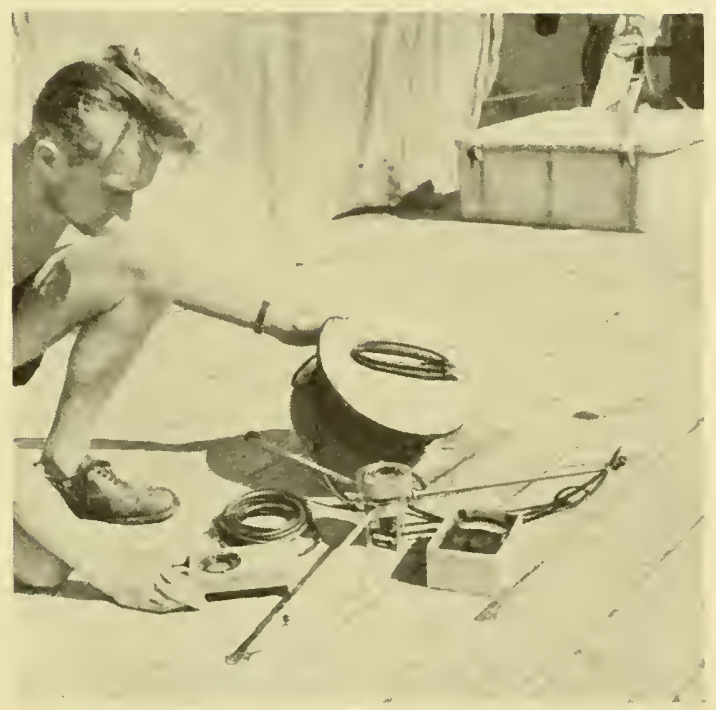

fluence of light on plants. Plant production is entirely dependent on the visible rays and a little of the ultra-violet part of the spectrum. Within this range the influence of the rays varies. The maximum energy in sunlight is provided by the green-yellow part of the spectrum.

Some of the light which strikes the surface is lost by reflection. The amount depends on the sun's altitude; and it is only when the sun is very low on the horizon that a considerable proportion of the light is reflected. At an altitude of over $30^{\circ}$ the percentage of reflected light is small. The altitude of the sun is also important in another respect: the rays penetrate deepest when they are vertical.

The penetration of light varies also with the wavelength; that is to say, with the colour. Here, however, there are wide regional differences, so that we must also consider the ways in which light is absorbed. The intensity of light as it penetrates the sea is reduced by the following factors: absorption by the water itself and by matter dissolved in it; scattering by the molecules of the water; absorption by organisms and particles; scattering by organisms and particles. Particles may be either organic or inorganic.

These factors have a somewhat different effect on light of different wavelengths. Pure water rapidly absorbs the red part of the spectrum, the green part much more slowly, and the blue part most slowly of all. The rays at both ends of the visible spectrum are absorbed with great intensity. Scattering by the molecules of the water is greatest in the blue 
part of the spectrum; but since the downwardly scattered portion is not lost and the absorption of blue rays is very slight, it is blue light which penetrates furthest in pure water. Green light comes next.

In very clear oceanic water, where plankton production is small, one per cent. of the blue light penetrates to a depth of about 130 metres, one per cent. of the green to about 80 metres, and one per cent. of the red to about I 5 metres.

In water masses containing a larger amount of organisms or particles it is the green rays which penetrate furthest. This is the case in coastal regions and very productive oceanic regions.

The variations are so great that no universal rule can be stated. In coastal regions, however, one per cent. of the green light very rarely penetrates deeper than 50 metres and usually much less than that. In Walvis Bay off the west coast of South Africa we traced one per cent. of the green light at a depth of 70 centimetres. In this water we found a small plankton alga in such large quantities that it turned the water brownish-red. This alga, which will be described by a Norwegian specialist on the basis of data collected by the expedition, has been named after the Galathea. It appears to secrete toxic matter which is lethal to fish. Large numbers of fish had died just before our arrival in the bay.

On the Galathea we made our light measurements from the stern. A photo-electric cell was enclosed in a watertight case and glass filters of various colours could be placed over the window, which faced upwards. The photometer was affixed to a wire which passed over a block suspended from a gallows. By means of an electric cable the photo-electric cell was also connected with a sensitive meter on the deck. Another photoelectric cell mounted on the deck was used for taking simultaneous readings of the variations in the light which fell on the sea surface. 


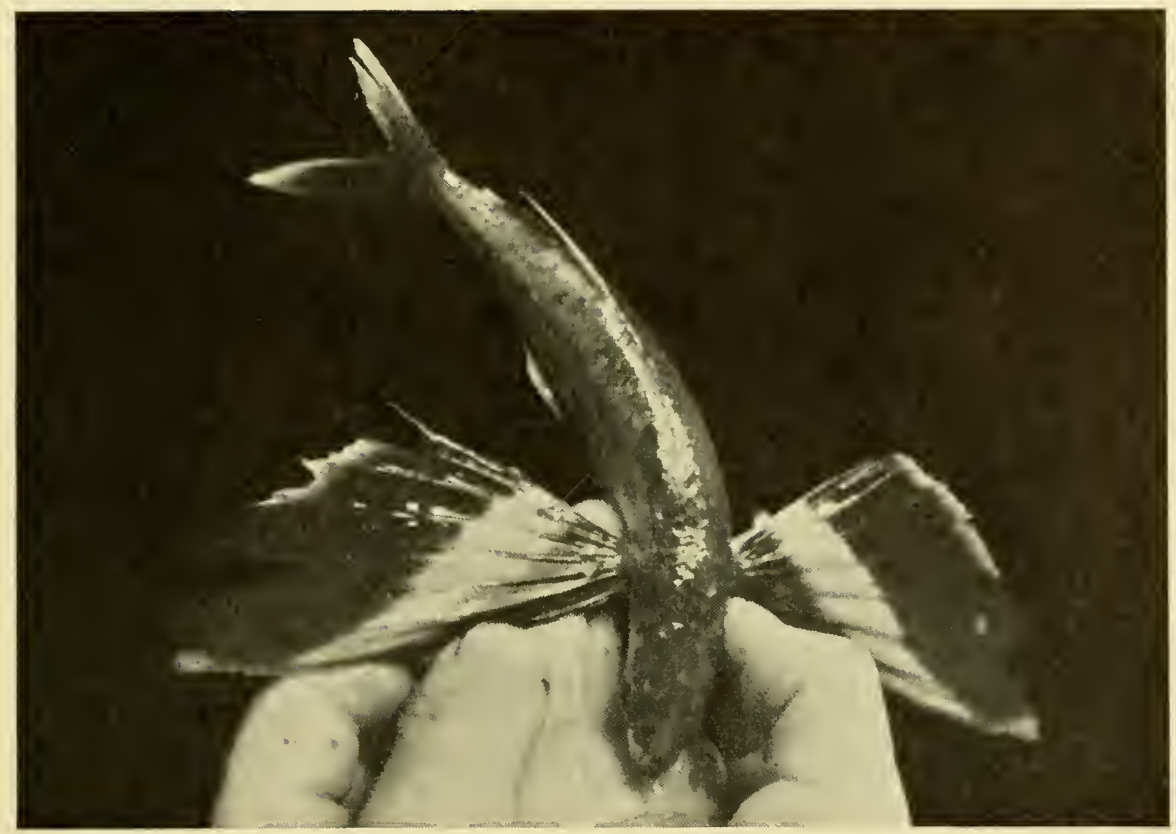

PELAGIC FAUNA

\author{
By P. L. KRAmP
}

Animals inhabit not only the sea-bed but the entire mass of water from bottom to surface and from shore to shore. The rich variety of pelagic fauna, as the creatures which live between the surface and the deep-sea floor are called, embraces a range of remarkable and frequently very beautiful zoological forms adapted, in many peculiar and extremely interesting ways, either to a life of active swimming ("nekton") or to floating and drifting with the current ("plankton").

Pelagic organisms are of immense importance in the economy of the sea. In the upper water layers, the "epipelagic" region which is reached by sunlight, there is plant life - the immense quantity of microscopic plank-

Using its tail-fin as a propeller, the flying-fish leaps out of the water and glides on the extended pectoral fins. 
ton algx, referred to in other chapters, which forms the ultimate food of all marine animals. Many small animals in these layers live directly on this vegetable plankton; they are then devoured by other animals, these in their turn serving as food for still larger animals. In the perpetual darkness beyond the limits of light penetration is the "bathypelagic" region, where only animals live. In the absence of plants these have to live on other animals, and perhaps to some extent on bacteria, which recent research suggests play a considerable part in the economy of the sea. By means of this food chain the production of organic matter by plant plankton, or phytoplankton, ultimately benefits even the bottom-living animals.

Although the prime object of the Galathea Expedition was the study of abyssal fauna, it followed as a matter of course that we should also study pelagic animals. The results were impressive. We found many new species and showed that many others have a much wider distribution than had been supposed.

'The pelagic fauna is so diverse and embraces so many of the principal groups of the animal kingdom that it will be possible to deal with only a few of the most interesting of the animals found. The large gear which we used fished much greater depths than ever before, bringing up creatures from previously unknown regions. Whenever we could we also fished for pelagic animals near the surface, especially in coastal waters, where large-scale expeditions have not devoted much attention to the pelagic fauna.

Standing under the ship's awning gazing down at the clear blue water, we saw little of the fauna which we knew to be there. We would catch a glimpse of a brightly coloured sea-snake, or a jellyfish with beautiful coloration. Flying-fishes being blue, we did not see them till they leapt from the water and became airborne. Many surface animals seek shade from the fierce light of the midday sun at lower depths, but though we knew they were there we did not see them even in the morning or evening, as they are more or less camouflaged. They may have many different colours: brown, yellow, and reddish-yellow are common, and pursuers will be deceived by striped and spotted coloration. But the predominant colour, especially in the Tropics, is blue. Many are pellucid, so that only a few of their organs, such as the eyes and the stomach, may be visible when they are swimming. Most fishes have dark backs and silvery sides, colours - or lack of colours - which presumably make them less conspicuous and so protect them from their enemies. In the sea as everywhere in nature the law of life is to eat and avoid being eaten!

Flying-fish are always interesting (Fig., p. 65). Occasionally we would 


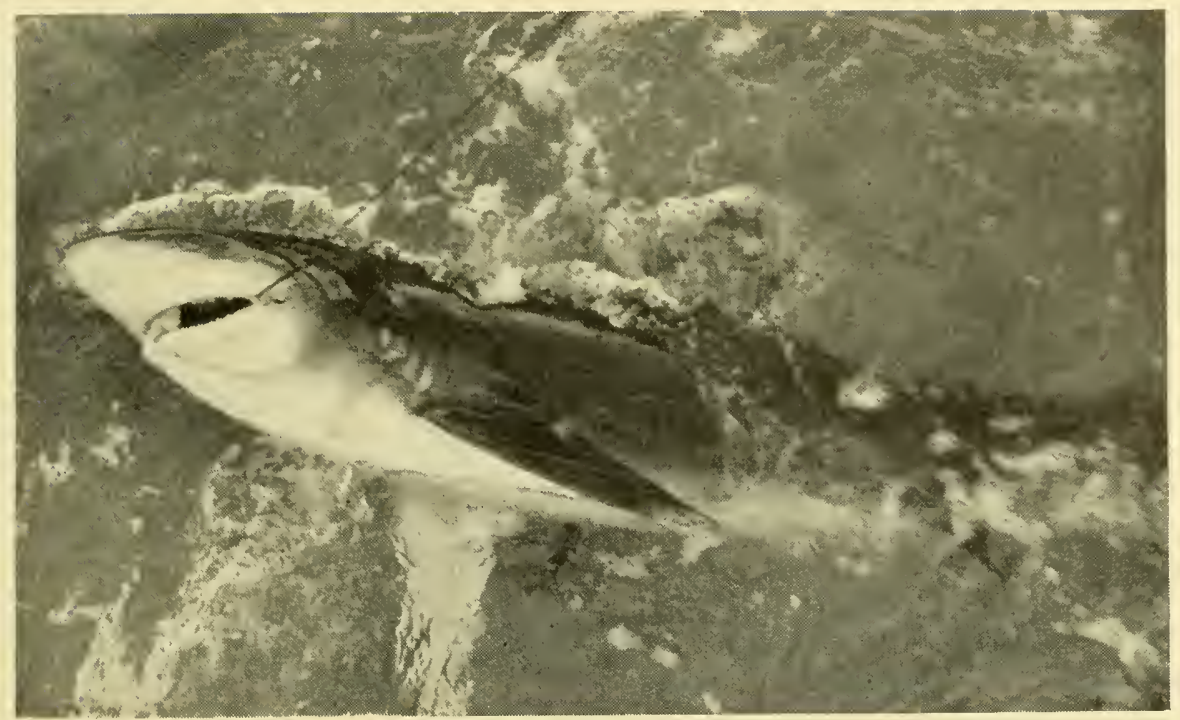

Shark on hook.

catch a shark (Fig., above), and then our attention would be attracted by the pilot fish (Naucrates), a kind of mackerel, blue with dark transverse bars, which follows sharks and feeds on their excrement or on scraps from their meals. We also saw sucking-fish (Remora remora), which is another mackerel. The anterior dorsal fin of this fish is modified as a large, grooved sucking disk by means of which it clings to sharks. When the shark has seized its prey the sucking-fish lets go and shares in the feast.

Whenever the ship was stationary we would suspend a railed platform over the side just above water-level, for a man to fish from. This platform was also used for nocturnal angling (Fig., p. 68). A beam of light would be directed into the water and soon there would be a swarm of fish, squids, and jellyfish, which the man on the platform would net and pass up to the deck for transmission to the ever hard-working zoologists in the laboratory. Others would fish for larger fish by line, sometimes getting big hauls though rarely any welcome variation of our diet. However, one evening off the Seychelles we caught a quantity of garfish and mackerel of species closely resembling those from our own seas, and we would occasionally "land" the large and savoury dorado (Coryphena).

We also caught many squids this way. We would sometimes come across them travelling in shoals at an astonishing speed, shining in the beam of our searchlight like gold-fish. While sheltering from a typhoon off 
the coast of Mindanao, we caught 49 specimens of Idiosepius pygmaus, which has reddish spots and is almost transparent. This is the smallest of the squids; it has very short arms and measures only i5 millimetres fully grown. We also found it near the Philippines and in the Java Sea. This squid was first described in I88 I by the Dane Japetus Steenstrup, from specimens found in the South China Sea and off Zamboanga in the Philippines. It was later found at a position near Japan and also at two positions off the Moluccas, but had not been seen since I898. So this was an interesting find. A remarkable octopus is the paper nautilus (Argonauta). The female of this genus lives in a single-chambered, thin, white calcareous shell. The two uppermost arms are very large and are folded round the outside of the shell when they are not being used as oars. The male is quite small and shell-less. Between Mombasa and the Seychelles we saw the remarkable sight of a number of Argonauta ensconced on the top of jellyfish, Crambionella orsini, which drifted in large numbers round the ship (Fig. p. 69). To the best of our knowledge this had never been seen before.

Besides the special forms of worms which always live pelagically, there are some bristle-worms which leave the bottom on reaching sexual maturity. Near the Seychelles we "landed" several specimens of a fine large bristle-worm, Notopygos gigas, I 7 centimetres in length and with

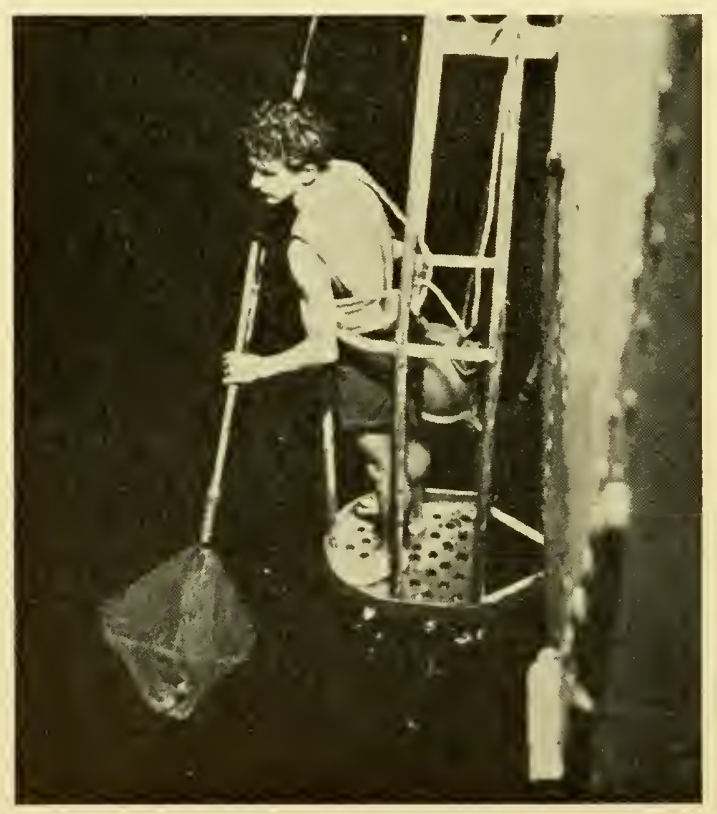

Nocturnal angling; on the look-out for small fishes and cephalopods attracted by the searchlight. 
Globe-fish (Diodon) caught off New Guinea. It blows itself up by swallowing air and water, and the spines stick out on all sides.

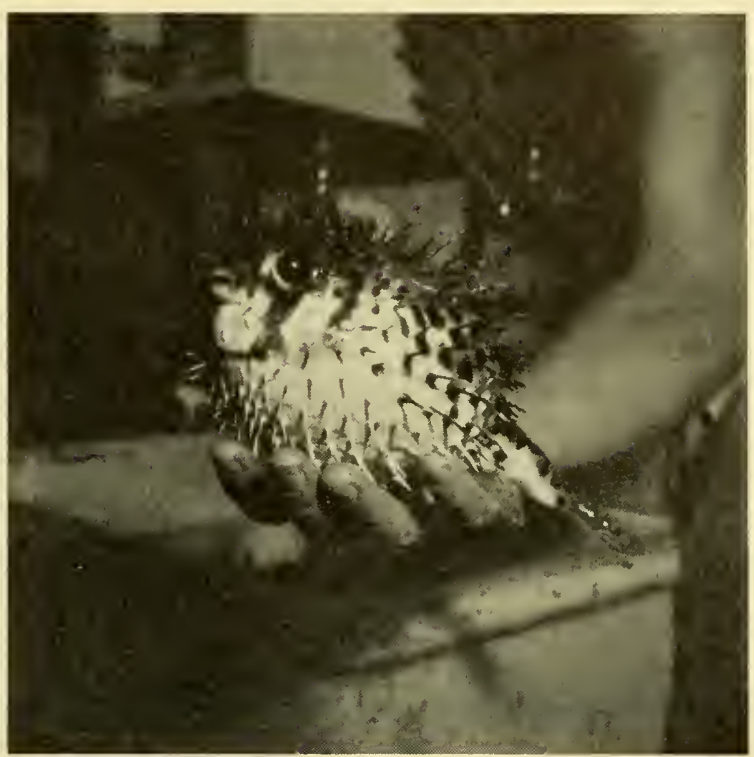

A paper nautilus (Argonauta), a remarkable pelagic octopus, which has attached itself to a jellyfish (Crambionella).

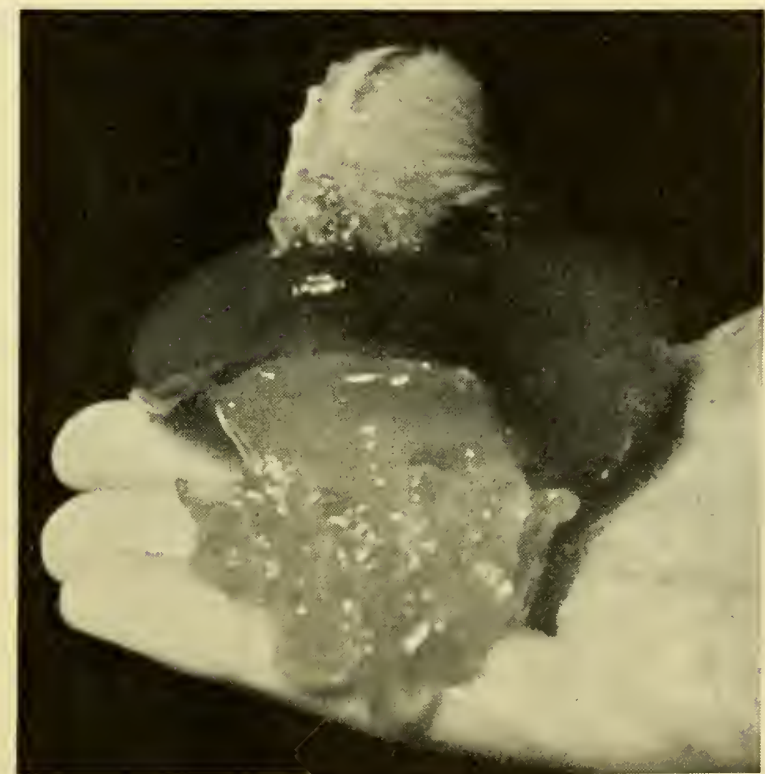

magnificent red and violet colours (Fig. p. 70). These worms are very fragile, but with care I succeeded in preserving them intact. The species was previously known from Timor in the Malay Archipelago and from the Bonin Islands south-east of Japan. 


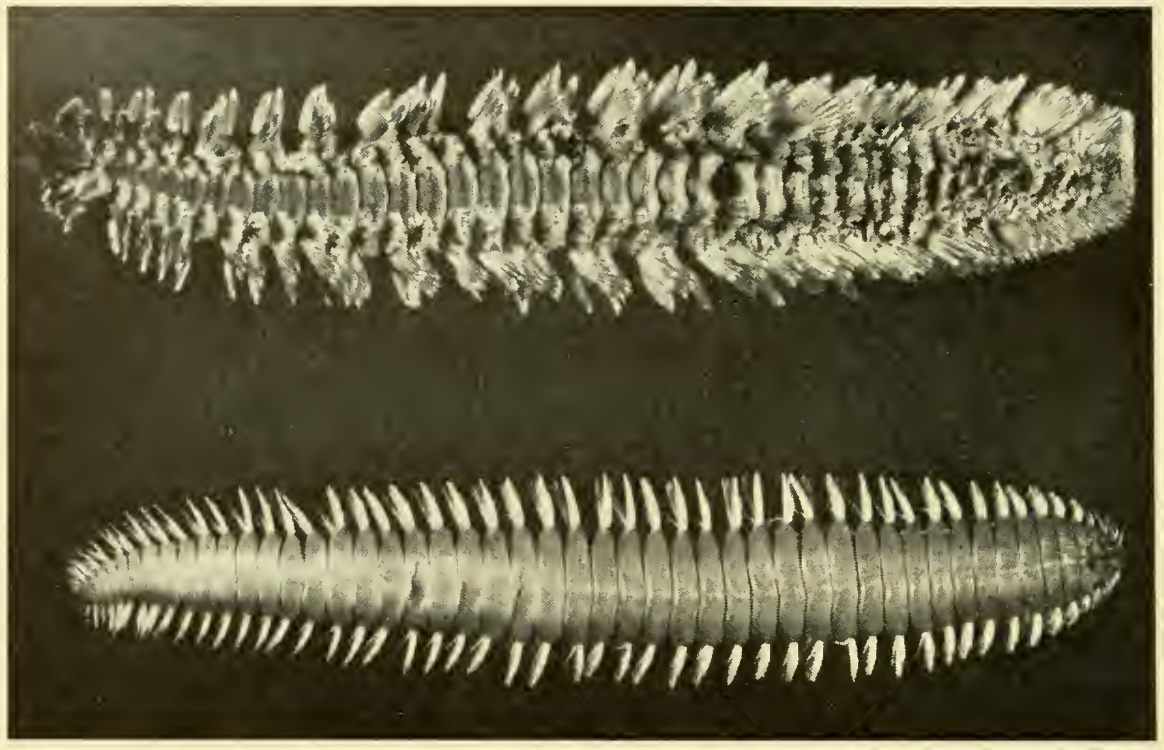

A large bristle-worm (Notopygos gigas), taken in angling off the Seychelles. Top, from above; below, the ventral side. Two-thirds natural size.

For gathering small pelagic fauna which could not be taken by dip net we used a net of silk, 50 centimetres in diameter. It was suspended over the side so that the creatures would drift into it with the current (Fig. p. 72). Sometimes also we used a large pankton net of stramin; and our large herring trawl on its way up from a bathypelagic haul would always catch some of the animals of the upper water levels. Crustaceans nearly always formed the bulk of the haul, and in the vicinity of land there was always a number of free-swimming larvæ of various bottom dwellers like snails, mussels, worms, echinoderms, and so on.

A selection of common epipelagic animals is shown in the figure on page $7 \mathrm{I}$, which also illustrates the great variety of ways in which animals can adapt themselves to pelagic life. Even pelagic animals are nearly always heavier than water and must provide against sinking too deep. To remain buoyant by swimming requires energy, but most fish and cephalopods manage without special contrivances. A sphere sinks more rapidly than a broad and flat object or a long and thin one. And so we find that many pelagic animals are broad and flat, or rod-shaped like the arrow-worms (Sagitta). Long extensions at the front, the back, or the sides are common means of floating and these are particularly pro- 


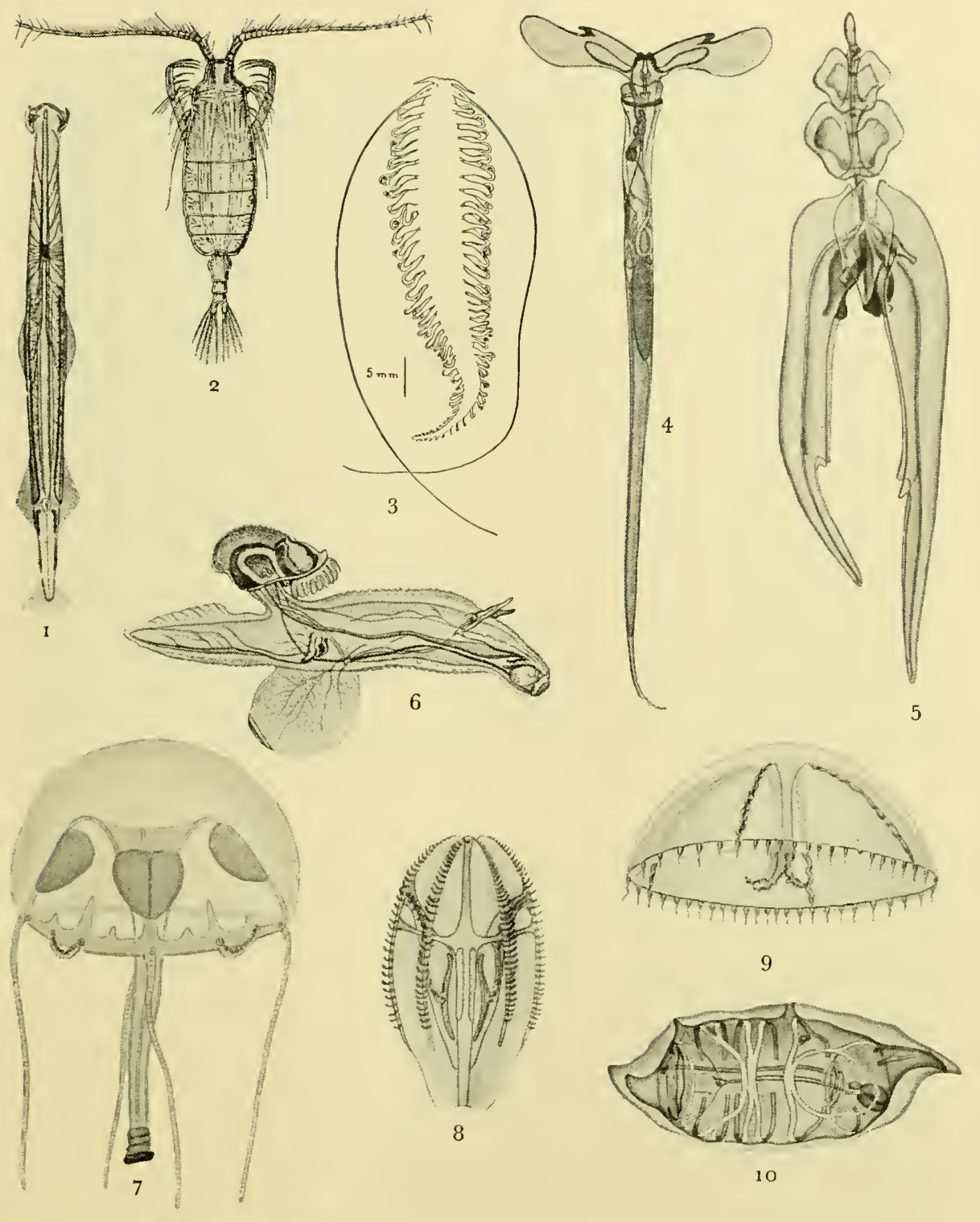

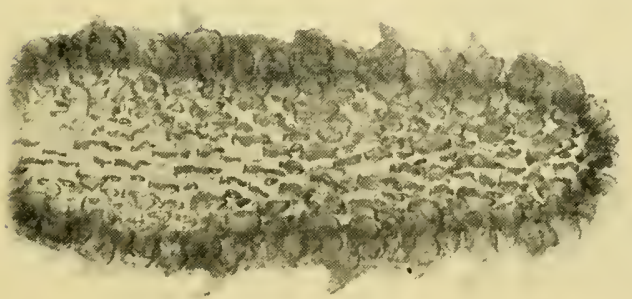

II
$A$ selection of pelagic animals:

I Arrow-worm (Sagitta). 2 Copepod.

3 Annelid worm (Tomopteris).

4 Pteropod (Creseis acicula).

5 Siphonophore (Nectalia). 6 Heteropod

(Carinaria). 7 Medusa (Liriope).

8 Ctenophore. 9 Medusa (Eirene).

Io Salp (Ritteriella). I I Pyrosome

(Pyrosoma). 
nounced in crustaceans, where they take the form of long feelers, spines, or bristles, which may even be feathery. Notable in shallow water are the many larvæ of crabs and other bottom-living crustaceans. A few annelid worms are adapted to pelagic life entirely, including the genus Tomopteris, which has no bristles but outspread parapodia and long feelers. Pelagic molluscs, especially pteropods and heteropods, have very thin and light shells. Globules of oil are found in some crustaceans (copepods) and in fish eggs, as also in some of the siphonophores, though others remain buoyant by means af air bladders. Finally, many animals have their specific gravity in relation to water much reduced by body walls which are thick and watery, that is to say, gelatinous. This especially applies to the salps, the beautifully luminescent pyrosomas, most jellyfish, and some of the microscopic protoza. Several different methods of flotation may sometimes be present in the same animal.

Every opportunity was taken to obtain samples of plankton. As each of our numerous samples contained representatives of nearly every group of pelagic fauna, it is obvious that only a minute proportion could be closely studied on board; for that the cooperation of a number of specialists is required. But when I was on board, between Mombasa and the Torres Strait, close attention was given to jellyfishes and whenever I had the opportunity I studied previous catches. We had a rich haul.

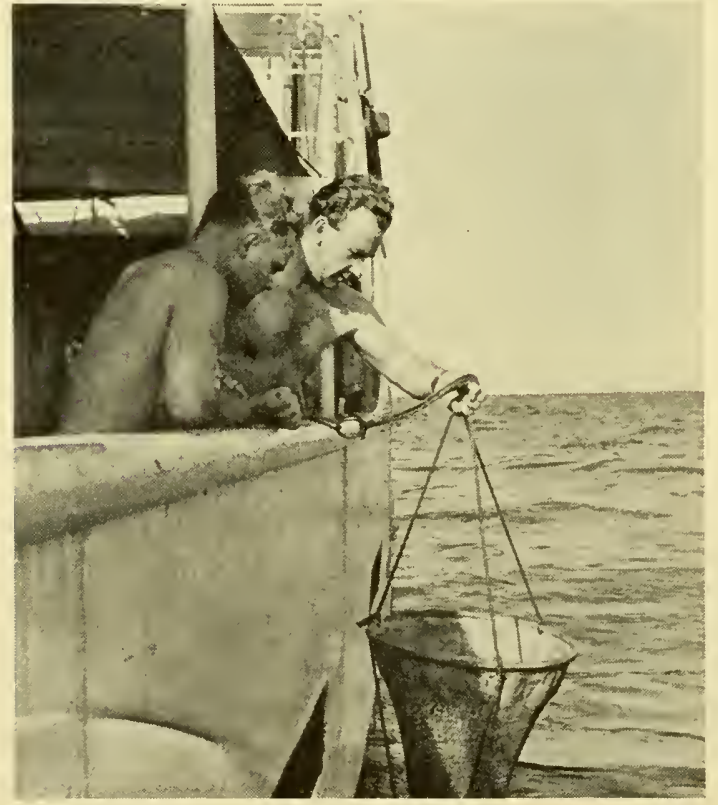

Suspending the silk-net over the side so that small animals will drift into it with the current while the ship is stationary. 


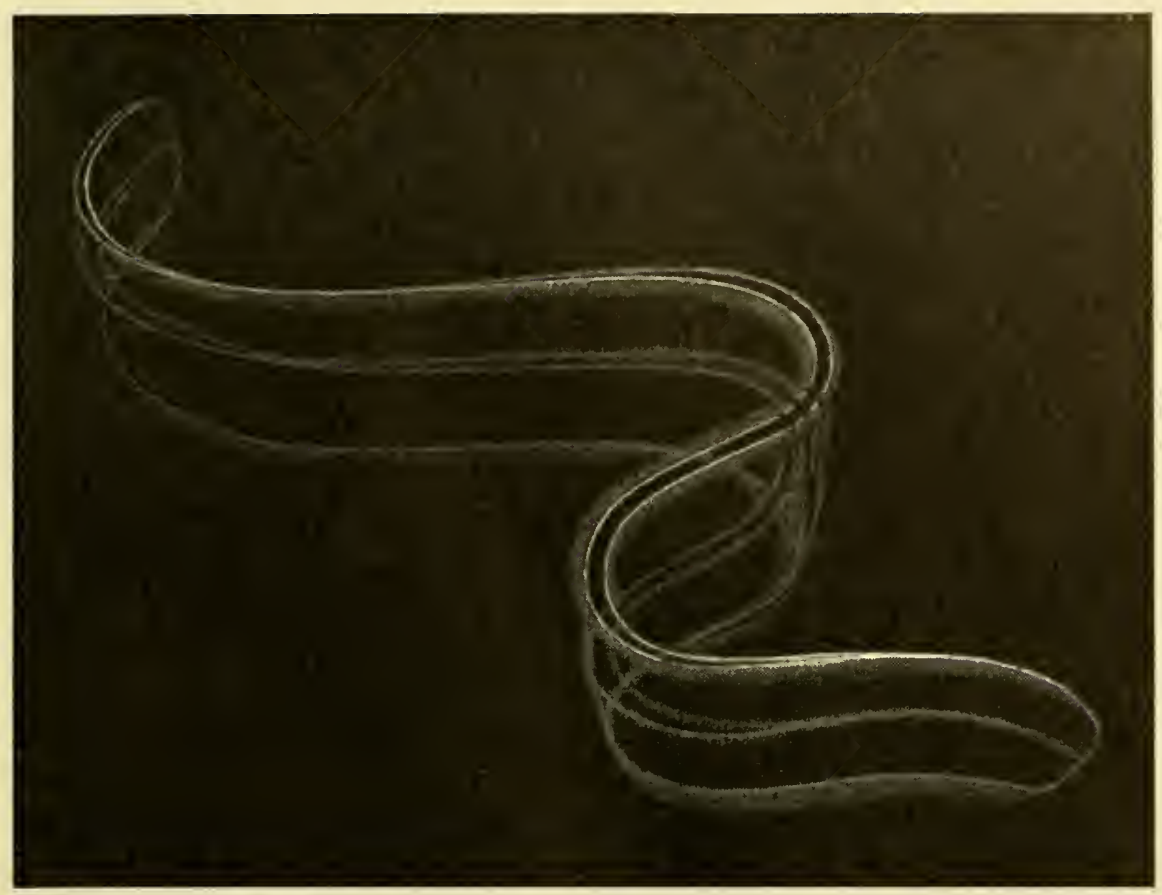

The ribbon-shaped ctenophore, Venus's girdle (Cestum veneris).

The ctenophores are pellucid, gelatinous animals which swim slowly by means of eight ciliated ribs. All are luminescent. Most of them are spherical or barrel-shaped, but one, Venus's girdle (Cestum veneris), is like a length of ribbon (Fig. above). We saw this on a number of occasions and were fascinated by the elegant creature's graceful movements and gorgeous yellow and purple colours. But as we stood watching it it would burst into a thousand pieces! A few ctenophores are adapted to crawling as well as swimming. Most of these strange creatures occur in the IndoMalay region. One evening as we lay at anchor near the Philippines, I found a small specimen of Ctenoplana (Fig. p. 74), clear with delicate brown markings. It was so full of life that I was able to observe it for a long time under the microscope, watching it assume the most singular shapes. Several times I saw it extend its two long, feathery tentacles from the two tubular projections on top.

Some of the most beautiful of marine creatures are the siphonophores. They form free-swimming colonies consisting of many different individuals, each with its own function in the colony: swimming-bells, digestive and reproductive members, protective bracts, and tentacles which defend 

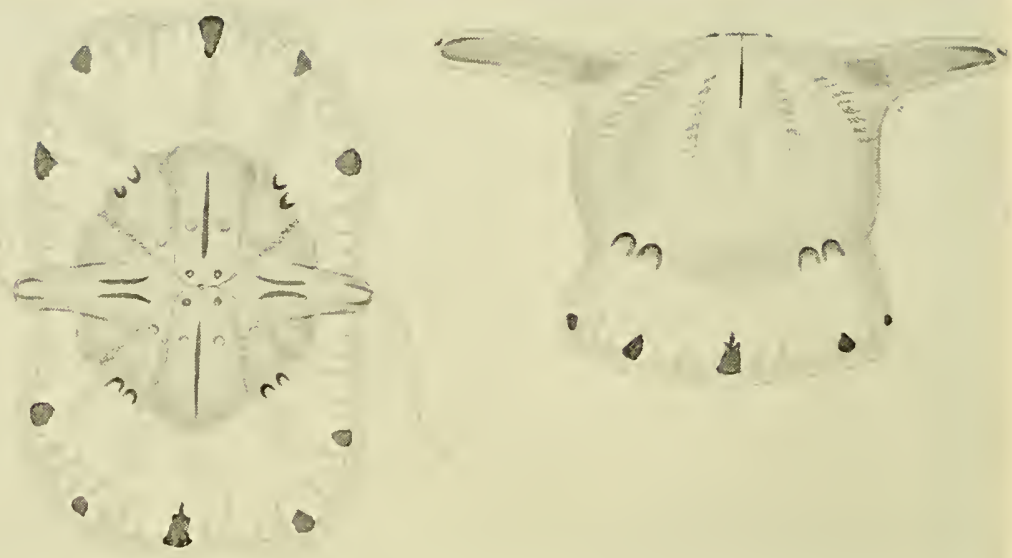

A ctenophore (Ctenoplana) which can both crawl and swim, drawn on board from life.

the colony with their stinging cells and catch its food. Some of the colonies are kept afloat by means of a small oil receptacle, while others have a small bladder of gas at the summit. Unfortunately, the colonies nearly always break up into their component parts when removed from the water. Most of them occur at all levels, but three species are so full of gas that they drift on the surface, where they are a familiar sight to all who sail

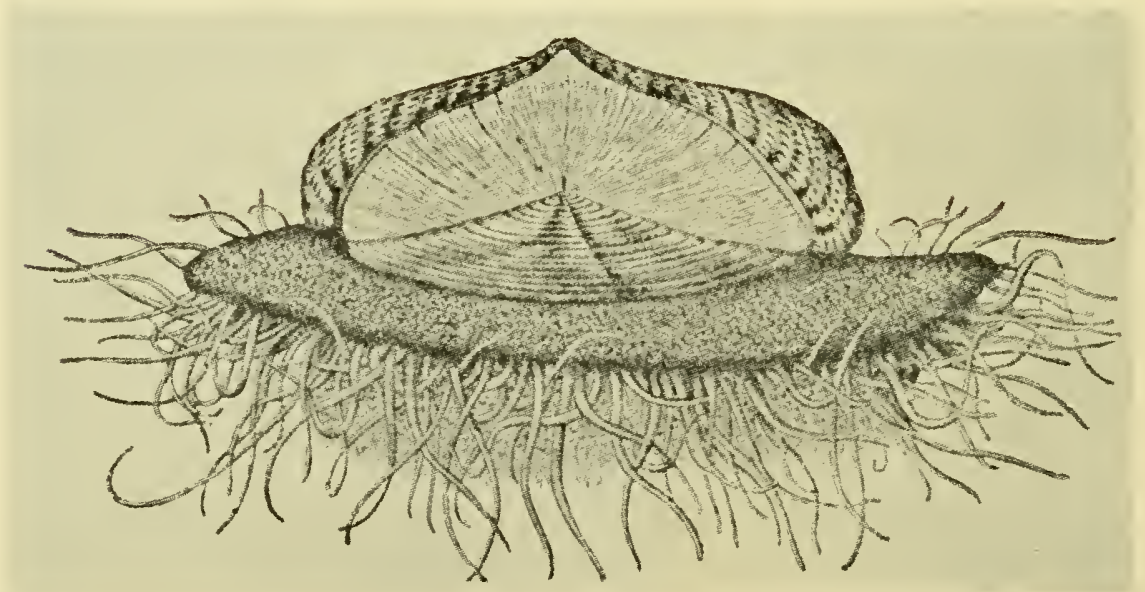

By-the-wind-sailor (Velella). 
the warmer seas. One of these is the Portuguese man-of-war (Physalia, Fig. adjoining), with a large parchment-like bladder, magnificently coloured. The various individuals are suspended in the water from the underside of the bladder. The tentacle members of the colony may be many metres in length and will impart a virulent sting. In the by-the-wind-sailor (Velella, Fig. p. 74) the place of the bladder is taken by a multi-chambered, oval-shaped disk. On the summit is an oblique crest, and when this "sail" is caught by the wind the whole colony is propelled like a ship sailing by the wind. It is sometimes attacked by one of the isopod crustaceans, the richly coloured little Idothea metallica. In an aquarium off South Africa we observed four of these small crustaceans devour a by-the-windsailor three centimetres long in 12 hours. Another sophonophore, Porpita, lacks the sail but has a circular disk. Usually, this creature is a beautiful blue; but in the Java Sea, besides the blue ones, we saw some that were a bright lemon colour.

The jellyfishes which were studied most of all during my stay on board were the medusæ. Most of these were readily identified, and it was useful to see them alive and in their natural forms and beautiful colours, which are mostly lost by preservation. Before reaching Australia we had found nearly i 50 different species of medusæ, 20 of them previously unknown. We were able to clear up many doubtful points about the demarcation of species, and also in a number of cases to describe the various stages of development. Many of these

The Portuguese man-of-war (Physalia).

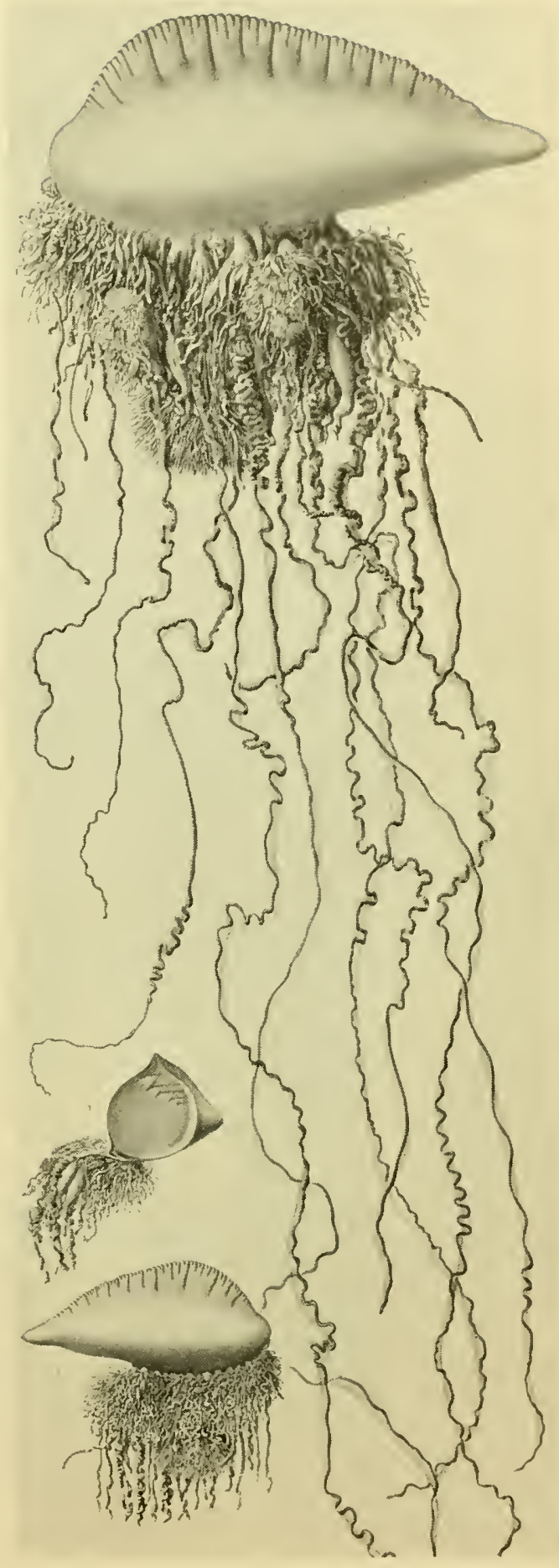


species were shown to be much more widely distributed than had been supposed. The members of one of the medusa orders, Trachylina, are "holopelagic"; that is to say, they are independent of the coasts and live and breed entirely in the open water. In the upper water reaches we found only well-known species of these. The other orders of medusæ are "meropelagic", which means that some stages of their development take place on the sea bed. The eggs hatch into small larvæ which descend to the bottom, cling to stones, shells, and similar objects, and grow into fixed polyps which propagate by budding. Often they will form large, branched colonies (hydroids) and develop a new generation of medusæ by budding. In many cases we do not know the stages of development, but we presume that this is the way it always happens. Most of these medusæ are "neritic", inhabiting coastal regions, and only the larger forms have so long a lifetime that they get carried out to sea by the currents, for though they swim, they do so only slowly. Their occurrence can give valuable information about the course of ocean currents. The majority belong to the small Hydromedusa, and it was chiefly among these that we found many new species. The large medusæ (Scyphomedusa) include the Rhizostoma, the numerous genera and species of which nearly all live in the Tropics. Without the single mouth of other medusæ, in the middle of the underside, these have eight highly curled oral arms with numerous fine pores, through which the creature pumps water into its canal system along with the tiny animals on which it lives. Belonging to this group is the beautiful brown and violet Crambionella orsini (Fig. p. 69). Previously known only from the Red Sea and Arabian Ocean, this proved extremely common all the way over from Africa to India. A Thysanostoma flagellata from Madagascar, with magnificent red stripes on the underside of the bell, was filmed swimming in an aquarium. Near Singapore we caught a Versura anadyomene, which, according to the literature, attains a diameter of 20 centimetres. This one was a giant of 60 centimetres, and a swarm of small fish and crabs had found shelter

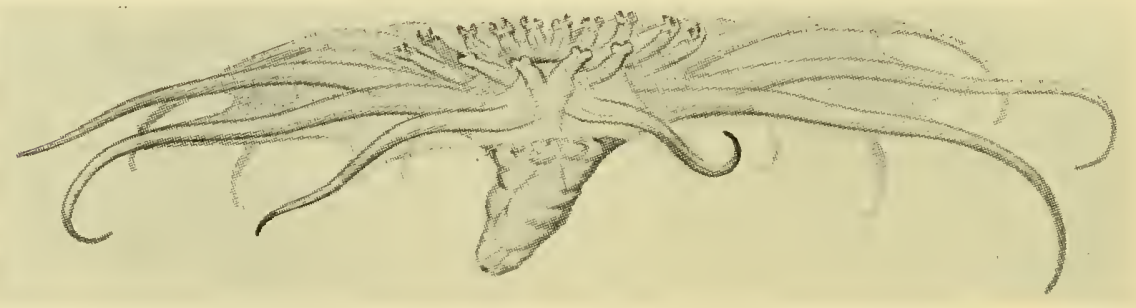

The bathypelagic sea-cucumber Pelagothuria, which lives at depths beyond I, 0oo metres. 


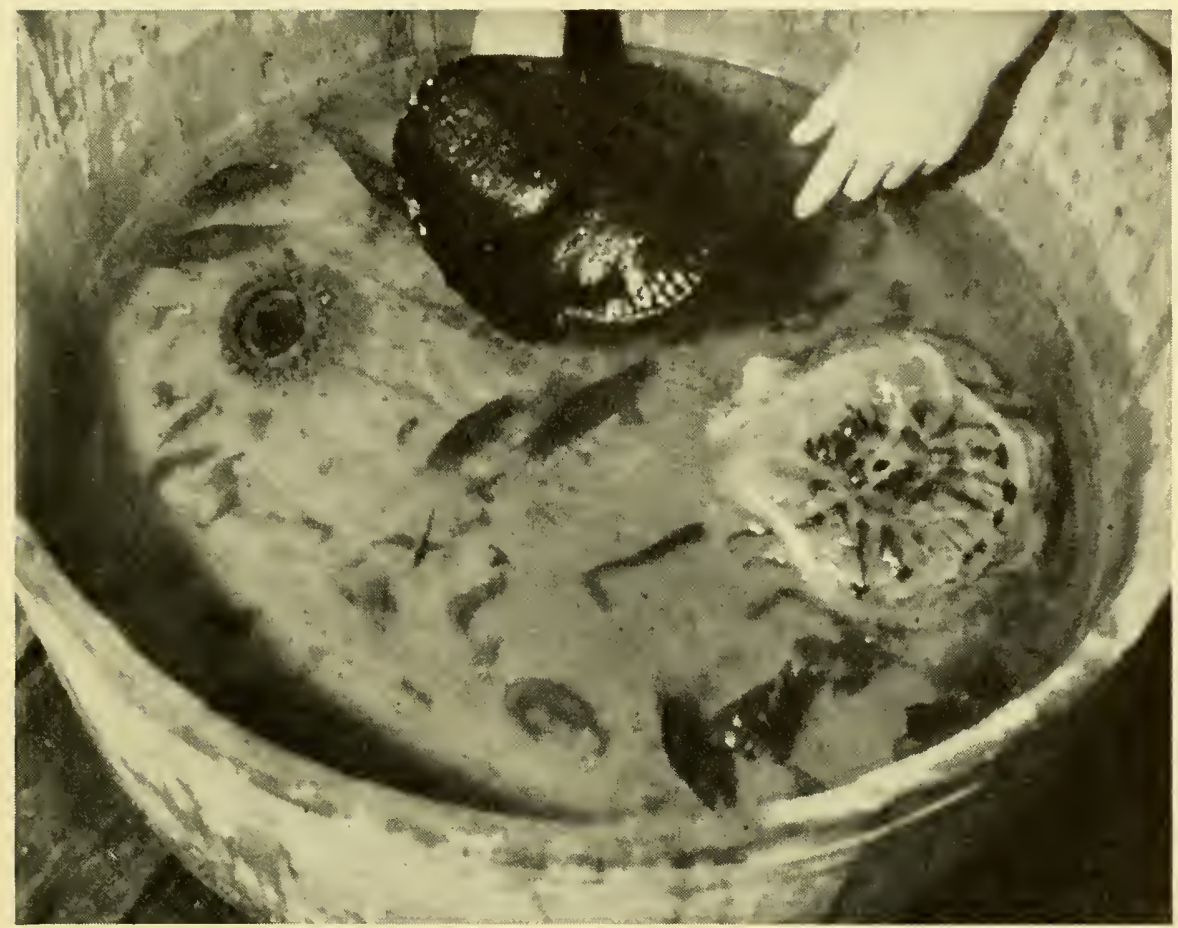

The catch from a bathypelagic trawl at about 3,500 metres in the China Sea. Left, the medusa Atolla; top, the sea-cucumber Galatheathuria; right, another sea-cucumber, Enypniastes. Also prawns and small fishes.

underneath it. The common jellyfish (Aurelia) occurs near almost all the coasts of the world in different varieties or closely related species. As a rule, expeditions cannot afford the space to store such large and common creatures, but we had an opportunity of comparing specimens found in many different places.

At deeper water levels nearly all fish and most cephalopods are black, or at least very dark, and crustaceans are red. The deep-water species of several zoological groups whose epipelagic species are colourless are also red. In the dark all colours are as invisible as black. Some sunlight penetrates to the upper portion of the bathypelagic region, but not the red rays, which are the first to be stopped. In this transitionary zone live a number of fishes and cephalopods which are not black like the usual deep-sea forms, but red like the prawns, red being invisible where red rays are absent. Incidentally, it is likely that there is a connection between red colours in animals and low temperatures; certain species of jellyfish 
which under other conditions are colourless may be a vivid red both in the cold ocean abyss and in surface water near the poles.

Many animals live mainly in the upper portion of the bathypelagic region, where there is still faint light. Probably the temperature, rather than the light of the surface, keeps them at these lower depths. In the tropical and subtropical belts there is a rather sharp dividing line between the warm surface water and the cold deep water. The boundary is marked by the isotherm of $10^{\circ}$, which at the Equator is at a depth of about $25^{\circ}$ metres, and at the North and South Tropics about 500 metres. Above this level there is a rapid rise in temperature and below it a rapid drop, resulting in a "discontinuity layer". Many pelagic animals collect round this level, making it a good hunting-ground for swift-moving predacious animals such as fish, squids, and prawns. Many of the small creatures rise nearer the surface at night and are followed by their hunters.

Even at the lowest depths it is never totally dark. Luminescent animals live at all levels, and especially at deep levels where there is no other light. Most deep-sea creatures are either dead or dying when brought up from the cold deep through the warm surface water, especially in the Tropics, and so we do not know how many of them are luminescent. There will certainly be many more than we know which can radiate light from some part of their body. Numerous bathypelagic fish, cephalopods, and crustaceans have special light organs, often of a highly complex structure. There are many variations, but in the most highly developed a luminous substance is secreted in glandular cells; the light is reflected by a cup-shaped reflector with a hood of dark pigment, and is emitted through a lens. In some it can be dimmed. Light organs may be sited in the oddest of places and their purpose is controversial. The stalked lantern borne by angler-fishes on their nose doubtless acts as a lure to prey; the distinctive patterns of luminiscent dots and spots of many fishes and cephalopods may serve to identify the sexes or help to keep the shoal together; some animals may illuminate their surroundings in order to find food. But in many cases the value of luminescence is a mystery, and particularly so in the case of the many luminescent creatures of the surface water, nearly all of which belong to the lowest orders and never in any way seek their prey but take what they chance to encounter. Many riddles remain to be solved in connection with the evolution of light organs and eyes in deep-sea animals. The Galathea Expedition, which fished at much greater depths than any of its predecessors, should provide many valuable clues when the material has been fully studied.

Nearly every group of pelagic fauna found in the surface water is also 

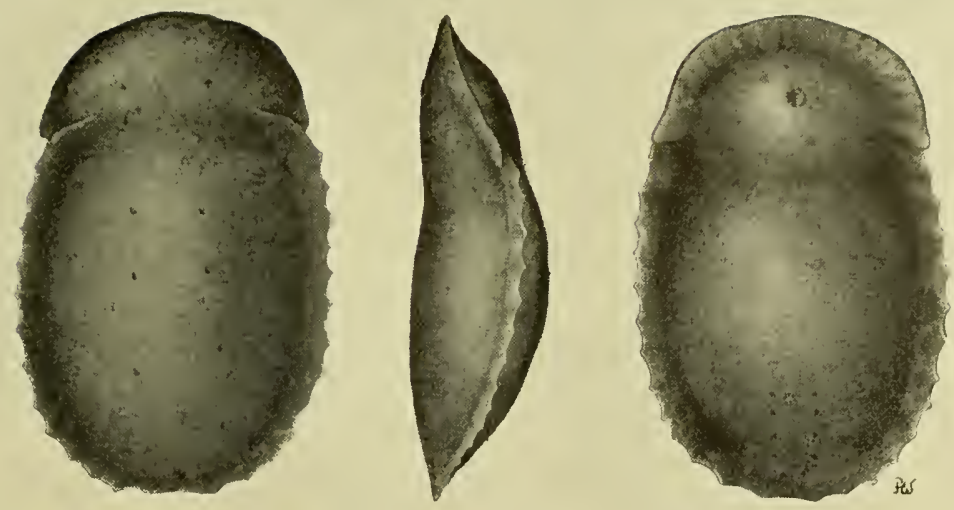

The new bathypelagic sea-cucumber Galatheathuria, seen from above, from the side, and fram below.

represented in the depths, though for the most part by other species, some of remarkable appearance. But in certain groups of otherwise typical bottom-dwellers there are also a few species which have adapted themselves to a free-swimming life.

Of the sea-cucumbers a few live pelagically. A few bottom-dwellers are able to ascend by wriggling up and down like leeches, but three forms are specially adapted to a pelagic mode of life. The first of these was found in I89 I off the west coast of Central America, and given the name Pelagothuria natatrix (Fig. p. 76). It has since been taken in several localities in the tropical parts of the Pacific and Indian Oceans. Only one species is known. It attains a length of Io centimetres and has a small, thin-walled body without the calcareous spicules characteristic of sea-cucumbers, and a large swimming fringe which almost encloses the mouth - it swims mouth upward. It is rose-coloured with a dark violet hind part. We found it at a number of stations between Africa and Ceylon (as many as $4 \mathrm{I}$ specimens in one trawl), in the Bay of Bengal, in the Kermadec Trench, and in the Gulf of Panama. The second genus is Enypniastes (formerly called Planktothuria). This also lacks calcareous spicules in the skin. It also has no swimming fringe, but remains buoyant by means of its very thick, gelatinous body-wall. Two species had been known, both of which we caught in the Bay of Bengal and, in considerable numbers, in the Great Australian Bight. 
In the China Sea, at a depth of between 3,400 and 3,800 metres, we found a third species. This is much larger than the others, being 25 centimetres in diameter, and is a pale, translucent blue with light-brown tentacles, Fig. p. 89). Also at this position we found an altogether new type, quite unrelated to the rest. It has been described as a new genus, Galatheathuria (Fig. p. go above). It is broad and oval in shape, is 22.5 centimetres long and 15 centimetres broad, and has a swimming fringe along either side. Its colour is dark violet and its consistency when fresh was rather firm. In the integument are numerous cruciform, calcareous spicules. It was a sensational find.

Many medusæ belonging to the bathypelagic region have either a very powerful musculature or are very thick and gelatinous.

The two magnificent medusæ, Atolla (Fig. p. 77) and Periphylla (Fig. below), were taken in nearly all of our bathypelagic hauls. They have vivid dark brown and dark bluish-violet colours, and both are widespread in the ocean depths. Atolla is even found in the icy deep of the Arctic Ocean, but is absent from the Mediterranean, being such a characteristically deep-sea species that it has never succeeded in crossing the threshold of the Straits of Gibraltar. Periphylla, on the other hand, is

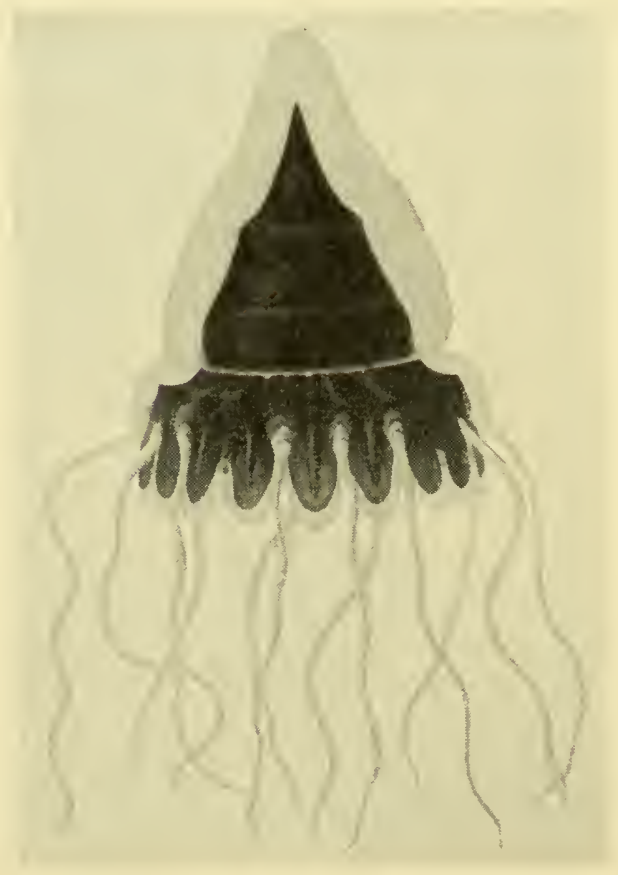

The deep-sea medusa Periphylla, which occurs in all the oceans. It can attain to a diameter of 25 centimetres. 


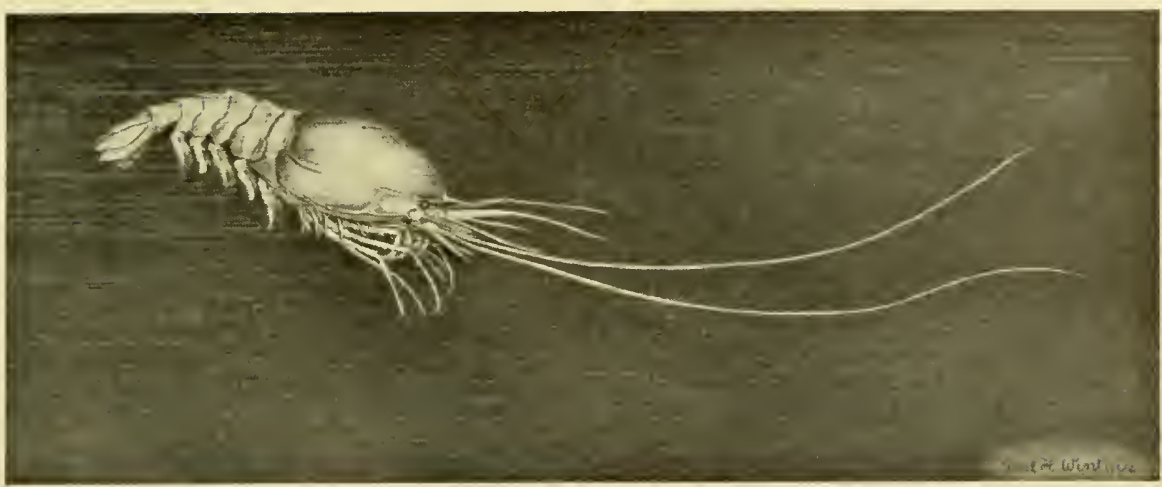

Scarlet deep-sea prawn, a new species of the genus Notostomus, I7 centimetres long without antenne; taken off East Africa at a depth of between 3,400 and 3,800 metres.

able to rise to upper water levels, though only in colder regions; in warm seas it stays below where the water is cold. The Galathea Expedition also found new species of deep-water medusæ. Of the genus Peryphyllopsis, which is related to Periphylla, there was only one known species, of which only two specimens had been seen, one in the eastern Indian Ocean and the other in the eastern Pacific. Both had been found in deep water and were six centimetres in diameter. We now found, between East Africa and the Seychelles, five specimens of a new species of this genus, six times the size of the others; and in the Bay of Bengal, also in deep water, we took one of the largest medusæ ever seen, a new species of the genus Cassiopea, nearlv a metre in diameter.

Crustaceans form a very substantial proportion of the animal population of the deep. Water fleas (Daphnia) and copepods are ubiquitous and provide an important source of food for other animals. A number of bathypelagic forms of amphipod were found, some with extraordinarily large eyes and others with a long, pointed head.

When the trawl came up from deep levels we could rely on finding in it brillant scarlet prawns, many of which would be very large. In general form they resemble the prawns of upper water levels and they are not noticeably adapted to life in the deep. A few from the extreme depths are blind. None of these has special light organs, but a few species, including some of the many belonging to the genus Acanthephyra, can envelop themselves in a cloud of luminous matter ejected from a pore under each eye. In the dark this will give as much concealment as the cloud of dark liquid in which a squid hides in the sunlit levels. We 


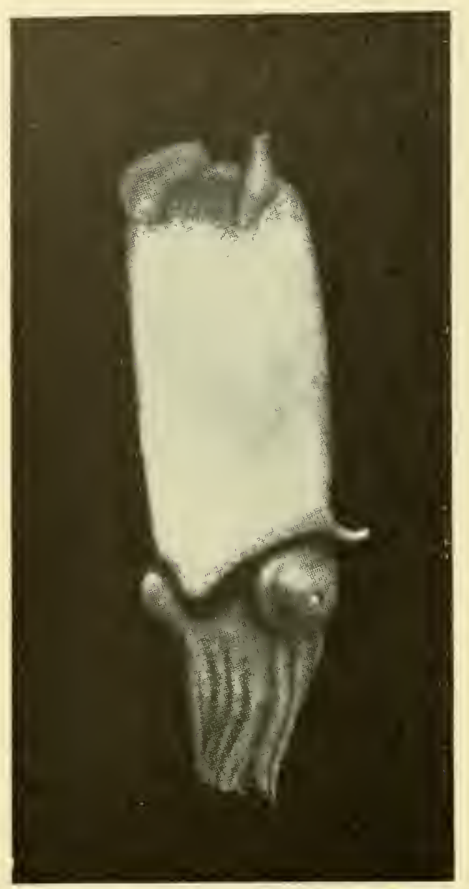

Spirula spirula, swimming. observed the same thing in another prawn, a Hoplophorus, and in an aquarium test we found this exceptionally animated when the temperature was between 15 and 20 degrees c.; it probably lived at a depth of $300-400$ metres. Notable among the numerous deep-sea prawns which we took is Hymenopenceus, the largest of the prawns, with a length of 30 centimetres from the tip of the frontal horn to the tip of the tail. It has unusually large abdominal legs with broad fringes of bristles, and must be a powerful swimmer. We found an exceptionally large and handsome species of the genus Notostomus, which has a high, sharp crest on the carapace. It was taken between Mombasa and the Seychelles at a depth of between 3,400 and 3,800 metres, and about I,500 metres from the bottom. It proved to be a new species (Fig. 8I).

Although there is plenty of meat on these giant deep-sea prawns, fishing for them in such deep waters would obviously not be profitable. But off Natal, at a depth of between 500 and 600 metres, we caught quantities of some large and palatable penæid prawns. The attention of the South African authorities was at once drawn to this prolific stock, which offers facilities for profitable fishing.

There are many bathypclagic squids and octopuses, some black, some a deep purple, and some translucent. Light organs are common, especially in the squids, and may occur in many places - on the body, the arms, the head, or the cyes. They may be few or many in number and of various types, primitive or highly complex. Most of the species are widespread in the oceans, though some have been seen on only a few occasions. We obtained several of these rare species.

Noteworthy among the squids is the genus Chiropsis, distinguished by its extraordinarily long arms. The single known species of this genus had been found by the Dana Expedition in the Atlantic. We found another in one of our deepest hauls, in the Kermadec Trench near New Zealand.

Another squid is the strange little Spirula spirula (Fig. above). This 
measures between seven and eight centimetres in length and has a whitish colour with rust-red markings. At the posterior end is a button-shaped light organ. But the strangest feature of Spirula spirula is an internal, spiral calcareous shell with a series of gas-filled chambers. The shells are very buoyant and are often washed ashore in large numbers, but the creature itself had rarely been seen until the Dana caught nearly a hundred specimens in the Atlantic and as many again in the Indian Ocean and the Pacific. We also caught many of them, and one evening in the Indian Ocean we took some live ones, which we were able to watch swimming about in the aquarium in their characteristic position, bottom up. We managed to film one of them in motion, actively moving up and down and from side to side until it succumbed to the fierce heat of the

The black deep-sea cephalopod Vampyroteuthis infernalis, which lives at depths of $1,000-2,000$ metres. The white spots ar light organs.

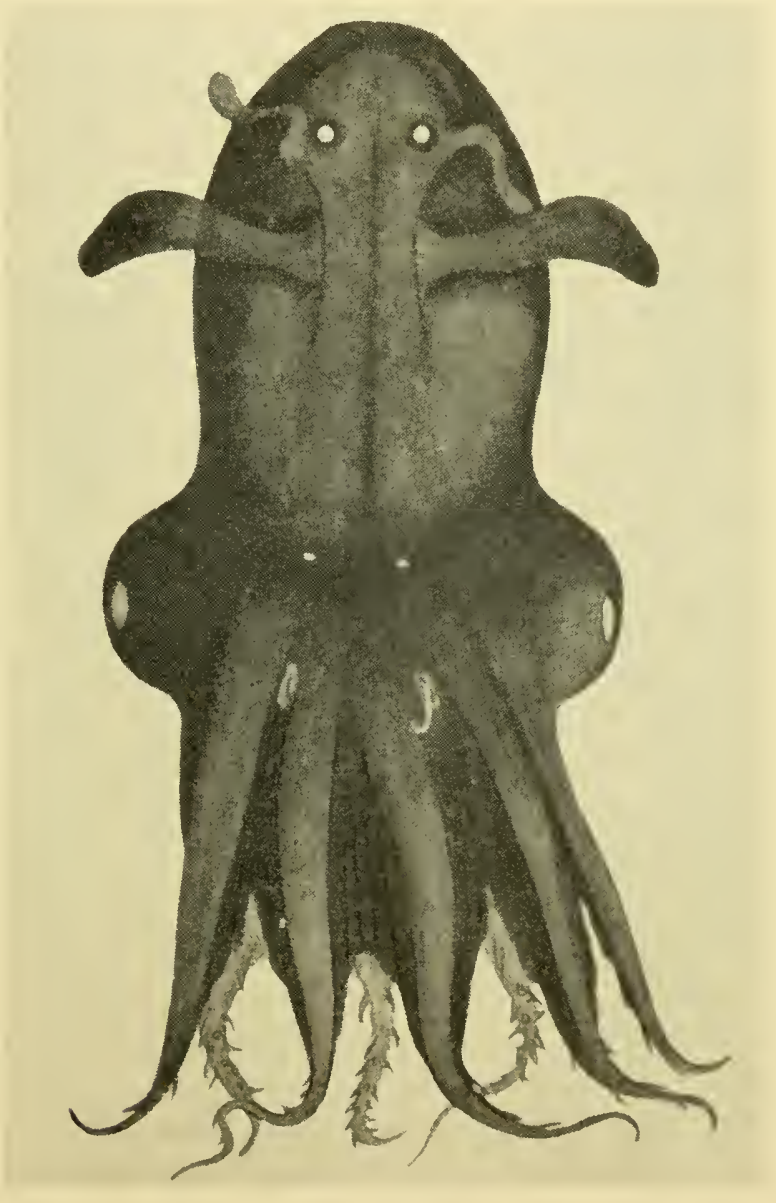


photographic lamp. Spirula inhabits all the great oceans, especially the midwaters from 200 metres downward, but is not found at the deepest levels. At a station off Natal, between 500 and 600 metres deep, we took no fewer than 26 specimens in a single haul.

Most of the octopuses are bottom-dwellers, but a few have successfully adapted themselves to a pelagic existence. The bodies of the pelagic forms are soft with a weakly developed musculature, and most have a thin membrane forming a web between the arms, often extending to the tips. They swim bottom up in graceful, pulsating motions like a jellyfish, moving their arms in and out. All are bathypelagic, though Alloposus, which we found at several stations in the Indian Ocean, and which had previously been known only from a few scattered localities in the warm regions of all three oceans, seems to keep fairly close in-shore, spending perhaps part of its time on the bottom. It has very large eyes and is translucent. A genuine deep-sea cephalopod is Vampyroteuthis infernalis (Fig. p. 83), which has been considered extremely rare. It is a velvety-black, broadwebbed creature with a few light organs on the body and fins. Several primitive features of its internal structure are regarded as evidence of its belonging to a group of cephalopods otherwise extinct since the Cretaceous period. We found it in the Bay of Bengal, in the Java Deep, and in the Kermadec Trench, always in very deep water. Off Durban, at a depth of about 3,000 metres, we took a specimen 22 centimetres long, twice the length of the longest hitherto recorded.

The most fantastic forms are found among the deep-sea fishes. The great majority of the really bathypelagic species are a uniform black, blackish brown, or blackish violet, matt and lustreless. Some have scales and some are without scales. The skeleton and musculature are more or less degenerate, the fishes presenting a loose and flabby appearance. It is popularly believed that animals accustomed to the massive pressure of deep waters will burst if brought to the surface. This is true only of fishes which have a closed swim-bladder, and real deep-sea fishes have no swimbladder. Some bathypelagic fishes are either blind or have very small eyes; others have "telescopic" eyes, which are thought to increase their powers of vision owing to the increased distance between lens and retina. Some have light organs and some have not. Many have large jaws and long teeth.

A deep-sea fish which is not noticeably adapted is Bathytroctes; it has a fairly normal fish shape, small teeth, and very large eyes, and in colour is blackish brown with a violet head. The genus Opisthoproctus is remarkable for its telescopic eyes in the shape of two parallel tubes, set like 
a pair of fixed, upturned binoculars. The fish has large, thin scales and its belly is as flat as the sole of a shoe. Gigantura also has telescopic eyes. Unlike most other fishes, it can see with both eyes at once. Gigantura is also notable for its extremely elongated tail-fin, as well as for its ability to swallow enormous prey. Another strange fish is Stylephorus (Fig.adjoining), which is related to the deal-fish;its binoculars can be turned both upward and forward. This is a silvery, ribbon-shaped fish, the two bottom rays of the caudal fin being elongated into an immensely long thread which may be twice as long as the fish's body. The large eyes are forwardly directed. But the strangest feature of all is the mouth. This is small and toothless, but can suddenly be thrust right forward, when the whole facial appearance will change simultaneously, so that the eyes turn upward instead of forward. All these and many more fishes were found on the expedition.

An unusually ferocious appearance is presented by the angler-fishes, a strange group in more ways than one. Some, like our common angler, Lophius piscatorius, are bottomdwellers; and a wide range of small species live in the Sargasso weed which drifts about on the surface of the oceans. The bathypelagic angler-fishes (Ceratioidea) form a special sub-order comprising nearly a hundred species. Most of these are small, short, and plump and have only a small tail, their swimming powers being rather poor. They are black and scaleless, and they have small gill-slits and small, almost rudimentary eyes. The jaws are huge with many long, spiky teeth which can be folded back when the mouth is closed. The stomach is very distensible. They have a stalky light organ (a transformed fin ray) on the nose, and a few also have a luminous chin-barbel. They occur most frequently at depths below 2,00o metres, though young individuals may be found at higher levels. They inhabit all the oceans, but predominantly the tropical and subtropical zones. In these dark depths it may be difficult for the sexes to find each other, a problem which the deepsea angler fishes have solved in a very remarkable way, unique among fishes. While quite small, the male fish grips some random part of the female with its jaws. Some-

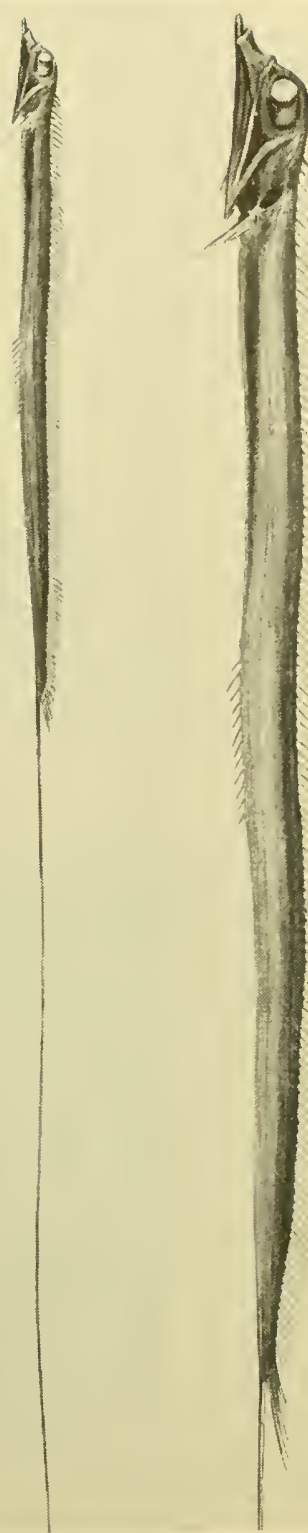

A deep-sea fish (Stylephorus) which swims with its head up ana tail down. The figure on the left is greatly reduced to show the full tail flament. Inhabits depths of $200-$ 400 metres. 
times there will be several males to one female. In time the mouth of the male becomes completely fused with the skin of the female, and its organs, except for the sex organs, degenerate, so that for the rest of its life it is nourished by the blood of the female. It is a marriage tie which cannot be broken. We caught a number of these remarkable fishes including, in the Gulf of Panama, the rare Borophryne, illustrated below with a dwarf male clinging to the ventral side. A specimen of a similar species, Melanocetes, was taken out of its glass whenever we had visitors on board, so that they could see it fold and unfold its teeth.

The depths of the ocean are sparsely populated; and so when an anglerfish is occasionally lucky enough to meet with a prey, it likes to have a square meal. The prey is lured by the light of the "lantern"; and when the angler-fish suddenly opens its jaws, the prey is simply sucked in and trapped by the teeth, which rise from their folded position once it is inside. The angler-fish is quite capable of swallowing a fish bigger than itself; but should its teeth close on a creature stronger than itself the result may be disaster, because it cannot release it.

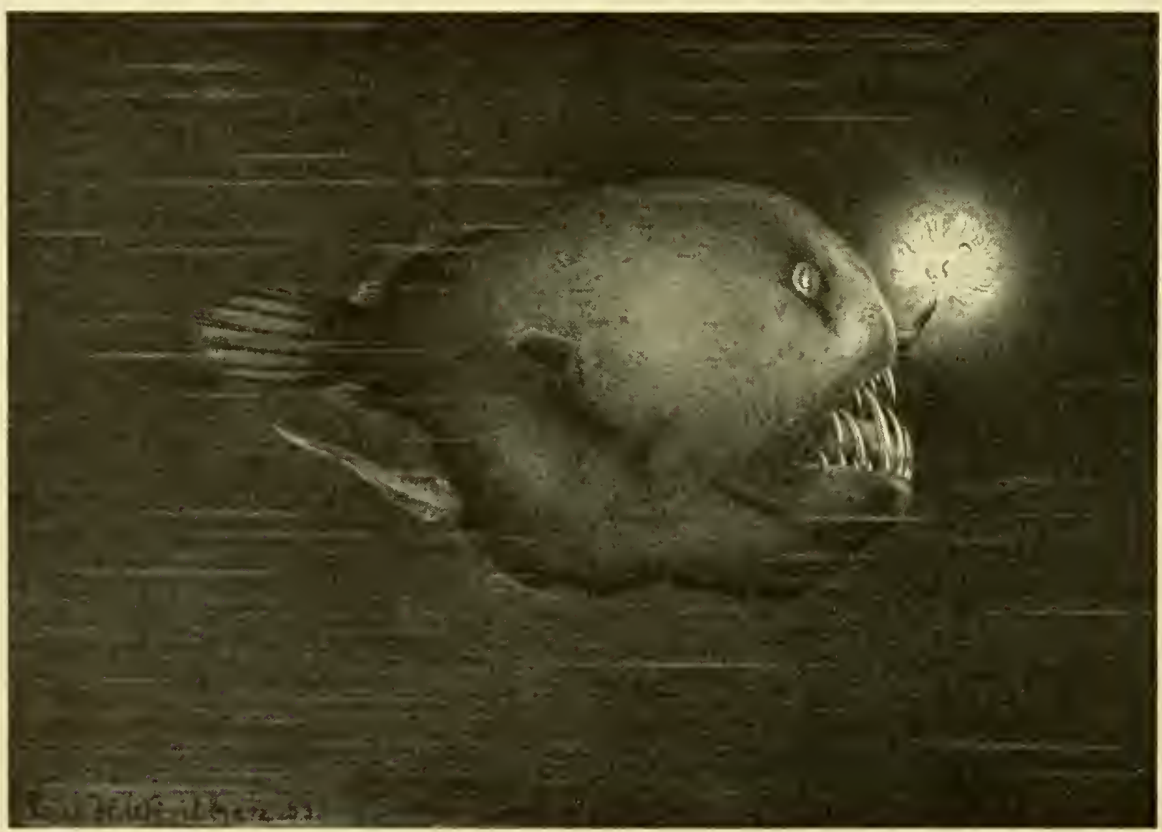

Deep-sea angler-fish (Borophryne), lamp on nose, and with a dwarf male grown on to the ventral side. 


\section{SEA SNAKES}

\section{By H. Volsøe}

When introduced, during my stay on the Galathea, as a specialist in sea snakes, I invariably got a look of polite interest mingled with a good proportion of scepticism. Clearly, most people doubted the existence of such things and thought I was joking. It was neccssary to put on a serious scientific face in order to convince them that there really are such creatures and that they probably have nothing at all to do with the Great Sea Serpent which obviously underlay their scepticism.

There are some fifty species of sea snakes. They form a well-defined group whose nearest relatives are the cobras, with which they are classed as Proteroglypha, a group characterized by a well-developed, rigidly attached fang at the front end of the upper jaw. The highly virulent venom flows through a canal in the fang into the wound inflicted by the snake's bite.

My interest in the subject springs from the fact that a number of years ago I worked on some sea snakes brought home by Danish fishery expeditions from the Persian Gulf. With the exception of one, which for a short time was kept alive in a jam-jar, the material consisted of preserved specimens. My study of these snakes and the literature about them convinced me that the biology of sea snakes presents many absorbing problems which we can only hope to solve by observing them in their natural environment and possibly making experiments on live animals. As the Galathea's route lay through the centre of their distribution - the waters around South-east Asia and Indonesia - I naturally seized the opportunity which this provided for collecting and observing sea snakes myself.

I boarded the ship at Mombasa and cherished a hope of finding my first sea snakes near the Seychelles, where one or two species have occasionally been caught, as they have further south near Madagascar. My hopes were doomed to disappointment. Despite a keen search all over the shallow plateau on which this group lies we failed to catch one. Inquiries among the local population confirmed the impression that sea snakes here are rare, and that most people have never seen one. We thus obtained corroboration of a strange feature in their geographical distribution: while the eastern side of the Indian Ocean teems with them, only two species, Enhydrina schistosa and Pelamis platurus, have succeeded in penetrating beyond Arabia down the East African coast, though Pelamis has man- 
aged to get as far south as the Cape. Here it stops, and in the Atlantic, strangely enough, no sea snake has ever been caught. We may conjecture that they are prevented from entering the Atlantic by the cold Benguela Current, which they encounter immediately they pass the southern tip of Africa. The fact is that sea snakes are distinctly tropical creatures, scarcely capable of thriving and brceding in the cold water along the west coast of South Africa. Probably, however, it is only a question of time before they appear in the Atlantic: their advance along the east coast of Africa is presumably of recent date, and though in the long run they would not survive in the Benguela Current, this would carry them northwards into the Gulf of Guinea, where they would doubtless find favourable conditions.

It is hardly likely to be an accident which has made Pelamis the pioncer in the westward advance of the sea snakes. While the great majority of sea snakes are closely linked to the coast, catching their prey on the bottom, this species has so far adapted itself to an aquatic existence that it has become pelagic; in other words, it is independent of the coasts and sea-bed and is able to catch its food among shoals of pelagic fish.

Ceylon, the next station on the Galathea's route, is one of the classic localities of sea snakes. Not only are a large number of species known from the coasts of this tropical island, but many of the species are extremely abudant. But here also my hopes of a catch were disappointed. We went straight into port at Colombo, and during our four days there the south-west monsoon blew so hard that hunting for sea snakes was out of the question. I was beginning to feel a little embarrassed, especially since before calling at Colombo I had given a lecture on sea snakes in which I had warned the crew against getting too near them owing to their venom. However, two days after we left Ceylon our luck changed. We had anchored in 14 metres of water off the former Danish colony of Tranquebar in south-east India. The motor-boat was launched and a small reconnaissance party set course towards the land. On our way back we ran alongside one of the native fishing boats, a remarkable type of vessel consisting of three slightly curved tree-trunks tied together. The waves continually wash over these boats, but as the natives are almost naked no harm is done. They were just hauling in their net when we came up with them, and suddenly I saw one of the fishermen put his arm into the net and pull out a writhing sea snake which, with an air of indifference, he threw overboard before I had time to call him. This was a bitter disappointment, but at least I now knew that there were sea snakes about. And sure enough, no sooner had we begun fishing with 


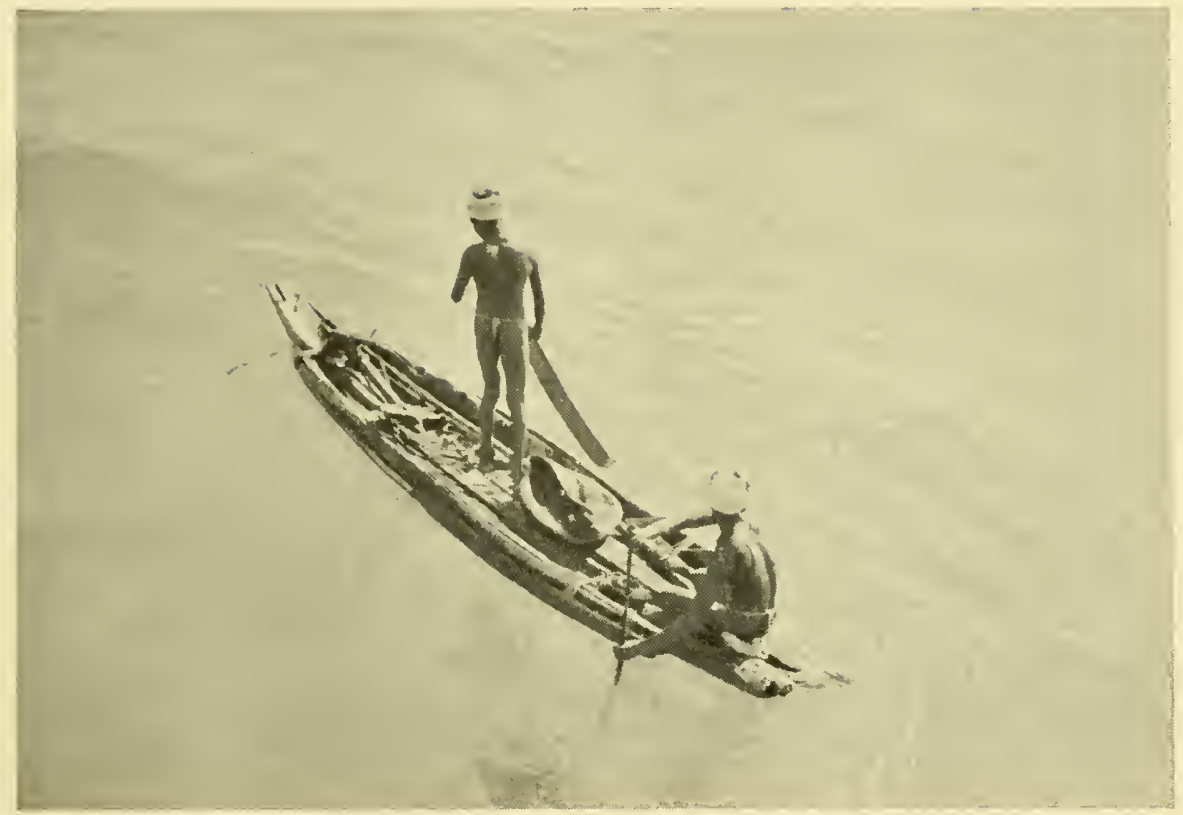

Indian fishermen in their primitive craft made from three tree-trunks of a special kind of lightweight wood.

a light that evening than we caught the first sea snake, and before long they were pouring in at such a rate that we had to make use of everything the Galathea possessed in the way of aquaria and tubs until such time as they could be killed and preserved. On that and the following day we had a total haul of 40 snakes belonging to six different species, and from then until we arrived at Singapore we made catches, though not in such large numbers, each time we entered shallow waters. Sea snakes were occasionally caught also after my return home, particularly in the shallow Gulf of Siam, which has long been noted for its profusion of snakes. The last were taken in the Gulf of Panama, though the sole species known here is the above-mentioned pelagic species, Pelamis platurus, the only sea snake that has crossed the Pacific. It is strange to think that this species stands at two points on the threshold of the still snake-less Atlantic - at the southern tip of Africa and at the Isthmus of Panama, where, theoretically at least, it should have a chance of slipping through the Panama Canal.

The catching of sea snakes is an extremely simple matter. When the ship is lying still they will drift towards you on the current, lying motionless in the surface water. When they come within reach you thrust a net 
under them and haul them up on board. Most are caught in this way at night with the aid of a light. In the daytime most sea snakes are presumably submerged, hunting their prey on the bottom and probably catching it visually, though this cannot be known for certain. From time to time they must come up to breathe, for, of course, like other snakes they breathe by means of lungs. How long they can remain submerged is uncertain, but by calculation based on the capacity of their lungs, metabolism, and other factors I have previously deduced that it is probably a matter of hours. After my departure some "drowning" tests were made on sea snakes. Although in these experiments the snakes at first writhed vigorously in their attempts to get out of the closed container, and so consumed far more oxygen than normally, they remained alive for over two hours, which agrees very well with the result I had arrived at by indirect means.

On the bottom the snakes doubtless lie quietly in wait for their prey, which they then catch by a rapid attack exactly like their terrestrial relatives. In their stomachs we found only bottom-dwelling fish, and eels of various species seem to be a special favourite. For the rest, there is undoubtedly a difference in the choice of prey and method of catching it as between different species of sea snake; the great variations in the shape of the head and the forepart of the body certainly suggest this. There is one genus, Microcephalophis, in which the head is no bigger than a fingernail and the forepart of the body no thicker than a little finger, while the hindpart is as thick as an arm. One is tempted to suppose that this snake crawls about coral recfs exploring narrow fissures
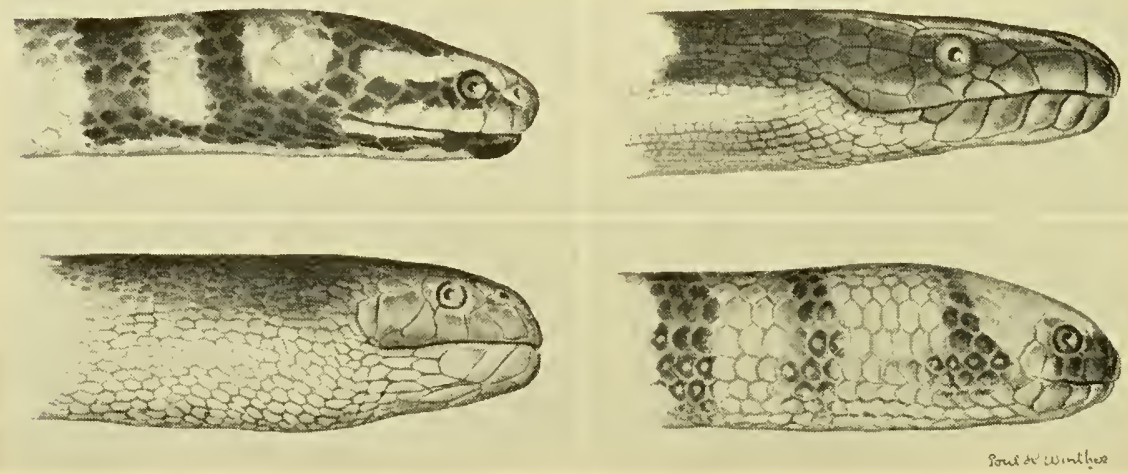

The physiognomy of sea snakes shows great variations. The four species illustrated reveal clear differences in shape of head, size of mouth, siting of eyes, coloration, and other features. 


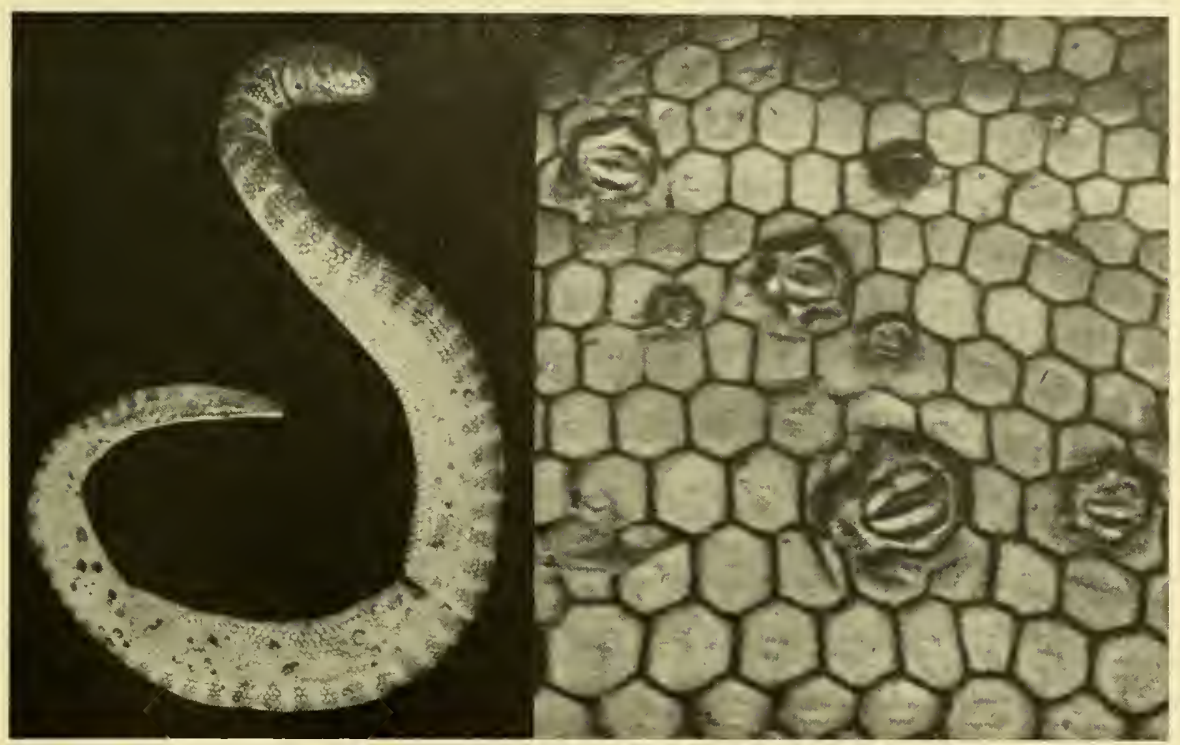

Left, sea snake overgrown with barnacles. Right, a small portion of the skin enlarged, showrng hexagonal scales (not overlapping) and barnacles with bivalvular shells. The barnacles attach themselves to the snakes as free-swimming larva.

with its thin forepart in search of the eels which constitute its only food.

When a sea snake is emptied out from a net on to the deck it is completely helpless. It writhes and wriggles but does not get anywhere. The ventral shields, which in snakes are normally an important means of crawling, are in most sea snakes very degenerate or totally absent; and, in addition, the hindpart of the body and the compressed, paddle-shaped tail have a pronounced downward curve which, on land, causes the animal to turn over on its side. However, helplessness when on land, as we shall shortly see, is not true of all sea snakes.

For all their helplessness we handled our sea snakes with some respect, seizing them behind the head with a pair of long tweezers and then grasping them by the tail with the other hand. How dangerous they are we do not know for certain, as the little information available is extremely contradictory. On the one hand, careful experiments have shown that the venom of sea snakes is ten times as toxic to certain animals as that of the cobra. A dog, for example, died from a bite in less than an hour. The effect of the venom of a sea snake, like that of a cobra, is to paralyze the central nerve system, death being due to asphyxiation owing to the paralysis of the respiratory system. The venom is particularly toxic to 
cold-blooded animals, and especially, as one would expect, to fish. On the other hand, very few cases are on record in which the bite is known to have been fatal to man, and the carelessness with which they are handled by fishermen is not suggestive of any great danger. The reason for this, as far as I can make out, is that most sea snakes are very disinclined to bite when out of the water. They made an extremely inoffensive impression when attacked with the tweezers, and in fact I was on the point of dispensing with this precaution when I was warned that not all sea snakes are equally placid. In the Straits of Malacca we caught some specimens of a comparatively large and clumsy species. When I grasped it in the usual manner it wriggled so violently that I several times dropped it, and it bit fiercely and vigorously at the tweezers. When I eventually got it into an aquarium where there were already some other sea snakes, it continued its frenzy, snapping at the other snakes and furiously attacking the glass walls of the aquarium. This little experience shows that there is reason to handle sea snakes with caution until we know more about the danger of the respective species.

Another incident on the Galathea scrves to illustrate that there are sea snakes and sea snakes. The aquaria in which we kept our live sea snakes were about half full of water. As none of the snakes had made any attempt to leave the water, and moreover were quite incapable of moving about on land, I suppose I had grown rather careless about covering up the aquaria. One night the pump engineer was having a cup of coffee in the quartermaster's mess after being relieved from duty when he had the shock of his life, at the sudden sight of a long snake slithering over the floor. It was a fairly easy matter to catch it and put it back in the aquarium, but feelings were rather excited until a "census" of all the snakes showed that this was the only one that had got out. To my shame I must confess that I slept through the whole episode, but being told of the affair the following morning I was at once able to establish the species. There is, in fact, only one species of sea snake in this region which is capable of betraying the confidence I had shown in it. It belongs to the genus Laticauda, which in several respects is more primitive than other sea snakes; among other things, it has well-developed ventral shields and altogether a more normal snake form. Doubtless it was these characteristics which enabled it to traverse the comparatively long way from the laboratory to the quartermaster's mess.

In an aquarium I had one day put two sea snakes. The next morning, I found on looking into it that there were five. The three newcomers were rather smaller than the other two, being about the size of a common 


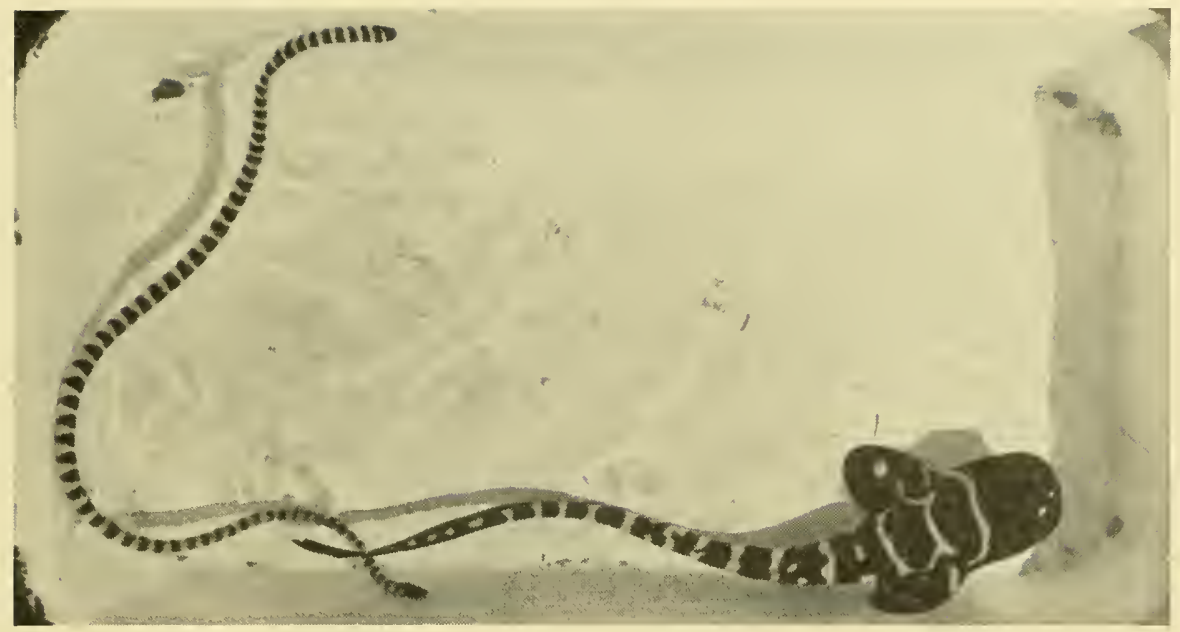

A marking of alternate dark and light bands is very common in sea snakes, especially in young individuals. The same coloration also occurs in many fishes, including the shark shown above, and many eels.

viper. As no snakes had been caught during the night, the only solution to the mystery was that one of the original two must have given birth to three young ones. At a first examination of the "young" this solution seemed rather improbable. In the first place, they were nearly half as long as the designated mother, and in the second, the coloration was quite different: whereas the young had a handsome coloration with sharply definęd dark and light rings, the parents had a dark back and a light belly. Moreover, the young made no impression of being newly born but behaved as though they had lived a long life in the water. All these things, however, are characteristic of sea snakes, and a closer inspection in fact proved that the young snakes belonged to the same species as the big ones, so that there can be little doubt that we had found the right solution.

These features of young sea snakes show, perhaps better than anything else, how well these creatures are adapted to an aquatic existence. Not only do they bring forth living young (many land snakes do that), but the young are born in a very advanced stage and with all the modifications found in the adult animal, so that they are immediately self-supporting in the struggle for existence. An Indian zoologist, incidentally, has recently shown that this advanced development is due to a transmission of food from the mother to the embryo, a placenta being formed round each egg as in mammals. If this were not the case, the young 
would have only the yolk of the egg on which to grow and so would never attain to so considerable a size.

The different coloration of the young is probably due to their different mode of life. Both forms of coloration - the alternate dark and light bands in the young and the dark back and light belly of the adults - are good examples of protective colouring. The light and dark bands cause the animal's contours to dissolve; to break up, as it were. This form of mimicry will be especially effective among algæ or branched corals. The dark back and light belly are a form of camouflage frequently met with in many pelagic fish, like, for example, herring and mackerel; as such creatures will normally be illuminated from above, the belly will appear darker, the back lighter, than in reality they are, with the result that the animal will seem to be uniformly coloured. It can therefore be said, with a fair amount of certainty, that the young frequent the coastal seaweed zone or coral reefs, while the adults swim in deeper water. A close study of the biology of sea snakes will doubtless confirm this theory. It is a curious fact that the adults usually retain the coloration of the young on the tail (see Fig. p. 95). This circumstance would seem to invalidate the theory just advanced, but in fact it provides the best conceivable confirmation of it: the tail is held vertically when the snake is swimming, and so, at best, it would serve no useful purpose to have it coloured like the body.

I indicated in the introduction to this chapter that sea snakes are hardly likely to have provided the model for the countless reports of the Great Sea Serpent. There are many reasons why this is so, including the one that no sea snake is ever longer than three metres and most are only about one metre long. The great majority of accounts of sea serpents also come from the Atlantic, where there are no sea snakes. Moreover, as already stated, all sea snakes with the exception of one small species occur quite near to the coast, while sea serpents are typical ocean-dwellers. Consequently, we must look to other zoological groups for the model of the great sea serpent - if there be any such.

Although this "exoneration" takes away some of the romance of sea snakes, this little group of animals, by its interesting adaptation to a new environment, is an absorbing subject for study. Several attempts have been made to obtain some specimens for the Danish Aquarium, and we also tried to do so. All attempts so far have failed owing to difficulties of transport. Sea snakes suffer from long transport over land, but it should be possible to bring them by air. This short chapter may suitably close with the hope that the attempt will one day succeed, so that the general 
public may enjoy the beautiful colours and graceful motions of sea snakes, and scientists have an opportunity of studying the many imperfectly known features in their biology.

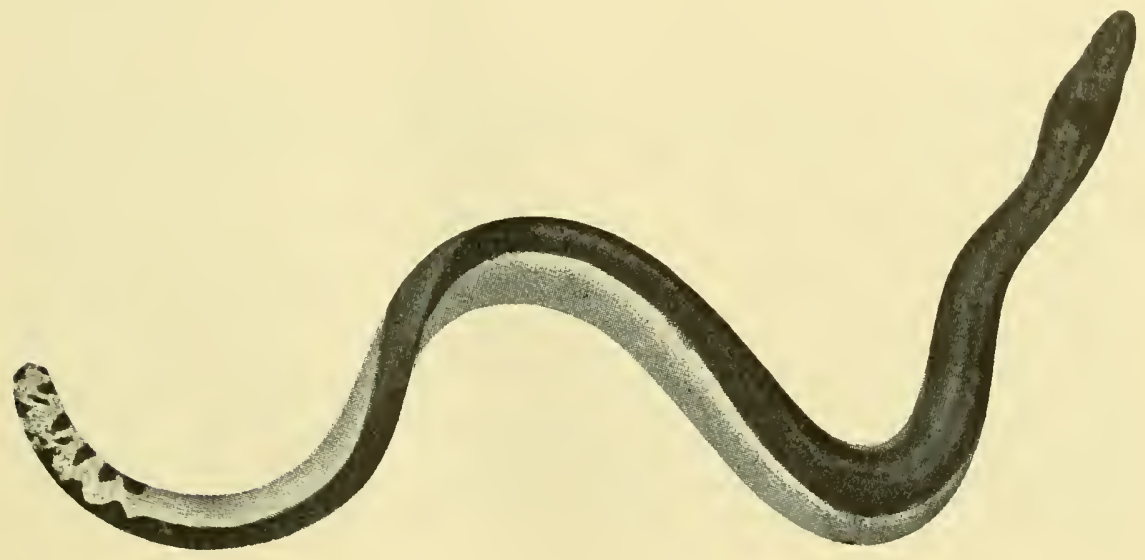

The most sea-adapted of all sea snakes. Head on the right, tail left. The back is black, the belly yellow. 


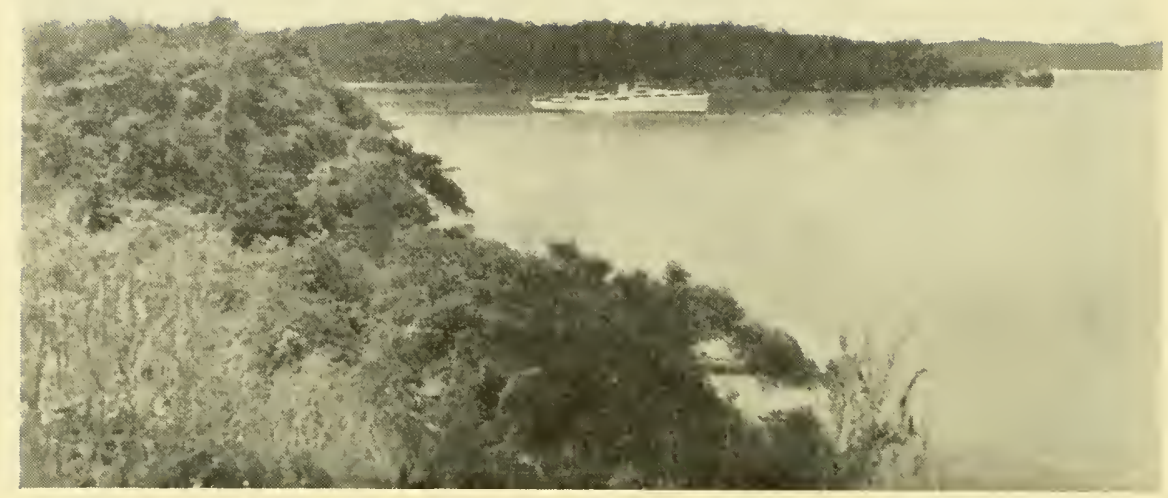

\title{
OUR VISIT TO THE NICOBARS
}

\author{
By H. Volsøe
}

We arrived on deck on Sunday morning, May 6th, 1951, to find the Galathea lying at anchor in a most beautiful natural harbour. The air was calm and mild, the sea like a mirror; and surrounding the harbour on all sides were wooded hills, broken here and there by bright-green patches of grass. Small bays along the coast were fringed with glistening white sand, and the slender trunks of palm-trees overhung the shore.

A few days before, we had left sweltering, dusty, and smelly Calcutta with its teeming and half-starved multitudes. The reek of temple incense and the stench from funeral pyres still clung to our nostrils. It was like waking up to find ourselves transported from Inferno into Paradise. Wc were bound for Singapore and were about half way across, at the Nicobars, the small group of islands which with the Andamans further north form a festoon of small islands linking up the northern tip of Sumatra with Burma. The heavy swell of the Indian Ocean breaks against the 
islands on the west, and on the east they are separated from the Malay Peninsula by the Andaman Sea nearly 4,00o metres deep.

Our reason for calling at the Nicobars was not merely that they lay athwart our path but equally that they once belonged to Denmark. It is a little remembered fact though it is less than a hundred years since we voluntarily - and freely - ceded them to Britain. The transfer of sovereignty had been preceded by more than a century of Danish attempts at colonization, all of which had failed after a few years of hopeless struggle against the unhealthy tropical climate. Many enterprising and adventurous Danes had lost their lives in these unsuccessful projects, the notorious Nicobar fever taking a heavy toll at every new attempt.

All this seemed very remote and unreal as we gazed at the magnificent scenery that morning. Yet Nankowry Harbour where we now were had witnessed several of these tragic attempts. One of our objects in calling at the place was to try to discover whether the early colonists had left any traces. Let me say at once that, on the whole, the result of our search was negative. All that remains of the Danish occupation on Nankowry Island is a few brick foundations; the rest has been wiped out by the tropical climate and vegetation. More thorough exploration and excavations might reveal a little more, but $I$ think it is safe to say that there are more relics of the Nicobars in Denmark than vice versa. The corvette Galathea, returning from the final Danish attempt at colonization in January-February I846, brought back copious ethnological collections to the National Museum in Copenhagen. It was also our object to supplement this material, so as to enable our ethnologists to ascertain what change had taken place in the native culture over the past century. Our third object was to collect fauna for the Copenhagen Zoological Museum. The first Galathea Expedition had already done so, but a considerable part of the collections, including the birds, had gone to the University of Kiel and is believed to have been lost. The islands have a distinctive and peculiar fauna which we were interested to have represented in our museum.

We thus had plenty to do, and in order not to waste the short time available the work was distributed in advance among various landing parties. Nankowry Harbour is actually a sound formed by two islands, Nankowry on the south and Camorta on the north. The parties were divided between the two islands.

Various formalities had to be gone through before we were able to land. The islands belong to India, with which they were included when India gained her independence in 1947. Presumably this was because 
they had formed an administration of British India; geographically and ethnologically it would have been more natural to unite them with Malaya. And so, by the irony of fate, after fighting so long for her own independence from Imperial rule, India is now herself an Imperialist power. However, our impression of India as a colonial Power was extremely favourable: though it would appear tempting to so overpopulated a country as India to avail herself of these fertile and sparsely populated islands in order to find room for some of her hungry millions, the Indians - like the British before them - seem generally inclined to leave the natives to themselves apart from affording them protection and humanitarian aid. Indeed, the first person to board our ship in Nankowry Harbour was an Indian doctor, who was also the leading civil authority. Dr. Ramanand made a very pleasing impression; he had an excellent command of English, and as he also spoke the native language and was obviously very popular with the natives he was of great assistance to us during our stay.

Formalities over, our first party went ashore. On each of the two islands there was a small native village consisting of the characteristic huts built on piles, exactly like the pictures in the old Danish accounts. We were at once surrounded by friendly, smiling natives, mostly boys and youths. Of the women we saw very little; and it would seem that the custom of hiding them on the arrival of a strange ship, referred to in all the old accounts, is still maintained. It is a precaution which does not appear to have prevented some intermingling, for physically the population made a somewhat heterogeneous impression, though the Malay type predominated. The men's dress consists, as it did a century ago, of a narrow cotton loin-cloth with the ends hanging like tails back and front. Sten Bille, giving a detailed account of the natives in his report of the first Galathea Expedition, repeatedly stresses their repulsive appearance, and especially that of the women, whose "ugliness exceeds anything one can imagine". It is a description which I certainly cannot endorse. Many of the men possessed handsome athletic figures, and the young women whom we saw later might be called good-looking even by European standards. Bille was undoubtedly judging them by European ideals, but apart from this some of the "barbaric". customs of his period appear to have been abandoned. It was customary, for example, in those days for the natives to smear their faces in lard and then rub in a bright-red pigment, while the men would invariably have a cigar suspended from their pierced ears. Both these forms of facial adornment seem to have gone. Nor did we find the natives' teeth so badly stained by betel-chewing as reported by 
Originally the natives of the Nicobar Islands lived in round, hive-shaped huts on piles, but under European influence some of these have been replaced by quadrilateral buildings built on piles.

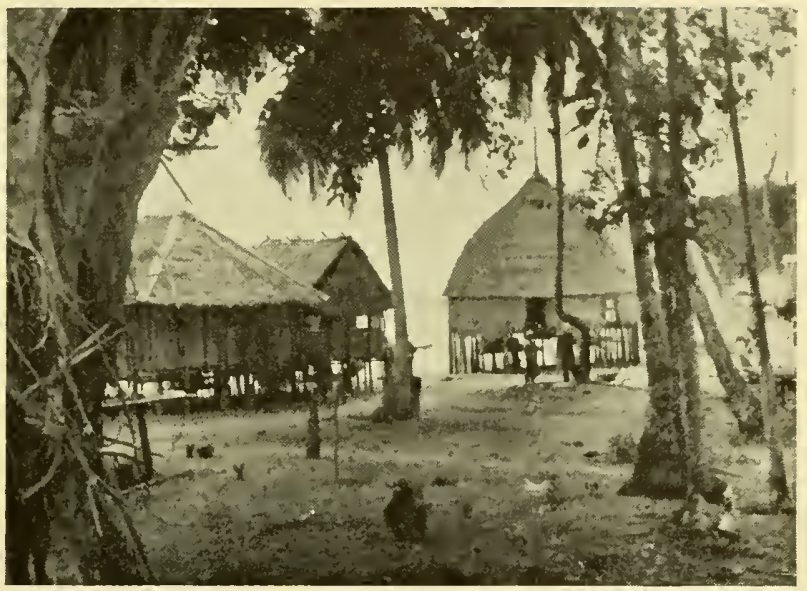

Bille, though why I cannot say, because betel-chewing is still common and dental care is unlikely.

The village of Nankowry, where I landed with a collecting party, stands in a small grove of coconut palms. Coconuts form the principal food, and as the coconut palm (at least in the more southerly islands) grows only along the coasts, all the villages are close to the shore. The forest began just at the back of the village. It was astonishingly luxurious, consisting of a great variety of trees all densely tangled with lianes and overgrown with epiphytic ferns and orchids. Many of the lianes were extremely thorny, and as the ground was very wet and clayey as well as thickly strewn with projecting roots, it was difficult to make headway, though native boys guided us along some beaten tracks. In the hot, humid, and stagnant air we were soon drenched in sweat. In this rain forest it was easier to understand that the climate could be unhealthy than it had been in the open sound. But we had all been more than usually careful to take our daily anti-malaria pill, though I must add that neither here nor anywhere else in the Nicobars did I notice a single mosquito, a fact probably connected with the time of our visit in the relatively dry reason at the end of the north-east monsoon period.

We had not gone far when the paths came to an end and all further advance was impossible. The scientists of the old Galathea had met with exactly the same difficulty when they had tried to penetrate into the interior. Now, as then, the native living-space seems to be a narrow coastal belt; they never go into the forests, all communication between the villages being either along the coast or by sea.

On our morning expedition we succeeded in bringing down a beautiful 
green parrot, some small reddish-brown pigeons, and a number af smaller birds. We found on our return to the village that Captain Greve and Dr. Bruun were making a courtesy call on the "Queen", the local native chief. Later in the day she paid a return visit to the Galathea, together with her daughter, her sons, and her brother. She was a dignified matron, and on the occasion of our visit attired in her best, a flowered cotton dress. As she did not speak English, Dr. Ramanand was obliged to interpret for us; and before leaving the ship, her Majesty and the rest of the royal family duly made their marks in the Galathea's visitors' book. The queen's house was a rather large, square building standing on piles, but apart from this there were many of the original cube-shaped huts in the village. The space underneath was peacefully shared by playing children, pigs, and poultry. On the sandy beach in front of the huts lay the native boats, outrigger canoes made from hollowed-out tree-trunks, very slender and gracefully shaped.

Our ship was to have left Nankowry Harbour the same evening, but we were informed by Dr. Ramanand that there was to be a big funeral celebration in a native village at the north of Camorta, and he offered to take a small party there by boat. This was a unique opportunity, and so it was decided that the Galathea should stay overnight. For the twelve chosen to go on this nocturnal expedition by motor-boat it was an amazing experience, an encounter with a primitive and uncorrupted culture of a kind not found in many places today. As we arrived unannounced, there was no question of a specially arranged display for tourists.

The queen from Nankowry accompanied us, as did her daughter and two sons, the last-named acting as pilots. Her brother also wished to come, but during the day's ceremonies he had partaken too freely of the liquid refreshments, and when he tried to board the motor-boat on rather shaky legs a stern glance from the authoritative queen made him desist.

The journey to the village of Moshoit was an experience in itself. It was dark when we entered the strait between Camorta and the island of Trincut to the east of it. Coral reefs extend from both of these islands, leaving a narrow winding fairway which in places is only I 00 metres wide. As the tide was in and it was calm weather the reefs were invisible, and we could not help but admire the native skill in navigating in these difficult waters. As it was, we had one narrow escape. When the pilots believed we were clear of the channel, the order was given for full speed ahead; but hardly had it been carried out when a collision with a coral reef sent us all sprawling about the boat. One of our pilots nearly fell overboard. However, we escaped with the shock. We could feel the 
Most young men had fine ath. letic figures. The population appeared to be strongly mixed.

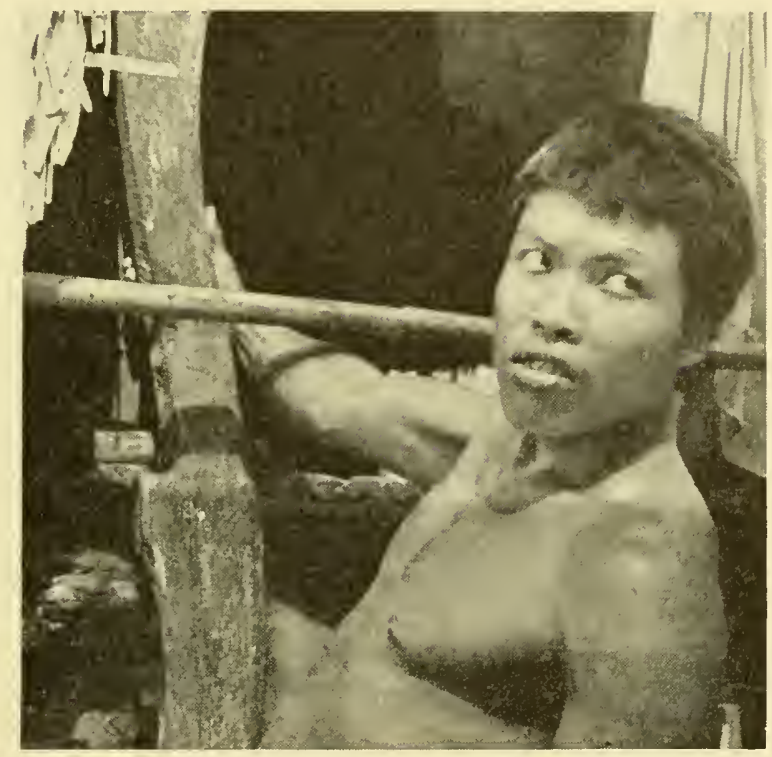

scraping of the coral, but then we slipped off into deep water once more and procecded without further mishap. After about two hours we saw lights ahead. It was Moskoit, our destination. Slackening speed as we approached the coast, we signalled with our pocket torches to summon the inhabitants, and eventually we saw lights coming towards us from the shore. We dropped anchor and stared intently into the dark. Suddenly, two very large outrigger canoes emerged from the blackness. Each was paddled by a crew of four or five and was gaily decorated with poles and coloured ribbons, and there was a beautifully carved "bowsprit" both fore and aft. Our party was divided between the two canoes, which, though they were so narrow that there was just room for one man on each thwart, could each hold between 15 and 20 persons. The crew applied themsclves to the paddles and we sped towards land. At every stroke the sea shone with phosphorescence. On the shore ahead of us natives stood holding torches and dark figures were running about in the light of them. In the background we could discern the circular huts on their piles.

When we got into shallow water the crew sprang into the sea and, to the accompaniment of quick cries, hauled the boats ashore so that we were able to step ashore dry-shod. An amazing scene met our eyes. A large crowd of reddish-brown natives, nearly all men and children wearing the customary loin-cloth, received us. Two men were holding 
torches made from bundles of dried palm leaves. A chorus of wailing women's voices issued from a large hut just by the landing-place.

On the shore in front of the hut stood a rusty old iron bedstead over which was erected a frame of bamboo canes decorated with flags. We learnt later on that the bed was a sort of cloak-room where guests left their things - sticks, weapons, and so forth - before entering the hut for the celebration. It had come from a British hospital, having been "liberated" by the natives when the British had evacuated the islands in 1942 .

The hut from which the wailing issued was one of the usual circular ones on piles but was very large, I think the largest in the village. You entered it by ascending a tree-trunk with steps carved in it. The inside of the hut was illuminated by the faint light of oil lamps, and a strong reek of burning oil, rancid pork, and cigarette smoke assailed us as we stepped inside. The grotesque sight which met our eyes almost took our breath away. Sitting cross-legged on the floor surrounding the central pole were a number of young women, each holding in her lap a human skull! The skulls were swathed in several layers of brightly coloured cotton material, some also in bath-towels, leaving only the "face" free. Over and above the cloth each skull had a head-dress, which in most cases con-

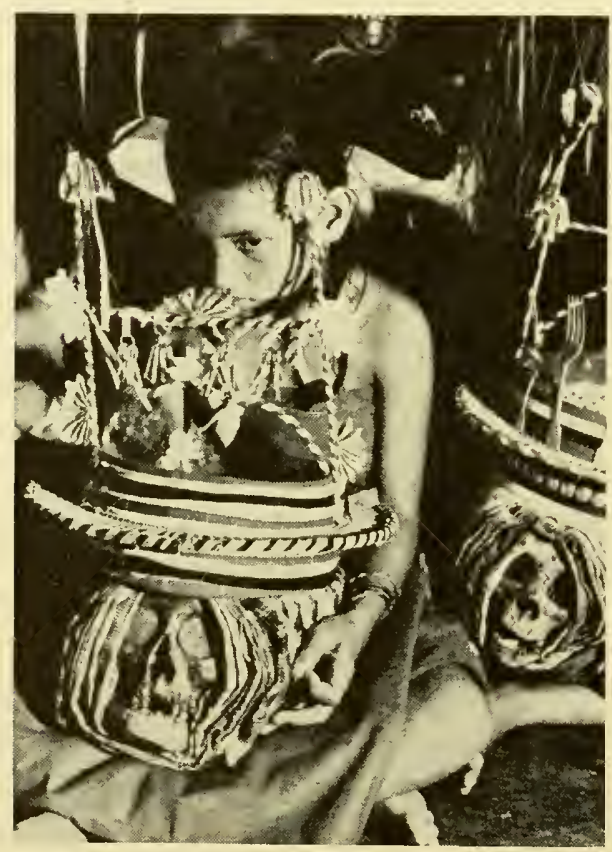

Each of the native women sat holding a fantastically decorated skull. In the 'scaffolding' of the front skull are bunches of keys, while the skull in the background is adorned with forks. 
The skull on the left bears a helmet, under the band of which is stuck a row of spoons. Headgear of this type is shown in use on page 106.

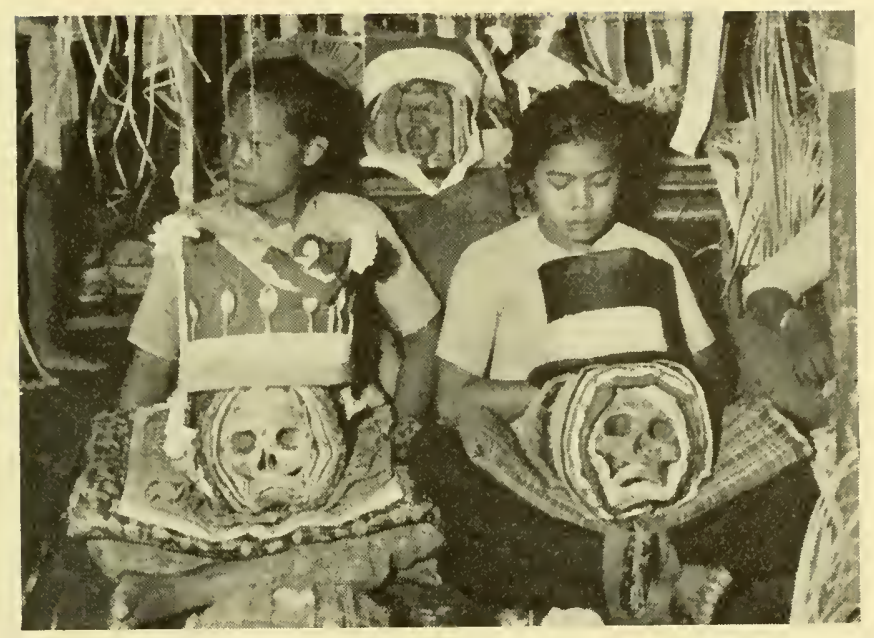

sisted of a tiered hat of plaited coir covered with strips of coloured cloth and surmounted by a "scaffolding" hung with bunting, bunches of keys, bracelets, copper coins, spoons, and plastic trinkets. One skull bore a topee embellished with tea-spoons stuck behind the ribbon; another had a black topper of old-fashioned type which was evidently considered fine enough to need no further decoration. The skulls themselves were of widely varying ages, some being dark and badly decayed by long burial, others new and "fresh". There were toothless old skulls, skulls with fine, wellpreserved teeth, and small skulls of children.

It was difficult to keep a straight face at the sight of all these grotesque features, but the gravity of the natives assured us that this was a serious occasion. The young women who were holding the skulls seemed unaware of our presence. Besides this inner circle, there was an outer circle of women sitting round the wall. At intervals the women would lay aside their home-made cigarettes and emit a chorus of wails. The chief identified some of the skulls for us - his father, brother, sister, etc. As there were between 25 and 30 in all, some of them must have been of great age; some which lay on a rusty old iron bed in the background, and which, though decorated, were not held, doubtless belonged to long-dead relatives whose identity had been wholly or partly forgotten.

Through Dr. Ramanand we gradually gained a fair understanding of the background to these ceremonies. They were held at irregular intervals depending on the host's wealth. The immediate occasion in the present case was the first anniversary of his father's death. Beginning a long time before the celebration is due to take place, a supply of food is laid 


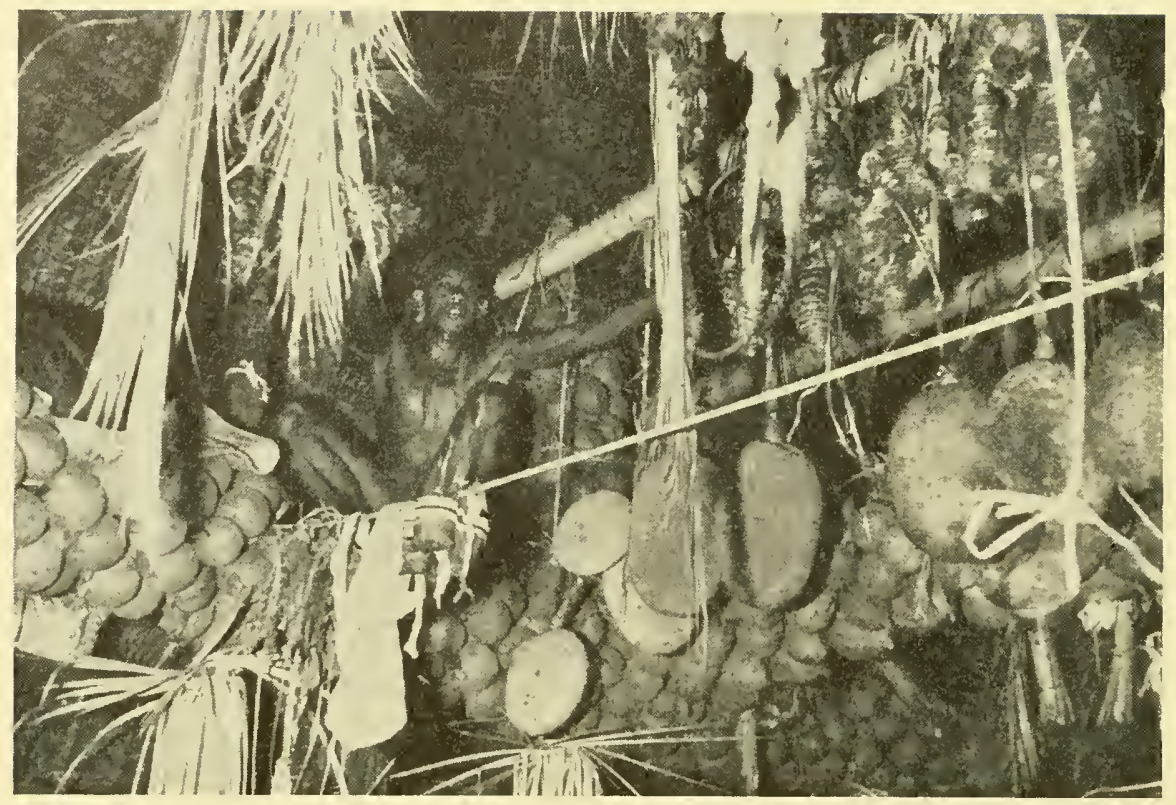

Under the roof of the hut hung a large supply of vegetable food. Here are coconuts, bread-fruits, jack-fruits, and yams.

in and the stock of pigs and poultry is built up in order to feed the numerous guests. The skulls of deceased relatives are disinterred, cleaned, and decorated as described with their own valuables, which seem chiefly to consist of various utensils of European origin that have ended up in the islands. Contributions to the party in kind are brought by the guests. In the hut loft hung large quantities of regetable stores, nicely sorted according to variety and decorated with yellow coconut-palm leaves. There were coconuts, yams, bananas, breadfruits, and jackfruits (a fruit akin to the breadfruit) by the hundred, as well as leaves and betel-nuts for chewing, and pandanus paste (from the fruit of the screw pine and an important food on the island) in handsome circular containers made from leaves and rattan cane. Pigs and poultry were kept until ready for killing in oblong coops under the hut. The celebrations had been in progress two days when we arrived, and judging from the amount of food still left it could go on for a long time. The number of pigs killed is kept count of by cutting a strip of flesh from the back and hanging it up under the hut roof. The host showed us with visible pride that there were already 32 such strips, an obvious sign that the party was an exceptionally large one. They were already smelling. 
After the celebration the skulls are re-buried in their coverings, ranged in definite order so that they can be identified when next they are wanted. The trimmings are carefully preserved till the next celcbration. When the skulls have taken part in a certain number of celebrations and the memory of the deceased person has been forgotten, they are buried for good.

It was difficult to tear oursclves away from this remarkable spectacle, but we were now invited to tea outside a neighbouring hut, where everything had been assembled that the village could produce in the way of chairs and seats, including a few old deck-chairs. Here we were rejoined by the queen, who had been unable to visit the hut as the canoe with her gifts had not yet arrived. She was offered a deck-chair, but her rather considerable weight being too much for it, it collapsed with a crash and her Majesty landed on the ground with both legs in the air. However, she took it all in good part and was given another chair. The refreshments consisted of sweet tea with bananas and jackfruits.

The tea-party was brought to an abrupt end by the sound of shouting which reached us from the landing-stage. On hurrying to the spot we were just in time to witness the arrival of two large and richly decorated canoes. To the accompaniment of gong-sounding, lamentations from the men, and a chorus of wails from the women, they were hauled ashore. They had come from the neighbouring island of Trincut, and one of the boats had brought the skull of a child, the host's son, who had died there, and which was now about to attend its first funeral ceremony.

Before the skull was taken into the hut two young men gave a display of single combat with poles on the beach. Their only dress was loin-cloths and black helmets of plaited coir. They aimed formidable blows at each other with solid poles that were longer than a man's height, parrying and ducking and taking fresh aim. The muscular brown figures looked splendid in the glow from the torches, and the whole performance was a powerful denial of the reputation for indolence foisted on the natives by earlier expeditions. It looked rather tough and both men took some hard knocks, but these combats, which are referred to in old Danish reports including Bille's, are now only sham fights. In the past they would often end in the death of one of the combatants; this time the fight was stopped when one of them had been forced on to his knees in the water. After the combat the skull was carried in procession into the hut on a litter of palm leaves. The host's brother, who led the procession, had a freshly killed and plucked chicken hanging round his neck. The meaning of this piece of symbolism we were unable to find out, and I am sure that we missed many 


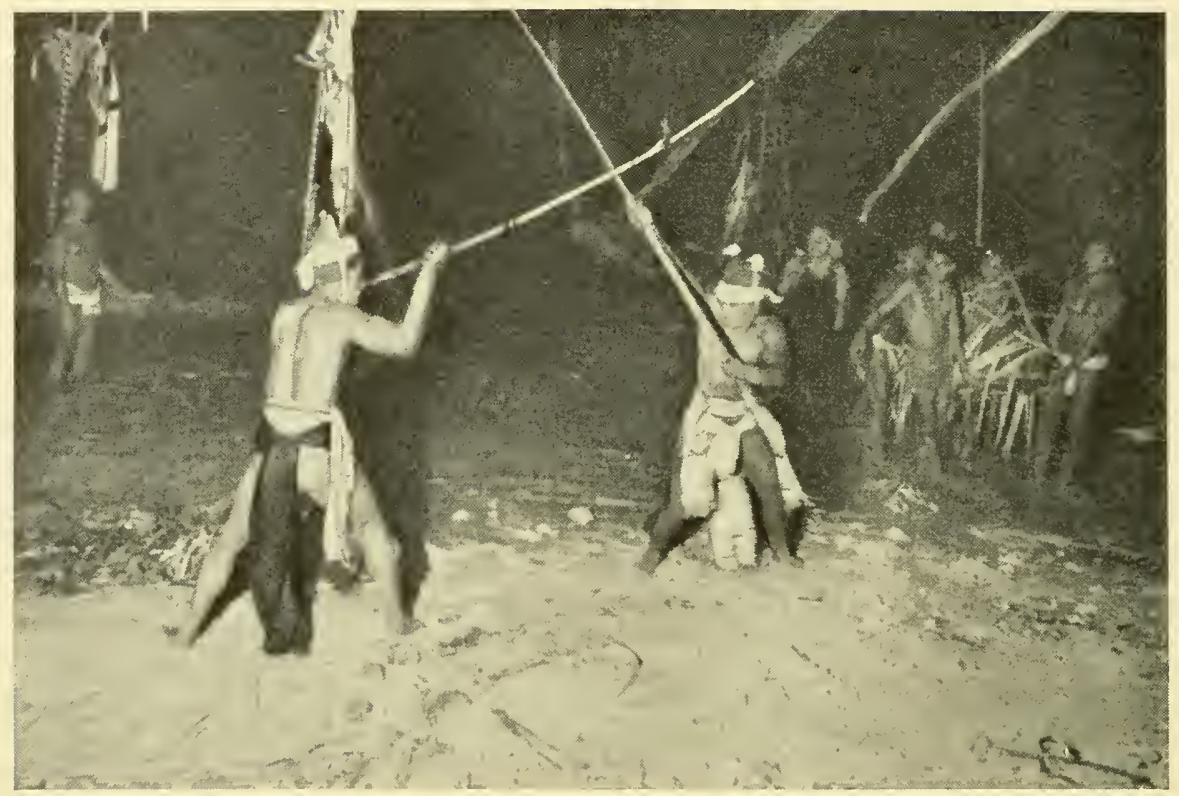

Single combats with poles are now only for display, though hard blows are exchanged. In the old days they would often end in the death of one of the combatants.

details of what happened in the half-light and the crowd. The wailing of the women in the hut was heard at varying pitch throughout the ceremony.

Before leaving, we re-entered the hut to watch a dance. Some I 5 men ranged themselves in a circle round the inner circle of the women holding skulls. Grasping one another by the arm, they began dancing to the accompaniment of a slow, monotonous chant, marking the rhythm by stamping on the floor. During the intervals the women lifted their voices in the obligatory chorus of wails. We recorded both the singing and the wailing on our wire-recorder.

It was now time to depart, and after a cordial leave-taking with our hosts we were paddled out to the motor-boat. The return journey was completed without mishap, and we were too tired and exhausted to wonder how the natives succeeded in finding their way in difficult waters in the pitch-black tropical night. At half-past three in the morning we were back on the Galathea, which presently weighed anchor and made course for the next island of Great Nicobar.

The following day, we proceeded down the east coast of Great Nicobar, which is the largest and most southerly island in the group. This coast 
consists of a series of shallow bays with sandy beaches, separated by rocky promontories. Behind the shore one saw undulating hills rising towards the interior. Overlying everything was a dark, dense forest extending from the coast to the highest peaks. In some of the bays stood a few huts surrounded by coconut groves, but generally speaking the habitation seemed extremely sparse.

At midday we cast anchor in a large bay at the southern extremity of Great Nicobar. This bay is still called Galathea Bay after the corvette Galathea, which stopped there for a few days in February 1846 in order to survey the waters and explore the land. Incidentally, it was interesting to see that even the latest British charts which we were using were based on the survey of the Nicobars made by the Galathea in 1846 .

Owing to the persistently heavy swell in this rather open bay, it was somewhat difficult to effect a landing. The first party succeeded in jumping on to a coral reef in half a metre of water, but soon afterwards the tide rose so high that the rest had to go ashore on the flat sandy beach. Eventually, a large proportion of the crew managed to land, and then we quickly separated, going off in different directions to attend to our various duties. In 1846 , there had been a village in the bay, but the in-

The host's brother arriving at the head of a procession, carrying the skull of the host's dead son. He has a newly killed chicken hanging round his neck.

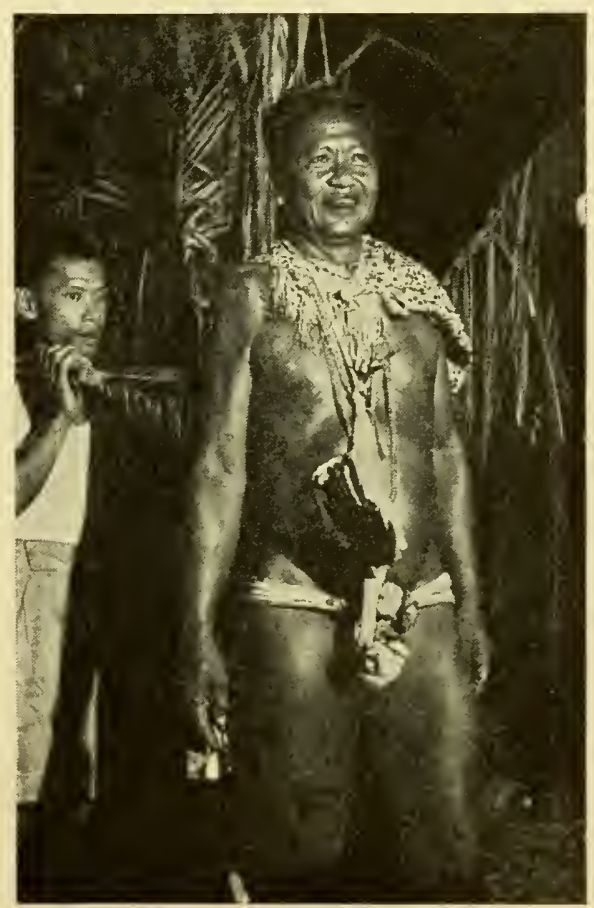


habitants had been very poor and had clearly been living on a subsistence level. The Dana Expedition of 1929 had paid a brief visit to Galathea Bay and a small party had gone ashore, including two young members, Lieutenant Greve and Mr. Bruun. They had found the shore deserted and abandoned. It had the same appearance when we landed with them on this occasion, but we succeeded in finding a solitary inhabited hut. There was nobody in, but pigs and poultry were active about the hut, and propped up against it were some very fine paddles which we should have liked to buy.

At the western extremity of Galathea Bay is the mouth of the only large river in the Nicobars, the Galathea River. It was on their expedition up this river that the personnel of the old Galathea had their one serious misadventure while in the Nicobars. After many troubles they had reached a large and recently abandoned village some way up the river, but had then been overtaken by a fierce tropical thunderstorm with pouring rain, and forced to spend the night there. That night led to the loss of four lives and the serious illness of 19 other members from Nicobar fever. Protected against malaria as we now were, we planned to emulate their attempt and penetrate up-river by motorboat. However, we soon found that the river-mouth was blocked by a sand-bank, which in view of the heavy swell and short time at our disposal we could not have negotiated. As a matter of fact, the river then was very small, so that it is doubtful whether we should have got very far up it.

We were consequently obliged to confine our collecting to the immediate vicinity of the bay, where there was quite enough to do. The shore teemed with agile burrowing crabs and fascinating hermit crabs; and the spiral shells of the small cephalopod Spirula lay there in quantities. Inside the forest dead silence reigned. It was a shore forest, consisting mainly of screw pines and having little undergrowth, so that is was possible to move about fairly freely in it. Seemingly, there were neither mammals nor birds, but as soon as we stood still a few birds would emerge from the dense foliage. I brought down a very handsome paradise flycatcher, pure white with black wing-shafts, a blue flycatcher, and various other small birds. While packing a bird, I heard noise coming from the top of a tree, and on looking up saw between 20 and 30 small, squirrel-like mammals, staring at the strange creature that was trespassing on their territory. Their quizzical manner of looking at me put me in mind of monkeys. Unfortunately, my only weapon was a small fowling-piece, and when I took a shot at them they fled with loud screams into the tree-tops. I heard on my return to the ship that another party had shot two "squirrels", and they 
Two spirit figures.

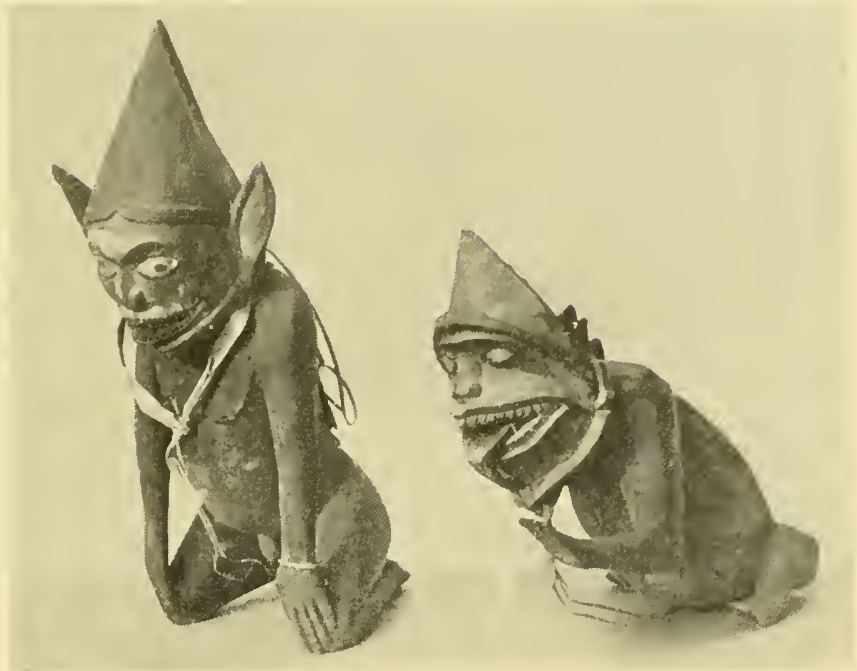

turned out to be the same creatures. They were tree-shrews, a strange family of mammals which used to be classed with the insectivora but are now included in the lemurs, a re-classification which I had unconsciously confirmed owing to their monkey-like behaviour.

After a short walk up the left bank of the Galathea River, which was overgrown with mangroves, I was obliged to return to our landing-point as the sun was setting and threatening clouds were gathering. I had not gone far when the rain poured down, and with astonishing suddenness it was dark. Re-embarkation was in full swing, but as the swell had increased with the shower it was slow work. Fortunately, we had with us a North Sea fisherman to row the boat in and out through the surf, but he could take only three at a time and had difficulty in finding his direction in the dark. We tried to light a bonfire on the beach, but though we struck all our dry matches we failed to get a light as everything was soon soaking wet in the steadily pouring rain. Only the fireflies, fluttering in myriads along the shore, seemed unaffected by it. The flashes of lightning and the rumbling of the thunder helped to create a dramatic situation. It was nine o'clock that evening before the last boat-load had arrived and the subsequent roll-call showed that all were safely on board.

At several places we had tried to buy one of the large and elegant native canoes for our National Museum, but they are made only on Great Nicobar and the natives had been reluctant to sell them. We therefore decided to make another attempt on the north coast of Great Nicobar. 


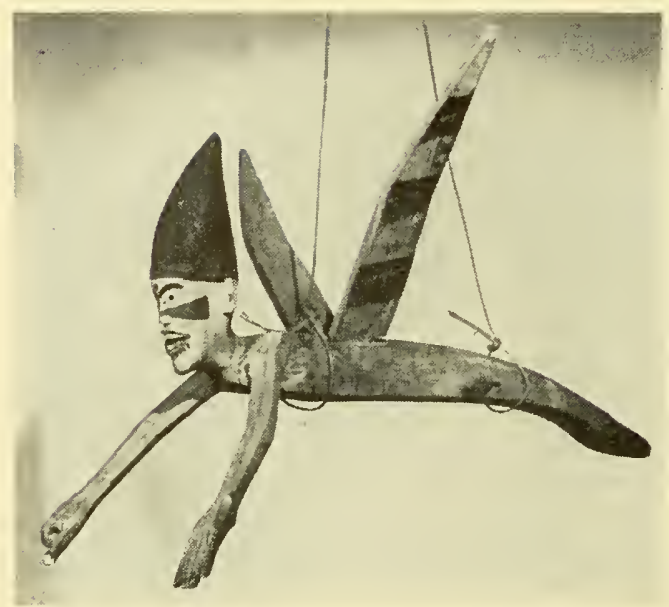

We took what opportunities we could to obtain ethnological material by bartering with the natives.

And so as soon as everybody was aboard we weighed anchor and turned north. Early the next morning, we anchored off the small island of Pulo Kondul, which lies close to the north coast of Great Nicobar, in the strait between this and Little Nicobar. There was a biggish native village on the island and the Indians had established a field-telegraph station there. With the station head's assistance, we succeeded in buying not only a fine large canoe but also a number of valuable ethnological objects, such as wooden statuettes and picture tables, and various utensils. All this material has meant a considerable addition to the Nicobar collections in the Danish National Museum. A comparison of the old and the new collection shows an astonishingly small change in native culture over the more than a hundred years which separate the two Galathea expeditions.

I had the opportunity of making an exciting collecting expedition in the rain forest which covered most of the mountainous little island. Following the coast for a short way, I came to another village whose inhabitants seemed to be boat-builders, because several half-finished canoes were lying about the shore. The tree-trunks from which they are made, and which are about 10 metres long, are first hollowed out with an axe and then smoothed on the inside by burning. As I was walking along a pass between overhanging rocks, I suddenly heard footsteps behind me, and turning round I stood face to face with a tall, dark, almost naked native with a large knife in his hand. I nodded and smiled to him, and without a word he joined me, staying with me the rest of the way. $\mathrm{He}$ helped me to find my way and the birds which I shot. Following a small stream, we went deeper into the rain forest. Large fern trees grew on 
either side of the stream. A monitor, one metre in length, hastily sought the shelter of a pile of brushwood. Soon the forest was so thick that further advance was out of the question. The native shook his head; so we sat down and had a smoke, before turning back and making our way along the coast by another route. I shot some small birds, including a mountain myna, which is a brillant black starling with yellow flaps on the head. At our landing-point we had a refreshing bath and slaked our thirst with the milk of fresh coconuts gathered at the top of a tall coconut palm by a little fellow who climbed the smooth trunk with great agility, holding a large knife in his hand. At twelve o'clock we weighed anchor and left the Nicobars for good. But I will not deny that, in the long Northern winter, some of us dream of one day returning to this paradise and resuming the scientific work which had all too quickly to be broken off. 


\title{
THE TEGHNIQUE OF TRAWLING
}

\author{
By B. Kullenberg
}

In deep-sea trawling we encounter difficulties not met with in inshore commercial fishing. One of these is our imperfect knowledge of the topography of the deep-sea floor, though to a large extent this has now been overcome by means of the self-registering echo-sounder, which can record a profile of the bottom even at the greatest of depths. Thus, the first task of a deep-sea research vessel is to find an expanse of fairly level bottom in the area to be trawled. But since it would take a great deal of time to put out marker-buoys, there can be no guarantee that exactly the same area will be trawled as was reconnoitred. The result may be unpleasant surprises in the shape of rough obstructions. If the situation threatens to be risky, there is no alternative but to discontinue the trawl.

Another difficulty is that of judging the length of wire which will be necessary in order to trawl the bottom and avoid waste of effort by dragging the free water masses. The time at the disposal of an oceanic research ship is so precious that failures must as far as possible be avoided.

In order to judge the minimum amount of wire that will be needed we must examine its position in the water, and the easiest way of doing this is by a theoretical analysis. The principle involved is the law of resistance to a short piece of wire, or cylinder. If a cylinder moves through water at right angles to its axis, then the resistance per unit length will be proportional to the diameter of the cylinder and the square of the speed. The proportionality factor, it is true, is slightly variable, but with the dimensions and speeds with which we are concerned it may be regarded as constant. If the cylinder moves longitudinally, the resistance will still be virtually proportional to the diameter and the square of the speed, but the proportionality factor will be only about seven per cent. of that governing the rectangular resistance.

However, we are mainly concerned with the resistance to a cylinder of which the axis forms an acute angle with the direction of motion, because nearly every part of the wire moves in this way. It is reasonable to divide the speed into two components, one at right angles to the axis of the cylinder and the other parallel with it. The resistance has a transversal and a longitudinal component, each determined by the corresponding component of the speed. The longitudinal component of the resistance is usually so small compared with the transversal one that the resultant 
The heart of the expedition, the large trawling winch.

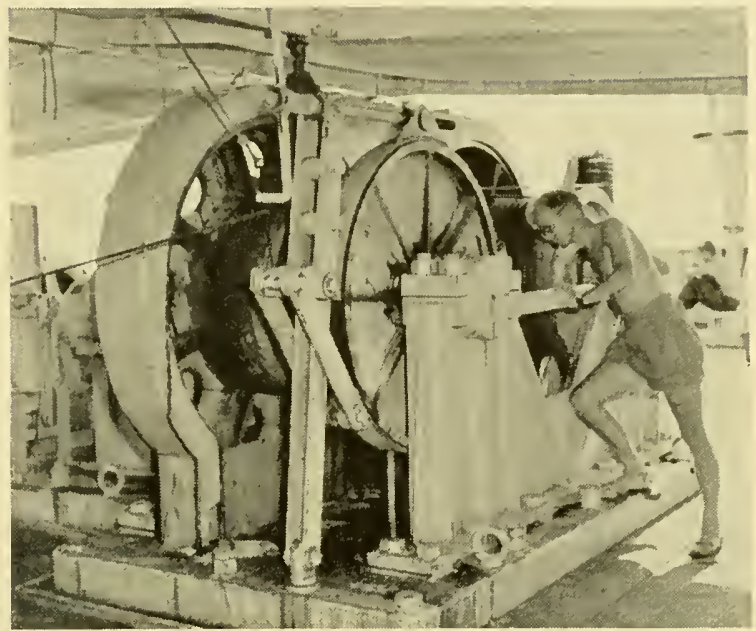

resistance is almost perpendicular to the cylinder axis, as shown in the drawing at the foot of the page.

If a wire of uniform thickness is dragged through the water unweighted and without touching the bottom it will form a straight line, the direction being determined by the resultant of the transversal resistance and the weight of the wire, the longitudinal resistance drag being without influence on the position of the wire. The greater the speed, the more the wire will approach the horizontal position; and the heavier the wire, the more it will approach the vertical. True, the resistance will increase with the diameter, but the weight will increase still faster. The resistance has a sustaining effect on the wire which partly offsets the effects of weight, with the result that the tension diminishes in ratio with increasing speed, at any rate in the speeds met with in practice.

If a wire is pulling a trawl, it can be assumed that just in front of the trawl it drags the bottom, and so is horizontal at its lower end. A mathematical calculation, which I cannot go into here, shows that in this case the wire on its way up to the vessel strives for the same position as it would have occupied if unloaded and not touching the bottom. This occurs the more speedly the less the tension produced by the trawl. The drawing on page I 44 shows the positions in deep-sea trawling of three wires of various thicknesses. It will be seen that the wires form a virtually straight line even quite near the bottom, and that the direction when close to the ship differs but slightly from the direction of the unloaded wire. The calculation gives the length of wire as a function of the 


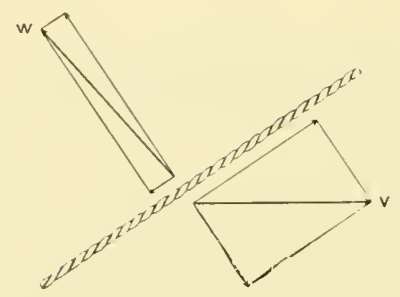

The resistance of the water is at right angles to the wire.

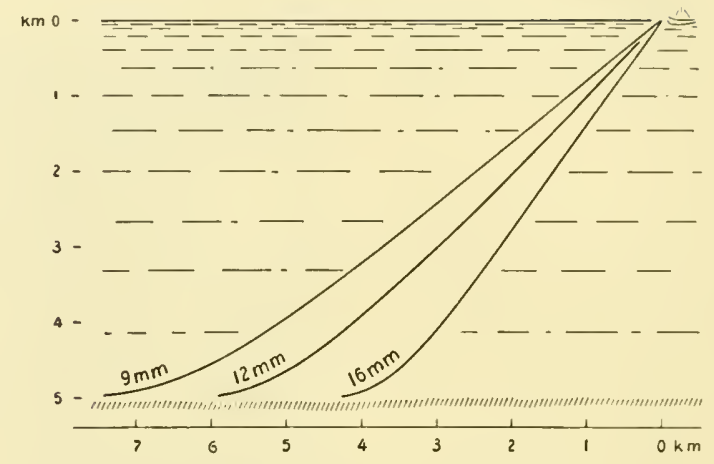

Position of the wire with various thicknesses.

direction at its upper end, the diameter, the resistance of the trawl to the water, and the depth. The three wires shown in the drawing vary greatly in length: with a diameter of nine millimetres, a depth of 5,000 metres, and a speed of two knots the length required is 9,60o metres; with a diameter of 12 millimetres, 7,900 metres; and with a diameter of 16 millimetres, 6,700 metres. Thus it pays to work with wires which are not too thin.

It is also important to know the speed at which the trawl travels along the bottom. In the oceans there is usually a comparatively shallow surface current, and the deep waters underlying this move very slowly. Owing to its shallowness the current will have no effect on the position of the wire cven though it is fast-flowing, particularly since the wire has its highest tension in the surface and is therefore very reluctant to curve. The ultimate direction of the wire is thus determined by its speed in relation to the deep water layers, and this is obtained by the mathematical calculation referred to above.

Deep-sea trawling is rarely carried out at speeds greater than two, or two and a half, knots. Generally speaking, therefore, it is best to go against the surface current when trawling; otherwise the ship may fail to make adequate speed and will be difficult to navigate. The regular collection of water samples at great depths provides a means of obtaining information about the direction of the surface current. In this kind of work the thin instrument wire will only remain vertical if the ship is made to go against the surface current at the same speed as the current.

If a very long wire is to have adequate strength it is essential that its diameter should increase from the lower end to the upper one, otherwise it will be incapable of bearing its own weight which is very considerable. 
The diameter is increased in stages, the wire being made up of a number of sections of different diameter joined together to form one length. The Galathea's wire, 12,000 metres long, was formed as shown in the table.

The Galathea's I2,00o-metre Trawling Wire.

\begin{tabular}{r|r|c|c}
\hline \multicolumn{1}{c|}{ Diameter } & Length & Weight in Water & Breaking Strain \\
\hline $9.3 \mathrm{~mm}$. & $3,600 \mathrm{~m}$. & $0.26 \mathrm{~kg} / \mathrm{m}$. & $7,140 \mathrm{~kg}$. \\
$11.6 \mathrm{~mm}$. & $1,750 \mathrm{~m}$. & $0.41 \mathrm{~kg} / \mathrm{m}$. & $11,100 \mathrm{~kg}$. \\
$13.2 \mathrm{~mm}$. & $770 \mathrm{~m}$. & $0.53 \mathrm{~kg} / \mathrm{m}$. & $12,600 \mathrm{~kg}$. \\
$14.7 \mathrm{~mm}$. & $1,330 \mathrm{~m}$. & $0.66 \mathrm{~kg} / \mathrm{m}$. & $15,600 \mathrm{~kg}$. \\
$17.1 \mathrm{~mm}$. & $1,730 \mathrm{~m}$. & $0.89 \mathrm{~kg} / \mathrm{m}$. & $21,000 \mathrm{~kg}$. \\
$19.6 \mathrm{~mm}$. & $1,080 \mathrm{~m}$. & $1.18 \mathrm{~kg} / \mathrm{m}$. & $25,000 \mathrm{~kg}$. \\
$20.2 \mathrm{~mm}$. & $980 \mathrm{~m}$. & $1.25 \mathrm{~kg} / \mathrm{m}$. & $29,200 \mathrm{~kg}$. \\
$21.8 \mathrm{~mm}$. & $760 \mathrm{~m}$. & $1.45 \mathrm{~kg} / \mathrm{m}$. & $33,900 \mathrm{~kg}$. \\
\hline
\end{tabular}

In trawling with this wire the lowermost section, with a diameter of 9.3 millimetres, practically attains a straight course before the transition to the next section with a diameter of I I.6 millimetres. This and all
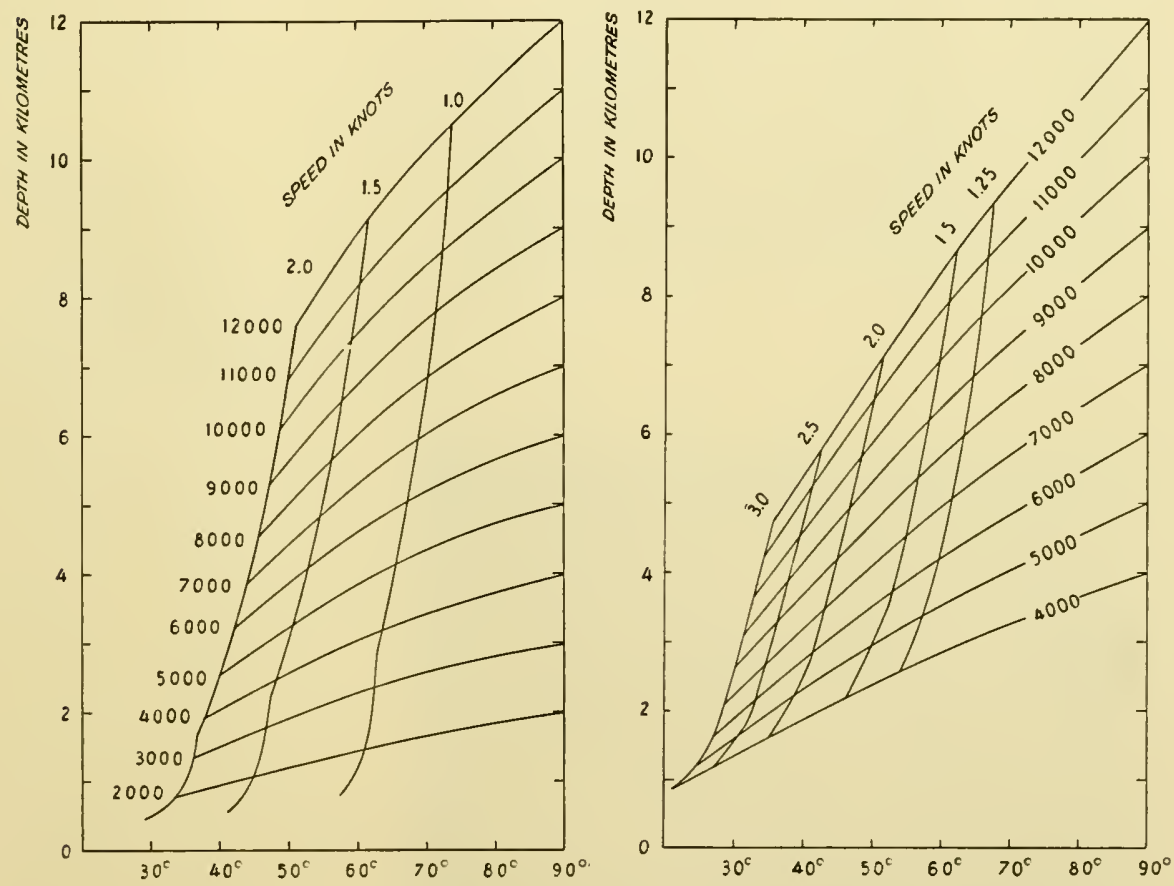

Diagrams used for calculating the length of wire to be paid out. a. Otter trawl. b. Sledge trawl. The abscissa is the angle. 


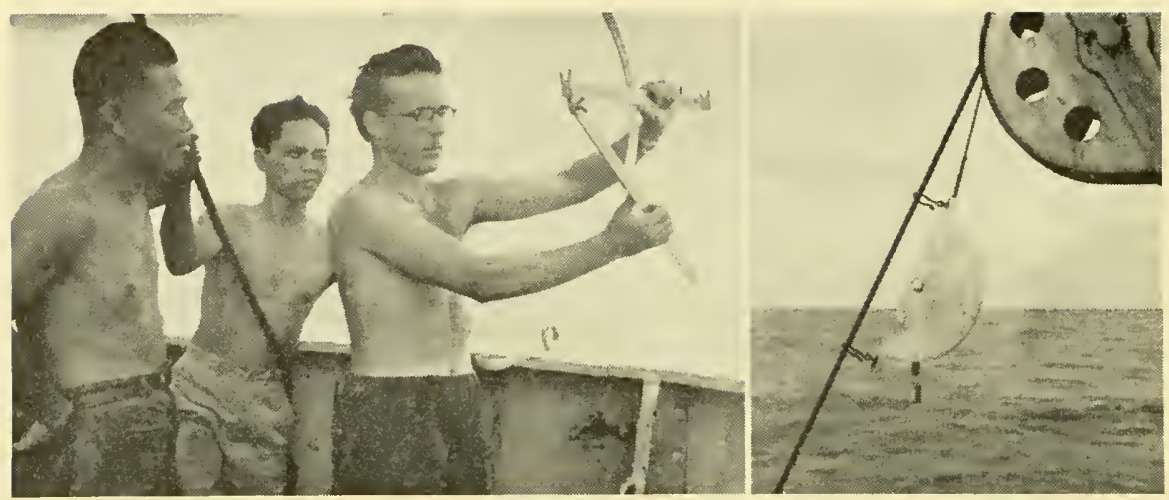

Gauging the angle zohile paying out; and angle gauge in position while trawling.

the following sections are nearly straight, and the greater the diameter the steeper they become. On the basis of calculations made for wires uniform in diameter we worked out diagrams showing the length of wire to be paid out in order that the trawl should reach the bottom, taking into account the depth and the desired speed, as well as the required angle of the wire on leaving the ship. The diagrams on p. I I 5 refer (a) to the otter trawl, and (b) to the sledge trawl. Two diagrams are necessary because the two types of trawl have a different drag.

As far as possible, the trawl is lowered while the vessel is travelling against the current. While the wire is being unwound the ship must move with sufficient speed to enable the trawl to go forward through the water; but in order that it may quickly sink to the bottom the speed should not be greater than necessary. It is not easy to tell for certain when the

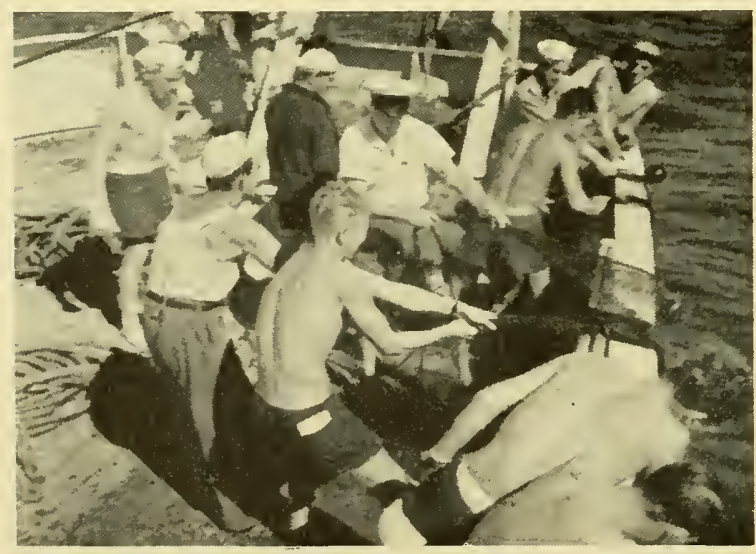

Pulling in the trawl. 
IVind and current have caused trouble; the trawl has come up with kinks in the wire. Fortunately, this rarely happened.

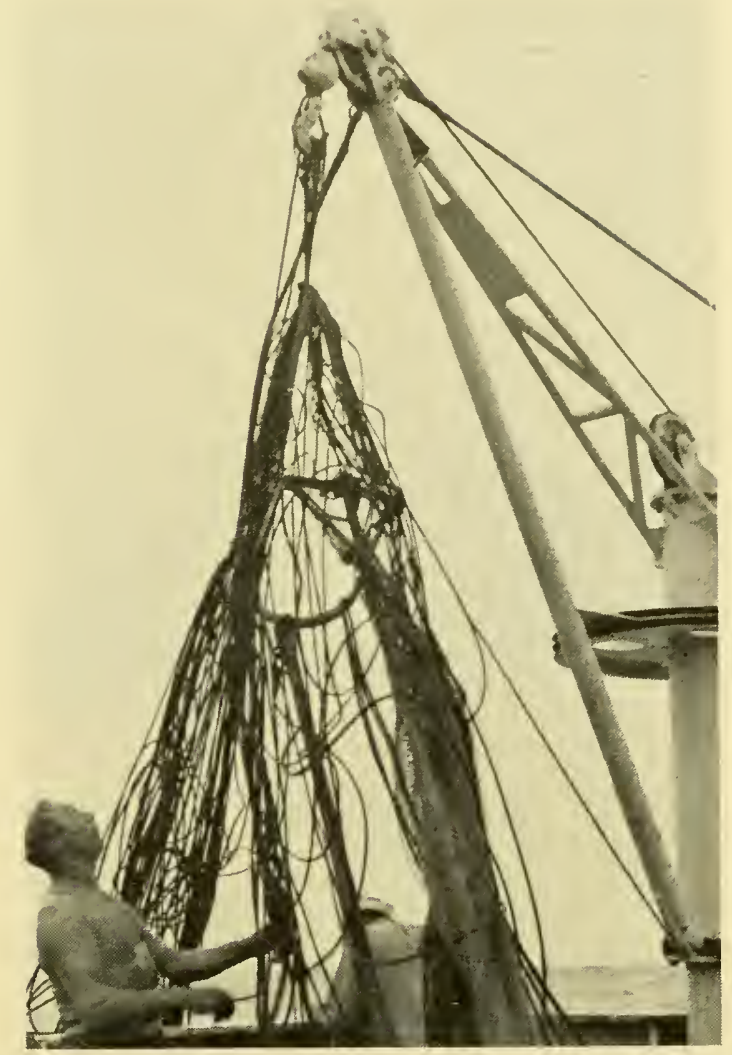

trawl has reached the botton, but provided that the vessel has maintained a steady speed while it was being lowered, it may be assumed that it reaches the bottom when the wire forms the correct angle after the calculated length has been paid out. If the angle is too small the speed of the propellers must be carefully reduced; and if too big, increased. The bottom is checked throughout by means of the echo-sounder, so that trawling can be discontinued should the configuration of the bottom become too irregular. It is also valuable to keep account of the tension of the wire, which can be done by means of a simple instrument known as a dynamometer. In certain cases it may be possible to avoid the loss of a trawl if an alarming increase in tension is observed in time and trawling is stopped. But as tension also varies with the direction of the wire it may be difficult to decide wheter increased tension is due to the boards having dug into the bottom or to the trawl being full of clay. Many oceanic research ships have employed an "accumulator" to protect the wire against 
sudden jerks due, for example, to the swell. This is quite unnecessary as the elasticity of the long wire affords ample protection. We therefore used no accumulator on the Galathea.

According to circumstances, trawling is stopped after an hour or two and the wire hauled in. Hauling in, like paying out, takes several hours. While it is in progress the ship's speed is reduced in order to prevent the trawl, which it is hoped will now be full, from travelling too swiftly through the water. It is outside the scope of this chapter to describe the excitement which animates the whole ship as the trawl approaches, and what takes place when it comes aboard. But all who have had the privilege of experiencing this direct encounter with the mysterious deep know that it is a happy moment when a tired but contented fishmaster and his men after a successful trawl can supply the ship's biologists with a good catch. And then begin the preparations for the next trawl. 


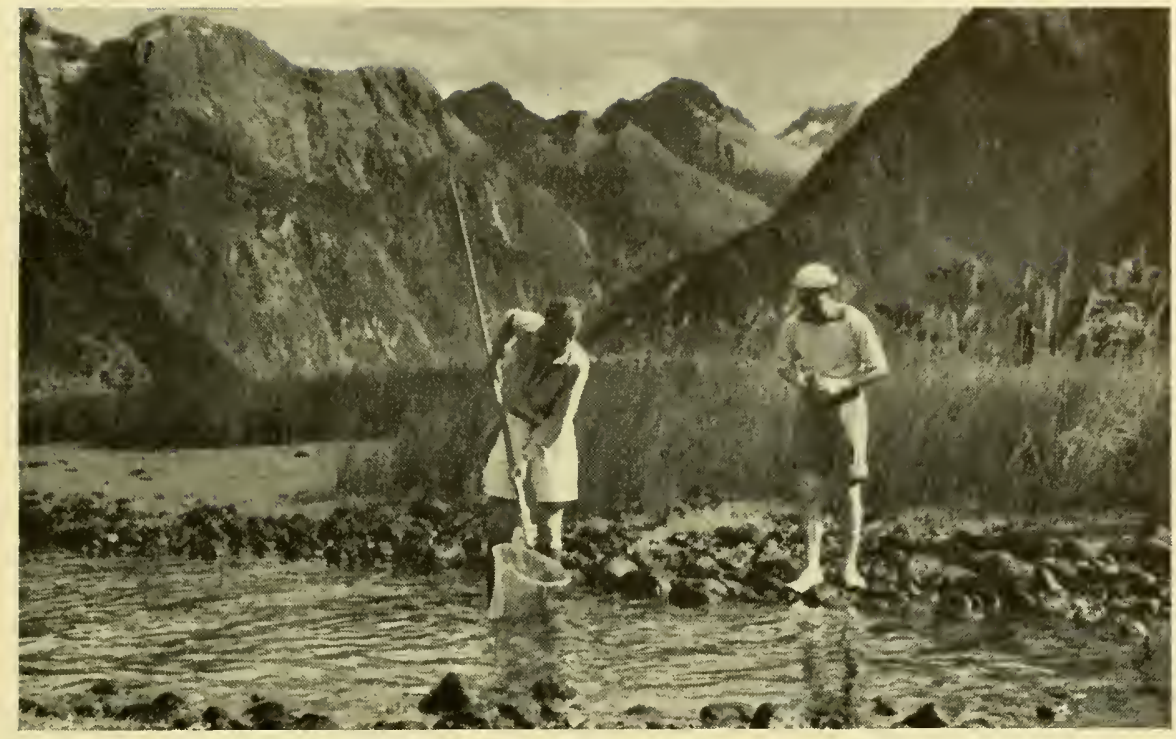

\title{
LOWER COASTAL ANIMALS
}

\author{
By Henning Lemahe
}

Although we were a deep-sea expedition primarily engaged in exploring the oceanic trenches, we also fished and collected in shallower waters. In the first place, we naturally took advantage of time spent in port and en route, and, in the second, it was sometimes necessary to work at shallower depths in order to test and check the efficiency of our gear. The object of collecting in shallow waters was two-fold: to supplement the collections of our Zoological Museum as needed, and to supplement the main objects of the expedition and make full use of our own time and the ship's capacity. In the following, I shall try to illustrate some aspects of our work on tidal coasts and coral reefs, in mangrove swamps, on the sand and clay flats of the continental shelf, and over the continental slope leading down to the deep ocean.

The expedition's zoologists went collecting whenever they had the opportunity. Collecting small fishes in very shaliow water in Milford Sound, New Zealand. 


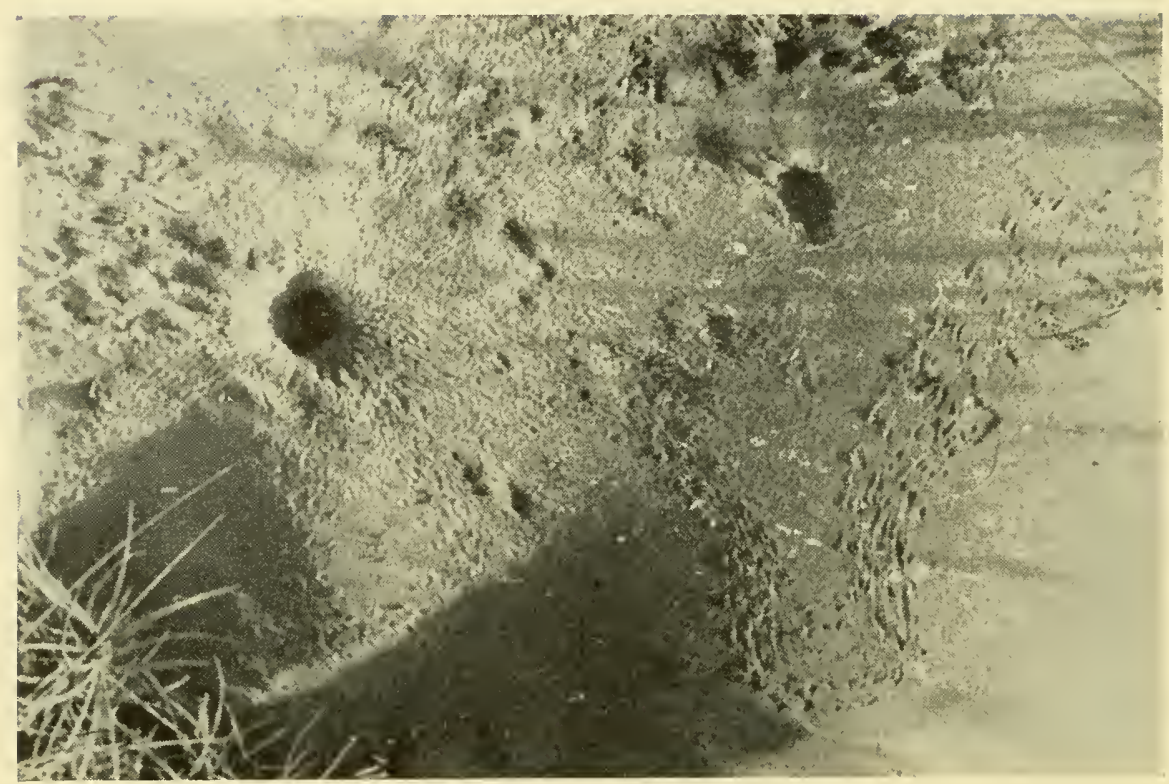

Holes and tracks of crabs (Ocypode) on the edge of the dunes. India.

A Dane, accustomed to no tide in Baltic waters, is invariably impressed by the tremendous part which tides play in the lives of shore animals throughout most of the world. It is the absence of tide which is exceptional, a difference between high and low tide of anything between half a metre and three metres being normal. Great variations occur in the conditions afforded for animal life in this zone; the drying of the shore is a major factor, and of course the higher up animals live in the tidal zone the shorter the period in which they remain covered, or at least wet. Periwinkles can venture fairly high because they are able to feed above the water level, grazing at night and in humid weather on the minute algx and other vegetable matter which they find on rocks. But there are few periwinkles below the high-water mark, their place being taken by species which cannot tolerate so much dessication and which follow the incoming and outgoing tide, feeding on the rocks at the water line. This applies to the limpet (Patella) and another gastropod with a conical shell (Siphonaria), to the broad, short-spiral genus Nerita so common in all warm climates, and to the coat-of-mail shells or chitons, which resemble limpets but have an eight-plated shell. We found these on every rocky coast observed, always under the same conditions. Every time an individual goes out on the receding tide it will stop at its own particular place, to 


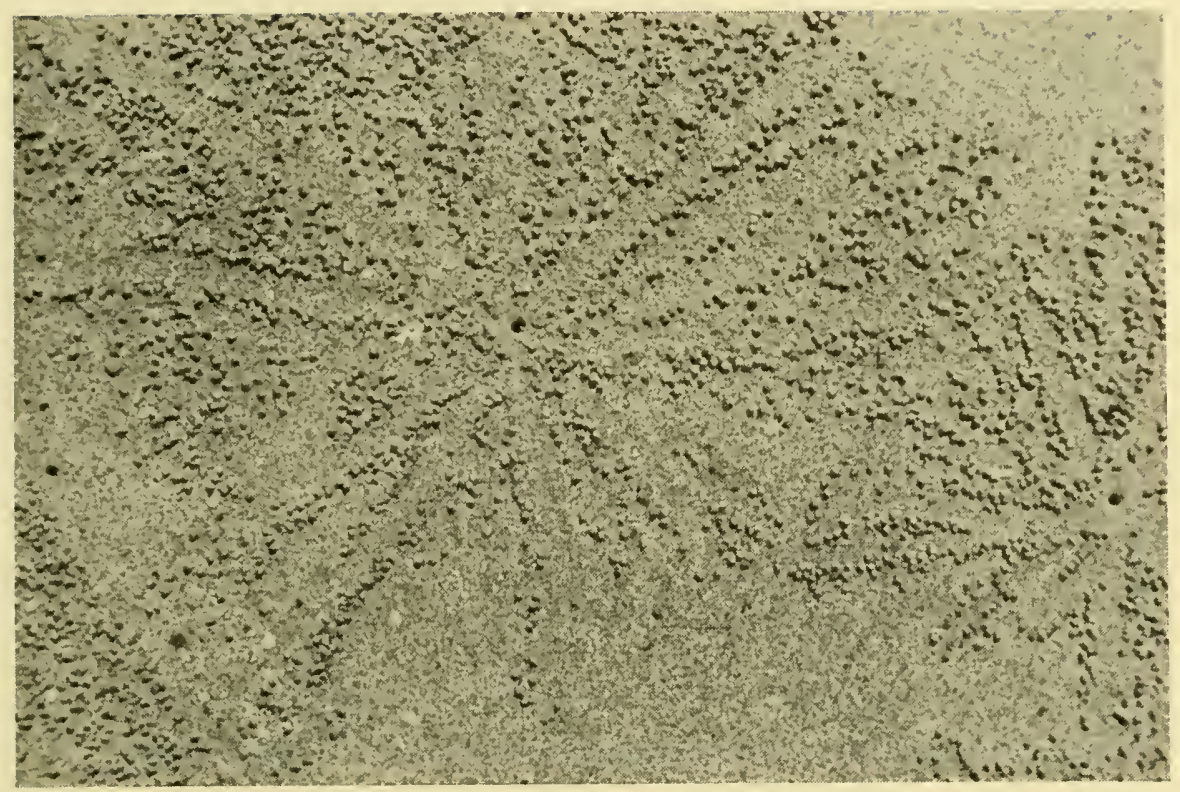

Sand patterns formed by small crabs on the beach. India.

which in some mysterious way it always finds its way back with unfailing accuracy.

Below these animals there is always a zone of oysters in warmer waters, if there is shelter from rough sea. A corresponding zone of mussels is found in colder latitudes, both south and north. A photograph taken on Campbell Island south of New Zealand, and showing both limpets and common mussels, could have been from the west coast of Sweden or Norway. But the beating of heavy surf on the rocks is too much for these bivalves. They get their food by filtering all manner of minute organisms from the water which passes through their gills. To do this their shells must be open, and shells cannot be kept open in heavy surf without coming apart. And so, both in the Tropics and in colder regions, we find instead of these a broad white strip inhabited by barnacles. These are crustaceans which have attached themselves to rocks or floating objects and have become surrounded by a conical shell cemented to the object. They have feathery tentacles which they protrude through a slit at the top of the shell. When the tentacles are withdrawn the slit closes, and by this means the creature can withstand the roughest surf. How far up the tidal zone both oysters and barnacles can live depends on the length of time they need to be immersed in order to catch their food. 


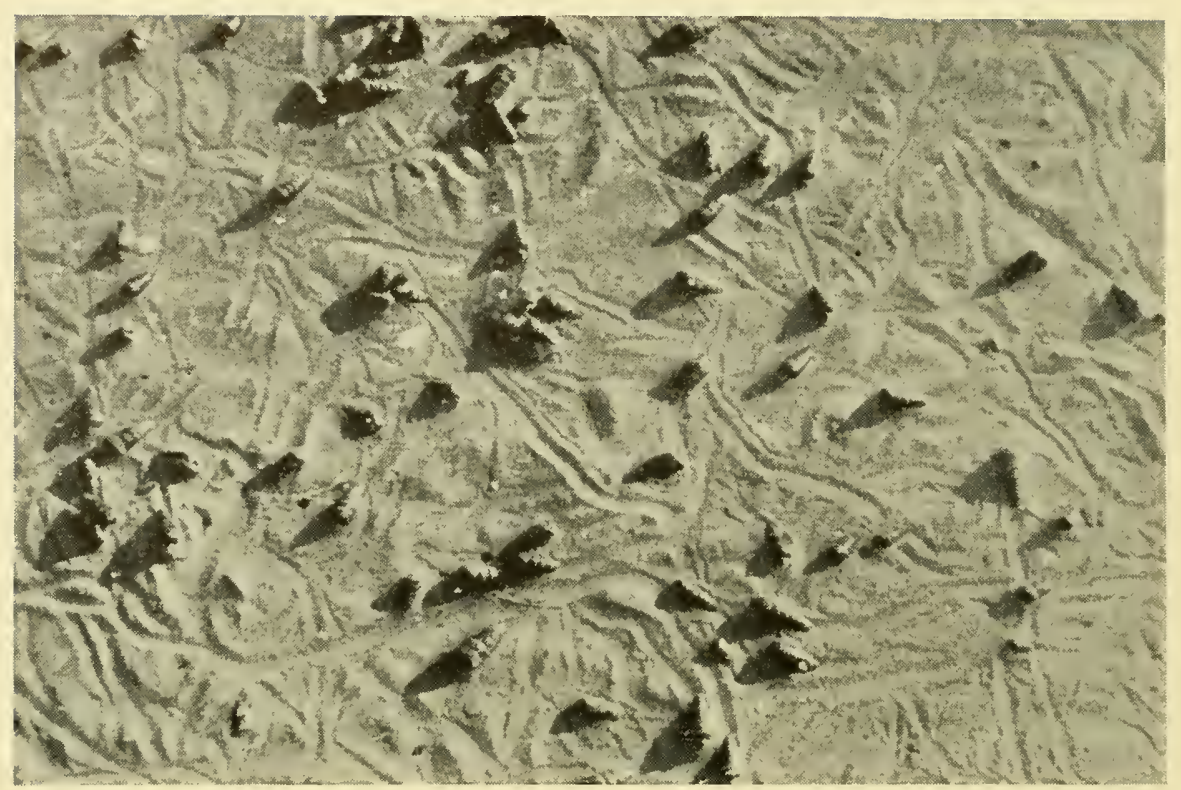

Tropical mud-flats are populated by a host of molluscs. India.

At the lowermost extent of the tidal zone are animals which cannot tolerate desiccation; the creatures we find here, in other words, are those which dwell in the next, shallow-water zone. But if the degree of desiccation determines the vertical distribution, it is the bed which conditions the horizontal. Rocks are admirably adapted for adhesion by clinging, suction, or cementing, but not so shifting sand or soft mud and clay. On all loose floors it is the burrowing animals which predominate, and they vary according to whether the bed is of gravel, sand, clay, or ooze.

The sandy shores all down the west coast of Africa presented a desolate appearance; but on closer inspection we found that they were not nearly so desolate as they had seemed. The fact is that they are badly adapted for animals to move about on by day. Only a few ghost crabs (Ocypode) are visible, running up and down with the breakers and looking like flecks of foam tossed hither and thither. Everywhere - not only in Africa but on all tropical sandy shores - are quantities of crab holes, many of them the size of rat holes, and these may be found close to the nearest coastal plants, on St. Thomas even among the coconut palms. The ghost crabs are typical roving animals, feeding on prey or carrion. Many smaller forms, such as Scopimera and Dotilla, live more peacefully on the 


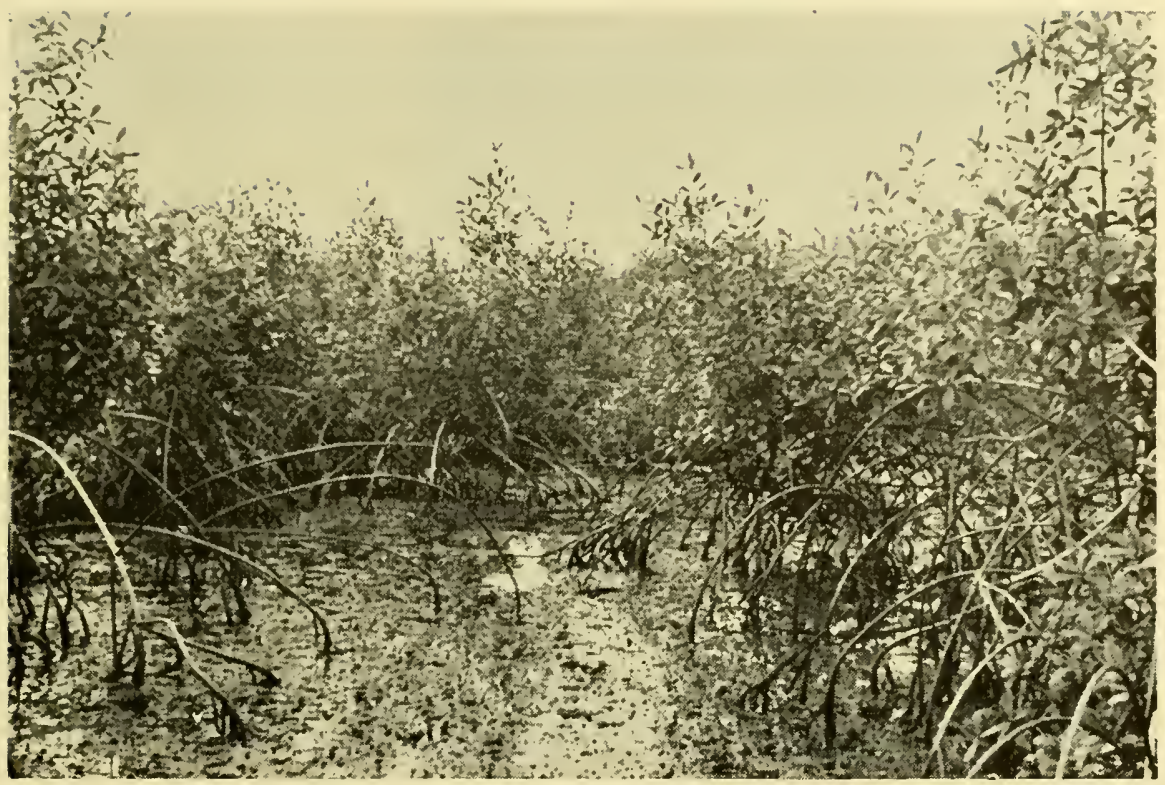

Mangrove swamp at Monrozia, Liberia. The upper part of the rootstock of the trees is fully exposed at low tide.

algal coating of grains of sand, which they will sometimes cement together and place in neat patterns round their holes (Fig. p. I 2 I).

No crabs are found living on beaches in the temperate zones, but in the southern regions we find sand shrimps just as in Northern Europe, but different species.

On sandy beaches in the Tropics, where we were able to get right out into the tidal zone and not merely to its edge, we would have our legs bitten by small creatures, always under the surface. The creatures which thus failed to distinguish between dead animals and live humans would be various isopods (Serolis). They live in symbiosis with some crab-like crustaceans which burrow into the bottom. On sheltered tropical coasts we found various snails crawling on the bottom, which in that case would rarely dry out. Predominant among these were some which in form resembled top-shells, except for a small siphon below the shell mouth (Cerithium, etc.). We would sometimes find them in considerable numbers.

Snails also predominated in this belt in temperate zones, though here they were quite small forms (Bittium).

Growing all over the Tropics in the most sheltered places is the vegeta- 
tion known as mangrove, and here we frequently made interesting observations. Quantities of crabs inhabit the extensive mud-flats between the aerial roots of mangrove trees. The fiddler-crabs (Uca) menacingly raise their single, gigantic claw, closing up their hole with it if forced to retreat into the mud. Many kinds of snail draw their trails across the surface. The fan mussel (Pinna), anything up to half a metre in length, lies buried, its paper-thin shell flush with the top of the mud, giving a nasty cut to the foot that treads on it.

We visited a similar, though tree-less, locality a little south of Sydney. Here we found a dense growth of grasswrack and various algx. Large bivalies (Arca among others) lay scattered over the flats, where big snails of the previously mentioned Cerithium type were crawling. There were also sea hares (Aplysia, Dolabella), which are large snails with a very small, almost internal shell. The easiest way of finding these was to tread on them. They are rather soft and slimy and it was like putting one's foot down on a firm, wet sponge. A purplish pigmentation, secreted by special glands, would then appear in the water. A closer inspection would reveal the snail, which might weigh as much as two kilograms. We carefully froze a few specimens and succeeded by this means in preserving one of the biggest for display in the Zoological Museum.

On another occasion - near Auckland - we had the good fortune to be invited to join an expedition to gather scallops (Pecten medius), a great delicacy in New Zealand. It was an extremely interesting excursion on an extensive flat, though there was not enough time to get far while the tide was still out. We started as soon as the bottom began to appear, making the best of the half hour at our disposal before it was again covered. The scallops were half buried and easy to see in the flat mud, where the covering of grasswrack was too open to conceal them (Fig. p. I 25).

Often in rock pools, where there is shallow water at low tide, or on the lowermost reach of the tidal zone itself when there is a specially low tide, it is possible to get a glimpse of the immensely rich fauna which characterizes the next marine zone, the shallow-water zone with a depth down to 10-30 metres. Desiccation plays no part here at all. Here there is light and here is produced the food on which, ultimately, all marine animals live; here the temperature is warmest, and here, finally, there is often sufficient movement in the water to enable many animals to sit and eat their fill of small marine organisms. Nevertheless, there are certain variations in this zone, due principally to the nature of the bottom. We can best illustrate this with an example taken from the tidal zone. Peri- 
The large New Zealand scallop (Pecten medius) is found in the lower reaches of the shore ooze. Manikua Harbour, New Zealand.

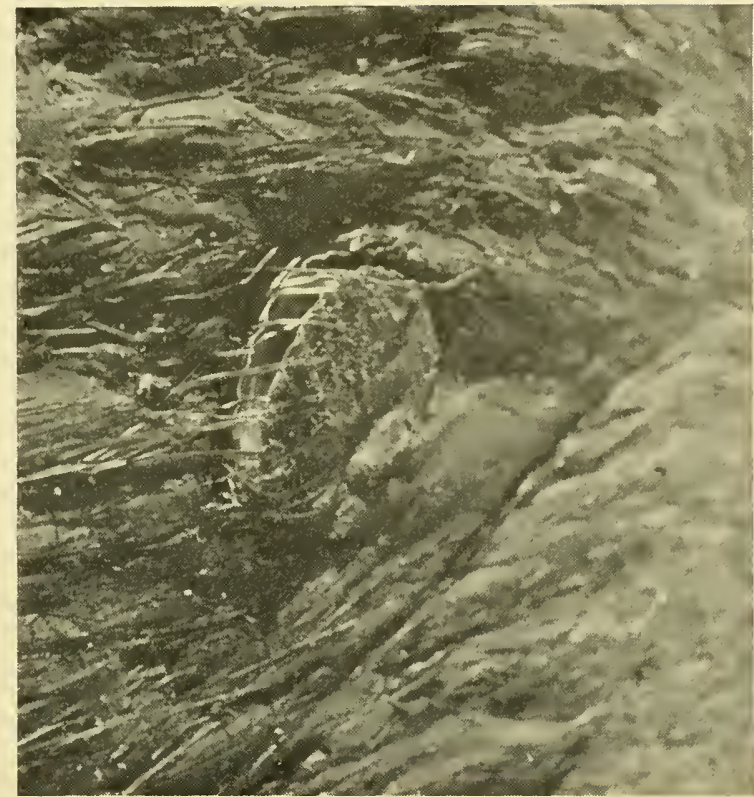

winkles are characteristic of rocks and stones, but are absent from sand and mud. But in mangrove swamps tree roots and trunks protrude and form a firm foundation on which animals can maintain themselves, and in mangrove swamps everywhere we found these snails on the projecting roots and lowermost branches. They were different species from those on the shores, but they were periwinkles, and they lived like other members of their family. Thus we see that two requirements of periwinkles are a firm foundation and adequate spindrift.

As pointed out by the Danish zoologist C. G. J. Petersen ( $860-$ I 928), it is a different set of animals which live on the loose bed from the ones which inhabit the firm parts that lie scattered about it, such as stones, dead shells, etc. Petersen distinguished between what he called the "infauna", belonging to the actual sea-bed or associated with its loose surface, and the "epifauna", which must have firm objects to which it can attach itself, at least in the early stages of growth. Periwinkles are thus epifauna, the creatures which live in the mud of the mangrove swamp being infauna.

On the Galathea we were often glad of an admixture of epifauna in our hauls from the soft bottom. Since a dredge is liable to get damaged in attempts to work it on submarine rocks and reefs, whether these are in shallow or deep water, we were usually afraid of fishing there. But we 
wanted to catch epifauna, and it was a relief to be able to do so without incurring additional risks.

There are some shallow-water localities which we were able to explore only on rare occasions. They include the entensive pastures of grasswrack (Zostera, Posidonia), which occur in sheltered places both in the Tropics and in temperate regions, and whose fauna is also represented in Northern Europe in the familiar pipe-fish, small snails, etc. They also include the similar expanses of mud or sand with little or no vegetation, like those on our own shallow shores. These tropical expanses closely resemble ours in appearance, and there, too, are places where the shallow water briefly exposes the lowermost part of this fauna. But on a closer inspection we find that the small heaps of sand on these tropical shores are made not by lug-worms but by another, rather remarkable, worm (Balanoglossus). Here also we find the carnivorous moon-snail (Natica), a mollusc which preys on bivalves by burrowing underneath them and drilling a hole in their shells before inserting its proboscis to devour them. The moon-snail's spawn, which is full of grains of sand, lies scattered about the surface. Numbers of starfish rove about here in search of food, and on rather sandy bottons we find the cake-urchins, whose perfectly flat shape has earned for them the popular name "sand dollars" (Laganum, Peronella). On bottoms of pure sand constantly whirled about by the rough surf we were, for obvious reason, rather chary of venturing. Here there are some tellins and wedge-shells (Tellina, Donax), molluscs which we were occasionally fortunate in finding above the surface. They are such rapid burrowers that they were difficult to photograph on the sand; it is to their skill in burrowing that they owe their survival in this rough habitat. There are also some crab-like crustaceans which burrow in these sandy parts.

On the firm bottom we usually find a much richer fauna, and in fact these are the richest of all marine localities. At the most southerly places visited by us we found, as in Northern Europe, dense growths of algx, though the fauna there was rather poor. On the rocks, in somewhat warmer regions - for example, off New Zealand and the Californian coast we found large numbers of animal sponges, sea anemones, polyzoa, tubebuilding worms, ascidians, etc. Carnivorous animals were running about above; crabs roved among the rocks; top-shells (Turbo), whelks (Murex), cone-shells (Conus), dog whelks (Purpura), and other creatures glided over the bottom. But the most interesting ones, when we succeeded in finding them, were Haliotis. The Maories have for centuries employed the brilliantly coloured mother-of-pearl of these shells as eyes for their 


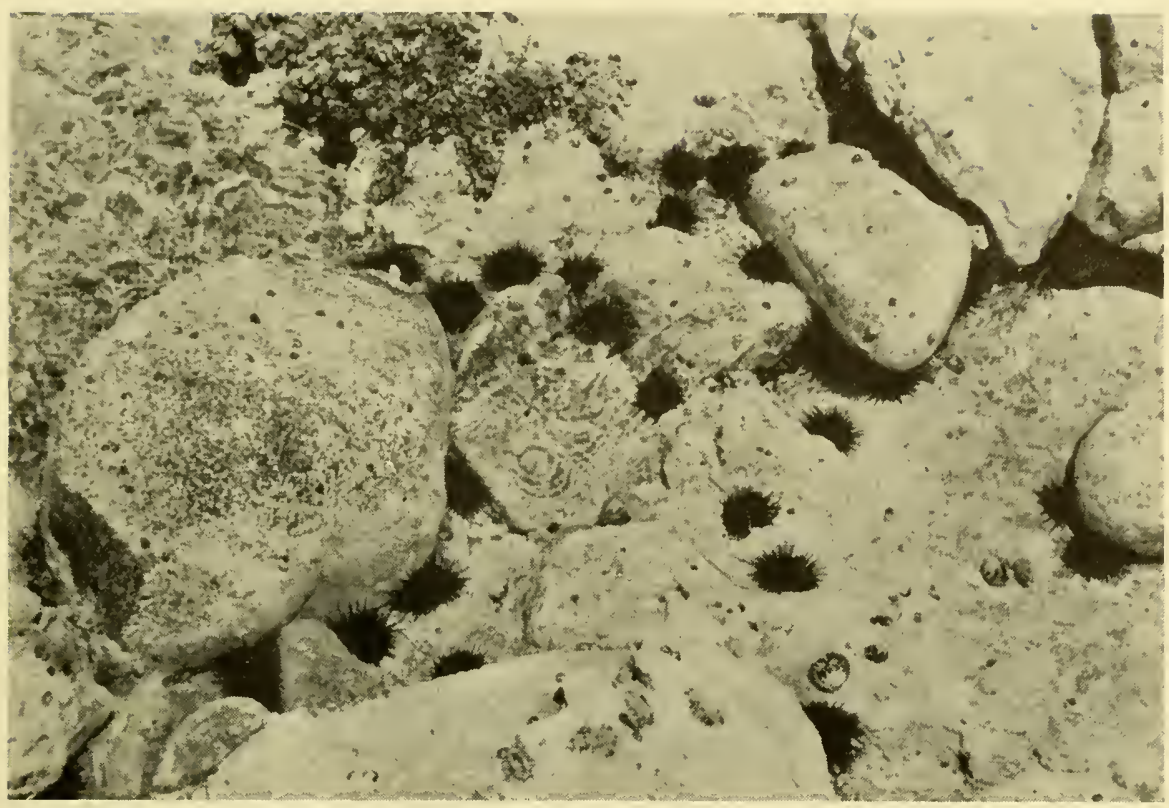

Sea-urchins (Echinometra) in the lower edge of the tidal zone. St. Thomas.

wooden statues. In California, where they go under the name abalone, interest in them is mainly gastronomic, and they are a delicacy considered well worth diving for.

But it is the Tropics which hold the record for fauna. Where the water temperature all the year round is more than $20^{\circ} \mathrm{C}$ we find, in shallow water, the kind of epifauna called coral reefs. Take such a coral reef on a day when the water is crystal clear and there is just enough movement to bring a steady flow of fresh food to the many sedentary animals there. Even hardened zoologists are caught in a fever of excitement when let loose in such a spot. Often the reef lies with its top just under the surface, so that one wades knee-deep in water with the risk of suddenly sinking up to the middle. Here we found large brown blocks which resembled boulders, but which were labyrinth corals (Poritis). In the white, decayed central portion we would often find a strange blue, broad and zigzag stripe which, when we stooped down, would shrink and vanish. This was the giant clam (Tridacna); and it was its vividly coloured soft parts which attracted attention when the shells were open. Erect, roughly branched corals (Acropora) shone with a brownish luminescence, and everywhere we trod on a confusion of finely branched coral stems, which all the time would crack and break, and threaten to send us sprawling. 
The risk of broken legs, and of cuts and gashes, is considerable in such places, but we faced it along with the risk of encountering poisonous sea snakes and other awkward inhabitants of coral reefs. It was only when we turned the coral blocks over that we saw the fauna in all its wealth and variety. Hiding underneath we would find sea-urchins, starfish, and especially brittle stars, whose arms like worms would be coiled round the coral branches. Here there were crabs in amazing variety, and quantities of worms; cowries fell out of the cavity along with cone shells; and, firmly attached among sponges and other colonizing forms of animal life, were oysters and other bivalves.

The deeper portions of coral reefs extend into a good 50 metres of water, but we had no desire to risk either our ship or our gear there. On various occasions, however, we saw samples of the fauna on other bottoms at corresponding depths of from 10 to 50 metres or so. These bottoms are often either of pure sand or sand mixed with clay, and they are populated by a fauna characterized more than anything else by the handsome Venus family of bivalves, which range, in various species, from the Arctic to the Tropics, always in this kind of locality. Here are commonly found numbers of brittle stars with arms of great flexibility (Amphiura), as well as many bivalves (Thyasira, Cultellus, among others), hearturchins (Echinocardium, Spatangus), many varieties of worms, and seapens (Pennatula, Virgularia, among others).

In the northern Bay of Bengal, at a depth of 50 metres, we trawled a bottom which appeared to be pure mud but was in fact mud finely mixed with sand. We found strange sea-cucumbers (Molpadida), worms, and numbers of swimming crabs, mantis crabs, etc. The last-named has a body the shape of a lobster's except that the forelegs are slender prehensile organs, while on its hind part the animal has some intensely sharp spines with which it delivers a sharp blow when handled. In this haul we also obtained the rare sea anemone Sphenopus marsupialis, which lives in a pouch-shaped tube constructed from grains of sand. This creature was first described, on the basis of some of its sand tubes belonging to a private Danish collection, in the I79os, but was not identified as a sea anemone, by the Danish zoologist Steenstrup, until i 856 . The specimens had been found at Tranquebar. Our new and valuable individuals of this Danish speciality were obtained at a position slightly to the north of the first discovery.

At a similar depth in the Strait of Macassar we located a really soft bed of the type found only in calm creeks and other places well beyond the reach of waves and current. It is identifiable at once by its fauna, in 
which stiff-armed brittle stars (Ophiura) are particularly prominent. To move about among stones and blocks of coral with five such rigid arms would be impossible, but they are admirably adapted to the soft, level bed. Here also we found heart-urchins, many kinds of worms, and some molluscs (Nucula and others). In the Strait of Macassar the quantities of empty shells on the bottom had facilitated the growth of a rich epifauna which included the feathery black corals (Antipatharia), large and handsome kinds mostly occurring in deeper waters. Here were polyps (Nematophanus), on which were brittle stars (Euryale), their arms twined tightly round the stalks of the polyp colonies, numbers of sea-mats or polyzoa, and various feather-stars.

It was seldom that we had opportunities for trawling in such shallow water. A little more often we were able, in out-of-the-way places, to explore the edge of the continental shelf between 50 and 200 metres deep. I remember a day in the Great Australian Bight when the grab was lowered to 80 metres. Although it closed in the normal manner, it was found when hauled up to be empty of bottom material, and so was classed as "non-quantitative", which is the worst that can be said of a bottom sample. However, I proceeded to sort the little that it did contain; and the more I examined it, the more interesting I found it to be. Evidently the grab had struck a pure rock bottom, more or less clearing it of fauna over the area of 0.2 square metre which it spanned, and so enabling us to form an impression of its appearance. The bottom had been covered with finely branched organisms which resembled red algæ but proved to be a mass of polyzoa colonies. These "growths" are inhabited by brittle stars, rare sea slugs (Doridunculus), isopods, and various other crustaceans, among them the squat lobster (Galathea), which resembles a small, slender, reddish crayfish but is much more active. From other trawls on the same kind of floor we know that we may expect to find the beautiful feather-stars (Comatula), either clinging to the rock or lazily whisking themselves through the water with their feathery arms.

At a point near by, our echo-sounder seemed to indicate a level bottom of about the same depth, and so we risked our new construction, the sixmetre-wide sledge trawl which carries two parallel three-metre bags. There is always a hope that one of these will come up, even though the other should break, and so it turned out on this occasion. One bag was missing and the other was badly torn - fortunately in a way, because the "little" that remained was enough to fill several large tubs. On this sandy bottom there had been a low "undergrowth" of animal sponges in a great variety of forms and brilliant colouring, in which a bright orange predominated. 
It was a gorgeous sight, which vanished as usual after preservation. There were large, fleshy fans, thick-walled cups, clumps the size of footballs, and many other bizarre forms; and mixed up with the rest were large colonies of polyzoa made up of criss-crossed flakes, hard and sharp like crispbread. Small wonder that the trawl gave way while being dragged through this mass of material.

A few trawls off San Thomé in West Africa and near the Kermadec lslands north of New Zealand showed us that the Tropics could improve even on this. The material which the Galathea's heavy gear could haul up here in a trice was fantastic. Near the island of Raoul in the Kermadec group we made three dredges at a depth of about 80 metres. One gave a haul which included a whole tub-ful of brilliantly coloured sea-urchins of great beauty, the size and shape of oranges, and equipped with long, sharp spines five centimetres in length which made us handle them with great care. Another haul was still richer, and it took several days to complete a rough sorting of these catches. There is no doubt that many of the animals found are quite new species, but a full study of them will take a long time.

Near Campbell Island, south of New Zealand, we tried a similar dredge, but owing to the cooler water here the results were much less striking. We seem to have becn more successful in a trawl on soft ground in Milford Sound on the west of South Island, New Zealand. We had hauled in the trawl and were clearing away the mud when one of our New Zealand guests exclaimed: "Why, there's Lucinoma (a bivalve), which my colleague Marwick is describing

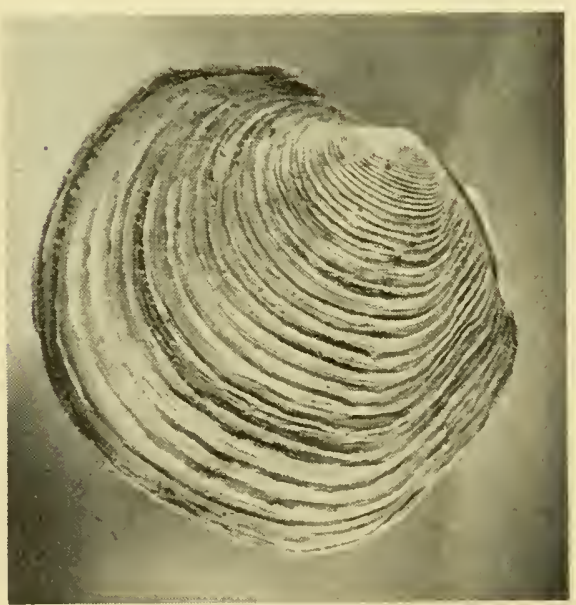

The bivalve Lucinoma galatheæ. from our Tertiary deposits!" He took some specimens home to his colleague and now one of our finds has been described as a type of the species, under the name Lucinoma galathea. This is the first of a good many new species which in the future will testify to the results of this expedition. We also found a small cap-shaped mollusc (Cocculina) which seems to be unknown. Among the empty shells were many unknown types now waiting to be described.

Beyond a depth of 200-300 
metres, in places where the hard rock does not protrude, one will normally find much oozy or muddy bottom, if not pure clay. Here, however, the fauna changes character under the influence of the lower temperature and poorer food supplies, for which reason we cannot expect such profilic hauls as over the shelf. Perhaps starfish exemplify this most clearly. In shallow northern waters occur the common starfishes (Asterias) and certain multiarmed starfishes (Coscinasterias), both notable for the well-developed sucking discs on their rays. They are able to turn their stomachs inside out thorugh their mouths, and so digest prey which may be too big to swallow. But prey so large as to require such extraordinary methods are mainly found in shallow water. Now starfish are incapable of detecting their prey at a distance and can catch only what they happen to touch as they roam about. The common starfish does not normally move at more than four or five metres an hour (other species up to nine metres), and so suitable food must not be too widely scattered.

Unlike the shallow-water species, deep-sea starfishes (Astropecten, etc.) have no sucking discs on the rays, which in their case are pointed. On a clay bed they can move very swiftly, many of them at the rate of more than 30 metres an hour, and they thus have a far wider range. They cannot turn out their stomachs, but then the likelihood of encountering large prey is slight because deepwater animals, on the average, are smaller and more widely scattered. These factors explain - at least partly - why it is the Astropecten group of starfishes which we find among the commonest and most characteristic animals at depths of 200 metres and more, down to the deep sea proper.

Outstanding among other representatives of the fauna at these depths - over the continental slope - are some remarkable sea-urchins (Echinothurida). Ordinary seaurchins are supported by a strong skeleton, which not only gives them their circular form but also holds up the body wall. The animal is thus roughly the shape of a tomato with the stalk side downwards. But when Echi-

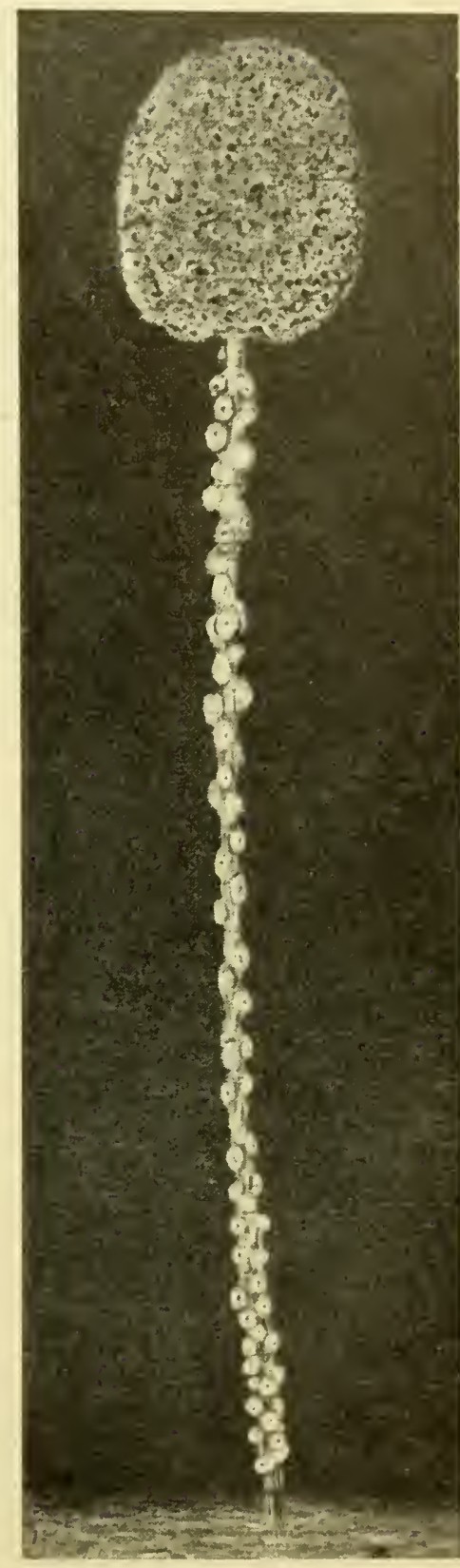

Silicious sponge (Hyalonema), with stalk covered with a colony of seaanemones (Polythoa). 


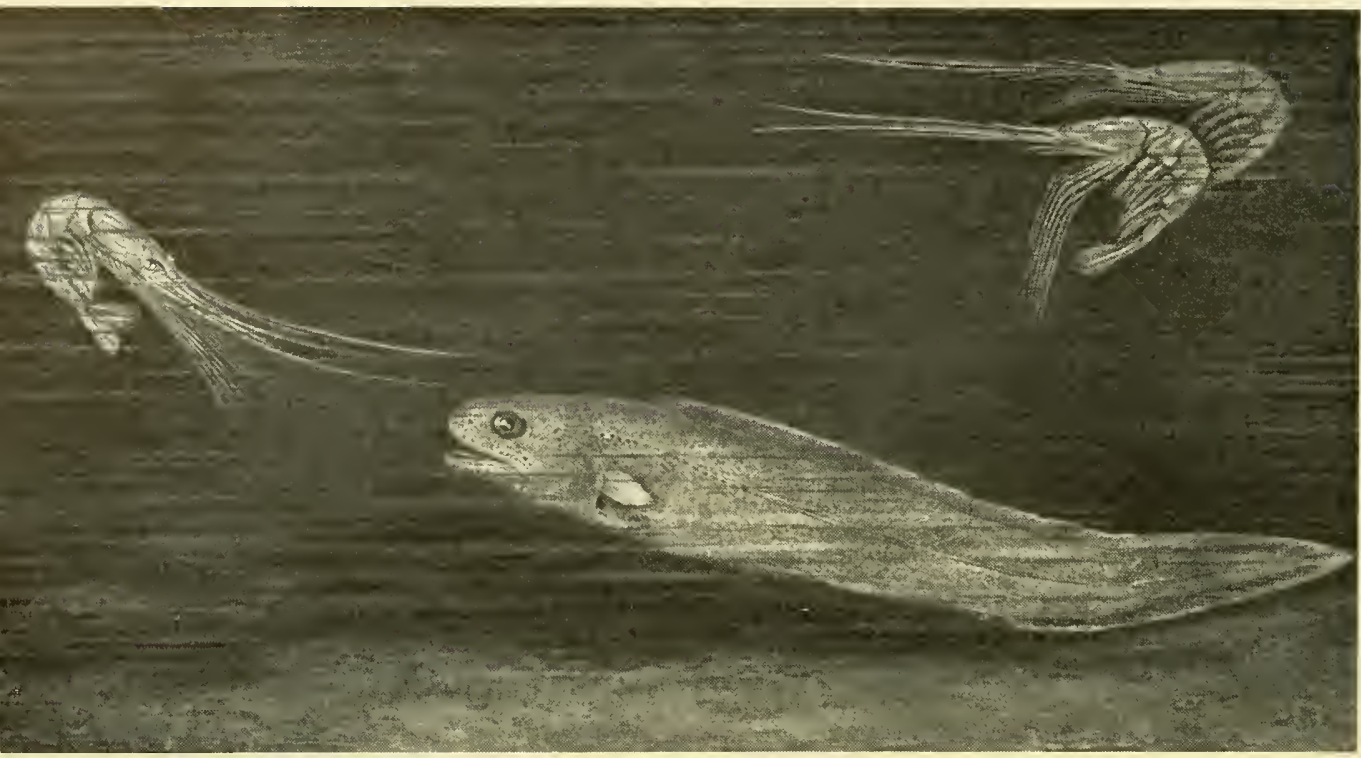

Coloconger eel chasing the prawn Nematocarcinus. South-west Africa, 700 metres.

nothurida come on deck they look like pancakes. Their skeletons are so weak that the body is sustained only by the water in the body cavity, and when that is pressed out the animal collapses. These creatures have to be carefully handled, as some of the species are poisonous and people have died after touching them. However, there are indications that it is especially some of the shallow-water forms (one species has been taken in $3^{\circ}$ metres of water) which are so toxic, for though we repeatedly had rich hauls of these animals on deck we fortunately experienced no case of poisoning. Conscious of the possibility of poisoning, we were always cautious about putting our hands into the mud which came up from the depths. Rubber gloves were very useful, in spite of the discomfort of wearing them in tropical heat.

There is not much to be said about the molluscs found at these depths. As a general rule, their shells get thinner with increasing depth. As for sponges, these - and especially the glass-sponges — become commoner. The commonest glass-sponges (Hyalonema) are flat, bowl-shaped, or funnel-shaped organisms at the end of a stout stalk through which runs a sheaf of siliceous needles which may be as much as 20-30 centimetres long. When the stalk is broken, as in the trawl it invariably was, these needles give a nasty prick. Sorting was rendered even more difficult by 
A clutch of octopus eggs on a piece of saturated driftwood. Gulf of Panama, $9{ }^{1} 5$ metres.

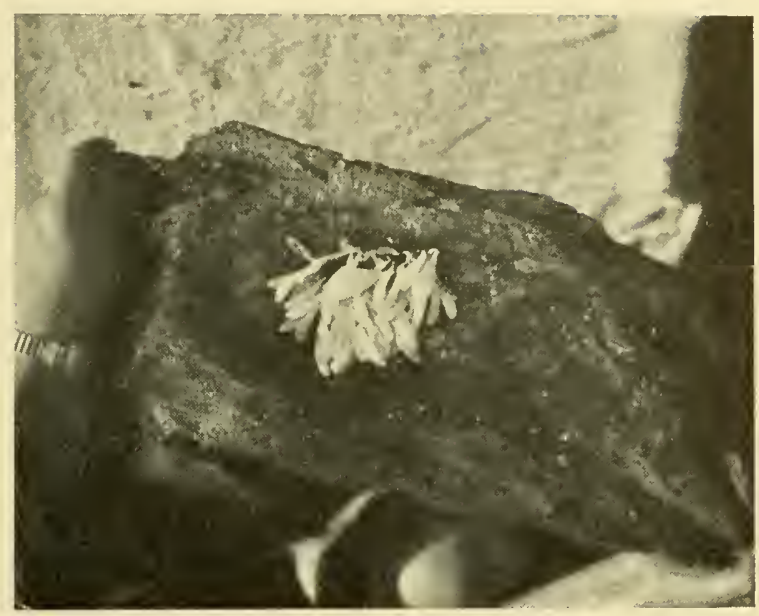

the fact that the broken sponge at once becomes a porous, semi-cohesive mass with the consistency of cotton-wool seeped with mud, and this made itself a regular nuisance by blocking our filters and wrapping itself round all our specimens.

Still, our trawls over the continental slope were among the most interesting, and we may fittingly close this chapter with an account of our big trawl at goo metres in the Gulf of Panama. This is a northern extension of the region off the west coast of South America, the region with the richest organic production in the world. And our hopes of a good haul were not disappointed; in order to save our net we had to split up the catch into four parts while it was still in the water. There were plenty of both fishes and prawns, which latter seem here to live near the bottom. We had also got the remains of feather-stars, a dozen starfishes, some sea-cucumbers, two species of large sea-anemones, and - strange to relate - a lump of half-rotted wood with a large clutch of the white, oblong egg capsules of an octopus adhering to it. If there were few molluscs and other small creatures, this was doubtless because our coarse-meshed gear had been for too long suspended in the surface layers. Among a fair number of crustaceans from the bottom were two squat lobsters (Galathea), five species of the related Munida, and some hermit crabs with their scarlet eggs. Sorting all these out was a race against time, as putrefaction takes place quickly in the tropical heat and we could not be sure that there were no rarities at the bottom until we had got everything out. By concentrated effort we managed to get the last of our specimens into preservatives in under four hours. 


\title{
GOASTAL FISH
}

\author{
By J. R. PfafF
}

Mud-skippers (Periophthalmus) are extremely common on muddy shores. The Galathea had collected a number in West Africa, but I myself saw them for the first time at the small port of Beira in Mozambique. The tide was out when I crossed the bridge which leads from the harbour to the town, and beneath me lay extensive mud-flats fringed with mangrove. I was watching the ubiquitous tropical crabs, along with the pelicans that had settled down in the background, when suddenly my attention was caught by some lizard-like creatures which were hopping about with great agility. Although they were on dry land, there could be no doubt that they were fish - mud-skippers, in fact. Small circular holes in the mud revealed their hiding-places. However, the spot was too inaccessible to permit closer observation and so I walked on towards the sweltering town. On returning an hour or two later I found the mudflats covered by the incoming tide. This is the typical habitat of mudskippers. I had better opportunities of studying these strange creatures later on, especially in Galathea Bay on Great Nicobar.

Walking along the shore of this bay I came to a small stream which teemed with them. They normally inhabit salt water, and the water in the lower reaches of this stream was sufficiently saline. They sat on stones, fallen branches, and mangrove roots, watching me with large, alert eyes closely set on top of the head like two peas. In order to moisten them they were occasionally drawn right into the head, where they would roll round in a most comical manner. Often the tip of the tail would be in the water; some naturalists think that mud-skippers may breathe with their tails, and at least they will get a certain amount of moisture by this means. They would usually sit with the forepart of the body slightly raised, holding on by the pectoral fins, which resemble small arms. This being a collecting expedition, however, we had to set about catching a few of them. It was easier said than done. No sooner was the net thrust out than they skipped nimbly away, and sat watching me with apparent amusement from a stone a couple of metres away. Strangely enough, they do not seek refuge in the water, but are able to "skate" over the surface with short, vigorous strokes of the tail fin. They are actually more terrestrial than aquatic animals. The only result of my persistent efforts was a few of the smallest individuals. 
At low water, nudskippers gambol about on exposed mud-flats and mangrove roots. When disturbed they hide in mud-holes, as in the background.

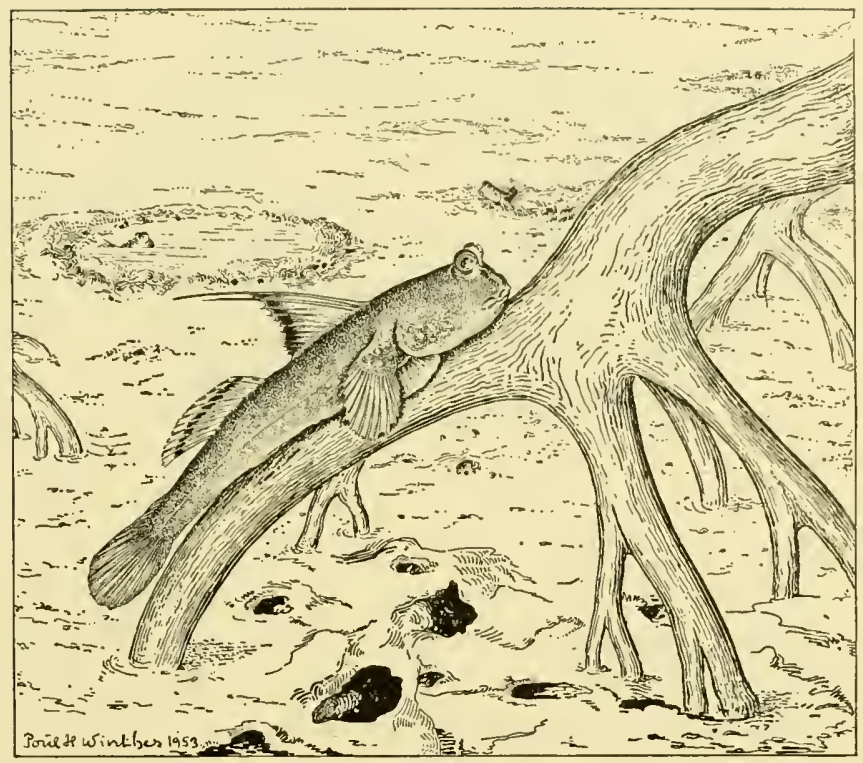

The mud-skippers belong to the gobies, a large family of small fish which are extremely characteristic of shallow water, both in Europe including Denmark, where we have ro species, and in the Tropics, where there are many more. In South Africa, which is only partly tropical, there are 42 known species. Most of the species resemble our native gobies, easily recognizable by their pelvic fins, which are united to form a kind of sucking-disc. But there are also more divergent forms, such as the almost eel-shaped Trypauchen, which lives buried in the sandy bed or among shingles, and which we found in the Java Sea.

'The mud-skipper calls to mind another group of small fish; namely, the blennies. Their nearest relative with us is the little butterfish, or gunnel (Pholis gunellus), though the family to which this belongs is not represented in warm seas. The favourite haunts of blennies are among rocks, and the easiest places in which to find them are rock pools at low tide. These are the haunts of many small fish, both swimming kinds like horse-mackerel, wrasse, and bass, and various blennies which will be found peeping out from underneath a rock. Try to catch them and they will often dart out of the water, a crowd of them together, and skip away across the rocks. In Britain they are popularly known as skippers or rockhoppers. Several of them, in fact, spend a large proportion of their time on the shore, like the mud-skippers, to which some species bear a close resemblance, for example in the prominent eyes, which some can move 


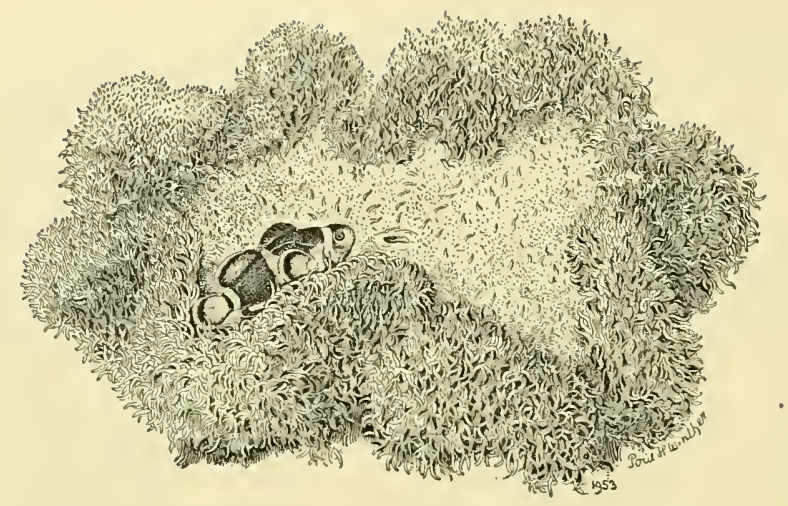

The actinia fish Ampiprion, one of the brilliantly coloured inhabitants of the coral reef, has taken up residence among the stinging tentacles of $a$ giant sea-anemone.

independently like a chameleon. It is an exciting sport catching these pretty and variegated fish. It is often possible to hook them, but the easiest method, perhaps unsportsmanlike but nevertheless extremely efficient, is to poison the water in the pool.

Of course, numerous other fish occur in this very shallow water, but the best and easiest impression of the enormous variety of fish is conveyed by going out to a coral reef. One day in May $195^{\text {I }}$ we set out from Singapore in our motor launch, chugging between green islands with palmclad beaches to the coral reef of Pulu Sudong, where we were put ashore in the dinghy. The tide was out, so that we were able to walk about the extensive reef, though hardly dryshod. In the innumerable pools and fissures of the reef there was an immense wealth of animal life: brilliantly coloured fish, including wrasse, parrot-fish, and beautiful little coral fish (Pomacentrus, Abudefduf, Dascyllus, and many others). The most interesting of the Pomacentridx is unquestionably Amphiprion percula. It lies rocking on its side in the stinging tentacles of a giant sea-anemone. To any other animal such an embrace would mean death, but this little creature is unaffected by the dangerous companionship; in fact, it feels so safe there that when we tried to take it it merely went further in. We here have one of the most remarkable examples of symbiosis, a state of association between two animals which benefits both. It is obvious that the fish obtains effective protection in the sea-anemone, and it is probable that this sedentary animal gets its share of the food which the fish brings home. Another example, of more doubtful symbiosis, was observed by us on other coral reefs, where a small fish of eel-like form, the fierasfer (Carapus), was seen to crawl backwards into sea-cucumbers. The case is doubtful because it is difficult to see the advantage to the sea-cucumber. We saw a further case of symbiotic association between a small angler-fish 
(Antennarius) and a sponge in which the fish had taken shelter. Sponge and fish were of exactly the same green colour. Many other remarkable fish live on coral reefs: Murcena, vicious eels with venomous teeth, snake eels (Ophichthys), with alternating light and dark transverse bands like sea snakes, and trigger-fish (Ballistes maculatus). This last has three spikes in the front dorsal fin, the first of them being very powerful and so arranged that it cannot be laid down until the second one has been laid back - a refinement which its enemies probably find difficult to understand.

Let us leave the shallow water and take a look at the animal population of the continental shelf, down to about 200 metres.

Although we were able to carry out a fairly large number of trawls in this sphere, they were necessarily rather haphazard and it is too much to expect that they would give a clear picture of the fauna of the continental shelf or result in any important new finds. Quite naturally, this is the best-known sea region, since it is here that all important commercial fishing takes place. A walk through the smelly fish-market of any tropical town will give a fair enough impression of the fish life of adjacent waters, because practically everything caught is brought ashore. We also took every opportunity, when visiting these markets, to buy anything we thought was of interest. But rather than dwell on this material we will consider the bottom fishes which we ourselves caught, in 17 or I 8 trawls, at depths ranging from io to 100 metres. The available space is totally inadequate to convey any real impression of the great variety of fish represented, as there werc 34 orders covering at least $5^{2}$ genera, some with several species each - altogether about 275 individuals. But at least the figures illustrate the great wealth of forms met with in tropical and subtropical seas. Even then, they do not include the still more numerous pelagic fishes taken in the same trawls.

A closer inspection shows two groups competing for first place - flatfishes and mail-cheeked fishes. Of flatfishes there are representatives of

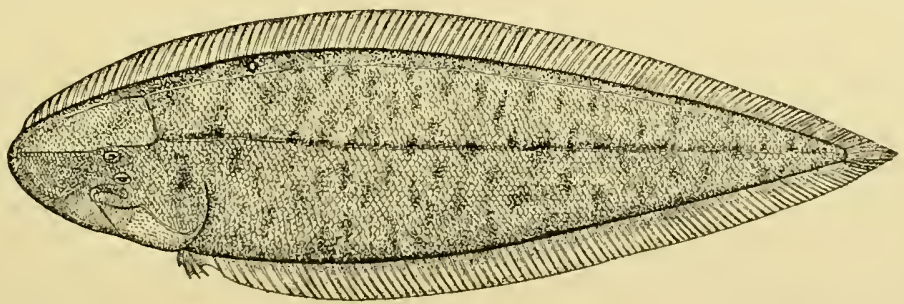

Cynoglossidx, a tropical flatfish from the Indo-Pacific continental shelf. 
the families so prominent in our own waters - turbots, flounders, and soles - and of a family of sole-like but narrower and more elongated flatfishes, Cynoglossidee.

Turning to the mail-cheeked fishes, we note the complete absence of bullheads but on the other hand a wealth of scorpion-fishes (Scorpanida), a family represented in our waters almost exclusively by the Norway haddock (Sebastes). The scorpion-fishes have a more normal fish form than the bullheads, being more like perch, but they are often liberally equipped with spines, spikes, and crests on the head, and frayed skin flaps all over, in addition to some very strong fin spines. It is wise to avoid these creatures, as they can be very painful and even poisonous, well deserving their name. Their colours are often brilliant reds, which may be taken as warning signals. In other cases they will present a motley of irregular brownish spots, light as well as dark. These are camouflage colours which make them extremely difficult to detect among the stones and rocks which they frequent.

Even more closely associated with the bottom is another group of mailcheeked fishes, the flatheads (Platycephalida). These are elongated fish with a flat, pointed head, upturned eyes, and a flattened body. They frequent the sandy bottom, where they cover themselves in sand like the flatfishes. As they are very numerous and grow to a respectable size, they are important commercial fish.

Some of the most interesting fish, from the point of view of natural history, which we encountered were the star-gazers (Uranoscopus), which are related to our native weavers (Trachinus). They are rather clumsily built and have a large, angular head with small eyes placed close together on the top and a completely vertical mouth. They have the habit of burying themselves in the sand with only mouth and eyes showing. They live on small animals, which they entice by sticking out from the mouth a red or white filament or skin-flap which resembles a worm. They are well protected both by their greyish colour and by their ability to inflict a painful shock by means of electric organs behind the eyes, formed by a modification of part of the eye musculature.

We found a variety of eels, besides the snake eel and muræna already mentioned. These last included the pompa (Thyrsoidea macrura), which, with a length of over three metres, is probably the longest known eel in the world. It is common from East Africa to Indonesia. Worthy of mention also are various conger eels (Congrida) and the worm-shaped Heterenchelys microphthalmus, which was exceedingly common all along the coast of tropical West Africa, where we usually took it in the grab. As 


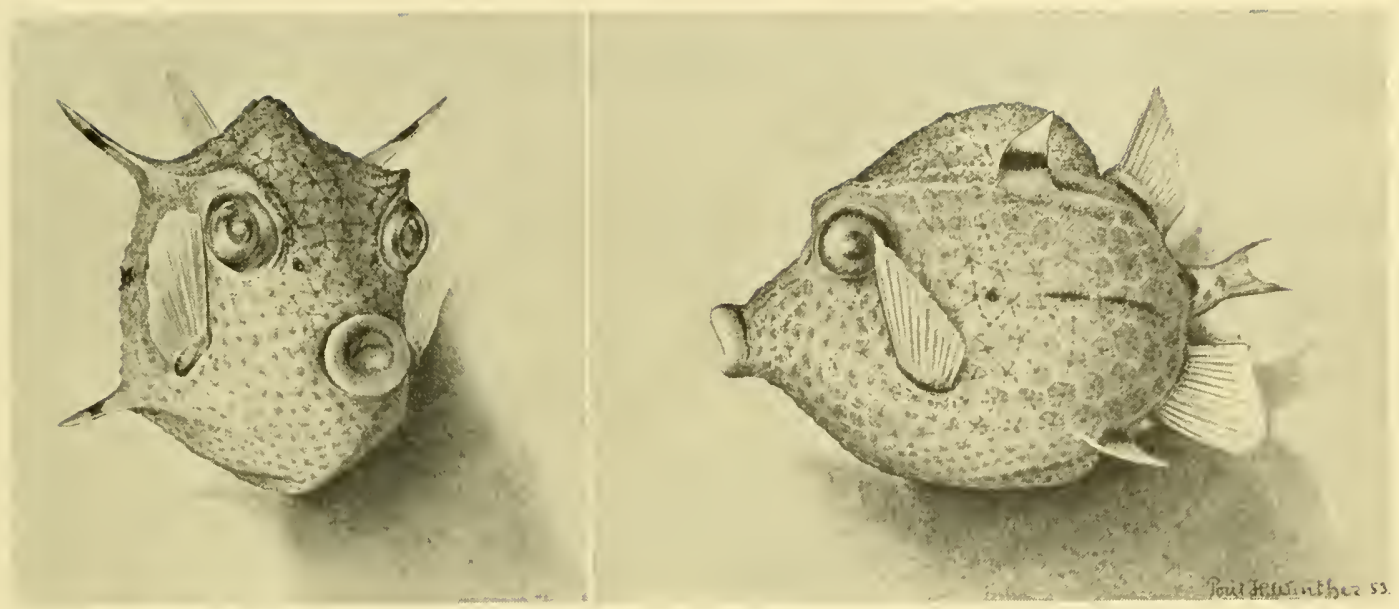

The Trunk-fish (Capropygia unistriata), from the Great Australian Bight, was a great 'hit' owing to its irresistible appearance.

we nearly always got only the forepart of these eels, it is to be supposed that they burrow so deep into the mud that they get cut by the jaws of the grab. Over the continental shelf we obtained a rich assortment of other fish or fish-like animals, ranging from the lancelet (Branchiostomida), hagfish (I o specimens of the genus Bdellostoma caught in Milford Sound, New Zealand), small sharks, and rays, to those old favourites the porcupine-fishes and puffer-fishes, both of which caused much fun on board by their ability to blow themselves up and roll their eyes. These little clowns are not nearly so harmless as they look, the flesh of many of them being deadly poisonous.

Let us conclude this random excursion into the world's principal fishing regions by presenting the fish which made incomparably the biggest hit, though for quite unscientific reasons. This was a little coffer- or trunkfish (Capropygia unistriata) caught in the Great Australian Bight. Unfortunately, the drawing cannot give its lovely colours, notably its pink stomach, though it shows its delightful kissing lips (Fig. above).

A glimpse into the fish life beyond the 200-metre limit was obtained on February 2I, I95I. We were in the Indian Ocean off the coast of Natal, a good way south of the Tropic of Capricorn. The big otter trawl was out dragging the sea-bed, we hoped, at a depth of 500-6oo metres while we were making a couple of knots' headway. There was peace and tranquillity on board, and a sense of expectation. With the hot sun dropping down towards the horizon, we had enjoyed our simple dinner 
and were relaxing over a cup of coffee. The silence had been broken by the sound of the winch hauling in the wire. Then suddenly the noise ceased; the gear was up and the ship was again travelling full speed ahead. We hurried on to the quarter-deck, which lay bathed in the beam from the spotlight, while all around was pitch-black night. The trawl came in over the rail and seemed to be well filled. The excitement was intense; the contents might be mud. But it was not mud. Unloosed from the bottom of the trawl fell a profusion of animals, which were quickly sorted into the water-filled tubs and trays ready waiting.

With the crew crowding round on the look-out for a coelacanth, or perhaps a minor sea serpent, the experts made a rapid survey of the haul and picked out the animals which called for most careful attention. While the material was being taken into the laboratory, the gear was got ready for another trawl, this time at a depth of about 700 metres. In the two trawls that evening, which together took I 70 minutes, we caught a total of 769 fish, besides a similar number of invertebrates. We were delighted with our luck, though it meant a night of feverish activity. No one who has not tried it can realize what it means to handle such a mass of material in such a few hours. It must all be preserved without delay, mostly in formalin, and the vapour from the formalin soon makes the air in the laboratory, which despite the hour is hot and heary, extremely uncomfortable. But there is no avoiding it, as without preservatives the material quickly begins to putrefy. Alcohol would be pleasanter but is too expensive. Some of the animals can be deep-frozen. Since we had to be ready for the next haul, most of the preserving bottles had to be taken to the hold, from where it was always difficult to get them up again. Under such conditions it was essential to identify the animals and label the bottles as accurately as possible. A total of 769 fish may not sound a lot compared with the number that would have been trawled in the North Sea, but in that case it would have comprised only a few specics. Let us see what sort of fish we had caught.

If we confine ourselves to the bottom fish, there were 576 specimens belonging to $3^{\circ}$ different genera, each represented by one species. An analysis showed that there were 48 sharks (two genera), two salmonoids (one genus), 147 representatives of the order Iniomi (two genera), seven codfishes (three genera), 225 rat-tailed fishes (six genera), I4 eels (two genera), three beryx-fishes (one genus), 54 brotulids (four genera), I 2 mail-cheeked fishes (three genera), 23 flatfishes (two genera), and 5 I angler-fishes (one genus). Easily the largest group, therefore, was the rat-tailed fishes, both in number of individuals and genera. The second 
largest group was the brotulids, and the third the cod-fishes, if not in number of individuals then in number of genera. Accidental causes may of course account for this order, and I shall make no attempt to base any statistics on so small a proportion of material. But if we compare this haul with the composition of our total haul of bottom fish in the region between 200 metres and 2,000 metres, we get an identical result. At I4 stations ranging from West Africa to the Gulf of Panama we fished 613 rat-tailed fishes, representing I 5 genera with 26 species, 319 brotulids representing 16 genera with 16 species, and 193 cod-fishes representing seven genera with io species.

The most dominant fishes over the continental shelf, the rat-tails or grenadiers (Macrouridee), are closely related to cod-fish. We have two of these in the Skagerrak: Coryphanoides rupestris and Malacocephalus lcevis, the former common and the latter a very rare visitor. The rat-tailed fishes are confined to deep water, though a few may occasionally venture over the continental shelf, and they are extremely typical of their habitat, having a large head with huge eyes, usually a chin-barbel, and a rapidly tapering body which terminates in a thread-like tail-tip. The mouth may be at the front of the head, but as a general rule is on the under-side, from where it may be projected as a short, wide tube. The snout is more or less projecting, and in some forms is extended into a long, conical tip. Like the well-developed lateral line, it contains sensitive organs, which are essential when the fish frequents deep waters where not even its large eyes can penetrate the absolute dark. The possession of these eyes, however, suggests that even species taken at depths below 500--60o metres make considerable migrations up into water levels where the eyes may be of use. Some of them, indeed, are accessible to fishing; but though the flesh is good, the people of most countries shrink from eating these remarkable messengers from another world. It was one of these odd

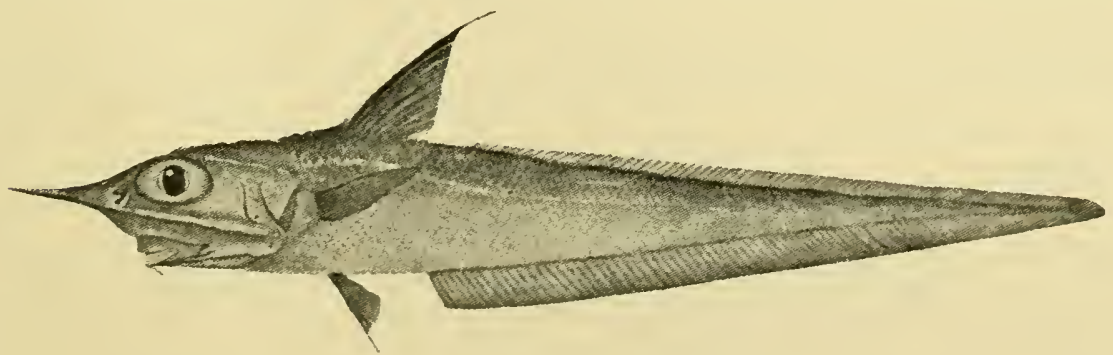

The rat-tailed fish Coelorhynchus parallelus is a typical representative of the fauna of the continental slope. Mozambique Channel, about 6oo metres. 
fishes which attracted most attention when the Galathea displayed her treasures to visitors, a long-nosed Trachyrinchus from South-west Africa. This was the favourite quarry of journalists and press photographers, not because of the interesting fact that it was new to the faunal region but solely on account of its appearance. Yet it could easily be mistaken for one of the commonest forms of all, the genus Coelorhynchus. Ten of the 26 rat-tailed fishes caught by the Galathea belonged to this species.

While some rat-tailed fishes are known only from very limited regions, others are widely distributed. The record in this respect is probably held by our old friend from the Skagerrak, Malacocephalus lavis, which we met with both off East Africa and off South Australia. The remarkable adaptability of this fish is indicated by the fact that off South Australia we caught it at I,350 metres, which is about its greatest known depth, while once near the Skaw it was taken in little more than roo metres of water.

We have seen that it is the brotulid fishes which form the next largest contingent of fish on the continental slope after the rat-tails. They provide us with a good example of how a common mode of life can influence the appearance of organisms; many brotulids so far resemble rat-tailed fishes that at a first inspection even a specialist may have difficulty in distinguishing them, though they are not closely related. The brotulid fishes belong to the order of perch and their nearest relatives are our native viviparous blenny. They are small or smallish fish which chiefly inhabit the Tropics, some near the coasts but most in deep water and some even at very great ocean depths. A few occur in such large numbers as to have some importance to fishing. Especially numerous in our trawls were the genera Dicrolene and Melanogrammus, of which in a single trawl at $93^{8}$ metres in the Gulf of Panama - the largest single trawl of the expedition we caught 60 and 90 specimens respectively. Altogether, we caught many brotulids in this position, including three specimens of Bythites, one of the few genera which occur outside tropical and near-tropical regions.

It may seem surprising that cod-fishes are so well represented on the continental slope, since this typically northern family is almost completely

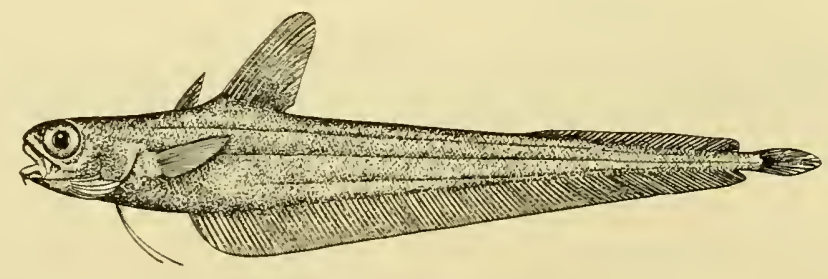

Tripterophycis gilchristi. 
absent from the tropical continental shelf. The high temperature has barred their distribution there, whereas forms which have sought the depths have been able to spread along the continental slope. Of the many forms, of which a number are widely distributed, it nust suffice to mention the small Tripterophycis gilchristi, which is about 20 centimetres long and is the only cod-fish with three dorsal fins and onc anal fin. Of this fish, which had previously been known only from the Cape and Indonesia, we caught 26 specimens off Durban and Io off Tasmania (Fig. p. 142).

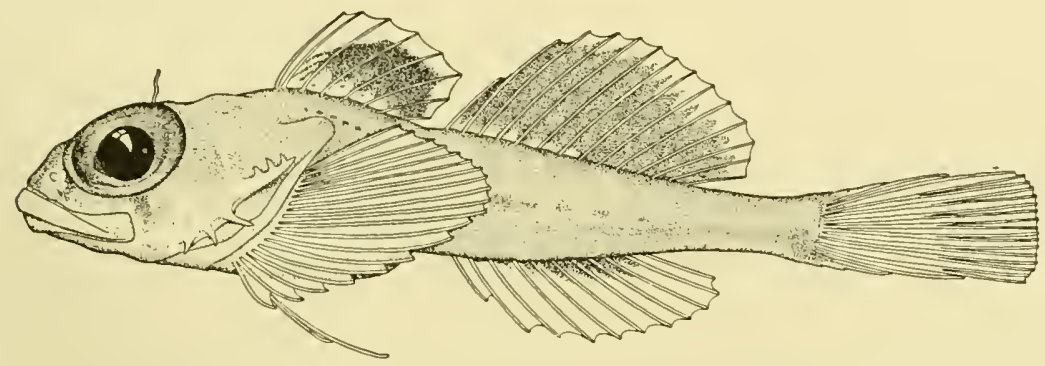

Antipodocottus galathex, the only known, true bullhead in the southern hemisphere.

Of the scorpion-fishes (Scorpanida), which were so prominent over the continental shelf, few have ventured into deep water. Altogether, we caught four species belonging to three genera, the decpest being at about I,300 metres off Dakar in West Africa. Some occur in considerable numbers at mid-water depths, such as the magnificent red sancord or jacopever (Helicolenus maculatus), which is common all round South Africa. We caught 39 specimens in a single trawl off Durban at about 500 metres. Actually this handsome fish, a near relative of the northern redfish (Helicolenus dactylopterus), is only partly a deep-sea fish, as it is met with well in over the continental shelf. Whereas the mail-cheeked fishes (Cataphracti) are richly represented in the Tropics by scorpion-fishes and others, especially over the continental shelf, the commonest northern European family of this order, the bullheads (Cottida), had never been known to occur in the southern hemisphere. It will be imagined what a sensation there was on board when on January 20, 1952, in a haul by the otter trawl at 600 metres in the Tasman Sea, we found four small bullheads, the largest of them being about six centimetres long. This find may prove to be one of the most sensational of the whole expedition. This newly discovered fish has been described by the American ichthyologist Rolf Bolin, who was with the expedition at the time, under the name 
Antipodocottus galathex. It is the only bullhead known to inhabit the southern hemisphere, where it is separated from its nearest relatives in Japan and California by literally oceans of water. Dr. Bolin has tried to imagine how this fish reached the Tasman Sea, in an exciting piece of detective work which can be only briefly summarized. The common ancestors of the present Californian, Japanese, and Tasman species must have lived off the Pacific coast of North America, some in shallow water and others at a couple of hundred metres. One of the deep-water species, which inhabited an area with a rather narrow temperature range of between $6^{\circ}$ and $9^{\circ}$ C., migrated during a very warm period westward along the northern fringe of the Pacific, and then in the next cold period was forced southward on the Asiatic side. This became the progenitor of the Japanese genus Stlengis, which has since evolved three species, while those which remained in American waters became the ancestors of the present seven Icelinus species. Alternating glacial and inter-glacial periods forced some of the Japanese bullheads, in their search for lower temperatures, down to deeper waters, and - owing to special oceanographical conditions - not to the north but still further south, along a route which probably followed the Ryukyu Islands, Formosa, the Philippines, New Guinea, the Solomon Islands, and the New Hebrides, to end up near Tasmania, where it now lives at a depth of 600 metres.

"Such a migration", writes Dr. Bolin, "must have been an arduous one, and it would have been possible only for a form living in comparatively deep water, water much deeper than is usually inhabited by fishes of this family. It is, therefore, not surprising that the migration has apparently been performed only once, and that Antipodocottus is the sole representative of its family in the southern hemisphere."

Of other Cataphracti, brief mention must be made of the Cottunculidex, small, degenerate bullheads, of which, in a trawl at r,ooo metres off Angola, we took a specimen of the genus Cottunculoides, about ro centimetres long. The three known species had been caught off the Cape, and the one which we obtained, besides being a quite new species, considerably extends the distribution of this genus.

Whereas the flatheads (Platycephalide), which were so common over

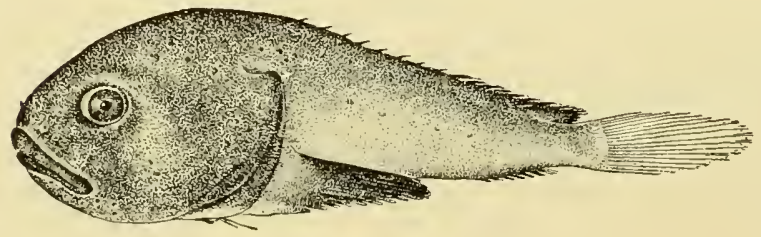

The bullhead Cottuncoloides from West Africa, $I$, ooo metres deep. 


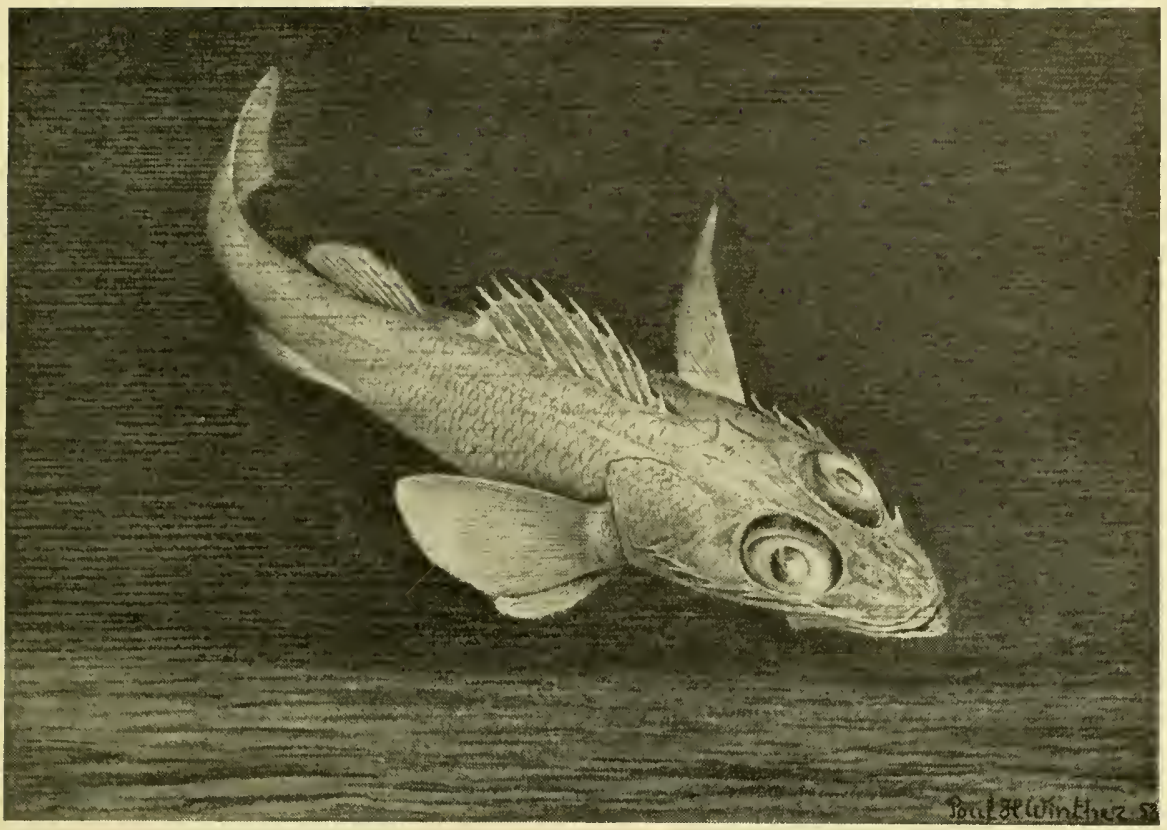

A mailed-cheek, Parabembras robinsoni, from $55^{\circ}$ metres, off $\mathcal{N a t a l}$.

the continental shelf, do not venture into deeper water, we find here the small, closely related family of Bembrida; though on the whole expedition we obtained only one specimen, a Parabembras robinsoni, at about $55^{\circ}$ metres off Natal. It is considerably more robust in structure than the flatheads, with serrated crests on the head, very large upturned eyes, and a magnificent red colour. In general, it bore a close resemblance to members of the Bembropsidx family, of which we obtained a few specimens in Indonesia. This is another example of the unifying influence of environment on animals which, like these, are not closely related but which live under the same conditions.

Of the sea robins (Peristediida), which resemble gurnards but are completely armoured and have a head which terminates in two flat extensions, we were fortunate, at two stations off Natal, in catching I I specimens of the species Peristedion weberi, of which there was only one known specimen, caught in the same area. The colour, previously unknown, was a pale yellowish red, with brick-red spots and stripes along the edges of the armour plates.

In one of our extremely rich hauls off the coast of Natal, at about .550 metres, we got 137 individuals of the order Iniomi, a group of fishes 
Also off Natal we obtained five specimens of a remarkable eel, Coloconger, not previously known from this area and probably a quite new species. "Slender as an eel" is a term which could not be applied to this deep-sea cel, which is so short and fat that at first sight it could easily be taken for a burbot-like cod (Fig. p. 132).

Flatfishes, which were so dominant on the soft bed of the continental shelf, have been less successful in adapting themselves to deeper water. One of the most fascinating forms caught on the Galathea was a flounder, Azygopus pinnifasciatus, taken in the sensational trawl at about 600 metres in the Tasman Sea. On the tail of this fish are some dark spots, two of which resemble eyes, and the theory has been advanced that their purpose is to make pursuers mistake the tail for the head. However, the fish lives at a depth which renders this camouflage illusory, as it is totally dark. If the theory is correct, it provides us with one of the proofs that decp-sea fish must have originated on the continental shelf.

Another remarkable flatfish is the deep-sea turbot (Chascanopsetta), of which we obtained I4 specimens off Natal at a depth of about 500

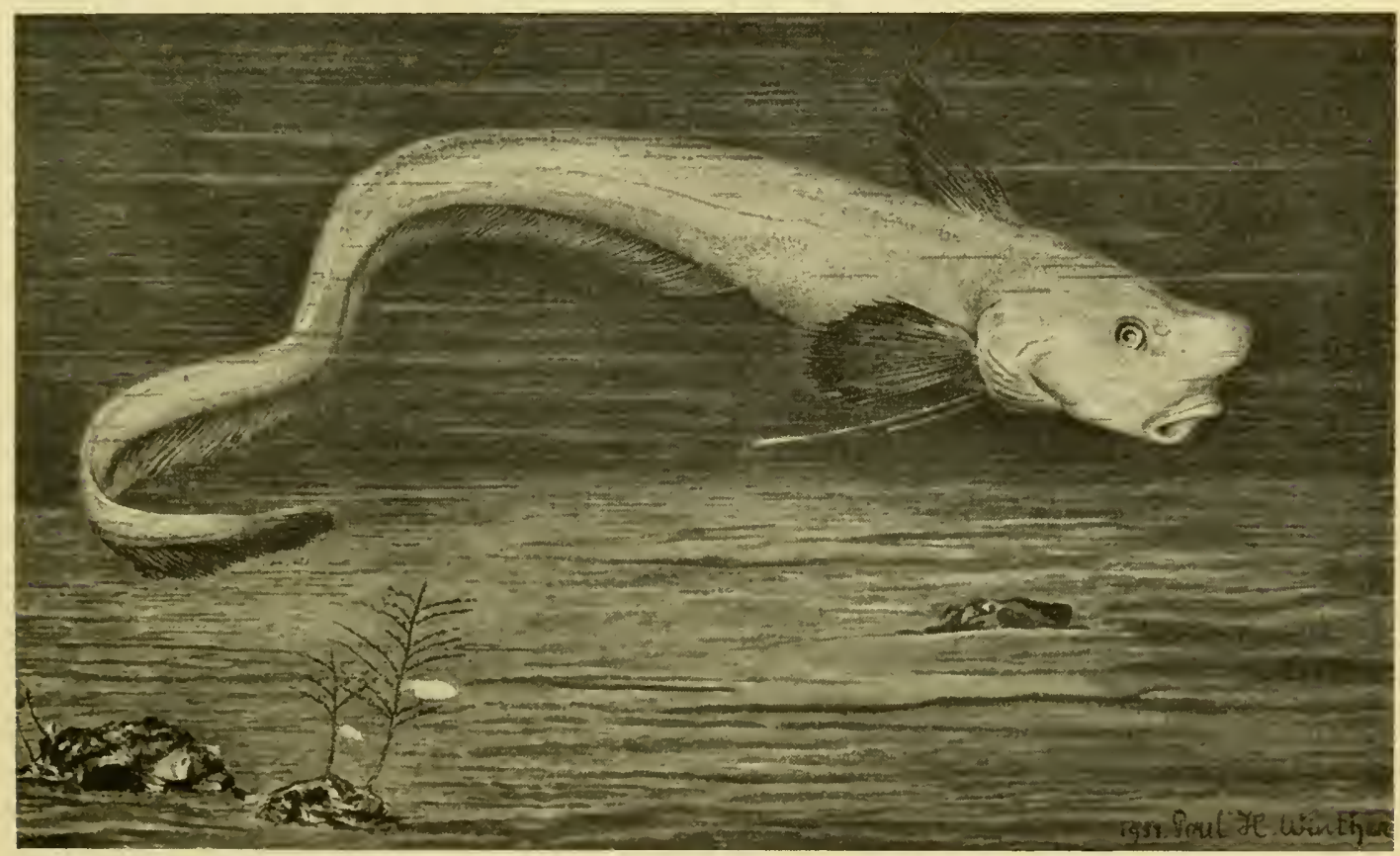

Ateleopus natalensis, an almost transparent fish, 60 centimetres long, from a depth of 500 metres off East Africa. In the foreground, cinder slag with hydroids on which are small goose barnacles (Scalpellum). 


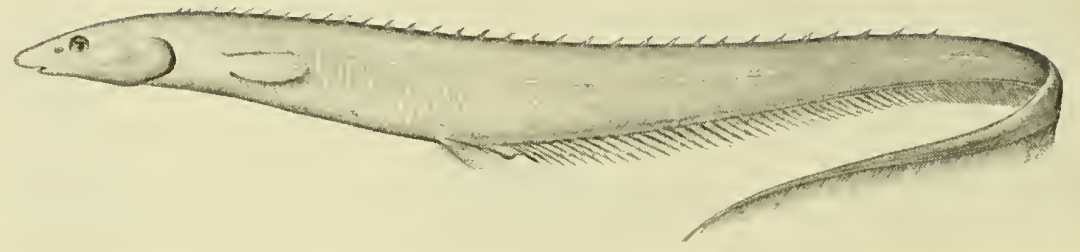

The spike-backed Notacanthus has free dorsal-fin spikes like a stickleback.

metres. Whereas flatfishes usually have a small mouth capable of catching only small animals, especially bottom-dwelling aninals, this turbot has an immense gape with long, movable tceth. It has adapted itself to catching fish and, like many deep-sea fish, can swallow a disproportionately large prey. It is well known from earlicr Danish deep-sea expeditions, which showed it to have very large pelagic larvæ.

We obtained numerous other strange deep-sea fishes in these regions: the eel-like "spiny eel" (Notacanthus), which has free spikes on the dorsal fins like a stickleback, and the related Halosauride taken at I,600 metres; the deep-sea salmonoid Argentina sphyrcena, also known from Northern European seas, which was caught off Natal; and many others.

Let us conclude with a couple of members of the angler-fish order (Pediculata), relatives of our common angler. Off Natal we caught 73 specimens of the rather clumsy but beautiful scarlet-coloured Chaunax pictus, which burrows into the bottom and lures its prey by means of its single, mobile fin barb placed on the snout. And, to form a final decorative vignette, we have the little, spinous rattle-fishes (Dibranchus, Halieutaa), which can be dried without loss of shape. They get their name from the Oriental custom of scooping out the insides and filling them with pebbles to make babies' rattles.

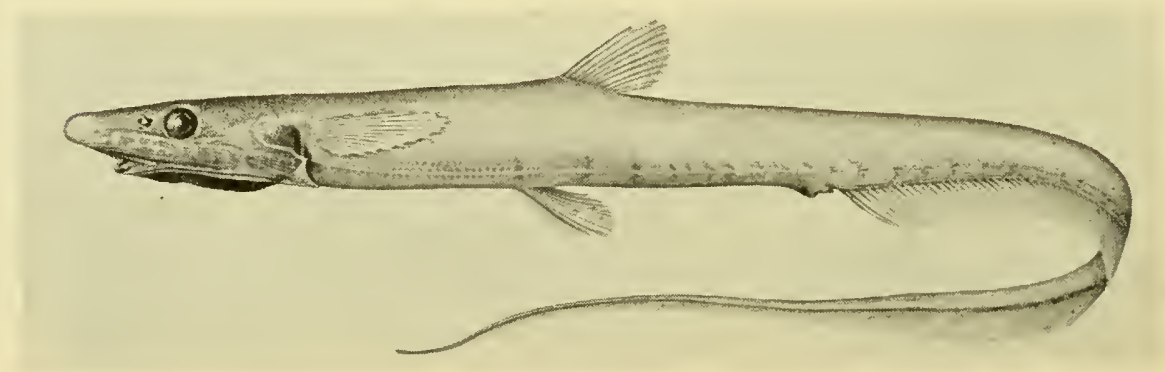

Halosaurus, a rarely seen fish from the deeper parts of the continental slope. 


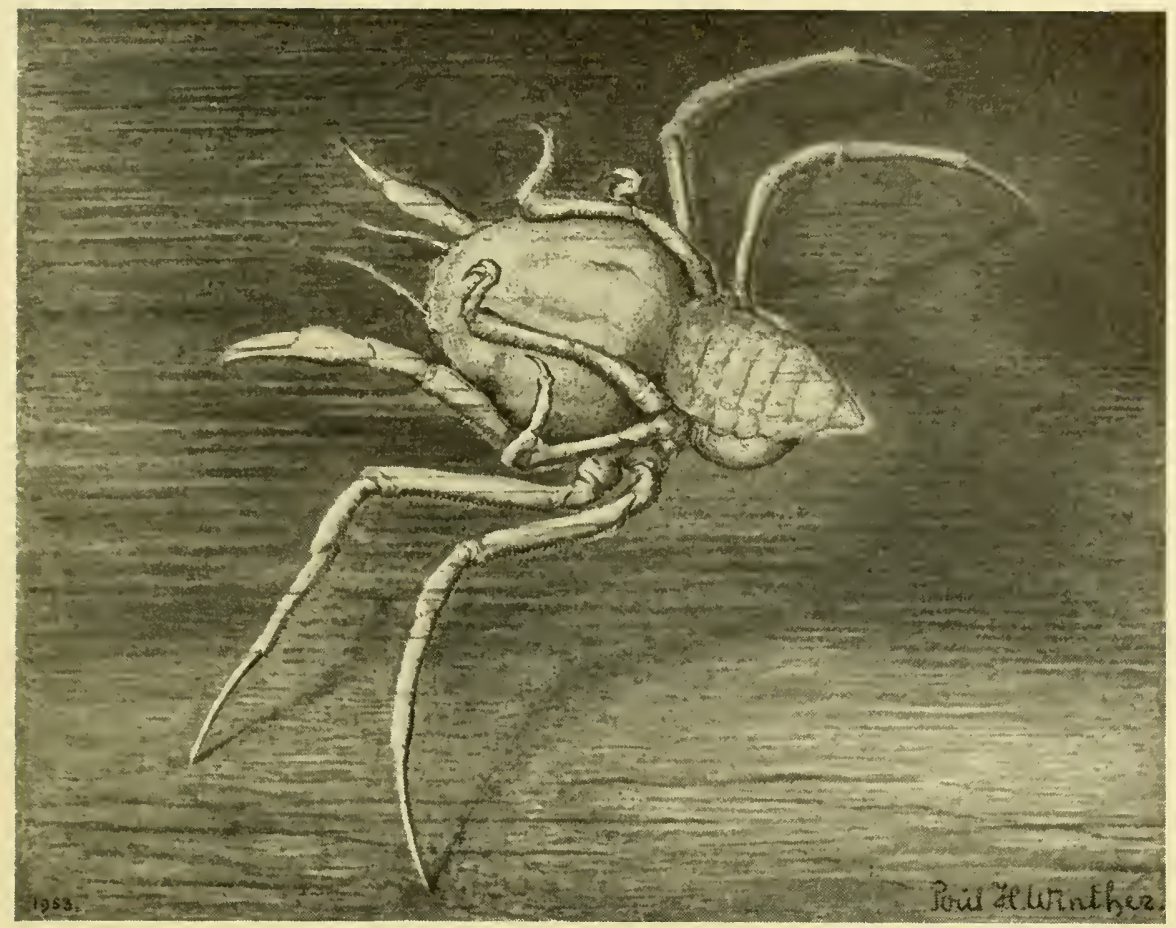

\title{
ANIMAL LIFE OF THE DEEP SEA BOTTOM
}

\author{
By A. F. Bruun
}

After crossing the threshold of the continental slope and having trouble adjusting our echo-sounder to rapidly increasing depths, we would come to a point, usually at about 2,000 metres, where the profile of the ocean bed would seem to settle down: the deep sea, the Galathea's real field of operations, would lie outstretched before us. Often the land would still be in sight, and then we would feel tempted to imagine ourselves at a level some 2,000 metres lower down, looking up the steep side of the slope with its great gorges, which are often as massive as deeply scored canyons on land. Down to a few years ago there were still geologists who thought that our ancestors of the Ice Age might have marvelled at this

Deep-sea crab (Ethusa), with parasitic crustaceans under the tail. Three-quarters natural size. 
sight; but the theory is no longer held, and the significance of this for us it that the deep sea must have been deep for millions of years. For that matter, as mentioned previously, more than half the sea area lies over depths greater than 4,000 metres, so that even a drastic lowering of the sea-level would still leave an extensive field for deep-sea research.

In order to convey an impression of the animal life out there as we got to know it on the Galathea, and correlate it with the discoveries of previous expeditions, it will be best to go out to between 4,000 and 5,000 metres. The fact is that between the fauna of the continental slope and that of the deep sea there is no very sharp dividing-line. Yet so many changes have taken place once we have passed the 4,00o-metre curve that we could always see whether a trawl had been really deep, or had only touched the lowermost part of the slope or its vicinity.

Nor is there any sudden change if we go still deeper, down to about 6,000 metres; but it will be best to deal separately with the special fauna which we found in the oceanic trenches. This will make it easier to appreciate the special characteristics of the hadal fauna, as it has now been called.

Let us first consider the facilities for life in general.

The perpetual darkness, the temperatures near freezing-point, and the slight variation in the chemical composition of the water have already been discussed. We have also seen how, before the Galathea Expedition, it had been shown that the water nearly everywhere is adequately supplied with oxygen, so enabling higher animals to thrive even at the greatest depths. In short, the characteristic feature is uniformity.

Yet certain things do change; above all, the pressure. For the purposes of the present discussion it is sufficiently accurate to regard a column of water Io metres deep as corresponding to a pressure of one atmosphere, which is the pressure of the air around us. This means that 26 per cent. of the bottom of all the seas is subject to a pressure of 200-400 atmosphcres, $5^{6}$ per cent. to $400-600$ atmospheres, and I.3 per cent to $600-$ $\mathrm{I}, \mathrm{Ooo}$ atmospheres, according to depth. It is still difficult to say anything definite about the significance of pressure. True, the French physiologist M. Fontaine has demonstrated, in laboratory tests, that the tissues of organisms which have lived under low pressure suffer irreparable damage under high pressure; but it will be obvious that what really is of interest here is a study of the organisms which actually derive from the abyssal depths, such as the bacterial cultures which Professor Claude E. Zobell is engaged in studying. However, there are, as we shall see, both animal species which only live at great depths and species which have a wide 
Fishing at night. The sledgetrawl frame has been bent by an obstacle on the bottom.

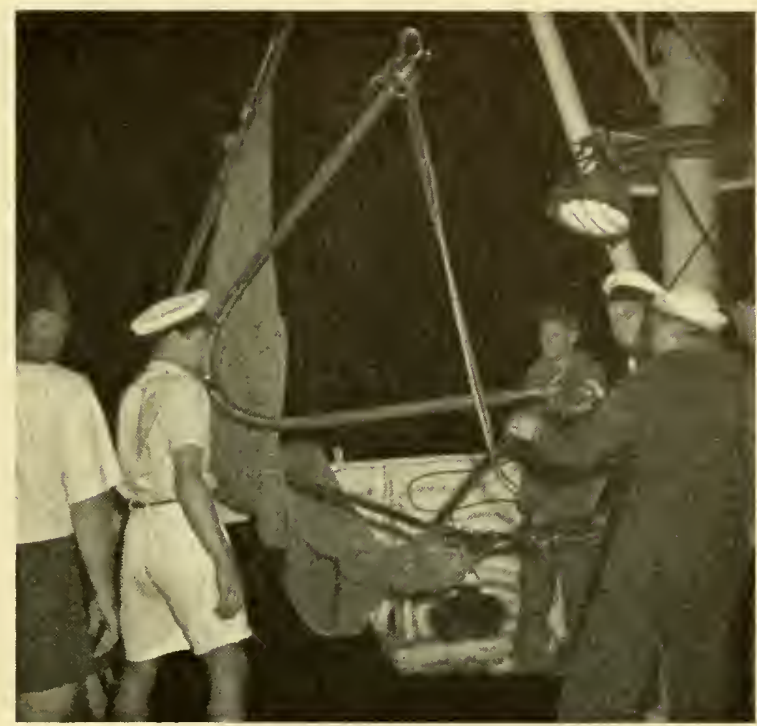

distribution extending from coastal regions right down to the oceanic trenches. Examples will be given when we come to the fauna of these trenches; meanwhile, suffice it to say that special adaptation to the high pressures must be assumed, even though the individual species may occur over an astonishingly wide range of depths. The difficulty of judging the significance of pressure in individual cases is complicated by two other important factors.

First, there is the nature of the bottom material. This is always very fine and can roughly be classed as clayey. Yet it varies a great deal, as the basic substance - deep-sea clay - may be mixed with a number of elements of organic origin. These may consist partly of the excrement of animals, of vegetable material which has drifted far out to sea before sinking to the bottom and being broken down by bacterical activity, and of the skeletons of small organisms which may occur in such vast quantities as to dominate the nature of the bed entirely. When organic elements make up at least one-third of the bed it is known as deep-sea ooze. In tropical and subtropical regions the predominant types are calcareous. The skeleton parts may here derive from the unicellular animals globigerinas, the commonest members of the group of Foraminifera which mostly live as plankton in the surface layers of the sea. From other layers of water come the skeletons of other small unicellular creatures, the Coccolithophorida, along with the shells of pteropod snails. 


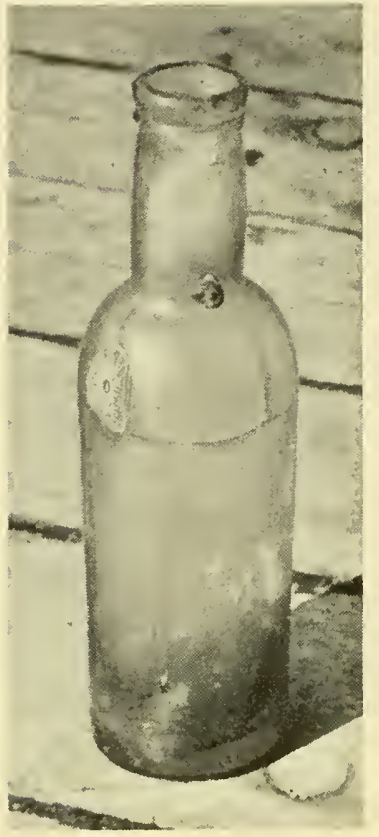

Bottle with two sea-anemones from the deep sea off Southwest Africa, 3,620 metres.

Siliceous oozes, too, are of both animal and vegetable origin. There is a broad belt of these running right across the Pacific near the Equator, in which the skeletons of the small unicellular animals radiolarians predominate. Far more important than these, however, are the frustules of the unicellular siliceous algæ, Diatoms, which dominate the bottom in a broad belt running round the earth at the Antarctic, as well as in a narrower strip across the northern Pacific; that is to say, in both cases in the cool occanic regions where every spring the siliceous algx make enormous growth.

Deep-sea clay and radiolarian ooze are unlikely to occur at depths short of about 4,0oo metres, and the average depth of the expanses which they cover may be put at 5,400 and 5,300 metres respectively. Diatom ooze and globigerina ooze lie at average depths of approximately 3,900 and 3,600 metres, so that, in fact, they form the transition to the continental slope. Pteropod oozes are only occasionally found as deep as about 3,500 metres and are altogether of minor importance; even in the Atlantic, from where the purest typical deposits are known, they form only a small percentage of the total area. The predominant deep-sea deposits, therefore, are deep-sea clay ( 38 per cent.), calcareous oozes, especially globigerina ooze (48 per cent.), and siliceous oozes, especially diatom ooze ( 14 per cent.)

From studies of shallower water we have a good deal of evidence to show that the nature of the bed plays a considerable part in the distribution of the fauna; we may speak of a sand-bed fauna and a mud-bed fauna, or of animals which inhabit rocks and reefs. But we are a long way from being able to say anything about the importance of the various types of deep-sea oozes to deep-sea fauna; nearly all the animals, to use a term taken from shallow water, may be called soft-bottom forms, those which require a solid foundation being poorly represented. True, there are expanses where it may be supposed that the bottom is pure rock, but they are very limited, one reason being that the deep ocean current is very slight, so that sedimentation can take place where in shallower water it would be swept away. Obviously, such hard expanses are difficult 
to fish, and our direct knowledge of the animals there derives mainly from the few which came up with gear that was torn by stones and rocks. Beyond that, when there arc solid objects on the bottom there will always be some sedentary species attached to them. The objects may be natural things like stoncs (see Fig. p. 178) or snailshells and stalks of glass-sponges (Fig. p. I3I), or things resulting from human activity like pieces of coal and cinders, which were found in the trawls fairly often. Even a whole bottle, fished up from 3,620 metres, had a couple of sca-anemones attached to it. The finding of this bottle, an old hand-blown type, and of the many cinders which we fished up from the decp sea, tells its own tale of man's conquest of the oceans. They gave rise to much speculation as to what geologists a thousand years hence would think if they were to find one of the $G a$ lathea's - fortunately few - lost trawl buckets in this cinders-strewn layer, which may soon cease to be added to in the age of oil-driven, and in time atomic-driven, ships...

Among the small attempts to tackle old problems with new methods must be mentioned in this connection the apparatus to which we gave the high-sounding name of "shooting-star rake". Shooting stars, of course, are meteors which burn out in the earth's atmosphere, the ashes and burnt-out particles from them falling on the earth - and hence on to the surface of the sea. These meteors may consist of various rocks or of

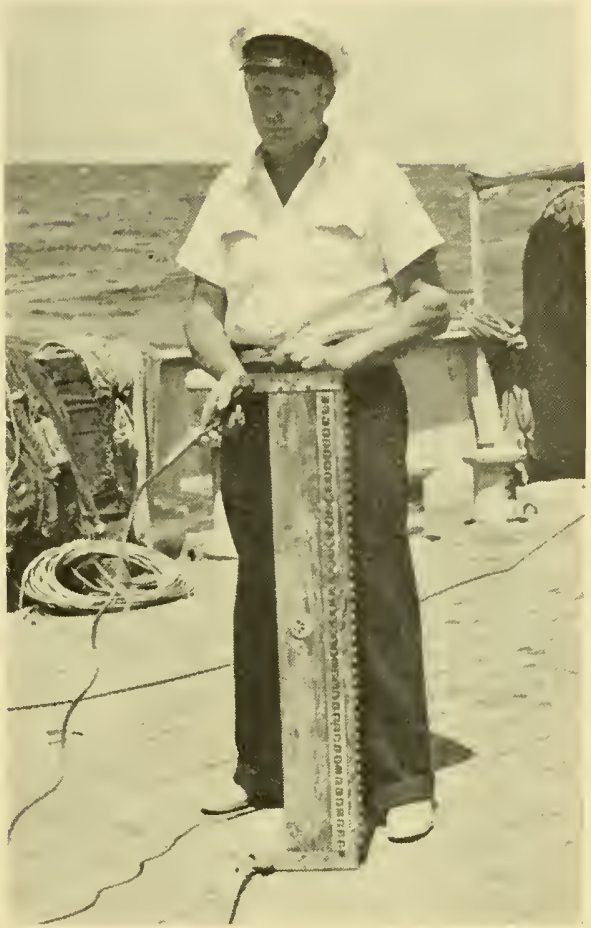

'Shooting-star rake', set with many.small magnets.
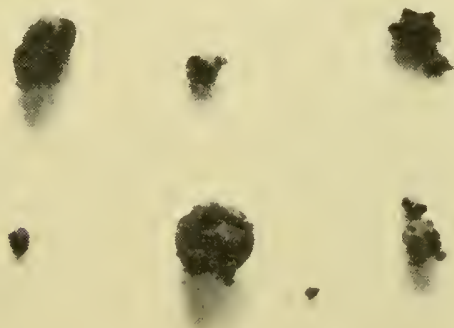

Magnetic particles obtained by the magnets. About three times natural size. South Atlantic, 5, 160 metres. 
almost pure iron. We also know that sedimentation on the deep-sea floor far from the coasts takes place very slowly, it being estimated that in many places a layer of one centimetre represents about a thousand years. We had the idea that, whereas iron meteors are very difficult to locate on the earth, we might expect, if we raked the bottom with a magnet, to find a number of the small pellets of iron which arise when drops of glowing iron strike the surface and sink to the bottom, from where specimens had previously been taken up in bottom samples. We obtained a series of very powerful magnets and had them mounted on our shooting-star rake, which we may call a sort of magnetic harrow (see figure on previous page). It gave successful results on the few occasions when we found the bed suitable for tests, and is a method which should certainly be developed and employed in the future.

While the significance of pressure and the nature of the bed to the distribution of the various animals remains obscure, there is one last factor which we must consider, one on which we ourselves are greatly dependent. We can overcome the cold or warmth of our environment and we can overcome many other things, but we must have food.

Professor E. Steemann Nielsen har discussed the origin of all sea-food in the plants of the uppermost water levels (see page 52 ). But the means by which it gets down to a depth of 4,00o- 6,000 metres, and right down to the abyssal io,ooo metres, is far from being fully elucidated.

It is commonly believed that a "rain" of dead plankton organisms sinks down to the bottom from the surface layers. But we must bear in mind that dead organisms are as rare a sight in the sea as they are on land. Sick or weak animals fall a prey to stronger enemies and are devoured; at most, a large whale or giant shark might sink to the bottom without being completely eaten. The microscopic plants sink very slowly, and must be consumed in the first few hundred metres; lower down they can certainly be traced only in very scanty quantities. This, no doubt, is why the discontinuity layer between the water masses in the warm, upper

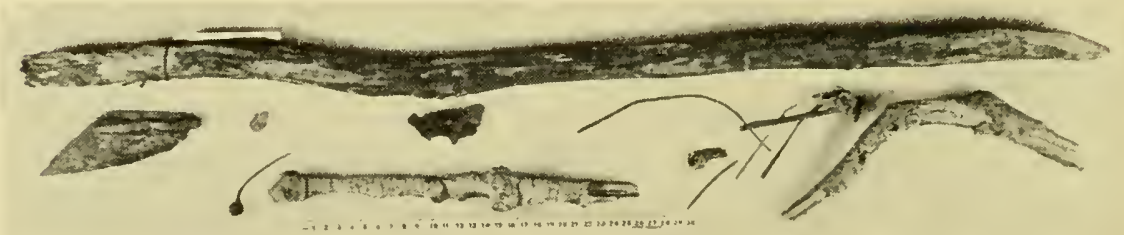

Vegetable matter trawled at 4,040 metres, south of Ceylon. 
The dinghy has been launched in order to make sure of a gond haul. A large branch can be seen in the middle of the trawl.

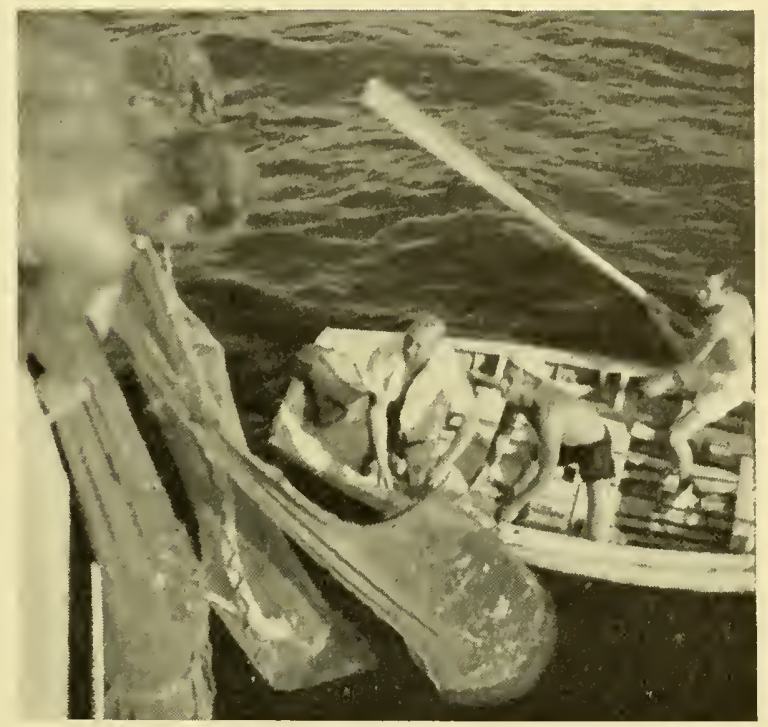

thermosphere and the cold, decper psychrosphere, referred to above by A. Kiilerich, is so rich in pelagic animals. Here the dark-loving pelagic animals of the thermosphere are stopped by the cold of the deep; and here also the animals of the psychrosphere, seeking the richer food levels above, are stopped by the higher temperatures. Lower down come the kilometre-thick layers where there is only a very little food available in the form of bacteria, which can utilize falling organic matter like excrement and other dead material. It is not surprising that higher animal life here is sparse.

Only at the bottom do we get a new accumulation. Everything ends here; and whereas in the deep, free water masses there were only a small number of bacteria to the cubic centimetre, and sometimes none at all, here they are teeming, breaking down all the material which still has a little radiant energy left in it - that is, all the dead organic matter - exactly as on land. Here we understood the link between the rich trawls which we brought up and the large quantities of dead vegetable material from the land (see Figs. p. I54 and p. I72, below) filling the trawl at the same time - branches, leaves, palm and mangrove fruits, and much else. Dead vegetable material of this kind can hardly be broken down by the gastric juices of animals; but bacteria can cope both with cellulose and with everything else, and they in turn can be consumed by mud-eaters which gorge themselves on the soft oozy bottom, such as bristle-worms, seacucumbers, and bivalves. And then a new link can be added to the food 
chain; namely, crustaceans, which eat the worms and in turn are eaten by fishes.

Dr. T. Mortensen, one of the Galathea Expedition's loyal and most interested supporters, was surprised during his world voyage as long ago as in I9I4-I6, and again in Indonesia in I922, to find large numbers of sea-urchins and other animals in deep water where there was an abundance of dead vegetation, and to find also that there were vegetable remains in the stomachs of some of the sea-urchins. Deep-sea sea-urchins are unlikely to be vegetarians, but must have found in the vegetable remains such an abundance of bacteria, protozoa, worms, and the like that if only they went on eating there would be sufficient digestible animal matter to sustain them.

But there is a further source of food supplies from above, which can almost be described by saying that some species bring their food with them from the surface layers. This applies, in fact, to a large proportion of all the fauna of the psychrospheric water; namely, all the species which breed in the surface layers. It includes both bathypelagic animals and forms which live high up on the continental slope or down in the abyssal zone.

We will take as an example a genus of deep-sea eels (Synaphobranchus), which in various species is distributed over the bottom of all the oceans down to about 3,50o metres. The Danish Ingolf Expedition took it off West Greenland, and many other expeditions, including the Galathea, have caught it all over tropical and subtropical regions, though never in the Mediterranean, which the cold water masses of the Atlantic are prevented from entering by the sill of the Straits of Gibraltar.

It is with these deep-sea eels as with our fresh-water eel: when ready to spawn they make for the warm thermospheric water. There and only there do we find the characteristic larvæ of these and all other eels, the so-called Leptocephali. Our European eels, as my teacher Johannes Schmidt found on his expedition years ago, migrate to the Sargasso Sea, north-east of the West Indies, and there we find their larva along with those of other eels, including the North Atlantic deep-sea eel. The larva live in the rich surface levels until their metamorphosis to elvers; then only do they migrate to the adult habitat, either fresh water or the cold deep-sea bottom as the case may be.

Here we must say a few words about the at times overwhelming lavishness of Nature with individual lives in order to maintain the whole - - in this case the species — generation after generation. First our own eel: countless myriads swarm over to our shores every spring, pushing up 


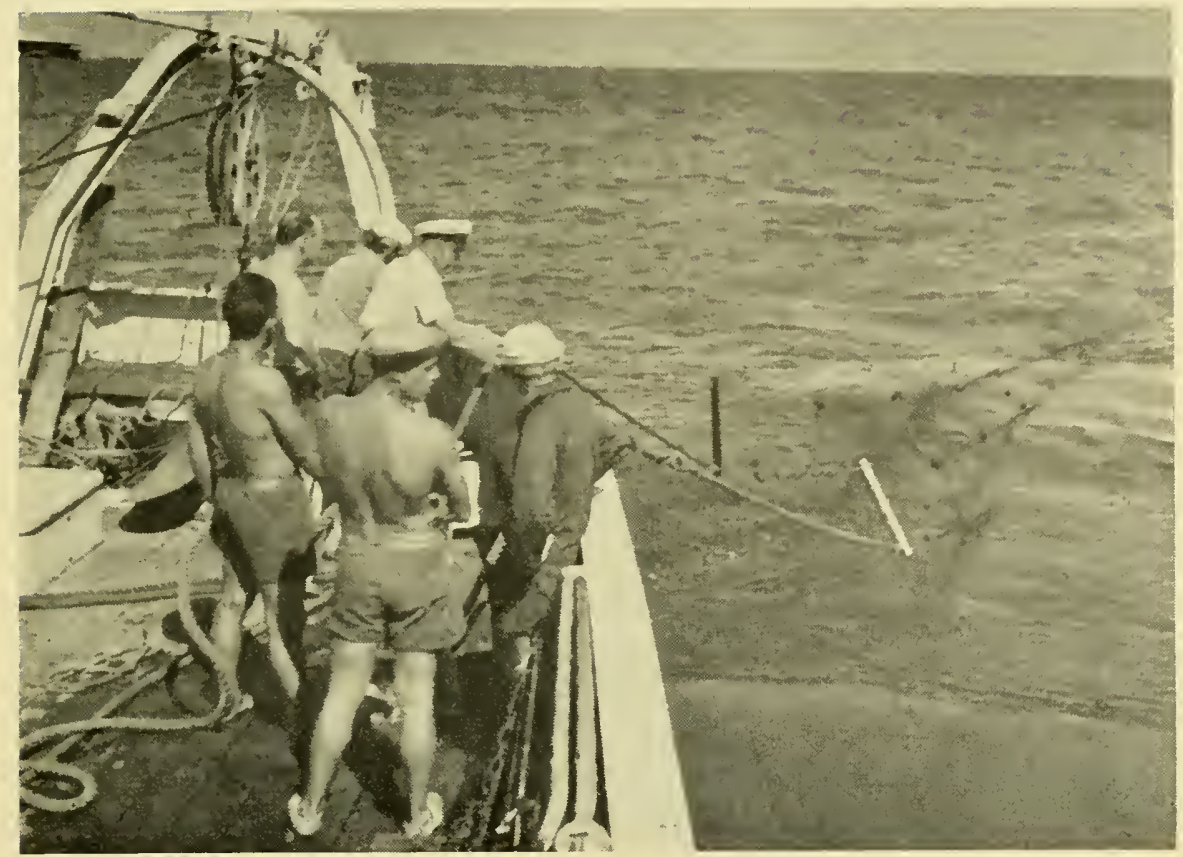

Putting out the large otter-trawl. The arms are still on the surface.

inlets and rivers and streams. Other animals prey on the palatable little fish all the time, making inroads into the stock. Enemies continue to prey on them throughout the whole period of their growth, man not least, when they have reached the size for fishing. Yet enough of them become sexually mature and are allowed to breed in such numbers that the stock is never in danger of dỵing out.

It is exactly the same with our deep-sea eel, Synaphobranchus. During the months when the elvers are migrating to the deep-sea bottom they must come falling into the greedy mouths of the ocean in myriads, like manna from heaven, filled with the radiant energy of the sun in the form of body tissues which contain all the supply of fats, proteins, and vitamins which, according to our experience on the Galathea, is more vital than anything else to the deep-sea fauna, its composition and volume.

After this brief survey of the environment we will take a look at the animals themselves.

It is always exciting to haul in a fishing implement. The fisherman for whom fishing is a means of existence knows this as well as the amateur 
who hopes to add another record to his list. The reason for the excitement, no doubt, is the element of luck involved; for with all the technicalities in perfect order, all experience applied to the utmost, there will always remain a large margin of luck, or, in more matter-of-fact language, the influence of outside factors.

This element of excitement is undoubtedly still more pronounced in deep-sea fishing. The great depth and the unfamiliar fishing-grounds have, of course, something to do with it; but so many hours passed from paying out the Galathea's trawl to hauling it in again that there would often be a change of watch, with the result that nearly half the ship's complement would be directly engaged in the work - on the bridge, in the engineroom, at the winches, and in the laboratory. Everything seemed to be concentrated in rapidly mounting excitement from the moment the word was passed that only 500 metres of wire remained.

When the hauling in began I was usually able to get a few hours' rest, with the big diesel engine roaring monotonously down below and the familiar clang of the engine-room telegraph occasionally asking for a reduction of speed. I would then have no difficulty in sleeping. But if the engine stopped or there were other unexpected changes of sound, I would be awake at once - and could usually go on resting because it was only a fuse that had gone, or there was a little trouble in changing the gear of the winch.

The concluding stages of the trawl, however, were as good as an alarmclock, and I would be out on the quarter-deck in the broiling sun or the starry tropical night. All the hours of the day and night were experienced in this way, with each one reflecting its own mood on the scene.

We will now turn to the results; but why not admit that there were occasional setbacks? More than once we had a torn trawl-bag and a sledgetrawl with its iron frame all crumpled up, to say nothing of the bitter sight of the empty end of the wire, with the entire gear lost. Fortunately, these were exceptions. In fact, the failures were fewer than expected, so that we returned home with a number of implements intact. The most

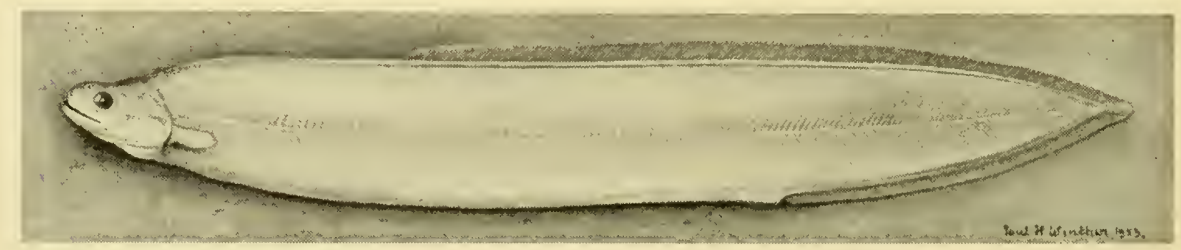

Stage of metamorphosis of deep-sea eel; caught at 4,040 metres in the Indian Ocean. 


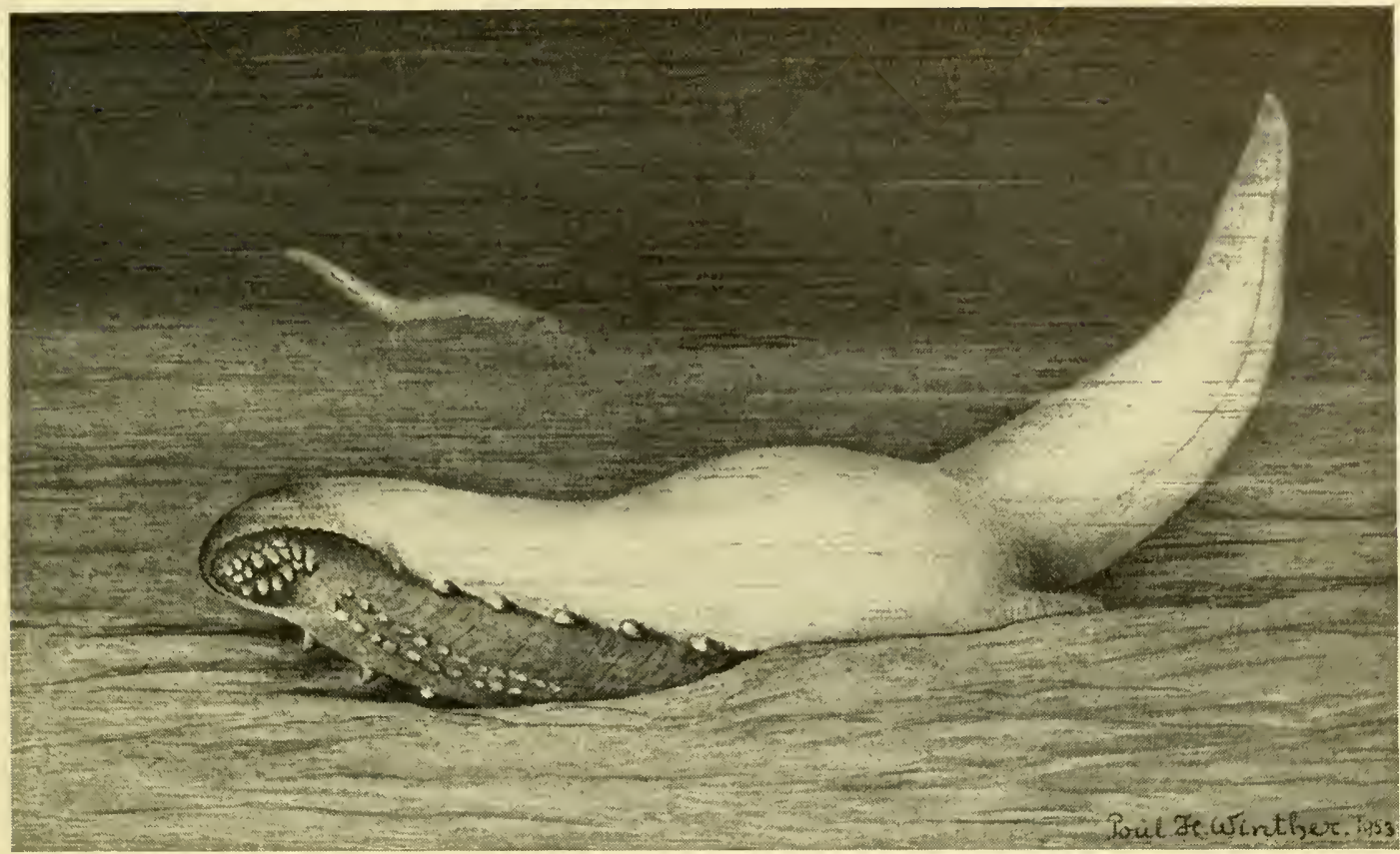

A large holothurian (Psychropotes), ploughing its way through the deep-sea ooze with its tail appendage raised. About half natural size.

disheartening experience of any, perhaps, was near New Zealand one day, when the trawl was brought up with a vast haul of many hectolitres and the fastening of the bag came loose, dropping all the contents into the sea again. It had never happened before and it never happened again; but our annoyance was not assuaged by the discovery of some 40 different species of animals which had been caught in the meshes of the trawl. We repeated the trawl and succecded in getting a fine catch; but an opportunity had been irrecoverably lost and two trawls are never quite the same, so we still dream of what we nearly caught in the first one.

But let us turn to the opposite extreme and choose a trawl in a region where Fortune smiled on us throughout; when, that is to say, wind, weather, and ocean bed were all ideal. On March Io, I95I, the Galathea lay between Madagascar and Mombasa with a perfectly level plain beneath her; one of the few regions where we can really speak of an extensive deep-sea plain with a depth round about 5 ,ooo metres. To be quite accurate, it was 4,820 metres here. The wind was slight, N. to E., and the current just as slight from the same direction, plus a gentle swell from the north-east. Fishing conditions were perfect, the temperature just 
too warm for our energy to be at its highest, the air being $30^{\circ} \mathrm{C}$ and the surface water nearly as warm.

Our large otter-trawl with a span of 32 metres had been paid out on 7,440 metres of wire, the angle of surface and wire had been maintained at about $5^{\circ}$, and, having towed at a speed of about 3.2 kilometres an hour, we had calculated that the trawl had been on the bottom for three hours. Paying out and hauling in took seven hours. The trawl had gone out at 2 p. m., and so it was dark night when it came up again at a quarter past twelve. Tubs and trays stood ready to receive the catch on the quarter-deck, and all lights were on. Expectations were high, as we had already made good trawls at similar depths in this stretch between Madagascar and Mombasa, and at the surface water there was a teeming life of which we had caught a good deal by angling and dip-netting during the trawling.

The bag was undone and the contents distributed among the biggest tubs. It was well smeared in light-coloured globigerina ooze, because in the outermost part of the bag we had placed a plastic bucket with the delibcrate intention of scooping up some of the bottom material containing the smallest animals. Many delicate creatures which would otherwise have suffered from the dragging of the trawl were thus brought up intact, wrapped in the fine clay.

The soft and slimy sea-cucumbers, paradoxically called echinoderms ("spiny-skinned") were in the majority. There were 30 of them, spread over at least seven different species, though two kinds predominated: the large Psychropotes, 20-30 centimetres long (eight specimens), and the white Deima, Io-15 centimetres long (eight specimens). Both Psychropotes and Deima belong to a special order of sea-cucumbers, the Elasipoda, which have their main distribution in the deep sea. They are quite handsome to look at as long as they are fresh; but like the aqueous tissues of jellyfish they contain a large quantity of fluid, and so are difficult to preserve in alcohol or formalin, which particularly affects their colour. Psychropotes as caught here had delicate reddish-violet hues, one having a lemon-yellow back. Mr. Bent Hansen, our specialist in sea-cucumbers, had a busy time making notes, drawing sketches, and copying the colours. Psychropotes is a singular creature, with its semi-cylindrical body and its great tail appendage rising like a sail behind it. This may possibly be used as a weak swimming-organ, though it is more probable that the animal ploughs its way forward through the deep-sea ooze, when the tail appendage will stand out above the bottom and serve as a kind of respiratory organ (Fig. p. I 59). The creature gets its food by gorging on the 

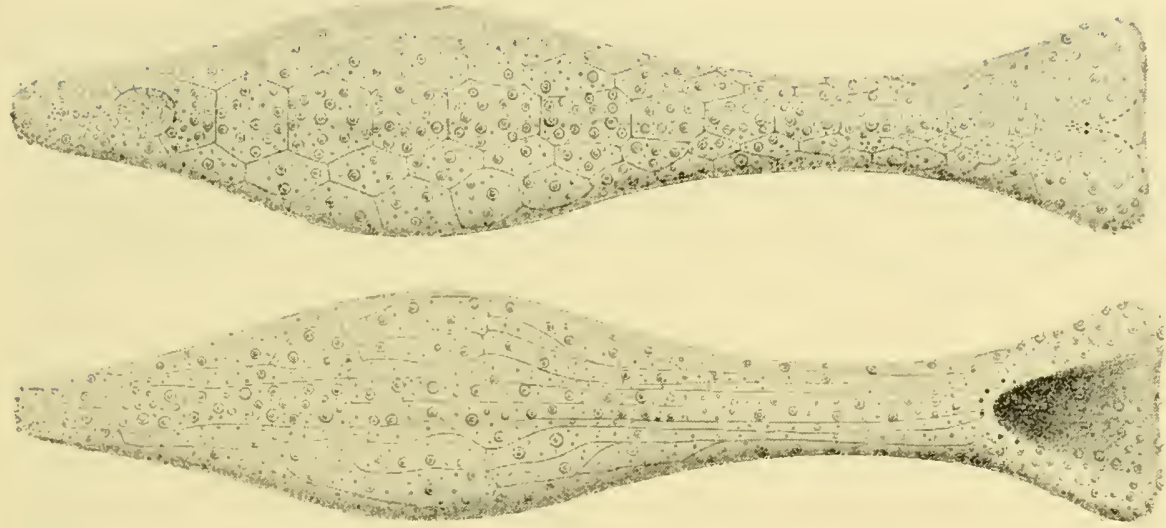

A sea-urchin (Echinosigra paradoxa), the most remarkable of all sea-urchins, with the mouth at the end of a neck-shaped extension. (After description by T. Mortensen).

deep-sea ooze like lug-worms or the sea-cucumbers we know from shallow water. The aqueous tissues and the low temperature probably enable the sea-cucumbers to live without much food. Probably also they have scarcely any foes, and only in one species did we find parasites in the form of roundworms.

Along with the sea-cucumbers another main group of echinoderms dominated the picture; namely, the brittle-stars. Whereas the sea-cucumbers impressed us by their size, the brittle-stars were more strikng for their numbers. In this trawl there were no fewer than 58 specimens, and sometimes we would get as many as several hundred. Considering the brittleness of their arms, which break at the slightest pressure, many times that number must have fallen in bits and pieces through the meshes of our trawl, both during the dragging along the bottom and the prolonged hauling in. It is still difficult to say how many species there were, but the bulk of those taken in this trawl (54) belong to a family, Ophiolepidida, which is well represented in the deep sea. The number of species of this family dwelling deeper than 3,000 metres has been reckoned at 49 , or just as many as in the other five deep-sea families together.

Except for the fact that these brittle-stars are invariably pale in colour and even white, they bear a close resemblance to the shallow-water species. The species which, later in the expedition, we found deeper down - in the Kermadec Trench — is, moreover, fairly closcly related to a couple of our commonest species in the North Sea and Kattegat, though it lives at 6,660 metres and is evidently common. There were 177 specimens of the species in the trawl from the Kermadec Trench. 
Whereas the food requirements of sea-cucumbers are fairly modest, the brittle-stars are rather voracious. They live on other small animals worms, bivalves, and the like - and from their presence in large numbers, in many parts of the deep sea, it may be inferred that there is there a rather prolific fauna; for a predator must be much fewer in numbers than its prey. In this trawl there were also I 2 starfishes, spread over three different species. These, too, prey on other animals, rather voraciously in fact. The remaining echinoderms found here - a small, irregular sea-urchin and a sea-lily - feed on small organisms rather like the sea-cucumbers.

At a couple of other stations in the Indian Ocean we caught some other strange sea-urchins; one of them, Pourtılesia auroræx, from 7,250 metres, was 1,400 metres deeper than any previously caught echinoderm. The two other species, though fished at the more moderate depths of 3,000 and 4,00o metres, were in every respect far more interesting. Their shells are without the typical oval shape, the anterior part being drawn out like a head on a neck (Fig. p. I6I). Moreover, they are extremely rare. Both species were taken by the Danish Ingolf Expedition in the North Atlantic and one has also been found in the southern South Atlantic. This last was first described by Wyville Thomson, one of the founders of deepsea research, while the other, which had been caught only by the Ingolf, was described by the Dane Dr. Theodor Mortensen. How we wished that we had him on board when we picked the brittle shells of his species, Echinosigra paradoxa, out of the trawl! Now our brief report of the catch had to suffice. This was just the sort of result we were wanting: to find out how far the various deep-sea animals are distributed. In this case there was a jump from 1,515 metres off southern Iceland to 3,300 metres in the middle of the Indian Ocean.

But let us take a close look at the catch, beginning with the most primitive group of animals, polyps and sponges. Here we find forms which are also common over the continental slope. There was a large Umbellula, the beautiful sea-pen with its colony of polyps gathered like a composite flower at the top of a long stalk. Sometimes we would obtain a number of these and have the good luck to see them emit a bluish light before they died, and we would picture to ourselves the fascinating sight of the sea-floor five kilometres down covered with them. There were also a couple of colonies of hydroids and a piece of an isis. And as usual there were some glass-sponges (Hyalonema) (Fig. p. I3I), which rather horribly live up to their name, the skeleton of the living body tissue consisting of pure silicon, clear as crystal and just as brittle. We had to be very careful 


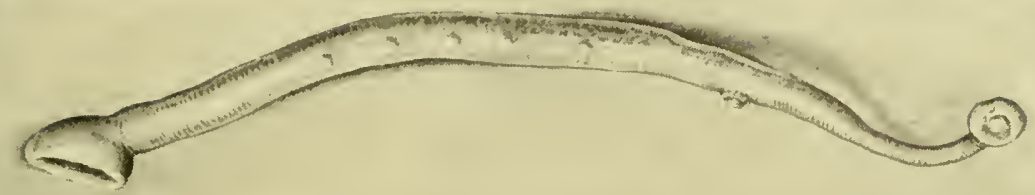

Fishes, even in the deep-sea, are troubled by blood-sucking leeches. Tasman Sea, 3,840 metres.

when getting in the trawl, and even then the horrid fragments caught in the meshes would stick in our fingers like splinters of glass. The stalks are twisted silica strands, very strong and rope-like. Deep-sea barnacles (Scalpellum), sea-anemones, and other polyps would find in them a welcome anchorage, raised above the bottom ooze.

There was another single-stalked animal form which occurred in fairly large numbers, a greyish, insignificant-looking sea-squirt. This creature lives by filtering microscopic organisms from the water, and so it must be raised above the bottom to avoid having its filtering organ blocked with mud if a large sea-cucumber should plough its way past.

Some of the bristle-worms are rather dull-looking creatures, but our specialist, Mr. Jorgen Kirkegaard, is sure to get something out of them, because there were many species and careful picking of the meshes produced quantities of them after every trawl. Their very numbers make them highly important because, here as in the sea elsewhere, they are a favourite food of fish and other larger animals. So also are bivalves, of which there were five different species, including some tender little scallops which must be regular tit-bits. Among other molluscs were a number of tusk-shells (Dentalium), and four species of snails, of which at least three must be considered carnivorous.

We come now to the crustaceans. The crabs were quite obviously from the bottom. There are, it is true, some swimming crabs, which may occur in the free water masses, but the creatures here were typical deep-sea crabs (Ethusa) (Fig. p. I 49), blind and pallid. From the fact that a female had orange-yellow eggs under the tail we may infer that their life history includes a free-swimming larval stage like that of shallow-water crabs. Not even in the deep sea do crabs escape their insidious parasites, the strange sac-like creatures which attach themselves under the crab's tail (Fig. p. I49). Only a close study reveals the fact that these also are crustaceans. All that is visible externally is the sac, but inside the miserable crab is is a system of finely branched roots. The crab is not actually killed, 


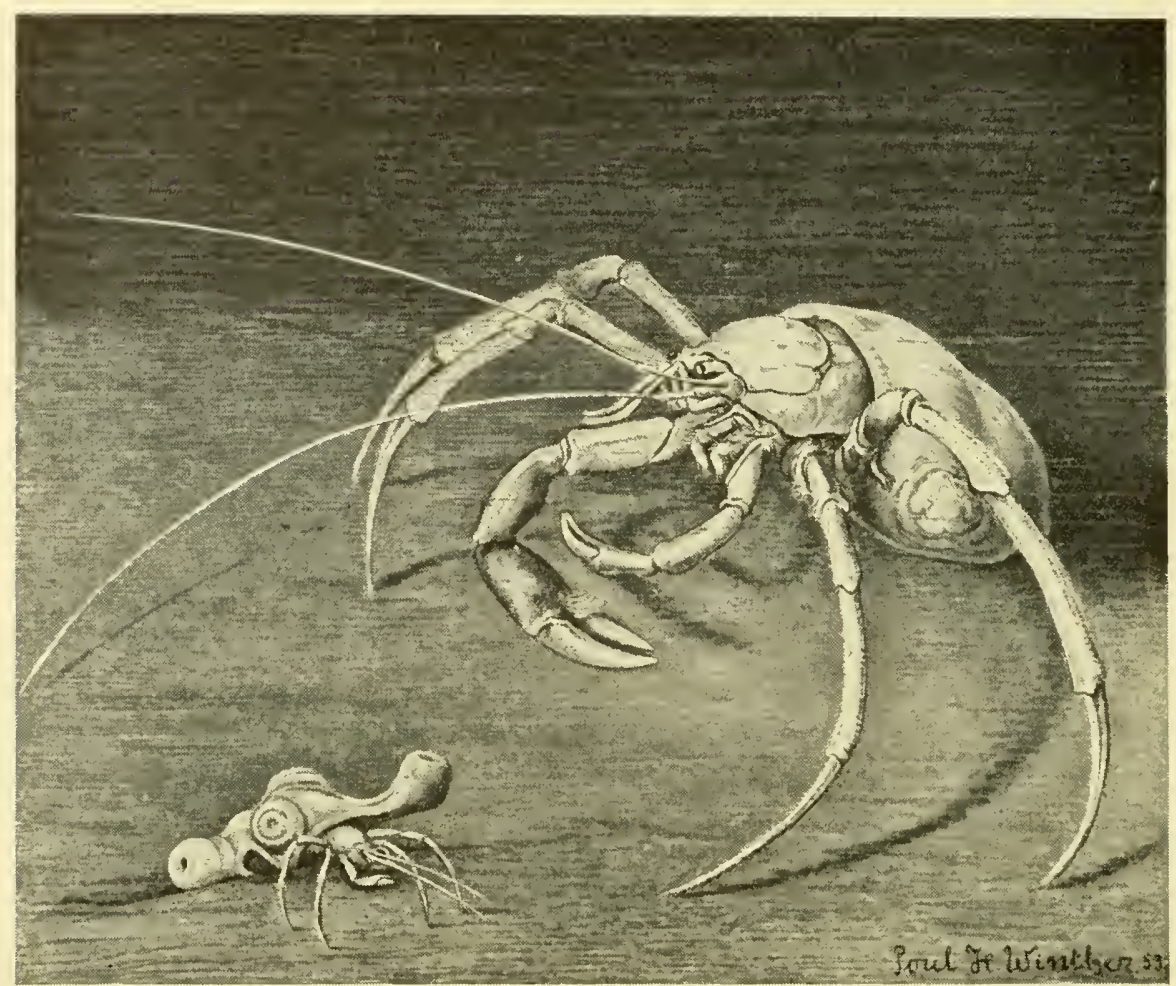

Two species of hermit crab (Parapagurus), one with a sea-anemone, the other with a whole colony of sea-anemones, on the shell. About two-thirds natural size.

but the reproductive organs fail to develop and the result is a condition of parasitic castration. Ethusa is related to the sponge crabs, having, as the picture shows, the last pair of legs swung up on its back. When considering what would be the natural position of the crab, we were tempted to draw it carrying a sponge between the dorsal legs in the manner of some of its shallow-water relatives. We could imagine the usefulness of carrying a glass-sponge in the claws to deceive a hungry fish which might come into contact with the crab in its blind search for food. But though often found, these deep-sea crabs always came up without anything between the dorsal claws, which is really not surprising considering the hours they had spent being tumbled about in the trawl.

Hermit crabs are other roving carnivorous animals in the deep. In this particular trawl there were 13 , the shells of 12 of which were overgrown by a reddish-violet sea-anemone (Fig. above), while one had a whole colony of coral-iike animals (Epizoanthus) surrounding it. This is one 
of the strange features of the hermit crabs which has followed them down to the decp.

That the crabs and hernit crabs were from the bottom is beyond question. But of the many prawns caught there were both species which we obtained only when the trawl had been on the bottom and others which we also got in the purely pelagic trawls, as described in the chapter on pelagic fauna (p. 8I). The same applies to such animals as amphipods, but as a rule it is not difficult to distinguish between the pale, heavilybuilt bottom forms (Fig. p. I66) and the more delicate pelagic forms. In any case it is generally true that the mode of life is transitionary, some of the animals being typical bottom-dwellers, others typically pelagic, and others again living freely over (but close to) the bottom and properly termed abysso-pelagic. It is therefore very much a matter of experience whether on board ship one decides that an animal is a bottom-dweller, or ncar-bottom-dweller, or whether it comes from the completely free water masses.

The fishes provide perhaps the clearest example of how these life forms may all be represented in a large trawl such as this, which had been on the bottom but which had also fished well in the water masses on the way up.

Here in our trawl were 54 fishes spread over 2 I species; but I could immediately pick out eight specimens which I had never seen on the world voyage of the Dana, when Johannes Schmidt carried out pelagic fishing right down to $3,000-4,000$ metres. In our trawl there were typical surface fishes like horse-mackerel (Decapterus), eel larvæ, and lanternfishes (Myctophida). There were deeper-dwelling hatchet-fishes (Sternoptyx, Argyropelecus, Polyipnus) and great rarities like the tubular-eycd Gigantura and Stylephorus (p. 85), or the real abysso-pelagic deep-sea angler-fishes (Melanocetus), and whale-fishes (Cetomimus) and many others. But there remained eight fishes, six of them belonging to one species, the other two representing one species each. One we had never seen before, and anything resembling it had been seen only once or twice before. This was at transparent, blind little fish (Fig. p. 167), in which the eyes are reduced to two barely visible black pricks deep under the skin. It belongs to the brotulid family, which has a few representives inshore, and even, on islands in the West Indies, in subterranean caves. These last, in their blindness and colourless skin, bear some resemblance to our deep-sea brotulid: it is Nature's reply to the life conditions in the perpetual darkness, where other senses than sight are important, and where in the struggle for existence colours are quite useless. The brotulids are the fish 


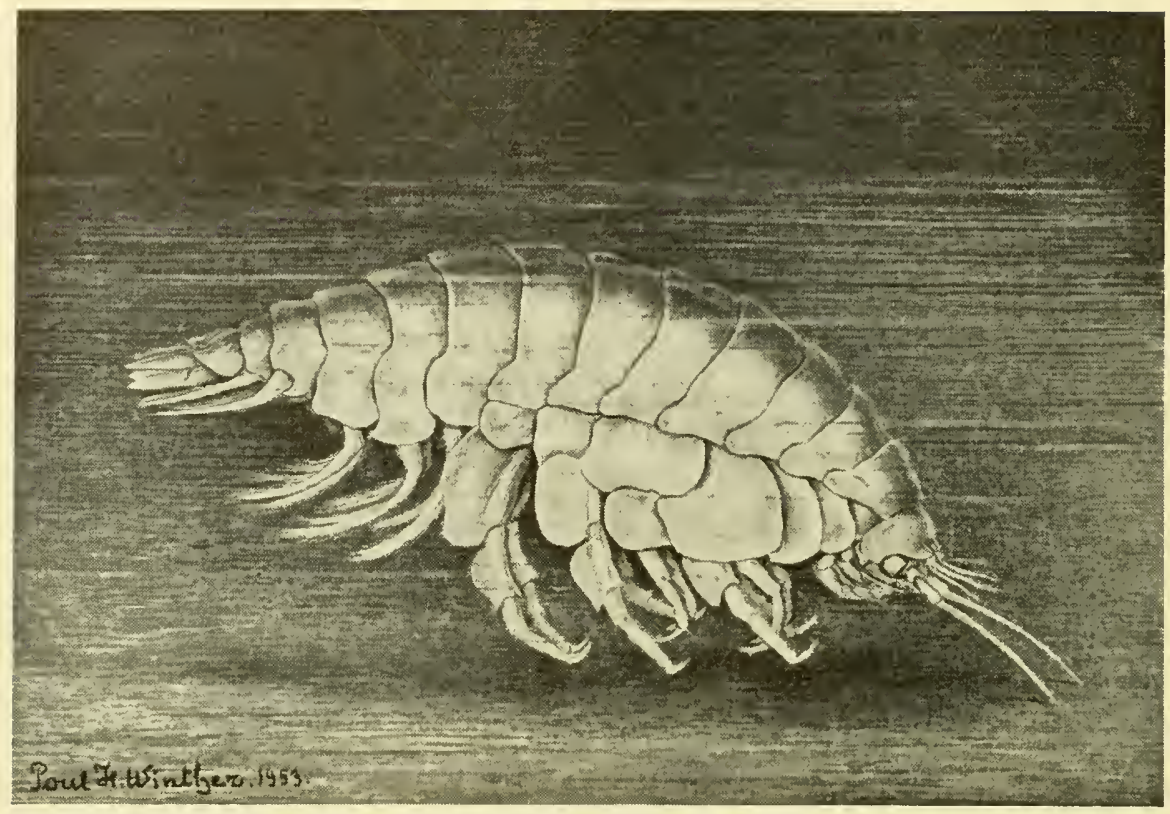

Amphipod crustacean (Eurythenes gryllus), nine centimetres long; caught both on the bottom and swimming well above it. 5,050 metres, Indian Ocean.

family which have most species in the deep; the great variety was confusing, and having only a small library on board we soon ran into difficulties in deciding whether what we had caught were new species or not. It will take some little time yet before we can be quite certain, because in many cases we must make direct comparison with earlier catches in museums scattered all over the world. The fact is that the brotulids have played every possible variation on the type which in our Northern European fish population is represented by the viviparous blenny or eel-pout; that is to say, a fish with a rather large head, a short body, and a long, rather compressed tail. The most specialized - one is tempted to say degenerate - type is the blind transparent fish just mentioned, of which we found several species, while the normal type is rather like the fish we caught deepest down (p. I85). The fact that in this trawl there was also another brotulid of the more common type was therefore not so strange.

The remaining six fishes (Fig. p. I69) were a very fine catch; only a few individuals were known, and here we took six in one trawl. This also is a blind species, with an elongated body, poorly developed muscles, and therefore low swimming powers. It has been known since the days of 
the Challenger and has been a source of wonder owing to the enormous flat, yellow organs on the top of its hcad. These organs have a cellular structure rather like honeycombs, and luminescent powers are ascribed to them. This is very probably correct, in which case they presumably serve to lure other weak-sighted deep-sea animals, so that the fish need only lie still on the bottom and snap its rather large mouth when it perccires movement in the water near the organ.

It will be obvious that with a trawl like the one described we had our hands full in the laboratory, preserving and logging - and getting ready for the next trawl. Lest it be thought that the trawl of March io was an altogether exceptional one, let me say that the following day we had one with 20 bottom-dwelling fishes, spread over eight species, from a depth of 4,820 metres, and a further onc on March i 3 , at 3,970 metres, when we took nine bottom fishes belonging to four species, before moving on to lower depths en route for Mombasa. The invertebrates were equally well represented; for example, there were, in the respective trawls, 83 and 27 hermit crabs and about 300 and 500 brittle-stars.

Considering that, according to a survey made in 1952, the total catches of bottom-dwelling fishes from depths greater than 4,000 metres known to have been got by all previous expeditions were I 8 individuals belonging to 36 species, our total haul of 133 is obviously a great advance. As a matter of fact, fishes are not the best illustration of the extent of the Galathea's collections, because, as we shall see later, they do not occur at the greatest depths. But there is good reason to believe that the volume of our catches of bottom-dwelling invertebrates will show a similar ratio to those of all previous deep-sea expeditions. However, it would be a

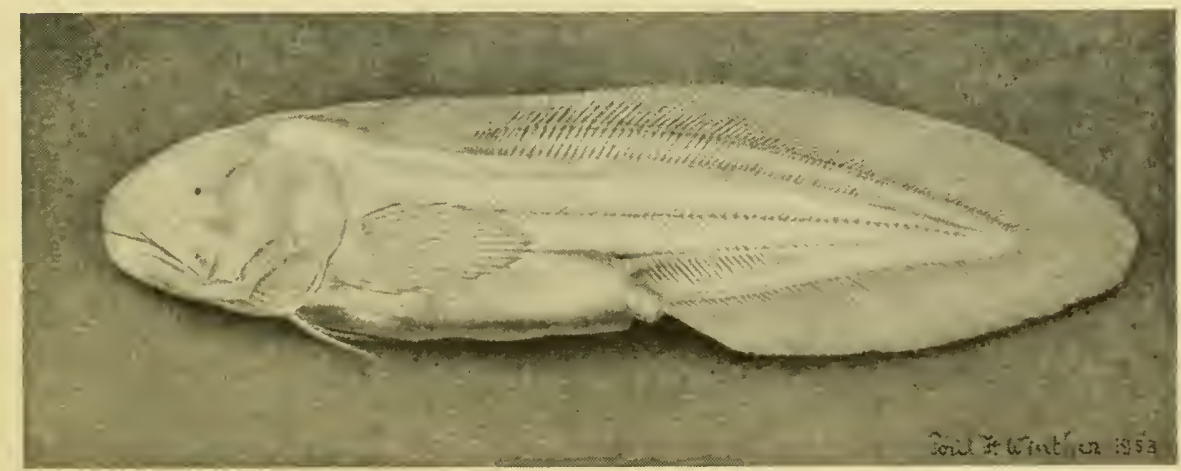

Semi-transparent blind brotulid (Aphyonus) from the Indian Ocean, 4,360 metres. Length, eight centimetres. 
well-nigh insuperable task to try to provide figures, as it would mean working through all previous reports.

In the foregoing we took the yield of a single trawl in order to give a picture of life at the great ocean depths. Clearly, it could be filled in with many details from all our other trawls. There were many animal forms which appeared only now and then, so that from a single trawl it is only possible to describe the general features of the fauna. In the deep sea, as in the North Sea, there are animals, such as sea-spiders, which are always so small in numbers that only a few will be obtained even in persistent fishing (Fig. 184).

But even rare catches have a wide interest beyond the fact of their rarity. We can proceed with the fishes and take an example from the brotulids, the strange Acanthonus (Fig. p. I 7o). We caught this at 2,620 metres in the Gulf of Guinea, along with 15 other bottom-dwelling fishes. We were overjoyed at such an early success; it was our second attempt with the large trawl and we already had a rarity taken only four times previously, the last time by the Norwegian Michael Sars Expedition of 19IO. We of course expected it to turn up again soon; but though we obtained many fishes in many trawls at relatively moderate depths of less than 4,00o metres, we did not meet with it again until the Gulf of Panama, at a depth of 3,7 10 metres, and in the very same region where the third specimen had been caught in $189 \mathrm{I}$. I shall refrain at this stage from drawing far-reaching conclusions from this specimen, but cannot help surmising that Acanthonus needs more food than so many other fishes with a more continuous deep-sea distribution. Hence we found it in the deep in the regions where Professor Steemann Nielsen demonstrated a large food production in the surface lavers - off West Africa and west of America.

One more brotulid, Typhlonus, must be mentioned, first for its appearance: an inmense swollen head and a small body which, like the long, compressed tail, is pale and semi-transparent (Fig. p. I7I). The head is soft, almost gelatinous, and discernible deep beneath the skin are what in the remote ancestors of the fishes were functioning eyes; but Typhlonus is quite blind. On the underside of the head is a horse-shoe mouth which can be protruded almost like a shovel, and it is presumably used for shovelling into the mud when the fish perceives a prey.

A parallel development is seen in quite a different family, which also belong to the typical deep-sea fishes; namely, the rat-tails (Macrourida). Of the special and very rare species Macrouroides (Fig. p. 172) we obtained only one specimen; and though it was taken in the large pelagic 


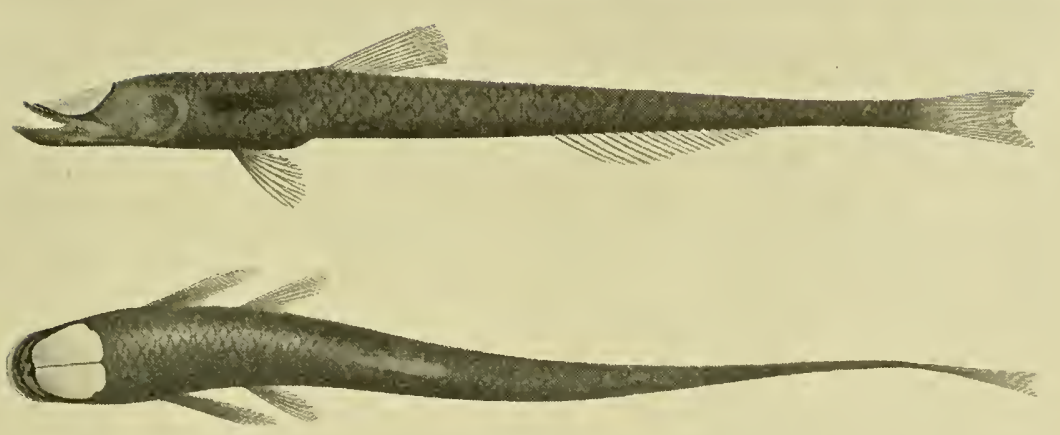

Blind deep-sea fish (Ipnops) with large yellow, plate-shaped organs on the head. Natural size.

trawl at about I,ooo metres from the bottom, which was 5,00o metres down, I have no doubt that the two spccies from two remotely related genera, Typhlonus and Macrouroides, have an identical manner of feeding.

But to return to Typhlonus; this was one of the fishes which had not been caught since the days of the Challenger in the 1870 ; and after catching Acanthonus we did not doubt that we should also obtain many Typhlonus once we had got properly started. The Challenger had taken only two, but we with our large trawl would surely get them by the dozen. So we thought.

Yet we had to wait nine months, till August 21, I95 I, when we were cheerfully making good headway southward from the Philippine Trench towards the Java Deep. There was not a great deal of time for fishing on the way, but we felt that we must make one attempt in the Celebes Sea, that strange inland sea with oceanic depths. The trawl went out at 5,09o metres and came up slightly torn; but in it was the fabulous fish $T y p h l_{0}$ nus in as many as five spccimens ranging from eight to 30 centimetres in length, besides nine other bottom fishes. It was in the Celebes Sea, 75 ycars before, that the Challenger had fished one of her specimens, the other bcing taken in the Pacific outside. We obtained no more on the rest of the voyage; and so, as in the case of Acanthonus, we must for the time being regard Typhlonus as an example of a decp-sea fish which has special requircments and therefore a more limited distribution than most others. A likely explanation is the food supply brought by drifting pieces of vegetation from rivers and mangrove swamps; there were some in the trawl, including a couple of palm fruits (Fig. p. 172), which were satu- 


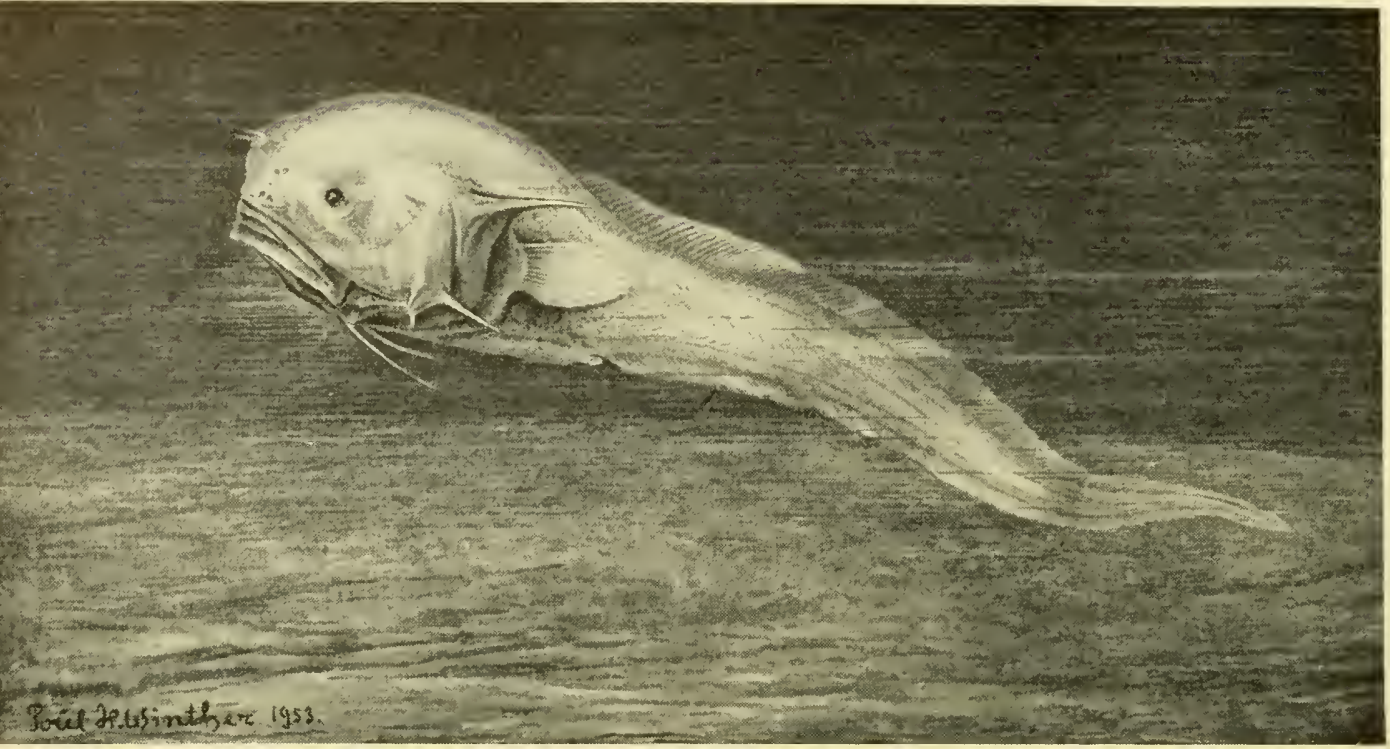

The semi-transparent brotulid (Acanthonus) with large gill-cover spines. From the Gulf of Guinea, 2,550 metres deep. Half natural size.

rated with water and had worms and bivalves boring in the decaying tissues.

It was always a good sign when there was an abundance of dead vegetation from the land in the trawl. In one such haul in the Mozambique Channel, at a depth of 3,40o metres, we obtained our only specimen of the remarkable Benthosaurus (Fig. p. I73). This belongs to the ray-fin family (Bathypteroida), which also have representatives in the deep-sea, though most of ours were taken over the continental slope; for example, no fewer than 42 in one trawl at 915 metres in the Gulf of Panama. They are characterized by having some of the fin rays cnormously prolonged. Our Benthosaurus was covered in mud, so that it came up almost undamaged, and, in particular, with the extraordinarily long rays of its tail and ventral fins intact. The fish is quite blind, so that we may infer that it sails over the sea-floor using the three long rays as feelers to report when there is anything worth investigating as possible food. Benthosaurus had previously been known only from the North Atlantic, where the American Blake Expedition caught two specimens, the Norwegian Michael Sars Expedition one, and the Swedish Skagerrak Expedition two. Thus ours was the sixth, and it extended the known area of distribution to the Indian Ocean. 


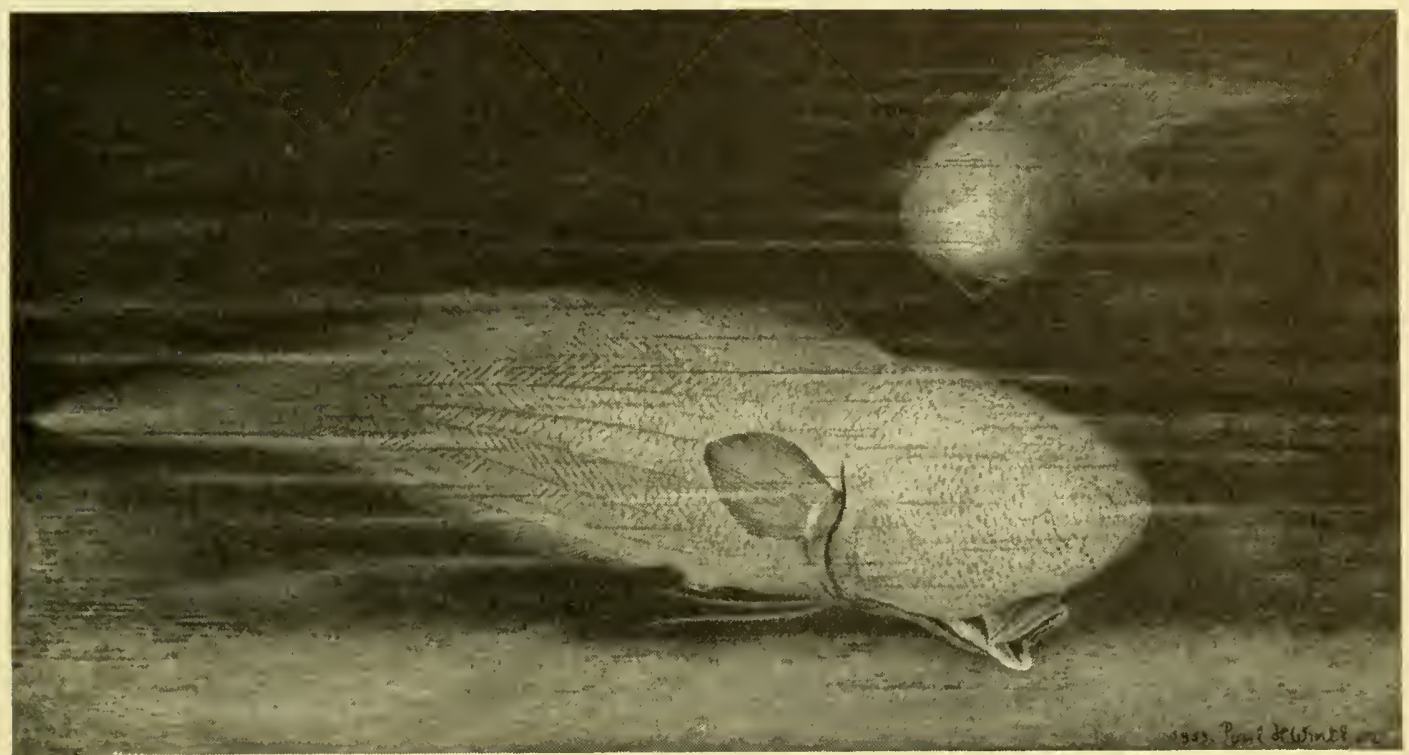

Typhlonus, showing the distended head and mouth on the underside. Caught in the Celebes Sea, at 5,09o metres. Half natural size.

Another typical deep-sea fish, Bathymicrops, which so far has been found only between depths of 4,255 and 6,000 metres, belongs to a family closely related to the ray-fins, but, apart from its blindness, this fish is not remarkable for its structure (Fig. p. I 74). But it is an illustrative example both of the wide distribution of certain deep-sea animals and of the relatively great contribution of the Scandinavian countries to deepsea exploration. It was first caught by the Norwegian Michael Sars Expedition in the North Atlantic in I9IO; it was found here again by the Swedish Albatross Expedition in 1948; and finally we on the Galathea Expedition found it both in the Indian Ocean and in the Pacific. Otherwise, only the British John Murray Expedition has found, in the Indian Ocean in 1932 , a closely related form, and we found that on the Galathea expedition too.

We have already remarked that the supply of food from the surface phytoplankton and drifting vegetation from the coasts may be an important factor in the distribution of deep-sea fauna. There is one other factor concerned with natural surface conditions which affects the distribution of deep-sea animals, and that is the water masses themselves: their temperature, salinity, and currents, and the facilities which these offer for the breeding of deep-sea animals. 


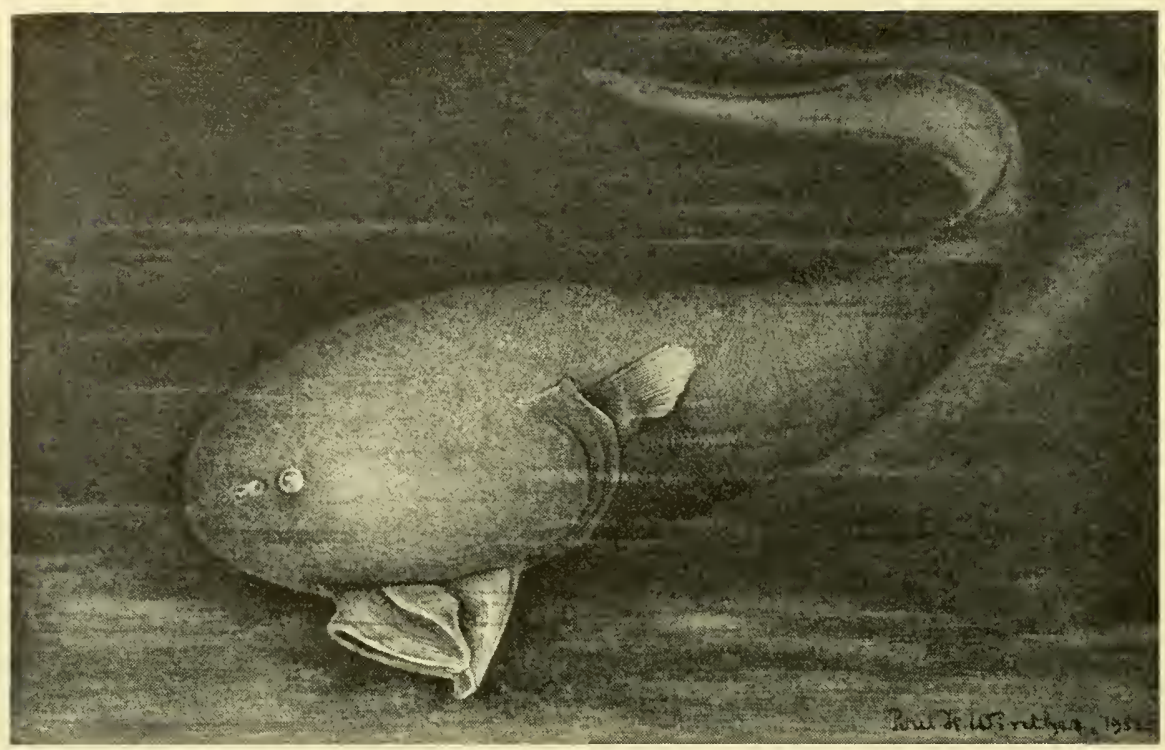

Rat-tailed fish (Macrourides), resembling in appearance Typhlonus, on the previous page, but very different anatomically. Half natural size.

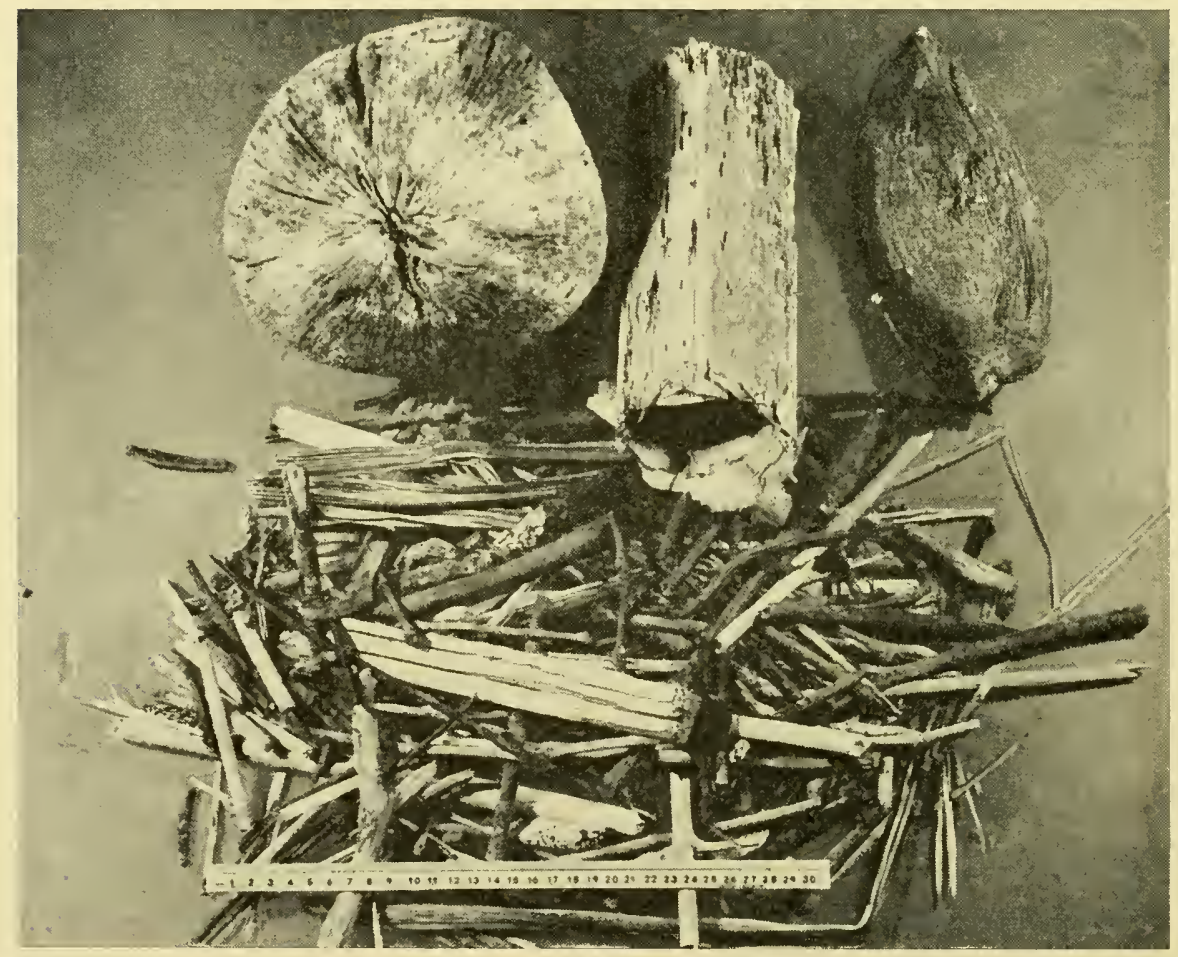

Remains of coconuts, bamboo, mangrove-tree fruits, and other plants taken, along with many animals, in a trawl 4,970 metres deep in the Sulu Sea. 


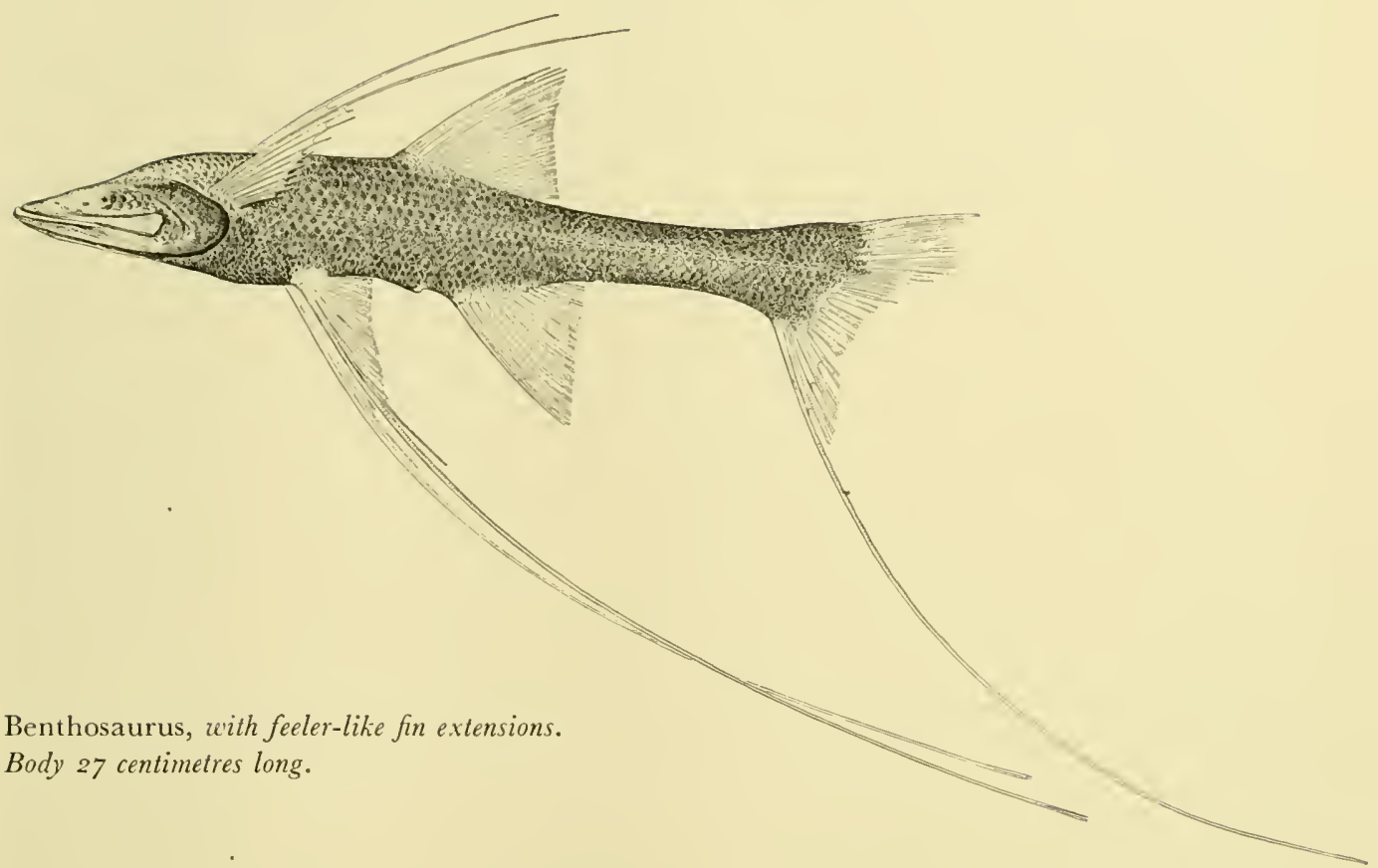

If we take a chart showing the distribution of some of the deep-sea eels we shall fail to understand it unless we correlate it with one showing the distribution of their larvæ. Clearly, when there are no suitable spawning grounds for the deep-sea eel Synaphobranchus in the eastern Pacific, we already have the explanation why we obtained no adult Synaphobranchus in our trawls off the west of America, though we got them, for example, in the Indian Ocean, where the Dana on her world voyage caught the larvæ at the surface (see above, p. 157).

The above reflections are also intended to show that deep-sea exploration is not to be viewed in isolation, but as a link - a very important link - in the chain of scientific research whose purpose is to gain an understanding of the significance of the oceans in the arrangement of our earth.

We would occasionally feel exhilerated by the great catches and the advancement of our knowledge which we thought they gave; but then suddenly a creature would turn op to show that our achievement also was but an inch on the way.

Take Galatheathauma, a creature with an appearance as formidable as the spelling of its name (Fig. I 75). It came up as late as May 6, r952, in one of the concluding trawls of the expedition, off tropical West Ame- 

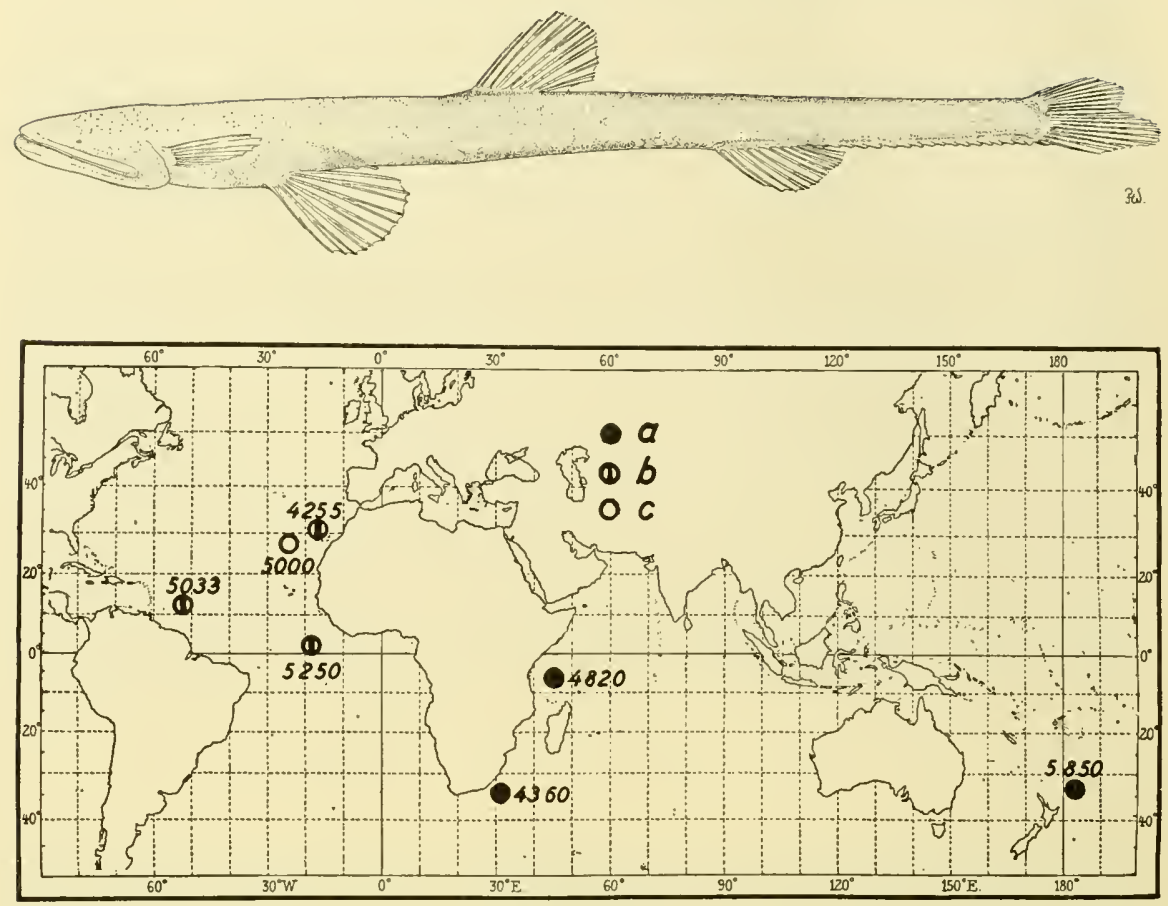

The blind fish Bathymicrops, caught by: a Galathea, b Albatross, c Michael Sars Expedition. The figures indicate the depth of the catch in metres.

rica. It was from a depth of 3,590 metres, "only" 3,590 metres, as, with our experience of five trenches exceeding 7,000 metres, we so grandly put it. Yet here was the most singular fish of the whole expedition, a black, broad-headed creature nearly half a metre in length. It was a deep-sea angler-fish; and to my colleagues' and my own delight I had to admit that I had seen nothing like it on the Dana.

'The fact is that the Dana material includes the world's largest collection of deep-sea angler-fishes. But our Galatheathauma is not in it. A description was given on page 85 of the bathypelagic angler-fishes with a light organ on a stalk on the nose; we also caught a number of these old aquaintances from the Dana in the Panama region.

Here we had an altogether different type. The large light organ is now inside the mouth, suspended from the roof behind pointed, curved teeth which fringe the upper jaw like a comb. We found that a small specimen, eight centimetres long, of a similar type had been taken by an American expedition in 1908 , in Indonesia in 1,385 metres of water and in a trawl which, like ours, had fished on the bottom. Compared with this and with 


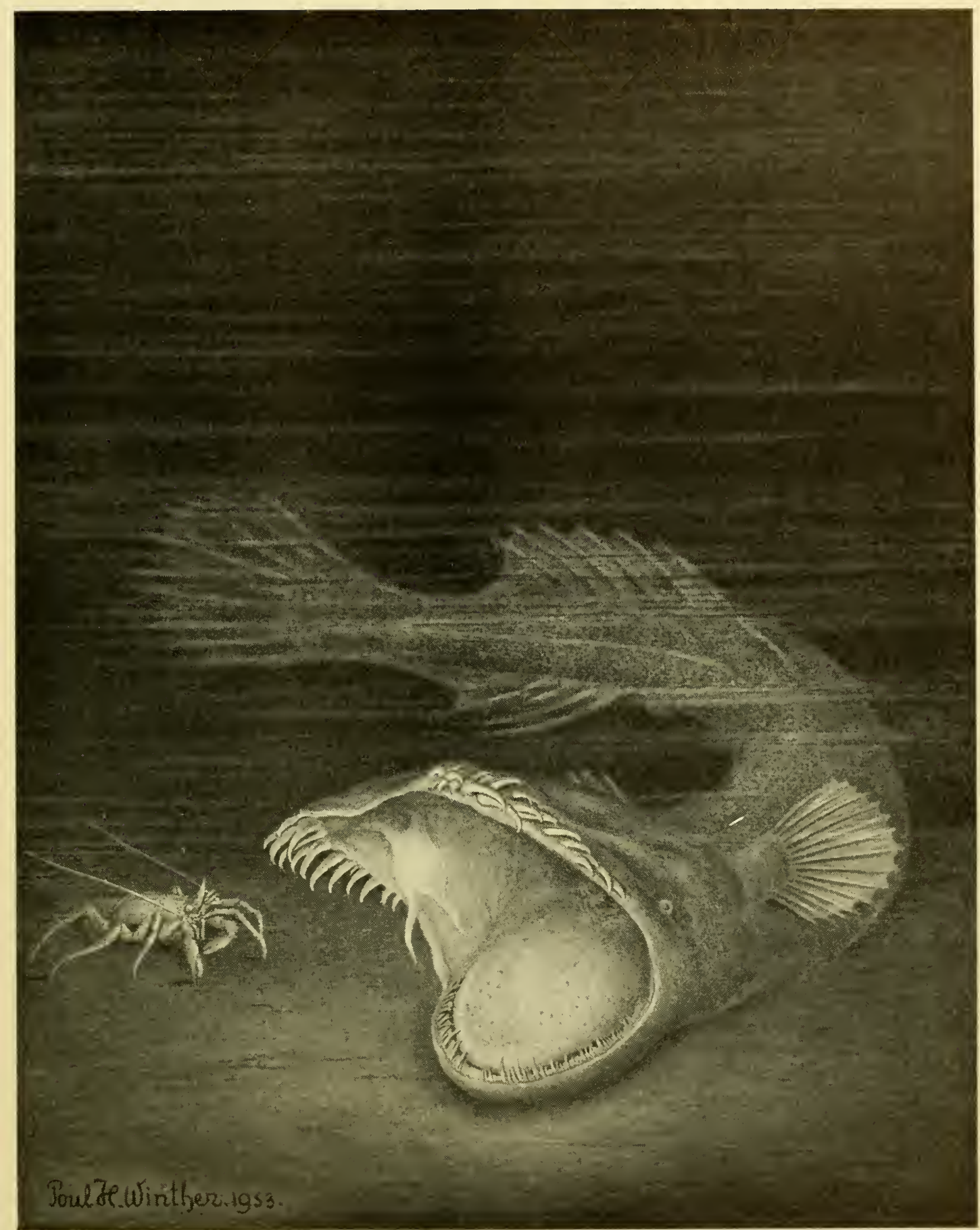

Galatheathauma axeli, the strange deep-sea angler-fish with the forked light organ in the mouth. This specimen, the only one known, represents a new genus and species. 


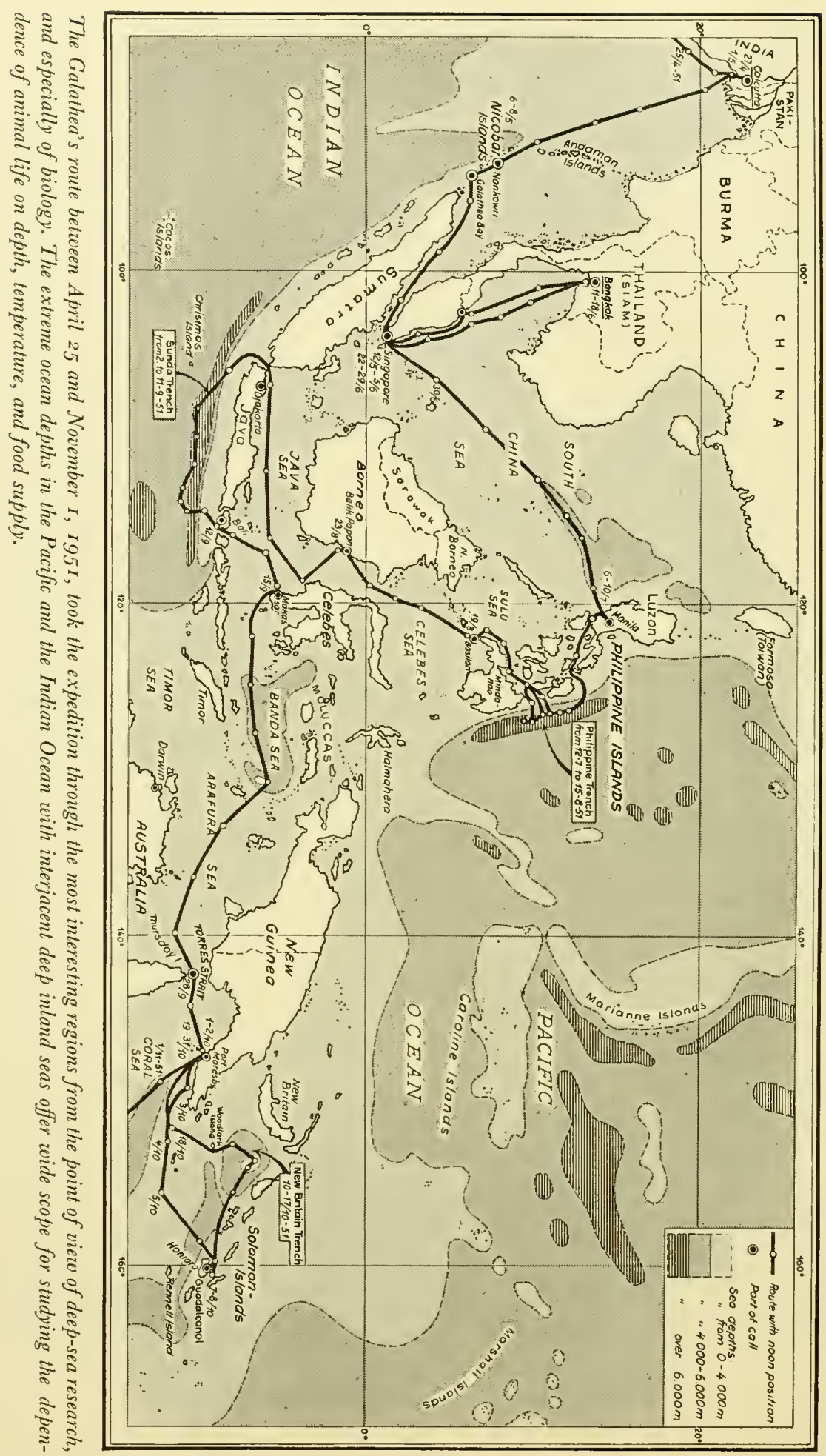


most other deep-sea angler-fishes, our Galatheathauma was a giant of 47 centimetres, and so different from any other that we were justified in giving it the new generic and specific name Galatheathauma axeli, after the names of our ship and the Chairman of our committee, H. R. H. Prince Axel. In a remote past the deep-sea angler-fishes shared a common ancestry with the angler of our North Atlantic coastal waters; but now most of them no longer live on the bottom like our native angler, but swim slowly around, lantern on nose, especially in the uppermost 2,000 metres of the cold psychrospheric layers which underly the warm, sunlit reaches.

There is a possibility that our fish was caught as the trawl was on its way up; but if that were so, it is strange that it had never been caught before. It seems to me to be far more probable that we here have a deepsea angler-fish which lives close to or on the bottom. There it need only lie with its jaws open, leaving the large light organ with its two fine extensions to lure the fish or prawn to it; then as soon as the prey is within reach of the long teeth the jaws will shut, the corners of the upper jaw falling down and trapping the prey against the lower jaw.

This living "mouse-trap" with bait is unquestionably the strangest catch of the Galathea Expedition, and altogether one of the oddest creatures in the teeming variety of the fish world. But we caught only one, right at the end of the cruise, and still no one has caught the Great Sea Serpent.

There, deep down in the clear water, was the faint outline of the large triangular bag of the sledge-trawl. It was pitch-black night, but the quarter-deck lay bathed in the beams of our spotlights. Standing by the trawl gallows, watching the trawl breaking surface, was the fishmaster, his arm waving in a slow circle.

At the winch all eyes were intently following the motions of his arm, as they slowed down and then came to a stop, the hand raised as a signal to stop hauling in. It all went with the fine rhythm of experienced teamwork, but the occasion was a special one: it was the first time that the indicator had stood at zero after reaching $12,16_{3}$ metres, the full length of our wire.

During the work of taking in the trawl and the two small dredges that had been fixed to the trawl frame (it took a few minutes but felt like an eternity), we prepared for the disappointment of seeing a bag without any bottom animals in it; for a failure, in short. We comforted ourselves with the thought that it was the first attempt with the full length of our new wire, that everything had gone like clockwork all night, that the wire 


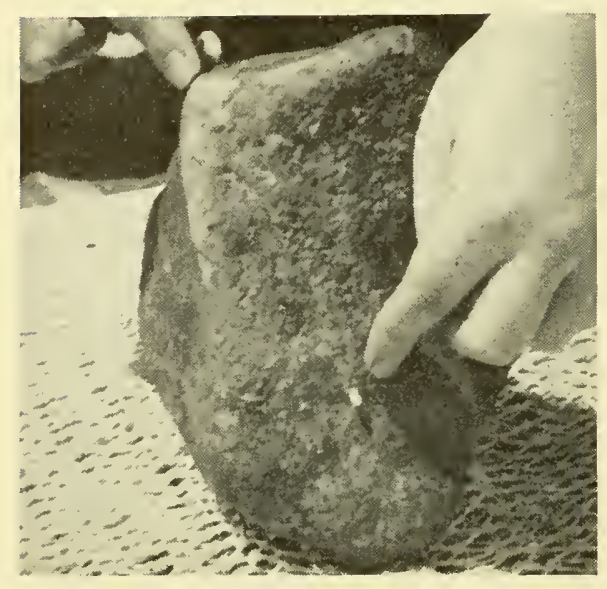

Stone with rounded edges from the Philippine Trench. The fingers are pointing to the seaanemones, which are whitish in colour. was safely home and we should be able to make a fresh attempt; yes, it was a relief to known that we should be able to try again, even in the Philippine Trench. For that was where we were, a little before dawn on July 22, 195I; at station No. 4i 8 . Then the facts came out in rapid succession. "There's clay on the frame!" somebody cried. "It's been on the bottom!" And then: "There are stones in the bag!" Everybody on board who could leave his job gathered round the big dishes while nervous fingers unloosed the cords so that the contents could be carefully removed.

We hardly noticed the red prawns, luminiscent euphausids, or black fishes; we all knew these to be pelagic animals, caught on the way up through the free water masses. But there, on a rather large stone, were some small whitish growths - sea-anemones! Even if no more animals had been found, this would still be the outstanding haul of the expedition (Fig. above). It was proof that higher animals can live deeper than ı o, ooo metres. Is it surprising that all were overjoyed? And that pleasure became excitement when out of the greyish clay with gravel and stones we picked altogether 25 sea-anemones, about 75 sea-cucumbers, five bivalves, one amphipod, and one bristle-worm? It was an unexpectedly rich variety of bottom-dwelling animals.

That the haul had been made on the bottom was obvious, and fortunately we had all the proofs that it was at 10,190 metres. We had carefully navigated according to the configuration of the bottom laboriously pieced together from our echo-sounding on many days before; on the bridge they had calculated the driftage due to current with such accuracy that our depth throughout had never been less than Io, Igo metres; wind and sea had been very slight from the north, almost head on, as favourable as they could possibly be. Forgotten was the long night vigil; our success had to be followed up, everything repeated if possible.

And repeated it was, except that the second time we trawled for only 90 minutes, compared with i 10 minutes the first time. We had to break off the trawl, which was made at between I0,145 and I0,210 metres, 
because the ship drifted over the eastern slope and wc preferred a rather shorter trawl at the desired greatest depths to the risk of an admixture from other depths, to say nothing of the danger of a torn trawl on the steep valley sides. This trawl produced I2 sea-ancmones four seacucumbers, and a bristle-worm bclonging to the species represented in the first trawl, besides the remains of five greenish little echiuroid worms and some decaying regetation washed out from the shore. The bottom substance here consisted of a number of rather firm lumps of clay.

The third trawl appeared to have been successful, but when we came to hauling in we found that the end 600 metres had got itself wrapped round the trawl, which had consequently failed to fish. Nor did the fourth trawl produce any bottom animals, as the trawl did not reach the bed, despite our usual carcful calculations according to Dr. Kullenberg's formula. At the fifth attempt some of the wire again got entangled in the trawl, though this time we obtained some sea-anemones, a seacucumber, and a bivalve of the species previously caught, as well as four small crustaceans (isopods, Fig. p. i 80). We made a sixth and last attempt, but were so troubled by bottom conditions, current, wind, and weather that we dared not send the trawl to the bottom. For 19 hours we struggled in vain to keep a level bottom long enough to have enabled us to fish the approximately five kilometres astern of us. It was a bitter disappointment to leave the Philippine Trench in this way, but such is the fisherman's lot and it could not eclipse our pleasure at the successful hauls.

We had found a whole little animal community. All the large groups of invertebrates were represented - polyps, worms, echinoderms, molluscs, and crustaceans (Fig. p. I80). The known depth limit of life had been pushed some 2.5 kilometres lower down; and whereas it might have been doubted whether we should find anything in the Philippine Trench, there is now no reasonable ground for supposing that life cannot also penetrate the few hundred metres further down to the new record depth of 10,863 metres in the Mariana Trench, provided that there, too, there is sufficient oxygen in the water. Our finds of a great variety of bottom deposits of clay, gravel, and stones in the Philippine Trench may provide a basis from which to explain why the water masses from the down-flowing depth at about 3,500 metres and beyond (see p. 40) can be so uniform and consequently so stable as they are. The general rule is that it takes wind or differences of density to create water-interchanging currents, and here there do not seem to be sufficient differences of density in the water masses. 

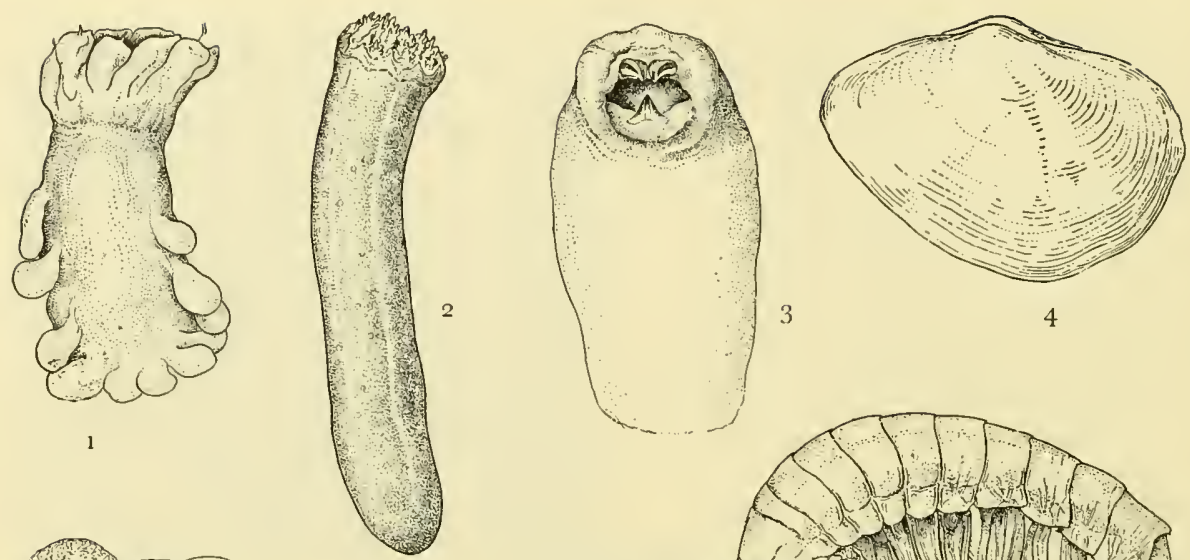

$3 \quad 4$

1
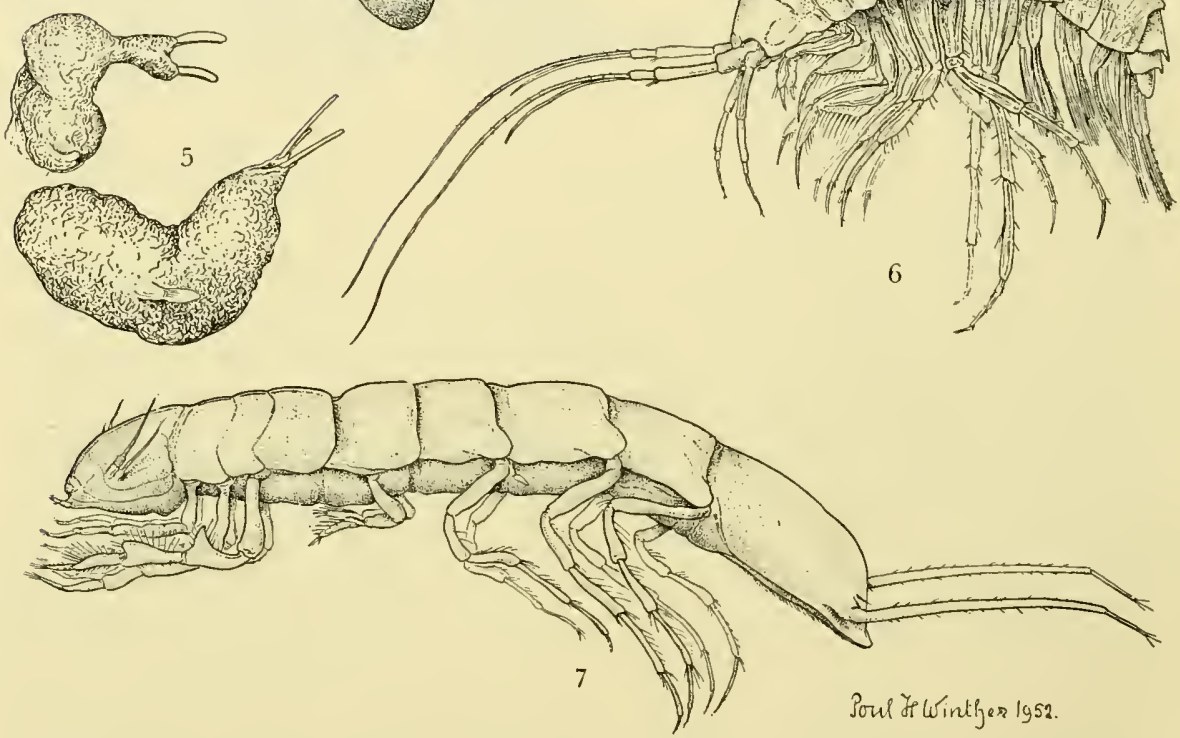

Animals caught in the Philippine Trench at Io,00o metres. I Sea-cucumber (Scotoplanes), I7 millimetres. 2 Sea-cucumber (Myriotrochus), seven millimetres. 3 Gullet of annelid (Macellicephala), seven millimetres. 4 Bivalve (Glomus), seven millimetres. 5 Echiuroid worm (Echiuroidea), about five millimetres. 6 Amphipod (Hirondellea), three millimetres. 7 Isopod crustacean (Macrostylis), six millimetres.

But in recent years it has gradually been realized that turbidity currents must play an important part under certain conditions. If rough weather whisks up clay in the sea water near the shores it is obvious that muddy liquid will have a greater specific density than clear sea water, and consequently will tend to settle in depressions of the continental shelf, in earthquake fissures or old river-beds where the sea-bed has been higher, 
or the mud current will form a cascade falling down over the continental slope. The current will now have become so much faster that, like a swiftly flowing river, it will carry with it sand and perhaps even larger constituents. This is the sequence which it is imagined was the chief and perhaps decisive factor in the formation of the vast steep-sided valleys which cut their way from old and large water courses like the Congo and Hudson rivers into the continental shelf, and which can be traced right down into the deep sea just outside.

If we apply this theory to the Philippine Trench there is good ground for supposing that a turbidity current starting in the narrow shelf region (and here there are typhoons, carthquakes, and submarine volcanoes to

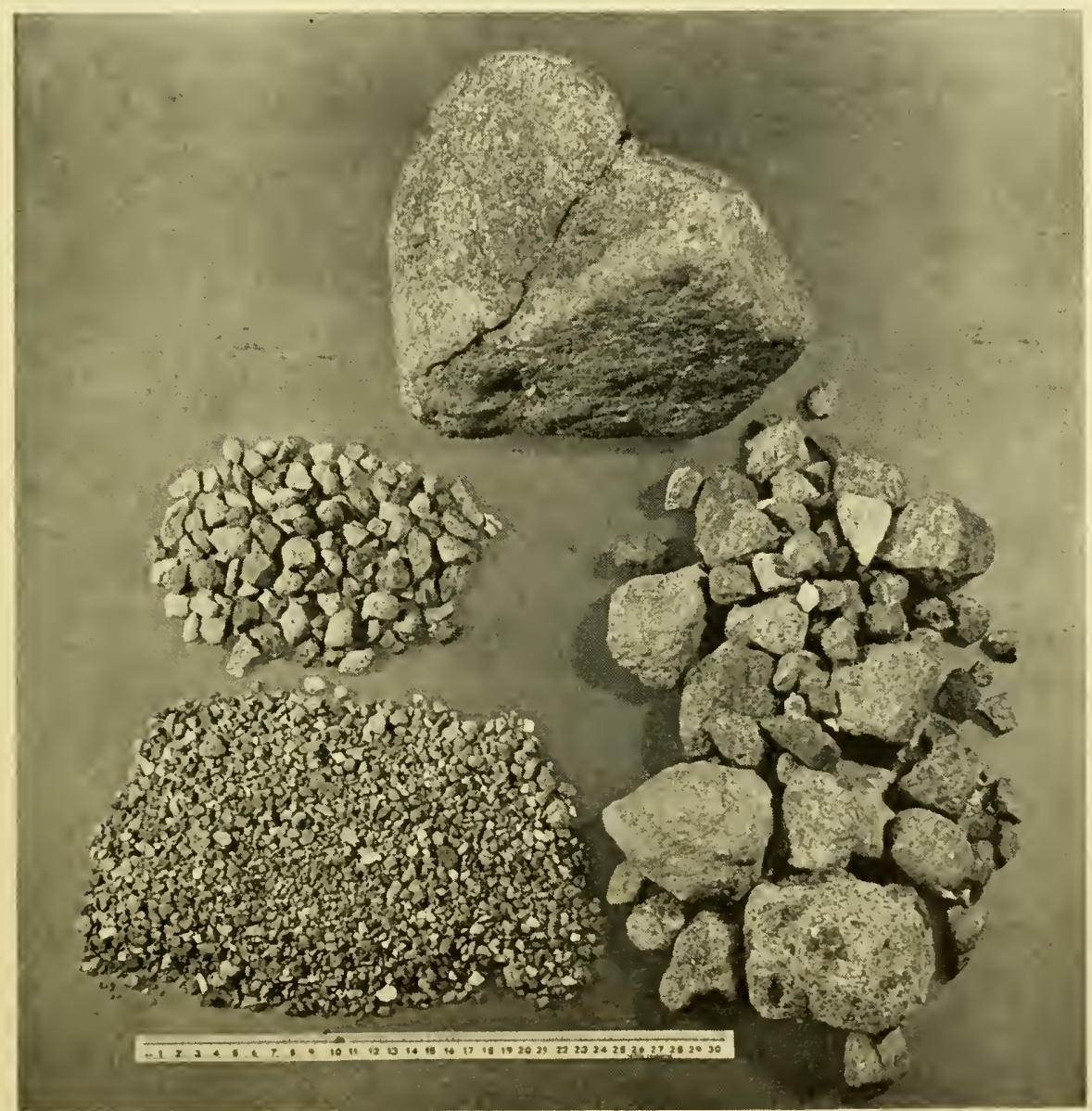

Sorted stones from the soft clay of the Philippine Trench. 
give it impetus) will flow right down to the bottom. In less than roo kilometres the depth falls by ro kilometres, from time to time in abrupt drops, as shown in the diagram based on our echo-soundings (page 33). Immense phenomena must take place here, and $I$ think that this is a possible explanation of why we found jagged stones and other rough bottom material in the clay from the otherwise flat valley bottom. Apart from this, the significant factor as far as animals are concerned is that fresh masses of water containing oxygen are dragged into the deep, providing their vital requirements of air to breathe ...

We now looked forward with a certain amount of confidence to the approaching oceanic trenches. The next was the Sunda Trench, which extends in an immense curve south of Java and westward towards Sumatra. The greatest depths of a little over 7,00o metres lie south of Java, and we made straight for them, as time was short and weather none too good the south-easterly wind and sea were strong at times and there was also some current. We did not spend much time on sounding, as we found that the configuration corresponded roughly to that of the Philippine Trench, with steep valley sides and a narrow strip of level bed. Here we experienced setbacks from the start, two sledge-trawls failing to reach the bottom and a third coming up with a torn bag. Only the two attached small dredges brought much bottom material, though it was good. There were five starfishes, seven sea-cucumbers, some black corals, a bristle-worm, five echiuroid worms, an amphipod, a tusk-shell, and io bivalves. We then risked our large otter-trawl at 7,130 metres, keeping it on the bottom for two hours and dragging it at a speed of a good 2.5 kilometres an hour. We should have liked to drag it a little faster, but that would have meant more wire to pay out and haul in, taking more time and involving risk, so we confined ourselves to paying out Io,6oo metres. The result was the greatest haul that has ever been made from this depth. First of all there were about 3,00o small deep-sea sea-cucumbers (Elpidia glacialis) of the same species as we had caught in the sledge-trawl, plus about II 4 of a rather larger species (Periamma naresi). Our expert, Mr. Bent Hansen, has not been able to differentiate the Elpidias from some found by the Ingolf Expeditions in the Arctic Ocean. It was an astonishing catch in the southern hemisphere. There were also five amphipods and four other crustaceans (Cumacea), and about $4^{\text {o }}$ sea-anemones which we recognized by their pale colour, though it is for the specialists to determine their ultimate relationship with those of the Philippine Trench. Two bristleworms in this trawl certainly belonged to species closely related to the one found in the Philippine Trench. Last but not least there was 


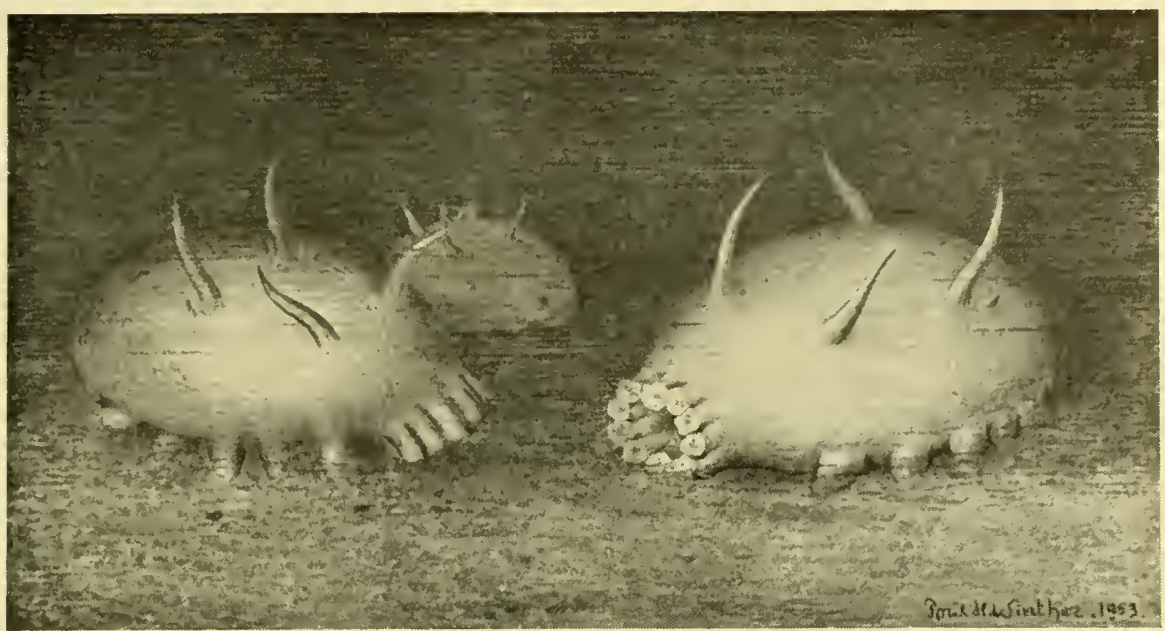

It is possible, and even probable, that these sea-cucumbers (Scotoplanes globosa) from the Kermadec Trench, at 6,66o metres, spend most of their time buried in the bottom. Length about eight centimetres.

a Bassogigas, a fish of the brotulid family (Fig. p. 185) about 17 centimetres long. This was the deepest live fish caught on the expedition, and it was I, Ioo metres deeper than any previously found fish. We took the same species again when we passed through the Bali Strait, at 3,820 metres, in the sledge-trawl along with two other bottom-dwelling fishes, which shows that this fish can live under very varying depths.

All in all, the Sunda Trench gave a very rich yield, and sledge-trawls at 3,820 and 3,000 metres nearby produced valuable material for the study of the variation of fauna with the depths, a factor which, though we had considered it, we had not dared to devote any time to in the Philippine Trench, where we were over the greatest depth we should meet with, according to the expedition's plans.

In the next trench of the Banda Deep we also concentrated on trawling at the greatest depths, about 7,000 and 7,500 metres. Here we had to consider our reserves of fuel oil, as there was no possibility of stocking up before Port Moresby in New Guinea; but the weather was good and it was fairly easy to find a suitably level bottom for fishing. The first attempt with the sledge-trawl failed to reach the bottom, but the next one, as well as two casts with the otter-trawl, gave quite a number of bottom animals. In the deepest trawl, at 7,250 metres, we obtained 19 sea-cucumbers (at least three species), a sea-urchin (Echinothuria) and parts of the shells of several others, some polyps (Stephanoscyphus), 
a bristle-worm (same species as in the Sunda Trench), six echiuroid worms, some piddocks in a screw-pine fruit which had sunk to the bottom, and a rather large amphipod. In the second trawl, at 6,6oo metres, there was only a sea-spider (the deepest ever caught), some piddocks in a sunken piece of wood, and a number of bristle-worms.

This was a rather varied fauna covering 18 species; but in view of the rich grab sample, which yielded four species of bristle-worms (see page 198), it was rather a disappointment not to find a wealth of individuals like that in the Sunda Trench.

Unfortunately, our reserves of oil hardly allowed us sufficient time in the New Britain Trench, especially since the configuration around the maximum depths of 9,000 metres proved very irregular. Here, apparently, there was no long, straight stretch with a level bed, and we lacked the time to familiarize ourselves with the special slope echoes which in the Philippine Trench had stood us in such good stead in differentiating between the two steep sides of the deep.

However, we tackled the job; and were forced to abandon three attempts to get the sledge-trawl to the bottom because we failed to keep the depth and drifted over the slopes. Nevertheless, there was a good deal about the two trawls which was successful; namely, 93 sea-cucumbers (three species) and some semi-transparent organisms attached to a stone. This was not many species; but the main point, that for the fourth time we had found numerous bottom animals in a trench never before fished, was itself an important result ...

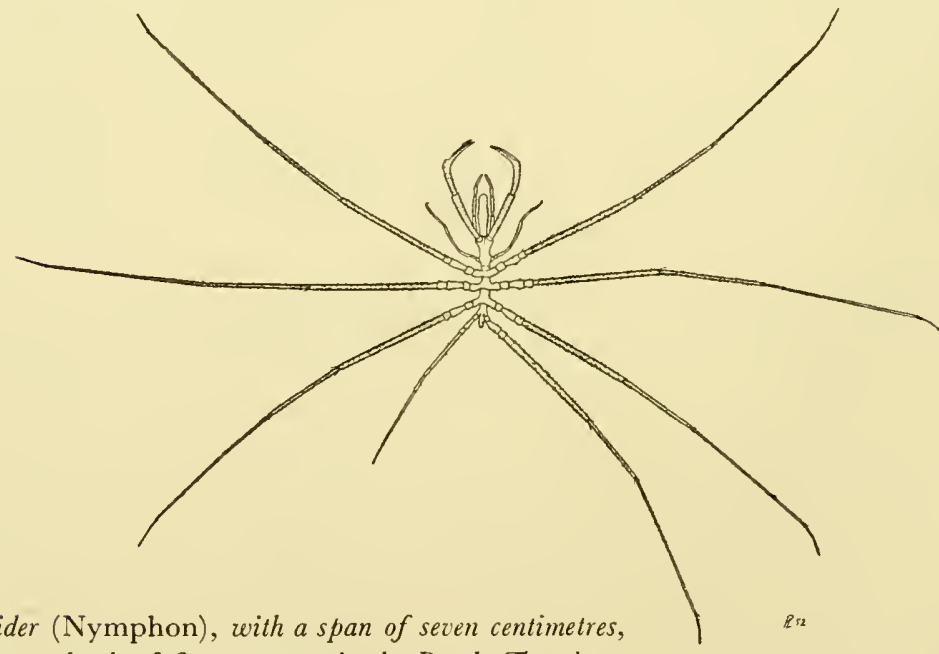

Sea-spider (Nymphon), with a span of seven centimetres, found at a depth of 6,490 metres in the Banda Trench. 


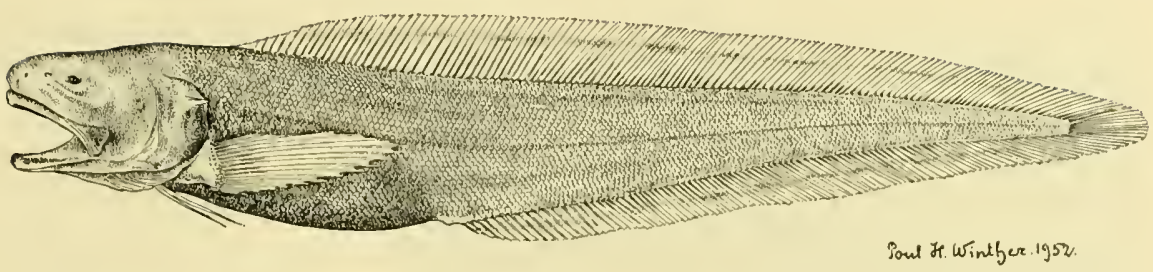

Bassogigas, a brotulid fish, I7 centimetres long; the deepest known occurrence of a fish, 7,130 metres.

Shortly after the exploration of the New Britain Trench in November I95 I, it was finally decided that the expedition would have to be curtailed by a good three months. This meant about a hundred working days fewer, since the time spent in port for inspection of machinery and for shipping oil, and also on the long voyage home, would be just as long, even though we worked on the way.

Consequently, we could rely on being able to explore only one more trench; namely, the great Kermadec-Tonga Trench, which extends right from New Zealand and up beyond the Tonga Islands, a distance of 2,000 kilometres. It is not to be wondered at that we strained every nerve to surpass ourselves. We had to round off our work by comparing the fauna at the bottom of a great trench with that higher up, stage by stage in the immediate vicinity.

The technical arrangements went with all the slickness acquired in 16 months of team-work and experience, and since, moreover, Fortune smiled on us with fair winds and weather and good fishing-grounds, both as regards bottom conditions and wealth of fauna, it is not surprising that we reached another peak of success.

We at once essayed the greatest depth within reasonable reach, which was 8,2 10 metres, having decided beforehand to return to Auckland to fill up with oil, so as to be able to fish as much as possible with the least possible cruising time. In the Tasman Sea we had just tested the double sledge-trawl with a mouth of six metres contructed by our chief engineer, and it had proved possible to get it down just as surely to the greatest depths as the three-metre type we had been using. And it came up with a haul exceeding the ones which had fully satisfied us in our old sledge-trawl. There were two species of sea-cucumber in about $\mathrm{I}, 800$ and $\mathrm{I} 60$ specimens respectively, a species of sea-lily (three individuals), two species of sea-anemones (five and seven individuals), three species of tanaid crustaceans, (four individuals altogether), two species of amphipods (two individuals), two species of bivalves (one and scren 


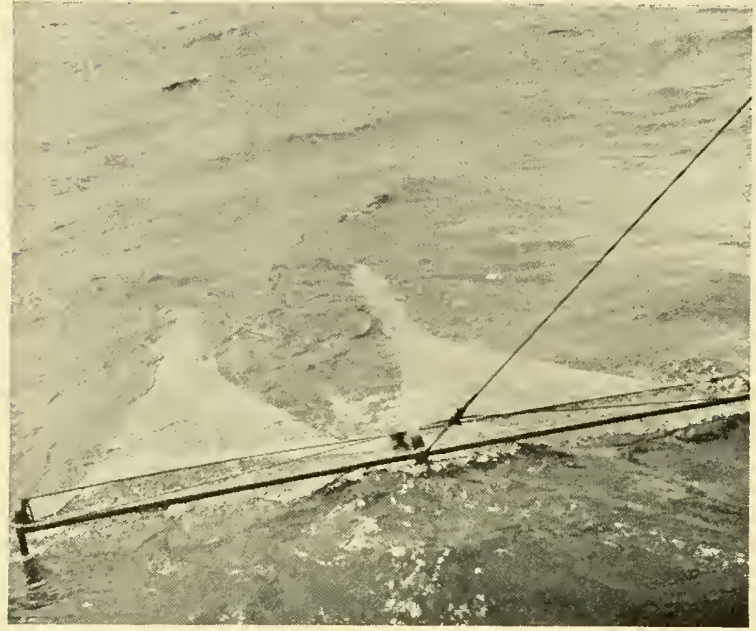

The double sledge-trawel, six metres wide, being lowercd into the deep.

individuals), one species of a gephyrean worm (two individuals), and five species of bristle-worms (about 65 individuals). This was a brilliant start - over 2,00o animals spread over 18 species.

And our luck held: one trawl after another came up alive with animals. We succeeded in making a whole series of trawls at lesser depths, up to 2,500 metres. By means of our echo-soundings we were fortunate in finding, without much difficulty, admirable trawling beds over to the south in the Kermadec Trench, where on the eastern side the transition to shallower water seems to be much steadier than we had previously experienced in the great trenches.

We made 16 trawls and brought up bottom-dwellers i2 times, the trawl in the remaining four cases failing to reach the bottom. As only two trawls, both successful, were from depths shallower than 4,500 metres, the percentage of failures was only 29 for the deepest trawls. This low figure had been previously achieved only by the Swedish Deep-sea Expedition, which in its I 4 trawls at depths beyond 4,000 metres had exactly the same percentage. Our annoyance at what we regarded as failures was hardly tempered by the fact that they gave us rare or unknown pelagic animals, because we should have got them with bottom-dwellers anyway; the 42 kilometres of wire which went out in vain and was laboriously hauled in again cost time, and that could not be replaced. It takes a cool temperament not to be upset when it is reported that the trawl has not been to the bottom when it should have gone down to 8,00o metres, and when the first one yielded 2,00o animals. Still, the aggregate results ex- 
ceeded our wildest hopes; our jars were filled with several thousand animals of at least 220 different species, and half of them were from depths beyond 6,000 metres, in short from the actual trench depths.

The Kermadec Trench thus gave us more than twice as many species as the four other trenches put together. This means that we now have a real basis for studying the dependence of the species on the depths or pressure, because in this rather limited region we can disregard the other influencing factors, in the first place food supply and in the second oxygen supply, temperature, and the minor factor of salinity.

The general impression obtained is that the number of species diminishes rapidly with the depth. In the deepest trawl we obtained 18 species, but in the four shallowest - at 4,510,4,410,2,630, and 2,470 metres there were, respectively, 57, 51, 55, and 45 species. Furthermore, we know that the trawl at 2,530 metres which yielded 45 species was a good deal richer, because we lost the bulk of the catch, which was so large that it burst one of the bindings of the trawl-bag. The trawls between 4,520 and 8,2 I o metres yielded at the most 38 species per trawl, so that the tendency is quite clear - a rapidly diminishing number of species with a rapidly increasing depth. The reason must chiefly be sought in the greater or lesser ability of the various species to live under very high pressure.

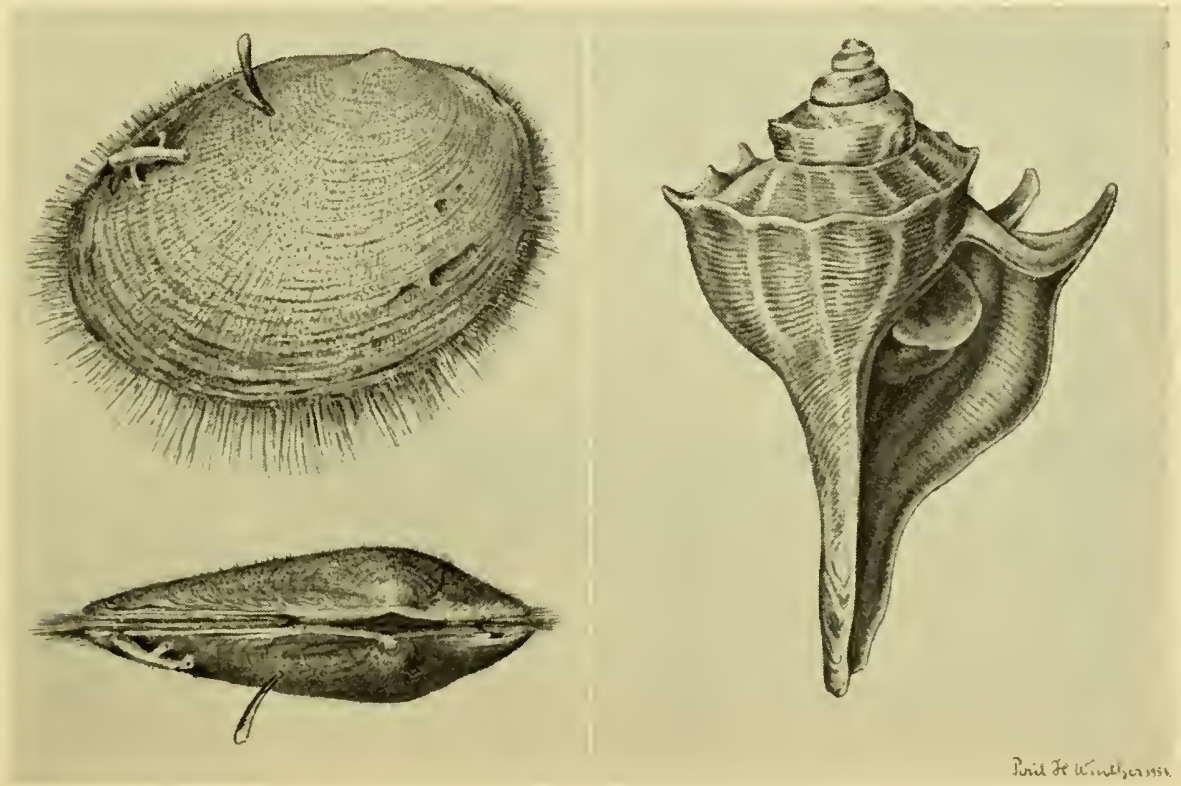

Bivalve, seen from above and from the side; 3,5.90 metres. Snail, from 2,63o metres. 

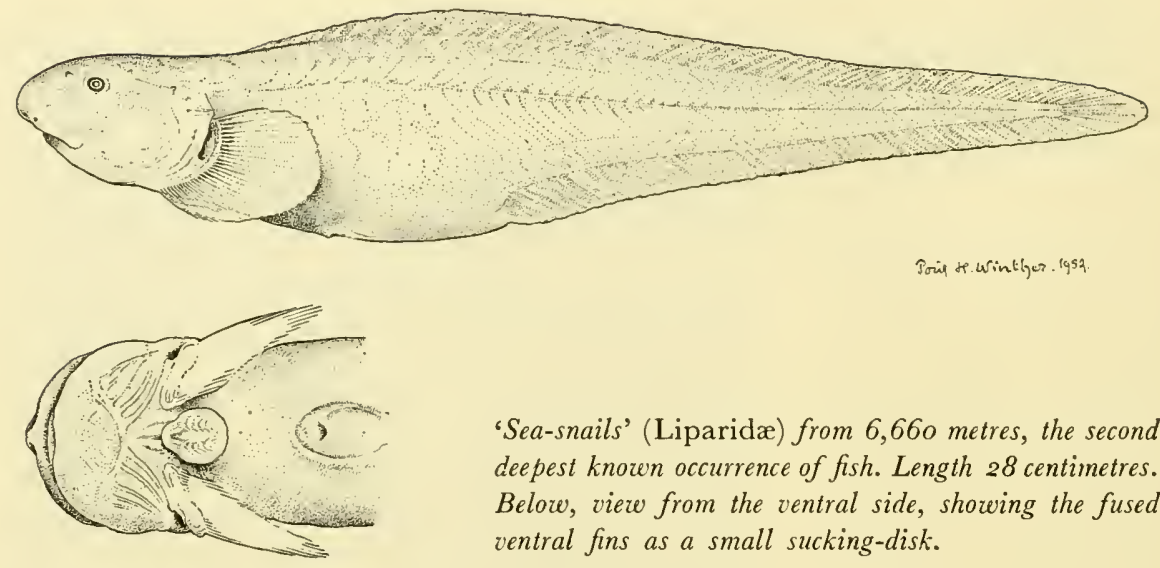

Soil मe. Wintiger . 1952

\begin{abstract}
'Sea-snails' (Liparidx) from 6,66o metres, the second deepest known occurrence of fish. Length 28 centimetres. Below, view from the ventral side, showing the fused ventral fins as a small sucking-disk.
\end{abstract}

This comes out most clearly, perhaps, if we look at the fishes, which in a way were a disappointment, inasmuch as we failed to beat our own record from the Sunda Trench, of the fish caught at 7, I 30 metres. Here at depths beyond 6,00o metres, we obtained only one species, a new "sea-snail", or liparid fish, in five specimens (Fig. above). Prince Albert of Monaco held the depth record of 6,035 metres for half a century; these sea-snails from 6,670 metres and the brotulid from the Sunda Trench are now the only catches made at appreciably lower depths. A good many fishes have been known from between 5,000 and 6,000 metres from earlier expeditions, and in a trawl at 5,900 metres we also caught ro bottom-dwelling fishes belonging to four different species. Taking the four trawls between 4,520 and 5,900 metres together, we get a total of 34 bottom fishes belonging to 13 species. The picture given by this is so clear that there is no need to pursue this examination further by taking lesser depths.

Let me make one further point. Among the many fishes which we caught - rat-tails, brotulids, deep-sea eels, and ray-fins (Bathypterois) - there were, in addition to the new sea-snail, a few other new species, one of which is so different from all other fishes that perhaps it should be classed as a new family. Alongside the fishes, most large groups of invertebrate marine animals were represented. We have not yet worked out the final figure, but there were so many zoologists on board that we were able to make a fairly reliable survey of the number of various bottom animals which we caught in this region, and at the same time correlate them with their depth distribution.

One thing was striking: crustaceans accounted for about a third of 
all the approximately 220 species - about 70 species. There were notably many amphipods and tanaids, mostly rather small, but also the large blind lobsters (Polycheles) (Fig. p. I9I) and their remarkable early stages (Eryoneicus), besides the large white squat lobsters (Munidopsis) (Fig. p. 192) and reddish hermit crabs with various sea-anemones on their shells. But the species vary according to depth, and so far only one of the 70 has been found to range right from 2,500 metres down to 7,000 metres. Sinilarly with the echinoderms, of which there were 43 species, only four of these being so little dependent on depth or pressure as the one crustacean.

Here we must pause to say a few words about the strange sea-cucumber Elpidia glacialis, which we had found in the Sunda Trench and again in the New Britain Trench. We now got it again; and Mr. Bent Hansen is still of the opinion that the specimens from these remote trenches belong to the same species as the individuals caught at depths ranging from 70 to 2,8 I4 metres in the Arctic, having compared them after our return with specimens caught there by the Ingolf and Godthaab expeditions.

Since the expedition, Mr. Jorgen Kirkegaard has studied all the bristleworms taken by us at depths beyond 6,0oo metres - in all the trenches which we explored - and in doing so has made many surprising discoveries. Only I I hadal species were previously known, but he has classified our material into 2 I species and of these three were new to science. Consequently, we can already say something about their distribution, and it is certain that much more will come to light when the rest of the rich material from depths above 6,0oo metres has been studied. It has been related how in the Kermadec Trench alone we took I 2 species, four of which we had already found in one of the other trenches. It is clear from this that, despite the tremendous distances between the

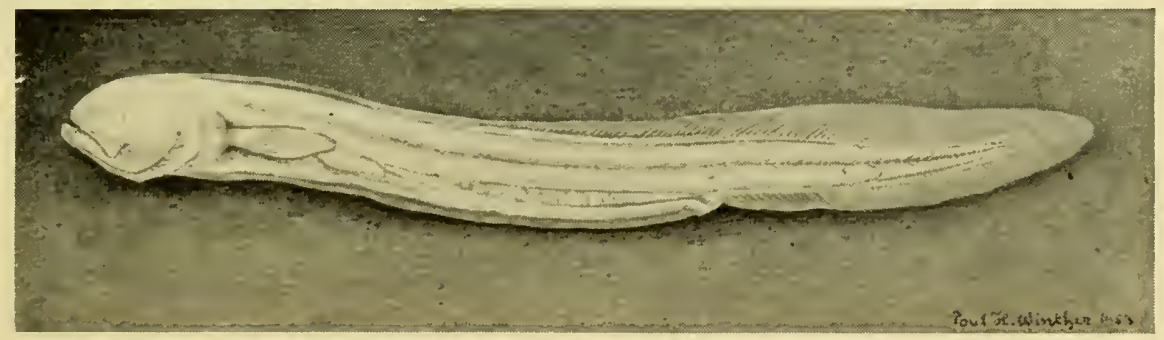

Blind, semi-transparent brotulid fish from 4, IIO metres. Natural size. North-east of New Zealand. 


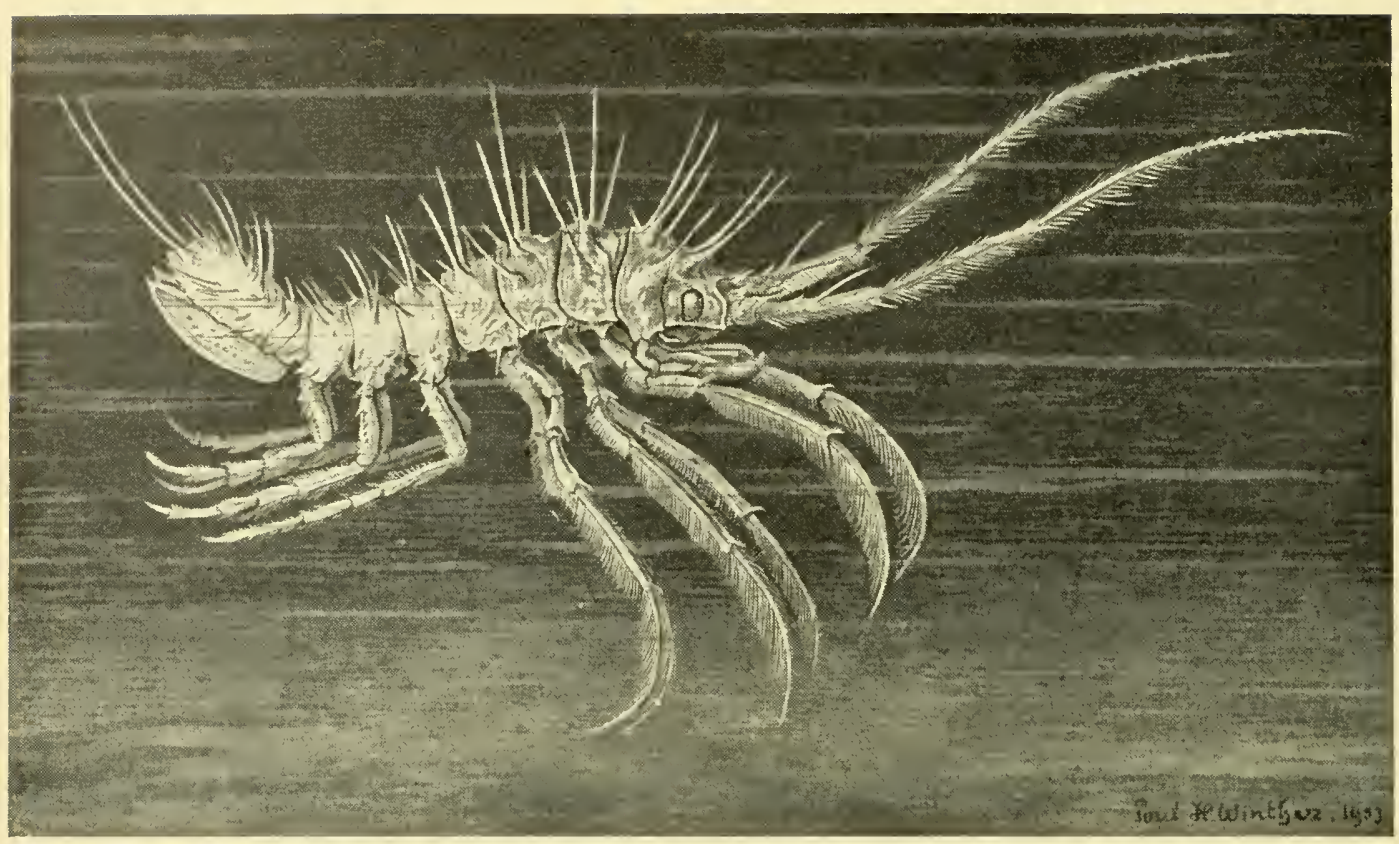

Spiny isopod crustacean (Arcturus) from 4,400 metres. Body five centimetres long.

Kcrmadec and the other trenches, there is a marked similarity in the composition of the fauna. This similarity may well prove to be still greater when further fishing is carried out; but the varying food requirements of the species may nevertheless result in differences (Fig. p. I92).

Among the bristle-worms caught by the Swedish Deep-sea Expedition was a new species, taken near the Azores and Canaries at 4,270 and 4,60o metres. We found this again on the opposite side of the globe in the Kermadec Trench, at four stations ranging from 6, I 40 to 6,960 metres. This will serve as an example of a deep-sea cosmopolite; so far, other species are known only from deep water in the Indo-Pacific region. But it is a very remarkable fact that three species have been found in shallow coastal water; apparently, therefore, they can tolerate enormous differences of pressure and temperature. For the present, however, we must presume that there are certain physiological differences between the stocks of shallow water and of the abyss, differences which are not evident in the external appearance, but are of the same character as the ones which enable Professor ZoBell's deep-sea bacteria to thrive under high pressures even though in outward form they are indistinguishable from surface bacteria. 
Our impression of the species of deep-sea bristle-worns, then, is that some are typically abyssal forms while others may occur almost anywhere. So mixed a company is hardly to be found in the other groups; here, as in the rest of the deep sea below the continental slope, the species are in most cases specially adapted to life in the trenches and arc found nowhere elsc.

The Galathea's contribution to our knowledge of the deepest depths of the ocean will be best appreciated by comparing it with the present state of our knowledge of the deepest occurrence of the larger animal groups. We will leave the question of records, and the fact that a similar general record-breaking achievement has not been seen as the result of one expedition since the days of the Challenger, and concentrate on its characteristic tendency, which has been to extend the downward limit of our knowledge. Of course, we should not regard these maximum depths as final in individual cases. Before we can do this there must be many more explorations of still more trenches, including those which may be presumed to be the richest in food in the world - the Andes deeps of the eastern Pacific, which we did not reach.
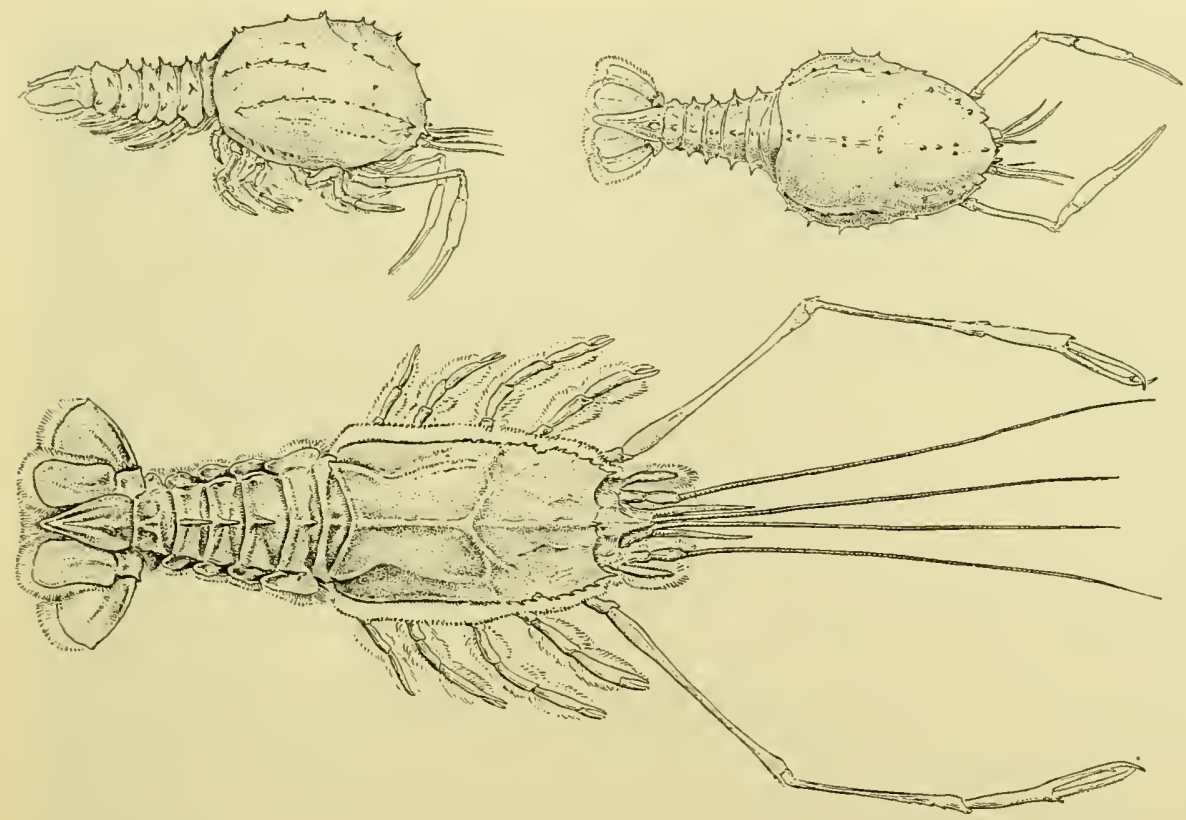

Blind lobster (Willemoesia); length of body 12 centimetres. Abov', young stage, seen from the side and from above; length of body four centimetres. Taken in the same trawl at 3,710 metres, off the Pucific coast of Central America. 

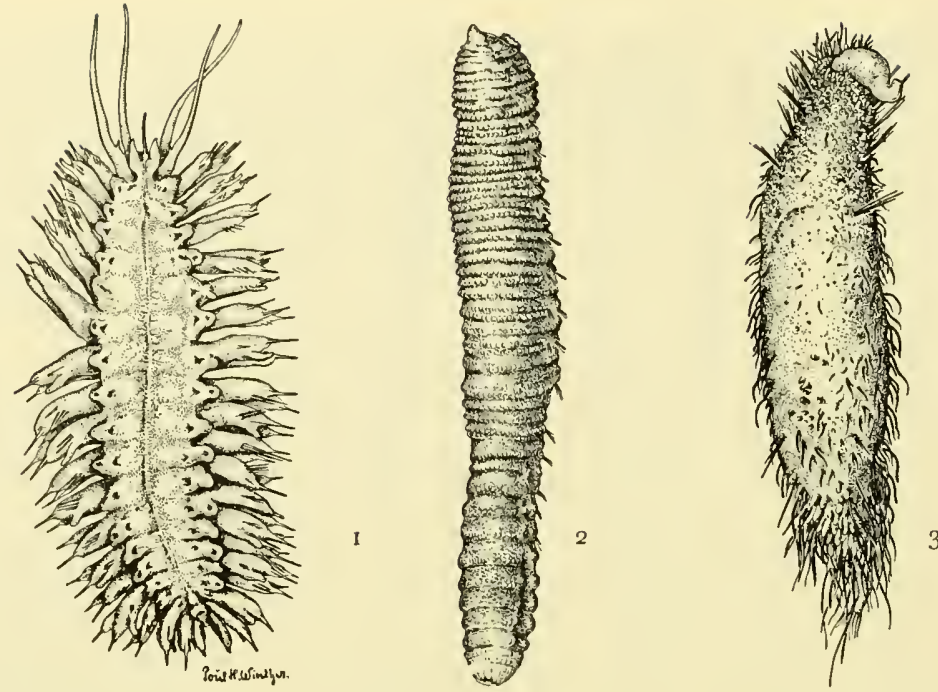

Bristle-worms (Polychæta). I Macellicephala, 3 centimetres, 6,740 metres deep.

2 Kesun abyssorum, I.8 centimetres, 8,2IO metres deep. 3 Ilyophagus bythincola, eight millimetres, 6,740 metres deep.

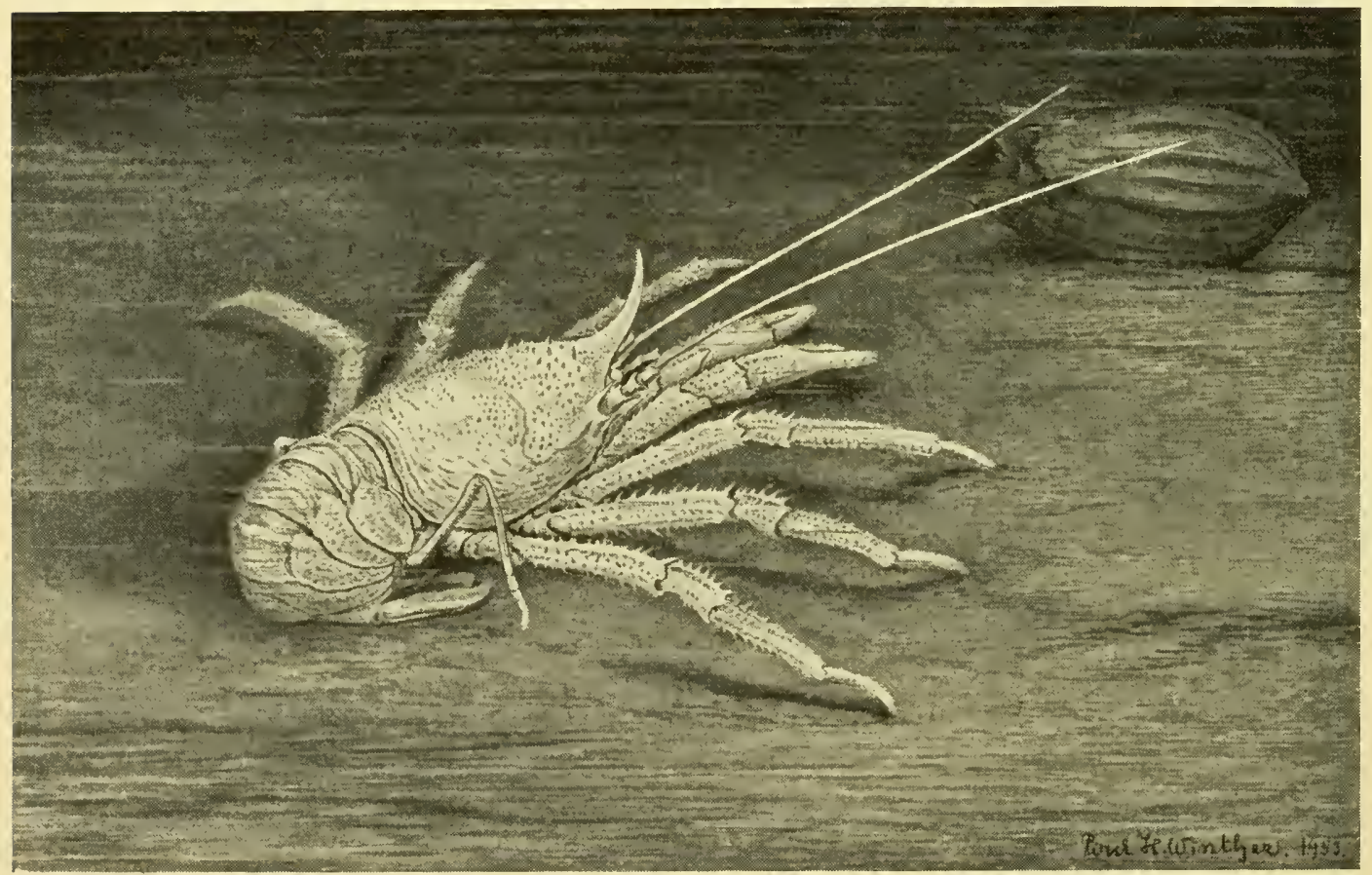

White squat lobster (Munidopsis), taken at 5,09o metres in the Celebes Sea. In the background, palm fruit from the same trawl. Half natural size. 


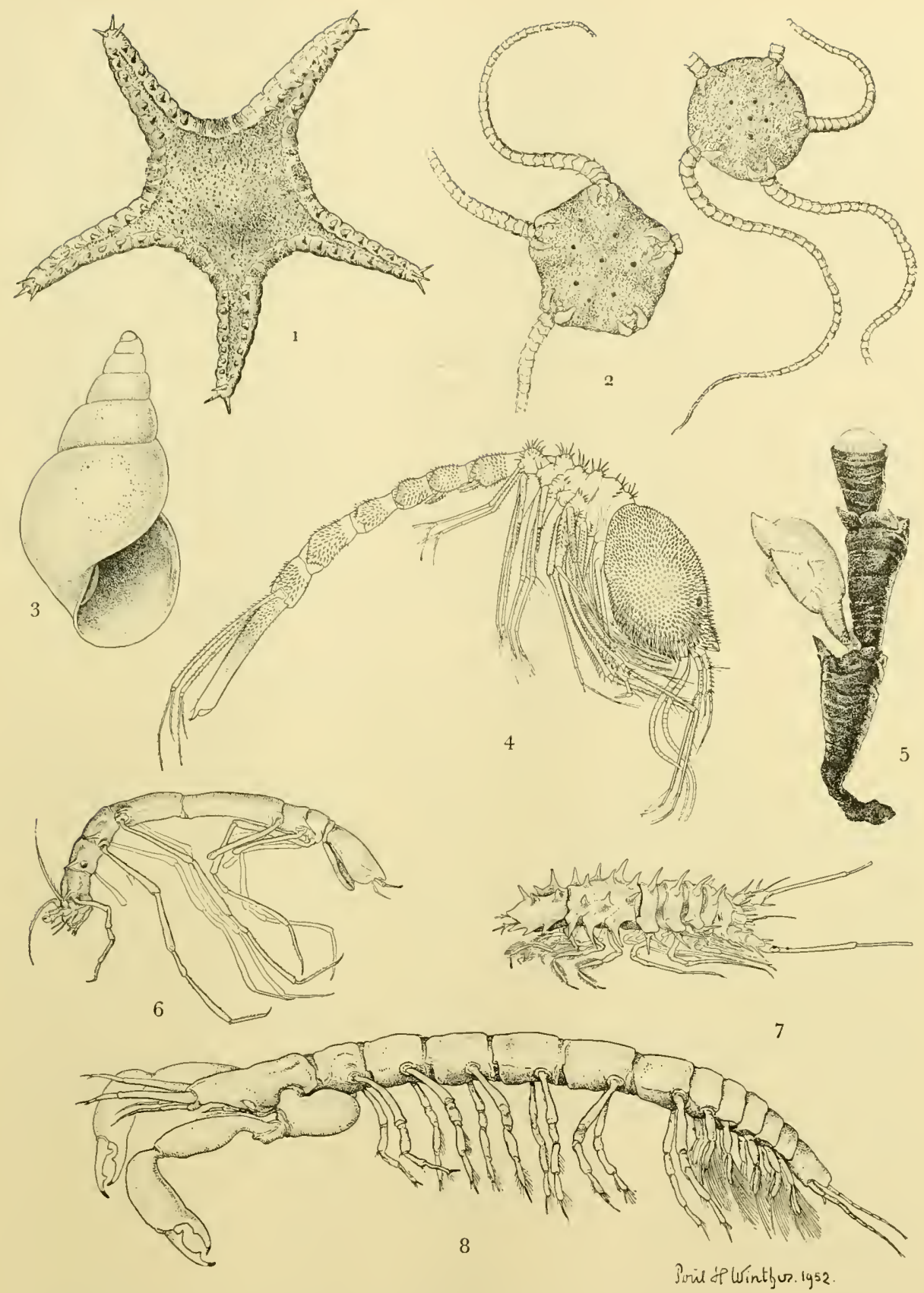

Various animals from the deepest occurrence. I Starfish (Eremicaster), $5.6 \mathrm{~cm} ., 7,630 \mathrm{~m}$. 2 Brittle-star (Ophiura loveni), disk $1.3 \mathrm{~cm} ., 6,660 \mathrm{~m} .3$ Snail (Odostomia), $4 \mathrm{~mm}$. , $8,210 \mathrm{~m} .4$ Cumacean (Diastylis), $3 \mathrm{~cm} ., 7,130 \mathrm{~m} .5$ Goose barnacle (Scalpellum), $3 \mathrm{~cm}$., on actinian 6,66o $\mathrm{m} .6$ Isopod (Ischnomesus) $\mathrm{I.3} \mathrm{cm} ., 6,960 \mathrm{~m} .7$ Isopod (Storthyngura), I. $6 \mathrm{~cm}$., 6,960 m. 8 Tanaid (Neotanais), $1.5 \mathrm{~cm} ., 8,210 \mathrm{~m}$. (I-3, 6-8, drawn by Poul H. Winther; $4-5$, by $P$. Larsson.) 
But in view of our successful trawls in the Kermadec Trench it is difficult to explain why animals like fishes, brittle-stars, sea-pens, and sea-mats, which were caught only at a little beyond 6,ooo metres, were absent from the rich hauls of individuals between 7,000 and 8,000 metres, unless we are to regard pressure as a limiting factor which only a minority of the thousands of species of marine animals have succeeded in overcoming.

The time set aside for biological work in the Kermadec Trench ran out. It had justified our boldest hopes, but perhaps that was the very reason why we felt so tantalized as we steamed north from Auckland towards Samoa, with the fascinating deep beneath us all the way. The worst moment of all was when the curve of our echo-sounder swung down to 9,700 metres; for, with a correction of plus 294, we were thus only 6 metres short of having found the first trench in the southern hemisphere with a depth of 10,000 metres. It was at $31^{\circ} 53^{\prime} \mathrm{S} ., 177^{\circ} 05^{\prime}$ $\mathrm{W}$.; and there was a fine bed for trawling, should anyone wish to try his hand.

\section{Deepest Occurrence of Some Animal Groups}

The symbol $<$ indicates less than

\begin{tabular}{|c|c|c|c|}
\hline Before Galathea & Galathea & $\begin{array}{l}\text { No. of } \\
\text { Species }\end{array}$ & Trench \\
\hline $5,85^{\circ}$ & I O, I $9^{\circ}$ & I & Philippine \\
\hline$<6$, ooo & I o, I 90 & I & - \\
\hline 7,625 & $10,19^{\circ}$ & 2 & - \\
\hline$<6$, ooo & I o, I 90 & I & - \\
\hline 8,100 & IO, I $5^{\circ}$ & I & 一 \\
\hline 7,625 & 9,790 & I & - \\
\hline 7,625 & 9,790 & I & - \\
\hline 4,39 I & 8,2 IO & I & Kermadec \\
\hline$<6,000$ & 8,210 & I & - \\
\hline 5,600 & 8,2 I 0 & I & 一 \\
\hline$<6,000$ & 8,2 IO & I & - \\
\hline 5,304 & 8,2 IO & I & - \\
\hline 6,035 & 7,630 & I & - \\
\hline $5,85^{\circ}$ & 7,250 & I & Banda \\
\hline$<6$, ooo & $7, \mathrm{I} 30$ & I & Sunda \\
\hline
\end{tabular}

Sea-anemones Actinaria ......

Echiuroid worms Echiuroidea

Sea-cucumbers Holothuroidea

Bivalves Bivalva

Bristle-worms Polychata ......

Amphipod crustaceans

Amphipoda

Isopod crustaceans Isopoda ...

Tanaid crustaceans

Tanaidacea

Sipunculoid worms

Sipunculoidea

Sea-lilies Crinoidea

Gastropods Gastropoda

Polyps Hydrozoa ..............

Starfishes Asteroidea

Sea-urchins Echinoidea

Cumacean crustaceans

Cumacea
$<6,000$ 


$\begin{array}{rccc}\text { Before Galathea } & \text { Galathea } & \begin{array}{c}\text { No. of } \\ \text { Species }\end{array} & \text { Trench } \\ 6,035 & 7, \text { I } 30 & \text { I } & - \\ <6,000 & 6,960 & 2 & \text { Kermadec } \\ <6,000 & 6,960 & \text { I } & - \\ <6,000 & 6,940 & \text { I } & \text { Sunda } \\ <6,000 & 6,940 & \text { I } & - \\ 6,035 & 6,660 & \text { I } & \text { Kermadec } \\ <6,000 & 6,660 & \text { I } & - \\ 5,850 & 6,620 & \text { I } & - \\ <6,000 & 6,620 & \text { I } & - \\ 4,540 & 6,480 & \text { I } & \text { Banda } \\ <6,000 & 6,140 & \text { I } & \text { Kermadec } \\ <6,000 & 6,140 & \text { I } & - \\ <4,000 & 5,850 & \text { I } & - \\ 5.719 & 5,850 & \text { I } & -\end{array}$




\title{
THE DENSITY OF ANIMALS \\ ON THE OCEAN FLOOR
}

\author{
By R. SPÄRCK
}

The usual method of exploring the ocean bed by trawling and dredging fails to provide a correct picture of the density of bottom animals. Of course, the trawl or dredge will bring up more specimens of a species if there are many than if there are few, but gear which is dragged, moving over the bottom more or less unevenly, cannot give a measurement in terms of number and weight per square metre. To get this we must use other gear.

Such gear was employed, nearly 50 years ago, by the Danish fisheries biologist C. G. J. Petersen, for measuring the amount of fish food on the sea bed. For many years small plaice have been transplanted from the western Limfjord, in Denmark, which is overpopulated with plaice, to the inner broads of the same fiord. where there is an abundance of food but where plaice never go of their own accord in any large numbers. The desire to get a fairly exact measurement of the number of living animals per square metre of bottom led Dr. Petersen to design a special sampler, known internationally as the Petersen grab. This consists of a pair of heavy steel jaws which will close tightly over a given area of bed. When the gear is lowered the jaws are open, but as it strikes the bottom and the cable slackens the jaws close, the grab sinking slightly into the bottom under its own weight. By this means a sample is obtained of one-tenth or one-fifth of a square metre of bottom, according to the size of grab used. When it has been hauled up on deck, the sample passes through a system of sieves which remove the sediment, leaving animals, stones, shells, and the rest behind. The animals can then be identified, counted, and weighed. Given a sufficient number of samples and fairly even distribution, it is possible to calculate the number and weight of the various species per square metre of sea bed.

Rather extensive samplings have been made in recent years with this grab, especially in Danish waters, off the Faroes, Iceland, and Greenland, in northern Russian waters, and in the Adriatic. Most of them, however, have been in shallow water and only a few have been at depths beyond I 00 metres - a few also at a little over $\mathrm{I}, 000$ metres. They have shown that only a comparatively small number of species occur in these waters in large quantities per square metre, and, furthermore, that the same 


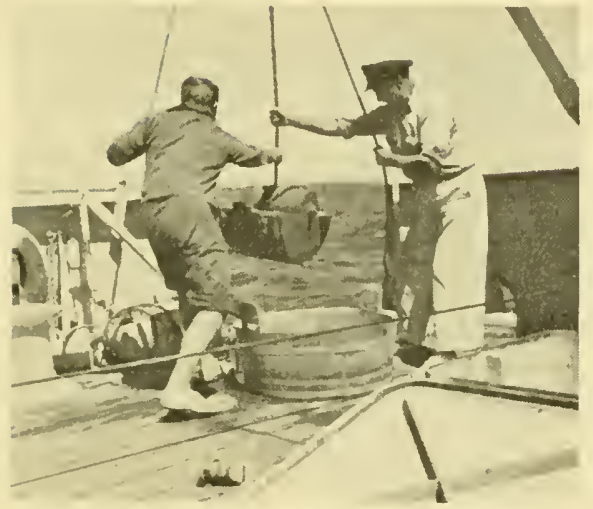

Swinging the Petersen grab on to the deck.

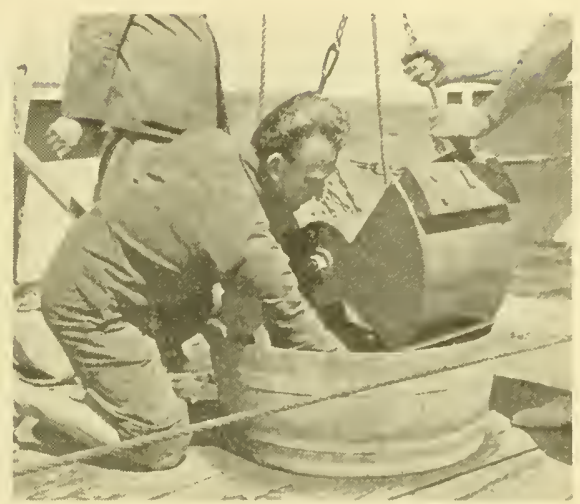

Emptying the grab.

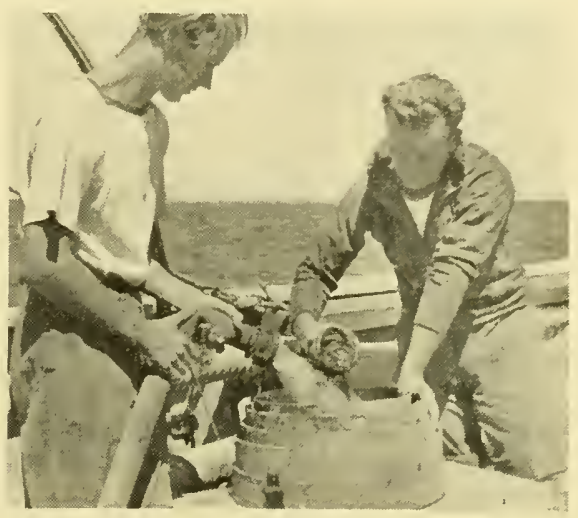

Sifting the sample.

waters can be divided into regions, each dominated by a few different species. A region such as this is termed an animal community and is named according to the small animals which predominate in it. From the European coastal waters explored a whole series of these animal communities has been described.

Such quantitative samplings of the composition of the bottom fauna had hardly ever been made outside northern European and Greenland waters, and never in the deep sea. It was one of the spccial objects of the Galathea Expedition to do this, and with our wide experience of the Petersen grab it was felt that we were exceptionally well equipped for the work. According to our instructions, our principal field of operations lay in the great ocean deeps, and particularly in depths beyond 4,000 metres. However, an exception was made as regards quantitative bottom sampling. This we were also to carry out in shallow water, so that, by 
means of a series of samplings in tropical waters and the southern hemisphere, we would obtain a basis of comparison between the animal communities of the North Atlantic and those of other waters.

It need hardly be said that the greatest interest attached to working the Petersen grab at the extreme depths, where it had never been worked before, and where therefore nothing could be known about the quantity of the fauna. It was to be expected that the number of animals there would be very small. Food production takes place in the uppermost layers, and the further we get from the source of production the poorer must we expect food conditions to be. It would not have been surprising if the fauna on the deep ocean floor had been so scattered that most of the samples contained no living animals at all.

So it was with great excitement that we awaited the result of our first sampling of the deep ocean bed, which took place on December i 9 , i950, off Angola. Would the grab bring up anything at all? Was the gear of any use at the great depths? The first attempt was a failure; the grab had not closed. But then it came up from 3,66o metres full of deep-sea ooze; and on sorting the material out we found that it contained three different species of polychæte worms, one of them a species common in Danish waters (Ammotrypane aulogaster), together with three small bivalves closely related to our common Leda. Thus in one-fifth of a square metre no fewer than four species were represented by six individuals weighing 0.3 grams, which corresponds to more than one gram and about 30 animals per square metre. Hence, this sample showed, first, that the gear can be operated at great depths, and, secondly, that there appears to be an astonishingly great wealth of species and density of individuals even on the deep ocean floor.

Confirmation of this was forthcoming. Altogether, we made 28 successful samplings of the deep ocean floor beyond 2,000 metres, seven of which were in the oceanic trenches deeper than 6,000 metres. The first fact to emerge was that few of the samples contained no animals at all. In the Philippine Trench we succeeded in getting a sample up from I 0,120 metres; it contained a small sea-cucumber weighing just under o.I gram, which corresponds to about five individuals and about half a gram per square metre. A couple of astonishingly rich samples were taken in the Weber Deep in the Banda Sea, at 7,280 and 6,580 metres respectively. The first yielded three species of animals and 6 individuals weighing 2.5 grams, and the second eight species and I I individuals weighing 2.1 grams. This gives a weight of no less than ro-r 2 grams and a density of about $60-70$ individuals per square metre. 
The contents of a section off the southern part of the IVest African coast. The quantity of animal life is greatest at $40-50$ metres.

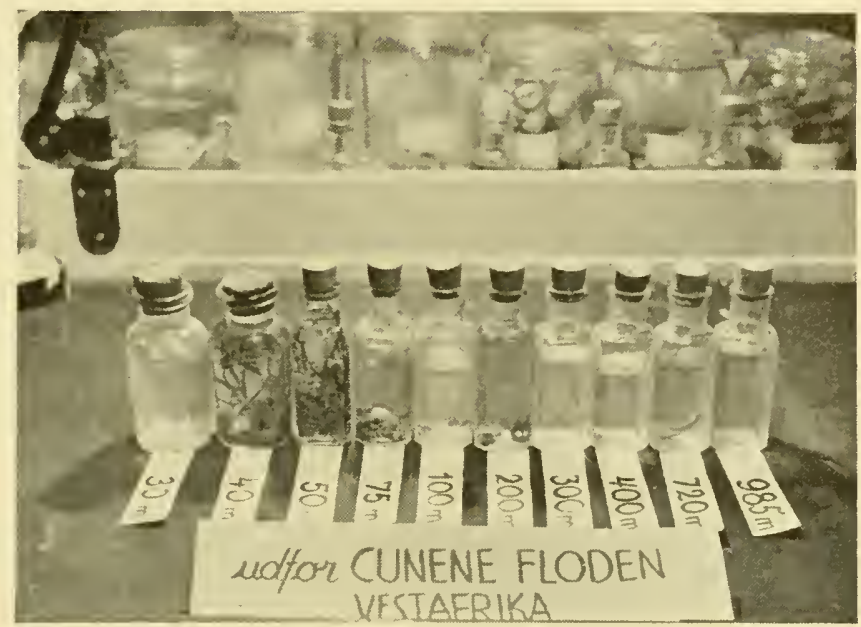

The result of our investigations in this field, therefore, is that on the ocean floor there are about ro animals per square metre with a total weight of about one gram. This is an astonishingly large figure considering that at a depth of a few hundred metres in Northern European and Mediterranean waters there are only a few grans of animals per square metre. This surprising density right down to between 5,000 and 8,000 metres suggests that food conditions in the abyss are not so poor as we have been inclined to think, and this in turn leads us to suppose that abyssal water currents must be stronger than formerly believed.

Although the relatively small number of samples so far obtained from the extreme depths will not allow of any comparison, or of the establishment of animal communities, there do seem to be certain variations corresponding to what we might expect. The deep samples taken off the southwest of Africa averaged 0.5 gram, off the Congo 0.37 gram, and off East $\Delta$ frica 0.2 gram. This agrees very well with the fact that food production is best off South-west Africa and poorer in the tropical Atlantic and the Indian Ocean. It is also very natural that the Banda Sea, an inland sea between the Moluccas and the small Sunda Islands, yielded strikingly rich samples, appreciably richer than the open ocean.

In addition to the deep-sea samples referred to, we used the Petersen grab for obtaining a considerable number of samples in shallower water, usually sectionally; that is to say, we took a series of samples extending from well inshore ( $10-20$ metres) out to the deep sea. Sections were thus sampled off the west and east coasts of Africa, in the Bay of Bengal, in the Gulf of Siam, in Milford Sound, New Zealand, off Campbell Island, 


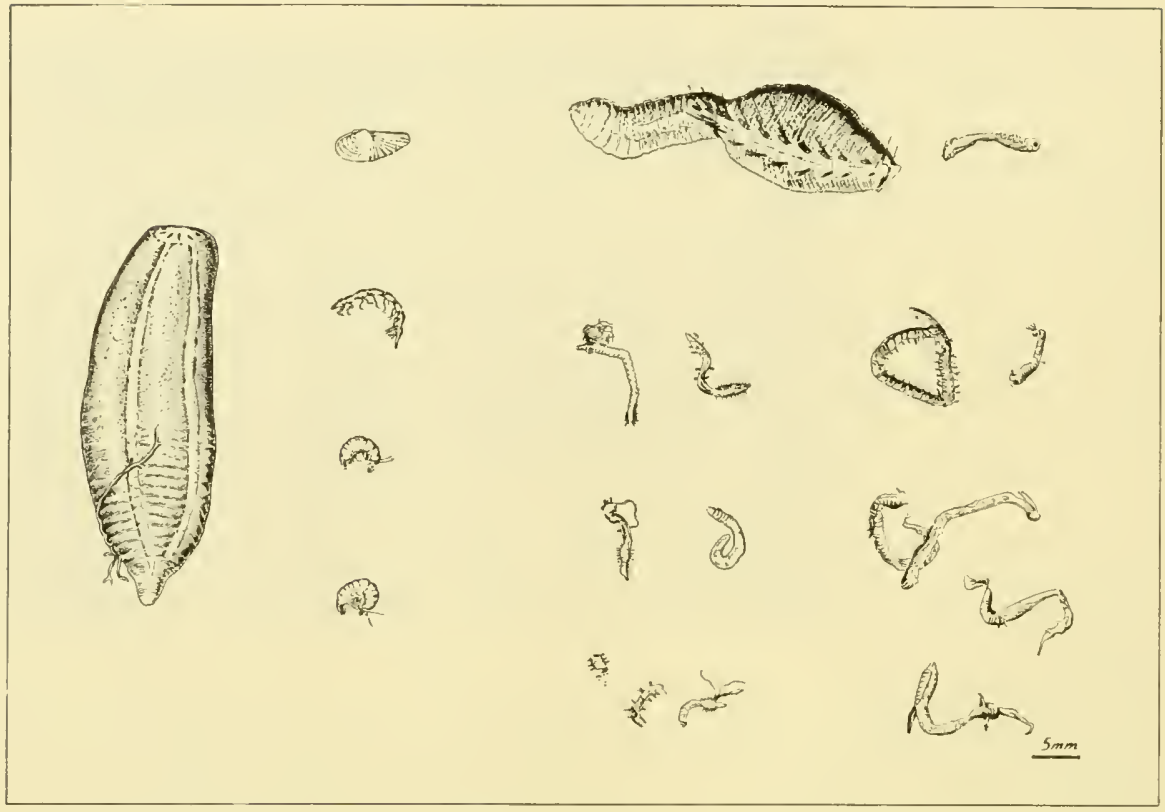

The contents of a bottom sample, one-fifth of a square metre, from the Banda Deep at 6,580 metres.

and in the Gulf of Panama. This is the first series of samples made with the same gear and technique in a series of tropical and subtropical waters and in the southern hemisphere. It shows that quantitatively the conditions of animal life on the level sea bed of these waters are similar to those in sampled European coastal waters. It is possible to establish a clear division into zones, characterized by one or a very few predominant specics, which may often occur in very large amounts. However, in tropical and subtropical coastal waters the weights per square metre are considerably lower than in such waters in North-west Europe, sometimes from 50 to Ioo times lower. The general rule is for the density of bottomdwelling animals to diminish with increasing distance from the coast. But in some tropical waters, for example near East Africa, the maximum density was not found near the coast but between Ioo and I5o metres out.

A series of samples taken off South-west Africa near Walvis Bay is of special interest. In the first place, these samples showed very high values, fully up to those found in Northern European waters. For example, there was the sample taken at 22 metres which contained 66.8 grams of living animals made up of about 2,500 specimens, including no fewer than 327 of the bristle-worm Pterampharete, 220 of the small razor-shell Cul- 
tellus, and as many as 1,9 Io of a small crustacean (a cumacean). This gives no less than 12,500 animals and 330 grams to the square metre; in short, a density of the same order as in Danish waters - and partly species of similar type. The small razor-shell, for instance, could easily be mistaken for the one common at similar depths in Danish waters, where it is one of the principal food animals of the plaice. The samples taken off South-west Africa thus reveal a very abundant fauna, fully in kecping with the biological investigations of production.

Off Walvis Bay, nearly every year, there is what is known as the "fish-death". It takes place when the sun is in zenith - about Christmas. Fish die in their thousands, drifting ashore and forming in many places almost a sea-wall of their dead. Various explanations of this phenomenon have been suggested. One is that sulphuretted hydrogen developed on the bottom produces an azoic zone off Walvis Bay; another that there is a prevalence of toxic substances secreted by micro-organisms, which here are particularly abundant owing to exceptionally favourable growth conditions. Our visit on Christmas Eve 1950 confirmed the latter theory. The water in the bay was then coloured brown by a small micro-organism, whereas, as indicated above, the bottom samples from the alleged azoic zone were extremely rich in live animals. It follows that the poison emanates not from the bottom, but from the surface waters which produce the large growth of micro-organisms.

This is only one example of the work carried out with the Petersen grab in shallow water. By employing this gear and demonstrating its usefulness not only in the deep ocean but also in coastal waters in various parts of the world, the Galathea Expedition successfully achieved this particular objective. 


\title{
BACTERIA IN THE DEEP SEA
}

\author{
By Cllaude E. Zobell and Righard Y. Morita \\ Scripps Institution of Oceanography \\ University of California, La Jolla
}

Bacteria are simple micro-organisms each consisting of a single cell. Some varicties, called cocci or coccus, are almost spherical or ball-shaped. Rod-shaped bacteria are called bacilli. Those that are curved like a comma are called vibrio. Spirilla is the term applied to spiral-shaped or complexly curved bacteria. Some bacilli and all vibrio and spirilla have flagella, long whip-like appendages that scrve as organs of locomotion.

Numerous genera of each of these four main morphological forms occur in the sea. The genera differ in shape, size, structure, and in many other characteristics, including food requirements, salinity preference, temperature tolerance, physiological activity, colour, and colonial behaviour. Their form and structure can be observed with a good microscope, but it is necessary to cultivate bacteria in nutrient mediums in order to understand their physiology and growth characteristics.

Bacterial cells of different species range in length from less than 0.2 to more than 100 microns; the average length of most marine species is between 0.5 and 5 microns. The average diameter is near one micron. (A micron is $1 / 10,000$ centimetre.)

In spite of their small sizc, bacteria are so numerous that they may constitute an appreciable part of the volume or total weight of living organisms in the sea. When food is plentiful and other environmental conditions are favourable, bacteria grow and reproduce at a remarkable rate. It is not uncommon for bacteria to reach maturity and reproduce (by transverse fission) in less than an hour.

For food, bacteria consume virtually all types of organic matter regardless of its composition or state - particulate, colloidal, or dissolved. All classes of carbohydrates, proteins, and lipids are digested by certain varieties of bacteria. They thrive on organic wastes such as animal cxcrement. They attack and quickly decompose the remains of both plants and animals. A few species of bacteria, known as pathogens, start to digest plants and animals even before the infected organisms are dead.

Because of their voracious appetites for all kinds of organic materials, bacteria are the principal scavengers in the sea. So effective are they in decomposing or mineralizing organic wastes that the ocean has been described as the world's largest and most efficient septic tank. Actually only 
about two-thirds of the carbon in organic compounds decomposed by bacteria is oxidized to carbon dioxide; the other one-third is used to build new bacterial cells. This may be important in the carbon economy or food cycles in the sea. Besides producing carbon dioxide, bacteria catalyze the conversion of waste organic matcrials into other plant nutrients, including ammonium, phosphates, and nitrates.

Most species of marine bacteria require organic compounds for their nutrition and growth. A few specics are unique, however, in being able to synthesize their protoplasm entircly from inorganic substances, much as green plants do. Instead of utilizing sunlight as a source of energy, though, as do the plants, these unique bacteria, called chemosynthetic autotrophs, oxidize either molecular hydrogen, hydrogen sulphide, methane, ammonium, nitrite, or other inorganic substances as an cnergy source. Such bacteria are probably the only primary producers of organic matter below the photosynthetic zone, the topmost layer of a few hundred metres of sea water penetrated by sunlight.

By virtue of their action on both organic and inorganic constituents, bacteria are believed to affect the chemical composition of sea water in many ways. In a like manner they may affect geochemical and geological conditions in marine bottom deposits.

It has been known for a long time that bacteria occur abundantly in shallow seas. There has been little opportunity, however, to look for bacteria in the deep sea. The Galathea Expedition was the first to afford facilities for collecting and examining material from the greatest known depths of the ocean, some samples coming from bottom deposits more than I0,000 meters below sea level. This nearly doubled the depths previously examined for the presence of living bacteria.

A feeling of intense excitement and expectation inspired every officer, seaman, and scientist on the Galathea as the first sample of mud from record-breaking depths was hauled aboard on July I5, 195I. This sample collected at Station No. 4 I $_{3}$ in the Philippine Trench came from a depth of 10,060 metres. A glimpse at material from such great depths was an exciting privilege.

Many questions raced through the minds or were on the lips of the fortunate few who first saw this mud sample: What is its chemical composition? What would it reveal regarding the nature of the deep sea floor? Is there any evidence of life in the bottom mud? Many authorities had questioned the existence of living organisms in oceanic abysses owing to the high hydrostatic pressure, low temperature, alleged lack of food, and other adverse cnvironmental conditions. 


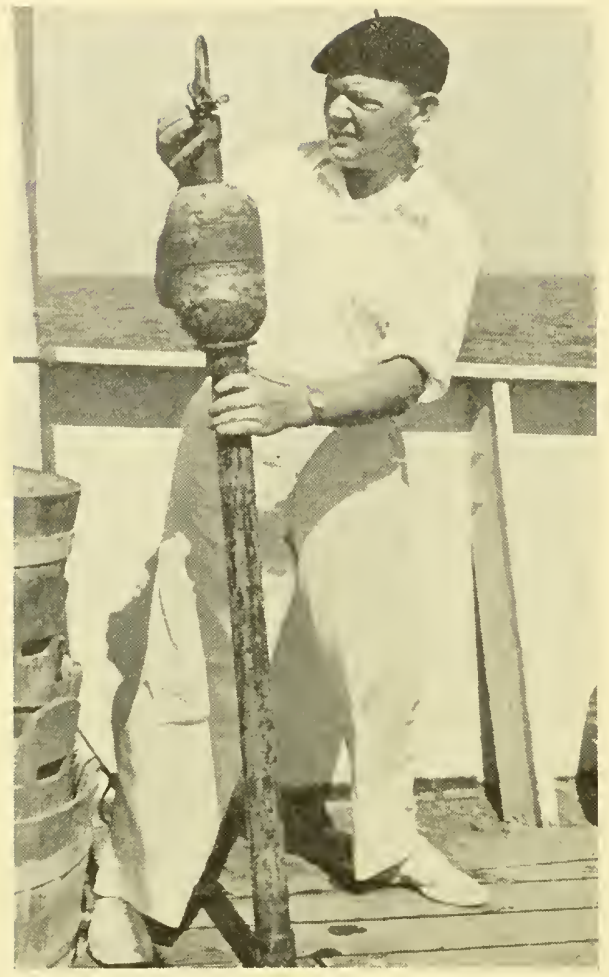

Dr. B. Kullenberg with his corer, a steel tube loaded on top with 50 kilograms of lead, and having a plastic tube inside. With the corer a sample of the bottom up to a metre long can be obtained for biological and geological study.

In order to avoid contaminating the mud sample, clean sterile instruments were employed to remove small portions for bacteriological analysis. Extremely thin films of the freshly collected material were spread on glass slides for examination with a microscope. A magnification of nearly a thousand diameters made it possible to see many small bodies in the mud. Under the microscope, some of these bodies appeared to be about the size and shape of the periods on this page. Others were curved, commalike bodies; more were straight rods resembling the printed dash or hyphen of various lengths and widths. Unquestionably they were bacteria cocci, vibrio, spirilla, and bacilli. Unfortunately, however, microscopic examination failed to prove whether the bacteria were living or dead or even fossil forms.

In order to determine if the bacteria were alive, small quantities of the mud were planted in glass tubes containing nutrient medium prepared with sea water, peptone, and yeast extract. In fact, several other different kinds of nutrient substances were used in different tubes, since nothing was known in July I95 I about the nutrient or food requirements of deepsea bacteria. 
Snall test tubes about the size of one's little finger, ro by $50 \mathrm{~mm}$, were used for these cultural tests. After seeding the nutrient medium with mud, cach tube was closed with a sterile neoprene stopper. The stoppers prevented extraneous microbes from getting into the tubes and also the neoprene stoppers functioned as pistons which pushed into the tube to compress the mixture of nutrient medium and mud until the hydrostatic pressure approximated that prevailing on the deep-sea floor. These pistons were pushed into the tubes under the influence of hydrostatic pressure in stout stecl cylinders designed for this purpose.

In families of 25 , the stoppered tubes were placed in the stainless steel cylinders designed to withstand internal pressures up to 2,00o atmospheres. After displacing the air from the cylinders with cold water, which also served as the hydraulic fluid, the cylinders were closed pressure-tight and connected by means of a hollow stainless steel tube to a hydraulic pump. The specimens from at depth of ro,o6o metres were pumped up to $\mathrm{r}, 000$ atmospheres at a temperature of $3^{\circ} \mathrm{C}$, approximately the pressure and temperature prevailing at the bottom of the Philippine Trench where the mud samples were collected.

After several days' incubation in the refrigerator, the pressure was released, the steel cylinders were opened, and the nutrient medium was examined for evidence of bacterial growth. It was found that bacteria from the deep-sea mud had reproduced in great numbers and, furthermore, they had affected the chemical composition of the medium. Thus, it was proved that the bacteria from the deep-sea floor were alive and physiologically active at a pressure of I,000 atmospheres; the first conclusive proof of living organisms occurring at such great depths and the

To prevent the bottle from being knocked over by the rolling of the ship, Professor ZoBell uses both fingers and toes when inoculating samples of bacteria.

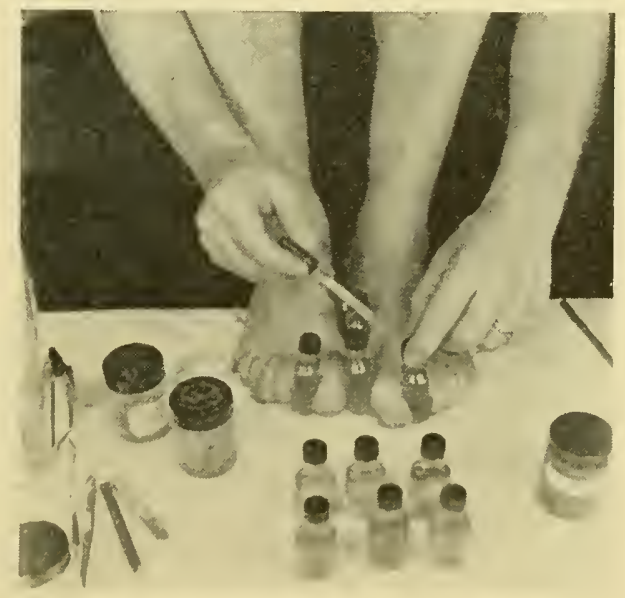




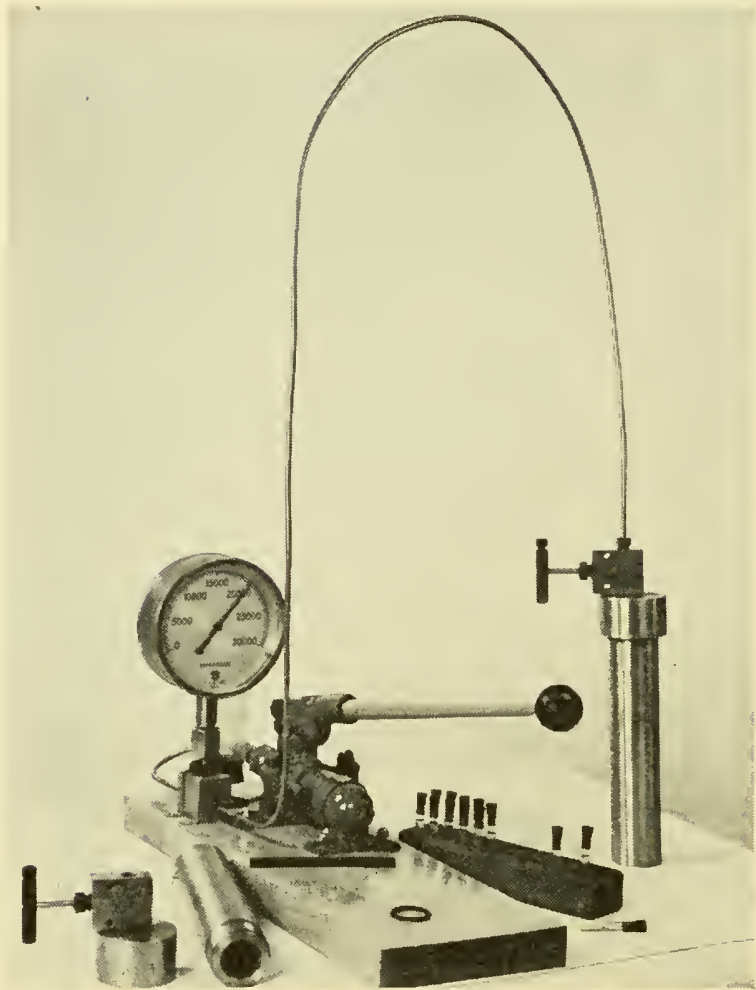

The hydraulic pump, by means of which the bacteria in the steel cylinder on the right can be subjected to a pressure. of $I$, ooo atmospheres, corresponding to the pressure of the surroundings at a depth of Io, ooo metres.

first proof of growth and activity of organisms at such a high pressure! Further evidence of microbial activity in the sediment was indicated by decreases in the ratio of organic carbon to nitrogen.

That the bacteria were actually from the deep sea and not adventitious contaminants was indicated by the fact that they grew in nutrient mediums when incubated at 1,000 atmospheres but not in similar mediums incubated at one atmosphere. Since the deep-sea forms seem to require high pressure, they have been described as barophilic, a term that means pressure-loving.

Additional observations on samples subsequently collected from other stations in the Philippine Trench, Java Deep, Weber Deep, New Britain Trench, and Kermadec-Tonga Trench established the occurrence of an abundant barophilic bacterial flora on the sea floor at depths ranging from 7,000 to 10,000 metres. The topmost layers of bottom deposits at the mud-water interface were found to contain from several hundred thousand to a few million living bacteria per mililitre (cc). The total weight of bacteria is estimated to be a minimum of 0.002 grams per square 
metre of deep-sea bottom; perhaps ten times this weight of bacteria live there. Large numbers of living bacteria were also demonstrated in water samples taken just off the bottom of the abyssal deeps investigated by the Galathea.

Although from 0.0002 to 0.02 grams of bacteria per square metre of ocean floor may be considered a small "standing crop" as compared with the crops harvested from fertile garden soil, this amount compares favourably with the total weight of animals found by zoologists on the Galathea Expedition. Since the bacteria grow rapidly and have a short generation time, they may produce several "crops" each year. How rapidly they grow or reproduce on the deep-sea floor is problematical, but in the laboratory it has been shown that bacteria reproduce every few hours in nutrient seawater medium held at the same pressure and temperature that prevail on the sea floor.

Bacteria reproduce by simple fission, the parent cell dividing to form two daughter cells. Under favourable conditions, the daughter cells reach maturity within two to twenty hours, during which time they reproduce by dividing to form four new cells. The resultant four give rise to eight, eight to 16, I 6 to $32,3^{2}$ to 64 , etc., assuming there is no mortality and all progeny find conditions favourable for growth and reproduction.

Obviously, not all of the bacteria in the ocean find conditions suitable for reproduction and many more never live long enough to reproduce. Perhaps the principal cause of bacterial mortality is the predatory animals which feed upon bacteria in much the same way that cattle or sheep graze the grass from pasture lands. The grazing cattle or sheep may leave

Micro-photograph of a culture of barophilic bacteria from the Kermadec Trench. They have been provisionally named Bathycoccus galathea. Magnified about 3,50o times.

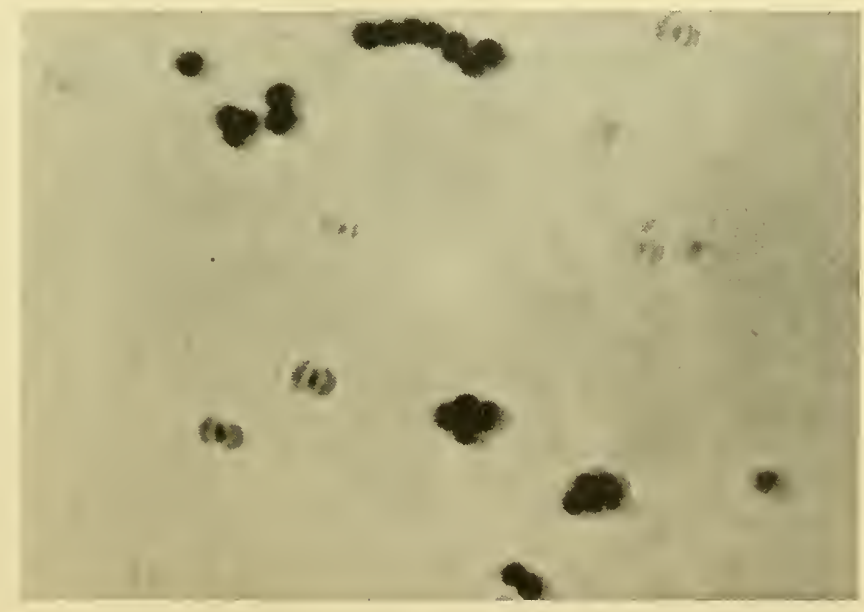


grass standing in the pasture, but more continues to grow. In a somewhat similar manner, marine animals are believed to graze off the bacteria until the standing crop is reduced to a few million per millimetre (cc).

Protozoans, worms, sponges, filter fceders, and mud-eaters are among the predatory animals known to ingest and digest bacteria as a source of food. What percentage of the food of deep-sea animals comes either directly or indirectly from bacteria remains problematical, but it may be appreciable. About the only other sources of food for deep-sea animals are the bodies or parts of animals and plants raining down from the photosynthetic zone. The Galathea Expedition obtained ample evidence that particulate organic matter from the photosynthetic zone does reach the deep-sea floor, but whether it is enough to nourish the animals there is questionable.

The thinking reader will also wonder how the deep-sea bacteria obtain their food or nourishment. In the first place, bacteria are more versatile than animals in the kinds and varicties of carbon compounds that they can utilize for food. Besides being able to utilize virtually all classes of organic matter regardless of complexity, many bacterial species can obtain all of their nutrient necessities from inorganic substances. Then, unlike most marine animals, there are bacteria which thrive on organic substances dissolved in sea water. Dissolved organic matter carried into oceanic abysses by circulating water is believed to be the principal source of nutriments for deep-sea bacteria.

Samples of sea water, filtered to remove all particulate matter, provide for the growth and reproduction of bacteria until the population may reach several hundred million per millilitre, since no animals are present in the filtered water to consume the bacteria. The utilization of dissolved organic matter by bacteria may be partly responsible for water samples from great depths sometimes containing less than one part per million, whercas samples from the photosynthetic zone may contain ten times as much organic matter in solution or suspension.

In addition to serving as a source of food for certain marine animals, bacteria may aid animals in the digestion of their food in much the same manner as the bacteria in the rumen of cattle or sheep aid these ruminants in the digestion of their food. Particles of cellulose, chitin, keratin, lignin, and other complex compounds swallowed by animals may be digested only with the help of bacteria residing in the animal's alimentary tract.

Accessory growth factors or vitamins synthesized by bacteria may contribute to the nutrition of animals in the deep sea. Vitamins of the B complex are produced by many marine bacteria. Some species produce caro- 
Plastic tube from Dr. Kullenberg's piston corer with a sample taken from the bottom of the Philippine Trench. Professor ZoBell is taking samples for bacterial culture.

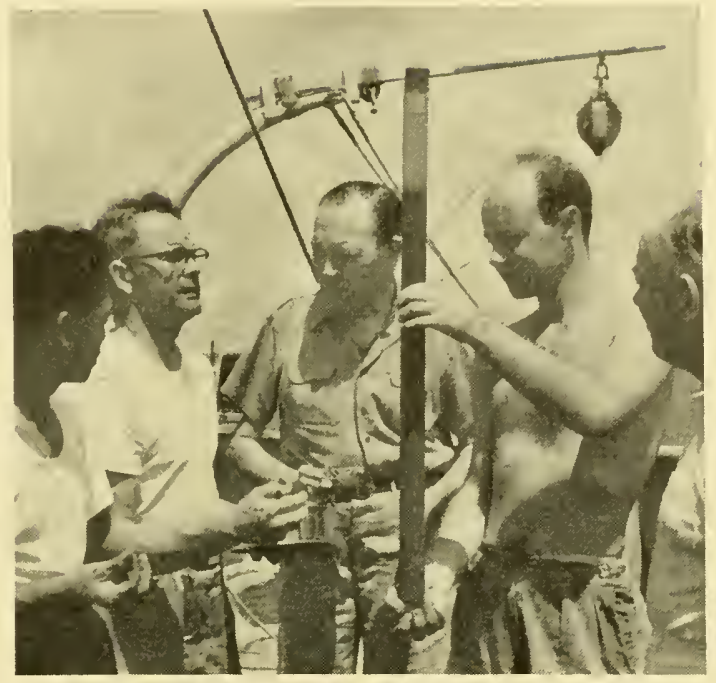

tenes, closely resembling vitamin $\mathrm{A}$, and several produce ergosterol, also known as provitamin $\mathrm{D}$. The synthesis of vitamin $\mathrm{B} 12$ by bacteria in the gut of chum salmon and Pacific herring has been reported.

Although the majority of the bacteria in the sea are beneficial to animals, a few species cause infectious diseases. Bacteriologists on the Galathea Expedition obtained no evidence of bacterial infections in deep-sea animals, but judging from observations on diseased animals collected from shallow coastal waters, one might expect to find pathogenic bacteria taking their toll of animal life in the deep sea also. Even though the infection by itself is not fatal, the pathogenic bacteria may incapacitate the host animal to a point where it may more readily fall prey to the everpresent predator. There is no sanctuary in the sea for the ill or the aged where only the fittest survive.

Certain pathogenic bacteria have the unique property of producing light in infected lesions, causing the latter to glow in the dark. However, only a few species of light-producing bacteria are known to be injurious to marine animals. They are mostly harmless varieties that grow embedded in the surface slime of shrimp, squid, fish, etc., or, in a few cases, in the bioluminescent organs of fish.

Curiously, the production of light by bacteria is affected by hydrostatic pressure. Many more observations will have to be made, however, before we will be able to generalize regarding the behaviour of bioluminescent bacteria from the deep sea. We have learned that certain physiolo- 
gical reactions of bacteria are accelerated by high pressures comparable to those prevailing on the deep-sea floor, whereas other reactions are retarded or completely stopped by such pressures. Likewise we have learned that reproduction, growth, and other vital activities of bacteria are affected in different ways by changes in pressure.

One of the important objectives of the Galathea Expedition was to bring back living micro-organisms taken from the deep sea to their response to high pressure and other physiological peculiarities could be studied under controlled conditions. Several cultures of bacteria, taken from the bottom of the Philippine Trench and other oceanic deeps, are now being cultivated in the microbiology laboratories at the Scripps Institution of Oceanography. These cultures are being kept alive and physiologically active at pressures and tempcratures approximating the conditions prevailing on the floor. From them it is hoped to learn many secrets of life. Learning how the protoplasm, physiology, and enzymes of these barophilic bacteria differ from surface-dwelling organisms that are ordinarily damaged by high pressure may contribute to our understanding of the equation of state in the fundamental processes of life.

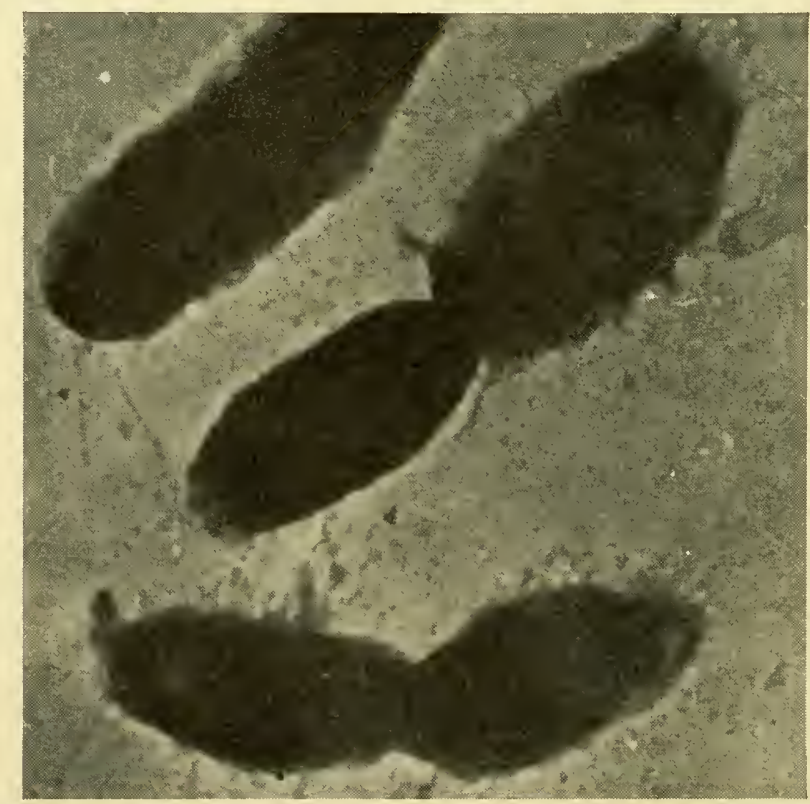

Deep-sea bacteria cultivated at a pressure of 1,000 atmospheres. Propagation by division is in progress. Magnification about 35,000 times. 


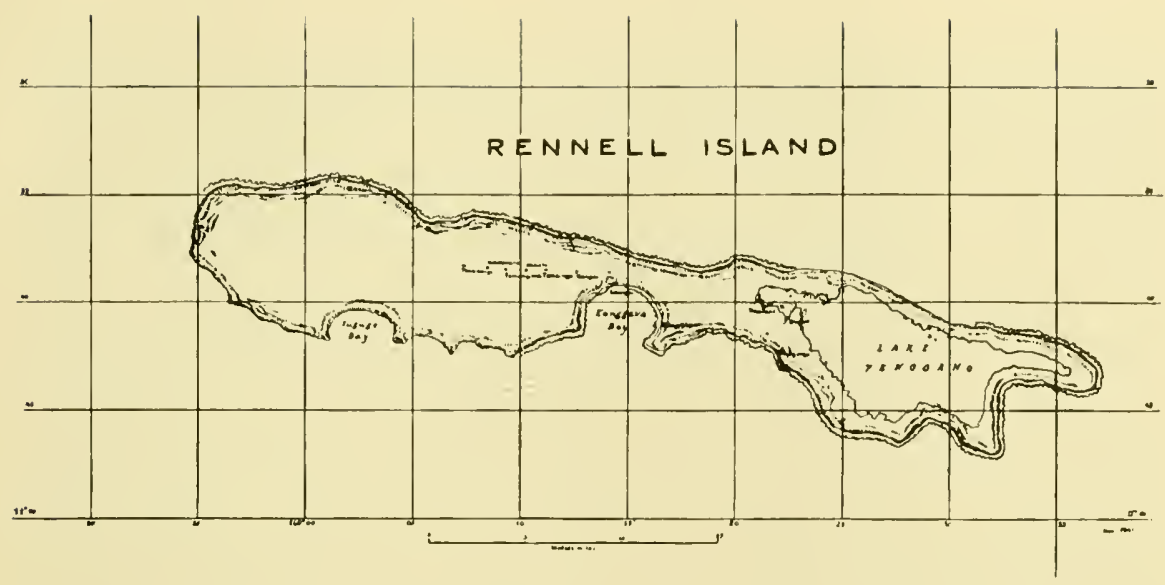

\title{
RENNELL - AN OUT OF THE WAY
}

\section{GORAL ISLAND}

\author{
By Torben WolfF
}

When a large expedition visits many scientifically interesting places, it naturally carries out sccondary studics where it can do so without prejudice to its primary objects. As will be described in a later chapter, Dr. Kaj Birket-Smith, of the National Museum in Copenhagen, joined the expedition with the intention of studying the primitive Polynesian population of the remote island of Rennell in the Solomon group, in the southwest Pacific. We had planned to drop Dr. Birket-Smith and a cameraman in the Solomons, leaving them to make their own way to Rennell, but en route from New Guinea it was decided that two zoologists might well be spared for a small separate expedition to Rennell Island to study its fauna.

In the normal course of events Rennell Island is closed to white visitors, but the British Resident Commissioner afforded us every facility, including the services as interpreter and Government representative of the district officer, Mr. A. Mackeith. The Resident Commissioner expressed surprise that it was a Danish expedition which wished to visit Rennell, and said that he had for several years corresponded with the British Muscum 
(Natural History) about sending out a few zoologists, but that the idea had had to be dropped owing to lack of funds. ${ }^{1}$

The Galathea left Honiara, the capital of the Solomons, on October 5, I 951, after landing the four of us with our films and preservatives, guns, ncts, and other gear. A few days later we were sailed over to Rennell to begin work.

The great majority of the islands in the Solomon group are formed from bed-rock (granite and gneiss) or lava. Rennell is unique in consisting entirely of coral limestone. It was originally an atoll, a ring-shaped coral reef enclosing a lagoon, which usually has a steep drop on the outer side into water several thousand metres deep. Imagine an elongated ringreef raised some I oo metres above sea-level, part of the lagoon having dried out owing to the upheaval, and you have Rennell, one of the largest and finest examples of a raised atoll in the world.

In shape, as seen from above, it resembles a long narrow dish, the edge being the former fringe reef which surrounds the whole island like a ridge. This ridge in places is only a few metres thick, forming a razorsharp and jagged wall. From the sea the island presents the appearance of a continuous wall of coral limestone $80-100$ metres high, overgrown with vegetation except where it is quite perpendicular. Along the coast runs a barrier reef formed after the upheaval, and the surf beats against this reef day and night.

There are indications at a few points that the upheaval must have taken place in two stages. On our laborious climb over the wall towards the sea we encountered, about half way up, a ridge, and inside this a narrow shclflike depression, before the final ascent to the top. This ridge and depression doubtless represent a former barrier reef and lagoon, formed during a lull in the upheaval.

As already mentioned, the original lagoon has been only partly dried up. The degree of upheaval not being everywhere the same, some of the lagoon has remained in the form of a lake at the eastern end of the island. With a length of about 25 kilometres and a width of $8-10$ kilometres, this is the largest lake in the South Seas. Its surface is now believed to be almost at sea-level, and as there is at least 60 metres of water at the eastern end the bottom is a good deal below sea-level. Towards the western end, the irregular bed of the original lagoon is visible in the form of a steadily increasing number of islets which, further west still, merge into a swamp and then give way to the undulating bottom of the central de-

1 A British Museum expedition was carried out later, in 1953. 


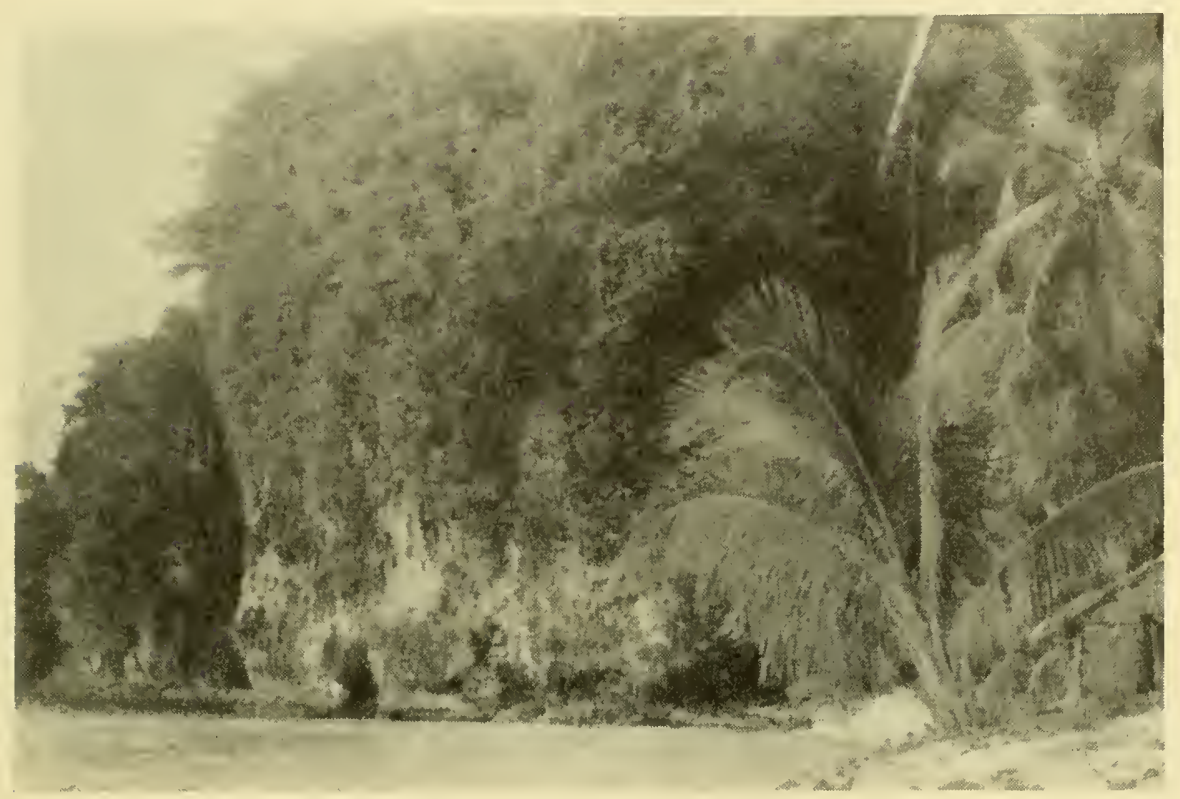

The coral limestone walls, partly covered with forest growth, rise sheer from the sea.

pression. Although in course of time the water has become nearly fresh, it is still brackish enough to be almost undrinkable.

Rennell is quite a sizeable island, being about 75 kilometres long and 10-I 5 kilometres across. It lies WNW-ESE, more or less in line with the prevailing trade winds, and is surrounded on all sides by ocean depths of between 2,000 and 4,000 metres.

In trying to form as correct a picture as possible of the fauna of so restricted an area it is necessary to choose a characterictic small section of each biotope - that is to say, of each locality (forest, shore, cultivated land, etc.) - and then study it in full, collecting animals living on vegetation, on the ground, and under the ground. We divided the island into five main biotopes: forest, cultivated land, lake and surroundings, shore, and coral reef.

The greater part of the area was covered by forest, and so we made a thorough study both of a forest biotope near the coast and of another in the middle of the island. The vegetation consisted of a comparatively dense and not very tall tropical rain forest, with a few giant trees projecting here and there.

The forest floor was astonishing. A thin layer of soil had formed here and there, but in the great majority of places the ground consisted of the 


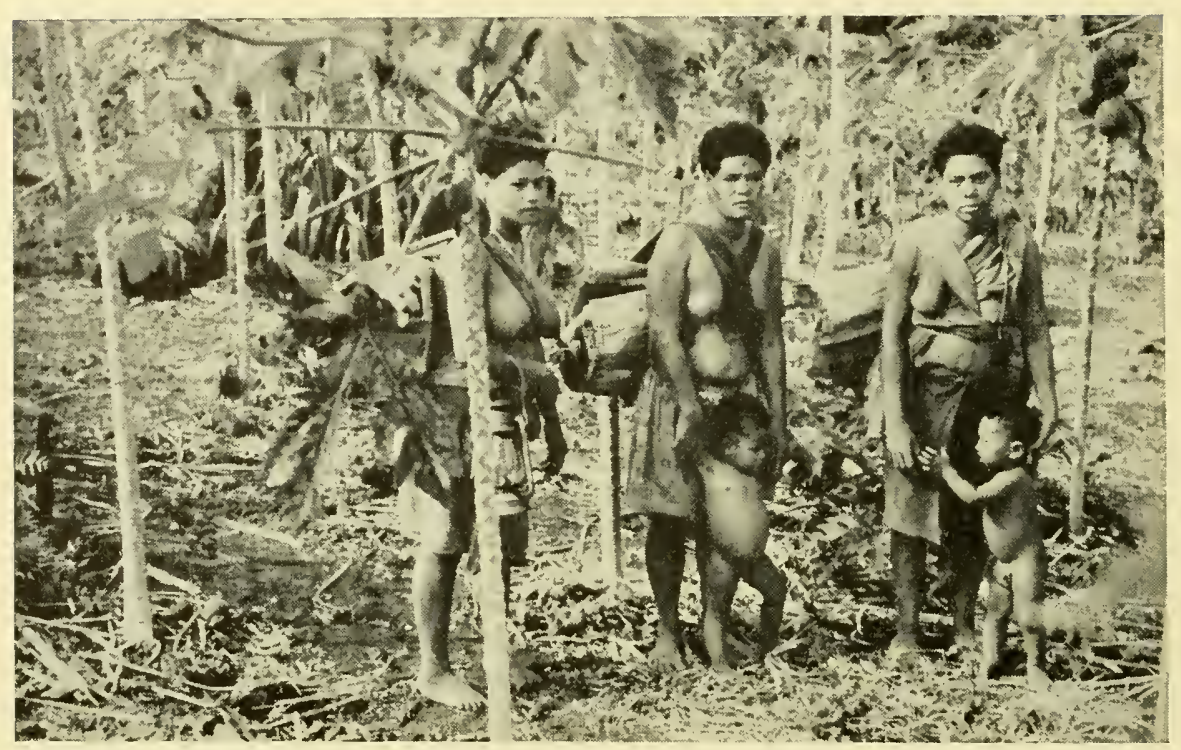

Rennellese in a plantation of papaya trees, which bear melon-like fruit.

bare coral rock, furrowed and pitted over the centuries by rain, an endless expanse of blocks of coral of all sizes, with razor-sharp edges, needlepointed tops, and gaping fissures. And weaving in and out among the blocks was a tangled mat of roots, tree-trunks, and lianes, in places quite impenetrable. Such few tracks as there were ran between and over the coral blocks, which would often be moss-grown, wet, and slippery, so that one false step might mean a nasty gash in the leg. The natives, used to this ground from childhood, get about with the greatest of ease, following the tracks at something between a march and a skip, carrying heavy loads on their shoulders and having nothing on their feet - except thick "rubber" soles of hard skin.

Here and there the forest is very open, the vegetation then consisting of a creeping, densely matted liane and a fern which proved to be the widely distributed tropical species Nephrolepis biserrata. We sent a rather large collection of seeds and fruits to the Botanical Gardens in Copenhagen, but unfortunately few of them retained their germinating power on arrival.

In a few places the layer of soil on and between the coral is deep enough to have made it worth while to burn the forest off, and here we found native "gardens" of coconut palms, papaya or paw-paw (a tree with a fruit like a melon), and the tuberous yam and taro plants. This biotope has its own special fauna, which we carefully studied, as we did that of 


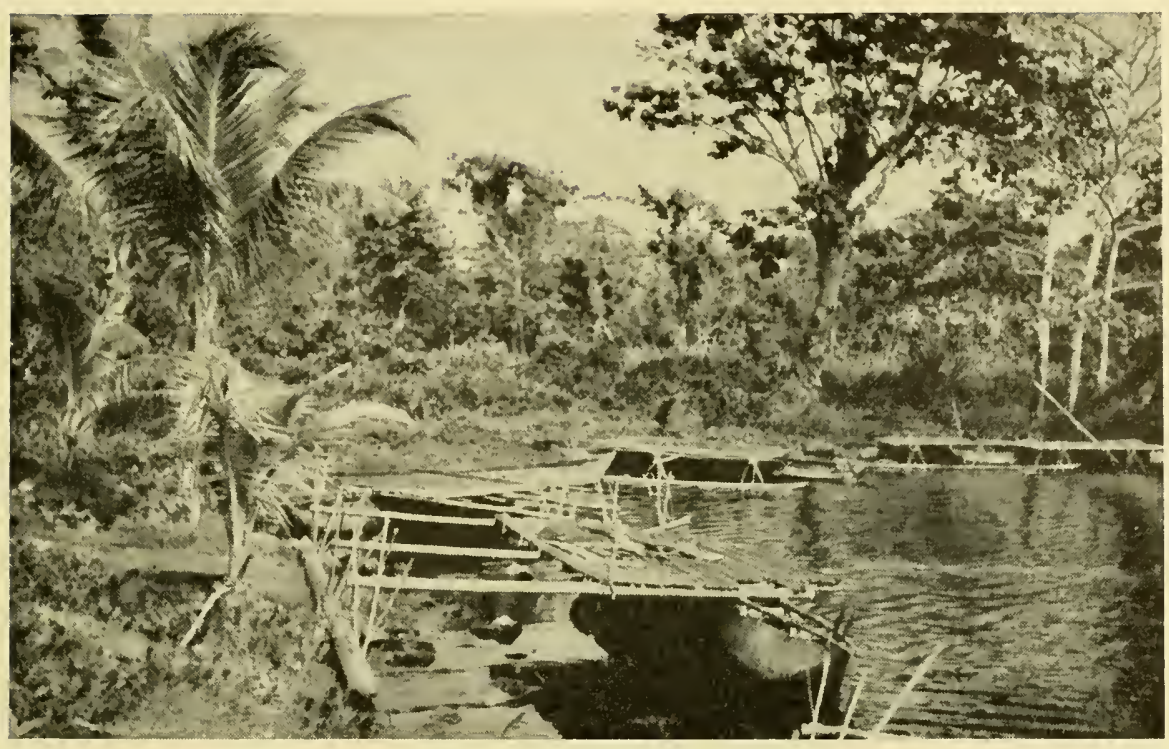

Outrigger canoes by the shore of Lake Te-Nggano, the largest fresh-water lake in the South Seas.

the lake and lake shore, the forest, and the cultivated land near the lake, to which we made a very strenuous and unfortunately rather brief excursion. Besides animals, we brought home samples of ooze from the lake, containing diatoms, which should provide important geological information.

Between the sea and the wall of limestone at various points along the coast - especially in sheltered bays - there is a strip of sand, which is densely planted with coconut palms. The village of Lavanggu, where in a large, good house we had made our headquarters, stood in the middle of one such coconut grove, which we examined for animal life as we did the beach. Finally, we extended our collecting to the coral reef, where at low tide we were able to wade. We thus succeeded in getting the shallowwater fauna represented.

Armed with collecting bottles and bigger receptacles as well as tweezers and insect nets, and aided by some eager boys and youths with wonderfully sharp eyes, we tackled our various biotopes, and succeeded in bringing back a large collection for sorting and preserving. In addition to this systematic method of collecting we distributed hundreds of beads, fishhooks, old razor blades, and so forth in payment for creatures large or small, two-legged, four-legged, or multi-legged, winged or wing-less, brought to us by natives at all hours of the day or night. We ourselves also went 
looking for bats and birds, both for the purpose of studying their habits and song and in order to shoot some for skinning. We studied the biology of ghost crabs, recorded colour descriptions of the small gaily coloured creatures of the coral reef, and gathered the local names of all larger animals, together with information about their importance as native food, and so on. A naturalist in so virgin a territory as Rennell need never be bored!

What were the animals which had found a home on this remote and inhospitable island since it had been raised out of the sea to become dry land some time in the Tertiary period?

The only previously known mammals were two species of a large fruiteating bat, a flying-fox (Pteropus geddiei and renelli), from the teeth of which the natives made fine necklaces. The bats were caught with a spear made from rattan thorns fixed to a long shaft, while slceping, suspended head downwards from tall trees in the daytime. We found three other species of bats, the smallest being no larger than the two end joints of a finger.

It was by chance that we discovered there were rats on the island. By drawing one we then made the natives understand that we wanted specimens of "kimoa", as they called them; the result was a number of fine rats. We subsequently learnt that the rats of Rennell lsland are by no means as rare or as shy as we had at first believed, for one night they boldly carried off some of my stuffed birds, tearing them to pieces in a corner of the hut. Their disappointment at finding the birds full of woodwool and cotton-wool must have been as great as my annoyance at wasted labour.

To begin with we paid little attention to the birds, since the American Whitney Expedition, which spent i 8 years collecting birds on the thousands of South Sea islands, had obtained and skinned 380 specimens on Rennell in 1928 and 1930. But finding ourselves with a little more time than expected and no more alcohol and formalin, we turned to the birds and succeeded in collecting more than 50. Incidentally, in the humid atmosphere and the primitive conditions under which we were working we had the utmost difficulty in getting our stuffed birds, butterflies, and other specimens to dry properly, while the myriads of tiny but incredibly voracious ants made storage something of a problem.

There were many large and conspicuous birds; on the lake, for example, a cormorant, a heron, an ibis (which we also saw strutting about in the forest), and two species of teal, which — unlike most other birds - the natives did not eat as they considered the flesh to be unclean. Consequently, the teal, being never hunted and having (like most of the other 
A chief catching doves. Normally he sits in the top of a large tree. In his right hand he is holding a stick with the decoy dove, in his left the wide-meshed net in which a small bird has been caught. A few papaya leaves on his head serve as camouflage.

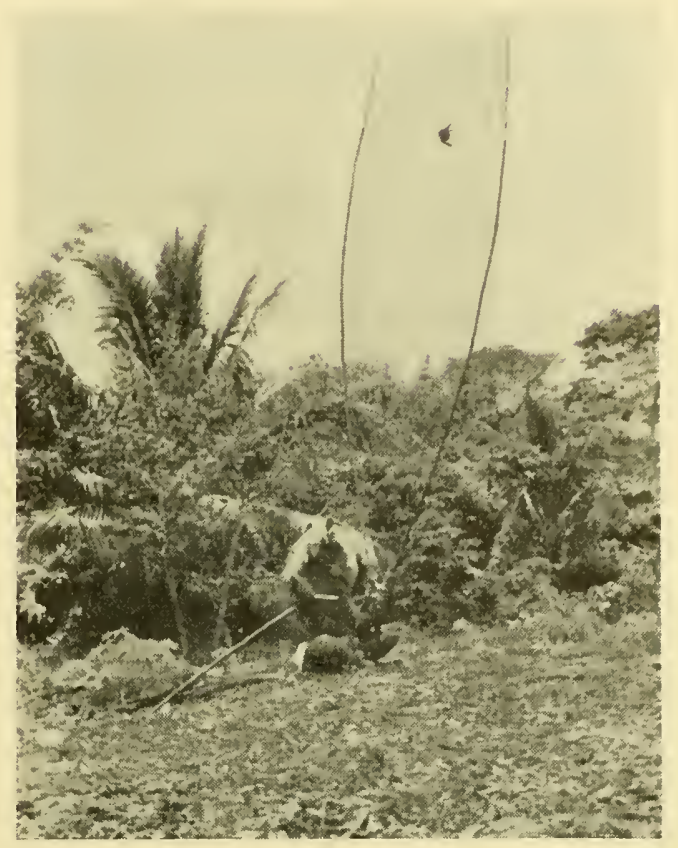

birds) no natural enemies, were perfectly tame. We also procured a couple of species of parrot, a blackbird rather like our Europcan blackbird, and a species of kingfisher which lived on insects and snails. We found its nest burrowed in a termitarium, where the young had only to peck a hole in the wall to obtain a rich meal of termites (white ants) which would come hurrying to repair it. But much to my surprise I found their stomachs filled, not with termites, but with small lizards, large cicadas, locusts, spiders, etc. At risk of life and limb I was obliged to kill a magnificent osprey with ether, after a native had broken its wing with a stone.

A rather common bird was the large bluish-grey Pacific dove (Ducula pacifica). The method of catching this bird is a secret jealously guarded by the chiefs, but is by means of large wide-meshed nets set up on a platform at the top of a tree. The catcher sits camouflaged with leaves, and decoys the doves by imitating their cooing while allowing a captive bird to fly up and down from a perch. The doves are then ingeniously caught in a large, oblong net. Smaller birds are captured in snares at the end of a long pole. The handsomest bird on Rennell Island is a greyish-green fruit-eating pigeon (Ptilinopus richardsii cyanopterus) with a chestnut breast and scarlet speculum. Also very handsome is a small scarlet and jet-black cardinal sunbird. 


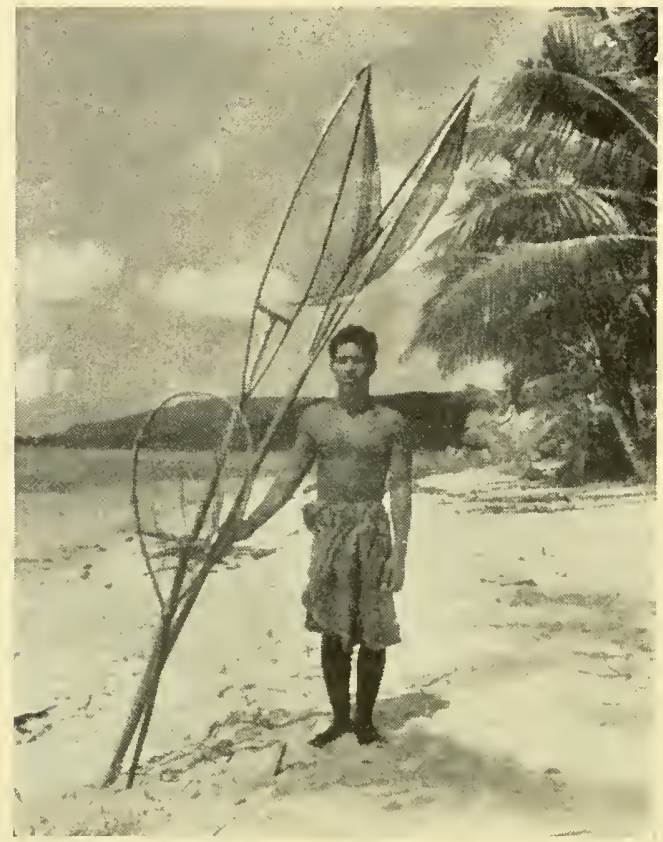

Three home-made fishing-nets for catching flying-fish by light; exactly the same method as used on board the Galathea (see page 68).

In the forest we caught three specimens of a large green-speckled monitor (a giant lizard), which, after thoroughly scratching and biting us, was manouevred into a jar of ether. There were many smaller lizards, and - ably assisted by the fleet-footed Rennellese - we obtained a fairly large collection of them. It is essential when comparing the fauna of an island or other restricted territory with that of neighbouring islands or territories to procure a series from every species. This is the only way of judging with any degree of certainty whether small structural differences between closely related species are constant or adventitious.

We also procured a number of amusing geckoes, which were to be seen darting about under hut roofs catching insects. Our haul of snakes included a strapping boa nearly two metres long. With a good deal of trouble we succeeded in tying it to a long pole, this being the only way of getting it alive to the village, where a strong dose of ether put an end to its life. We also found a species of the primitive blindworms, which live a very secluded life, and which incidentally are characteristic of a number of isolated islands.

One of our most interesting finds was a sea snake, caught in the lake. The small group of snakes which live in the sea has been discussed in an carlier chapter. One species of these was trapped in the salt-water lagoon 
by the upheaval, but succecded in adapting itself to the increasingly fresh lakc-water. As a result of this adaptation the lake form is considerably darker in colour than the ancestral form caught off the island, and constitutes a separate subspecies. Curiously enough, we had evidence of the same thing on the Philippine island of Luzon, where we heard of an isolated species of sea snake which inhabited an old crater lake that had once been connected with the sea. We failed to obtain a specimen at the time, but our Philippine friends promised to send us one. A comparison of the two lake forms is sure to prove interesting.

There are no water-courses on Rennell Island, for the simple reason that rain-water immediately sinks in between the corals. For the same reason there are no frogs, toads, or newts on the island. But one will occasionally find little pockets of water between large coral blocks, small crystal-clear pools which probably have subterranean inflow and outfall, and in one of these water holes, a couple of metres across, we made a sensational discovery - a fine eel with the length and thickness of a man's arm. It was in the centre of the island, five kilometres from the nearest sea-shore and some 25 kilometres from the lake. How it had got there overland or by means of subterranean channels - is a mystery.

In the lake we caught smaller eels and some fishes which were rather like goby. These we also found in small water holes in the interior. In the sea we took many gaily coloured coral-reef fishes and large flyingfishes, which on moonless nights the natives lure to their canocs by burning torches made from dead palm leaves, and then skilfully catch in home-made nets. Sharks, considered a great delicacy, are caught on huge wooden hooks. Smaller fish are taken on ingenious mussel-shell hooks, speared, or drugged with the juice of a liane, which is pounded out into the small pools left on the coral reef by the receding tide. The native also

Crab-holes made by Ocypode. The species on the right has piled the sand into a heap; the one on the left has scattered it.

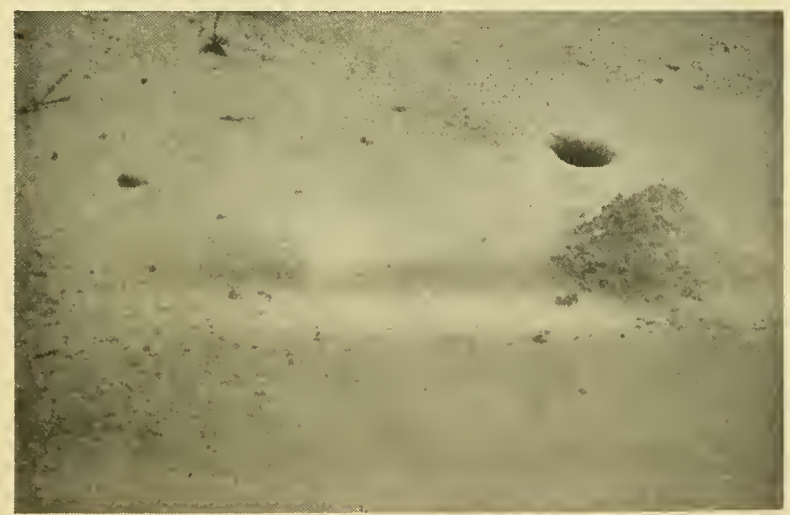


employ large home-made dip nets, which they spread on the outer side of the reef. The fish is driven into them by splashing the water. Traps are similarly used in the lake.

Among the invertebrates we particularly observed a great number of spiders. Their commonness is due to the ability of small spiders to spread over large areas by means of wind, suspended from the self-spun threads known as gossamer. This was how spiders succeeded in being the first animals to invade the volcanic island of Krakatoa, only a year after the disastrous eruption of 1883 which destroyed all life there.

We collected large numbers of insects, including dragon-flies, wasps, beetles, butterflies, grasshoppers, and some stick-insects, I o-15 centimetres in length, which ejected a fine spray of a milky liquid when handled. In soil and touchwood we found a great variety of larvæ, some nearly I 5 centimetres long — fat, pale, and maggot-like larva of wood-borers. The Rennellese must surely have thought us a little odd when they saw us pop these into alcohol instead of into our mouths, as to them there is no greater delicacy!

Finally, we collected many snails (including a fine, dull-green species which lived on coconut leaves), centipedes, millipedes, harvest mites, woodlice, earthworms, and similar inconspicuous creatures, which to a scientist can speak volumes about immigration routes, adaptability, and so forth.

The large, agile ghost crabs (Ocypode), which live on the foreshore, are interesting. They are nocturnal animals which dig long spiral galleries, removing the excavated sand from the mouth of the burrow and throwing it up into a hillock. At the slightest approach they vanish into their holes, and it is a long time before they venture out again.

In the lake we caught shrimps and amphipods; in the forest, land crabs and many hermit crabs, which yearly make the long, laborious journey over the cliff face in order to breed in the open sea, carrying house and home with them in the form of a snail-shell to protect their soft, spiral hind part. We also procured a fine specimen of a robber crab (Birgus latro), the claws of which can bite off a man's finger. This crab lives in the forest, but at night will prowl into the coconut plantations, where it is said to climb the trees and cut the stalks of young coconuts. At any rate, it is able to tear off the tough layer of coir and, inserting the point of its claw in the "eye" of the coconut, break the shell to get at the nut and eat it.

And then there were the land leeches, which drop down from overhanging leaves on to passers-by and suck their blood. As these creatures are 
A medium-sized specimen of the robber crab of Rennell Island. Total length 48 centimetres.

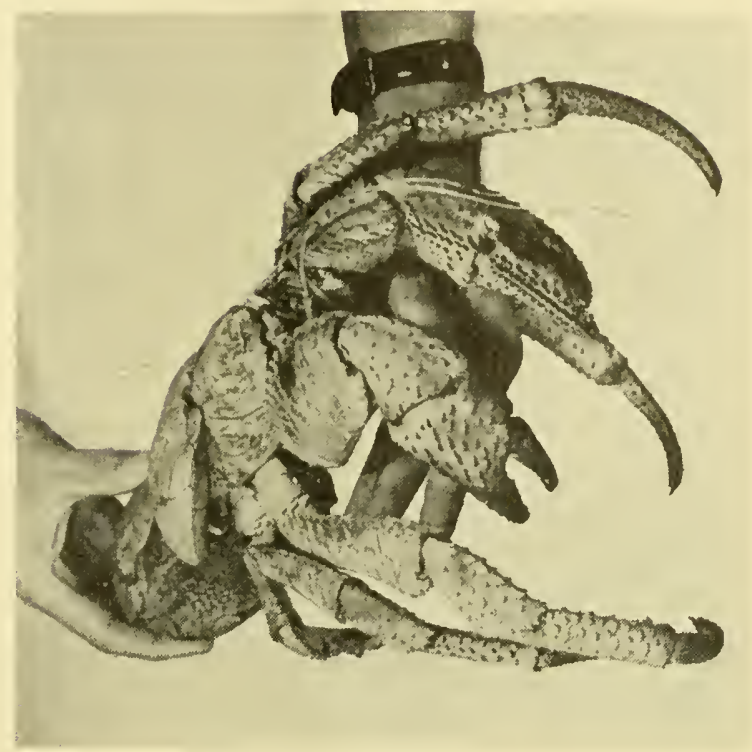

very little known, we carefully preserved each little parasite which we picked off one another.

Needless to say, I have mentioned only a fraction of the animals collected during our month on Rennell Island. I have said nothing, for example, of the many small creatures of the coral reef - brilliantly coloured crabs and shrimps, beautiful snails and bivalves, starfishes and brittle-stars, worms, and so on.

Although the impression may have been conveyed of a fauna as rich as on larger tropical islands or on the mainland, in fact, after the first thorough study of a given biotope, we came across many individuals belonging to species which we had already collected. This leads me to think that we succeeded in procuring a fairly full collection of the animals to be found on Rennell Island at that season.

We may now ask a few questions: Where did the fauna of Rennell Island come from; and how did it get there? How did the animals succeed in adapting themselves to the environment; and to what extent has the environment affected their appearance? The answers to these questions cannot really be given until the collected material has been studied by specialists. But, as mentioned already, the birds of the island were fairly well known, owing to the work of the Whitney Expedition. As I shall try to show, this knowledge of the bird fauna has already brought us a good step nearer to a solution of the problems. 
The Whitney Expedition found 38 species of birds on Rennell Island, to which we were able to add four more. Of these, 35 species breed on the island. It has been shown that in the time they have lived in isolation no fewer than 23 of the 35 have become so differentiated that they must now be classed as separate species or subspecies endemic to Rennell Island. This is an extremely high proportion.

Of these 23 endemic birds, eight are most closely related to near species in the Solomon Islands, while eight others have their nearest relatives on the Santa Cruz and New Hebrides islands. It is a remarkable fact, however, that, whereas the nearest large island in the Solomon group to the north is only 150 kilometres away, the distance to the Santa Cruz Islands to the east is as much as 600 kilometres. There are two possible explanations of the mystery. First, the prevailing winds in this region are easterly and south-easterly ( 56 per cent.), only one-sixth being northerly. Secondly, the geography of some of the Santa Cruz Islands is not very different from that of Rennell, whereas the Solomons are mountainous with a substratum of granite or lava.

For a species to spread from one region to another there must be at least one specimen of either sex. A close study of the habits of the Rennell birds and their nearest relatives shows that nearly all the small birds on Rennell Island are gregarious. The inference is that the bird invasion chiefly took the form of small wind-driven or storm-driven flocks.

It has already been noted that most of the birds have lived long enough on Rennell to have become differentiated into separate species or subspecies (as indicated by differences in size, length and thickness of beak, colour of coat, habits, food, and so on). Now, when we compare the endemic Rennell birds whose nearest relatives live on the Santa Cruz Islands (and New Hebrides) with the endemic Rennell birds which have their nearest relatives in the Solomon Islands, we find that the former show greater differences from their ancestors (the Santa Cruz birds) than the latter do from theirs (the Solomon Island birds). In fact, the Rennell birds related to the Santa Cruz birds have in most cases split off into separate genera and species, while those related to the Solomon Island birds usually differ only to the extent of forming seperate subspecies.

The explanation may lie in the fact that the distance from Rennell to the Santa Cruz Islands is so much greater than from Rennell to the nearest islands of the Solomon group that the proportion of Santa Cruz birds, in spite of the prevailing winds, is much smaller than that of birds which have come - though at long intervals - from the Solomons. The Santa Cruz birds would thus have a greater tendency to split off into separate 
species, being more or less undisturbed by new invasions of the same original species.

Before our return to Copenhagen, I sent our collection of butterflies of the genus Euploea on request to a British specialist who has been studying the occurrence of this genus in the Pacific for many years. His examination of the three Rennell species of the genus has shown that they constitute new forms unknown in the Solomons. On the other hand, they are closely related to species in New Guinea and undoubtedly originate from them. This suggests that an invasion may have taken place from that large island by way of the Louisiade Islands. The fact that a species of Euploea very common on the Solomon Islands was not contained in our large collection of butterflies suggests also that there is no connection so far as these butterflies are concerned - between Rennell Island and the relatively near Solomon Islands.

This is just a little of what may be deduced from the results of the Whitney Expedition and our own collections of birds and certain butterflies. It will be fascinating to see how far a study of the other groups of the island's fauna will confirm or disprove the theories advanced, and how many other interesting problems will be elucidated.

The Rennell collections, which comprise many thousands of animals belonging to many hundreds of species, are being studied by specialists in Denmark, England, and elsewhere. In due course the results of this and the British Museum expedition will be published jointly under the title The Natural History of Rennell Island, British Solomon Islands. 


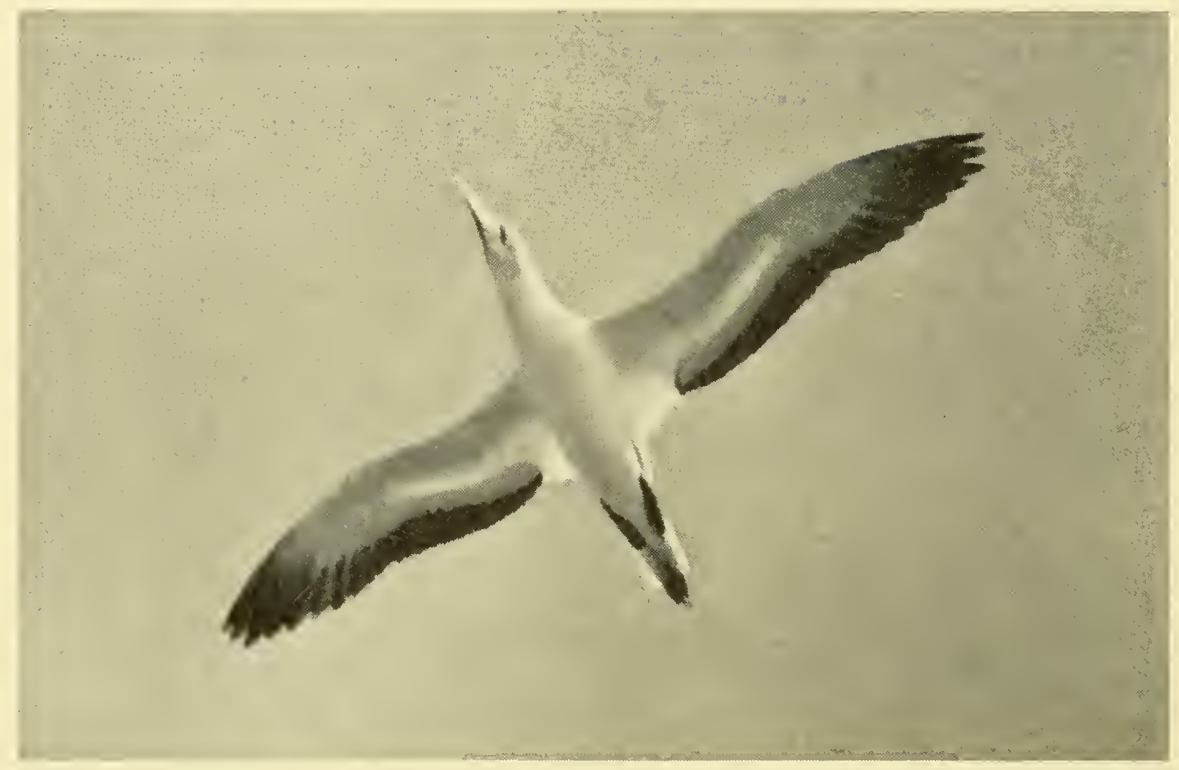

\section{OCEANIC BIRD LIFE}

\section{By L. Ferdinand}

After flying across three continents in five days, I alighted rather breathlessly in Macassar, in Celebes, to find mysclf in a hot, tropical climate. It had been late summer when I had left home and the trees were still green, though cold nights foretold the coming of winter. The Galathea called at the port the day following my arrival and the next afternoon, in Scptember 1951, we put to sea.

We were barely out of Macassar when, sailing over the ship in easy, gliding flight, the first frigate-birds appeared. After making a brief swoop over the mainmast, they flew off. This was my welcome from the stateliest bird of the tropical seas, their best and handsomest flyer, though also their greatest robber. My hardened companions, scarcly noticing the birds, shook their heads at the enthusiasm of the new arrival.

The Australian gannet (Sula serrator) soaring over a rocky islet off New Zealand, where this species breeds. It differs from its cousin of the North Atlantic (Sula bassana) in having dark tail feathers and black wing feathers. 
On one of our very first days in the Banda Sea, just south of Celebes, a wader the size of a dunlin, with a double white bar on the wings, rose from near our ship's bows and flew off, kecping close to the surface. It was a grey phalarope (Phalaropus fulicarius), a small swimming and wading bird, in its tropical winter quarters. Until a few years ago, it was a complete mystery where this bird, and its cousin the red-necked phalarope (Phalaropus lobatus), went to in winter. It was known that they bred in the far north, both in the old world and in the new. We now know that they spend the winter half-year on the open sea in various tropical parts, weathering the roughest of storms and living on small surface animals and plankton. A few months later - in April - we were to meet them again, flying in flocks of from $5^{\circ}$ to 60 off Lower California, near Mexico, on their spring migration to breeding places in Alaska and northern Canada. It was the only bird of passage which we saw in Indonesian waters, where marine bird life is dominated by the tropical Sula, and to a lesser extent by the tropical terns.

From Celebes we sailed due east for Torres Strait and the northern tip of Australia, crossing first the Banda Sea and then the Arafura Sea. As we spent a good week fishing in the Banda Sea, I had ample opportunity to familiarize myself with the sea-birds there, and soon I had seen most types of tropical birds, all of which I was to get to know as well as I knew our European sparrows and starlings.

In these waters, where there are so many islands, one is seldom more than a hundred kilometres from land, so that, ornithologically speaking, they may be regarded as coastal waters, a description well borne out by the bird life. There was a greater abundance of birds than we saw anywhere else in the open seas of the Tropics, while the species observed were mostly of coastal birds.

The commonest was the brown booby (Sula leucogaster), a small bird with warm-brown plumage except for the white posterior half of the belly. Another common bird was a white booby with black wing-tips, the red-footed booby (Sula sula). Both species were seen in large numbers, often flocking together. We saw especially many of them while fishing in the Banda Deep, when they would mainly be flying east in the morning and west in the evening. This leads me to think that we were close to their breeding grounds, and that they were passing us on their way to and from fishing grounds somewhere east of our position. We also saw here some brown-winged terns (Sterna ancetheta), which strongly resembled our conmon terns, both in size and in habits.

A few frigate-birds (Fregatta ariel) and tropic-birds came into sight 
for brief moments. As a rule, they took no notice of the ship, though occasionally the beautiful long-tailed white tropic-bird would follow us for half an hour or so. Birds differ considerably in their reactions to a ship. Some, such as the wandering albatrosses and pomarine skuas, will follow one for days, others for only a short time; some will keep well away from ships, scarcely coming within view; others again remain quite unconcerned, only moving out of the way when the ship is almost on top of them. These various reactions have nothing to do with their near or distant relationship, and two closely related species will often react quite differently.

The relative abundance of bird life in the Banda Sea is explained by the wealth of animal life in the surface water. This in turn is due to the abundance of microscopic phytoplankton, which has exceptionally good growth conditions because the outflow of many rivers brings plentiful supplies of food.

The furthest tropical outpost of Australia is Thursday Island, in the coral-filled Torres Strait. Here a series of islands forms a bridge between the Australian mainland and the island of New Guinca. Two days spent in victualling at Thursday Island provided several of us with an opportunity to make excursions ashore.

Early one morning a friendly Australian took a small party in his motorlaunch to one of the smallest of the islands in the Torres Strait. We had been told dramatic tales about all the big crocodiles we could expect to find along the mangrove shores. With luck we might even see a dugong. Though we kept a sharp look-out for them in the morning light, we saw neither crocodiles nor dugongs. But we had a good day on a small tropical bird island.

A dozen low trees and bushes on the highest point (about five metres above sea-level) formed the only "wood". Some of the trees were white and leafless from the excrement of cormorants which were nesting in them, and there was also an osprey's nest. Both the little pied cormorant (Microcarbo melanoleucos) and the osprey (Pandion haliaëtus) made off when we landed. There were neither young nor eggs in the nests.

Three species of tern flapped and screamed over our heads. Their nests on the bare rocks all contained newly laid cggs. Least abundant were the large Sterna bergii, a species common all round Australia. The other species were typical terns, the brown-winged tern (Sterna ancetheta) and a small one, rather like the little tern (Sterna albifrons), with a crescent-shaped black crown, the black-naped tern (Sterna sumatrana). Altogether, I should say there would be about 50 pairs of terns. The brown- 
winged tern, with its long neck and slow, almost skua-like wing-strokes, made several sham attacks on our heads from behind, diving so low that we felt the beat of its wings.

On our return journey from this peaceful little island we saw a few frigate-birds soaring majestically aloft between the islands, and of course we again kept a good look-out for crocodiles, though without seeing any.

On Thursday Island itself, which is only a couple of kilometres across at any part, I saw two old acquaintances from Europe, the common sandpiper (Tringa hypoleucos) and the whimbrel (Numenius phocopus). It was homely among all these foreign birds to hear the sandpiper's soft warning "Hee-dididee-ee hee-dididee-ee" and the rippling cry of the whimbrel. Although later on I was to see and hear many familiar waders of the northern hemisphere, I could never accustom myself to finding them in such strange surroundings as the mangrove swamps and mud-flats of New Guinea and the coral reefs and sandy shores of the Solomon Islands, places where simultaneously one would hear the unmelodious cries of the laughing jackass and gaudy parrots. All the northern waders which I came across in the Tropics - the turnstone (Arenaria interpres), the bar-tailed godwit (Limosa lapponica), the greenshank (Tringa nebularia), the sandpiper, and the whimbrel - I had associated with a definite Danish type of landscape at a definite season of the year, and so it was strange to see them in what were their normal winter quarters. Most of the birds were Arctic waders, probably from eastern Siberia, and at many places along the south coast of New Guinea they were the predominant birds on mud-flats and in mangrove swamps. Not all of these waders stop in the Tropics: several species go on to South Australia and New Zealand. The most southerly point at which I saw any of these northern visitors was Dunedin in South Island, New Zealand, where I observed a small flock of godwits.

Along the south coast of New Guinea and eastward towards the Solomon Islands and the Solomon Sea there were not so many sea-birds as in the Indonesian region. But when passing the Louisiade Islands, which as regards birds life are rather unknown, we saw more than at any other single place in the Tropics. Here we observed several hundred frigatebirds, several species of tern, and thousands of boobies, and for the first time I saw the common noddy (Anous stolidus), which was the commonest tern in the area. It would often be seen with brown-winged terns, a few boobies, and shearwaters (Puffinus) in large mixed flocks of up to several hundred individuals. The noddy, which is coal-black except for the white forehead, differs from other terns in fishing like gulls; instead of 
diving into the water, it catches the fish at the surface with flapping wings. The noddies form a group which is widely distributed in all the tropical and subtropical waters of the world, its range extending with that of the flying-fishes to the northern and southern subtropical cross-currents.

A few days south from New Guinea on our way to Australia we encountered the giant birds of the Southern Seas, the albatrosses, first singly and then in slowly increasing numbers as we travelled further south. At the same time we saw the first Australian gannet (Sula serrator), which bears a strong resemblance to our North Atlantic gannet (Sula bassana). In both cases they were strays or migrants from breeding-grounds much further south. They were the forerunners of the Antarctic bird world; and day by day, as their numbers increased, the typically tropical seabirds dwindled, to disappear altogether a little south of Brisbane.

On the morning we lay outside Sydney, waiting for a pilot, there were 20-25 albatrosses (Diomedea exulans and D. chlororhynchos), swimming round the ship, eating the waste that was thrown overboard. All along the east coast of Australia we were greatly surprised to see a large number of pomarine skuas (Stercorarius pomarimus), which persistently followed the ship. On some days there would be as many as 20 to 30 at a time. These, too, were Arctic birds in their winter quarters.

It was spring (November-December) when we sailed along the Australian east coast, and the sooty shearwaters (Puffinus griseus) were making their way to their breeding grounds along the coasts and on the islands of New Zealand. We would see these dark-brown sheerwaters, about the size of gulls, every day, travelling in flocks of tens of thousands. There were especially many of them off Sydney. They will have spent the southern winter roving about good feeding grounds in the northern Pacific. The routes which these large numbers of birds take to their winter quarters is unknown. In Monterey Bay, California, in April I952, we saw several hundred sooty shearwaters, as well as other southern shearwaters. In New Zealand we caught a few specimens of the same species in their nesting tunnels.

The climate of southern Australia is very similar to that of south-west Europe. There are no typically tropical birds down here, where we find the first representatives of the groups which predominate further south. Hidden away in small colonies along the southern and south-eastern coasts of Australia lives the little penguin (Eudyptula minor). It is difficult to catch sight of from the sea, both because it rarely ventures many kilometres from the coast and because, like other penguins, it swims so deep in the water. 
South of Melbourne lies the small and secluded Phillipp Island, linked to the mainland by a causeway. It has a broad sandy beach, sand-dunes overgrown with marram-grass, and pools. Breeding on the pools were numerous black swans (Cygnus atrata), and there were also some small flocks of the small sharp-tailed sandpiper (Calidris acuminata); but the most interesting birds, the shearwaters, were among the dunes, which were riddled with hundreds of their nesting tunnels. The entrances were the size of large rat-holes and the strong smell, almost of sheep, betrayed at once that the holes were inhabited by petrels. If you put your arm into these holes you would often get a sharp nip, but on plucking up courage could pull out an adult short-tailed shearwater (Puffinus teniurostris). This is a cousin of the sooty shearwater, and closely resembles it in habits and appearance.

Our excursion to Philipp Island was arranged so as to enable us to spend the night among the dunes and witness the fascinating scene in a penguin and petrel colony when the birds return to their breeding-grounds after dark.

The little penguin was found among the dunes in a colony of several hundred pairs, along with the shearwaters. The nesting tunnels of the penguins were larger in diameter than those of the shearwaters, and were shorter. At that time (December) there were large young in the nests. During the day they would be left to themselves while the parents were out catching fish for them. Two hours after dark the penguins came ashore. They caine in riding the surf in small flocks of $10-20$ birds or fewer, and walked the short distance to the dunes. Though it was pitchdark with an overcast sky and showery rain, they made straight for their nests, following well-worn tracks.

The shearwaters arrived at about the same time. Their colony was as alive with birds during the evening and night as it had been dead during the day. If you were lucky, you would catch a glimpse in the light of a pocket torch of countless birds in swift flight. Coming from the black night sky was the continuous call of arriving birds. They were answered by their mates in the nests, so that one heard duets between birds in flight and others in the ground under one's feet. When the incoming bird found its hole it vanished into it at once, and then the noise began in earnest. The ioy of reunion reached an astonishing pitch, as though they had really missed each other.

All the smaller tubinares (small petrels and shearwaters) with a few exceptions are nocturnal birds on their breeding-grounds. It is as though these birds, which outside the breeding season spend all their time on the 
open occan, are afraid of the land, only coming ashore at night when they have to for breeding. Moreover, they all inhabit self-made tunnels which in the case of some species may be up to a couple of metres long. Unfortunately they are very helpless on land, being incapable of defending themselves against their worst enemy the rat, which enters their tunnels and devours adult birds, young, and eggs. The destruction of these defenceless birds by rats is said to have been disastrous to many species of petrels. On Campbell Island, for example, we were told that they had been almost exterminated and now bred only on islets and rocks off the coasts.

There are few place in the world where sea-bird life is as rich and varied as in the waters surrounding New Zealand. The country extends from the stormy west-wind belt in the south to the calm subtropical zone in the north. This climatic zonation, together with its situation in the Pacific, has resulted in a varied bird life. In New Zealand waters one finds breeding representatives both of subtropical and sub-antarctic birds, and even migrants and stray birds from the Antarctic islands. Nowhere else did we see so many birds during the day as we did off New Zealand, both on the open sea and along the coasts. Standing on the bridge, there was always something to see. Small petrels predominated. Nearly half of the world's albatrosses and petrels breed in New Zealand and on surrounding islands. These enormous numbers of birds breed in a relatively limited area, some on capes and small islands along the coasts and some on a small number of bird islands out at sea.

North, east, and south of New Zealand are a number of scattered islands in the Pacific. Most of these are uninhabited, and a few are only large rocks. Others are rather larger, and overgrown with inaccessible woods and hills. All these islands are well known for their bird life, and some, including Campbell Island and the Kermadecs, are famous bird islands. Hundreds of thousands of sea-birds inhabit them - albatrosses, penguins, shearwaters, Cape pigeons, giant petrels, diving petrels, small petrels, great skuas, and one species of gull. On a few of the islands live land birds which are found nowhere else in the world. Most of the seabirds, especially outside the breeding season, range over a very wide sea area in the southern Pacific - no one knows how far.

Every sea region has its characteristic bird fauna like every land region, though the distribution of sea-birds, both as to species and numbers, is more even than that of land birds. Generally speaking, sea-birds are distributed in a circular zone round the earth, a fact which is particularly evident in the southern hemisphere. The reasons for this are the food potentialities, and, though the birds spend most of their time in the air, it is 


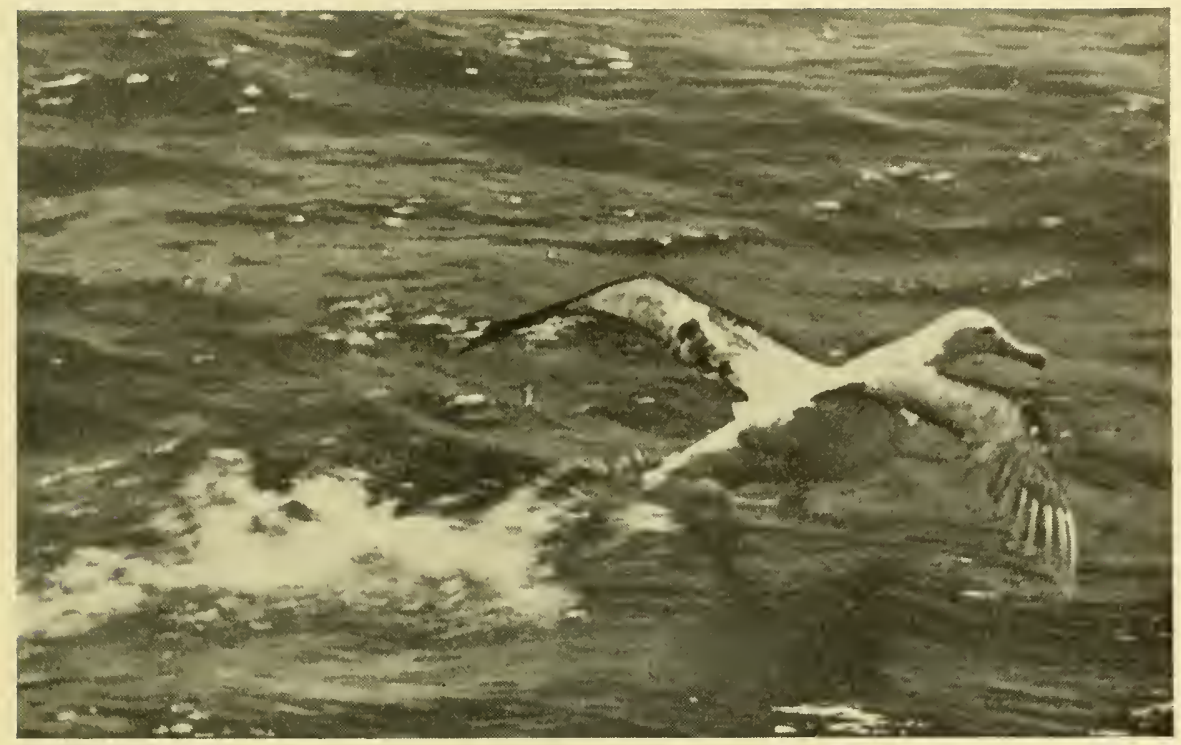

A wandering albatross (Diomedea exulans) taking off from the surface. Like an aeroplane, it starts best when head on to the wind.

the food at the surface of the sea which substains them. The amount and the nature of the food governs the numbers and the species of birds in any particular area.

The two bird sanctuaries off New Zealand of which we saw most were Campbell Island, which will be discussed in another chapter, and the Kermadecs, to which I shall return later.

One of the most interesting of all sea-birds is the wandering albatross (Diomedea exulans). In the first place, it has the biggest wing-span of any bird ( $3-3^{1 / 2}$ metres from tip to tip); and, in the second, it has the habit, more than any other bird, of following ships, thereby enabling us to observe it at close quarters. Throughout the southern hemisphere this imposing glider will be seen in the wake of ships. Its natural food is cuttlefish, but it also eats a good deal of the scraps that are thrown overboard. Its ability to glide is amazing and it can do so, its wings quite rigid, for hours on end, elegantly taking advantage of the winds thrown up from rolling waves. Albatrosses sweep acros the sea in wide circular movements and can glide in the wake of a ship whatever the direction of the wind. Now they will be hard by the ship, now right out on the horizon; and often they will ride the waves several nautical miles astern, eating the scraps. 


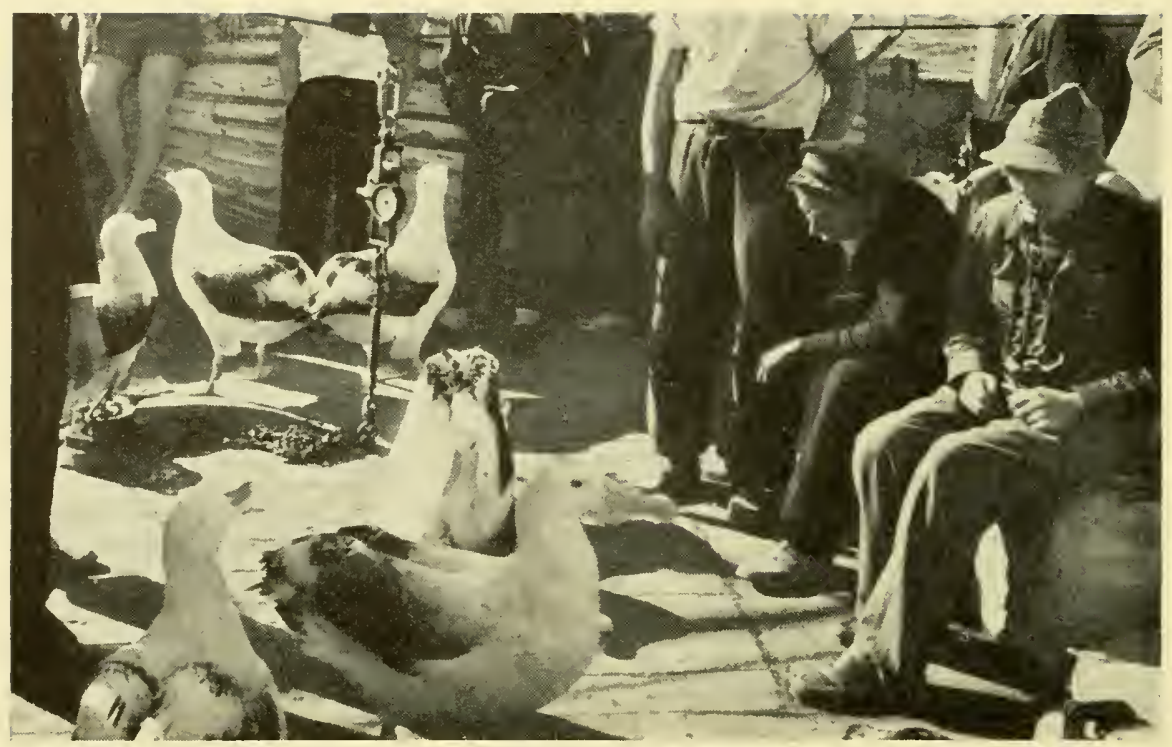

A flock of wandering albatrosses on the Galathea's quarter-deck in the Tasman Sea. They resembled heavy, clumsy geese, and were unable to take off from the deck as the 'runway' was too short.

There were exceptionally many wandering albatrosses round the Galathea while she was fishing in the Tasman Sea, along the west and southeast coasts of New Zealand. By means of a special device that was used in the old sailing days we succeeded in catching a number of them. The device consists of a triangular piece of metal with bait attached. In calm weather and when travelling at slow speed, we paid out the triangle on a long line with a piece of cork to keep it afloat. When the albatrosses went for the bait the strongly curved tips of their bills would get caught in the metal, and by holding the line tight it was possible to haul the birds aboard.

One day we had 22 of these wandering albatrosses walking about the quarterdeck, to the great amusement of the whole ship. They were unable to take off as they require a "runway" with a headwind, and there is none on a quarter-deck. It was interesting to watch their greeting display as they waddled about the deck. They would crane their necks, bill in air, clacking with their bills as they did so. Some of the birds were ringed and individually coloured on the wings, breast, or head for recognition purposes, but we never saw any of our released birds again.

Besides these large albatrosses, we saw five or six smaller species in considerably smaller numbers round New Zealand. On our way to Campbell 
Island we observed the large southern skua (Catharacta skua lönnbergi), which is a subspecies of the great skua of the North Atlantic. This skua is the worst robber and carrion-eater in the entire South Seas. The species of sea-birds on North Island, New Zealand, were different from those on South Island. In Hauraki Bay, near Auckland, the bird life was especially rich and distinctive. The Australian gannet (Sula serrator) occurred here in large colonies on islets and rocks. We went out to visit one such colony, which consisted of a few hundred pairs. As in all gannet colonies, the nests were very close together; and it was a fine sight to see these large white birds come gliding in a ceaseless stream to the colony after foraging in the sea. During our visit, which took place in February, most of the young were nearly fledged.

In Hauraki Bay we observed the characteristic grey-backed shearwater (Puffinus bulleri), with its remarkable, slow wing-stroke and the Wshaped marking on the back and wing coverts. The whereabouts of this bird's breeding grounds was unknown until about 20 years ago, when a New Zealand ornithologist found it breeding on some capes and peninsulas on the east side of North Island.

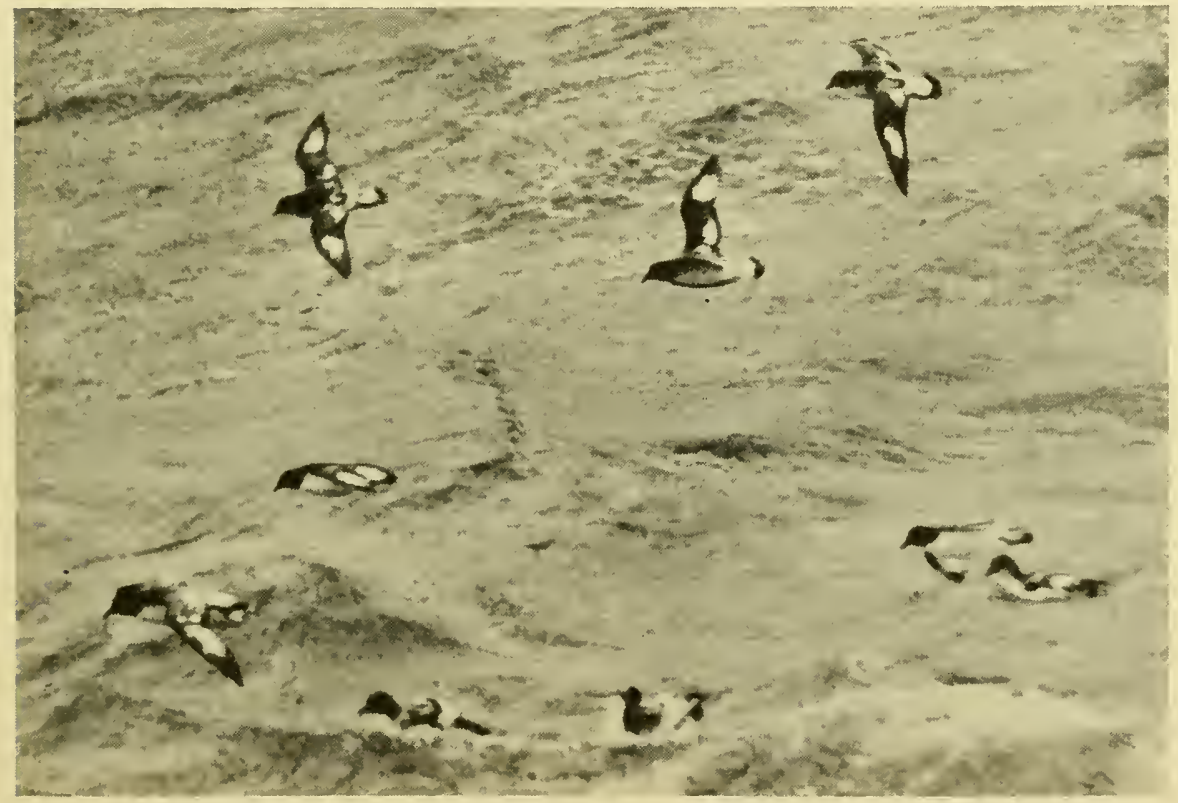

Cape pigeons (Daption capensis) by the ship's side in heavy sea near Campbell Island. This petrel, about the size of a black-headed gull (Larus ridibundus), is characteristic of the cold waters round the South Pole. It often seeks its food round whaling ships. 


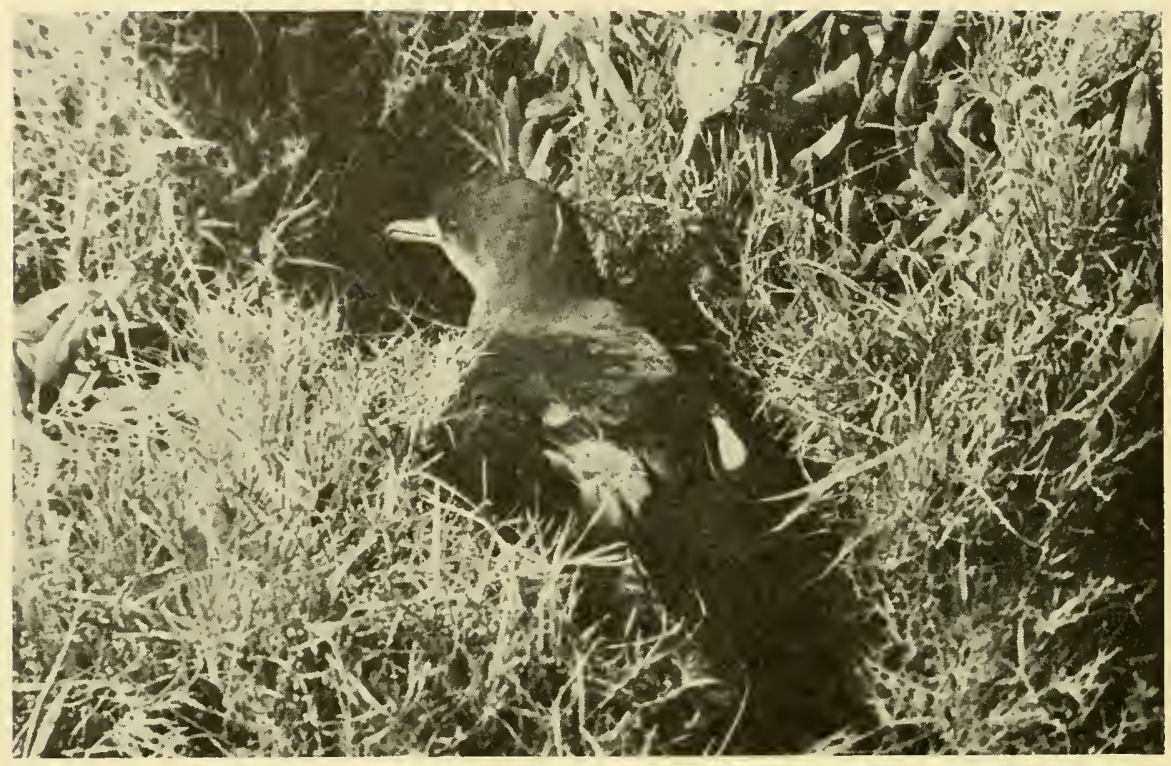

The wedge-tailed shearwater at the entrance to its nesting burrow on a shelving coast south of Sydney. The commonest species of shearwater in the tropical and subtropical parts of the Pacific, it closely resembles the sooty shearwater, which breeds off New Zealand. The photograph was taken at night by artificial light, just after the bird had come in from the sea.

Leaving New Zealand waters, we made course for Hawaii, and so gained a further opportunity of observing tropical and subtropical bird life. To my regret I was never able to go ashore on a large tropical bird island, but when we anchored for a few hours off the Kermadec Islands, north of New Zealand, I succeeded, through my binoculars, in obtaining a striking impression of the immense numbers of birds which breed on these islands. There must have been, not thousands, but hundreds of thousands of nesting birds, among which were four species of shearwaters, two species of noddies (Anous minutus and A. cinereus), the blue-faced booby (Sula dactylatra), and the red-tailed tropic-bird (Phaëthon-rubricauda). Most of the birds live on some small rocky islands a few kilometres from the main island of the group.

The regions of the trade winds are barren and almost birdless and for days on end not a single bird will be seen. Besides locally breeding seabirds, it is possible in tropical waters to observe sea-birds from the colder zones of both the northern and the southern hemisphere, either in passage or in their winter quarters. All four species of skuas, for example, may be seen migrating here, and in a few places we observed both the pomarine 
skua (Stercorarius pomarinus) and the Arctic skua (Stercorarius parasiticus).

The observations which we were able to make while fishing in the Kermadec Trench were particularly thorough, and we established, for the first time, that birds which breed in the Kermadecs range well to the south of the islands in search of food. We saw birds from these islands Icss than 150 kilometres eastward of the northern tip of South Island, New Zealand, some of them belonging to species very rarely found near that country.

On our voyage across the Pacific from Samoa to Hawaii the daily number of birds observed increased rapidly. This was particularly noticeable between the Equator and latitude $5^{\circ}$ N., though we were then many hundreds of kilometres from the nearest islands. We also saw here many more flying-fishes than in the trade-wind belts to the south and north. These facts provide clear testimony of the existence of the rich equatorial counter-current, which flows from the southern tip of the Philippines to the Gulf of Panama. Analyses of the surface water, and Professor Steemann Niclsen's measurements of production, confirmed that there is a considerable increase here in the amount of phosphates and plankton.

In the vicinity of Hawaii, in addition to the sea-birds typical of the Tropics, we saw our first black-footed albatross (Diomedea nigripes), which followed the ship in exactly the same way as its cousins of the southern hemisphere. Like the wandering albatross, it ate the scraps that were thrown overboard and would often ride the sea in small flocks.
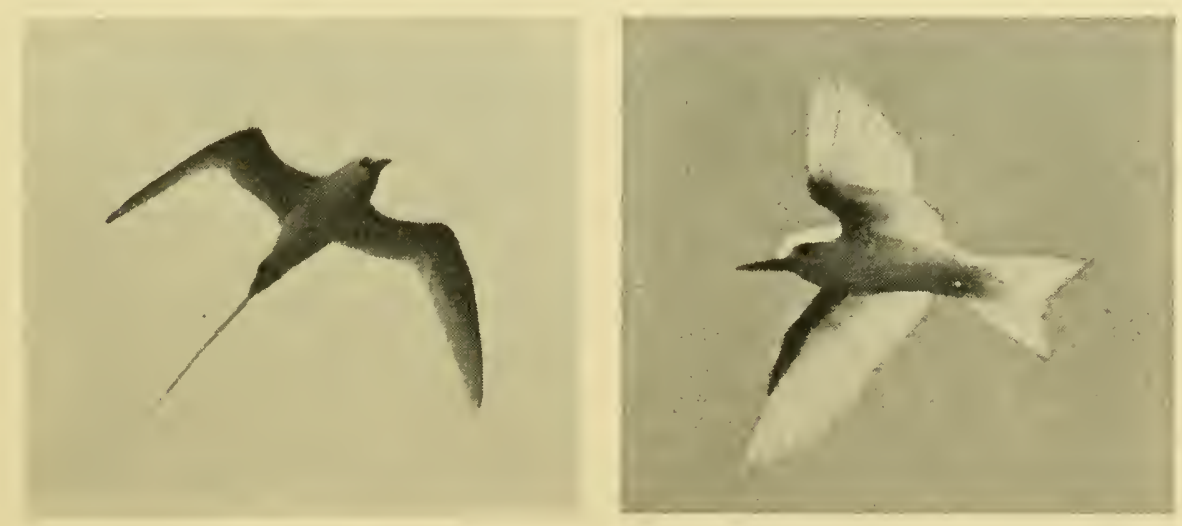

Two of the commonest and most beautiful birds of the South Seas, the red-tailed tropic-bird (Phaëton rubricaudus) and the fairy tern (Gygis alba). Both are almost pure white, and it is a fine sight to see them against the tropical blue sky. We found them especially in the central Pacific around Samoa. 
While cruising in the rich Californian current we saw several birds of passage both from the Bering Strait in the Arctic and from the Antarctic, including the tufted puffin (Fratercula cirrhata) and the horned puffin (Fratercula corniculata), both off San Francisco. A little further south, as already mentioned, we saw hundreds of sooty shearwaters (Puffinus griseus) from the Antarctic.

One dark and misty afternoon in May $195^{2}$ we anchored near the San Benito Islands off Lower California, with the intention of trying to catch one of the northern elephant seals. In this we were unsuccessful, but our lights attracted hundreds of small petrels and small Californian auks (two species), the beams being quite flecked with black.

In the Atlantic we saw very few birds, as much of our voyage was through the birdless trade-wind belts and the Sargasso Sea. Our most remarkable experience here was of the autumn migration of the Tristan great shearwater (Puffinus gravis). This bird, which breeds on Tristan da Cunha in the South Atlantic, crossed our course in the Sargasso Sea on its northward flight to winter quarters in the North Atlantic.

It will be clear from the foregoing that the great oceans are by no means birdless regions. Varying food conditions, variable temperatures and winds, and various types of breeding ground provide the basis for a varied and abundant bird life. Bird-lovers could do a great deal to improve our knowledge of sea-birds if they would study them on their sea journeys and make notes of their observations. Bird life at sea is as interesting as bird life on land, and is much less familiar. 


\title{
GEOMAGNETIC INVESTIGATIONS
}

\author{
B) Niels Arley
}

Although we have been navigating by compass for many centuries, we are still ignorant of the cause of the Earth's magnetism. We are equally ignorant of why both the sun and certain stars are magnetic, a fact which can be demonstrated by analyzing thcir emission spectra. All we know is that terrestrial magnetism is active both on the Earth's surface, at altitudes within the reach of aircraft, balloons, and rockets, and in bore holes and mine shafts, and consequently that it is not merely a local or surface phenomenon.

The magnetic force of the Earth may be described as that of a bar magnet, a dipole magnetism, as it is called; and it can be shown, as was first shown by Gauss at the beginning of the nineteenth century, that most of that which causes the magnetism of the Earth is located inside the Earth itself. But whether the interior of the Earth is uniformly magnetized like a bar magnet or whether that which induces the magnetic force is concentrated in the core we do not know, any more than we know the causes. Over a large field outside the seat of the causes, and independently of their physical nature, we find that the magnetic force varies in the manner characteristic of dipolc magnetic forces; that is to say, it diminishes in the ratio of one divided by the third power of the distance from the Earth's centre. This has recently been confirmed in the United States by measurements made up to an altitude af 120 kilometres by means of magnetometers sent up by rocket. If we wish to study the various theories about the cause of terrestrial magnetism we must make detailed and exact measurements of the magnetic force below the Earth's surface. Such measurements have been made in mine shafts, but as these are only a kilometre or two deep and are invariably surrounded by rocks which are more or less magnetic, the measurements are not very reliable. In the sea we can go down to greater depths and will encounter fewer disturbances, provided of course that we do not go too close to the bottom.

Measurements of this kind acquired special interest during the planning of the Galathea Expedition when, in 1947, Professor P. M. S. Blackett put forward an epoch-making ncw thcory which, if correct, would explain at one and the same time the magnetism of the Earth, the sun, and the stars. According to his theory, any body which rotated would become magnetic. Pending confirmation of this or one of the earlier 
theories the cause of the Earth's magnetism still remains a mystery, and for this reason it is an important scientific object to measure the change in magnetic force below the Earth's surface. If the force is of the dipole character referred to, it will increase at the rate of about one-half per thousand per kilometre the deeper we go. But according to Professor Blackett's theory the change will be slightly different, the vertical part of the magnetic force probably increasing in the same way as a dipole force, the horizontal probably diminishing by about one per thousand per kilometre. In either case it is a question of a minute effect which only highly sensitive magnetometers will be capable of registering. As already shown, it is not so important to measure the change above the Earth because, independently of the physical nature of the causes, this follows the same law. Moreover, we already have a means of studying the magnetic force of the Earth at distances several times as great as the Earth's radius in cosmic radiation. This consists of electrically charged particles (the nuclei of hydrogen and other atoms), which when approaching the Earth from outer space are deflected by the Earth's magnetism.

The measuring of magnetic force at great depths was pioneer work for which Denmark was particularly well equipped in view of her long experience in the construction of precision magnetometers, and our plans based on that experience were the result of team-work by a number of scientific institutions.

Magnetometers which register and record changes in magnetic force have existed for many years and can work to an accuracy of about a gamma, which is a hundred-thousandth of the unit of magnetic induction known as a gauss. Thus in principle the instruments needed for our work were available; what we had to do was to adapt them to our special requirements. Our main problem was to find a design which would occupy little space and which would operate both when stationary and when in motion, since it would be suspended from a cable which in turn would be suspended from a ship that might be rolling in a swell.

Our three instruments were mounted on gimbals like ships' compasses. The first measures the vertical component, $Z$, of the magnetic intensity. The principle, as indicated in the diagram, is that the bulk of $Z$ is compensated by the magnetic force from a fixed, vertical bar magnet at a point where a horizontal registering magnetic needle is pivoted on a horizontal axis. If $Z$ changes - for example, when the instrument is lowered through the sea - the registering magnetic needle will be slightly deflected from its horizontal position. This will be registered in the usual optical manner by the reflection of a ray of light from a mirror mounted 
on the necdle, and will then be recorded on a strip of film rotated by clockwork. In order to convert the deflection to the intensity of the measured magnetic force, the instrument is previously adjusted by means of known magnetic intensities.

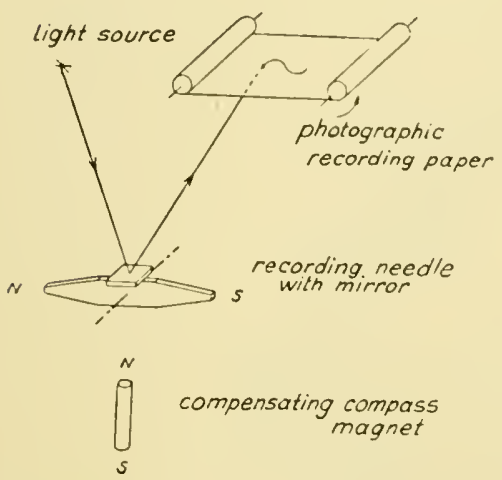

Principle of the Z-needle instrument.

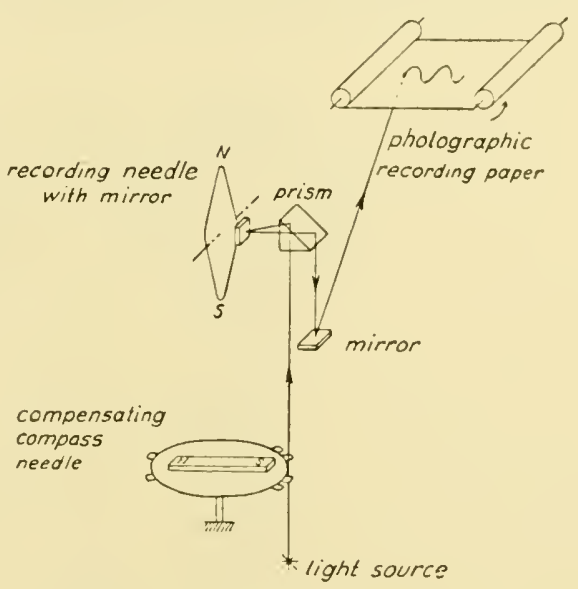

Principle of the H-needle instrument.

The two other instruments are for measuring the horizontal part, $H$, of the Earth's magnetism. The principle of one of these is shown in the diagram, and resembles that of the $\mathrm{Z}$ instrument. Most of $H$ is compensated by a horizontal magnet at a point where a vertical registering magnetic necdle is pivoted on a horizontal axis. If $H$ changes - for example, when the instrument is lowered through the sea - the vertical registering needle will be defected from the vertical in the manner described above. If the needle swung the whole time in the vertical plane of the magnetic force, the magnetic North-South direction (the magnetic meridian), it would be possible to read the intensity of $H$ on the film strip, provided that the instrument had been previously adjusted by means of known magnetic intensities. The difficulty is to ensure a recording in the meridian. For this reason the compensating magnet is pivoted so that is also functions as a compass. The whole instrument is, furthermore, slowly rotated by clockwork, the compass needle shading the ray of light when the meridian is passed, so that the position of this can be read on the strip of film.

In the other $H$ instrument, shown in the second diagram, a small coil is rapidly rotated (in our case $15-25$ times a second) round a vertical axis. The horizontal component, $H$, of the Earth's magnetism will then induce an alternating current in the coil, with a frequency $n$ equal to the 
rotation frequency of the coil ("frequency" meaning the number of rotations per second). The intensity of this faint alternating current is proportional to the product of the frequency $n$ and $H$. Here again, however, it is not $H$ itself which we measure but $H$ minus the compensating force

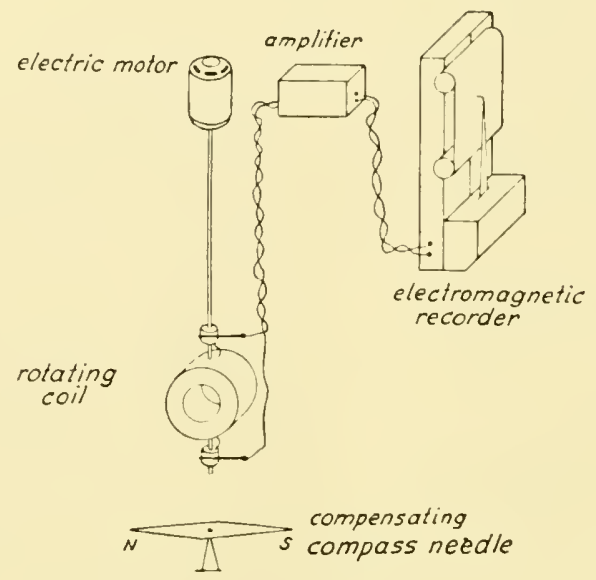

Principle of the $\mathrm{H}$-coil instrument.

from a suitably mounted compass needle, this being essential in order to obtain a sufficient degree of accuracy. If this faint current is then amplified by a special amplifier, the current can be recorded as in a barograph. If the instrument is previously adjusted by means of known magnetic intensities, we shall be able to read the intensity of $H$ on the graph. The essential point of this instrument is that it is possible to design the amplifier so that the given amplification is proportional to the current frequency $n$, equal to the rotation frequency of the coil. In this way we ensure that the registered current is dependent only on the magnetic force $H$ which is to be measured, and not on the rotation frequency $n$. This is essential, as $n$ cannot be kept constant with the accuracy required in measurements of this kind.

We knew that the problem of the instruments could be solved in principle, and that it was largely a matter of experimental physics whether the measurements could be made sufficiently accurate for the small variations of, probably, $1 / 2$ - I per thousand per kilometres of depth. But we encountered a serious difficulty when we came to consider the containers, as the instruments could function only in ordinary air and under normal pressure. The containers, which for structural reasons are spherical, must satisfy certain conditions. In the first place they must be made from non- 
magnetic material, and in the second from material strong enough to withstand the enormous pressurcs to which they would be subjected. For our spherical containers the maximum stresses, corresponding to a water depth of 10,000 metres and thus a pressure of 1,000 atmospheres, are
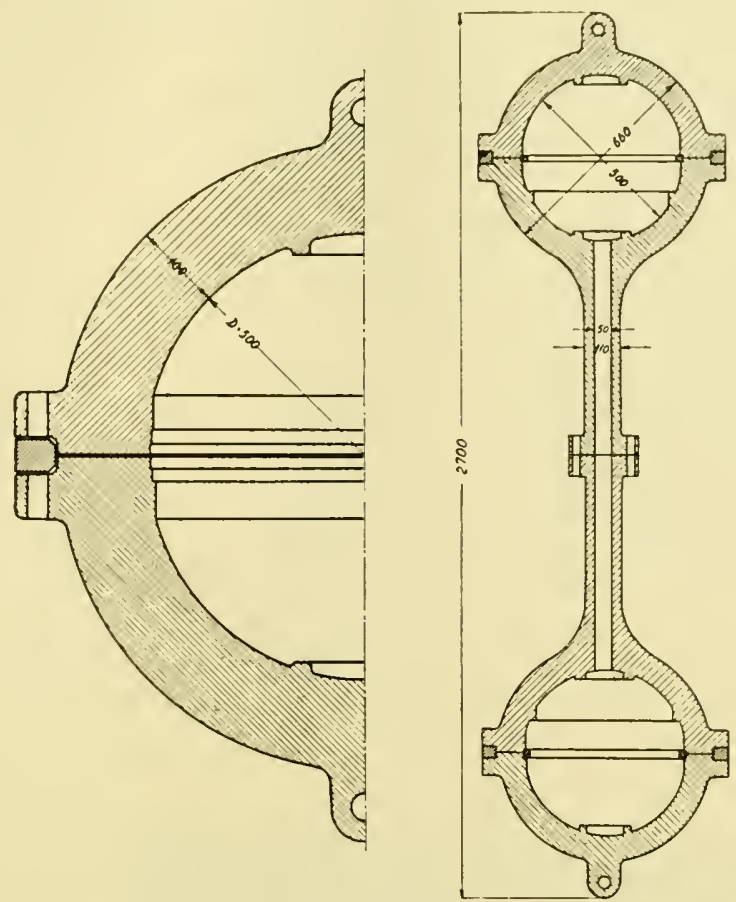

Workshop drawing of single and double sphere.

about 25 kilograms per square millimetre. In other words, the limits of elastic proportionality of the material (the point at which the pressure of the water and the compression of the material cease to be proportional) must be of at least that order. Thirdly, the spheres must be formed from two hemispheres which may be easily opened and closed and which will be fully watertight.

We tested a number of materials for these properties with little success, as the strength of most known alloys depends on the very fact that they contain a small quantity of iron. Stainless steel seemed to be the most suitable material, being only slightly magnetic; but unfortunately its magnetism increases with increasing pressure, and so we were afraid to use it. A further objection was that it would hardly have been strong enough; the total weight of instruments and container had to be restricted 
to I,80o kilograms - the maximum tensile strength of our I 2-kilometre cable, allowing a reasonable safety factor of about three - with the result that the thickness of the material would have had to be kept down to a dangerously low minimum.

This was the position in April I 950, and it looked as though we should either have to abandon our project or be satisfied with containers which would withstand the pressure of only a couple of thousand metres. At this stage a Danish firm sprang to our rescue and succeeded, at very short notice, in producing an entirely new bronze alloy with all the desired qualities. Of course we named it Galathea Bronze.

The alloy having been produced, the next problem was to get the spheres made in the few months which remained before the expedition's departure. Another Danish firm undertook the work and a third supplied a specially constructed bronze cable to connect the spheres with the longsteel wire, so as to prevent the magnetism of this from interfering with the instruments.

The drawings on page 24 I show the single sphere, built to hold either a $Z$-needle or an $H$-needle magnetometer, and the double sphere which in the lower space contains the rotating $H$ coil and in the upper the motor (which via an axle through the tube, drives the coil), the amplifier, the recorder, and the necessary accumulators and batteries. The figures on pages $242-45$ show the spheres in action at various stages.

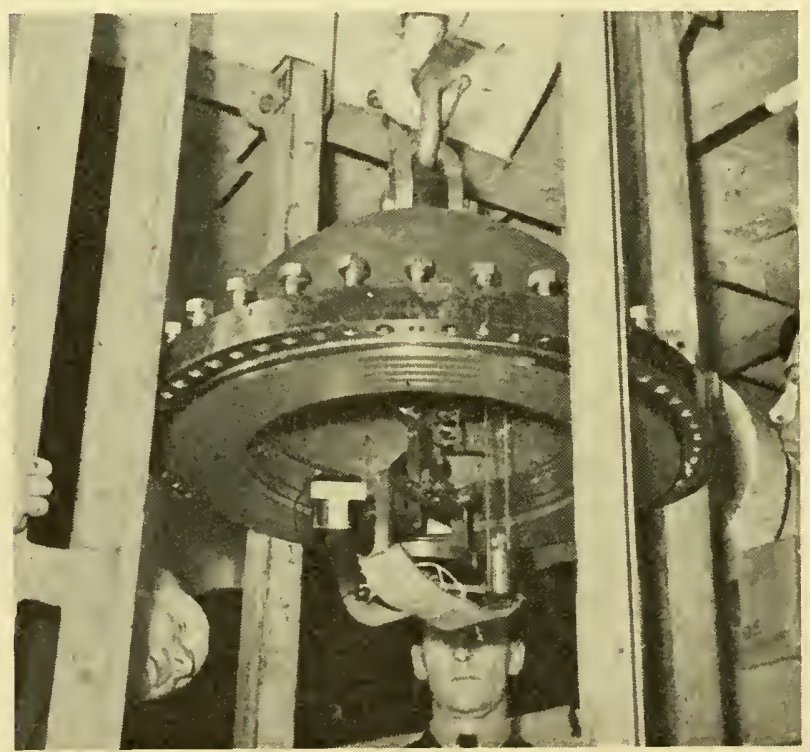

$H$-needle instrument placed in sphere. 
The upper half of the double sphere with the $H$-coil instrument in position. Left, the amplifier; centre, the accumulators which supply the current to the motor located below them; and right, the recorder.

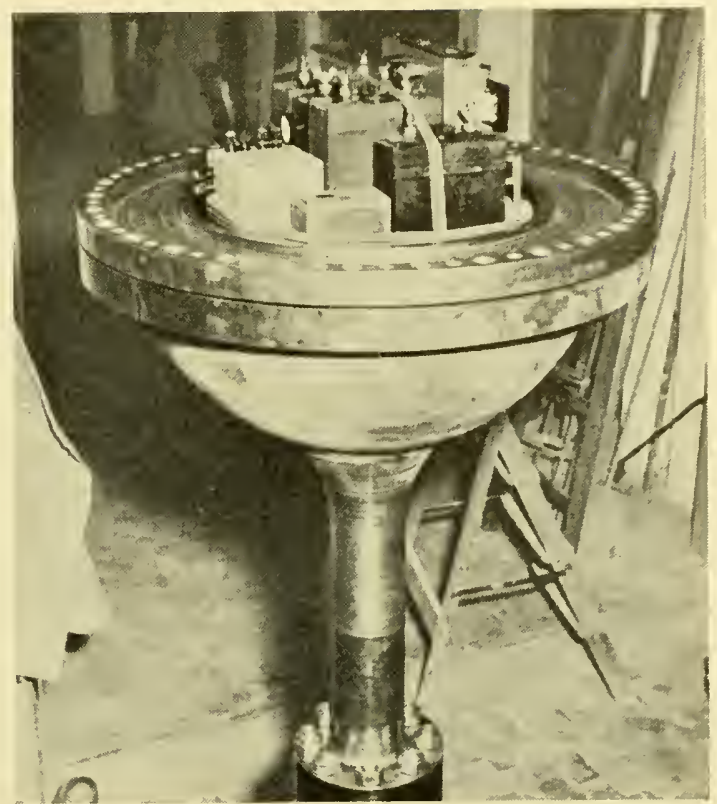

Not unnaturally in a pioneer venture of this kind, and one involving a continual race against time, various alterations had to be made in the light of our experience as we went on. The spinning of the wire cable caused our spheres to rotate at a speed which affected the accuracy of the instruments. We solved this problem by means of a ball-and-socket joint and a damping device, both specially constructed. After the preliminary surveys off Africa the instruments were returned to Copenhagen and tested in a specially designed apparatus which reproduced the motions in the spheres. These were measured on the ship by means of a special motion-measuring instrument sent out by air, the registered motions being regularly radioed to the laboratory in Copenhagen. As a result of this interesting cooperation in experimental physics between two groups of workers at opposite ends of the Earth the instruments were re-designed, and after a final check in Professor M. L. Oliphant's laboratory at the University of Canberra were ready for operations in the Pacific.

Meanwhile, the elasticity and watertightness of the spheres were tested at extreme depths down to I0,06o metres off the Philippines. Unfortunately, it is technically impossible to produce artificial pressure chambers which can exert on objects 2.7 metres high an outward pressure of 1,000 atmospheres like that in these deep waters, and so we were obliged to make the sea our laboratory. The double sphere came up fully watertight 


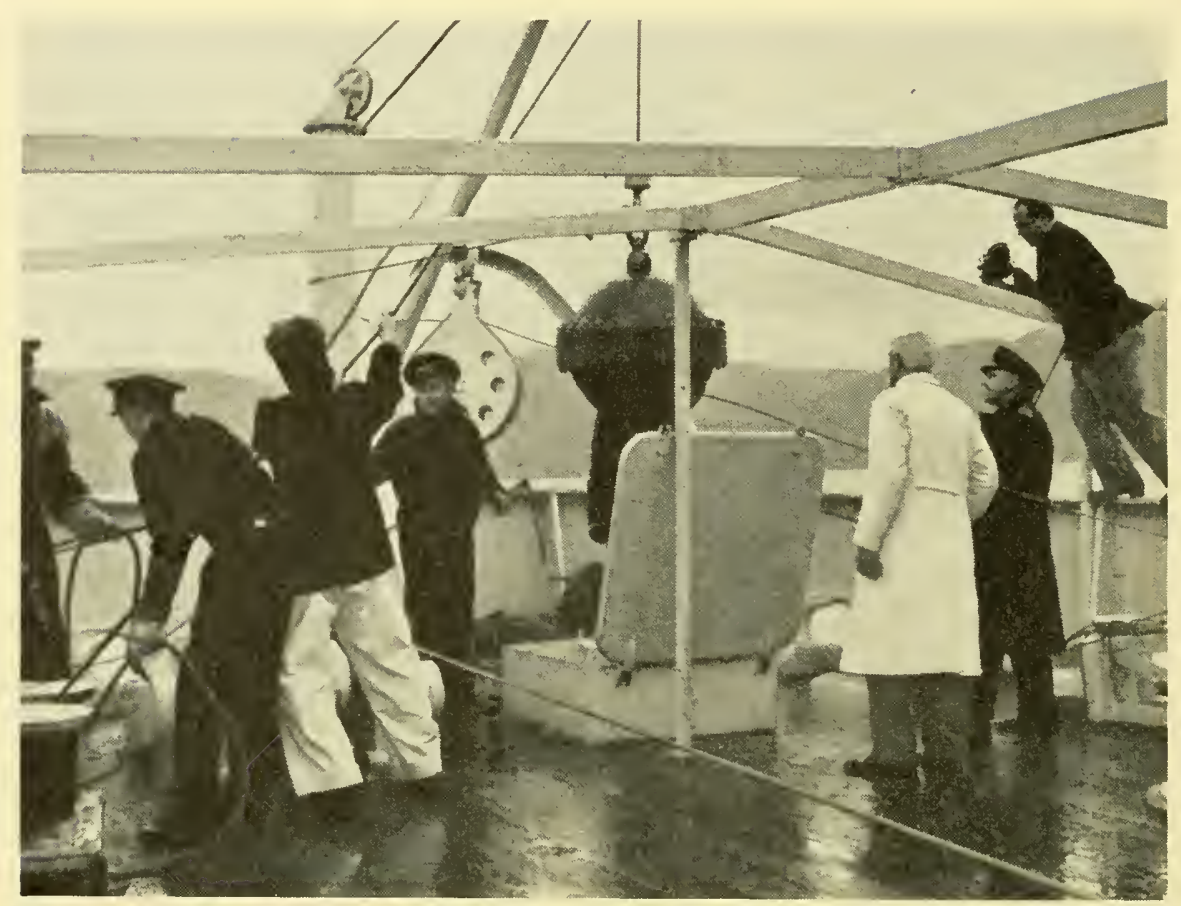

The single sphere coming up the shaft on the way out.

from all depths, including 7,0oo metres, the lowest depth at which we were able to test it, but the single sphere contained a couple of litres of sea water. As this sphere had been cast first and the casting of a new alloy is a difficult process, there was nothing remarkable in the inconsistancy, which was thought to be due to casting stresses. We made various grindings of the single sphere on instructions sent out from the factory by radio, and in due course succecded in equalizing the stresses so far that only a couple of cubic centimetres of water seeped in even at extreme depths. The instruments could easily be protected against this.

The final magnetic work was carried out in the Kermadec-Tonga Trench and in the Gulf of Panama. After various preliminary surveys to test the adjusting and handling of the instruments at sea, the effect of the ship's manoeuvres on the measuring, the influence of bottom conditions, and so forth, measurements were eventually made, on May Io-1 1, I952, at a depth of between 3,00o and 4,00o metres and with the desired accuracy of about Io gammas. Unfortunately, owing to lack of time, they were made at only one station and the measurements were disturbed by the proximity of the bottom. Nevertheless, by demonstrating that it is techni- 
cally possible to measure the magnetic force of the Earth sufficiently accurately down to at least 3,000-4,00o metres, and probably deeper, we had achieved the first geomagnetic objective of the expedition, in spite of many difficulties and the race against time. We now had the experience and the technical basis for attempting the second objective, which was the systematic three-dimensional survering of terrestrial magnetism in the sea.

As stated earlier, the expedition had to be cut short owing to rapidly mounting costs. We were thus prevented from following up our initial success on this occasion. However, on the basis of the experiments described and the experience thereby gained it is our hope that before long a new deep-sea expedition, either from Scandinavia or from some other country, will continue the work from the point at which we had to leave off.

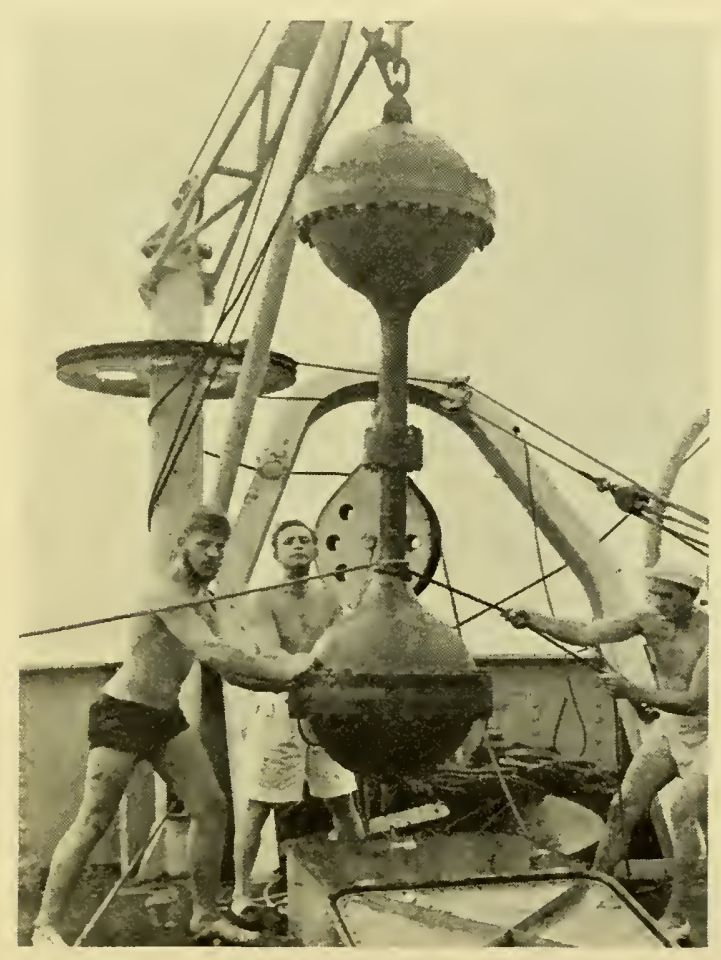

The double sphere on the way down the shaft after being out at $I, 800$ metres. 


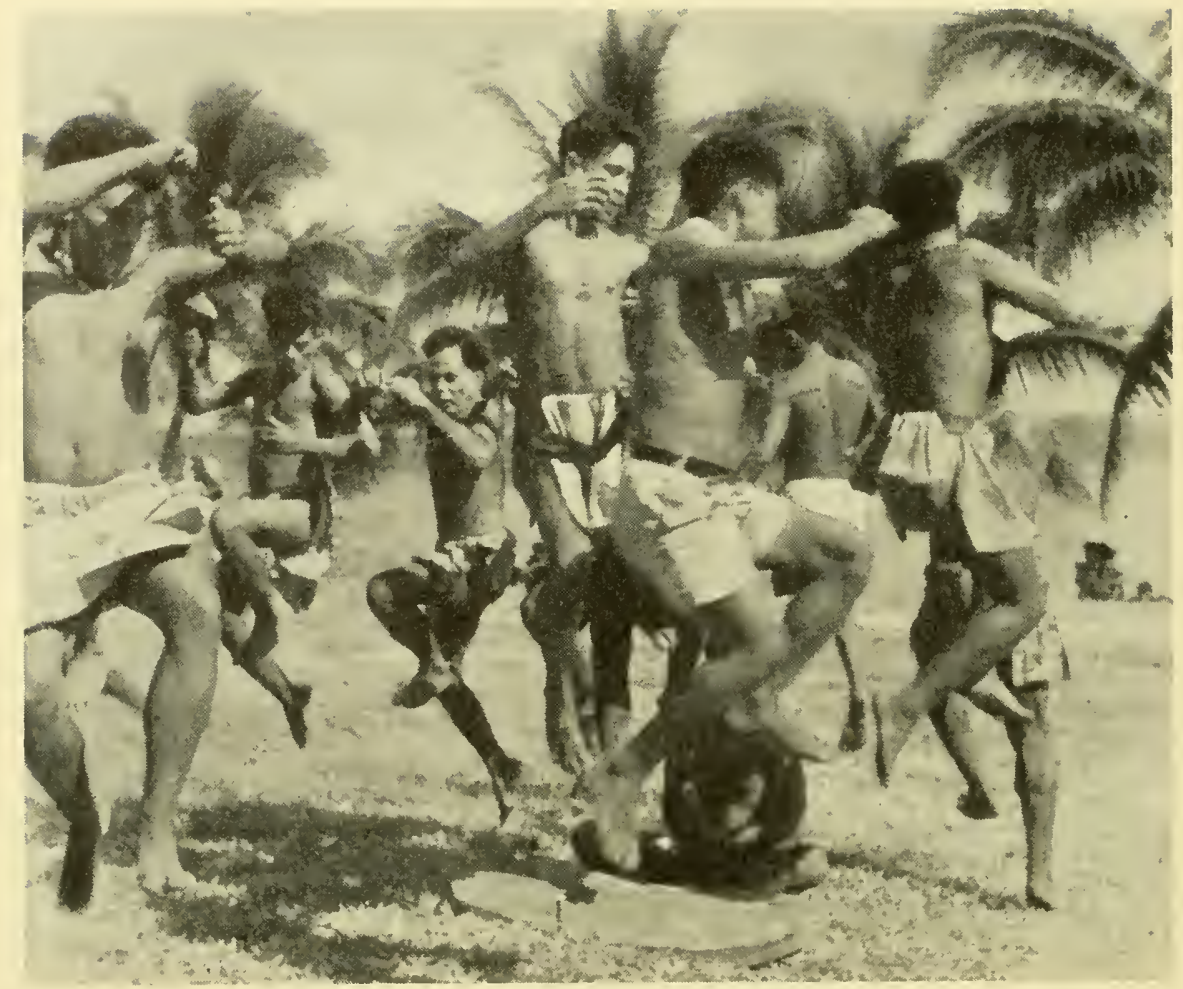

\section{ETHNOLOGIGAL STUDIES}

\section{By Kaj Birket-Smith}

Deep-sea expeditions and ethnological work are usually rather incompatible; but as one of the deepest oceanic regions is in the Pacific to the south of the Solomon Islands and the Galathea planned to explore it, I realized that here was a unique opportunity to visit Rennell Island, one of the most interesting and least known islands in these parts. The Carlsberg Foundation and the Wenner-Gren Foundation for Anthropological Research, New York, generously provided the funds; and so, at noon on June 19, 195I, I found myself standing on the ship's deck, watching the

The dance ends with the men making a tremendous jump on to the wooden board, the only musical instrument of the Rennellese. 
iridescent pagodas of Bangkok fade into the mist above the muddy waters of the Menam river.

Rennell Island was the destination, but as luck would have it work began in the Philippines. At Manila I met, to our mutual surprise, an old school friend and fellow-student, who turned out to be Professor of Zoology in the University of the Philippines; and - an even more incredible piece of luck - his wife belonged by birth to the Bontoc Igorot, one of the heathen and almost independent tribes of head hunters in northern Luzon. Her relatives still lived high up there in the remote mountains. The result was an unforgettable week in one of the small Igorot villages. No one betrayed any designs on our heads: on the contrary, we were warmly welcomed and were able not only to obtain considerable collections for the National Museum in Copenhagen, but also to study the Igorots' highly developed methods of rice cultivation and attend their harvest festival, never previously described. My companion, Mr. Peter Rasmussen, was able to take a unique film of this festival and of the natives' daily life.

Java, Bali, through Torres Strait to New Guinea - fleeting visits calculated to tempt an ethnologist to make a longer stay - and then, finally, the Solomon Islands and Rennell. The island rises from the crystalclear tropical ocean like an almost perpendicular, green-clad wall. Mau-

The Igorot in the mountains of the Philippines have retained their picturesque appearance.

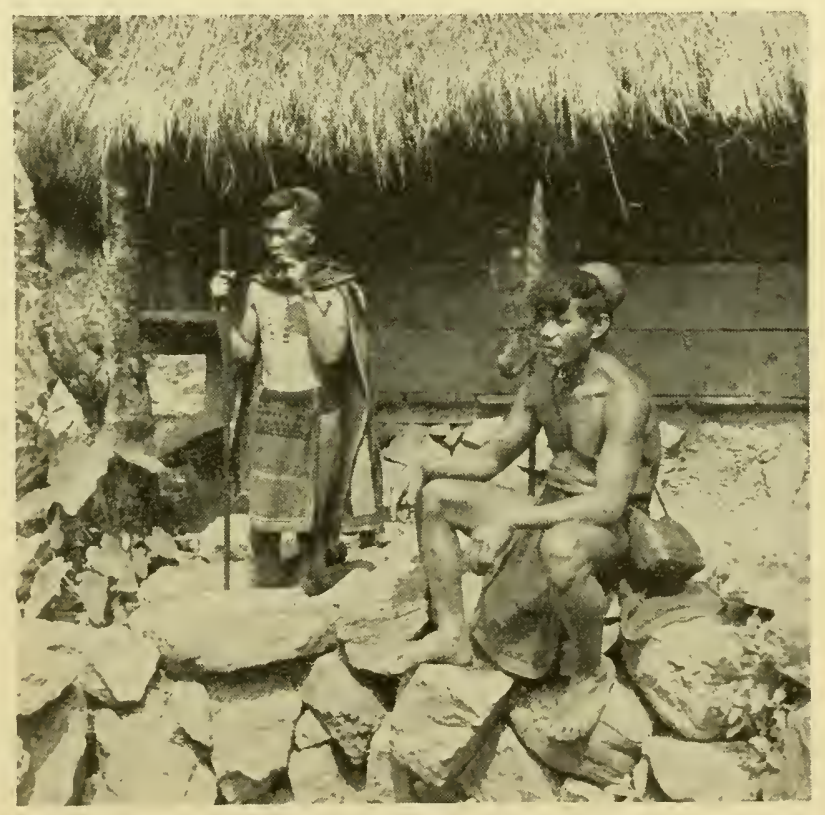




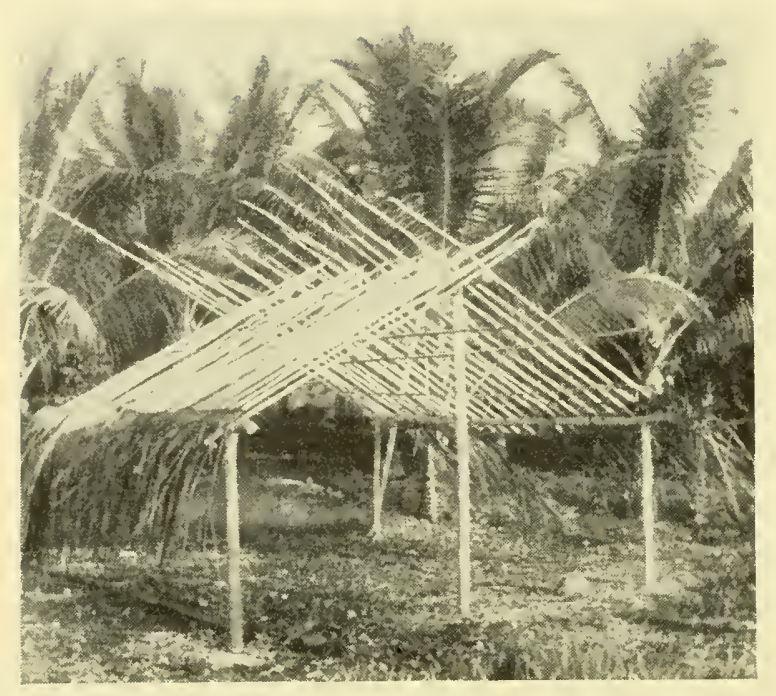

This half-finished house show's its simple construction. The roof is covered with palm leaves and such walls as there are will consist only of mats. Rennell Island.

tiki-tiki fished it up from the bottom of the sea, and his father, Atanggangga, who could give all things life, covered it with woods. But then father and son quarrelled, and in his anger Mau-tiki-tiki turned the island upside down so that his father was drowned. It is because the island lies bottom side up that it is so rough and unapproachable. The inaccessibility, the remoteness, and the natural poverty are the reasons why Rennell Island has been left in undisturbed peace for so long.

What is it that makes this small island so attractive to ethnologists? Generally speaking, the Solonon Islands are inhabited by dark-skinned Melanesians, who used to have the reputation of being some of the most savage tribes in the Pacific, many of them head hunters and cannibals. North of the Solomon Islands proper, however, is a strip of small islands - Mortlock, Tasman, Lord Howe, Sikaiana, etc. — where the inhabitants are fair-skinned Polynesians, and this applies to Rennell and its small neighbour Bellona Island. This fact has given rise to a good deal of speculation. The islands were once thought to have been resting places during the migration of the Polynesians from their original home in the Philippines to the eastern Pacific; but the view generally held now is that their population is more likely to have originated as a backwash from the east.

Unfortunately, the physical features of the Rennellese provide us with no solution to this problem. Although I did not have an opportunity of making anthropometric observations, the combination of fair skin, facial 
features almost European, and curly or bushy hair suggests rather a physical kinship with the Micronesians, which would agree with the facts on Lord Howe, for instance. Yet their language and culture both have definite Polynesian characteristics. There is a tradition which may prove of importance to the solution of this problem. It says that when the ancestors of the Rennellese, led by the chief Kaitu'u, arrived at their present home from Ubea (possibly Uvea, or Wallis Island, between Samoa and Fiji) they found there an earlier population to whom they gave the name Hiti. They claim, to be sure, to have exterminated the Hiti, but this should no doubt be taken with a certain amount of reserve.

For more than a hundred years after its discovery in 1794 Rennell Island was left to itself, and two missionaries who tried to settle there about I9I I were quickly put to death. When connections with the island were established in earnest, about 25 years ago, it might have been thought that scientists would have flocked to it. In fact, only two ethnologists had visited it before me: the Australian H. Ian Hogbin, who spent two months there in 1927 but owing to bad luck got virtually nothing out of his visit; and the American Gordon Macgregor, who in a fortnight collected much information about the religion and sacrificial rites.

At that time the Rennellese were still in the Stone Age - or rather, a shell age, for the coral limestone of which the island consists is useless for tool-making and the only available stones were the ones found among the roots of driftwood or, exceptionally, in the limestone. The natives were therefore obliged to use the shells of the giant clam for adzes

Drinking water is scarce on Rennell Island, and natives must often make do with the brackish water which trickles out of coastal cliffs.

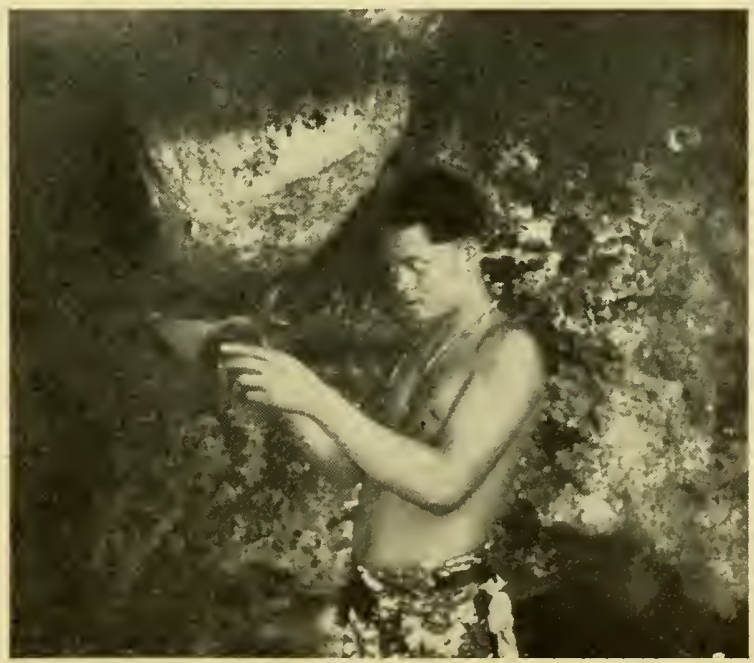




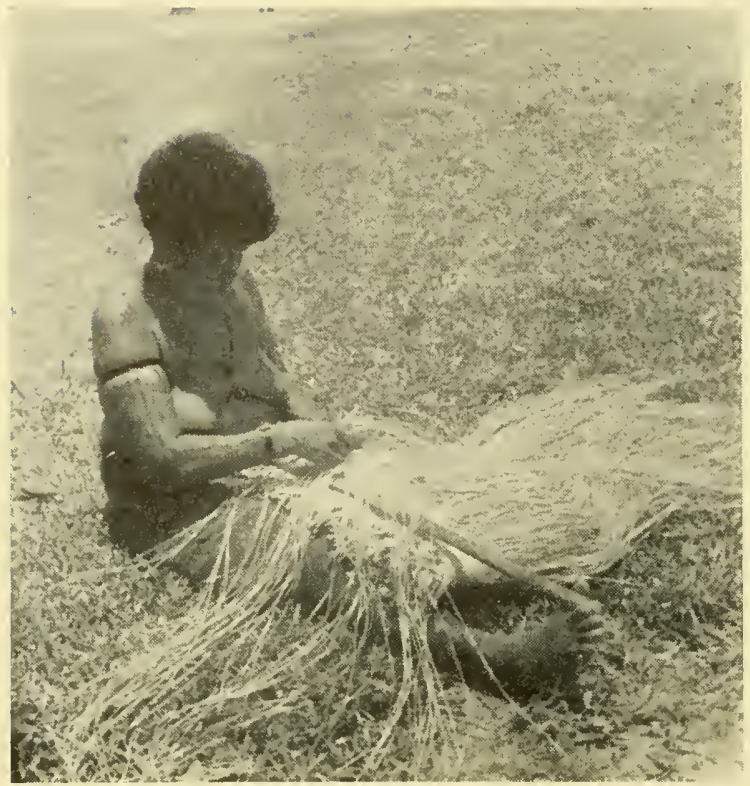

Mat-weaving is one of the daily occupations of Rennellese women.

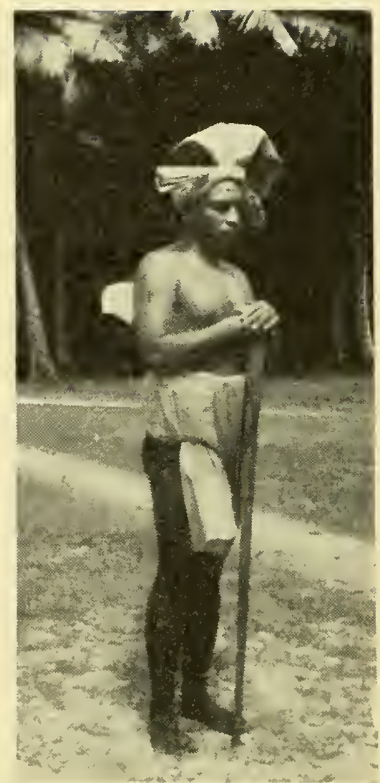

$A$ chief in old-fashioned bast dress.

and other tools. Razors were made from sharks' teeth. However, these primitive implements have now given way to articles made from iron; while the simple temples where the chiefs used to offer their prayers and sacrifice to Te Hainggi Atua, Te Hua-i-Nggavenga, and other gods are falling into decay in the forest, as every Sunday nowadays the islanders attend the chapels of the Presbyterian and Seventh Day Adventist missions. But no white man, whether he be missionary, trader, or civil servant, is allowed to settle on the island and no one may go ashore without the permission of the British authorities at Honiara, after previous medical examination. I am unable to say how deeply the Rennellese believe in the new religion; but I am certain that if the small vessels which call at the island once every month or two months for copra for some reason should fail to come, they would easily revert to their original mode of life, so alive are all their old traditions.

We stayed at the village of Lavanggu, a new development as a result of the anchorage at Kanggava Bay. In the old days the place was taboo, since it was here that the souls of the dead foregathered before leaving for the realm of death, which was thought to lie on two distant islands out in the ocean. Here there is a narrow strip of sandy shore a few hundred 
metres long and some 50 metres broad, with the cliff rising steeply behind it. The houses are scattered about in the green shade of coconut palms; simple, rectangular buildings, mostly raised on low piles, with roofs of screw-pine or coconut leaves, and walls - where such exist - of the same material. Simple though they are, these houses constitute an architectural advance on the original dwellings, which neither had walls nor were raised above ground level. Here and there one still sees primitive huts consisting of two rows of palm leaves stuck obliquely into the ground so as to meet at the top, and even temporary shelters made from two or three palm leaves, or perhaps only one. In the rainy season, the inhabitants must be miserably cold on their simple beds, which consist of no more than a thin mat and a wooden neck rest.

We quickly accustomed ourselves to life at Lavanggu. Time passed slowly and almost imperceptibly. The natives rise at dawn, though otherwise we did not get an impression of great diligence. In the morning, some of the women climbered the cliff side to fetch yam and taro from the plantations, which are often a long way from the houses, returning with their haul in coarscly woven baskets of coconut leaves at noon. Drinking water is a great problem. Failing rain water one must make do with the brackish water which oozes out of the cliff side; but fortunately there is a good substitute in the cool milk of coconuts. In the village they busied themselves with their various jobs: a woman sat weaving mats, a man shaping a new paddle or making a fishing net. The greatest activity was displayed by the numbers of hens and ducks which ran about among the houses. Incidentally, they are a new addition to the culture, the only domestic animal

Planting yam. Yams are climb. ing plants, and so stakes are put in for them to grow up. Rennell Island.

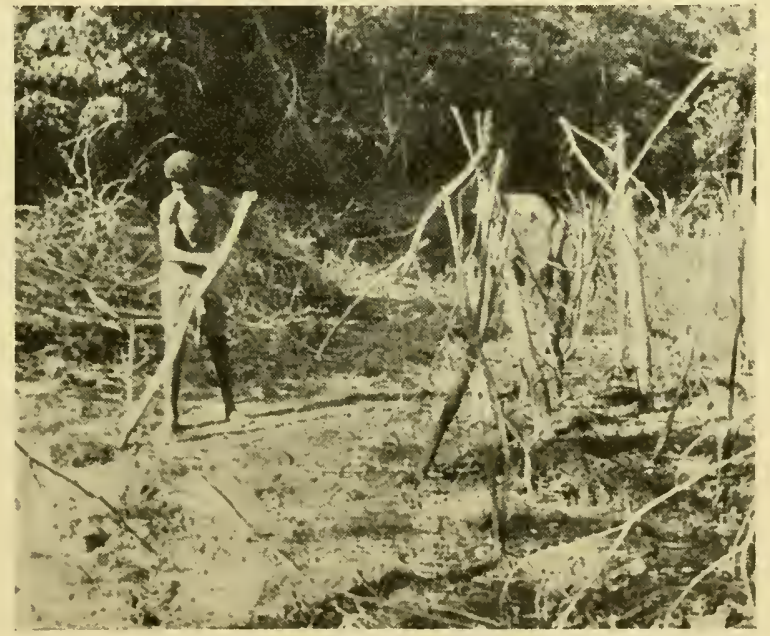


previously being the dog. Darkness falls early in the Tropics, and unless you are so up-to-date as to possess a paraffin lamp you go to bed early. But on dark moonless nights the men put to sea in their canoes and catch flying-fish in long pole nets by torchlight.

Gradually we made progress in collecting both articles for the museum and information about the past. Originally the island was divided into six areas each with its own chief, the chief of Te Nggano furthest east being paramount. Both he and and his colleagues were believed to descend from the gods, for which reason they and their families were holy. To this day they are loth to see their children play with other children. On certain occasions the gods would take up their abode in their heads, as shown by their falling into a trance; and they had the right to proclaim a thing taboo and appropriate anything they liked. This also had its practical advantages, as food which threatened to become scarce after great feasting could be temporarily declared taboo. The symbol of the chief's office was a large, heavy wooden staff, sacred like himself. No images were made of the gods, but special paddles and long, fantastically carved spears were regarded as symbols of divinity.

The districts would often be at war together, when the weapons used would be various kinds of clubs, javelins, and - rare things among Polynesians - bows and arrows. Javelins and arrows were tipped with human bone, and so the victors would endeavour to secure the leg and arm bones of their fallen enenies. They might even carry off a head, which they would then set up on a pole at the assembly place, or Nggoto Manggae, during the dance of victory. But there no real head hunting, nor was there any cannibalism.

Most of the men and women, with the exception of the very youngest, are magnificently tattooed on chest, arms, and legs. The operation, beginning at puberty and extending over several years, is performed with a toothed instrument roughly the shape of a miniature adze, and the patterns depend on the bearer's age, sex, and rank. 'The richest patterns are reserved for chiefs and their families, and may not be executed except in association with a special ceremony. Armlets of delicately woven straw are worn, as well as ear-rings made from tortoise-shell and other materials; but the costliest ornament is a necklace of flying-fox teeth, which has almost the character of money. The dress is as simple as the adornment. Women wear a loin cloth. The men's dress used to consist of a long strip of tapa drawn between the legs and wound tightly round the waist. The material was produced by beating the bast layer of two species of wild figs with a coarsely grooved wooden mallet, and was dyed a vivid yellow 

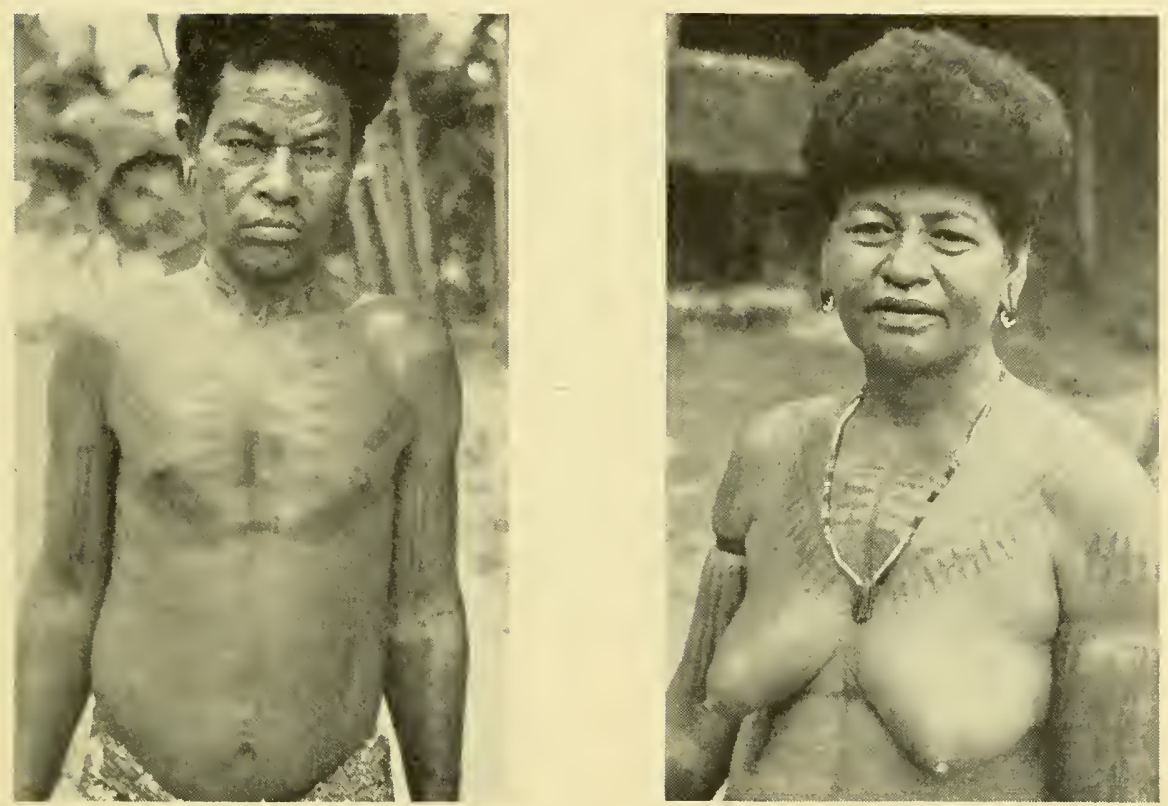

Blue-black tattoo patterns in the form of sea-birds, fishes, etc. stand out clearly against the fair skin of the Rennellese.

by dipping and rubbing in turmeric juice. The chiefs also wore a headdress of the same material, a plaited fan stuck in behind the breech cloth completing the sparing attire.

'There are very few real villages on Rennell, the whole population having originally lived in small, scattered groups of houses. It is only rarely that they are situated near the unapproachable coast, and indeed the native connection with the sea is astonishingly slight by Polynesian standards. The craft used both off-shore and on the lake are rather poor outrigger canoes hollowed out from large tree-trunks and equipped on the lake but not, surprisingly, on the sea - with mat sails. Small wonder that fishing is of minor importance, though some sharks, flyingfishes, eels, and the brilliantly coloured fishes which dart in and out among the branches of the coral reef are caught both with nets and with various kinds of hook. The island's paucity of higher fauna affords little scope for hunting, which is largely restricted to catching Pacific doves in large nets by means of decoy birds, a privilege of the chiefs. The teal which abound by the lake are considered unclean. Consequently, agriculture is the principal means of livelihood.

And yet the soil is very poor - or rather, the only cultivable land con- 
sists of small pockets of red soil scattered about among the hard rock. Agriculture in such places is carried on by extremely primitive means, since, as there are neither springs nor water-courses, and rain-water is immediately absorbed by the coral limestone, there are no facilities for irrigation, such as there are in many other parts of Polynesia. First, the men clear the forest. If the clearing is being made on a slope, the lowermost trees are cut only half through, so that they fall under the weight of trees higher up. After the felled trees have been allowed to dry for two or three months, the vegetation is burnt, the ash being left. The soil is then worked with digging ticks and planted immediately, beforc the weeds have time to grow. The plants grown are the ones found more or less anywhere in the tropical Pacific - two species of yam, taro, sweet potatoes, and the like. Screw-pines are also cultivated, as well as bread-fruit and bananas, and there are small plantations of coconut palms and papaya. But the tuberous plants seem to be by far the most important food plants, with the possible exception of the coconut palm.

A man can acquire land by inheritance but also by clearing. The great problem, however, is that nearly all suitable land is already cultivated, and the population is increasing slowly. About I, ooo persons live on the island at the moment. A few years ago it was proposed to transfer the whole population to another island and the British authorities had already purchased sufficient land; but when it came to the point the Rennellese were reluctant to leave their ancestral home. During our stay there the island was visited by the Resident Commissioner, who summoned a meeting at Lavanggu. More than roo men, including all the chiefs, attended it, sitting in the shade of a small coconut grove. It was by no means easy to get their honest opinion, but in the end it was decided to make a fresh attempt at transfer. The Commissioner undertook to try to find a place where about 50 families would be able to live for two years and then change about with others. In this way the connection with Rennell would not be broken altogether.

Not that anxiety about the future is much in evidence. The Polynesians are cheerful people who love singing and dancing. The only musical instrument known on Rennell is as simple as could be: a large crescent-shaped wooden board, the edge of which is beaten with a couple of short sticks. I remember an evening at Te Avamanggo, a small collection of houses in the interior. Dr. Wolff and our camera man, Mr. M. Hoyer, sat outside our house singing together with some young men and women, and the spirits of the party gradually mounted. All at once, the men ranged themselves in a row, each holding a couple of long poles, which they 
Outrigger boat off the wooded coast of Rennell Island.

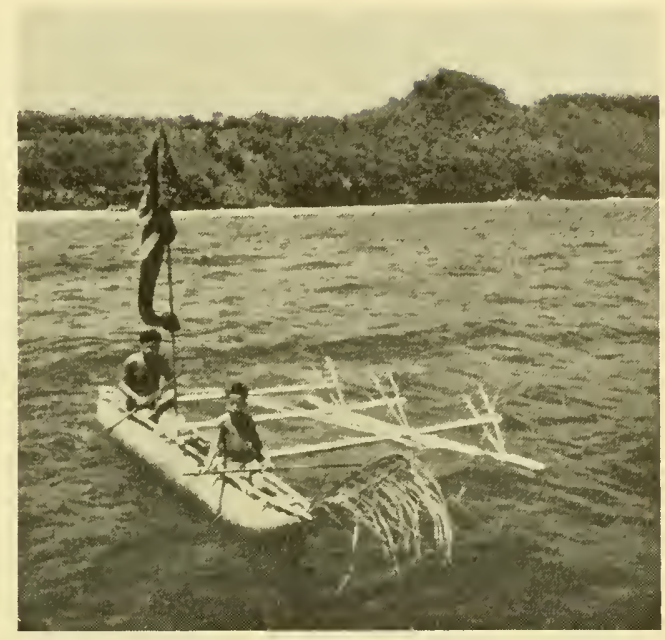

swung up and down as, with long bounds and rhythmical motions of their arms and bodies, they advanced singing. It was Te Ngonggole, the song of the flying-foxes. Dance followed dance. One of the most eager members of the party was an elderly man who persistently corrected the younger people when they went wrong. Next came Te Hauhau Kongoa, the "breech-cloth dance", a long, serpentine dance which moves rhythmically in and out. Wilder and wilder grew the motions, and in long jumps the choir wound itself round the "orchestra". Finally the women were roused, treading a slow and stately ring dance as the men gradually withdrew. Drifting clouds veiled the moon; from the fringe of the forest a bat swept noiselessly over the grass-clad clearing. On that evening we experienced all the South Sea magic of Pierre Loti and Robert Louis Stevenson!

What was the result of our month's stay? First, a new piece in the great mosaic which one day will form a coherent picture showing the long history of man. To understand what this means it is necessary to cast a glance at the Polynesian past. In spite of all the fantastic claims to the contrary, scarcely any scientist doubts that they once migrated from the Indian archipelago. Race, language, and culture all point that way. Once settled on the Pacific islands, however, they were subject to an evolution which has had a varied effect on the separate island groups. To the east, Tahiti became a sort of cultural centre, its influence traceable over large areas; the western groups, chiefly Samoa and Tonga, were influenced by Melanesian Fiji.

The most conspicuous feature in the culture of Rennell Island is its relative poverty. It is generally true that the coral islands of the Pacific 
have a culture lower than the volcanic islands, for the simple reason that they have far fewer natural resources. But in the case of Rennell this cannot be the whole story. Here much of that which in western Polynesia is due to Fijian influence is absent, probably owing to Rennell's remote situation. Most other elements in its culture are more or less old-fashioned, and occur throughout Polynesia. Both facts may suggest that the Rennellese were separated from their kinsmen at a relatively early period. The question of whether there was an earlier population on the island (I am thinking here of the above-mentioned Hiti), and of their bearing on the matter, cannot be answered at the moment. Hiti is a widespread Polynesian term which occurs, for instance, in place-names like Viti (i. e., Fiji) and Tahiti.

But quite apart from the contributions to Polynesian prehistory which may be obtained from a study of the ethonology of Rennell Island, it is always a matter of importance to get to know a strange culture, and find out how it functions and has adapted itself to local conditions. In this way, the investigations of even a remote and insignificant South Sea island can contribute its mite to the knowledge of man, which is the ultimate aim of all cultural studies. 


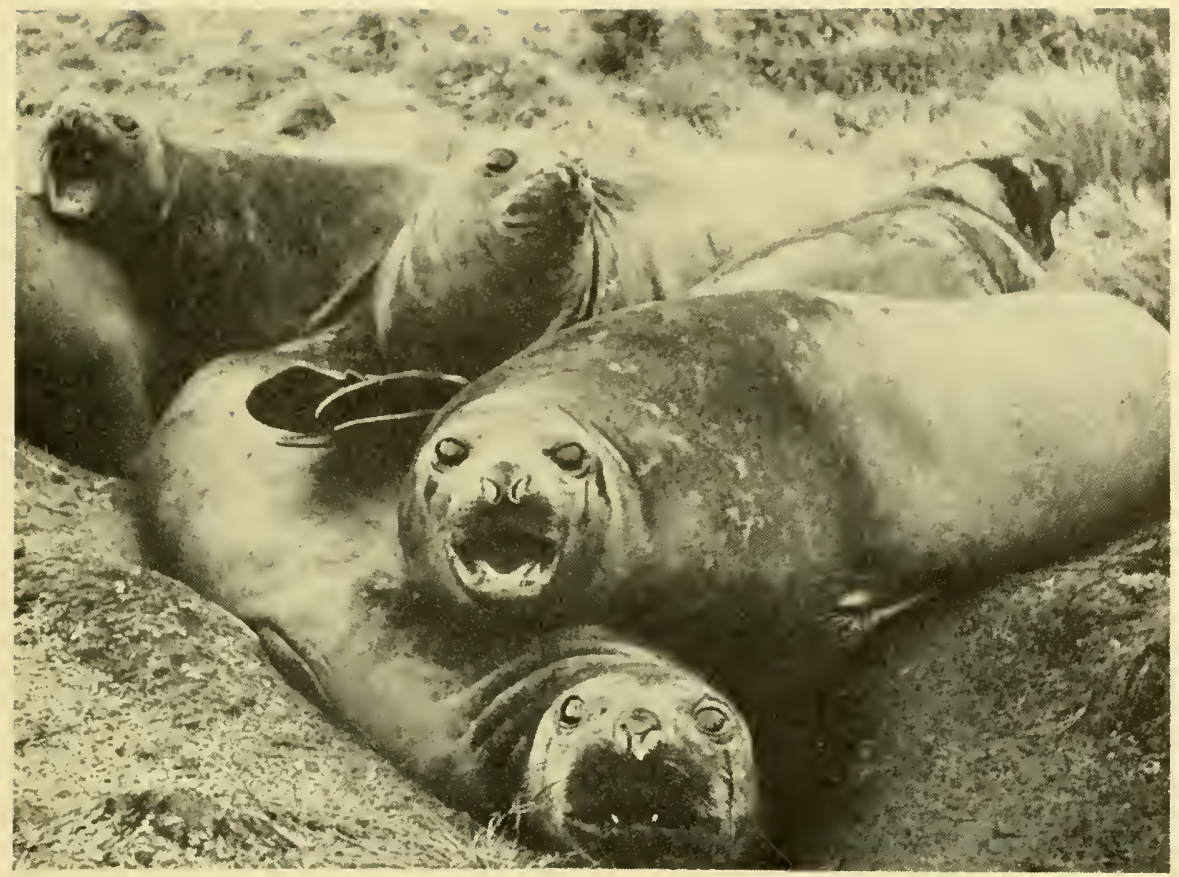

\title{
CAMPBELL ISLAND - \\ HOME OF ELEPHANT SEALS AND \\ ALBATROSSES
}

\author{
By Magnus Degerbøl
}

"Are the anchors holding?"

"No, we're drifting."

"Then we'd better go ahead on the engine."

I put my head out over the top deck as this conversation took place on the bridge. It was New Year's Eve 195 I and the Galathea was in Perseverance Harbour, Campbell Island, a good 700 kilometres south of New Zealand. A snowstorm was sweeping through the sound, veiling the nearby rocky coasts as in howling gusts it developed into a gale, the snow ... But no, this is all wrong. We were in the southern hemisphere and New Year is Midsummer there. It was one of those gales which are only too common 
in these latitudes, and which even here in the sound will whip off the surface water, sending it pulverized into the air like the finest, frosty snow.

Campbell Island lies in the path of the west winds in the "furious fifties", at latitude $52^{\circ} 30^{\prime} \mathrm{S}$. and longitude $169^{\circ} \mathrm{E}$. The waves raised near Cape Horn roll in a heavy swell round the world without encountering any land to break them. Only a few islets, of which Campbell Island is one, remain as crumbling breakwaters in the track of this perpetually rolling current formed by the west winds, forgotten reminants of past volcanic action.

It is not a large island, the widest point being only some I 7 kilometres across. It was discovered in 1810 by Captain Hasselburgh on board the Perseverance. After taking part in a punitive expedition against the warlike Maories of New Zealand at the beginning of that year, the ship had been fitted out at Sydney for a cruise to the southern seas with the object of finding new hunting-grounds of the valuable fur seals and elephant seals, the stock of which had already been gravcly depleted at the known hunting-grounds, owing to over-exploitation. Hasselburgh succeeded not only in discovering Campbell Island, which he named after the shipowner, but also the Auckland Islands, where seals were abundant.

However, the island gained a bad reputation from the start. Hasselburgh capized and was drowned in one of the sudden squalls. There was another accident the following year, when five men who had rowed out in a boat vanished without trace. From then on Campbell Island was rarely
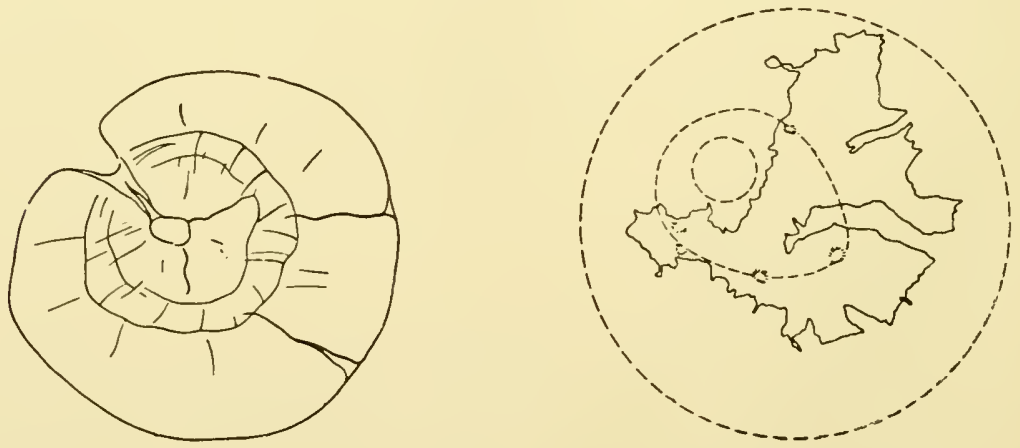

Campbell Island was created by violent volcanic action at the end of the Tertiary period (left figure). The western part of the original, regular cone of the volcano, together with the crater itseif, has been submerged. In the Glacial period, glaciers ploughed deep valleys in the eastern side of the island; these were later submerged and now form deep fjords, the largest of which is Perseverance Harbour. 
visited. Whalers returning to Tasmania from the Ross Sea in the Antarctic, and driven off their course by the ceaseless storms, might drift in towards its inhospitable coasts, but as there was nothing to tempt them to stay on the island they would quickly leave it.

A turning-point was reached in 1890 , when sheep were introduced. Partly for humanitarian reasons, in order to provide shipwrecked sailors with meat, and partly in an attempt to introduce husbandry, domestic animals - sheep, goats, pigs, cows, and rabbits - have been put ashore on several of these sub-Antarctic islands. Rational stock-breeding has always failed, but some animals have remained and run wild, subsequently becoming a serious menace to the original fauna and flora. This is what happened on Campbell Island. Sheep-farming was introduced on rational lines in 1896 , and in 1907 there are stated to have been no fewer than 8,000 sheep on the island. But conditions proved unfavourable in the long run; navigation was too difficult, the solitude too great for the Maori shepherds, and the climate too wet and rough. In 1927 the sheep-breeding station was abandoned, but several thousand sheep were left behind. They have held out fairly well. We found them fit and healthy, and so active that even a big-game hunter would find good sport in getting within shooting range of them on the wet and rather inaccessible mountain-sides. But the birth-rate is low and the stock appears to be declining.

During the war, the New Zealand Government established a permanent coastguard, now a meteorological station, on the island. From three to five men spend a year at a time at this remote spot, where a dank mist invariably drifts down the mountain-sides or alternates with pouring rain (it rains or snows on about 280 days in a year), hours of sunshine being minimal. The temperature is fairly constant, rarely exceeding $15^{\circ} \mathrm{C}$., frost never lasting long. For a number of animals - albatrosses, petrels, penguins, elephant seals, and sea-lions - this lonely island is a natural sanctuary to which they return to breed after months of roving on or across the open Pacific.

The view of Campbell Island from the sea or from Perseverance Harbour reminds one of the Faroe Islands. There are the same mist formations and varied lighting over green mountain-sides, the same chilliness and the same rumbling surf. A closer inspection, and especially a walk over the island, soon reveals the differences. Here we find not the open green hill slopes of the Faroes, but tussock grassland. The tussocks, up to two metres high, consist largely of Poa litorosa, a plant typical not only of Campbell Island but of all the windswept sub-Antarctic islands.

There are no trees on Campbell Island. From a distance the more 
sheltered parts appear to be overgrown, up to a height of a couple of hundred metres, by a dense "juniper" scrub. This consists of two species of Dracophyllum (D. scoparium and the rarer, rather lighter-coloured D. longifolium), plants with very delicate, nettle-like leaves. They can attain a height of five metres and form an almost impenetrable thicket. In spite of the high rainfall, the flora of Campbell Island is xerophilous (i. e. adapted to a dry climate), as the strong wind has a desiccating effect on plants which rise above the ground.

Surprisingly large and beautiful flowers are met with in the original flora. There is an outstanding lily, the Ross lily (Chrysobactron rossii). Owing to its acrid taste, it is not eaten by sheep and so in recent years has spread rapidly, forming extensive, dense growths of knee-deep, linear leaves from which rise strong stems bearing yellow flower heads the size of maize cobs. There are other extremely beautiful plants among the Compositce, three species of Pleurophyllum being particularly conspicuous, though, because sheep are fond of them, they are now found only in inaccessible places. Very striking is $P l$. speciosum, the leaves of which may measure two metres across when open. The stems which grow from these rosette-shaped leaves may bear between 25 and 30 flower heads. The two other species af Pleurophyllum (Pl. hookeri and Pl. criniferum) present a different appearance, having tall flower stems rather reminiscent of our mullein but in place of this plant's single yellow flowers, large heads of white ray-flowers and dark disc-flowers. Another striking plant is an Araliacea, Stilbocarpa polaris, with large, rather kidney-shaped and pleated leaves.

In the depressing mood which easily asserts itself in this damp and cloudy island the sight of this floral beauty is heart-warming. If one has sought rest and shelter behind a scarp and the sun suddenly breaks through and picks out these plants, often surrounded by lush green bracken, it is easy to imagine oneself in a more luxurious region.

If one were asked to name the two outstanding species of animals on Campbell Island they would be the elephant seal and the royal albatross. The elephant seal is remarkable for its size and bizarre appearance; old males may measure more than six metres (nearly 20 feet) in length, and when angered can inflate their proboscis into a small trunk. The royal albatross is one of the grandest and most majestic of birds. To see this glider, with a wing span which may approach four metres, motionless on rigid snow-white wings yet rising and falling in elegant curves over the foaming waves of the rough and perpetually changing sea, is one of the great experiences. 


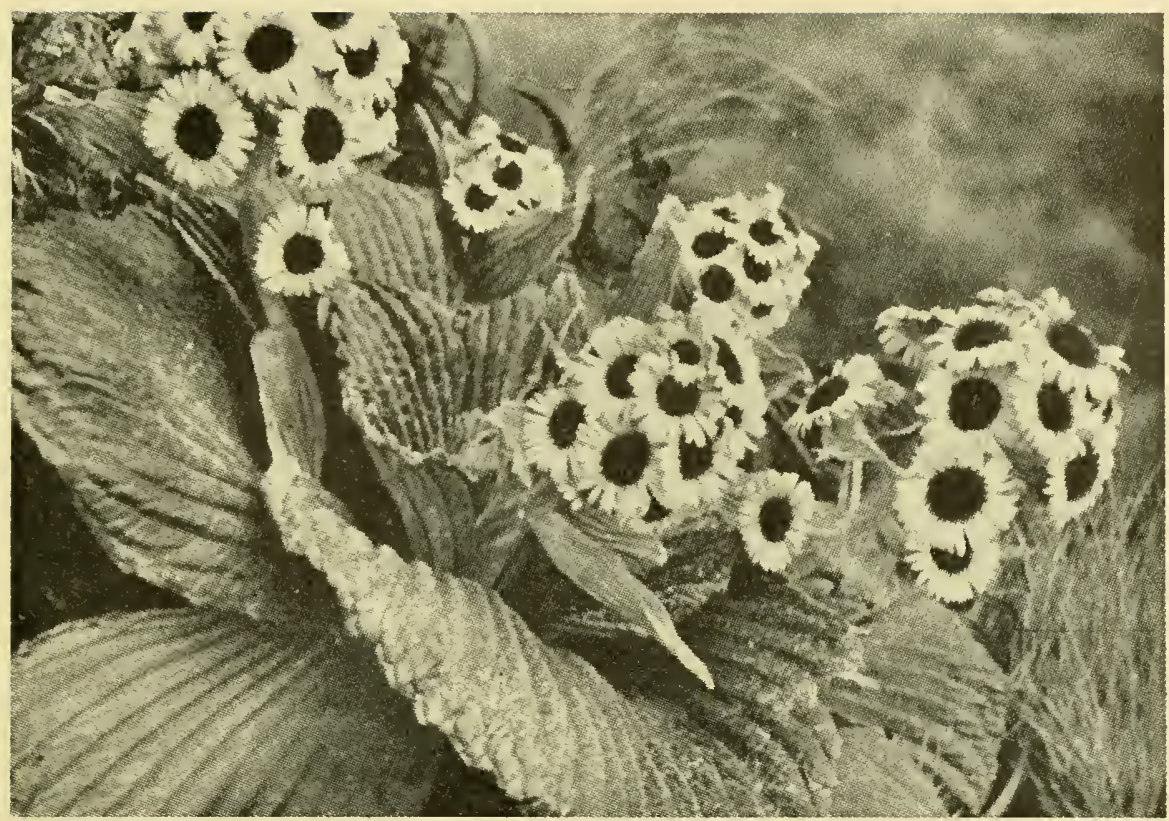

Surprisingly large and beautiful flowers grow on Campbell Island, especially species of Composita. Very striking is Pleurophyllum speciosum; tall stems, rising from enormous leaves, bear up to a score of flower heads.

Elephant seals are widely distributed throughout the circumpolar, subAntarctic region. Along with whales, they have been hunted for centuries on account of their blubber, as fitting out ships was more profitable than growing oleaginous plants. But on Campbell Island they were rare, when they occurred at all, and the present stock of a couple of thousand is a fine example of the results of protection. In 19I6, Tasmania began to protect the heavily reduced stock on the Macquaric Islands, some 400 kilometres south-west of Campbell Island. In the course of these 35 years the number has grown rapidly, and it is believed to be the surplus population from there which has settled on Campbell Island.

You notice them as soon as you enter Perseverance Harbour. Some lie like shapeless lumps beneath the extensive ledges of rock formed by the crosion of the sea, others resemble wet boulders among sea-shore rocks smoothed and rounded by the sea, while others again are camouflaged so as to resemble sea-serpents among the tangle of brown algæ growing some 5-10 metres long on the shores. But most of them scem to be on the banks of the inner sound. Through field glasses they can be seen lying close together, partly concealed among the tussocks. 
January is the season at which they go ashore for moulting. As in other seals the hair comes off in large strips with a thin layer of top skin, in a manner unique among mammals. It takes from three to six weeks to get rid of the old hair and for a new fur to form, and throughout this period the animals are sluggish and inactive, and do not eat. The most typical and peculiar grounds on Campbell Island are among the vegetation, up to a score of metres from the shore. To meet elephant seals here is surprising and rather startling. It is for all the world like the wallowing-ground of pigs. With a score of big animals congregated in such a spot the grass may be worn and yellow as in a scorched field. Soon their heavy bodies, which may weigh a couple of tons, will form deep holes in the soft, peaty soil and they will lie in hollows like bath-tubs, wallows as they are called. In their more pronounced form these are simply peat trenches, which owing the daily rain quickly become filled with water, the peat and the excrement of the animals producing a glorious slush. They are having a mud bath, which will doubtless be balm to a peeling and itching skin. These deep ditches are not without danger, as the clumsy creatures may have difficulty in getting out of them again. In most of these wallows are the numerous remains of skeletons, of animals which have evidently dug their own graves.

Often, however, the elephant seals will lie among the tussocks, which may be the height of a man, and then it is impossible to estimate their numbers. I remember my first walk through such a camouflaged wallowing-ground. I was trying to find my way through some close tussocks when, with a sudden roar, a strange colossus of an animal rose up several metres in front of me, and from large, pink jaws with yellow stumps of teeth flung a "stink bomb" at me. Rather startled, I stepped aside, to be seized by a strange feeling as the ground beneath me began to move, slowly rotating. as though there was an earthquake. I had stepped into a trench containing a group of sleeping animals. Retreating a few more steps, I stood on the narrow grass verge between two deep trenches. I quietly sat down to look at the animals as they slumbered around me, torpid like immense slugs. There was something suspicious about one of the ditches, the surface seeming to rise and fall slowly, as though Mother Earth were gently breathing. And there, two metres ahead, I saw bubbles issuing from the broad nostrils of a small trunk, and, just behind it, a large, coal-black, shining eye - the rest was mud. Even down there were animals.

For the rest, all is peace and quiet, though a strong stench pervades the place and there is an incredible number of large flies. So long as the 
Sea-lion on the beach.

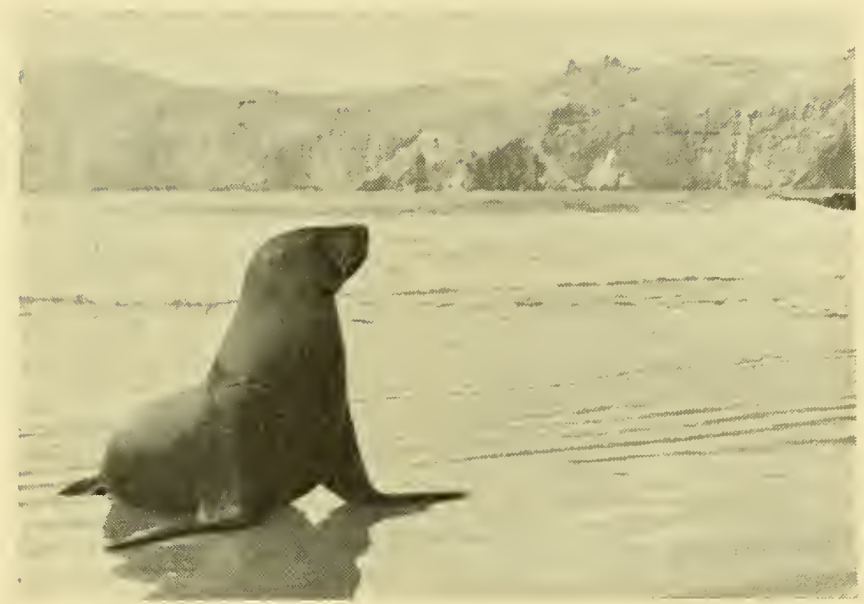

elephant seals are left alone they seldom leave the spot, but they are not motionless. Lying in every possible position, they scratch themselves now here, now there, with the large claws of their fore flippers. These are not rigid organs but are extremely flexible, and there is scarcely a part of the body which they cannot reach. It is comical to see the creatures scratch themselves under the chin or on the forehead. They lie sublimely composed with closed eyes and wrinkled brows, their whole appearance radiating deep reflection and supreme bliss. The long hind flippers they will scratch against each other. Incidentally, the hair is so loose that one can pluck it off by the handful.

When moulting, the animals have a most odd appearance. A young male, say, may have got new pale-grey fur on its head and back, the rest of the body being still covered with the old pale-yellow hair. It will then look as though covered with an old sack with holes in. Others present a moth-eaten appearance. Any self-respecting museum would take steps to remove such objects from its collections at the earliest possible opportunity! There is a rather wide range of colours, from a shiny dark-grey and pale grey to a warm chocolate-brown. Older animals are all extensively scarred. In the females the scars are particularly evident at the back of the neck, where the male grips them by the teeth during mating. In the males scars are mostly on the neck and head, but also occur on the body - sure signs of fierce fighting.

When we were there, in January, the animals which had resorted to land were mainly the younger ones, the older individuals - male as well as female - coming a little later. We therefore had to search for spe- 
cimens suitable for a museum group. But under the guidance of Dr. Falla, Director of the Wellington Museum, who had accompanied us as the special representative of the New Zealand Government, and who possessed local knowledge, we were able to find what we wanted. We were permitted to select two adult males, an old female, and a couple of young animals.

To shoot them presents no difficulties. In the manner of hunters, shouting and waving our arms and with occasional gentle kicks, we drove them, down to the shore, where they could be easily flayed. So as not to damage the skull and skin, our experienced big-game hunter, Dr. Boje Benzon, shot them through the open mouth at a metre's range, hitting the cervical vertebra and killing them instantly.

Elephant seals which have only recently come ashore will sometimes be active enough when disturbed to try to return to the sea. Being true seals, they are unable to draw their rear limbs up under the body like sea-lions, but have to drag them, like dead and flabby members, behind them. Nothing will drive such an animal from its chosen course - a dead straight line to the sea. It tumbles forward over sleeping elephant seals, over shrubs and large stones on the shore; undulating like a giant caterpillar and with heavy flops, it gets along faster than a man can move over this difficult ground. It is incredible that after such a journey the animal should have a whole bone or organ left in its body. But once it is in the water the clumsy creature is transformed; the large back feet fan out, the water froths around them as though they were a ship's propellers, and soon the animal is gliding about with the suppleness of an eel.

These are the creatures which adopt the menacing attitude to which I have referred, roaring with wide-open jaws. When they are excited many of the delicate blood vessels of the roof of the mouth will burst, and the blood will trickle out, as the tears roll from their large eyes to form a moist and glistening strip down the neck. It is indeed a strange blend of impressive energy and wretched helplessness.

I must confess that I was rather anxious about the possibility of getting these giants well enough skinned to display in a museum. But again the Galathea was well equipped. A flying squad headed by the "butcher" was ready to take action as soon as a suitable animal was found; experts who could flay and roughly skeletonize a full-grown elephant seal in a couple of hours, in rain, wind, fog, or half-light. It was a great relief that, along with small animals, the skins could be put straight into the deepfreezer, so saving the troublesome work of curing.

When they have finished moulting, adult elephant scals return to the 
Moulting elephant seal.

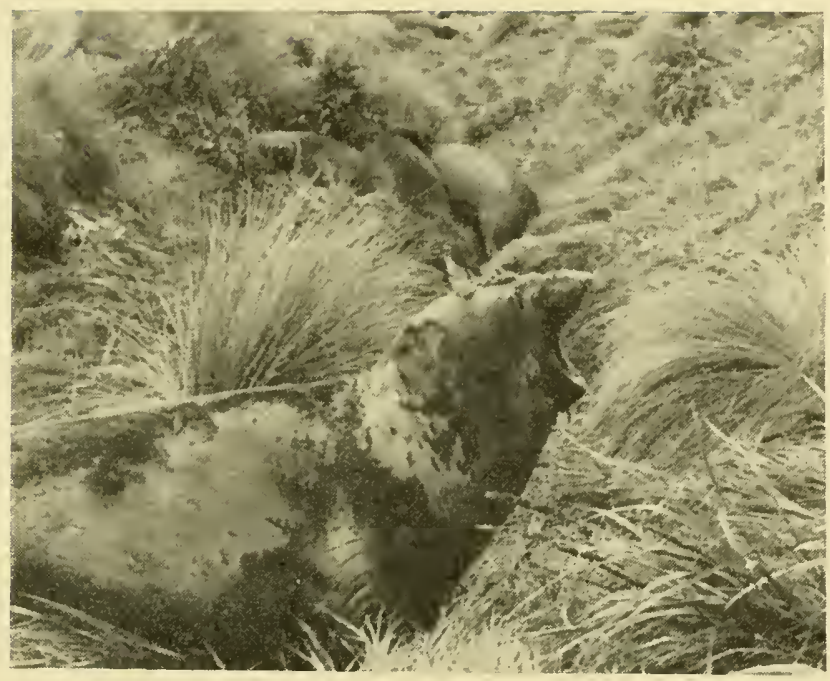

sea until the breeding season in September-October, though young animals will be found on Ciampbell Island at all times of the year.

Only a few sea-lions were seen in Perseverance Harbour. One of them gave fine evidence of the astonishing vitality and mobility of the species. It was extremely aggressive. When we stepped ashore it would come flying through the water in a lightning attack, barking and hobbling over the rocks and stones of the shore until within a couple of metres of us. We could understand why a Danish zoologist, collecting animals on this shore some 40 years earlier, had been startled into sacrificing the collected animals and the bucket which held them by throwing them at the head of one such yapping cur. Fur seals were not observed in Perseverance Harbour, but they are found on a number of the coasts.

As soon as an elephant seal had been shot and flaying had begun, the island's scavengers, the Antarctic great skuas, would be on the spot, tugging at the emptied entrails. Soon we began throwing lumps of blubber to them; larger and larger hunks, and in the end pieces as thick as an arm, were swallowed in the fraction of a minute. It was amazing that such pieces could pass through their throats, and still more astonishing that they could find room for them in their stomachs; but it was not long before they were so fat and bloated that their feathers bristled, and so heavy that they were unable to fly until some ballast had been thrown overboard. The great skua is a typically voracious sea-bird which misses nothing edible, and in fact the inedible seems to go down with the rest.

Campbell Island is the island par cxcellence of royal albatrosses. It was 


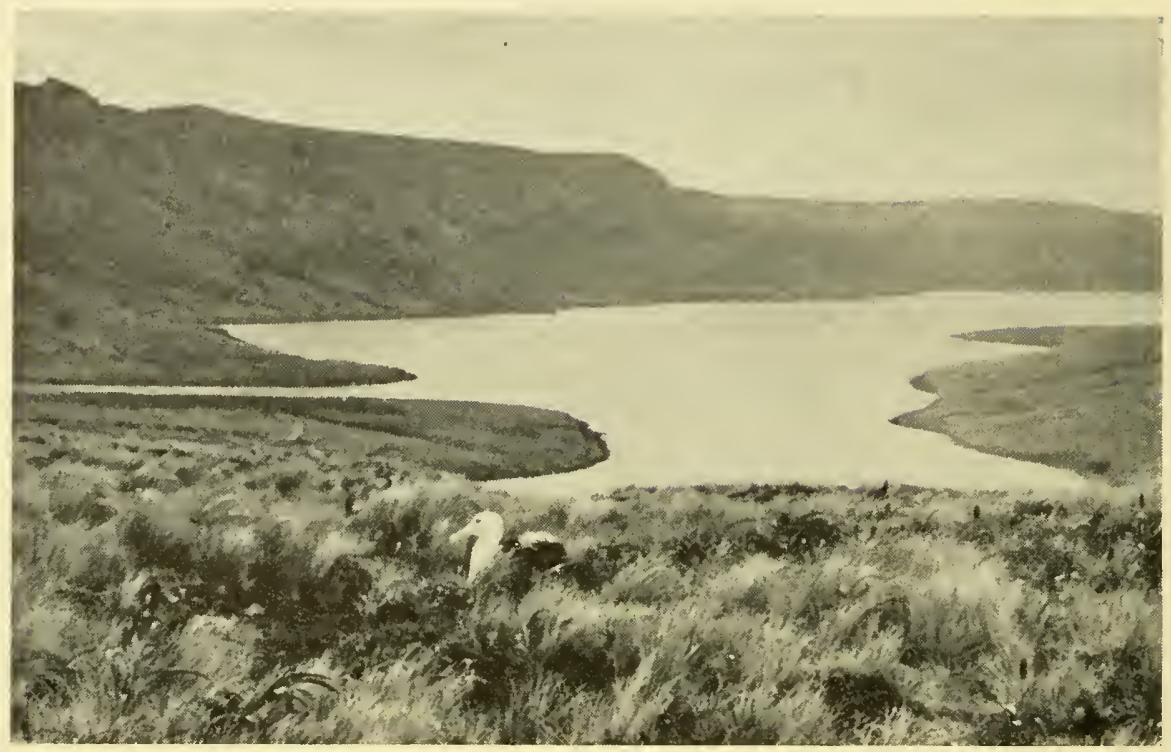

View of Perseverance Harbour from a height of 200 metres, showing tussock grass and brooding royal albatross in the foreground. When seen in lonely fight over the rough and perpetually changing sea, this bird seems a most exclusive and unapproachable creature, but on its breedinggrounds the handsome glider is rather gooselike.

early famous for its large white albatrosses. Both royal and wandering albatrosses soar over the island; but whereas the latter breed on a number of islands in the sub-Antarctic, the chief breeding-ground of the royal albatross is Campbell Island, where it is estimated that there are about 5,00o breeding pairs. They nest a couple of hundred metres up the gently sloping cliff sides, above the scrub where the tussock grass predominates. From the Galathea's deck, lighting permitting (we evidently had more sunshine during our week's stay than was due to us according to the statistics), we could see small white spots in the cliff face and through our glasses make out that they were breeding birds.

Many people have seen gliding albatrosses; but to see the royal albatrosses in their breeding-grounds on an insignificiant little island at the edge of the civilized world is reserved for the few; and only a handful of mortals, the station officials on Campbell Island, have been able to study them all the year round - a royal recompense for years of isolation and privation. When seen in solitary flight the royal albatross seems an extremely exclusive and unapproachable creature, but seen here in its breeding-grounds it presents an altogether different aspect. It is 


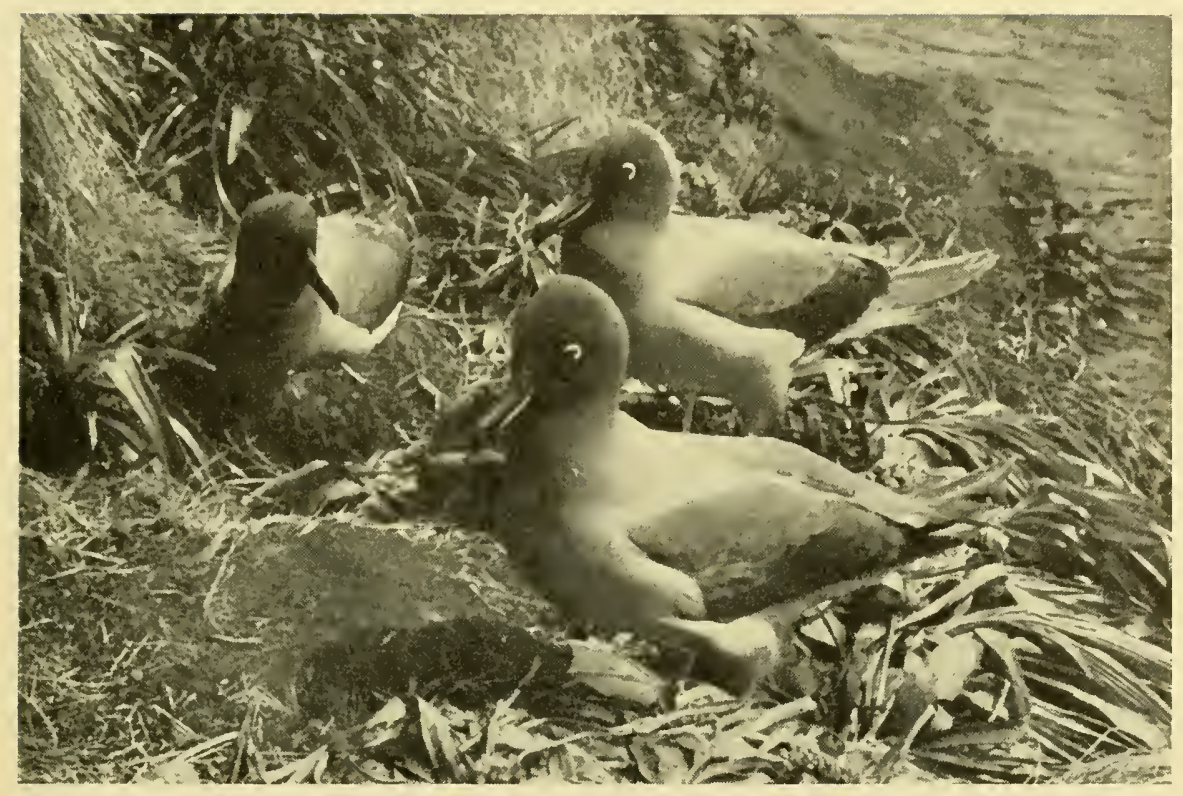

Sooty albatross. The delicate hues and white, crescent-shaped mark behind the eye give this bird a special charm, which is enhanced by the grace and elegance with which it alights and takes off from its nest. This is on rock ledges, often overlooking the sea.

like a peep behind the scenes. What remains of the beautiful glider is rather like a goose, though a most charming goose. With gentle motions it welcomes the visitor to its family circle. The usual animal fear of man is unknown to it. One of the parents will be sitting on the large, raised nest, in shape rather like a big mole-hill, and it will allow you to go right up to it. It may clap its bill a little; but then it will rise slightly so as to reveai the large white egg, give a little turn with the enormous bill as if to make sure you have really seen it, and quietly settle down again.

After strange wedding ceremonies the eggs are laid at the end of November and beginning of December; hatching takes no less than 79 days, which is a record in the bird kingdom. During all this time the egg is so well protected that the ubiquitous great skua gets no chance to snatch it. But the first week after hatching is the most dangerous in the bird's whole life history. According to observations by the biologist I. H. Sorensen, one of the station officials, no less than 50 per cent. perish in this one week. Only after about nine months are the young fully fledged. During all this time they are fed by the parents, at first mainly on fish but later chiefly on cuttle-fish. Owing to their long breeding period these 
birds lay at most one egg every other year. A comparison with the breeding habits of another bird which lays very large eggs, though from five to eight a year - namely, the European wild swan - serves to show that a bird with so small a rate of reproduction as the albatross would scarcely survive the struggle for existence but for the very fact that it inhabits so isolated - and, indeed, protected - a region.

Besides these two species, three other species of albatrosses are found on Campbell Island: the sooty, the black-browed, and the grey-hcaded. Most people who have seen albatrosses in the wild agree that for beauty, grace, and charm the sooty albatross bears the prize. The delicate hues and the white crescent behind the eye give it a special attractiveness, which is enhanced by the ease and elegance with which it alights and takes off from its nest, built on ledges of rock, often overlooking the sea. One has scarcely time to see it lift its wings before it merges into the air currents.

As the remaining two albatrosses breed in large colonies on the northern side of the island, I saw these only in the air. The same applies to the giant petrel, which, orving to its dark colouring, has something of the appearance of the sooty albatross, though it is larger (having a wing-span of over two metres) and not nearly so elegant a glider, as from time to time it flaps its wings. Indeed, it would be grossly unjust to compare this coarse bird with its small, pig-like eyes, which if you approach will squirt a jet of stinking regurgitated oil at you, with the beautiful sooty albatross.

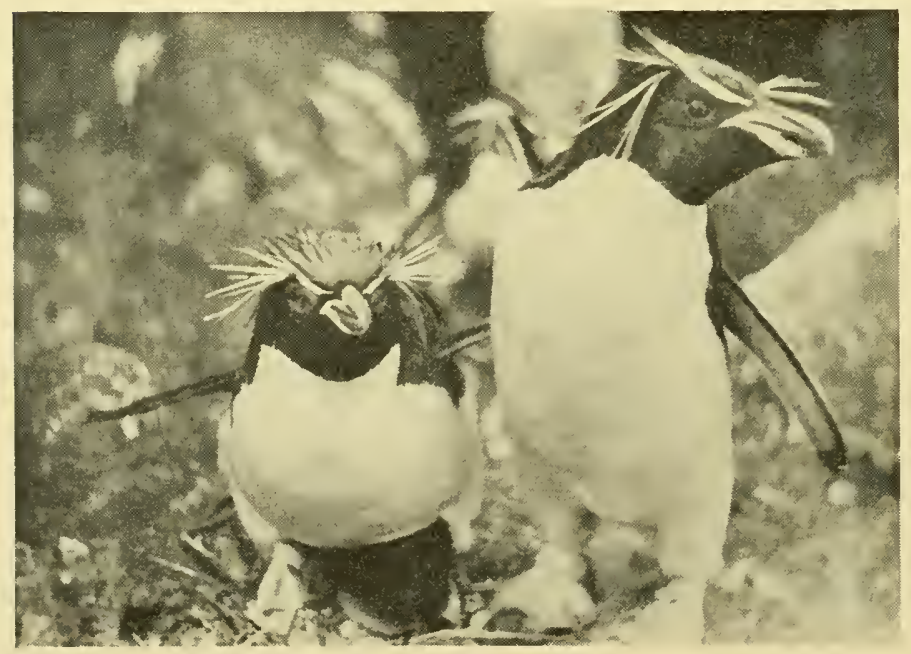

A family of rockhopper penguins. The young bird is almost hidden by the female. 


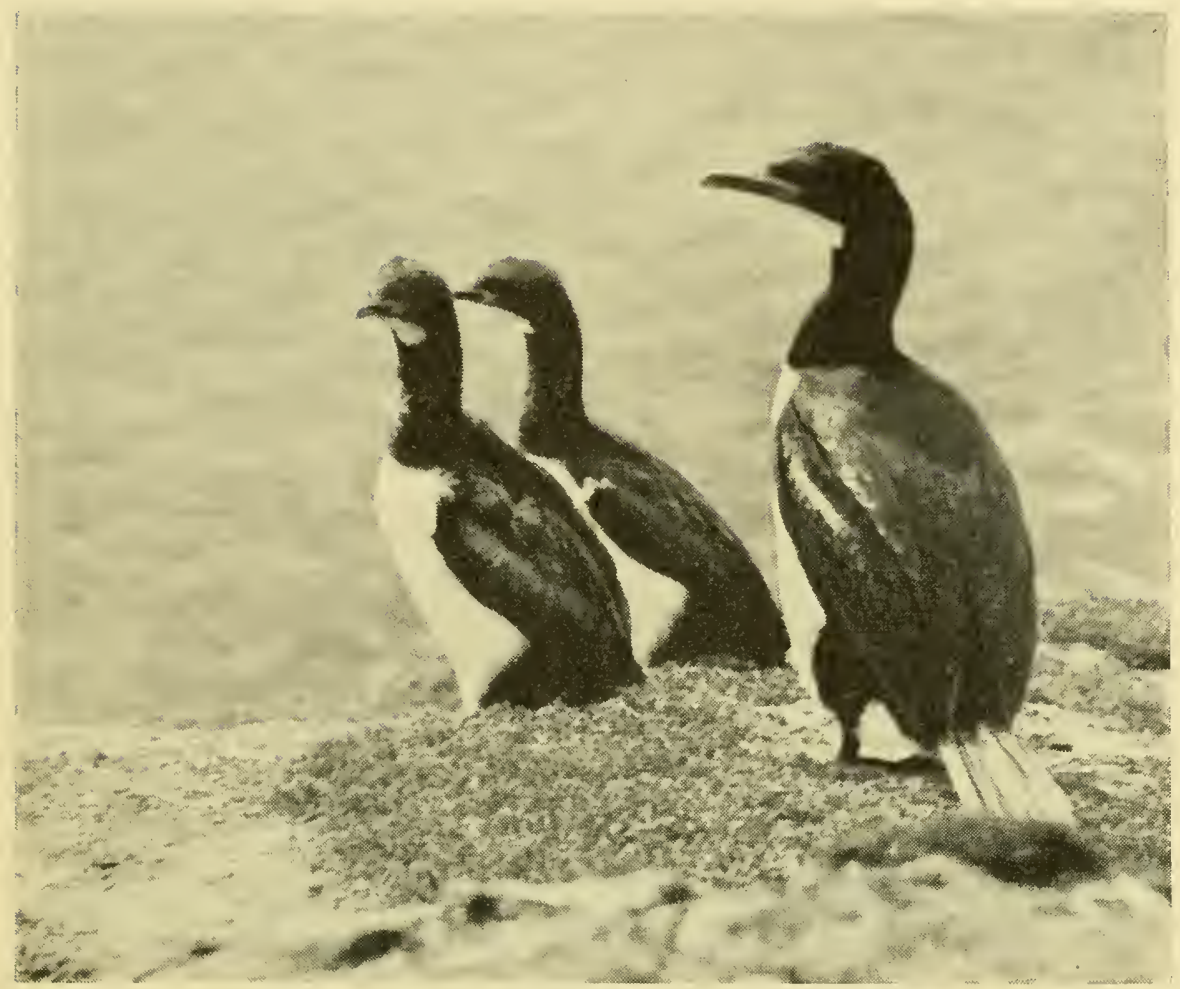

The rare Campbell cormorant.

Other large birds characteristic of Campbell Island are the cormorant and two species of penguins - the rock-hopper and the yellow-eyed penguin. In a sail round the bay there is no missing the white-bellied cormorant, sitting about on the rocks. But what is an Antarctic zoological expedition without penguins, preferably in large flocks? In this respect, Campbell Island was no risapointment, either. A colony of rock-hoppers at the foot of Mount Paris on the western side of the island is estimated to comprise half a million of these droll caricatures of man. The rather severe "evening-dress" plumage of these birds is relieved by bristling yellow feathers behind red eyes. With legs together they take metre-long hops from rock to rock, as though in high spirits, their small wings standing out behind like fluttering dress tails. In Perseverance Harbour I saw the yellow-eyed penguin. We had gone in to the coast in our motor-boat to have our lunch when a pair of the gay fellows appeared. We found their young in the Dracophyll scrub behind. At this time of the year they 
are as big as their parents, but still covered by short, thick black down. They look like a cross between a teddy bear and the roc.

The harsh and piercing screams of large sca-birds go well with the rugged scenery of Campbell Island. But there are gentler tones. The melodious piping of the blackbird can be heard from sheltered defiles. It sounds gay, though one feels that it is rather out of place. Surprisingly, a number of other small birds have succeeded in making the long journey to Campbell Island, including starlings, redpolls, sparrows, hedge-sparrows, and white-eyes. It has been easier for rats, which have been taken there and which are now rather numerous, to the detriment of a number of the island's birds and plants.

We brought back from Campbell Island representatives of the following species:

Mammals: Sea elephant (Mirounga leonina Linnceus), two not quite fully grown males, an old female, two youngish males, one young male.

Sea-lion (Neophoca cinerea (Per. et Les.)), a youngish male.

Birds (chiefly collected by the ship's surgeon, Dr. Lorenz Ferdinand):

Wandering albatross (Diomedea exulans Linnæus), 20 specimens.

Royal albatross (Diomedea epomophora Lesson), two specimens, two eggs.

Sooty albatross (Phoebetria palpebrata Forster), two specimens.

Giant petrel (Macronectes giganteus Gmelin), three specimens.

Antarctic great skua (Catharacta lönnbergi Matthews), eight specimens. Black-backed gull (Larus dominicanus Lichtenstein), I6 specimens in various plumage.

Australian gull (Larus nova-hollandia Stephens), one specimen.

Tern (Sterna vittata Gmelin), two specimens.

Campbell Island cormorant (Phalacrocorax campbelli Filhol), two specimens.

Cape pigeon (Daption capensis Linnæus), two specimens, breeding birds.

Rock-hopper penguin (Eudyptes cristatus Miller), two adults and two young.

Yellow-eyed penguin (Megadyptes antipodes Hombron \& Jacquinot), two adults and one young specimens.

Sclater's penguin (Megadyptes sclateri Buller), one specimen.

White-eye (Zosterops lateralis Latham), one specimen. 
Hedge-sparrow (Prunella modularis Linnæus), one young. Redpoll (Carduelis flammea Linnæus), 43 specimens.

After a week's work both on land and in Perseverance Harbour we left on January 6, having seen Campbell Island in all sorts of weather rain, fog, hail, sunshine, gales - except calm weather. It is the storms which give the island its character. My last impression of Campbell Island from the rolling deck of the Galathea is of a succession of pillars of smoke rising as from warm and comfortable homes; but it was the waterfalls being whipped upwards by the storm.

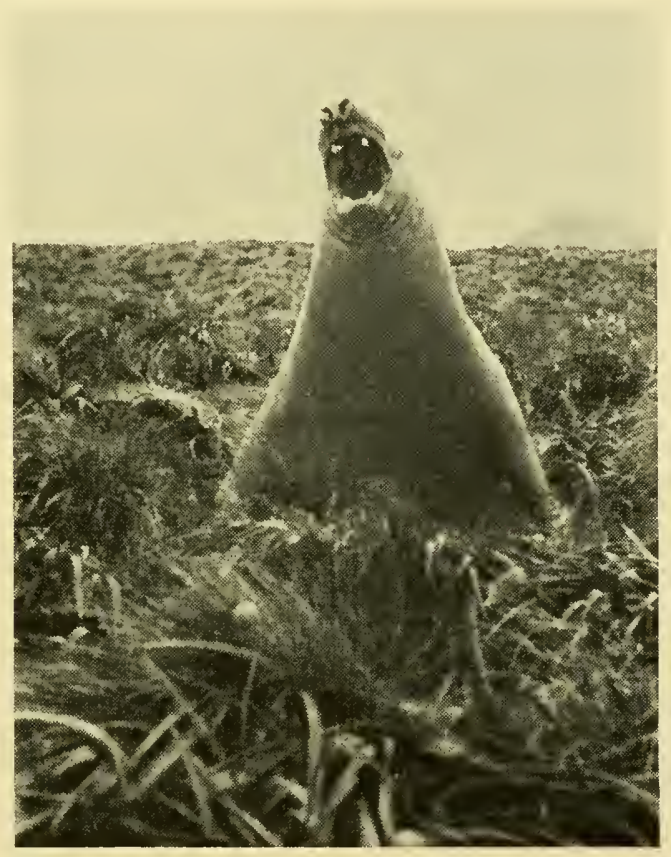

Roaring elephant seal in tussock grass. 


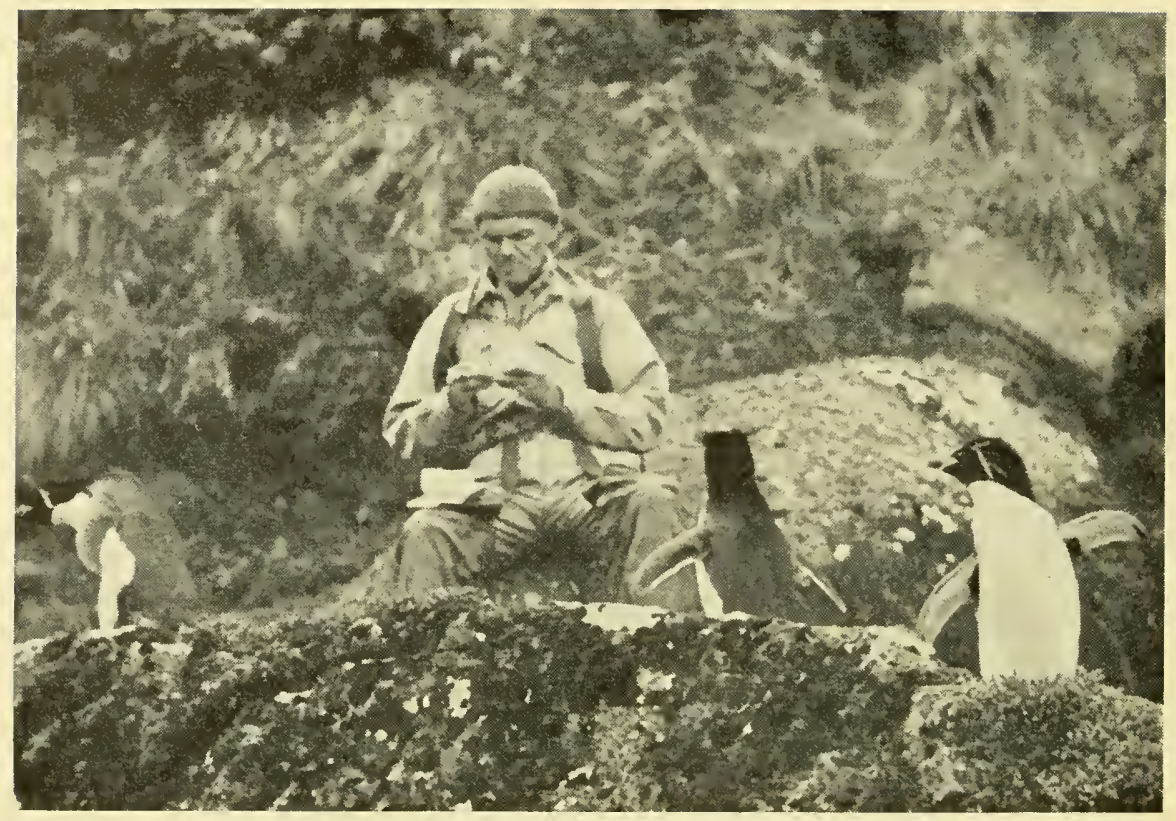

CONTAGT WITH INTERNATIONAL SGIENGE

By Torben WolfF

When frontiers are closed scientific research stagnates. We had a good example of this in Germany during the Nazi regime, and even in Denmark the five years of occupation imposed limits on free research. No science can thrive without foreign contacts. And oceanography, concerned with the physical conditions of the oceans, their flora and fauna, and the utilization of these for the benefit of hungry man, is surely one of the most international of all the sciences. The sea affects us all, at once separating and uniting us; and practically every civilized nation has made its contribution, large or small, to its exploration.

It follows that during the planning of the Galathea Expedition considerable importance was attached to the development of contacts with scientists and scientific institutions wherever its work might lead it. The

Dr. R. A. Falla, New Zealand, causes a stir in the penguin colony of Campbell Island. 
contacts were made in three ways. First, advance invitations were extended to a number of marine biologists to spend a period of time with the expedition working on their particular subjects, both on their own behalf and in the interests of the expedition as a whole. Secondly, notices were sent out through the Ministry for Foreign Affairs inviting the countries which we planned to visit to appoint one or more oceanographical representatives to join the ship for short periods as guests while she was operating in or near their waters.

Thirdly, our stay in most of the ports at which we called was marked by great mutual scientific hospitality (if I may to describe it). We always made a point of inviting as many local scientists and students to visit the ship as possible, and in return we ourselves received many invitations to visit universities and other institutions, as well as the homes of colleagues. The happy combination of naval vessel and research ship, incidentally, brought us into touch with wider circles, and enabled us to represent our country much better, than either the one or the other would have done.

Of the international scientists who joined the expedition for a special purpose no more need be said about the Americans Professor C. Zobell and Dr. R. Morita and the Swede Dr. Kullenberg, as they have described their particular contributions to the success of the expedition in earlier chapters. Another Swede, the zoologist Dr. O. Nybelin, took part in the trial trip to Norway, giving us the benefit of his thorough knowledge of the large winch used on the Swedish Albatross Expedition.

It was on an afternoon in Colombo that Dr. Grace Pickford, professor at Yale University, arrived. The only member of the expedition who knew her was Dr. Bruun, and there was a little murmuring in corners at this invasion of our masculine stronghold by a woman. But like other foreign members she quickly slipped into our fellowship. She had published important studies of the Dana's deep-sea cephalopod Vampyroteuthis (see page 84), but like many other zoologists she had never had an opportunity of seeing and studying this rare deep-sea animal when freshly caught. She did on the Galathea, and the enthusiasm with which she rummaged in the tubs of deep-sea animals in search of her beloved "Vamps" will long be remembered.

Repairs to our large winch at Singapore took some little time and like the rest of us Dr. Pickford longed to get back to work in the South China Sea. In the meantime, she gained access to the extensive collection of unstudied octopuses in the Raffles Museum, and before our departure from Singapore had a study of it ready for printing. She also organized 


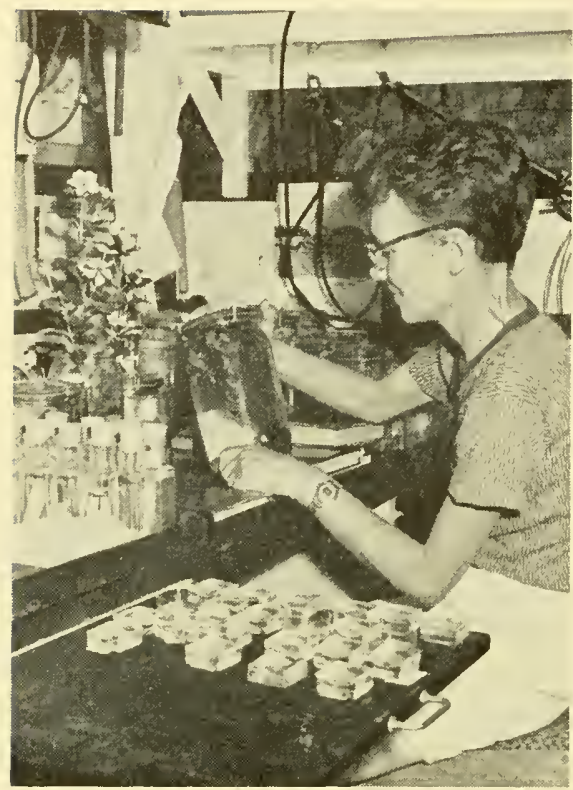

Dr. Grace Pickford in the Galathea's laboratory, with one of her prized 'Vamps'.

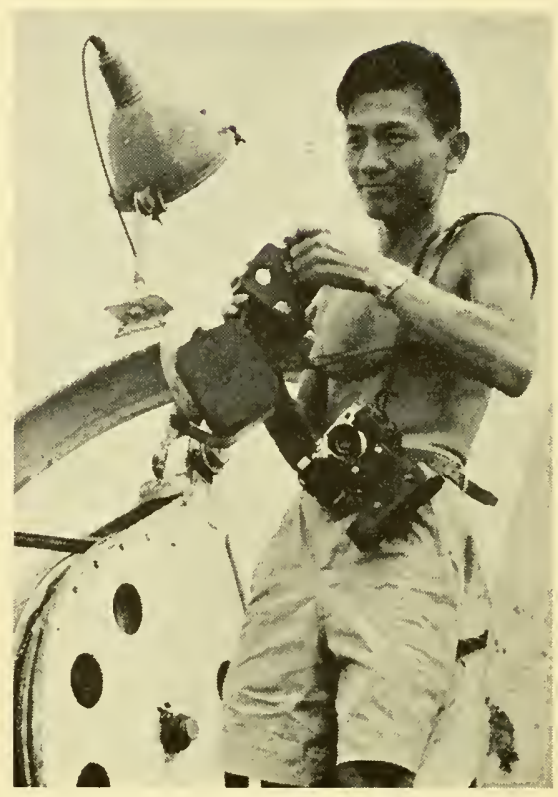

Mr. Swarng Chavernphol filming on the trawl gallows of the quarter-deck.

an extensive collection of octopuses from native traps along the coast and would go buying them up in fish-markets and hunting for them on coral reefs, where she impressed us all by her fearlessness in thrusting her hands into all the holes and crevices, occasionally hauling out large, angry octopuses and having the greatest difficulty in persuading them to let go of her arm before she could lever them into the collecting jars.

At Manila, Dr. Pickford had to leave us and her place was taken by Professor Torsten Gislén from the Swedish university of Lund. Professor Gislén's speciality was sea-lilies, but our haul of these creatures was unfortunately meagre. However, he busied himself with many other things, was the keenest of many keen searchers among the coral reefs of the Philippines and elsewhere, and wrote long articles for Swedish journals describing his own and our experiences and successes during the months which he spent with us on the stretch between Singapore and Thursday Island.

Professor Rolf Bolin of the Hopkins Marine Station in California was another old friend of Danish zoologists and the Dana Expedition, having studied in Copenhagen the Dana's collections of silvery pearlsides - fishes with lateral light organs resembling rows of port-holes. Boarding 
the ship in New Zealand, Dr. Bolin travelled back with us across the Pacific to California. The first printed result of his work on the Galathea is his interesting study of the new fish genus Antipodocottus, found in the Tasman Sea near New Zealand, as related on page 143. In the day-today work of sorting and provisionally classifying our hauls of fish his help was invaluable. Great was his enthusiasm when after a successful trawl he was able to pick out representatives of very rare or unknown species of fish, which he helped us to preserve to best possible advantage.

Twenty-six other foreign scientists, from eight different countries, were our guests for periods which usually ranged from a fortnight to a month. It is impossible to name them all. Those who stayed with us longest we remember especially well. One of these was Dr. Raghu Prasad, the fisheries biologist from Mandapam Marine Biological Station in South India. Apart from his scientific qualifications he was of invaluable assistance during our visits to the former Danish colonies of Tranquebar and the Nicobar Islands, when he functioned as interpreter and could assure the natives that we were not so warlike as our ship might have suggested.

Then there was the Siamese, Mr. Swarng Chavernphol, who on the deck of the Galathea examined species of fish and sea-cucumber not sold in the otherwise well-stocked fish-market of Bangkok. And there were the four Filipinos who had been invited to join us on the exciting days over the great trench which takes its name from their country. From Indonesia

Professor Torsten Gislén from Sweden, with a freshly caught sea-lily.

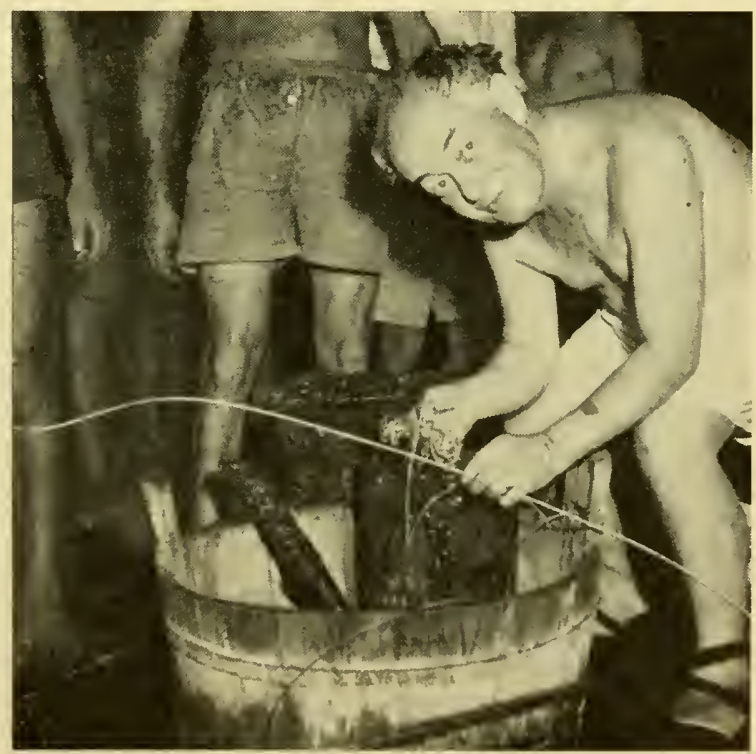


came two Dutch scientists, Dr. J. D. Hardenberg and Mr. C. Veen, who after spending several years as prisoners of war under the Japanese had been retained in the services of the new State of Indonesia. Among our Australian guests was Mr. Gilbert Whitley, an expert on fishes, whose excitement at seeing so many "names" in the fish world gathered together in one place was as great as was Dr. Bolin's later on. Mr. Whitley travelled with us from Brisbane to Sydney on a sort of return ticket, having gone with the Dana in the reverse direction in 1929. Another Australian guest was Miss Isobel Bennett, who succeeded in obtaining valuable supplementary measurements of temperature for her great work on the natural conditions of the Australian coast.

But the best contact of all, as well as the most valuable interchange of knowledge, was gained while the Galathea was in New Zealand waters. The New Zealand islands are so isolated that their fauna and flora are unique and highly specialized, as exemplified in that wingless bird, the kiwi, and in the kauri pine, a tree which can attain to a height of 80 metres. In many parts of New Zealand, especially in the vicinity of large towns, animals and plants introduced from abroad have ousted the native species and combating them has become a great national problem. Wise from experience, the New Zealanders have enforced strict protective measures, from which exemption is rarely given. However, our New Zealand colleagues included eminent scientists who were able to explain to their

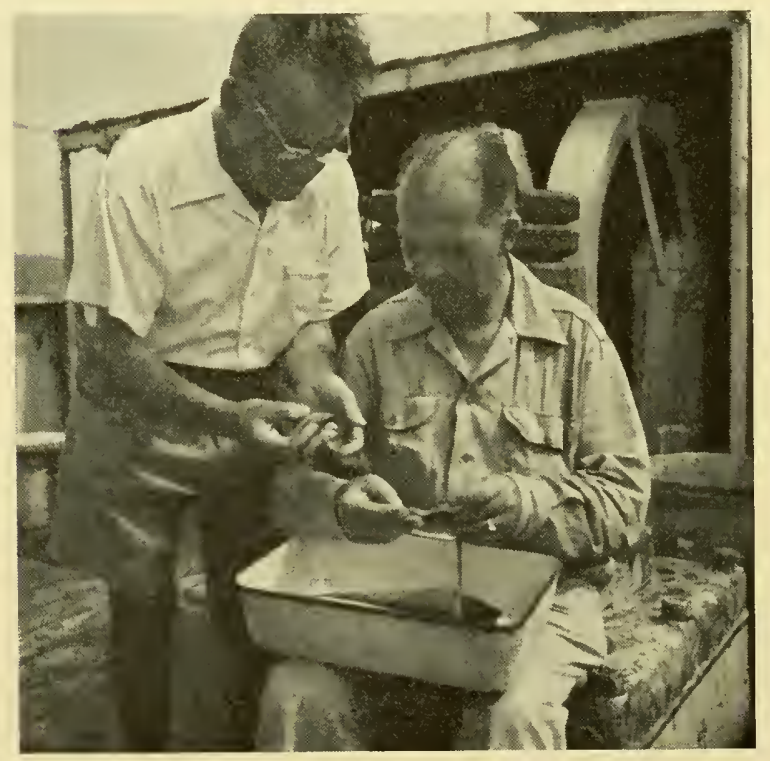

Mr. C. Veen and Dr. F. D. T. Hardenberg from Indonesia, admiring rare fishes. 


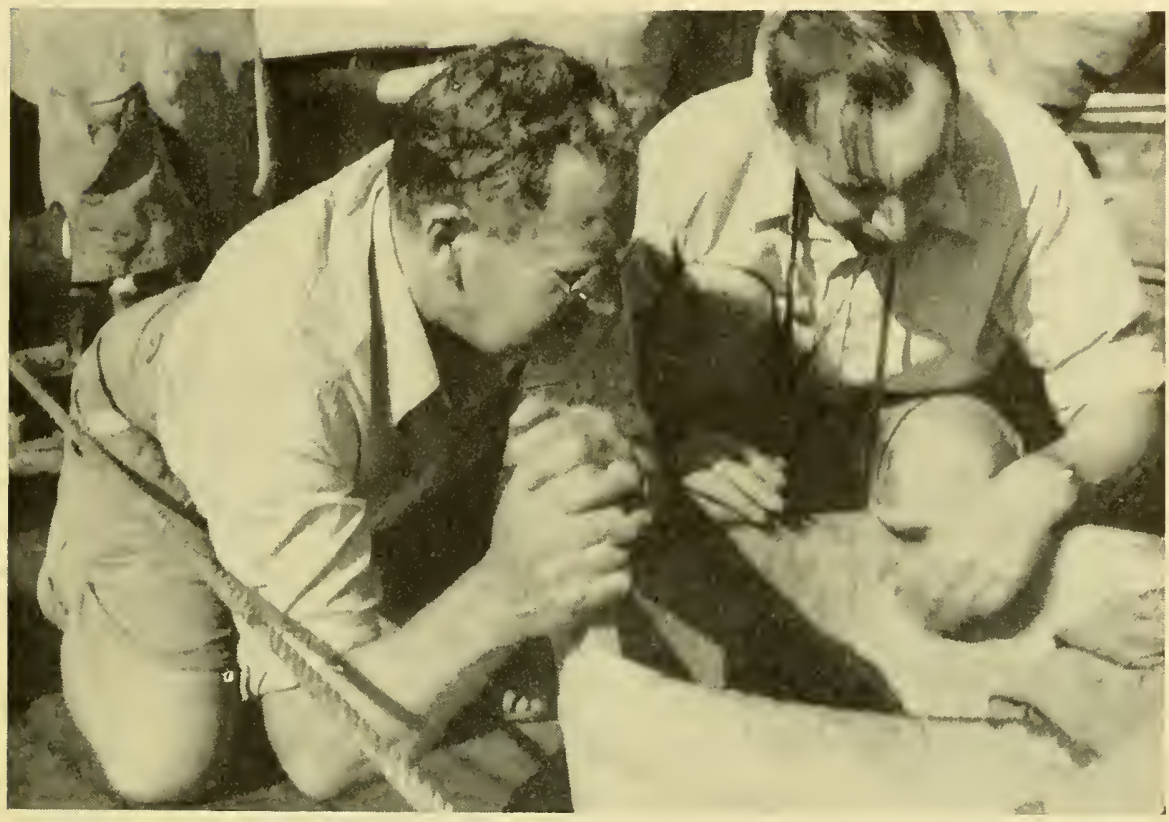

Mr. W. Baden Powell and Mr. R. K. Dell of New Zealand, eagerly searching for new species of molluscs from the Kernadec Trench.

authorities the importance of the expedition in increasing our knowledge of the little-known fauna of coastal waters. The result was a wide measure of good will which enabled us to bring home collections of great scientific value.

As our guests during the visit to Campbell Island we had Dr. R. A. Falla, Director of the Dominion Museum in Wellington (who had also been on the Dana in 1929), and his assistant, Mr. John Moreland. From earlier visits they knew the island like the backs of their own hands, and without the help of these distinguished field zoologists our success would have been immeasurably less than it was. Later on, when from Dunedin we slipped round South Island through the invariably stormswept Fouveaux Strait towards the western sounds, we took with us Dr. Elizabeth Batham, head of the Marine Biological Station of Portobello, and Dr. C. A. Fleming, a specialist in bivalves. They gave us great assistance, being glad of an opportunity to fish in depths from which they had been precluded through lack of a suitable ship and apparatus.

But the persons for whom we were privileged to provide the greatest experience were Mr. W. B. Powell and Mr. R. K. Dell, specialists in 
molluscs, and Dr. E. G. Turbott, the ornithologist, who were with us during our exploration of the Io-kilometre-deep Kermadec Trench, to the north of New Zealand. They were delighted at the rich hauls we made there, declaring that many of the molluscan species were new to science.

While operating in New Zealand waters it was decided that all collections made there from depths of less than 400 metres should be worked up by local research workers, and before our departure a large part of the material so obtained had been sorted out and handed over to specialists, who received it as a most welcome addition to their already extensive collections.

Our social and scientific contact with these colleagues, and the many other sea-going guests of the expedition whose names I have been unable to mention, was all the more valuable since as a rule it extended over a fairly long period. But compared with the hundreds of scientists and students with whom we had often all too brief contact while in port these "long-staying" guests and colleagues were a very small minority.

In order to avoid repetition I shall in the following confine myself to a few characteristic examples of this form of scientific contact. But I should point that there was scarcely one visit to any large port during which the ship was not shown, from keel to masthead, to scores and often hundreds of persons of all ages and every colour, and when we too were not the recipients of a hospitality which on occasion could be overwhelming.

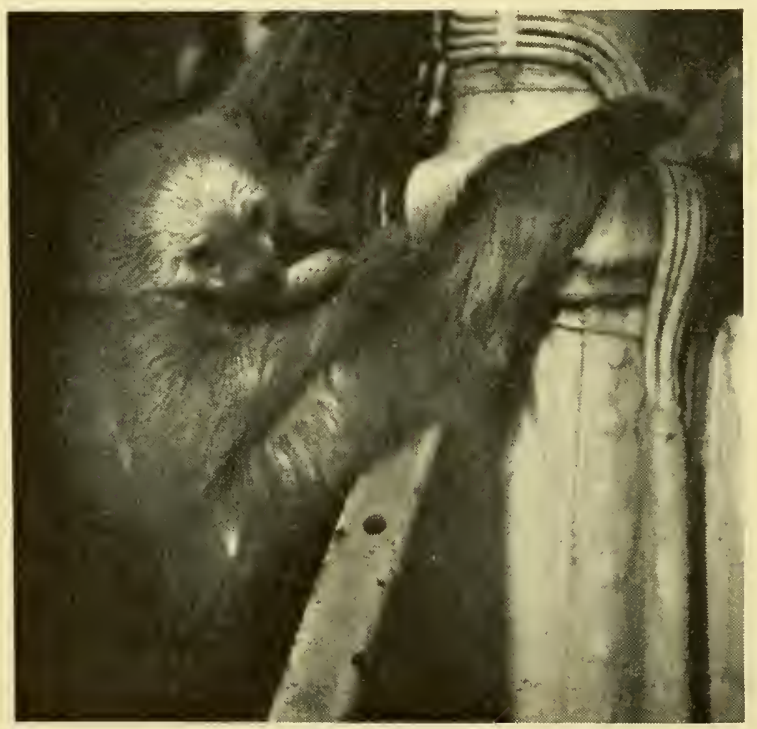

One of two amusing sloths acquired in Panama for the Copenhagen Zoo. 


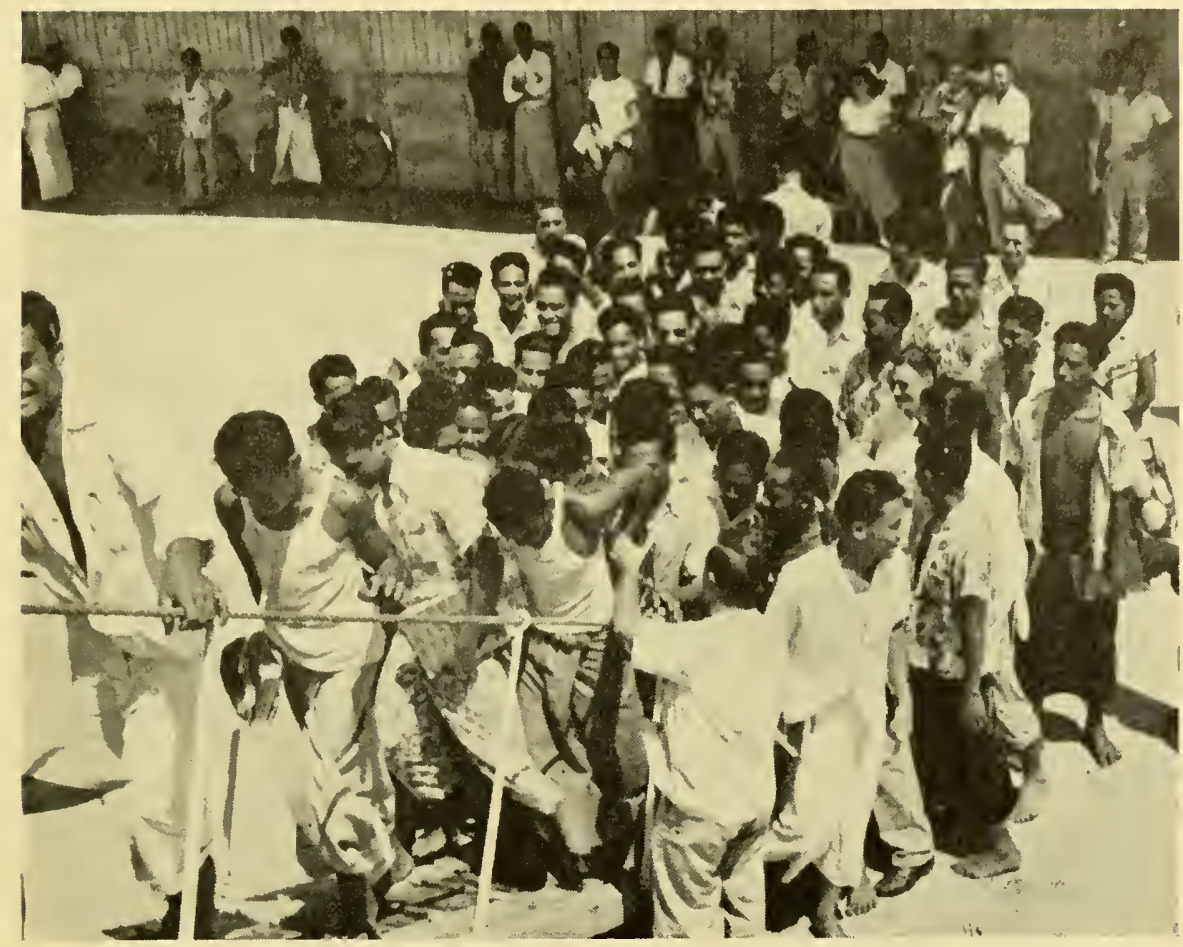

A visit by Samoan students.

The commander of the old corvette Galathea, Admiral Steen Bille, wrote in his report of the arrival at Plymouth: "The next morning at 8 o'clock we saluted the fortress with 2 I guns and the British admiral's flag with 17 guns, to which an equivalent number were given in reply." Just over a hundred years later, when the frigate Galathea called at Plymouth on her world voyage, the ceremony was repeated. And as the mist rose we saw in front of the fortress the large grey building which houses one of Europe's oldest marine biological stations, and which has been visited by all Danish oceanographical expeditions in the present century. Professor Johannes Schmidt and his assistants had stopped here in the trawler Thor and later the Dana, before proceeding on their way to more distant places, and the Danish Atlantide Expedition to West Africa had also been given a send-off from here. True to past tradition, there was open house at Plymouth to visitors from the Galathea, and we in turn proudly exhibited our ship to many expert and envious friends and colleagues. Two years later they were the first to welcome us back to Europe after 


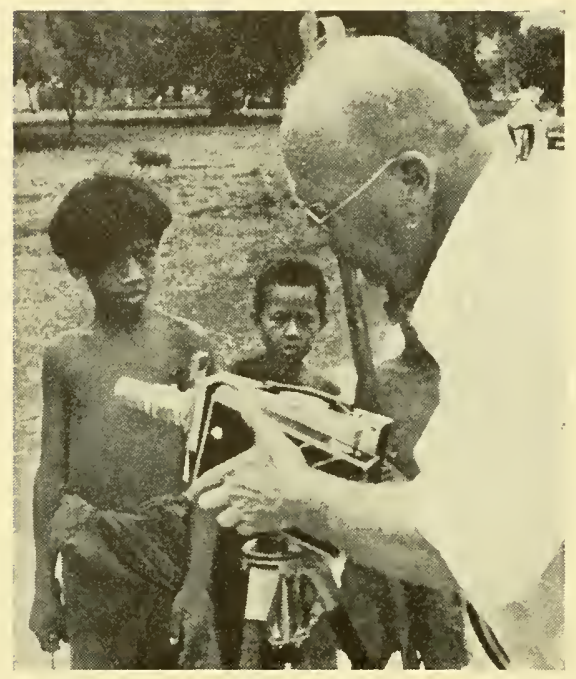

Professor Rolf Bolin, California, filming in the Tonga Islands.

our successful expedition. To be given such a cordial welcome by the Plymouth Laboratory, with all that its name implies, was felt by us to be a great privilege.

Elsewhere ours was the first Danish oceanographical research ship to visit such large and internationally known marine biological stations as the Hopkins Marine Station in California, to which reference has already been made, and the Scripps Institution of Oceanography, south of Los Angeles, which is the largest in the world. At the Scripps Institution Professor Zobell and Dr. Morita enabled us to see everything and to talk to scores of scientists, who afterwards paid visits in their amphibian craft to the Galathea as she lay at anchor opposite the institution. One episode will illustrate the readiness of the staff of the Scripps Institution to assist us. After a number of our very valuable precision thermometers had been crushed by the massive pressure during our first temperature measurements in the Philippine Trench, we received in response to a telegraphic message a loan of six new thermometers, which were flown to us across the Pacific and reached us within the week.

We would also receive valuable assistance in altogether different ways. For example, cautious inquiries of the amazing Dr. Paulian at Diego Suarez in Madagascar resulted in a gift of three delightful lemurs, along with other animals for the Copenhagen $\mathrm{Zoo}$, besides rare aquatic plants for the Botanical Gardens in Copenhagen. Similarly at Panama, where Mr. James Zetek - an old friend of the Dana and the Monsunen - 
reported our visit in the local papers, mentioning our interest in live animals for the Zoo. As a result, the ship was crowded with people wanting to give or sell to us sloths, kinkajous, crocodiles, and many other animals. If the Galathea on her homeward voyage resembled more a floating menagerie than a respectable research ship it was due to James Zetck and our interesting visit to the biological station in the rain forest of Barro Colorado.

What are the net results of all this? And what can it mean to the future?

No oceanographical expedition before us had been able to invite so many visitors to the ship, for shorter or for longer periods. It is our hope, shared by all our guests, that with this idea we have established a tradition. But more important than anything else are the great many contacts which we wcre able to make during the expedition. It was extremely valuable to make the personal acquaintance of colleagues in other parts of the world, to exchange ideas with them, and to learn from their methods and opinions. 


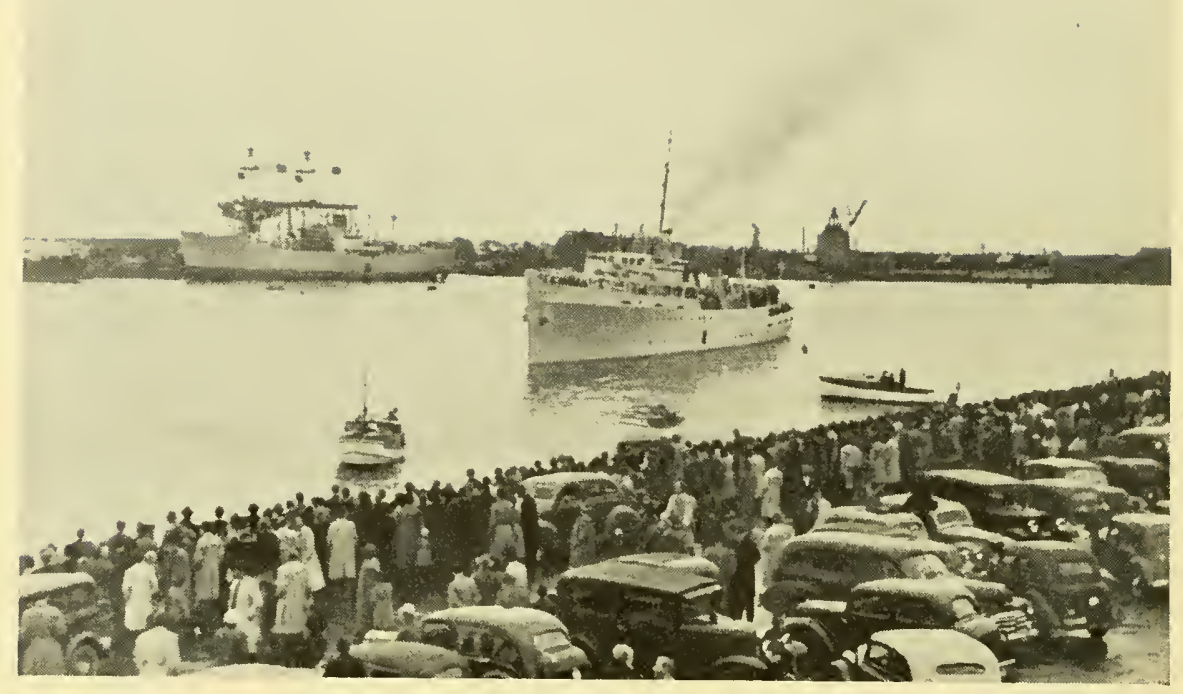

\title{
FILMS, PRESS, AND RADIO ON THE EXPEDITION
}

\author{
By Hakon Mielche
}

The inclusion in the Galathea Expedition of a public relations department to cater for the Press, films, and the radio was such a new departure in this kind of enterprise that it was bound to evoke a good deal of comment, not to say criticism, among scientists. To an older generation the word "publicity" meant the ballyhoo associated with the showmanship of Barnum, which they saw perpetuated in the "sensational discoveries" of the smart pseudo-scientific magazine articles of today. They shuddered at the idea of shipping the big drum with the 12,00o-metre wire cable.

Actually, the idea of including an up-to-date information department was as old as the project of the expedition itself; and the work which it did was only an extension of the century of cooperation between Danish science and the Danish Admiralty, under which the Admiralty had "shown the flag" while carrying the scientists to their stations. Now there was to be more positive action by means of Press conferences about the expedition 
and its predecessors, its objects and provisional results, and about the country which had sponsored it. We also intended to lecture and show films about Denmark, and to endeavour to interest local broadcasting services not only in the expedition but also in our country, in the hope that our visits would be of lasting benefit to Danish interests.

My part in it began in 1941, when my imagination was fired by a newspaper report given by Dr. Bruun. Who would not be stimulated by his quiet statement that the Great Sea Serpent might be more than just a sailor's yarn, that it might be capable of scientific explanation? The Dana Expedition had found eel larvæ of an unprecedented size nearly two metres long. If the development of such giants was at all commensurate with that of the larvæ of our European eels it is conceivable that the adults might reach the enormous length of 25 metres - quite long enough, in fact, to corroborate the accounts of deep-sea monsters recorded by the mariners of old.

Known species of eel live close to the bottom, also in the deep sea, and they will not rise to the surface when they die. Here then is a possible explanation of why no dead sea serpents had ever been reported, either on the sea or as having been washed ashore. A more than usually strong

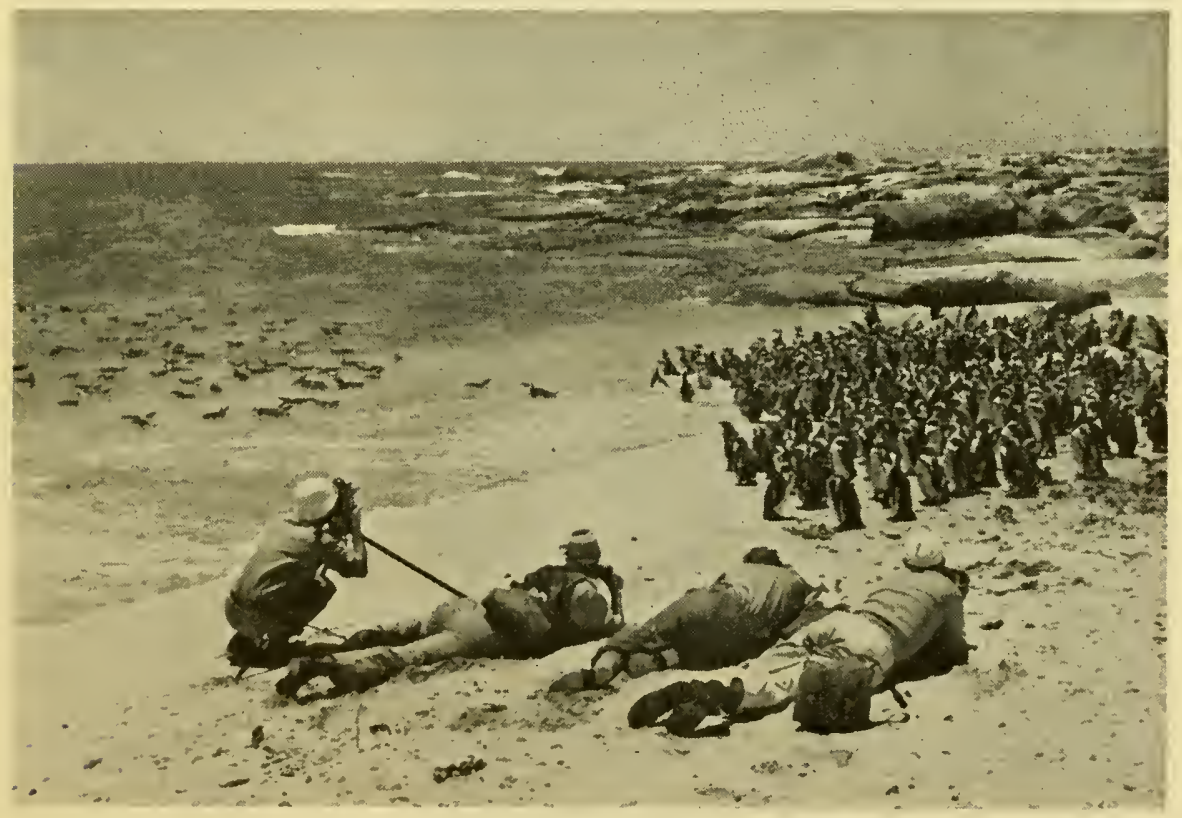

The cameraman in close collaboration with scientists on Dassen Island, a small penguin island off South Africa. 

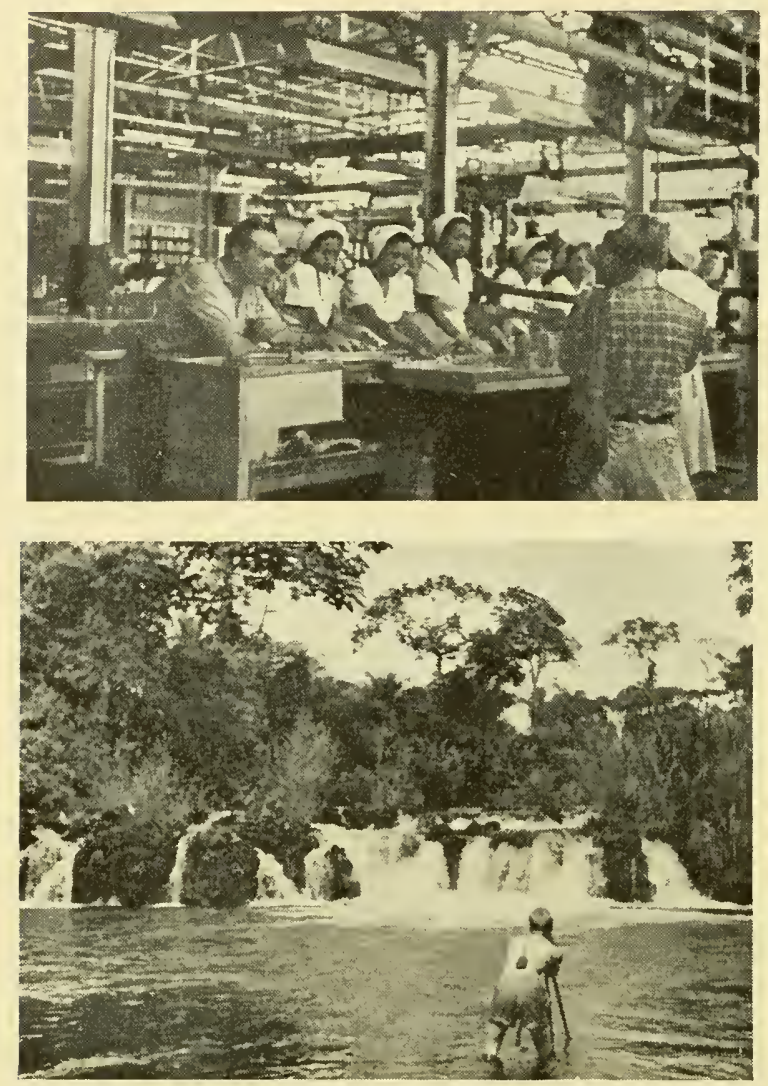

On Mindanao in

the Philippines a colour film about pineapples was made.
Film cameramen went through fire and water to get good results. From Victoria, British Cameroons.

current or a struggle with an enemy might on occasion have brought the giant eel into the surface levels, and the violent serpentine writhings repeatedly described in the reports might conceivably be the creature's death struggle before it finally descended into the perpetual darkness.

This was the point at which my imagination was caught, and the result of it all was that a few days later I volunteered my services on the deepsea expedition to come, and felt myself from then on increasingly caught in its net, even before any of us had any idea whether it was likely to energe from our dreams and get a deck under its feet. For, though Dr. Bruun's hypothesis about the giant eel might be proved incorrect, this expedition would be exploring hitherto unknown depths. And what man would not like to be on a modern voyage of discovery, one where the lands waiting to be discovered lay under the ship's keel instead of westward of her bows? Even though the sea serpent escaped our hook, there was still a prospect of other exciting discoveries. 
The two-year voyage was to start as soon as possible after the war, and would revive our reputation in this particular field of culture.

Apart from a grant of 50,00o kroner from the Danish Expeditions Fund, the information department was fully self-supporting, getting its income from the sale of material to newspapers and magazines, the Danish

\section{At Capetown}

the expedition witnessed the annual coon carnival, which was recorded.

It was not always easy to get the natives to play up to the camera; but a smile and a cigarette would do wonders.
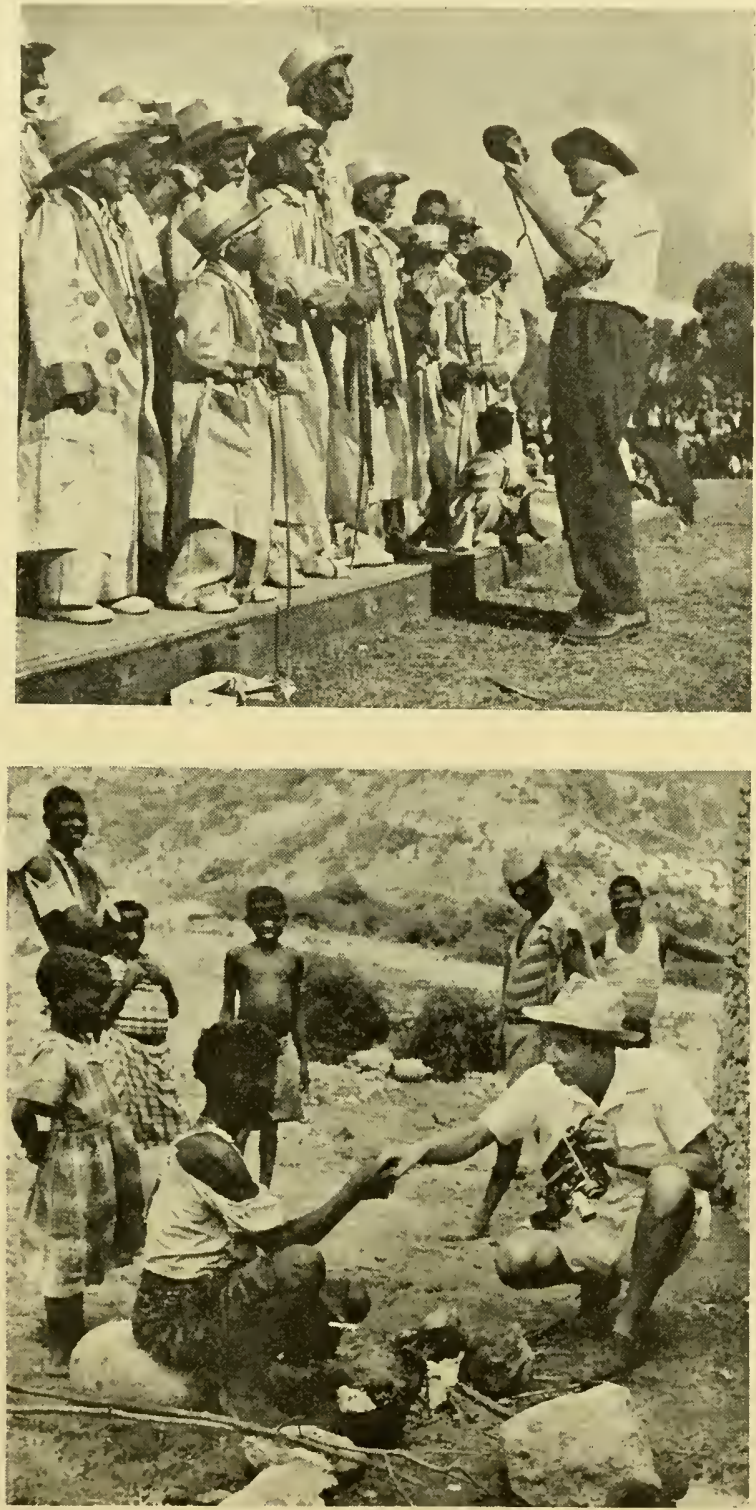
radio, and the Danish Government Film Committee. By far the biggest item on the expenditure side was the cost of film material, and a number of films were produced at a loss; but this was covered by profits from articles, picture series, and broadcasts to Denmark. Thus, for nearly two years the expedition's information department carried out a valuable information service on behalf of our country at no cost to the Government, while its members also took a hand in spreading a knowledge of the expedition's objects and methods.

The Galathea was front-page news in Portugal, in West, South, and East Africa, in Ceylon, India, Malaya, Siam, the Philippines, Indonesia, Australia, New Zealand, and the United States. We were good "copy" in every language, both for the local Press, radio, and film newsreels and for the international Press agencies. And when we were over the Philippine Trench, in July and August I95 I, and nearly every hour brought its new world record, the news was flashed to Reuter's correspondent in Manila, and from there to headlines all over the world — from Talking Drums on the Gold Coast to Le Figaro and the New York Times.

The information service had its most hectic hours in port. We hardly cver had more than four days at our disposal, often only two, and would be horribly conscious of the impossibility of discharging all our self-imposed tasks. At the end of the stay we would hang dead-tired over the gunwale, but with a fairly good conscience because we had accomplished most of them.

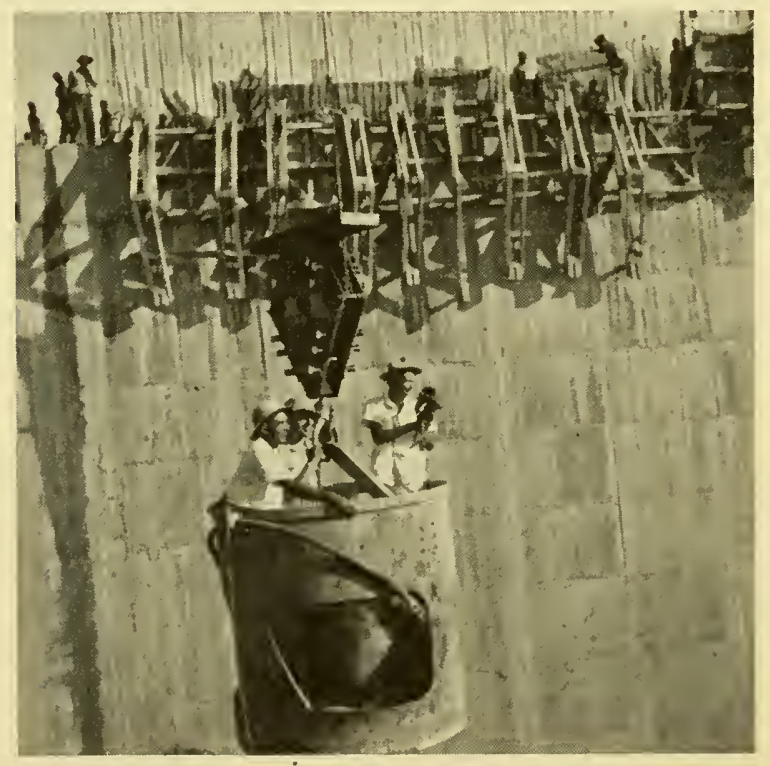

Filming Danish engineering work at Loanda, Angola, from a conveyor bucket suspended over an enormous dam. 


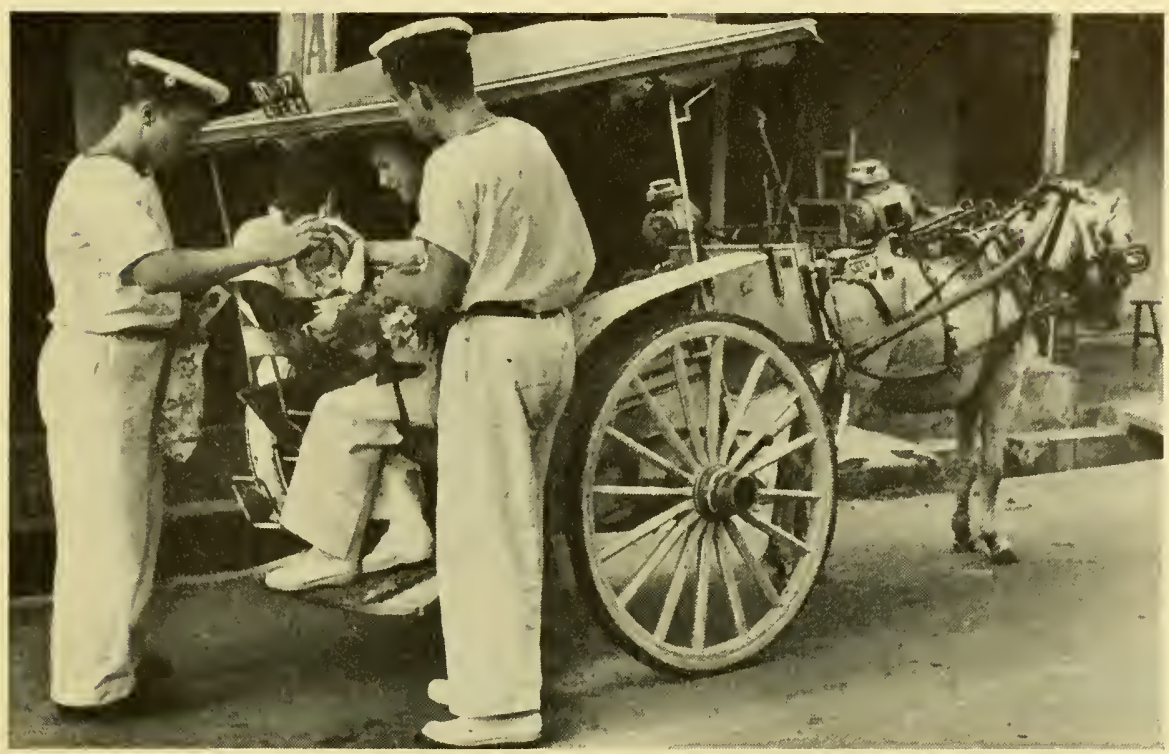

National-service men from the Galathea on an excursion to Den Pasar, Bali.

Let me try to convey some idea of one such visit, taking at random the capital of an exotic country with a small Danish community consisting mainly of business men. The Danish consulate had arranged for a Press conference an hour after our arrival; that is to say, as soon as the official visits had been exchanged with the local civil and naval authorities and the Embassy or Consulate. Reporters and cameramen flocked on board the moment the uniformed officials had left. But even before the arrival of these officials, the information service jeep had been swung ashore to enable our photographers to start work. Possibly they would go to the airport to buy tickets for a jungle station where elephants were known to work; possibly drive 200-300 kilometres to get pictures of a rubber plantation or ricefields; possibly wander about the town, taking shorts of the colourful street life and temples. The rough programme had been worked out in advance and sent on by airmail to local Danish representatives, without whose aid we should have been unable to carry out our work in the time at our disposal.

On our route we encountered every shade and colour of skin, and every category of journalist, from inexperienced small-town news-hunters to star reporters who rapidly grasped the most involved scientific problems, and had obviously read the subject up beforehand. A Press conference would begin with a sketch of the expedition's history and the peculiar method 


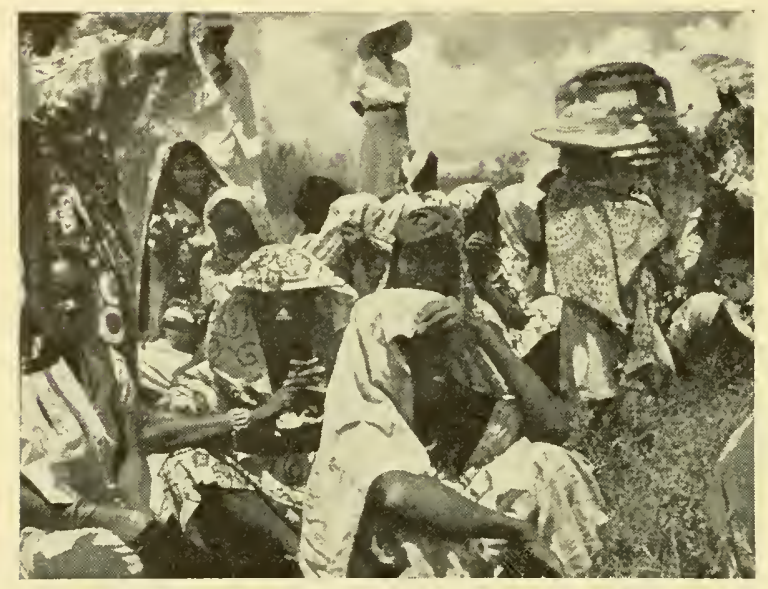

While the singing of the crowd on the shore rose to ecstatic heights,

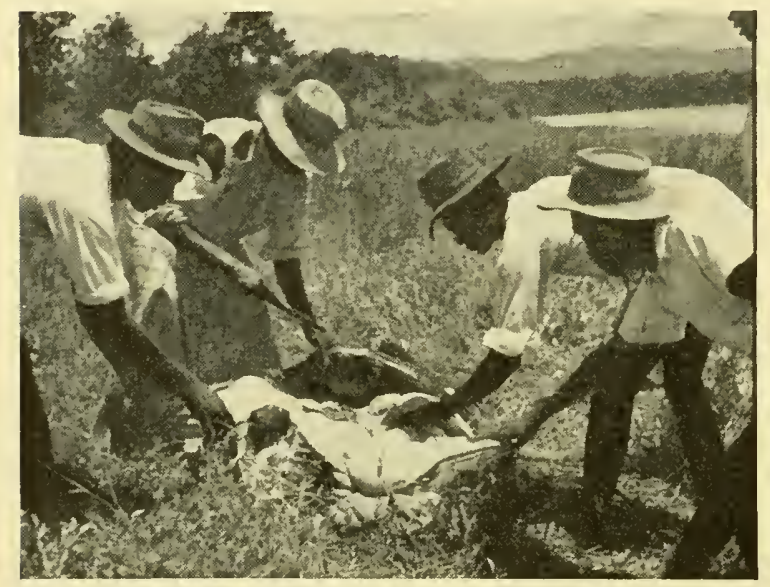

...the priests performed the ceremonial slaughtering of the ox.

From the crocodile feast on Madagascar.

of financing it. Then Dr. Bruun would give a talk about its work, and this would be followed by questions. Soon the next party would be expected and the first would be tactfully passed on to the laboratory, where a few young zoologists would explain our most popular rarities.

Meanwhile, we would be talking to reporters from the local broadcasting service and television service if there was one, or making appointments with the producers of newsreels. Cables would be connected up to recording vans, microphones carried about all over, and film cameras would whir as we took animals out of jars of formalin and demonstrated the luminous organs of fishes. Dr. Bruun would be fetched to the microphone. We would make sound effects for use in feature programmes, dig out gramophone records for Danish musical programmes, and some of us 
would occasionally go to the studios to perform with scientists in dramatic reconstructions of fishing at io kilometres.

And when the whole invasion of Press, radio, and film people was safely off the ship it would be strange not to find a loitering representative of the leading local paper wanting a scoop. Experience soon taught us to have a reward up our sleeves for such enterprise.

That evening and the next morning we could reap the fruits of our labour in column-long articles and reports on front pages and series of pictures on the back page, though there would never be time to read them till we were once more at sea.

There would be a great variety of jobs to be done. The Governor would give a reception. The local naval authorities or the local Danish society would give us all a wonderful excursion with an al fresco lunch. A cameraman would be wanted to photograph the proceedings. Word would come from the Consulate that a few hundred kilometres inland a native tribe was holding some ritual feast, and of course a photographer had to go. The tea harvest was in progress in the valleys and we needed some shots of it to complete our film about tea-growing.

There were six hours for filming in. Before ten and after four the light was too red for colour work. And from twelve to two nobody would go out in the sun. Six times four gave 24 working hours when the rain did not pour down, as in many places it did while we were in the middle of the work. Yet we succeeded in making between 25 and 30 films all told. Naturally we had a high percentage of wasted film, but we believed in getting something, even though conditions were not of the best.

Preparing for the great sacrificial festival in the village of Kabiufa, in the central heights of New Guinea.

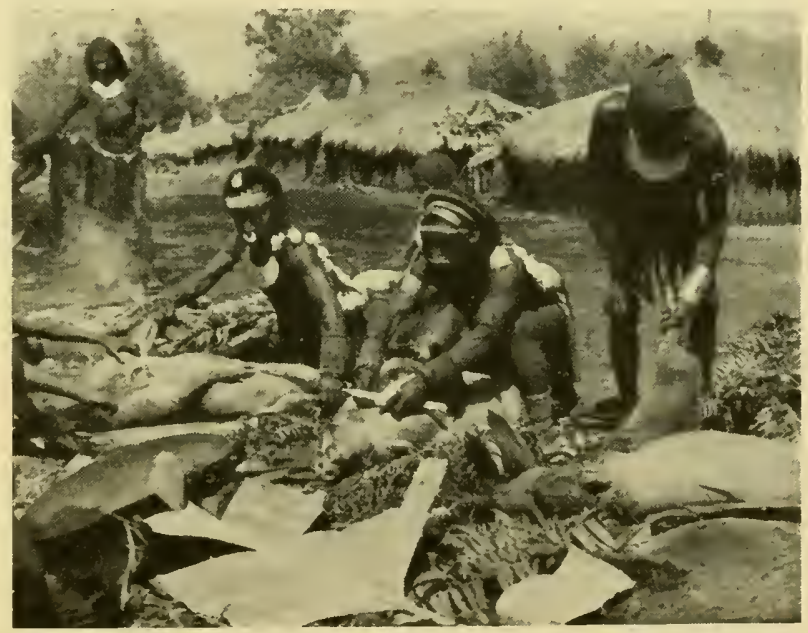


After sunset we would usually hold a short conference to check the day's results and pool new ideas. Then a motor horn would sound impatiently on the quay and we would put on our white dinner jackets and adjust our ties, stick our Galathea badge in our lapels, and drive off to give a lecture accompanied by films about Denmark to an audience of $600-700$, many of whom would afterwards reveal an astonishing knowledge of the distant country from which we came. We met Indonesians who knew more about Danish social services than we knew ourselves, and Siamese and Indians who beat us in discussions about the music of Carl Nielsen and the philosophy of Soren Kierkegaard.

Scenes from bacon factories had to be cut from films before they could be shown in countries where the pig is an unclean animal; likewise, we would have to cut out pictures of Danish bathing beauties because white women could not be shown semi-nude. There were a lot of things to think about ...

Sometimes the three of us who ran the information service would have to part company. In the Philippines Mr. Rasmussen accompanied Dr. Birket-Smith into the northern mountains of Luzon and in New Guinea Mr. Hoyer went with other scientists to Rennell Island, as described in previous chapters. In New Guinea. Mr. Rasmussen and I hitch-hiked by plane from Port Moresby into the interior. After a flight in a small singleengined machine through mountain passes at a height of 3,000 metres, on

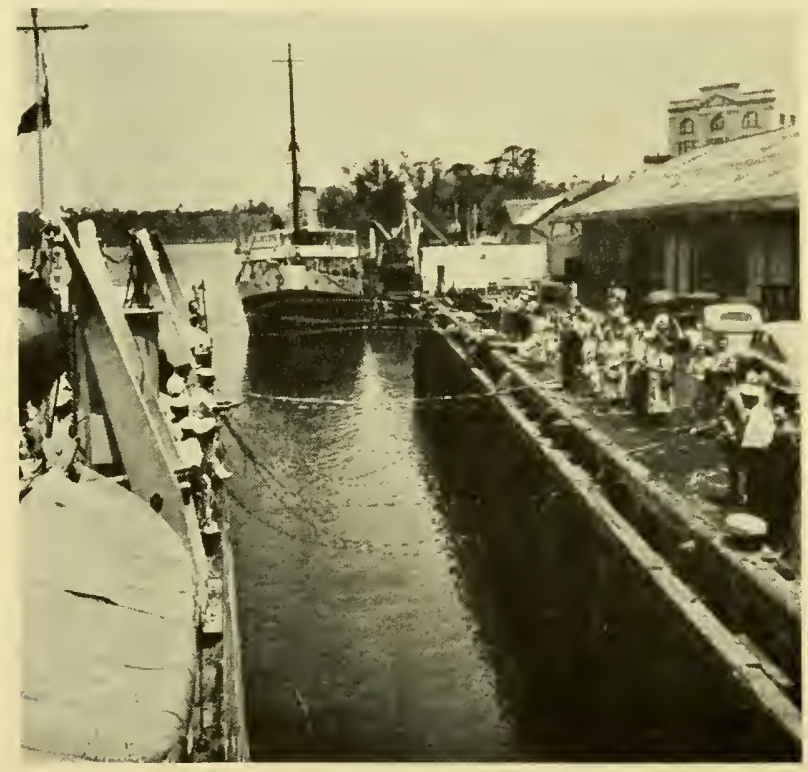

The Danish colony at Brisbane taking leave of the Galathea. 
In the dark-room.

The photographic department had plenty

to do between ports.

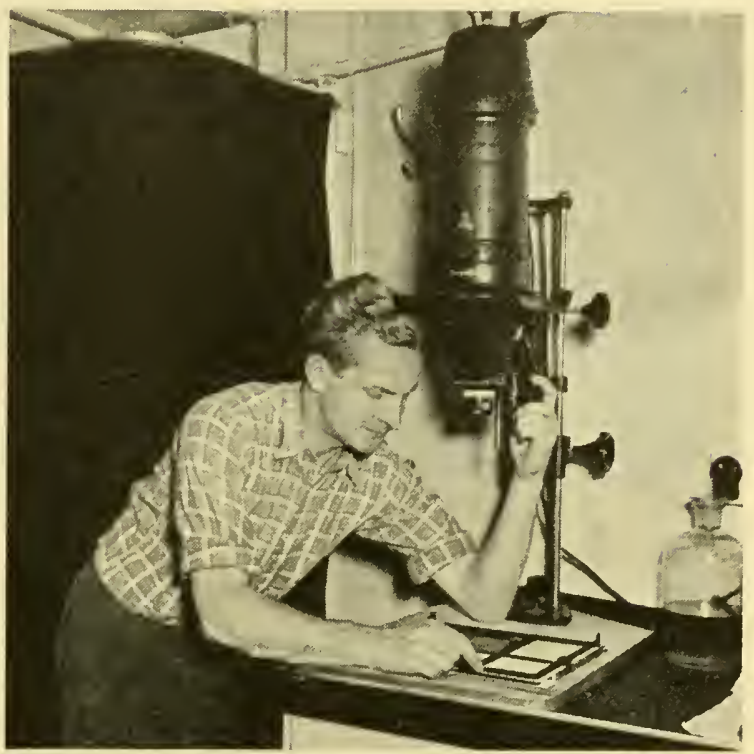

the border-line of the plane's performance, we flew over a dense jungle where there are tribes which to this day have never seen a white man. We saw the smoke from their fires and knew that a forced landing would bring us face to face with cannibals, if we survived it. Two hours later we landed on a bumpy lawn at a Government outpost, where they are endeavouring to lead a population of 40,000 from the Stone Age to the Atomic Age with the minimum of mental disturbance. It is only a score of years since they encountered civilization.

We became bosom friends with a chief who smelt of rancid lard, that being the day cream of the natives hereabouts. I shall never forget the cordiality with which he rubbed noses with me, transferring the blue and green pigments with which his cheeks and nose were smeared to my face. Or how, the next moment, he threw his ape-like arms around me and lifted me up to show his strength, ruining my brand-new khaki suit because his chest and stomach and thighs were smeared in a thick layer of rancid grease.

But the friendship bore fruit. We had had the good luck to land right in the middle of the annual sacrificial feast, at which some fifty pigs met their deaths by clubbing in honour of the gods, while dancing to the rhythm of the drums was so intense that the camera tripod began dancing in step. And we got it all.

This film took three days. A short about rice-growing in Indonesia was 


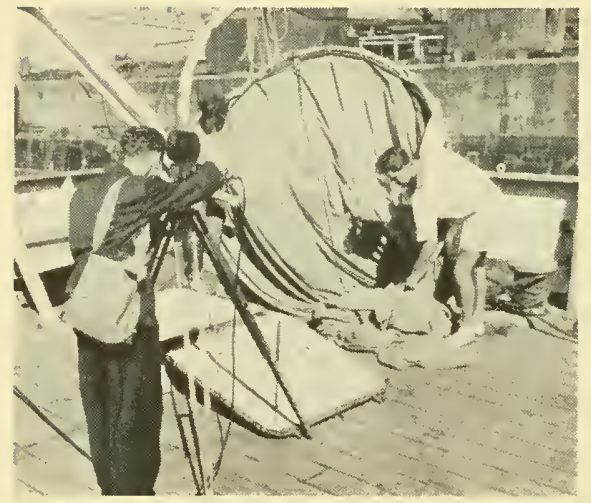

Foreign cameramen came on board and we helped them to take newsreels of our gear and rare catches.

completed in three hours, from the cultivation of the fields to the planting of the young rice, the growth of green shoots, the ripening rice, the harvesting, the carting away, and the threshing. We made over 25 educational shorts, plus three full-length films about the expedition for use with lectures. On board the ship we filmed and took colour photographs of working methods for scientific use. We photographed fishes and snails, bristle-worms and dolphins, albatrosses and jellyfishes; and on shore we got shots of penguins and elephant seals, of sugar-growing on Hawaii, and of former Danish colonies.

Like a magnet our ship attracted Danes from far and near. Three farmers in Kenya flew I, ooo kilometres by chartered sports plane to meet us. Old men who had not spoken Danish for 50 years came, as did young emigrants full of homesickness.

We gave 35 lectures with colour films about Denmark, and a like number about the expedition. Reports about us exceeded 2,00o columns,

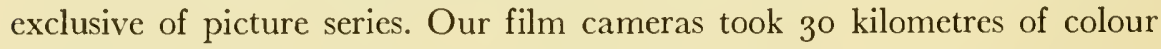
film; we brought home 2,000 monochrome photographs and a similar number of colour pictures, many for purely scientific use. A film taken on board at Capetown by the African Mirror has bcen shown in every little hamlet in British Africa which can boast of a corrugated-iron shed of a cinema. We broadcast about Denmark and the expedition in London, Plymouth, Lisbon, Teneriffe, Dakar, Capetown, Durban, Johannesburg, Nairobi, Colombo, Calcutta, Singapore, Manila, Djakarta, Port Moresby, Los Angeles, Mexico City, and once more in Plymouth and London. We were TV stars in America, and broadcast in pidgin English to the natives of New Guinea about the Danish royal family and Danish agriculture and shipping. 
The information service was an innovation and like all infants we had our tecthing troubles. Neverthcless, we gained a good deal of experience which may be uscful to future expeditions of this kind. The department was the smallest of the three services which for nearly two years cooperated on one deck. Deep-sea research was our banner; science formed the ram behind which we advanced with our typewriters, microphones, and cameras. Let me end this chapter, and this book, by saying that the scientific discoveries of this expedition were a revelation to me. If often they were difficult to comprehend, it was-ncvertheless an exciting assignment to try to explain them to the ordinary man, for it is he who must be encouraged to take an interest in scientific research and to appreciate its importance in the field of human welfare.

The Galathea Expedition marked a further step forward in the study of the Seven Seas; but as Dr. Bruun has said, the Great Sea Serpent has yet to be caught.

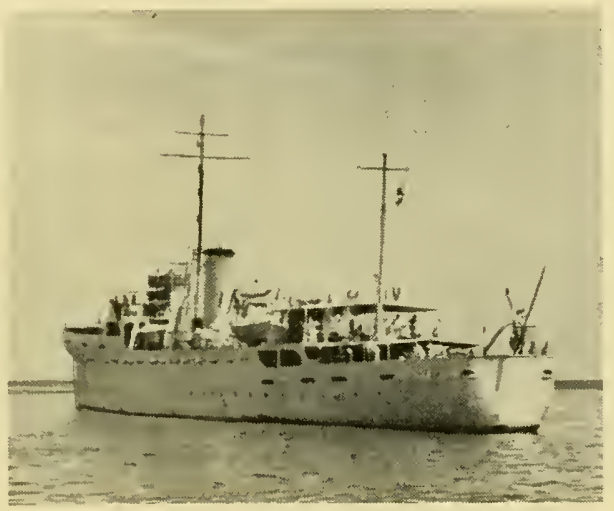




\section{INDEX}

abalone, 127

Acanthonus, 168

Albatross Expedition, 12, 62

albatross, 228

- , black-browed, 268

- , black-footed, 235

- , grey-headed, 268

- , royal, 260,266

- , sooty, 268

- , wandering, 231, 266

algæ, 53

angler-fishes, 85, I $65, \quad 174$

Anous minutus, cinereus, 234

- , stolidus, 227

Aplysia, 124

Arcturus, I9o

Arenaria interpres, 227

Argonauta, 68

Argyropelecus, 165

arrow-worms, 70

Aurelia, 77

Bacteria, deep-sea, 202

__ , food, 202

- , quantity, 207

-. , and vitamins, 208

Banda Deep, 183

barnacles, I $6_{3}$

Bathymicrops, I 7 I

bathypelagic region, 66

Bathypteroidæ, I 70

Benthosaurus, 170

Bille, Steen, 98

birds, oceanic, 224

Birgus latro, 220

bivalves, I 28

Blackett's theory, 237

booby, 225

bristle-worms, 68, I89, 200

brittle-stars, I 29, I6 I

Brotulidx, I 42, I 66 ,

by-the-wind-sailor, 75
G 1 2, 55

C 14 method, 55

Calidris acuminata, 229

Camorta, Ioo

Campbell Island, 257

Cape Johnson, ship. 32, 34, 35

carbon, 55

Carduelis flammea, 27 I

Carlsberg Foundation

Expedition, I 2

Catharacta lönnbergii, 233

Cephalopoda, 82

Cetomimus, 165

Challenger Expedition, I4

Chrysobactron rossii, 260

clam, 127

Coccolithophorida, $15 \mathrm{I}$

coral, I 27

cormorant, 226

Cottunculidx, I 44

crabs, deep-sea, 163

- , ghost, 122, 220

- , fiddler, 124

- , robber, 220

Crustacea, 8 I

Ctenophora, 73

Ctenoplana, 73

Cygnus atrata, 229

Dana Expedition, I 2

Dana $I$ and $I I$, ships, I 4

Danish Expeditions Fund, I 5

Daption capensis, 270

Darwin, Charles, I 3

Decapterus, ${ }_{1} 6_{5}$

deep-sea angler-fishes, I 74

- clay, I5I

- crabs, I $_{3}$

- eels, 156

- oozes, I 5 I

- sea-snails, 188

Deima, I6o
Dentalium, 163

diatoms, 152

Diomedea chlororhynchos, 228

- epomophora, 270

- exulans, 228, 231, 270

- nigripes, 235

Dolabella, I 24

dorado, 67

Dracophyllum, 260

- longifolium, 260 scoparium, 260

Ducula pacifica, 217

echinoderms, 160

Echinosigra paradoxa, 162

Echiuroidea, I 80

echo-sounding, 29

eels, I 56

Elasipoda, 160

elephant seals, 260

Elpidia glacialis, I $82, \quad$ I 89

Emden, ship, 32, 35

Enhydrina, 87

epifauna, 125

epipelagic, 65

Epizoanthus, 164

Erjoneicus, 189

Ethusa, 163

Eudyptus cristatus, 270

Eudyptula minor, 228

Euploea, 223

feather-stars, I 29

flatfishes, I 37

flying-fishes, 66

flying-foxes, 2 I 6

fody, Madagascar 45

food chain 154

Foraminifera I 5 I

Fratercula cirrhata $23^{6}$

- corniculata 236

Fregatta ariel, 225 
Friendship, ship, 16 frigate-birds, 225

Galathea Expedition, background and origin, I 2 .

- , cost, 17

- , first, 12,

- objects, 26

Galathea, ship, 13

- , equipment. I9 , purchase, 18

Galatheathauma, I73

gannet, 228,233

geomagnetism, 237

Gigantura, 165

glass-sponge, 132,162

Globigerina, 152

Glomus, 180

godwit, 227

greenshank, 227

Gy'gis alba, 45, 235

H-coil instrument, 239

H-needle instrument, 239

hedge-sparrow, 270, $27 \mathrm{I}$

Heteropoda, 7 I

holopelagic, 76

Hydromedusæ, 76

Idiosepius, 68

Igorot, 247

infauna, 125

Ipnops, I 66, 169

Isopoda, 123

jellyfishes, 68, 75

Kermadec Trench, 186

lantern-fishes, $16_{5}$

Larus dominicanus, 270

Larus nova-hollandia, 270

Laticauda, 92

Leith, ship, 18

Leptocephali, 156

light organs, 78

- penetration, 58,62

Limosa lapponica, 227 limpet, 120

Liparida, 188

lobsters, I 29, 133, 189

Lodoicea, $4^{6}, 4^{8}$

Macellicephala, 180

Macronectes giganteus, 270

Macrostylis, 180

Macrouroides, 169

Madagascar fody, 45

mangrove, 124

Medusa, 75, 80

Megadyptes antipodes, 270

- , sclateri, 270

Melanocetus, ${ }^{1} 6_{5}$

meropelagic, 76

Mirounga leonina, 270

molluscs, 130

mudskipper, 134

Munidopsis, 189

Myctophida, 165

Myriotrochus, I 80

Nankowry, 97. 99

nekton, 65

neritic, 76

New Britain Trench, 184

Nicobars, 96

nitrates, 59

noddy, 234

Notopygos, 68

Numenius phaopus, 227

nutrient salts, $5^{8}$

octopus, 82

Ocypode, 122, 220

oozes, deep-sea, 15 I

Ophiolepidida, I 6 I

osprey, 226

oysters, I 2 I

Pandion haliaëtus, 226

paper nautilus, 68

pelagic fauna, 65

Pelamis, 87

penguin, blue, 228

- little, 228 penguin, rockhopper, 269

- yellow-eyed, 269

- Sclater's, 270

Petersen grab, I 96

Phaëthon rubricauda, 234

Phalaropus fulicarius, 225 lobatus, 225

Phalocrocorax campbelli, 270

Philippine Trench, 32, 178

Phoebetria palpebrata, 270

phosphates, 59

Physalia, 75

pigeon. Cape, 270

- fruit, 217

pilot-fish, 67

Planet Deep, 32

plankton, 54,

Pleurophyllum, 260

- criniferum, 260

- hookeri, 260

- speciosum, 260

Poa litorosa, 259

Polycheles, 189

Polyipnus, 165

Porpita, 75

Portuguese man-of-war, 75

Pourtalesia aurora, 162

prawns, deep-sea, $8 \mathrm{I}$

pressure, importance of, I 50

Prunella modularis, $27 \mathrm{I}$

Psychropotes, 160

Psychrosphere 37

Pteropoda, 7 I

Pteropus, 2 I 6

Ptilinopus, 217

puffins, 234

Puffinus bulleri, 233

- gravis, 236

- griseus, 228, 236

- teniurostris, 229

Pyrosoma, 71, 72

Radiolaria, 152

rat-tailed fishes, I 41, 169

redpoll, 270,271

Remora remora, 67 
Rennell Island, 211,246 robber crab, 220

rockhopper penguin, 269

Ross lily, 26o

salp, $7 \mathrm{I}$

sandpiper, 227,229

Sargasso Sea, 6o

scallop, I 24

Scalpellum, 163

Schmidt, Johannes, 14

Scotoplanes, 180

Scyphomedusce, 76

sea-anemones, 128

- cucumbers, 79, 128 , $160, \quad 182$

- hares, I 24

- lions, 265,270

- mats

- serpents, 87, 94

- slugs, 129

- snails, 188

- snakes, 87

- urchins, 131

Seychelles, 42

sheerwater, 227, 228, 233

- , great, 236

— , short-tailed, 229

- , sooty, 236

siphonophores, 73

skua, 228, 233, 235 sparrow, 270

Spirula, 82

starfish, I 3 I

starling, 270

Stercorarius parasiticus,

235

- pomarinus, 235

Sterna anænatha, 224

- bergii, 226

- sumatrana, 226

- vittata, 270

Sternoptyx, 165

Stilbocarpa polaris, 260

Style phorus, 85, 165

Sula dactylatra, 234

- leucogaster, 225

- serrator, 228, 233

- sula, 225

Sunda Trench, 182

swan, 229

Sy'naphobranchus, 156,173

temperature, distribution of 37

tern, 45,225

- fairy, 45, 235

thermometer, reversing, 36

thermosphere, 37

thrush, 270

tidal zone, I 21 tides, I 20

tortoise, giant, 46

trawl, 20, II 3

- winch, 21

trawling technique, I 12

tree-shrews, 108

Trincut, 100

Tringa hypoleucos, 227

- nebularia, 227

tropic-bird, red-tailed, 234

turnstone, 227

Typhlonus, 168

Umbellula, 162

Vampyroteuthis infernalis, 84

Velella, 75

Venus's girdle, 73

Walvis Bay, 201

whalefishes, 165

white-eye, 270

Willemoesia, 191

Willebrord Snellius, ship. 32

wire cable, 20, I I 2

- , thickness of, I 14

Z-needle instrument, 238

Zosterops lateralis, 270 


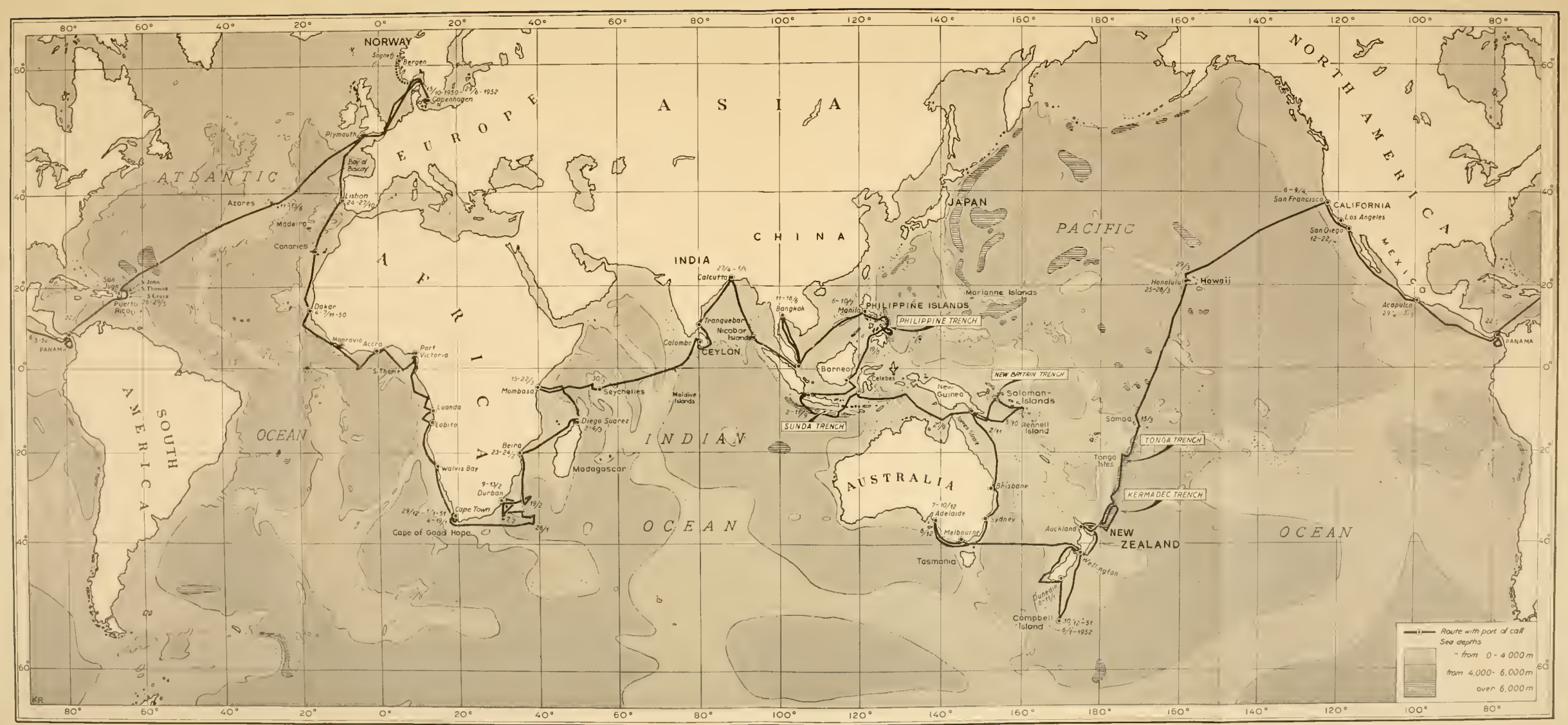






